\title{
Quantitative evaluation of mining-induced changes to spring discharge above a mine in the northern Appalachian coal field
}

Joshua M. Silvis

West Virginia University

Follow this and additional works at: https://researchrepository.wvu.edu/etd

\section{Recommended Citation}

Silvis, Joshua M., "Quantitative evaluation of mining-induced changes to spring discharge above a mine in the northern Appalachian coal field" (2009). Graduate Theses, Dissertations, and Problem Reports. 2804. https://researchrepository.wvu.edu/etd/2804

This Thesis is protected by copyright and/or related rights. It has been brought to you by the The Research Repository @ WVU with permission from the rights-holder(s). You are free to use this Thesis in any way that is permitted by the copyright and related rights legislation that applies to your use. For other uses you must obtain permission from the rights-holder(s) directly, unless additional rights are indicated by a Creative Commons license in the record and/ or on the work itself. This Thesis has been accepted for inclusion in WVU Graduate Theses, Dissertations, and Problem Reports collection by an authorized administrator of The Research Repository @ WVU. For more information, please contact researchrepository@mail.wvu.edu. 


\title{
QUANTITATIVE EVALUATION OF MINING-INDUCED CHANGES TO SPRING DISCHARGE ABOVE A MINE IN THE NORTHERN APPALACHIAN COAL FIELD
}

\author{
by \\ Joshua M. Silvis \\ Thesis submitted to the Eberly College of Arts and Sciences \\ at West Virginia University \\ in partial fulfillment of the requirements \\ for the degree of \\ Master of Science \\ in \\ Geology
}

\author{
Approved by \\ Henry W. Rauch, Ph.D., Committee Chairperson \\ Dorothy J. Vesper, Ph.D. \\ David L. Bartsch, M.S. \\ Department of Geology
}

Morgantown, West Virginia

2009

Keywords: Longwall Mining, Environmental Effects, Spring Discharge Response, Recharge Line, Natural Variation, Evapotranspiration Condition

Copyright 2009 Joshua M. Silvis 


\title{
Abstract \\ QUANTITATIVE EVALUATION OF MINING-INDUCED CHANGES TO SPRING DISCHARGE ABOVE A MINE IN THE NORTHERN APPALACHIAN COAL FIELD
}

\author{
by Joshua M. Silvis
}

The objectives of this research were to develop methods to discern between naturally occurring reductions in spring discharge from mining-induced reductions to spring discharge, evaluate available hydrologic, geologic, topographic, and mine-specific variables to determine which variables are related to mining-induced spring discharge impairment, and evaluate the variables to determine the seasonality differences or similarities among the variable effects. The study area is at one mine site in the northern Appalachian coal basin.

Overburden thickness of the researched ground water sources above the mined coal bed level range from 135 feet to 550 feet. The overburden geology consists of cyclothemic deposits of sandstones, siltstones, shales, limestones, clays, and coal that comprise the Conemaugh and Monongahela Groups of Pennsylvanian age, and the lower part of the Dunkard Group, Washington and Greene Formations, undifferentiated, of Pennsylvanian and Permian age. The terrain of the research area is typical of the Appalachian Plateau physiographic province, having broad ridges, deeply incised valleys, and highly defined dendritic drainage. Land use is dominantly for farming. Average annual precipitation in the research area is 43 inches.

Mining-induced subsidence resulted in a partial environmental effect to springs. Spring discharge responses for 77 springs were evaluated across subsidence events. The methodological procedure developed through numerous, iterative investigations differentiated quantitative values separating natural changes in spring discharge from mining-induced changes to spring discharge. The influences of precipitation and evapotranspiration conditions were accounted for during the natural variation analysis used to determine if changes to spring discharge were mining-induced.

In addition, topographic, geologic, hydrologic, and mine-specific variables were statistically examined for significance of influence on spring discharge impairment during low and high evapotranspiration seasons. 


\section{ACKNOWLEDGEMENTS}

The author wishes to thank his fiancée, co-workers, colleagues, family, and friends for the motivation and support expressed throughout the research. The author was not alone with the sacrifices that had to be made in order to acquire completion.

The author wishes to thank the coal company for providing the opportunity, and data, intrinsic to this research project. The author is very grateful for this opportunity and if possible, will pass similar prospects onto other eager graduate students.

Most of all, the author wishes to thank Dr. Henry W. Rauch for the countless hours spent together, in a conference room, office, and over the phone. Although the research extended over five years due to employment, Dr. Rauch remained as dedicated as the author. 


\section{TABLE OF CONTENTS}

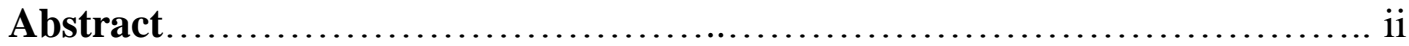

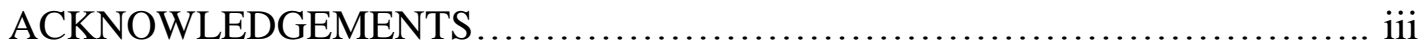

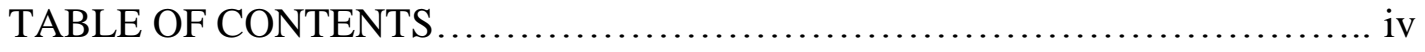

LIST OF FIGURES......................................................

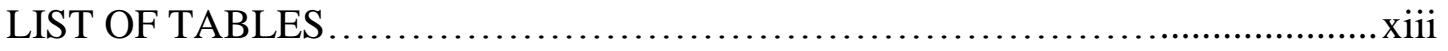

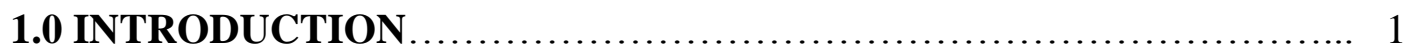

1.1 Background..................................................... 1

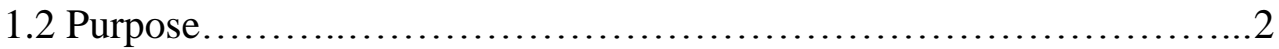

2.0 LITERATURE REVIEW ............................................ 5

2.1 Theory of Overburden Strata Movement..............................5

2.2 Stress-Relief Fractures.............................................

2.3 Environmental Effects on Ground Water and Surface Water.............9

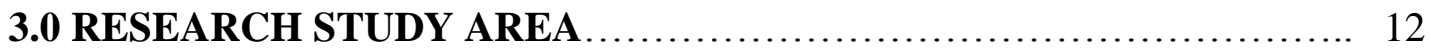

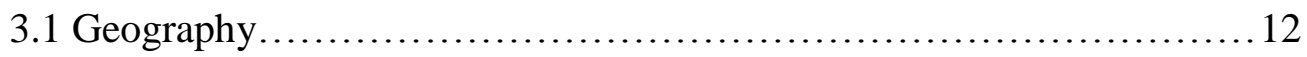

3.2 Precipitation...................................................... 15

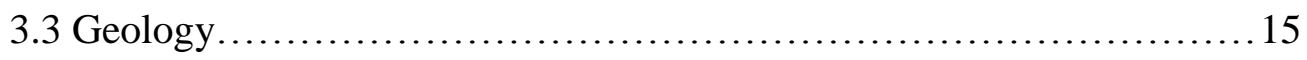

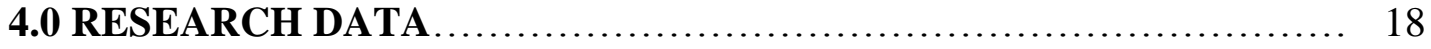

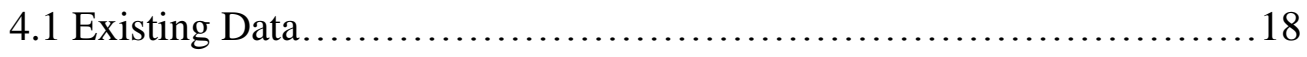

4.2 Measured Data................................................. 21

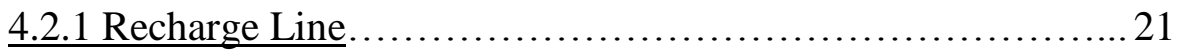

4.2.2 Spring Proximity to Nearest Surface Drainage Feature..........23 
4.2.3 Spring Elevation .......................................... 25

4.2.4 Overburden Thickness........................................ 25

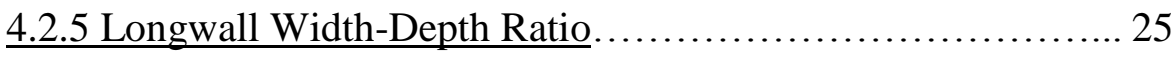

4.2.6 Spring Location Above a Longwall Panel.....................2 26

5.0 GENERAL METHODS OF INVESTIGATION_....................... 27

5.1 Statistical Examination.......................................... 28

5.1.1 Median Contingency Test..................................29

5.1.2 Chi Square Contingency Test................................ 31

5.1.3 Fisher Exact Probability Contingency Test.................... 32

5.1.4 Guidelines Used for Apparent Data Trends.....................33

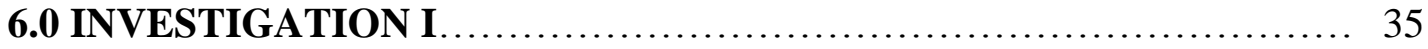

6.1 Methods of Investigation I...................................... 35

6.1.1 Spring Discharge Hydrograph Interpretation...................35

6.2 Results from Investigation I..................................... 36

6.2.1 Spring Discharge Response................................. 36

6.2.2 Spring Discharge Response Statistical Examination

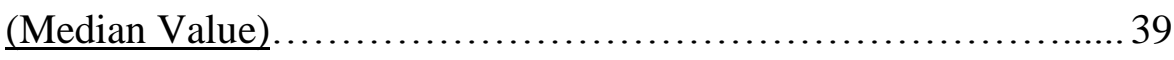

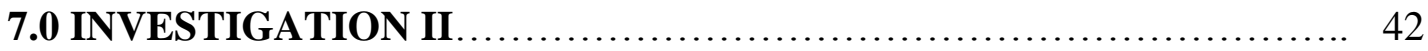

7.1 Methods of Investigation II....................................... 42

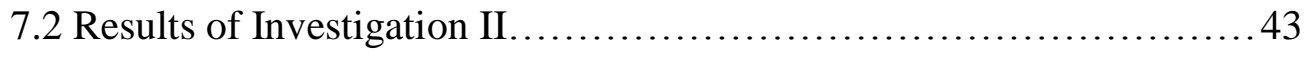

7.2.1 Spring Discharge Response.............................. 43

7.2.2 Spring Discharge Response Statistical Examination 


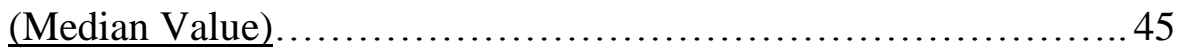

7.2.2.1 All Springs (see Table 4)..........................45

7.2.2.2 Springs Located Above Longwall Panels

(see Table 5).......................................47

7.2.2.3 Springs Located Above Main and Submain

Development (see Table 6)............................49

7.2.2.4 Springs Located Within Off Panel Mining

Environments (see Table 7)............................ 49

7.2.2.5 Springs Located Within the SCPA Boundary

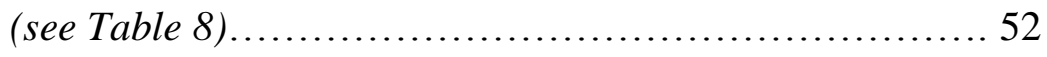

8.0 INVESTIGATION III .......................................... 55

8.1 Methods of Investigation III................................. 55

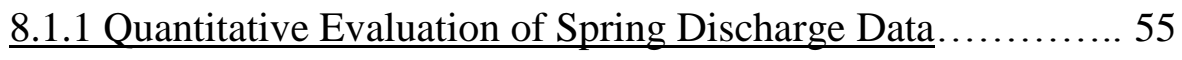

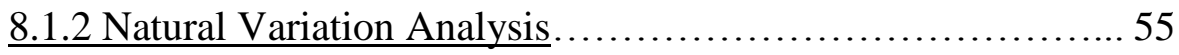

8.1.2.1 Evapotranspiration Condition....................56

8.1.2.2 Precipitation ................................ 56

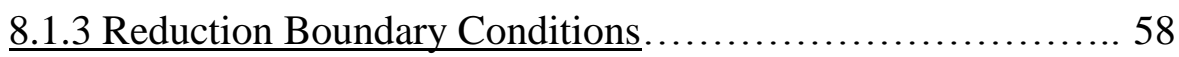

8.1.4 Quantitative Evaluation of Additional Dependent

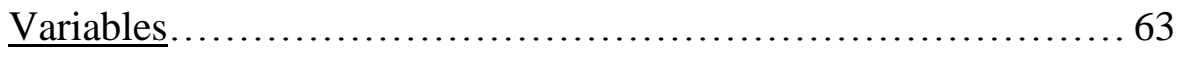

8.1.4.1 Recharge Line.............................. 63

8.1.4.2 Spring Proximity to Nearest Surface Drainage

Feature.......................................... 65 


\subsubsection{Pre-Mining Average Low Flow Spring}

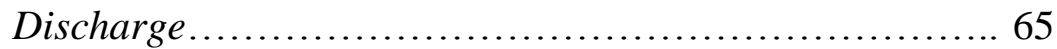

8.2 Results of Investigation III................................. 65

8.2.1 Quantitative Evaluation of Spring Discharge Data............ 65

8.2.2 Natural Variation Analysis............................... 69

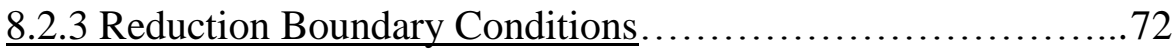

8.2.4 Spring Discharge Response.............................. 77

8.2.4.1 Optimum Boundary Reduction.................... 77

8.2.4.2 Absolute Boundary Reduction.................... 80

8.2.5 Spring Discharge Response Statistical Examination

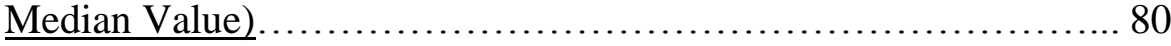

8.2.5.1 Low Evapotranspiration Condition - Optimum

ReductionBoundary...................................85

8.2.5.2 Low Evapotranspiration Condition - Absolute

Reduction Boundary...................................86

8.2.5.3 High Evapotranspiration Condition - Optimum

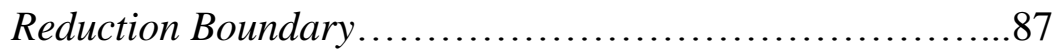

8.2.5.4 High Evapotranspiration Condition - Absolute

Reduction Boundary.................................. 88

\subsubsection{Degree of Spring Discharge Response Statistical}

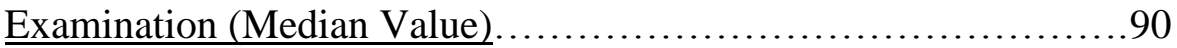

8.2.6.1 Low Evapotranspiration Condition - Optimum 
Reduction Boundary.

8.2.6.2 Low Evapotranspiration Condition - Absolute

Reduction Boundary.....

8.2.6.3 High Evapotranspiration Condition - Optimum

Reduction Boundary.

8.2.6.4 High Evapotranspiration Condition - Absolute

Reduction Boundary.... 95

9.0 INVESTIGATION IV 97

9.1 Methods of Investigation IV 97

9.2 Results of Investigation IV 97

9.2.1 Spring Discharge Response Statistical Examination

(Interpreted Best Fit Value).

9.2.1.1 Low Evapotranspiration Condition - Optimum

Reduction Boundary

9.2.1.2 Low Evapotranspiration Condition - Absolute

Reduction Boundary. 102

9.2.1.3 High Evapotranspiration Condition - Optimum

Reduction Boundary.... 103

9.2.1.4 High Evapotranspiration Condition - Absolute

Reduction Boundary 104

9.2.2 Degree of Spring Discharge Response Statistical

Examination (Interpreted Best Fit Value) $. . . \ldots \ldots \ldots \ldots \ldots \ldots \ldots . \ldots . \ldots 106$

viii 
9.2.2.1 Low Evapotranspiration Condition - Optimum

Reduction Boundary................................ 109

9.2.2.2 Low Evapotranspiration Condition - Absolute

Reduction Boundary................................ 110

9.2.2.3 High Evapotranspiration Condition - Optimum

Reduction Boundary..................................112

9.2.2.4 High Evapotranspiration Condition - Absolute

Reduction Boundary................................. 112

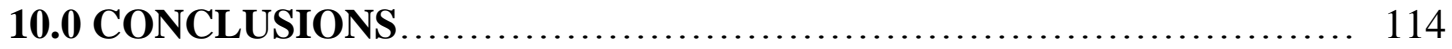

11.0 DISCUSSION AND THEORY ................................... 117

11.1 Independent Variable Analysis.................................. 118

$\underline{11.1 .1 \text { Bedrock Stratigraphy } \ldots \ldots \ldots \ldots \ldots \ldots \ldots \ldots \ldots \ldots \ldots \ldots \ldots \ldots} 120$

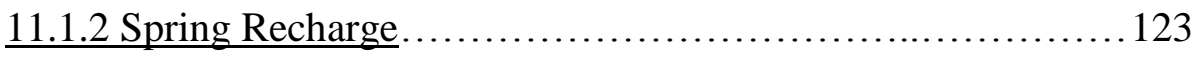

12.0 RECOMMENDATIONS ......................................... 127

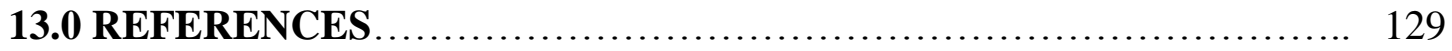

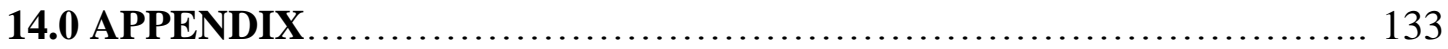

APPENDIX A: Spring Discharge Hydrographs Used to Assess Spring

Discharge Response to Mining-Induced Subsidence as Discussed in

Methods of Investigation I....................................... 133

APPENDIX B: Quantitative Data Related to the Hydrologic, Geologic,

Topographic, and Mine-Specific Variables Discussed in Methods of

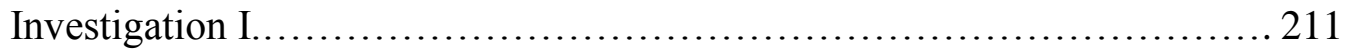


APPENDIX C: Quantitative Data Related to the Additional Hydrologic, Geologic, Topographic, and Mine-Specific Variables Discussed in Methods of Investigation III.

APPENDIX D: Data Used to Calculate Changes to Spring Discharge Across

Subsidence Events During Low and High Evapotranspiration Conditions as Discussed in Methods of Investigation III. 220

APPENDIX E: Figures Illustrating the Statistically Significant Variables Identified from the Spring Discharge Response to Mining-Induced Subsidence Analysis through the Use of the Calculated Median Values as Discussed in Results of Investigation III.

APPENDIX F: Figures Illustrating the Statistically Significant Variables Identified from the Degree of Spring Discharge Impairment to MiningInduced Subsidence Analysis through the Use of the Calculated Median Values as Discussed in Results of Investigation III.

APPENDIX G: Figures Illustrating the Statistically Significant Variables Identified from the Spring Discharge Response to Mining-Induced Subsidence Analysis through the Use of the Interpreted Best Fit Values as Discussed in Results of Investigation IV 261

APPENDIX H: Figures Illustrating the Statistically Significant Variables Identified from the Degree of Spring Discharge Impairment to MiningInduced Subsidence Analysis through the Use of the Interpreted Best Fit Values as Discussed in Results of Investigation IV. 292 


\section{LIST OF FIGURES}

Figure 1. Research Study Area ............................................ 13

Figure 2. Simplified Longwall Mine Design at the Research Study Area........... 14

Figure 3. Simplified Stratigraphic Column for the Rock Units within the

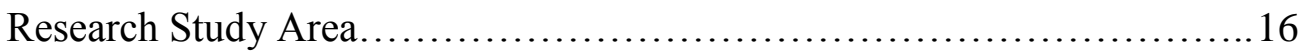

Figure 4. Structural Contour Map for the Mined Coal Seam Within the Research Study Area............................................................ 17

Figure 5. Schematic Depiction of a Contact Spring............................. 19

Figure 6. Schematic Depiction of the Recharge Line for a Spring..........................22

Figure 7. Schematic Depiction of the Gradient Line from Spring Location to the Nearest Surface Drainage Feature....................................................... 24

Figure 8. Conceptual Example of a 2x2 Contingency Table Test Using Overburden Thickness as the Independent Variable....................... 30

Figure 9. Conceptual Example of the Three Possible Hypotheses Related to the $2 \times 2$ Contingency Table Tests Using Overburden Thickness as the Independent Variable ..................................................... 31

Figure 10. 2x2 Contingency Table Test Used for Investigation I................ 39

Figure 11. $2 \times 2$ Contingency Table Test Used for Investigation II................ 45

Figure 12. Schematic Depiction of the Recharge Line Length Component Perpendicular to Longwall Panel Face for Springs Overlying Longwall Panels

Figure 13. Pre-Mine to Post-Mine Spring Discharge Comparison for Averaged 
Spring Discharge and Precipitation Normalized Averaged Spring Discharge

Data Collected During Low Evapotranspiration Seasonal Conditions........66

Figure 14. Pre-Mine to Post-Mine Spring Discharge Comparison for Averaged

Spring Discharge and Precipitation Normalized Averaged Spring Discharge

Data Collected During High Evapotranspiration Seasonal Conditions.......67

Figure 15. $2 \times 2$ Contingency Table Test Used for the Natural Variation

Analysis Associated with Investigation III............................. 74

Figure 16. $2 \times 2$ Contingency Table Test Used for Spring Discharge

Response, Investigation III...................................... 84

Figure 17. $2 \times 2$ Contingency Table Test Used for the Degree (Mild Versus

Severe) of Spring Discharge Response for the Impaired Spring Group,

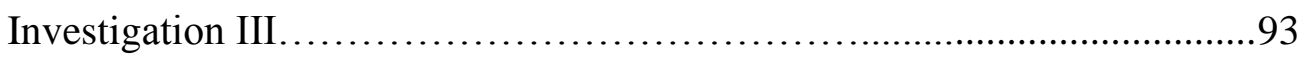

Figure 18. 2x2 Contingency Table Test Used for Spring Discharge

Response, Investigation IV .......................................... 100

Figure 19. $2 \times 2$ Contingency Table Test Used for the Degree (Mild Versus

Severe) of Spring Discharge Response for the Impaired Spring Group,

Investigation IV

Figure 20. Scatter Plot Showing Direct Relationship Between Spring Vertical

Relief and Lateral Distance to Nearest Surface Drainage Feature.

Figure 21. Scatter Plot Showing Direct Relationship Between Recharge Line

Length and Recharge Line Vertical Relief............................ 124 


\section{LIST OF TABLES}

Table 1. Results of Spring Discharge Hydrograph Interpretation as Discussed in Methods of Investigation I.................................. 37

Table 2. Results from Methods of Investigation I. Chi Square Contingency and Fisher Exact Probability Test Results Evaluated with the Calculated Median Values 40

Table 3. Results of Spring Discharge Hydrograph Interpretation as Discussed in Methods of Investigation II

Table 4. Results from Methods of Investigation II. Chi Square Contingency and Fisher Exact Probability Test Results for All Springs Evaluated with the Calculated Median Values 46

Table 5. Results from Methods of Investigation II. Chi Square Contingency and Fisher Exact Probability Test Results for Springs Located Above Longwall Panels Evaluated with the Calculated Median Values

Table 6. Results from Methods of Investigation II. Chi Square Contingency and Fisher Exact Probability Test Results for Springs Located Above Main and Submain Development Evaluated with the Calculated Median Values....... 50

Table 7. Results from Methods of Investigation II. Chi Square Contingency and Fisher Exact Probability Test Results for Springs Located Within Off Panel Mining Environments Evaluated with the Calculated Median Values........51

Table 8. Results from Methods of Investigation II. Chi Square Contingency and Fisher Exact Probability Test Results for Springs Located Within the SCPA 
Boundary Evaluated with the Calculated Median Values.................. 53

Table 9. Monthly Precipitation Data................................... 59

Table 10. Results from the Natural Variation Analysis During Low and High

Evapotranspiration Conditions Using Averaged Spring Discharge Data as

Discussed in Methods of Investigation III............................. 70

Table 11. Results from the Natural Variation Analysis During Low and High Evapotranspiration Conditions Using Normalized Average Spring Discharge

Data as Discussed in Methods of Investigation III....................... 71

Table 12. Data Types and Use Associated with Four Spring Discharge Scenarios as Discussed in Methods of Investigation III............................. 73

Table 13. Results from the Optimum Partition Tests Used to Determine the Optimum Reduction Boundaries as Discussed in Methods of Investigation

III............................................................ 75

Table 14. Results from the Optimum Partition Tests Used to Determine the Absolute Reduction Boundaries as Discussed in Methods of Investigation III............................................................. 78

Table 15. Spring Discharge Response to Mining-Induced Subsidence Evaluated at the Optimum Spring Discharge Reduction Boundary During Low and High Evapotranspiration Conditions.

Table 16. Spring Discharge Response to Mining-Induced Subsidence Evaluated at the Optimum Spring Discharge Reduction Boundary During Low and High Evapotranspiration Conditions....................... 81 
Table 17. Results from Methods of Investigation III. Chi Square Contingency Test Results Used to Determine Spring Discharge Response to MiningInduced Subsidence through the Use of the Calculated Median Values...... 82

Table 18. Results from Methods of Investigation III. Fisher Exact Probability Results Used to Determine Spring Discharge Response to Mining-Induced Subsidence through the Use of the Calculated Median Values...............83

Table 19. Results from Methods of Investigation IV. Chi Square Contingency Test Results Used to Determine the Degree of Spring Discharge Impairment to Mining-Induced Subsidence through the Use of the Calculated Median Values

Table 20. Results from Methods of Investigation III. Fisher Exact Probability Test Results Used to Determine the Degree of Spring Discharge Impairment to Mining-Induced Subsidence through the Use of the Calculated Median Values 92

Table 21. Results from Methods of Investigation III. Chi Square Contingency Test Results Used to Determine Spring Discharge Response to MiningInduced Subsidence through the Use of the Interpreted Best Fit Values..... 98

Table 22. Results from Methods of Investigation III. Fisher Exact Probability Results Used to Determine Spring Discharge Response to Mining-Induced Subsidence through the Use of the Interpreted Best Fit Values.............. 99

Table 23. Results from Methods of Investigation IV. Chi Square Contingency Test Results Used to Determine the Degree of Spring Discharge Impairment 
to Mining-Induced Subsidence through the Use of the Interpreted Best Fit

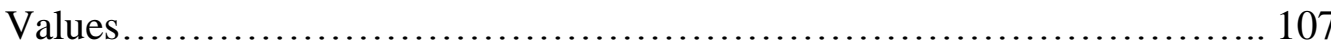

Table 24. Results from Methods of Investigation III. Fisher Exact Probability

Test Results Used to Determine the Degree of Spring Discharge Impairment to Mining-Induced Subsidence through the Use of the Interpreted Best Fit Values........................................................ 108

Table 25. Error Probability Calculated for Significant Data Trends Derived from Fisher Exact Probability Tests for Methods of Investigation I through IV at the 0.10 Alpha Level of Significance................................ 119 


\section{INTRODUCTION}

\subsection{Background}

Coal production in the United States in 2007 totaled 1,145.6 million short tons. Coal operations located in the Appalachian Region accounted for 33\% (or 377.1 million short tons) of the 2007 production. Total U.S. coal consumption in 2007 was 1128.8 million short tons, an increase of 16.5 million short tons as compared to 2006 production. Almost 93\% of the coal consumed in the U.S. in 2007 was within the electric power sector; and the remaining 7\% was consumed within other industrial and coking coal plants and residential and commercial users (Freme, 2008).

The coal extraction techniques applicable to this research are continuous and longwall underground mining; therefore open cast mining techniques, such as strip and mountaintop removal, will not be discussed. Longwall mining was first introduced to the Appalachian Region during the 1970s (Peng and Chiang, 1984). In 1981, 118 longwall panels were being operated at longwall mines. The number of active longwall panels decreased to 80 in 1995 and 52 in 2007 with 32 longwall panels within the Appalachian Region (Parizek and Ramani, 1995; Fiscor, 2008). The decrease in the number of operated longwall panels was due to increased longwall panel widths, lengths, and production rates, which made fewer, actively mined longwall panels more practical for operators. 
Longwall mining is preferred over continuous mining for underground mines because the technique is safer for the coal miners, yields approximately $30 \%$ more coal $(75 \%-90 \%$

coal recovery), and the subsidence associated with longwall coal extraction is more predictable and controlled than the subsidence associated with continuous coal extraction (Coe and Stowe, 1984).

Longwall mining is an integral component of the Appalachian Region economy. However, adverse environmental effects resulting from mining-induced subsidence commonly occur, such as aquifer dewatering, spring discharge impairment, and surface water flow diminuition or loss.

\subsection{Purpose}

Mining operators within the Appalachian Region examine case studies to assist in predicting probable hydrologic consequences (PHC) through the evaluation of mininginduced subsidence effects to ground water and surface water. These PHC reports characterize the prevailing hydrologic and geologic conditions inherent to unmined ground water and surface water supplies and predict their response to mining-induced subsidence.

The purpose of this research was to document and evaluate spring flow responses associated with underground longwall mining subsidence. Spring discharge impairment 
data trends were evaluated to determine the statistically significant hydrologic, geologic, topographic, and mine-specific variables which associate with and could be used to predict mining-induced subsidence dewatering responses of springs that overlie underground coal mines.

Previous hydrologic, geologic, topographic, and mine-specific variables researched by others, such as overburden thickness and vertical proximity to baseflow elevation, have been proven to be related to surface and ground water diminution or loss. This research has been supplemented with additional hydrologic, topographic, and mine-specific variables that have not been evaluated in the above cited research. Essentially, variables that were perceived by the author to be associated with potentially creating adverse environmental effects to local hydrology were evaluated to determine which variables are related to mining-induced spring discharge impairment; i.e., spring discharge diminution or loss. The objectives of this research were as follows:

1. Evaluate available hydrologic, geologic, topographic, and mine-specific independent variables to determine which independent variables are related to mining-induced spring discharge impairment, in terms of occurrence and degree of impairment.

2. Evaluate the data trends and results at various degrees of sophistication to determine if increasing the discrimination of data through increasingly sophisticated approaches would yield better data trends and results than through the use of the simplest approach. Four investigative approaches of varying sophistication were used for this objective. 
3. Offer recommendations for further mining related spring discharge impairment evaluation. 


\subsection{LITERATURE REVIEW}

The following literature review was conducted to determine the variables that may result in flow disruption of streams and decreased production from ground water wells. These variables were used to assess their degree of association with spring discharge impairment to understand the environmental effects of underground mining imposed upon springs.

A literature review was conducted for the purposes of:

- summarizing the theory of overburden strata movement related to longwall coal extraction,

- gaining an understanding of the regional stress-relief fracturing model inherent to Appalachian stress relieved valleys, and

- reviewing the environmental effects imposed on ground water and surface water systems.

\subsection{Theory of Overburden Strata Movement}

During longwall coal extraction, the overburden is subjected to stress and strain (various degrees of movement). Primary factors that influence subsidence-induced ground movement include the thickness and physical properties of the overburden, the width and length of the longwall panel being extracted, the thickness and inclination of the coal bed being mined, and the surface topography (PA DEP, 1999). According to the movement characteristics, the damaged overburden can be divided into four subsidence zones starting at the mined coal bed and proceeding vertically upward (Peng, 1992).

1. caved zone 


\section{2. fractured zone}

3. continuous bending deformation zone and

4. surface zone.

After the extraction of coal, the immediate mine roof caves irregularly and fills up the mined void with rock rubble (gob). The strata in this caved zone not only lose their continuity completely, the strata also lose their stratified bedding. The caved zone is normally 2 to 8 times the mine opening height (Peng, 1992).

The fractured zone is located immediately above the caved zone. The characteristics of the fractured zone are strata breakage and loss of continuity; however, the stratified beddings remain. The severity of strata breakage reduces from the bottom of the fractured zone to the top of the fractured zone. The permeability of the strata increases greatly. The fractured zone is generally 20 to 30 times the mine opening height (Peng, 1992).

Strata located above the fractured zone deform through ductile mechanics. The strata continuity and stratified beddings remain. Open fractures do occur within the continuous bending deformation zone; however, these fractures do not propagate vertically through the continuous bending deformation zone (Peng, 1992).

The surface zone has also been defined as the surface subsidence or surface fractured

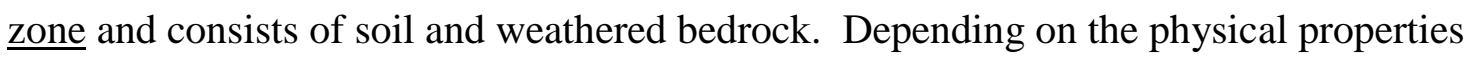


of the soil and weathered bedrock, subsidence fractures may dilate when the active face is within close proximity and constrict when the subsidence event has been completed. However, some fractures, especially fractures located within tensional zones above the longwall panel, remain dilated when the subsidence event has been completed (Peng, 1992).

A fifth zone has recently been defined as the dilated zone, which is a zone of increased permeability and storativity adjacent to a longwall panel. The dilated zone is stratigraphically located above the fractured zone and below the continuous bending deformation zone (Kendorski, 2001).

It is important to understand that the overburden subsidence deformation model described above is a framework to understand how natural mining-induced fractures propagate to shallower zones. In addition, the apertures, or widths, of pre-existing fractures, such as stress relieved fractures, can increase due to overburden deformation.

\subsection{Stress-Relief Fractures}

In the Appalachian Plateau, there are two systems of fractures, or joints, cross-cutting the sedimentary rocks of Mississippian, Pennsylvanian, and Permian stratigraphic sections. The 'macro' system of fractures is a result of tectonic activity that caused the deformation in the Valley and Ridge Geologic Province to the east. The 'micro' system of fractures 
developed due to local de-stessing of the nearly flatlying strata during downcutting of the deeply incised stream valleys (Borchers and Wyrick, 1981).

This 'micro' system of stress-relief fractures is a shallow near-surface phenomenon. They generally do not occur deeper than 200 feet below land surface. Stress-relief vertical fractures are categorized as either vertical tension fractures or vertical compressional shear fractures. Vertical tension fractures result from unequal horizontal stress applied to valley walls through erosion. Strata in the valley walls sag toward the valley center, fracture subvertically, and eventually slip downslope along subhorizontal bedding-plane fractures. Vertical compressional shear fractures form when verticalcompressional stress on rocks of the valley floor is relieved through erosion of the overlying strata. The weight of the rocks in the hills flanking the valley causes the midvalley strata to bow upward, separating along lateral bedding planes and cracking vertically and forming compressional shear fracturing (Borchers and Wyrick, 1981).

Similar to the formation of vertical compressional shear fractures, stress-relief lateral fractures form from the weathering and erosion of overlying strata in the valley centers. The valley strata bow upward in response to isostatic rebound to create lateral separations along bedding partings (Borchers and Wyrick, 1981). 


\subsection{Environmental Effects on Ground Water and Surface Water}

Adverse environmental effects resulting from mining-induced subsidence on ground water supplies are minimal in valley bottoms, increase in magnitude from valley walls to hillsides, and are greatest at hilltops (Tieman and Rauch, 1986; Leavitt and Gibbens, 1992; Donohue and Parizek, 1994; Carver and Rauch, 1994; Elsworth and Liu, 1995). In general, greater effects occur for ground water supplies located at topographic highs and effects are least for valley bottoms.

Groundwater supplies located below local baseflow stream elevation are affected to a lesser degree than those supplies located above local baseflow stream elevation (Tieman and Rauch, 1986; Leavitt and Gibbens, 1992).

Location of the ground water supply above the longwall panel controls the degree to which ground water supplies are affected. The overburden exhibits tensional and compressional deformation within the quarter-panel and mid-panel mining environments, respectively. The degree to which ground water supplies are affected generally decreases from mid-panel to the off-panel mining environment, which is often stress neutral (Walker et al., 1986; Walker, 1988; Rauch, 1989; Matetic and Trevits, 1992; Trevits and Matetic, 1991; Matetic et al., 1991; and Leavitt and Gibbens, 1992).

The degree to which ground water supplies (water wells and springs) are affected is greatest during the period of maximum subsidence (or maximum tensional strain) as the 
longwall panel face passes beneath the supply. The rate of water table decline decreases as ground strain transitions from tensional deformation to compressional deformation (Hill and Price, 1983; Walker, 1988; Roosendaal et al., 1990; and Trevits and Matetic, 1991).

Possible adverse environmental effects resulting from mining-induced subsidence on streams include flow diminuition due to induced vertical leakage in response to the artificial lowering of the phreatic surface; pooling of streams due to superimposition of the subsidence trough on low-gradient systems; and local reversal of the hydraulic gradient. Conversely, streams that recover from mining-induced subsidence through natural attenuation processes, such as clay gouging, sedimentation, and chemical precipitate formation, display a more uniform discharge (Carver and Rauch, 1994). The greater uniformity in seasonal streamflow following post-subsidence stabilization is perceived to be a function of lower post-mine baseflow recession, which reflects increased sustainable aquifer discharge and storage capacity.

An inverse relationship exists between overburden thickness and the degree to which ground water and surface water supplies are affected. The greater thickness of overburden between the supply and the coal bed being mined, the lesser the degree to which the supply is affected (Owili-Eger and Johnson, 1987; Stoner, 1983; Rauch et al., 1984; Cifelli and Rauch, 1986; Carver and Rauch, 1994; Dixon and Rauch, 1988; Rauch, 1989; Dixon and Rauch, 1990; and Donohue and Parizek, 1994). 
A higher percentage of soft rock there is within the overburden decreases the degree to which ground water and surface water supplies are affected due to distinctly different deformation mechanics between hard and soft rock units (Rauch, 1989). Hard rock units, sandstones and limestones, respond to subsidence-induced ground movement through tensional mechanics, creating and/or enlarging the apertures of existing fractures. Soft rock units, shales, claystones, and coals, respond to subsidence-induced ground movement through ductile mechanics; however, shales are susceptible to increasing vertical permeability. Claystone has the potential to effectively seal fractures created from subsidence-induced ground movement due to its ability to deform through ductile mechanics. In addition, claystone is intrinsically resistive to ground water flow and is effective at precluding vertical transmission of ground water and surface water. 


\subsection{RESEARCH STUDY AREA}

Research was conducted for one mine site in the northern Appalachian Coal Basin

(Figure 1). The particular research study area was made apparent to the author through contacts among other colleagues. The study area is typical of other mine sites in the Appalachian Plateau physiographic province, has well documented longwall mining history and well documented spring discharge data collected prior to, during, and after subsidence. In exchange for the spring discharge data, it was agreed that the coal mining company name and specific mine location of the research area remain anonymous.

The research study area is located above two developed blocks of coal. The eastern block of coal was extracted to the north with longwall panels being recovered to the west and the western block of coal was extracted to the south with longwall panels being recovered to the east (Figure 2). The width of the longwall panels ranged from 860 to 1020 feet. The longwall panels are oriented nearly east to west, along $91.5-271.5$ degree orientation.

\subsection{Geography}

The terrain of the research area is typical of the Appalachian Plateau physiographic province, having broad ridges, deeply incised valleys, highly defined dendritic drainage. Land use is dominantly for farming. Surface elevation of the researched springs ranges from 930 feet to 1310 feet above mean sea level. 


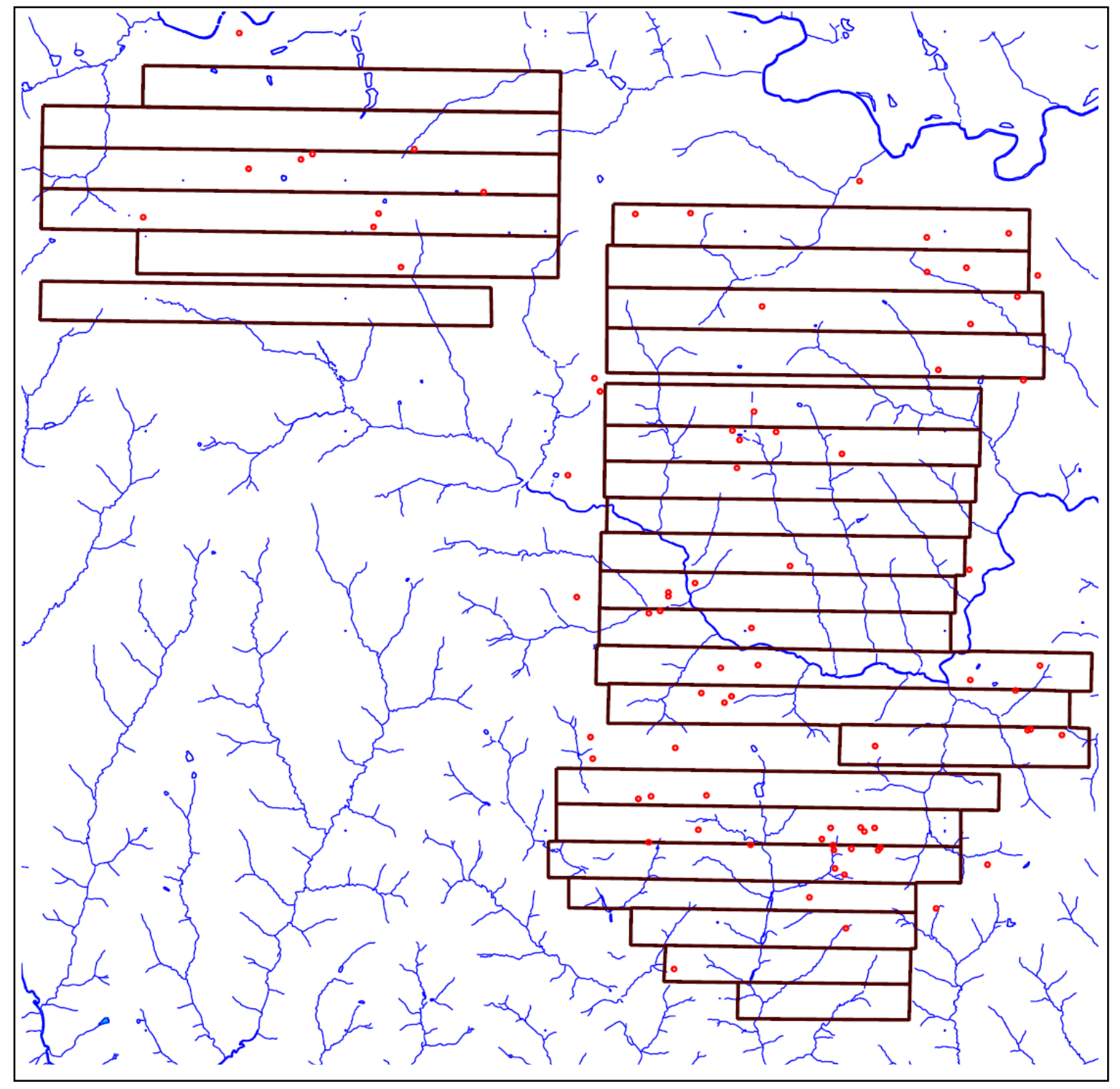

Figure 1. Research Study Area. Longwall panels were extracted counter-clockwise, beginning in the southeast. Springs locations are identified as solid red dots. 


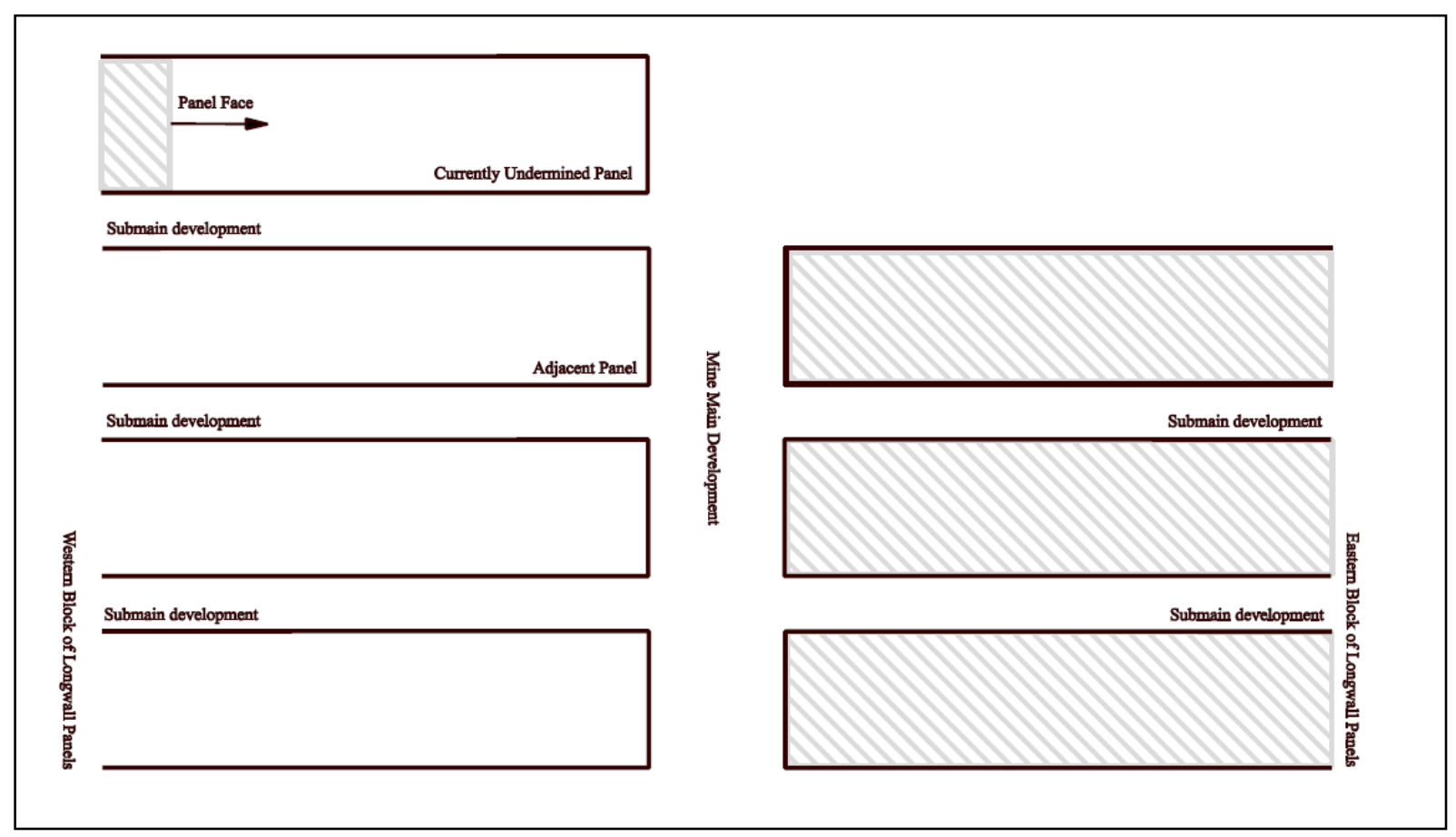

Figure 2. Simplified Longwall Mine Design at the Research Study Area. 


\subsection{Precipitation}

Average annual precipitation in the research area is 43 inches. Based on the 30 -year precipitation record, the average precipitation is approximately 3.6 inches per month; January (2.5 inches) typically receives the least precipitation and July (4.8 inches) typically receives the most precipitation (Schumacher, 2007).

\subsection{Geology}

Overburden geology consists primarily of cyclothemic deposits of sandstones, siltstones, shales, limestones, clays, and coal beds of Pennsylvanian and Permian Age. The strata comprise the Conemaugh and Monongahela Groups of Pennsylvanian age, and the lower part of the Dunkard Group, Washington and Greene Formations, undifferentiated, of Pennsylvanian and Permian age (Figure 3). The strata form a gentle monocline that dips to the southeast (Figure 4) at an average rate of 18 feet per mile (Berryhill, 1963).

Overburden thickness of the researched ground water sources above the mined coal bed level range from 135 feet to 550 feet. The majority of the soils overlying the strata are well-drained to moderately well-drained with a silt loam surface over clay loam subsoils (Schumacher, 2007). 


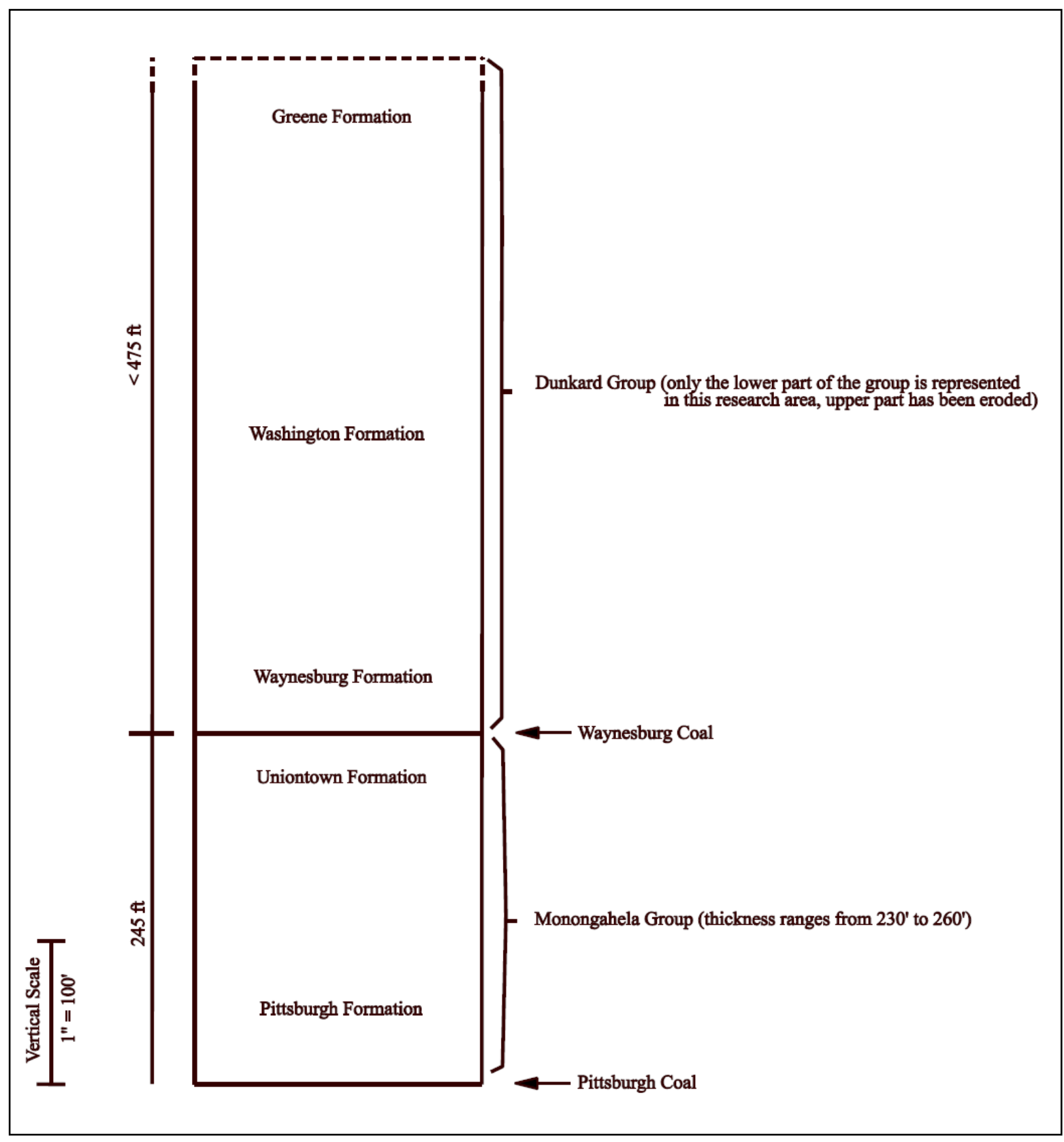

Figure 3. Simplified Stratigraphic Column for the Rock Units Within the Research Study Area. 


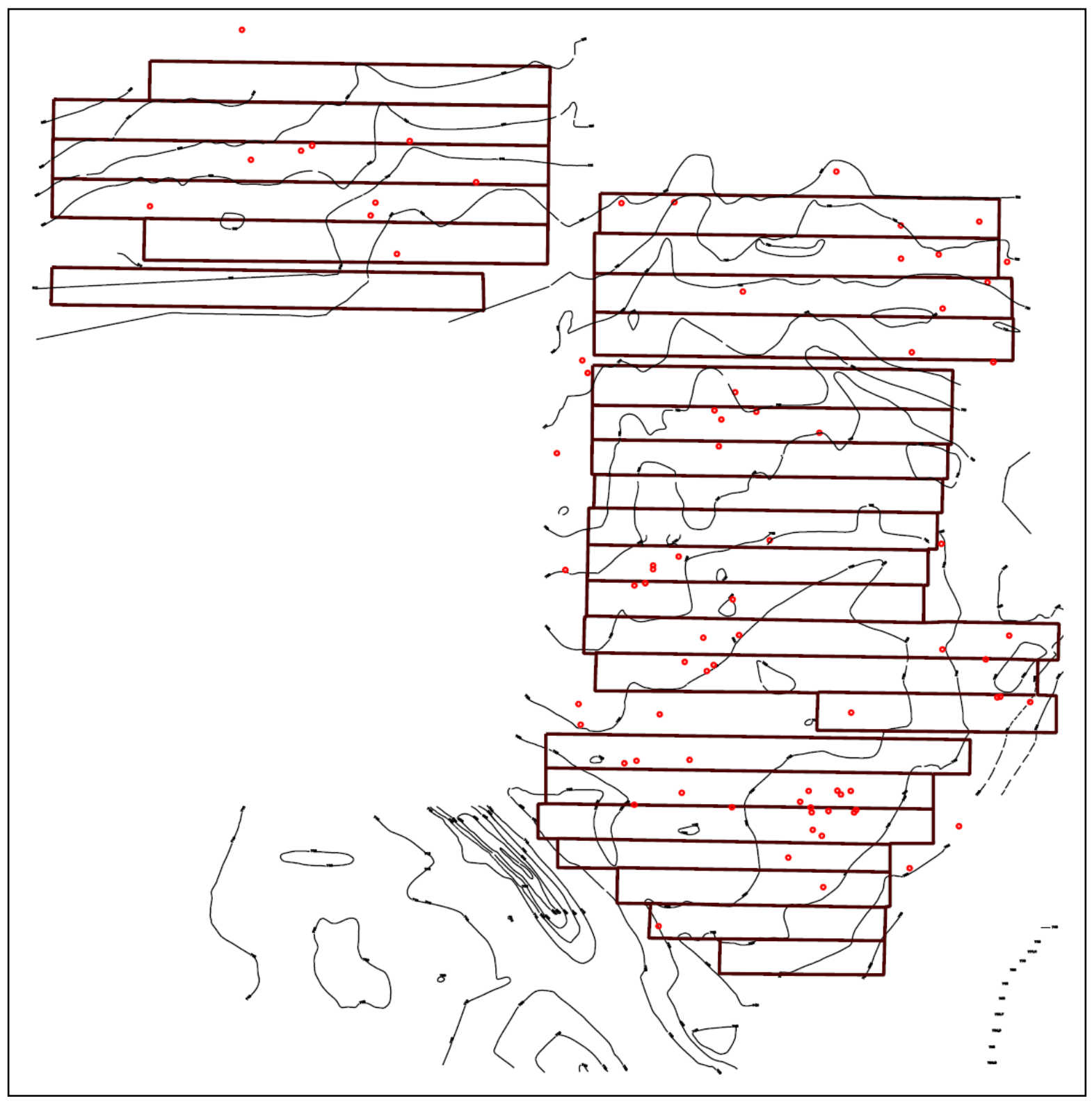

Figure 4. Structural Contour Map for the Mined Coal Seam Within the Research Study Area. Structural contour intervals are $5 \mathrm{ft}$ for the depicted map. Strata are in general dipping to the southeast (lower right). 


\subsection{RESEARCH DATA}

Two types of data were used for the research - existing and measured. The existing and measured data are located in Appendices A and B, respectively.

\subsection{Existing Data}

The existing data were provided by the coal company and consists of spring discharge measurements, spring emergence locations on ground surface (daylight locations), underground mine workings, mining progress timing maps for the mined longwall panels, unmined coal locations, and bottom of coal elevations.

The spring discharge data were collected previous to this research by coal company personnel and not the author. Spring discharge yields were collected monthly for a minimum of 12 months prior to the local subsidence event and 12 months following the subsidence event, in accordance with the state regulatory agency protocol established during issuance of the underground mining activity permit. The springs are assumed to be contact springs - springs that form at a lithologic contact (Figure 5). Locations of the springs were measured and collected using Global Positioning System (GPS) instrumentation. Spring discharge yields were measured using the timed-volumetric technique. Precision error associated with the measurement technique is assumed to be +/- 10 percent and consistent among measurements.

Spring discharge hydrographs were drafted by the author. These hydrographs graphically display the discharge data through the measurement period. In addition, information 


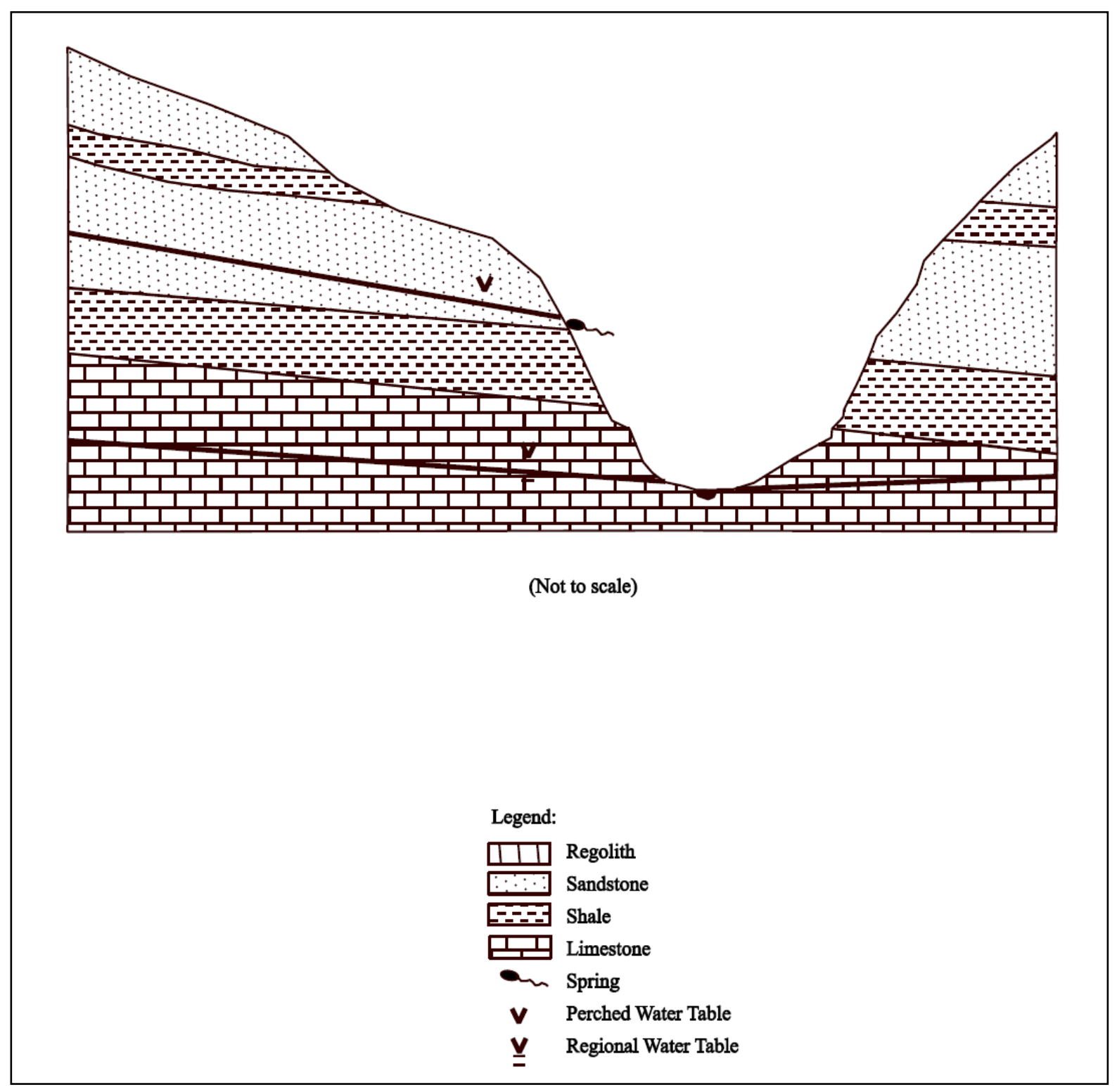

Figure 5. Schematic Depiction of a Contact Spring. 
related to underground longwall activity during the measurement period is shown. The spring discharge hydrographs are located in Appendix A.

The existing spring data were field verified to assess data quality. Information such as accuracy of mapped spring locations, spring use at time of visitation, degree of spring development and construction type, and spring yield at time of visitation were collected. The author was able to visit 57 of the 77 springs to assess data quality and $100 \%$ were mapped properly within +/- 30 feet (accuracy associated with the GPS unit used). The degree of spring development and construction type did not provide adequate quality and assurance of data for the author to make a distinction between different degree of spring development (effectiveness to capture water), construction type, or if post-mine modifications were made to existing spring supplies following the subsidence event. Therefore, the springs are assumed to have the same degree of spring development and construction type.

In addition, anecdotal information, such as historical spring discharge patterns, post-mine spring discharge activity and location(s), and spring discharge disruption observations, were collected by the author from conversations with surface property owners. Familiarity with local drainage features, surface bedrock types, and mining-induced subsidence effects to ground surface, structures, and infrastructure were also noted. 


\subsection{Measured Data}

The measured data were computed by the author. The independent variable data were investigated due to known relationships between hydrologic, geologic, topographic, and mine-specific variables to mining-induced hydrologic changes, as previously discussed in 2.3 Environmental Effects on Ground Water and Surface Water. Quantitative information was obtained for the independent variables for later use in examining statistical data trends of these variables associated with underground longwall mine subsidence. The independent variable data are located in Appendix B and include the recharge line, spring proximity to nearest surface drainage feature, spring elevation, overburden thickness, width-depth ratio, and spring location above a longwall panel.

\subsubsection{Recharge Line}

The recharge line is a conceptual analog to the topographic subsurface drainage and recharge basin of a spring. The recharge line concept was modified from an earlier study (Cifelli and Rauch, 1986). The recharge line concept assumes that ground water flows down-dip along the steepest hydraulic gradient through homogenous and isotropic conditions (Fetter, 2001).

The recharge line is drawn in the linear up-slope direction perpendicular to topographic map elevation contour lines from the spring emergent location on ground surface (daylight location) to its first inflection point; or deviation from a straight line (Figure 6). The author decided to terminate the recharge line at its first inflection point due to the 


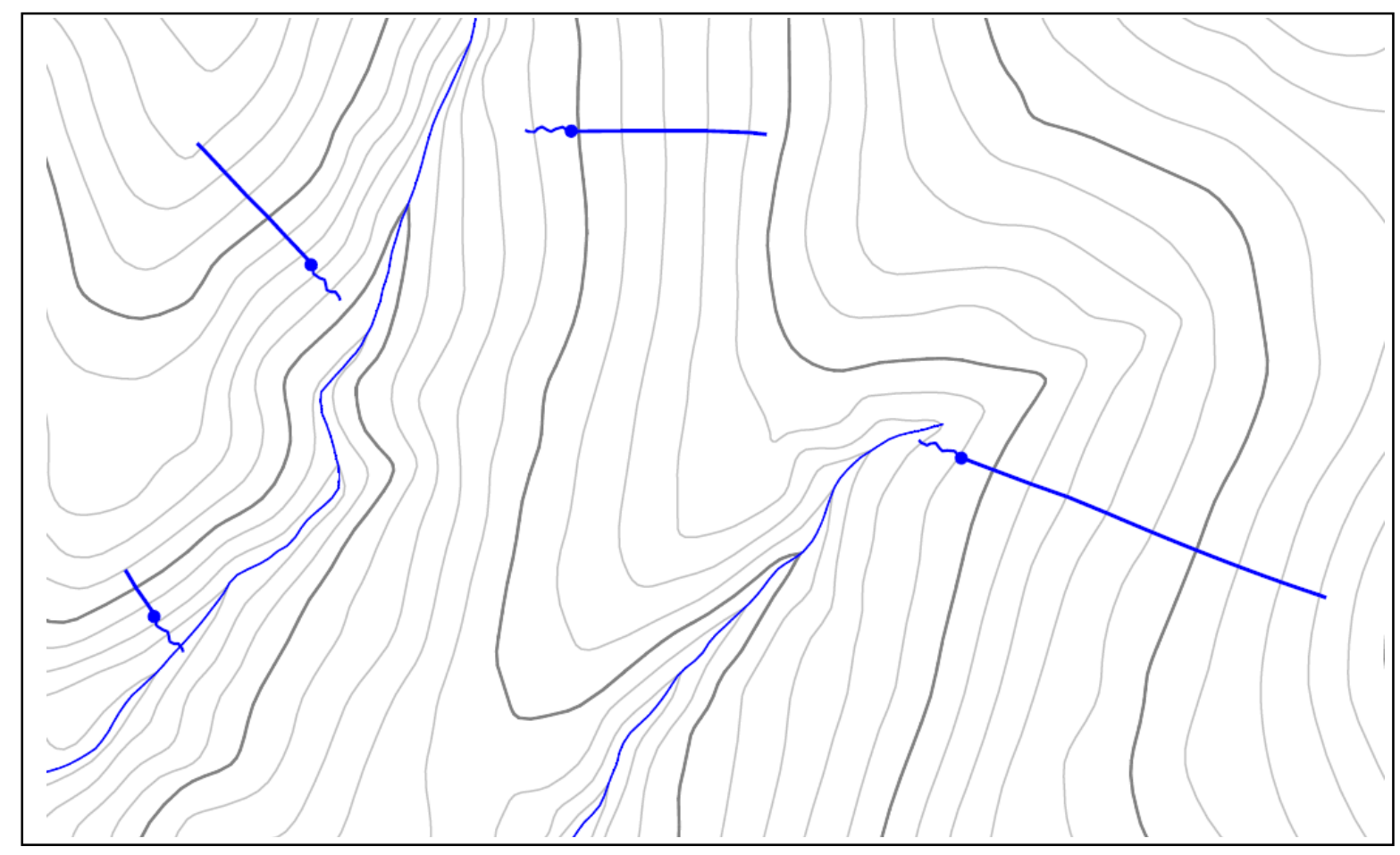

Figure 6. Schematic Depiction of the Recharge Line for a Spring. Topographic contour intervals are 10ft for the depicted map. 
assumptions that 1.) most springs in the Appalachian Plateau physiographic province occur along fractures and 2.) fractures, whether stress-relieved or tectonic, are linear.

The recharge line is a linear representation akin to the main stem of a tributary stream within a dendritic surface drainage system. The length, vertical relief, and gradient (percentage slope) of the recharge line were measured from USGS 7'30" quadrangle maps and the spring geographic location maps provided by the coal company. Due to the researcher's length measurements using an engineer rule and the 10ft topographic contour spacing inherent to USGS quadrangle maps, the errors associated with recharge line length, vertical relief, and gradient were assumed to be $+/-10 \mathrm{ft},+/-5 \mathrm{ft}$, and $+/-5.5$ percent, respectively. The assumed gradient error of $+/-5.5$ percent was derived from the use of the averaged values of all the measured recharge line lengths and vertical reliefs in Appendix B.

\subsubsection{Spring Proximity to Nearest Surface Drainage Feature}

A spring's pre-mining proximity to the nearest surface drainage feature is equal to the shortest horizontal and vertical distance discharge water from a spring would travel on ground surface to the nearest surface drainage feature shown on the USGS 7'30" quadrangle maps (Figure 7). The stream order of each surface drainage feature was evaluated. Vertical relief and gradient to the nearest surface drainage features were measured from USGS 7’30" quadrangle maps and the spring geographic location maps 


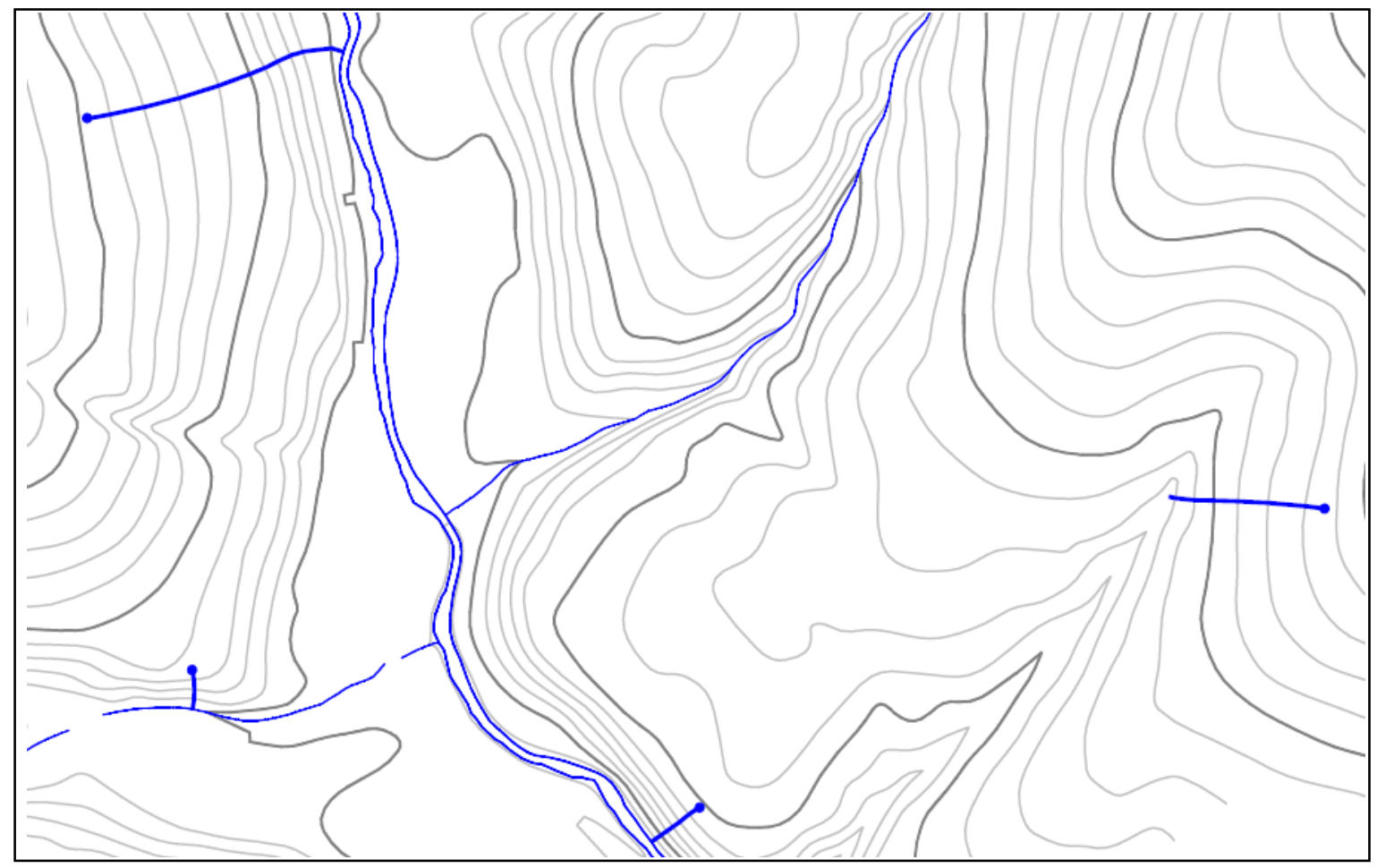

Figure 7. Schematic Depiction of the Gradient Line from Spring Location to the Nearest Surface Drainage Feature. Topographic contour intervals are 10ft for the depicted map. 
provided by the coal company. Due to the researcher's length measurements using an engineer rule and the 10ft topographic contour spacing inherent to USGS quadrangle maps, the errors associated with a spring's horizontal and vertical distances to the nearest stream were assumed to be $+/-10 \mathrm{ft}$ and $+/-5 \mathrm{ft}$, respectively.

\subsubsection{Spring Elevation}

The pre-mining elevations of the springs at their daylight locations were identified through interpolation of USGS 7'30" quadrangle maps. The error associated with premining elevations of the springs was assumed to be $+/-5 \mathrm{ft}$.

\subsubsection{Overburden Thickness}

Overburden thickness was determined from subtraction of the bottom of coal elevation directly beneath the spring, as determined by coal structural contour maps, from the daylight elevation of the spring. The error associated with overburden thickness was assumed to be $+/-5 \mathrm{ft}$.

\subsubsection{Longwall Width-Depth Ratio}

The width-depth ratio was calculated for springs located above mined longwall panels. The width of the mined longwall panel is the measured panel width perpendicular to the panel length between the closest ribs, or walls, of the support pillars between the headgate and tailgate submain developments paralleling the longwall panel. The ratio was determined from division of the measured longwall panel width by the panel 
overburden thickness previously calculated for the springs. The error associated with width-depth ratio was assumed to be $+/-0.16$ (unitless). The assumed width-depth ratio of $+/-0.16$ was derived from the use of the $+/-5 \mathrm{ft}$ error associated with the overburden thickness and +/-10ft error associated with the researcher's panel width measurements using an engineer rule. The errors were applied to the minimum and maximum calculated width-depth ratios in Appendix B to determine the maximum error that could be introduced.

\subsubsection{Spring Location Above a Longwall Panel}

The surface trace position of a spring above a longwall panel was determined from the width of the longwall panel and the lateral edge distance the spring is from the surface trace of the closest rib of the support pillars within the tailgate / headgate submain developments paralleling the longwall panel for the eastern / western blocks. The position above the longwall panel was determined from division of the measured lateral edge distance by the longwall panel width. The error associated with the surface trace position was assumed to be $+/-0.02$ (unitless). The assumed surface trace position error was derived from the use of the $+/$-10ft error associated with the researchers panel width and length measurements using an engineer rule. The errors were applied to the minimum and maximum calculated surface trace positions in Appendix B to determine the maximum error that could be introduced. 


\subsection{GENERAL METHODS OF STATISTICAL ANALYSIS}

The investigative sequence used to document and evaluate spring flow responses associated with underground longwall mine subsidence has been dissected into four separate investigations for the purpose of determining if an increase in the discrimination of data through more sophisticated approaches would yield better data trends and results than through the use of the simplest approach. These investigations, I through IV, are presented in chronological order of completion. The methodologies inherent to the more sophisticated investigations are reflections of the results from previous investigations. The dependent variable data, spring discharge, and the independent variable data, such as overburden thickness, were statistically examined to determine if basic, fundamental data trends exist.

The research itself focused entirely on spring discharge impairment trends. Apparent data trends were statistically examined to determine which independent variables were statistically significant at the appropriate alpha level of significance for the chi-square and Fisher exact probability contingency statistical tests used. The methodology was revised three times in an effort to discriminate the data more effectively. Boundary conditions to discern between naturally-occurring changes in spring discharge from mining-induced changes to spring discharge were eventually introduced to the research as a tool to evaluate more effectively the 'gray area springs' or springs with an indeterminate hydrologic response to subsidence as evident in the spring discharge hydrographs. In addition, seasonal evapotranspiration condition and precipitation were 
evaluated to discern between spring discharge impairment trends during low and high periods of evapotranspiration between deficit and surplus departures from the 30-yr average normal precipitation.

\subsection{Statistical Examination}

Statistical tests are used to establish and determine basic data trends between two variables in a simple statistical manner. There are two types of statistical tests that could be used to identify data trends - parametric and nonparametric.

Parametric statistical testing was not considered for this study because it involves assumptions, such as normally distributed interval or ratio data, of the data that were not relevant to this study.

The existing data were randomly chosen by the coal company for this research and therefore, are a representative sample population of all the target population springs located within the research study area. In addition, the intent of the statistical examination involved the comparison of the statistical tests computed probability of error, associated with the trend relationship between spring discharge and the independent variables, to the alpha level of significance specific to the statistical test strength. This comparison would not have been reliable if parametric statistical testing had been done due to the nature of the tested data. 
Nonparametric statistical tests were chosen for this study because they do not make assumptions for the type of data used, such as nominal, ordinal, interval, or ratio data. Nonparametric statistical tests apply the contingency test approach, which is applicable to all four types of data. Nonparametric statistical tests are more conservative than parametric statistical tests, and are more reliable for determining basic data trends. In addition, the dependent variable data (spring discharge) are noisy; that is, the spring discharge data are influenced by recent precipitation, seasonal evapotranspiration condition, degree and type of spring construction and development. Therefore, the use of a simpler statistical testing approach was warranted.

Nonparametric statistical testing was used to determine the hydrologic, geologic, topographic, and mine-specific independent variables that are statistically related to (show data trends with) mining-induced changes to spring discharge. The following testing procedures were applied to each independent variable:

- Median Contingency Test

- Chi Square Contingency Test

- Fisher Exact Probability Contingency Test

\subsubsection{Median Contingency Test}

The median contingency test procedure was used to determine if the two independent spring data groups differed in central tendencies; more specifically, if differences between the two independent groups could be drawn from a population with the same median value (Siegel, 1956). For example, springs that were concluded to be flow 
impaired by mining-induced subsidence were compared to springs that were concluded to not be affected by mining-induced subsidence. These two groups were then compared to an independent variable, such as overburden thickness (Figure 8).

\begin{tabular}{|c|c|c|c|}
\hline \multirow{3}{*}{$\begin{array}{l}\text { \# of Springs }>/=\text { Overburden Thickness Median } \\
\text { \# of Springs }<\text { Overburden Thickness Median }\end{array}$} & Group 1 & Group 2 & Total \\
\hline & A & $\mathrm{B}$ & \multirow{2}{*}{$\begin{array}{l}\mathrm{A}+\mathrm{B} \\
\mathrm{C}+\mathrm{D}\end{array}$} \\
\hline & $\mathrm{C}$ & $\mathrm{D}$ & \\
\hline
\end{tabular}

where, Group 1, springs whose discharge was impaired by mining-induced subsidence, and Group 2 , springs whose discharge was not affected by mining-induced subsidence, are the independent spring data groups.

Figure 8: Conceptual Example of a 2x2 Contingency Table Test Using Overburden Thickness as the Independent Variable.

The median test procedure resulted in the formulation of one of three hypotheses - null (no space relationship), alternative (direct relationship), and alternative (inverse relationship), through the use of the contingency table approach (Figure 9). If the author judged that moderate to strong data trends, either alternative (direct) or alternative (inverse), were apparent within the frequency distribution, Chi square contingency and Fisher exact probability statistical tests were computed. 
Figure 9(a): Example of Null Hypothesis Categorical Distribution

\# of Springs $>/=$ Overburden Thickness Median

\# of Springs < Overburden Thickness Median

\begin{tabular}{|c|c|}
\multicolumn{1}{c|}{ Group 1 } & Group 2 \\
\hline 4 & 5 \\
\hline 5 & 4 \\
\hline
\end{tabular}

Figure 9(b): Example of Alternative (Direct) Hypothesis Categorical Distribution

\# of Springs $>/=$ Overburden Thickness Median

\# of Springs < Overburden Thickness Median

\begin{tabular}{|c|c|}
\multicolumn{1}{c}{ Group 1 } & Group 2 \\
\hline 10 & 3 \\
\hline 2 & 9 \\
\hline
\end{tabular}

Figure 9(c): Example of Alternative (Inverse) Hypothesis Categorical Distribution

\# of Springs $>/=$ Overburden Thickness Median

\# of Springs < Overburden Thickness Median

\begin{tabular}{|c|c|} 
Group 1 & Group 2 \\
\hline 1 & 7 \\
\hline 0 & 2 \\
\hline
\end{tabular}

Figure 9: Conceptual Example of the Three Possible Hypotheses Related to the 2x2 Contingency Table Tests Using Overburden Thickness as the Independent Variable.

\subsubsection{Chi Square Contingency Test}

The hypothesis under test was conducted using the Chi square $2 \times 2$ contingency table, as previously discussed (Siegel, 1956). The testing hypothesis, or alternative hypothesis, was that the two dependent spring groups defined by spring discharge differed with respect to some independent variable, such as overburden thickness, and therefore with respect to the spring frequency associated with each contingency table category. For example, overburden thickness for springs whose discharge was impaired by mininginduced subsidence was less than the overburden thickness for springs whose discharge was not affected by mining-induced subsidence. The null hypothesis was that the two independent groups did not differ with respect to some variable, such as overburden thickness, and therefore with respect to the frequency associated with each table category. For example, overburden thickness for springs whose discharge was impaired by mining- 
induced subsidence was equal to the overburden thickness for springs whose discharge was not affected by mining-induced subsidence.

The Chi square value, $\mathrm{X}^{2}$, was determined from a published Chi square distribution table under one degree of freedom. The Chi square value was calculated using Equation 1 (Siegel, 1956). The higher the $X^{2}$ value, the more likely a significant data trend exists. An alternative hypothesis was accepted if the probability of error (p) was less than the 0.20 alpha significance level. An alternative hypothesis was rejected if the calculated probability of error was greater than 0.20 alpha. Essentially, the computed probability of error relative to alpha 0.20 either caused acceptance or rejection of the null hypothesis (test of equal distribution). The 0.20 alpha was used because of the conservative nature of this statistical test.

$$
\begin{array}{ll}
\mathrm{X}^{2}(\mathrm{at} \mathrm{df}=1)= & \frac{\mathrm{N}(\mathrm{abs}[\mathrm{AD}-\mathrm{BC}]-\mathrm{N} / 2)^{2}}{(\mathrm{~A}+\mathrm{B})(\mathrm{C}+\mathrm{D})(\mathrm{A}+\mathrm{C})(\mathrm{B}+\mathrm{D})} \quad \text { Equation } 1
\end{array}
$$

\subsubsection{Fisher Exact Probability Contingency Test}

The Fisher exact probability test was used in conjunction with the Chi square contingency test. The Fisher exact probability test computes the probability of error for a data trend of the counted frequency distribution using the same Chi square $2 \times 2$ contingency table approach. The Fisher exact probability was calculated using Equation 2 (Siegel, 1956). Fisher exact probability tests involve Equation 2 computations for 
probability of error values for each data trend scenario, as extreme or more extreme than that identified in the $2 \times 2$ table. The cumulative final probability of error is the sum of all the data trend scenario probabilities.

$\mathrm{p}=\quad \frac{(\mathrm{A}+\mathrm{B}) !(\mathrm{C}+\mathrm{D}) !(\mathrm{A}+\mathrm{C}) !(\mathrm{B}+\mathrm{D}) !}{\mathrm{N} ! \mathrm{A} ! \mathrm{B} ! \mathrm{C} ! \mathrm{D} !} \quad$ Equation 2

An alternative hypothesis using the Fisher exact probability test was accepted if the calculated cumulative probability of error was less than 0.10 alpha. An alternative hypothesis was rejected (and the null hypothesis was accepted) if the probability of error was greater than 0.10 alpha. The Fisher exact probability test is more powerful than the Chi square contingency test; therefore, its alpha level of significance is less. This is evident in Equation 1, for Chi Square, where the 'N/2' term makes this test more conservative and weaker, to remove the bias of small numbers from the contingency table. This conservative factor is not used or needed for calculation of the Fisher exact probability.

\subsubsection{Guidelines Used for Apparent Data Trend Testing}

Chi square contingency and Fisher exact probability tests yield different probability of error values for apparent $2 \times 2$ data table trends. The Chi square probability test results in a range of probability of error values, and is a more conservative test. The Fisher exact probability test is statistically more powerful than the Chi square test and results in an exact calculated probability of error that can be compared more directly to alpha. Due to 
the ease of probability computation, Fisher exact probability tests were evaluated for all variable data trends that had a calculated $\mathrm{X}^{2}$ of 0.50 or greater. Also, Chi square probability tests are not reliable for sample populations $(A+B+C+D)$ less than 20 (Siegel, 1956), which was the case for most data trends examined within this study. Therefore, Fisher exact probability tests were conducted for all apparent data trends. 


\subsection{INVESTIGATION I}

\subsection{Methods of Investigation I}

The methodology used to evaluate the relationship of the known and predicted hydrologic, geologic, topographic, and mine-specific independent variables to mininginduced spring discharge impairment involved the following steps:

1. Prepare spring discharge hydrographs to evaluate for possible changes to spring discharge across a mined panel subsidence event through the seasonal comparison of pre-mine and post-mine spring discharge data.

2. Statistically examine the categorical distribution of spring response relative to the timing of mining-induced subsidence through the calculated median values of the hydrologic, geologic, topographic, and mine-specific independent variables to determine statistical association of these variables.

\subsubsection{Spring Discharge Hydrograph Interpretation}

Spring discharge hydrographs (discharge versus time data plots) were drafted to help determine if spring discharge changed due to a local mining-induced subsidence event. The discharge hydrographs were qualitatively examined through seasonal comparison (same season per-mining versus post-mining) across the subsidence event to determine apparent spring discharge response to the subsidence event. See Appendix A for these data plots. 
Three qualitative discharge response scenarios were used for this initial investigation; impaired, unaffected, and indeterminate (Table 1). Spring discharge responses were considered to be impaired due to mine subsidence if the spring did not flow after mining occurred. Spring discharge responses were considered unaffected if the discharge rates and frequency observed during post-mine monitoring mimicked the discharge rates and frequency observed during the pre-mine monitoring data collection period. Springs that had a partial reduction in discharge rate and/or frequency between pre-mine and postmine monitoring were considered to have an indeterminate response to the subsidence event that may have been caused by the subsidence or related to a naturally-occurring variable.

\subsection{Results from Investigation I}

\subsubsection{Spring Discharge Response}

A total of 77 spring discharge hydrographs were drafted to assess spring discharge response to mining-induced subsidence. A total of 29 springs, or $38 \%$ of the sample population, yielded indeterminate (equivocal) evidence as to whether the observed changes in spring discharge were due to naturally occurring circumstances or mininginduced change resultant from the effects of recent subsidence. Of the remaining springs, spring discharge response for $15(20 \%)$ was unaffected and for $25(32 \%)$ discharge was impaired. Eight springs, or 10\%, were omitted from the investigation due to lack of sufficient data needed for seasonal comparison across the subsidence event. 
Table 1: Results of Spring Discharge Hydrograph Interpretation as Discussed in Methods of Investigation I.

\begin{tabular}{|c|c|c|c|}
\hline Spring No. & Spring Discharge Response & Spring No. & Spring Discharge Response \\
\hline 32 & Unaffected & 41 & Impaired \\
\hline 33 & Unaffected & 63 & Impaired \\
\hline 52 & Unaffected & 64 & Impaired \\
\hline 78 & Unaffected & 83 & Impaired \\
\hline 79 & Unaffected & 84 & Impaired \\
\hline 99 & Unaffected & 90 & Impaired \\
\hline 102 & Unaffected & 94 & Impaired \\
\hline 118 & Unaffected & 101 & Impaired \\
\hline 183 & Unaffected & 155 & Impaired \\
\hline 253 & Unaffected & 157 & Impaired \\
\hline 266 & Unaffected & 162 & Impaired \\
\hline 268 & Unaffected & 165 & Impaired \\
\hline 269 & Unaffected & 166 & Impaired \\
\hline 271 & Unaffected & 167 & Impaired \\
\hline 297 & Unaffected & 173 & Impaired \\
\hline 38 & Indeterminate Impairment & 174 & Impaired \\
\hline 39 & Indeterminate Impairment & 199 & Impaired \\
\hline 43 & Indeterminate Impairment & 248 & Impaired \\
\hline 44 & Indeterminate Impairment & 249 & Impaired \\
\hline 91 & Indeterminate Impairment & 254 & Impaired \\
\hline 92 & Indeterminate Impairment & 259 & Impaired \\
\hline 93 & Indeterminate Impairment & 263 & Impaired \\
\hline 97 & Indeterminate Impairment & 272 & Impaired \\
\hline $99 a$ & Indeterminate Impairment & 54 & Omitted \\
\hline $102 a$ & Indeterminate Impairment & $79 a$ & Omitted \\
\hline 106 & Indeterminate Impairment & 154 & Omitted \\
\hline 107 & Indeterminate Impairment & 177 & Omitted \\
\hline 152 & Indeterminate Impairment & 224 & Omitted \\
\hline 169 & Indeterminate Impairment & 260 & Omitted \\
\hline 170 & Indeterminate Impairment & 261 & Omitted \\
\hline 171 & Indeterminate Impairment & 262 & Omitted \\
\hline 175 & Indeterminate Impairment & & \\
\hline 176 & Indeterminate Impairment & & \\
\hline 179 & Indeterminate Impairment & & \\
\hline 198 & Indeterminate Impairment & & \\
\hline 216 & Indeterminate Impairment & & \\
\hline 226 & Indeterminate Impairment & & \\
\hline 256 & Indeterminate Impairment & & \\
\hline 258 & Indeterminate Impairment & & \\
\hline 265 & Indeterminate Impairment & & \\
\hline 267 & Indeterminate Impairment & & \\
\hline 270 & Indeterminate Impairment & & \\
\hline 273 & Indeterminate Impairment & & \\
\hline 274 & Indeterminate Impairment & & \\
\hline 35 & Impaired & & \\
\hline 36 & Impaired & & \\
\hline
\end{tabular}


The following procedure was used to examine the 29 springs that had an indeterminate response to subsidence. The implementation of this procedure permitted the statistical examination of the entire sample population minus the springs omitted due to lack of data.

The median values of the hydrologic, geologic, topographic, and mine-specific independent variables for each of the spring discharge response categories - discharge impaired, unaffected, and indeterminate, were calculated. These median values were compared to determine if the indeterminate response category would be added to the discharge impaired or unaffected response categories. The rationale for this procedure assumes the hydrologic, geologic, topographic, and mine-specific independent variables are associated with spring discharge response.

The 29 springs that had an indeterminate response to subsidence were included in the statistical investigation based on the median values associated with the variables. The discharge impaired response category was supplemented with the 29 indeterminate response category springs if the median value calculated for the indeterminate response category was arithmetically closer to the median value calculated for the discharge impaired response category than the median value calculated for the unaffected response category, and vice versa. Essentially, the 29 springs comprising the indeterminate response category were supplemented to either the discharge impaired or unaffected response categories according to the calculated median values. 


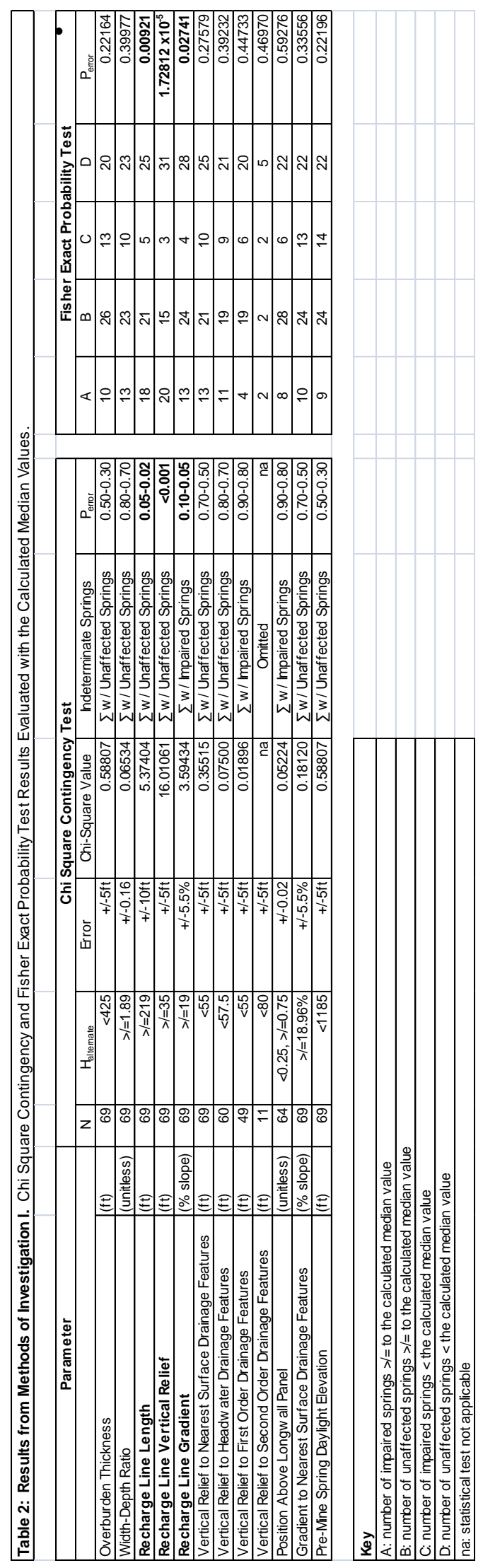


Spring discharge impairment is associated with recharge line relief greater than or equal to the calculated median value of 35 feet $(+/-5 \mathrm{ft})$.

- Spring discharge impairment is associated with recharge line gradient greater than or equal to the calculated median value of 19 percent $(+/-5.5$ percent).

The use of Chi square contingency tests resulted in calculated error probabilities of 0.05$0.02,<0.001$, and $0.10-0.05$, respectively for the above alternative hypotheses. The use of Fisher exact probability tests resulted in calculated error probabilities of 0.00921, $1.728 \times 10^{(-5)}$, and 0.02741 , respectively. The remaining alternative hypotheses examined for the variables were rejected by the Chi square contingency and Fisher exact probability tests.

Based upon the statistical results, the use of recharge line length, recharge line vertical relief, and recharge line gradient resulted in 99 percent, 99 percent, and 97 percent degree of confidence that a significant data trend exists, as determined from the complement of alpha, for these respective independent variables. 


\subsection{INVESTIGATION II}

\subsection{Methods of Investigation II}

The methodology used in Investigation I permitted an initial examination of spring discharge response to mining-induced subsidence through the evaluation of known and predicted variables; however, the methodology did not account for the degree of spring discharge impairment. The methodology used in Investigation II uses the same methodology as used in Investigation I to address this issue but redefines the spring response categories. Qualitative spring response categories were defined in order to discern among permanently impaired springs, temporarily impaired springs, background low flow discharge impaired springs, and unaffected springs through statistical examination of the variables.

Spring discharge responses were considered permanently impaired if the spring did not flow after mining occurred. Spring discharge responses were considered temporarily impaired if post-mine monitoring visitations initially consisted of no flow observations and spring discharge recovered, partially or totally, during the post-mine monitoring data collection period. Spring discharge responses were considered background low flow discharge impaired if observations indicated a partial reduction in low flow discharge across the subsidence event. Spring discharge responses were considered unaffected if the discharge rates and frequency observed during post-mine monitoring mimicked the discharge rates and frequency observed during the pre-mine monitoring data collection period. 
In addition, springs were evaluated according to mining environment. The following groups were evaluated to determine statistical significance of the variables.

- All springs

- Springs located directly above longwall panels

- Springs located directly above main and submain mine development sections

- Springs located directly above the off panel mining environment (over unmined coal)

- Springs located within the Subsidence Control Plan Area (SCPA) which is within the permit boundaries

\subsection{Results of Investigation II}

\subsubsection{Spring Discharge Response}

Of the 77 springs, data from 63 springs were used to assess the degree of spring discharge response to mining-induced subsidence (Table 3). Fourteen springs were omitted from the statistical examination; of these, six springs continued to yield indeterminate response to mining-induced subsidence and eight springs were omitted due to lack of data needed for seasonal comparison across the subsidence event.

Spring discharge response showed that 46 (73\%) of the 63 springs were impaired and 17 (27\%) of the springs were unaffected. Of the 46 impaired springs, 25 springs (54\%) were permanently impaired through the duration of the post-mine monitoring program which typically lasts 2 years, 17 springs (37\%) were temporarily impaired (for an average of 5.6 months, Table 3), and four springs (9\%) had reduction in background low flow discharge. 
Table 3: Results of Spring Discharge Hydrograph Interpretation as Discussed in Methods of Investigation II.

\begin{tabular}{|c|c|c|c|c|}
\hline Spring No. & Spring Discharge Response & Extent of Temporary Impairment & Spring No. & Spring Discharge Response \\
\hline & & (months) & & \\
\hline 35 & Permanently Impaired & & 32 & Unaffected \\
\hline 36 & Permanently Impaired & & 33 & Unaffected \\
\hline 41 & Permanently Impaired & & 52 & Unaffected \\
\hline 63 & Permanently Impaired & & 78 & Unaffected \\
\hline 64 & Permanently Impaired & & 79 & Unaffected \\
\hline 83 & Permanently Impaired & & 99 & Unaffected \\
\hline 84 & Permanently Impaired & & 102 & Unaffected \\
\hline 90 & Permanently Impaired & & 118 & Unaffected \\
\hline 94 & Permanently Impaired & & 170 & Unaffected \\
\hline 101 & Permanently Impaired & & 171 & Unaffected \\
\hline 155 & Permanently Impaired & & 183 & Unaffected \\
\hline 157 & Permanently Impaired & & 253 & Unaffected \\
\hline 162 & Permanently Impaired & & 266 & Unaffected \\
\hline 166 & Permanently Impaired & & 269 & Unaffected \\
\hline 167 & Permanently Impaired & & 297 & Unaffected \\
\hline 173 & Permanently Impaired & & 268 & Unaffected \\
\hline 174 & Permanently Impaired & & 271 & Unaffected \\
\hline 179 & Permanently Impaired & & 93 & Indeterminate Impairment \\
\hline 199 & Permanently Impaired & & $99 a$ & Indeterminate Impairment \\
\hline 248 & Permanently Impaired & & 107 & Indeterminate Impairment \\
\hline 249 & Permanently Impaired & & 198 & Indeterminate Impairment \\
\hline 254 & Permanently Impaired & & 216 & Indeterminate Impairment \\
\hline 259 & Permanently Impaired & & 273 & Indeterminate Impairment \\
\hline 263 & Permanently Impaired & & 54 & Omitted \\
\hline 272 & Permanently Impaired & & $79 a$ & Omitted \\
\hline 92 & Reduction in Low Flow Discharge & & 154 & Omitted \\
\hline 152 & Reduction in Low Flow Discharge & & 177 & Omitted \\
\hline 169 & Reduction in Low Flow Discharge & & 224 & Omitted \\
\hline 265 & Reduction in Low Flow Discharge & & 260 & Omitted \\
\hline 38 & Temporary Impaired & 10 & 261 & Omitted \\
\hline 39 & Temporary Impaired & 8 & 262 & Omitted \\
\hline 43 & Temporary Impaired & 4 & & \\
\hline 44 & Temporary Impaired & 9 & & \\
\hline 91 & Temporary Impaired & 3 & & \\
\hline 97 & Temporary Impaired & 5 & & \\
\hline 106 & Temporary Impaired & 1 & & \\
\hline 165 & Temporary Impaired & 2 & & \\
\hline 175 & Temporary Impaired & 4 & & \\
\hline 176 & Temporary Impaired & 3 & & \\
\hline 226 & Temporary Impaired & 9 & & \\
\hline 256 & Temporary Impaired & 11 & & \\
\hline 258 & Temporary Impaired & 6 & & \\
\hline 267 & Temporary Impaired & 6 & & \\
\hline 270 & Temporary Impaired & 4 & & \\
\hline 274 & Temporary Impaired & 9 & & \\
\hline $102 a$ & Temporary Impaired & 2 & & \\
\hline
\end{tabular}




\subsubsection{Spring Discharge Response Statistical Examination (Median Value)}

The results from the Chi square contingency and Fisher exact probability statistical examinations of spring discharge response data are provided in Tables 4 through 8 , according to mining environment. The variables were examined for statistically significant data trends through the use of the calculated median values and the contingency table approach (Figure 11).

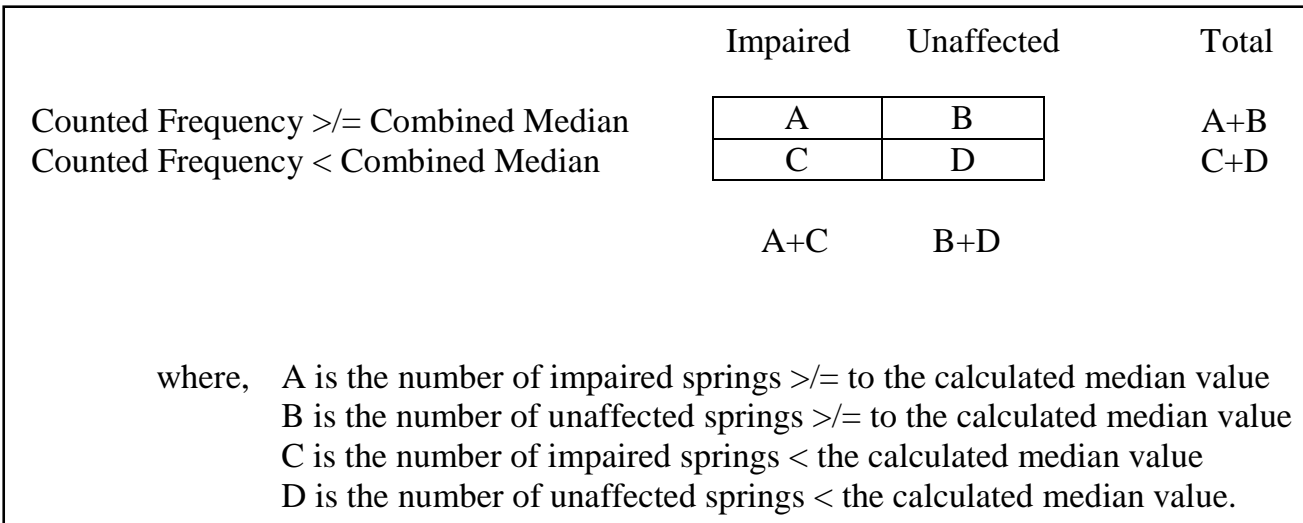

Figure 11: 2x2 Contingency Table Test Used for Investigation II.

\subsubsection{All Springs (see Table 4)}

Nonparametric statistical tests resulted in acceptance of the alternative hypothesis for recharge line length, recharge line vertical relief, and recharge line gradient for these springs. The significant alternative hypothesis statements are as follows:

- Spring discharge impairment is associated with recharge line length greater than or equal to the calculated median value of 219 feet $(+/-10 \mathrm{ft})$. 


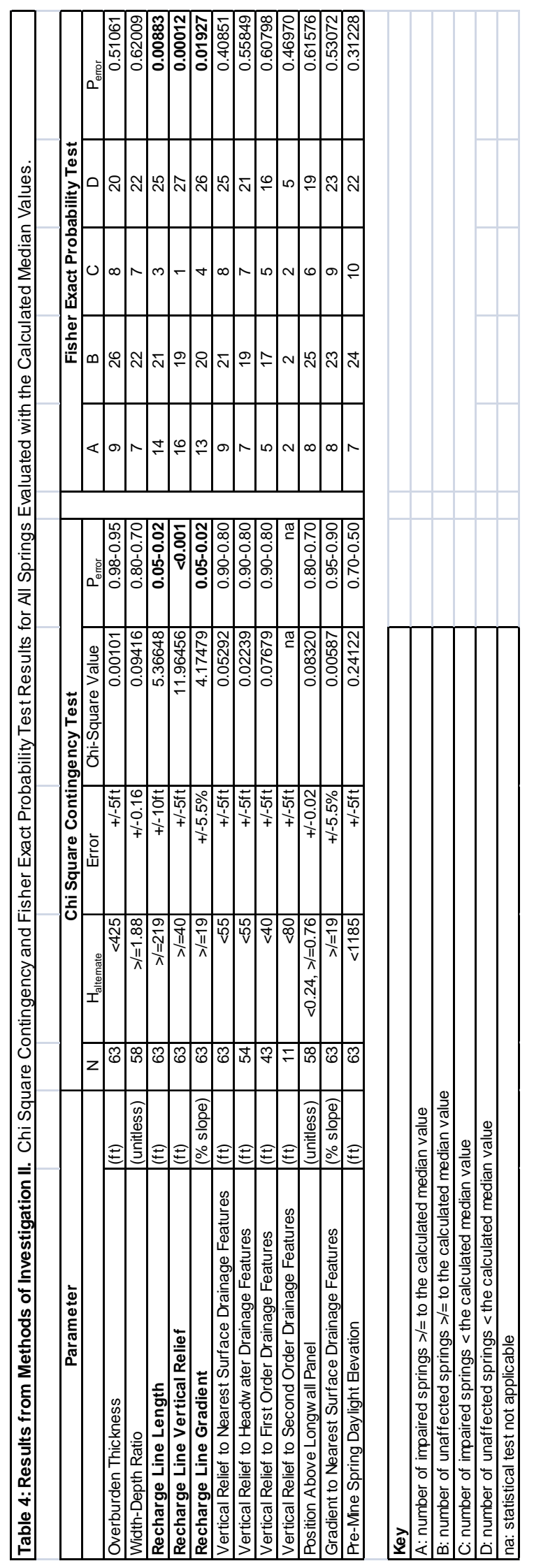


- Spring discharge impairment is associated with recharge line relief greater than or equal to the calculated median value of 40 feet $(+/-5 \mathrm{ft})$.

- Spring discharge impairment is associated with recharge line gradient greater than or equal to the calculated median value of 19 percent (+/- 5.5 percent).

The use of Chi square contingency tests resulted in calculated error probabilities of 0.05$0.02,<0.001$, and $0.05-0.02$, respectively, for the above data trends. The use of Fisher exact probability tests resulted in calculated error probabilities of $0.00883,0.00011$, and 0.01926, respectively. The remaining alternative hypotheses examined for the variables were rejected by the Chi square contingency and Fisher exact probability tests.

Based upon the statistical results, the use of recharge line length, relief, and gradient resulted in 99 percent, 99 percent, and 98 percent degree of confidence that a significant data trend exists, as determined from the complement of alpha, for these respective independent variables.

\subsubsection{Springs Located Above Longwall Panels (see Table 5)}

Nonparametric statistical tests resulted in acceptance of the alternative hypothesis for recharge line vertical relief and recharge line gradient for these springs. The significant alternative hypothesis statements are as follows:

- Spring discharge impairment is associated with recharge line relief greater than or equal to the calculated median value of 40 feet $(+/-5 \mathrm{ft})$. 


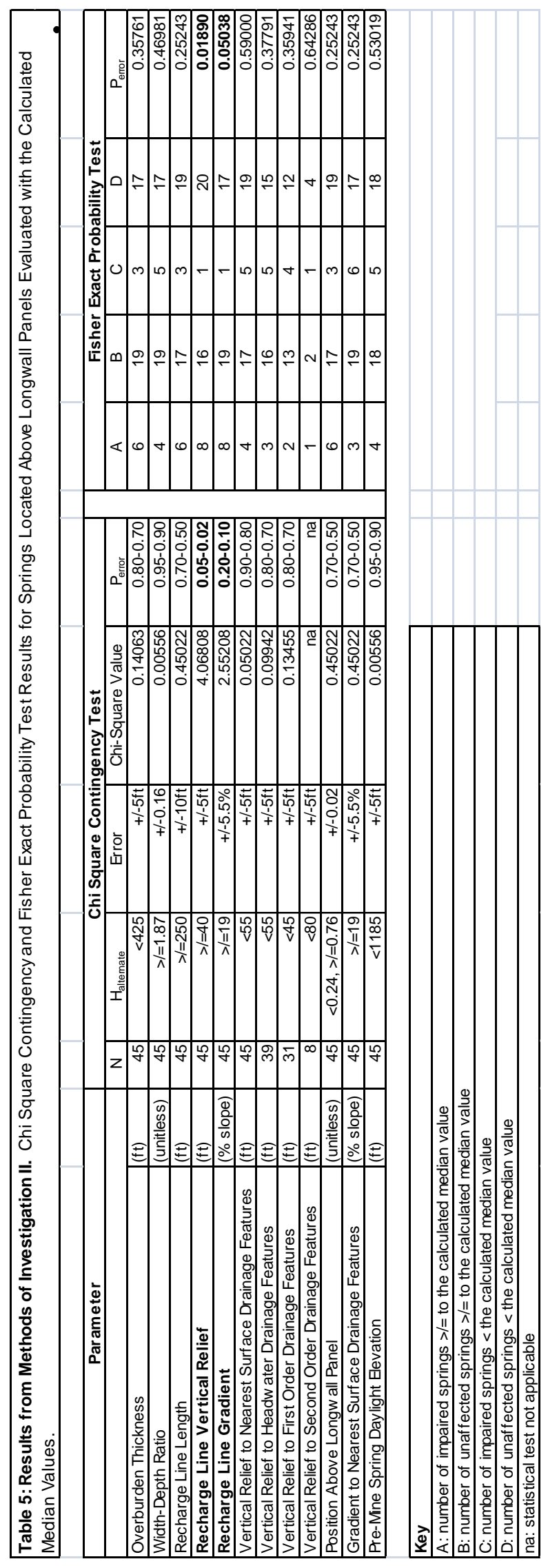


Spring discharge impairment is associated with recharge line gradient greater than or equal to the calculated median value of 19 percent $(+/-5.5$ percent $)$.

The use of Chi square contingency tests resulted in calculated error probabilities of 0.050.02 and $0.20-0.10$, respectively, for the above data trends. The use of Fisher exact probability tests resulted in calculated error probabilities of 0.01890 and 0.05038 , respectively. The remaining alternative hypotheses examined for the variables were rejected by the Chi square contingency and Fisher exact probability tests. Based upon the statistical results, the use of recharge line relief and gradient resulted in 98 percent and 95 percent degree of confidence that a significant data trend exists, as determined from the complement of alpha, for these respective independent variables.

\subsubsection{Springs Located Above Main and Submain Development (see Table 6)}

Nonparametric statistical tests resulted in rejection of all the alternative hypotheses for these springs, therefore, there are no statistically significant relationships between spring impairment and the independent variables for springs located above main and submain development environments.

\subsubsection{Springs Located Within Off Panel Mining Environments (see Table 7)}

Nonparametric statistical tests resulted in acceptance of the alternative hypothesis for recharge line vertical relief for these springs. This significant alternative hypothesis statement is as follows: 


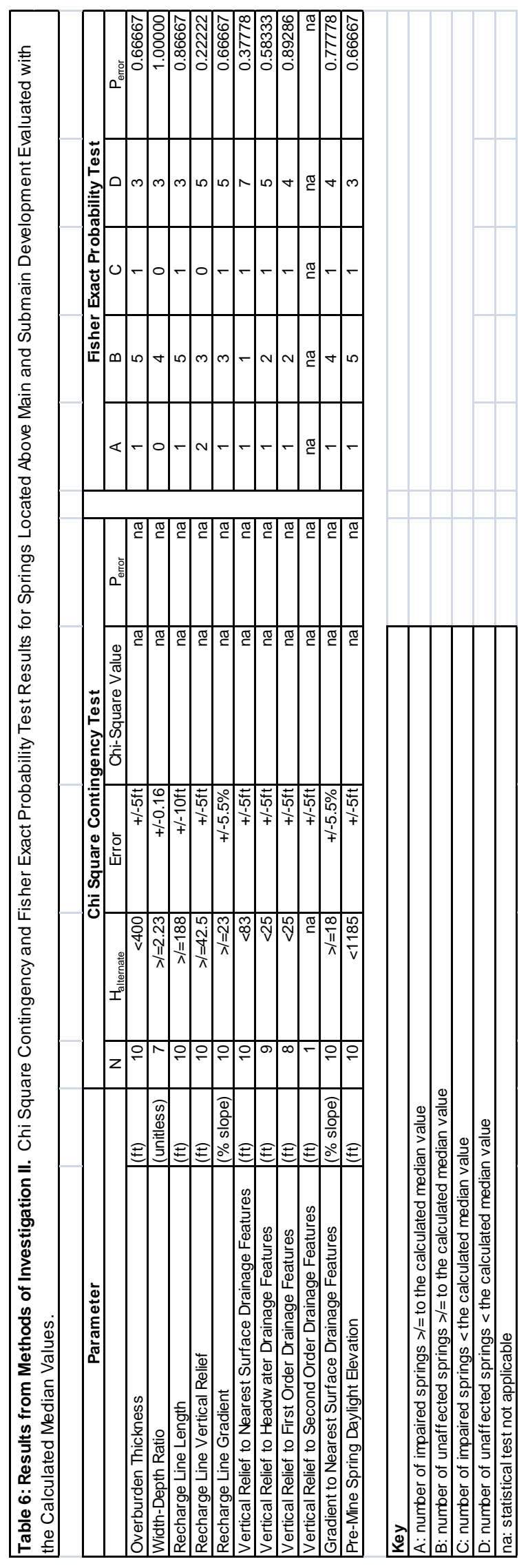




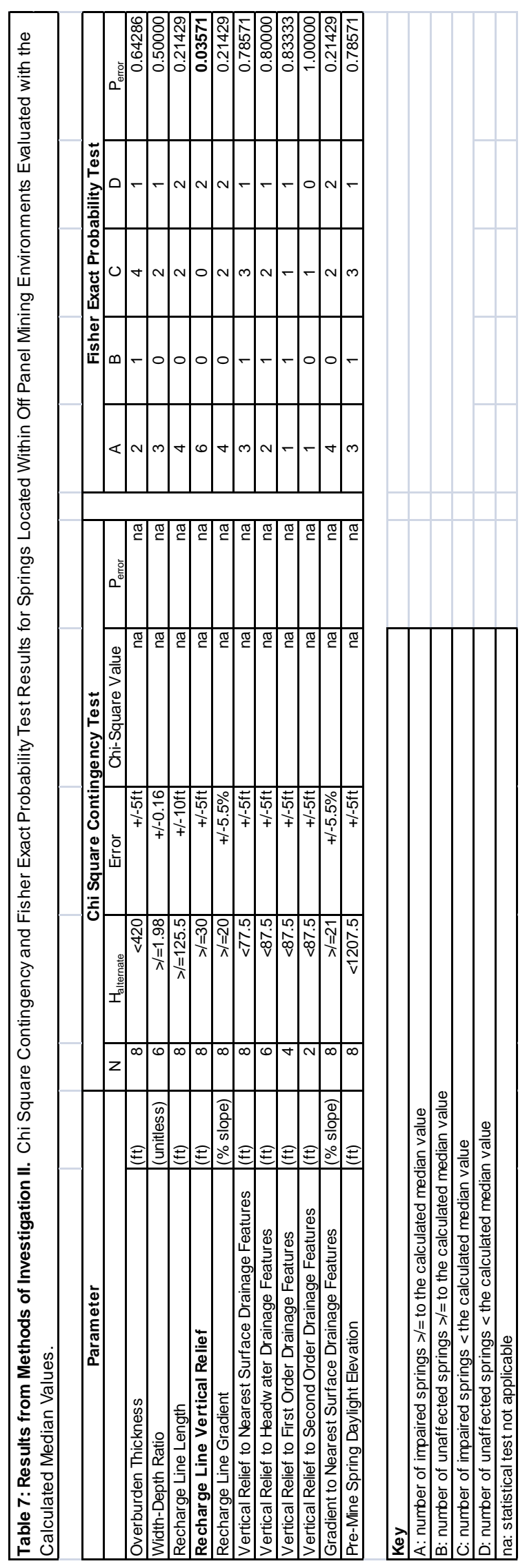


- Spring discharge impairment is associated with recharge line relief greater than or equal to the calculated median value of 30 feet $(+/-5 \mathrm{ft})$.

The use of the Fisher exact probability test resulted in a calculated error probability of 0.03571. The remaining alternative hypotheses examined for other variables were rejected by the Fisher exact probability tests.

Based upon the statistical results, the use of recharge line relief resulted in a 96 percent degree of confidence that a significant data trend exists, as determined from the complement of alpha, for this independent variable.

\subsubsection{Springs Located Within the SCPA Boundary (see Table 8)}

Nonparametric statistical tests resulted in acceptance of the alternative hypothesis for recharge line length, recharge line vertical relief, and recharge line gradient. The significant alternative hypothesis statements are as follows:

- Spring discharge impairment is associated with recharge line length greater than or equal to calculated median value of 219 feet $(+/-10 \mathrm{ft})$.

- Spring discharge impairment is associated with recharge line relief greater than or equal to the calculated median value of 40 feet $(+/-5 \mathrm{ft})$.

- Spring discharge impairment is associated with recharge line gradient greater than or equal to the calculated median value of 19 percent (+/- 5.5 percent).

The use of Chi square contingency tests resulted in calculated error probabilities of 0.20$0.10,0.02-0.01$, and 0.10.-0.05, respectively, for the above data trends. The use of Fisher 


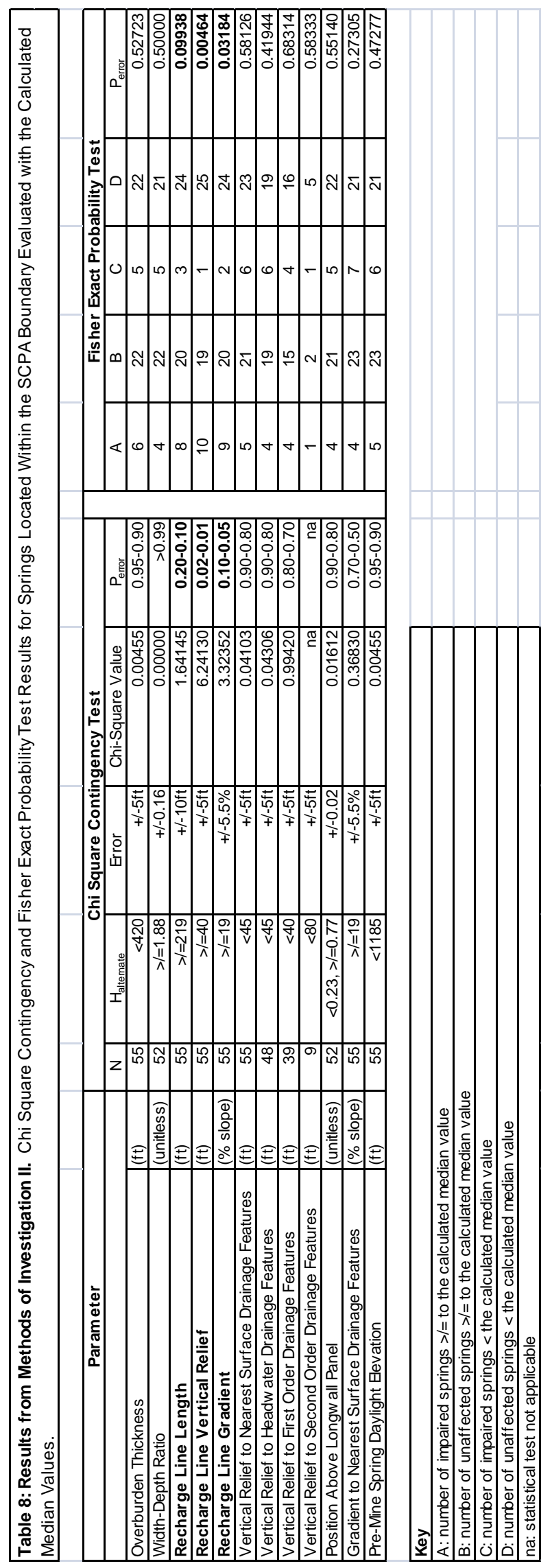


exact probability tests resulted in calculated error probabilities of $0.09938,0.00464$, and 0.03184 , respectively. The remaining alternative hypotheses examined for all other variables were rejected by the Chi square contingency and Fisher exact probability tests.

Based upon the statistical results, the use of recharge line length, relief, and gradient resulted in 90 percent, 99 percent, and 97 percent degree of confidence that a significant data trend exists, as determined from the complement of alpha, for these respective independent variables. 


\subsection{INVESTIGATION III}

\subsection{Methods of Investigation III}

The methodology of Investigations I and II permitted the initial evaluation of spring discharge response to mining-induced subsidence events through the use of median values calculated for hydrologic, geologic, topographic, and mine-specific independent variables but did not account for natural variations in evapotranspiration seasonal conditions and precipitation. The methodology used for Investigation III examined these natural seasonal conditions and applied techniques to control for their respective influence on spring discharge. In addition, the methodology for Investigation III removed the subjectivity inherent to interpretation of spring discharge hydrographs. Spring discharge responses were derived from the existing spring discharge data.

\subsubsection{Quantitative Evaluation of Spring Discharge Data}

Previous investigations, I and II, used qualitative (categorical) analysis to determine spring discharge data trends. Discharge, Q, graphs were drafted for Investigation III to determine if spring discharge data trends were apparent between the pre-mining discharge data and post-mining discharge data. These $\mathrm{Q}$ plots were to be used to determine if quantitative evaluation of the spring discharge data was feasible.

\subsubsection{Natural Variation Analysis}

The purpose of the natural variation analysis was to allow for greater discrimination of the spring discharge data as these data were compared across (before versus after) a 
subsidence event. The objective was to decipher between naturally occurring changes in spring discharge from mining-induced changes to spring discharge, which was predominantly manifested in the indeterminate spring discharge response category of Investigations I and II. The natural variation in evapotranspiration seasonal condition and precipitation were examined to determine the techniques that could be implemented to control for their respective influence on spring discharge.

\subsubsection{Evapotranspiration Condition}

Control of evapotranspiration condition was accomplished through the comparison of pre-mine spring discharge data collected during similar evapotranspiration seasonal conditions within two pre-mining consecutive years; for example, fall of 1998 and fall of 1999. In addition, the evaluation periods would be comprised of identical months for

which the data were collected; for example, September through November of 1998 could be compared to September through November of 1999. Utilization of this technique assumed that the evapotranspiration conditions would be addressed, and thus satisfies the objective for the natural variation analysis.

\subsubsection{Precipitation}

Precipitation cannot be assumed to be consistent within two consecutive seasonal evaluation periods like evapotranspiration can. Precipitation can be controlled through a normalization technique; however, this technique is dependent upon determining the period of antecedent precipitation to be used; in other words, which precipitation data in 
the precipitation record should be used for the normalization technique. Normalization of the spring discharge data means that the spring discharge data were to be divided by antecedent precipitation over some time period. Essentially, the question involved the need to determine the quantification of time between the precipitation (storm) recharge event and the time when that recharge arrived at the spring discharge location.

An attempt at determining the elapsed time between ground water recharge and spring discharge for storm events was conducted for several springs. The antecedent precipitation data prior to times of spring discharge measurements were investigated in numerous configurations - single day (singular) data, consecutive day (cumulative) data, singular data and cumulative data collected at one week, two, weeks, three weeks, one month, two months, et cetera antecedently. However, conclusions could not be drawn from the evaluation for the following reason.

The technique used for determining the elapsed time between storm event recharge and spring discharge was similar to a type curve fitting technique; however, the monitoring frequencies associated with spring discharge data collection and precipitation data collection were different; spring discharge data were collected once per month and precipitation data were collected daily. Alignment of the type curves could not be accomplished due to the unknown temporal positioning associated with the spring discharge data; i.e., is the spring discharge measurement representative of the upward- 
rising limb of a hydrograph or the falling limb of a hydrograph, if a detailed hydrograph were available.

Due to the unsuccessful attempt at determining the length and antecedent extent of the evaluation period, monthly precipitation data (Table 9) recorded during the months when spring discharge was measured were used to account for the precipitation effects of the spring discharge data. This partially controlled for the impact of precipitation on spring discharge in an attempt to satisfy the objective associated with the natural variation analysis.

The use of the precipitation data would be more indicative of seasonal fluctuations in precipitation and related less to recharge for a spring. Knowledge of the departure from normal precipitation, or deviation from the 30 year average, would focus upon the degree of fluctuation within the precipitation record; i.e., surmise if the evaluation period is within a precipitation deficit or surplus. Spring discharge is assumed to be lower during times of precipitation deficit, or low precipitation event activity, and higher during times of precipitation surplus, or high precipitation event activity.

\subsubsection{Reduction Boundary Conditions}

As stated previously, the purpose of the natural variation analysis was to allow for greater discrimination of the spring discharge data as the data were compared across a 


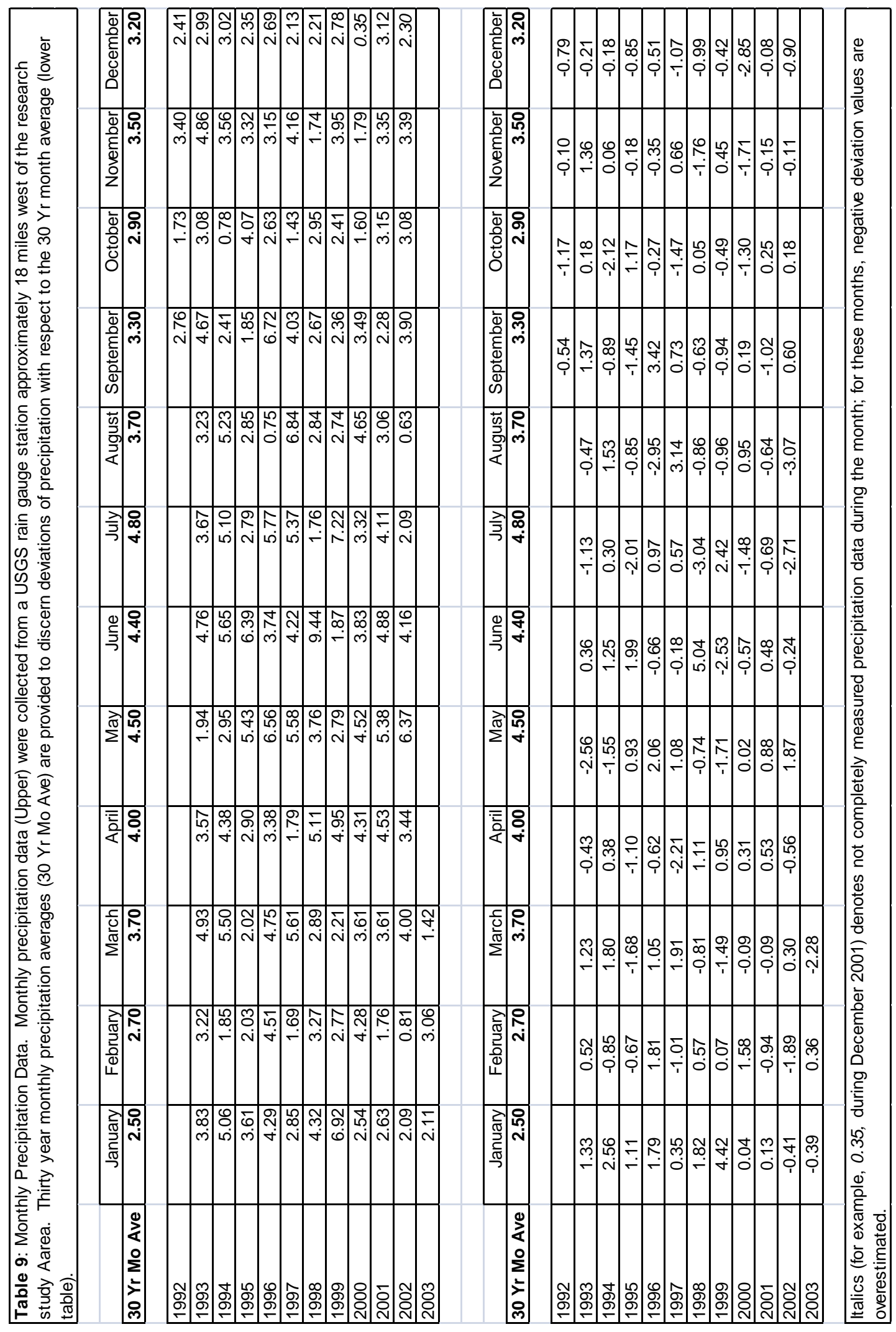


subsidence event (before vs. after mining). Appropriate boundary conditions, or acceptable tolerance values derived from naturally occurring changes in spring discharge, were used to separate naturally occurring changes in spring discharge from mininginduced changes to spring discharge. The boundary conditions were derived from the evaluation of several spring discharge scenarios.

The data used for the spring discharge scenarios were not distorted but rather applied in different ways. The scenarios differ in context for use of the spring discharge data (averaged spring discharge data or precipitation normalized averaged spring discharge data) with regard to seasonal evapotranspiration condition (low or high).

The spring discharge data were evaluated through two techniques - averaged and precipitation normalized averaged. The averaging technique was used to average the spring discharge data during the evaluation period; for example, spring discharge measured during the months of May, June, and July was averaged. The averaged spring discharge data were further discriminated through normalization of the pre-mine averaged spring discharge data and post-mine averaged spring discharge data with precipitation data collected during the same evaluation periods; for example, spring discharge measured during the months of May, June, and July was averaged and divided by the averaged precipitation recorded during the months of May, June, and July. The averaged spring discharge data and the normalized averaged spring discharge data would be evaluated during similar seasonal evapotranspiration conditions. Two separate 
investigations were later examined - spring discharge impairment and degree of spring discharge impairment.

Two types of spring discharge reduction boundary conditions were evaluated - optimum and absolute. The spring discharge reduction boundary conditions were determined through the use of nonparametric statistical tests and optimum partition testing. The optimum partition (or optimum spring discharge reduction boundary) would be the spring discharge reduction boundary that had the lowest calculated probability of error and spring misclassification percentage during contingency table data testing. Essentially, the optimum spring discharge reduction boundary is assumed to be close to the true reduction boundary if more data existed. The absolute spring discharge reduction boundaries were identified at the partition where zero control springs were misclassified, or at the partition with the maximum spring discharge natural reduction. The optimum and absolute spring discharge reduction boundaries were statistically derived during both low and high evapotranspiration seasonal conditions to permit examination of the hydrologic, geologic, topographic, and mine-specific independent variables during low and high evapotranspiration seasonal conditions.

The following three steps outline the statistical procedure to discern between naturally occurring changes in spring discharge and mining-induced changes to spring discharge.

1. Determine the boundary conditions associated with naturally occurring changes in spring discharge through the statistical examination of the 
control (pre-mine) group against the spring discharge data collected after subsidence events, during low and high evapotranspiration seasonal conditions separately.

2. Determine if an apparent mining-induced change to spring discharge occurred across a subsidence event through the evaluation of the pre-mine and post-mine averaged spring discharge and precipitation normalized averaged spring discharge data and if so, quantify the magnitude of the change to spring discharge during low and high evapotranspiration seasonal conditions, separately.

3. Compare the magnitude of the apparent mining-induced change to spring discharge to the calculated boundary conditions during low and high evapotranspiration seasonal conditions, separately, to determine if the change in spring discharge was due to naturally occurring changes or mining-induced changes.

Due to the subjectivity inherent to the natural variation analysis, the following procedural data conditions were used.

- Averaged spring discharge data contained a minimum of 2 months of data and maximum of 4 months of data.

- Data within one month of a subsidence event were omitted from calculating the averaged spring discharge.

- Obvious anomalies, or abnormal, single-event peaks or troughs, in the data record were omitted by the author from calculating the averaged spring discharge.

- Thirty-year average monthly precipitation values were used for months without precipitation data or unrecorded precipitation data. 


\section{$\underline{\text { 8.1.4 Quantitative Evaluation of Additional Dependent Variables }}$}

In addition to the hydrologic, geologic, topographic, and mine-specific independent variables listed in 4.2 Measured Data, the following independent variables were added to Investigation III. The measured data for these additional variables are located in Appendix C.

\subsubsection{Recharge Line}

The length component of the recharge line perpendicular to the longwall panel face was arithmetically calculated (Figure 12). The error associated with this variable was assumed to be $+/-10 \mathrm{ft}$.

The recharge line, as described in 4.2 Measured Data, was further examined to determine if a subsidence event beginning at the origin (uphill end) of the recharge line and terminating at the spring daylight position was statistically different than if the subsidence event began at the spring daylight position and terminated at the origin of the recharge line. In addition, the percentage of the recharge line subsided was calculated.

Pre-mining origin (uphill) elevation data of the recharge lines were extracted from USGS 7’30" Quadrangle maps. The error associated with the pre-mining origin elevation of the recharge line was assumed to be $+/-5 \mathrm{ft}$. 


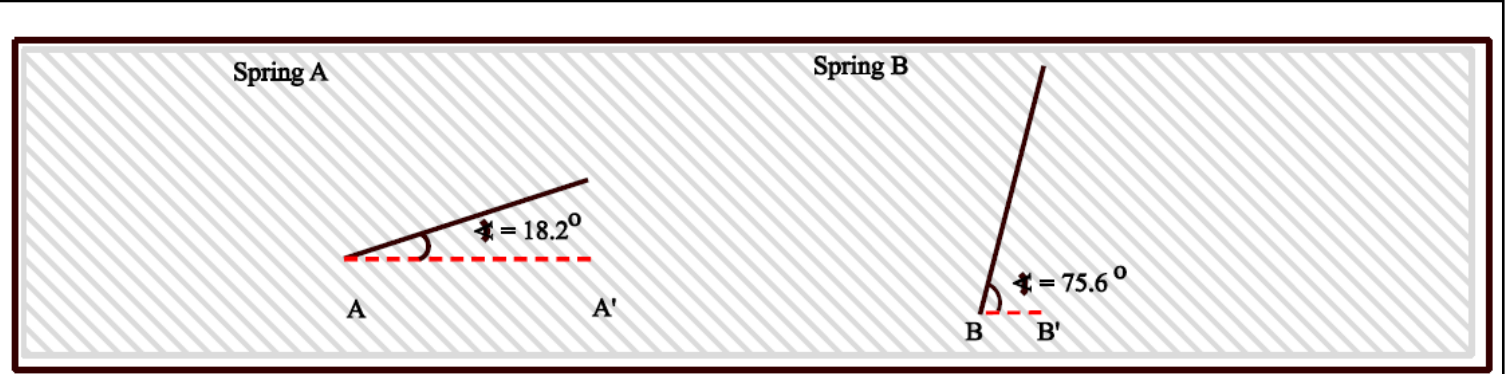

Calculation Used to Determine the Recharge Line Length Component (RLLC) Perpendicular to Longwall Panel Face.

RLLC identified as A-A' \& B-B' on the figure above.

Recharge lines lengths (RLL) for Spring A and $B$ are both 800 feet.

Formula: RLLC $=\cos (\$) \times R L$

A-A' $=760$ feet

$\mathrm{B}^{\mathrm{A}} \mathrm{B}^{\prime}=199$ feet

Figure 12. Schematic Depiction of the Recharge Line Length Component Perpendicular to Longwall Panel Face for Springs Overlying Longwall Panels. Recharge lines at acute angles to the longwall panel face have less length perpendicular to the longwall panel face. 


\subsubsection{Spring Proximity to Nearest Surface Drainage Feature}

A spring's pre-mining lateral distance to the nearest surface drainage feature had been previously measured to calculate the gradient (percent slope) from a spring to the nearest surface drainage feature; however, the lateral distance a spring was from the nearest surface drainage feature was not statistically examined for Investigations I and II. The error associated with a spring's lateral distance to the nearest stream was assumed to be $+/-10 \mathrm{ft}$.

\subsubsection{Pre-Mining Average Low Flow Spring Discharge}

The pre-mining average low flow spring discharge was calculated to determine if the mining-induced response from springs with higher low flow average discharges were statistically different than springs with lower low flow average discharges.

\subsection{Results of Investigation III}

\subsubsection{Quantitative Evaluation of Spring Discharge Data}

Discharge, Q, plots were graphed for Investigation III to determine if spring discharge data trends were apparent between the pre-mining discharge data and post-mining discharge data.

The Q plots created for pre-mining to post-mining spring discharge comparisons during low (Figure 13) and high (Figure 14) evapotranspiration seasonal conditions resulted in a distinction between three spring discharge response categories - unaffected spring 


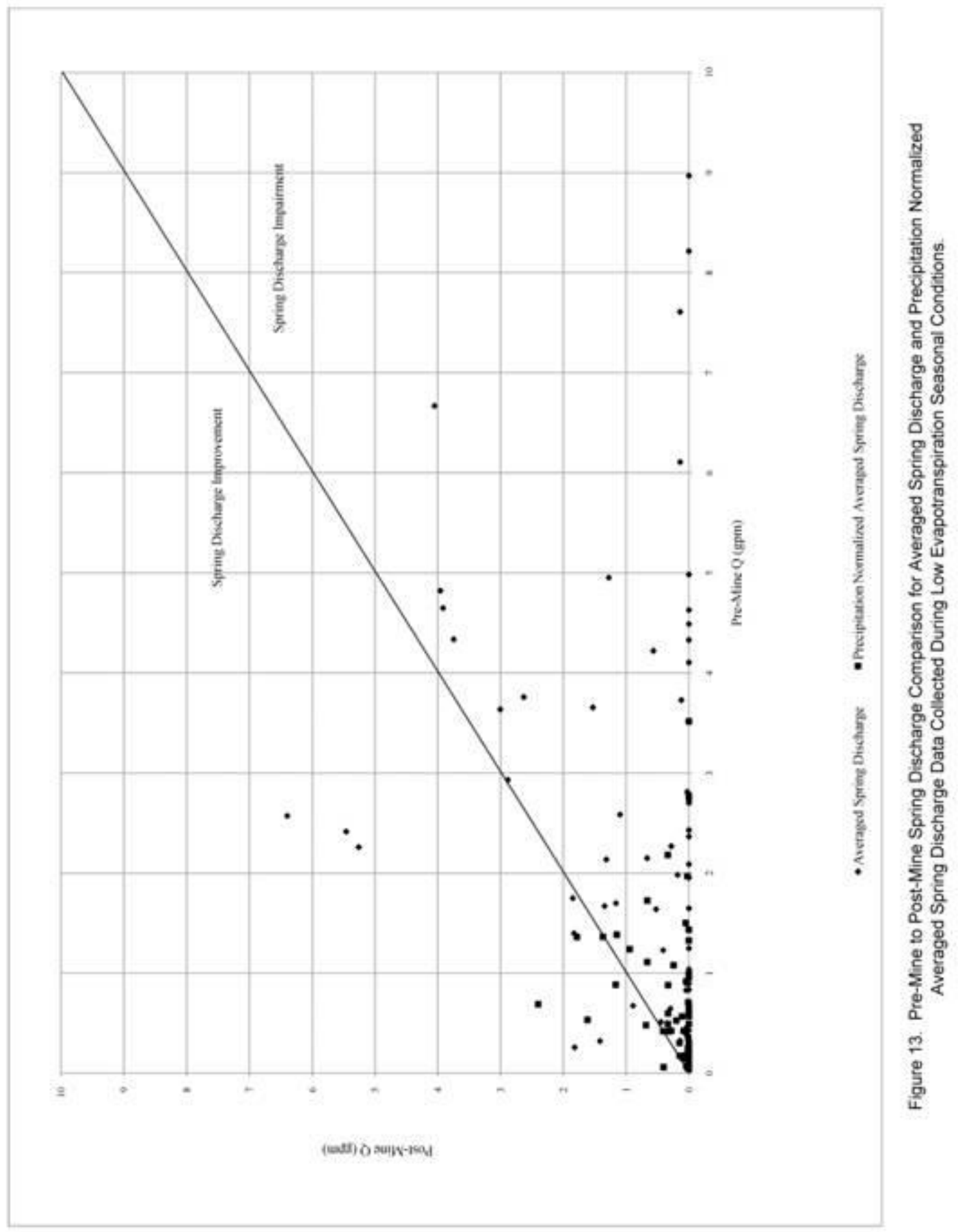




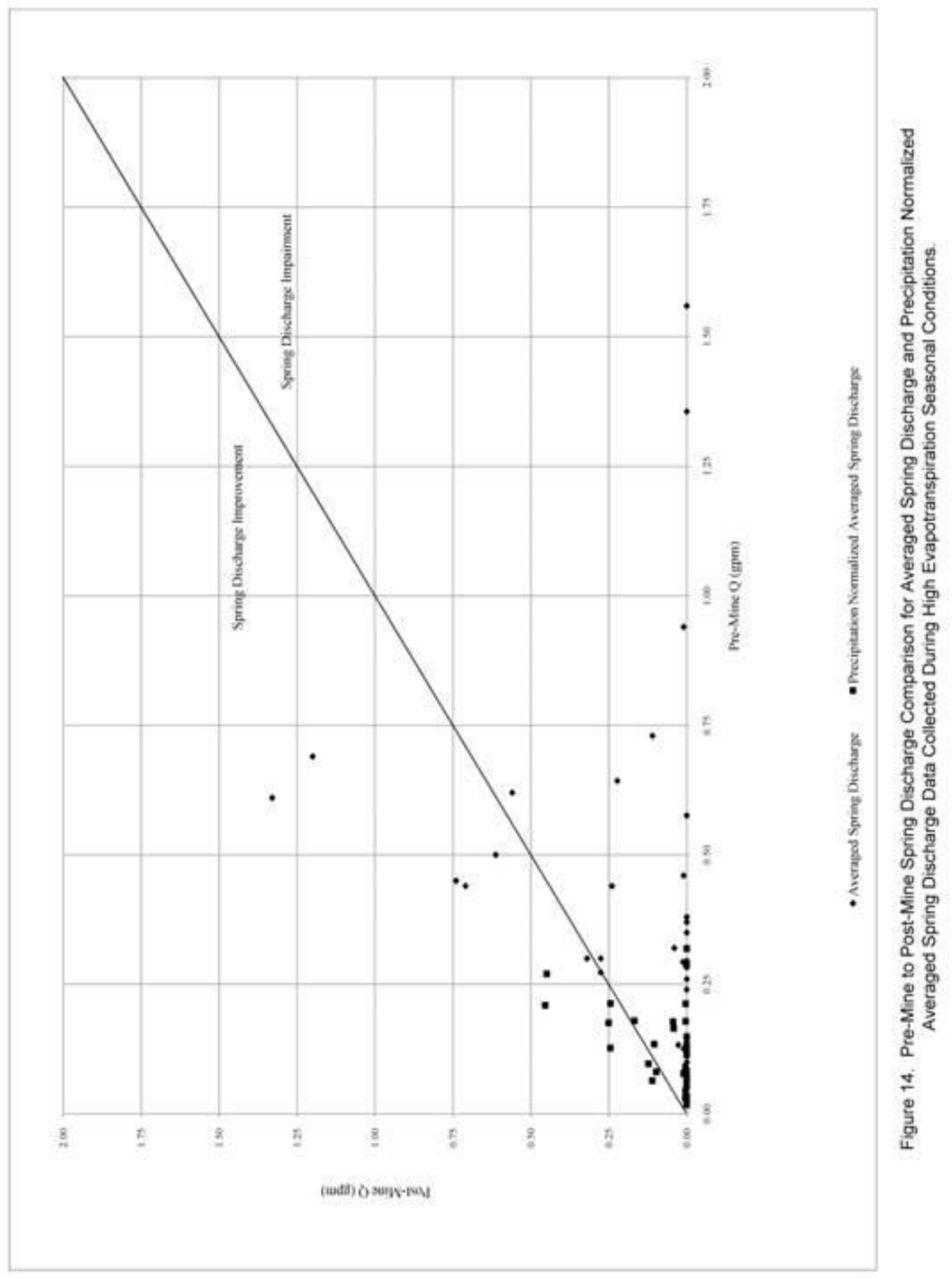


discharge, spring discharge improvement and spring discharge impairment. The springs that plotted on the 45 degree line, which differentiates spring discharge improvement from spring discharge impairment, were considered unaffected from the effects of mining-induced subsidence. Springs with comparatively higher post-mine Q values than pre-mine $\mathrm{Q}$ values were considered to have an improvement to spring discharge from the effects of mining-induced subsidence. Springs with comparatively lower post-mine Q values than pre-mine $Q$ values were considered to have an impairment to spring discharge from the effects of mining-induced subsidence.

The Q plots differentiated the degree of spring discharge impairment. This discrimination warranted evaluation of the spring discharge data to determine if the degree of spring discharge impairment was related to (show trends with) the independent variables.

The variability associated with the spring discharge data supports the differentiation of data according to evapotranspiration seasonal conditions. The averaged spring discharge data collected during low evapotranspiration seasonal conditions (Figure 13) were more variable than the averaged spring discharge data collected during high evapotranspiration seasonal conditions (Figure 14) - maximum Q collected during low and high evapotranspiration seasonal conditions were $8.97 \mathrm{gpm}$ and $1.56 \mathrm{gpm}$, respectively. 
Spring discharge data trends (spring discharge response categories, degree of spring discharge impairment, and evapotranspiration seasonal conditions) were apparent within the Q plots. Quantitative evaluation of the pre-mine and post-mine spring discharge data was acceptable.

\subsubsection{Natural Variation Analysis}

A total of 13 springs within the research study area were used to determine natural variation in spring discharge. These 13 springs were chosen for natural variation analysis because the data collection period for these springs exceeded 12 months, therefore, evaluation of naturally-occurring changes to spring discharge during two consecutive, pre-mine years was possible. Pre-mine data for the remaining 64 springs was not adequate enough to include in the natural variation analysis. The pre-mining spring discharge data used for these 13 springs resulted in 12 springs with discharge measured during low evapotranspiration conditions (November through May) and nine springs with discharge measured during high evapotranspiration conditions (May through November).

The use of the averaged spring discharge data resulted in naturally occurring (unmined) reduction in spring discharge as high as $88 \%$ during low evapotranspiration conditions, and as high as $72 \%$ during high evapotranspiration conditions (Table 10). Use of the precipitation normalized averaged spring discharge data resulted in naturally occurring reduction in spring discharge as high as $86 \%$ during low evapotranspiration conditions, and as high as 69\% during high evapotranspiration conditions (Table 11). 


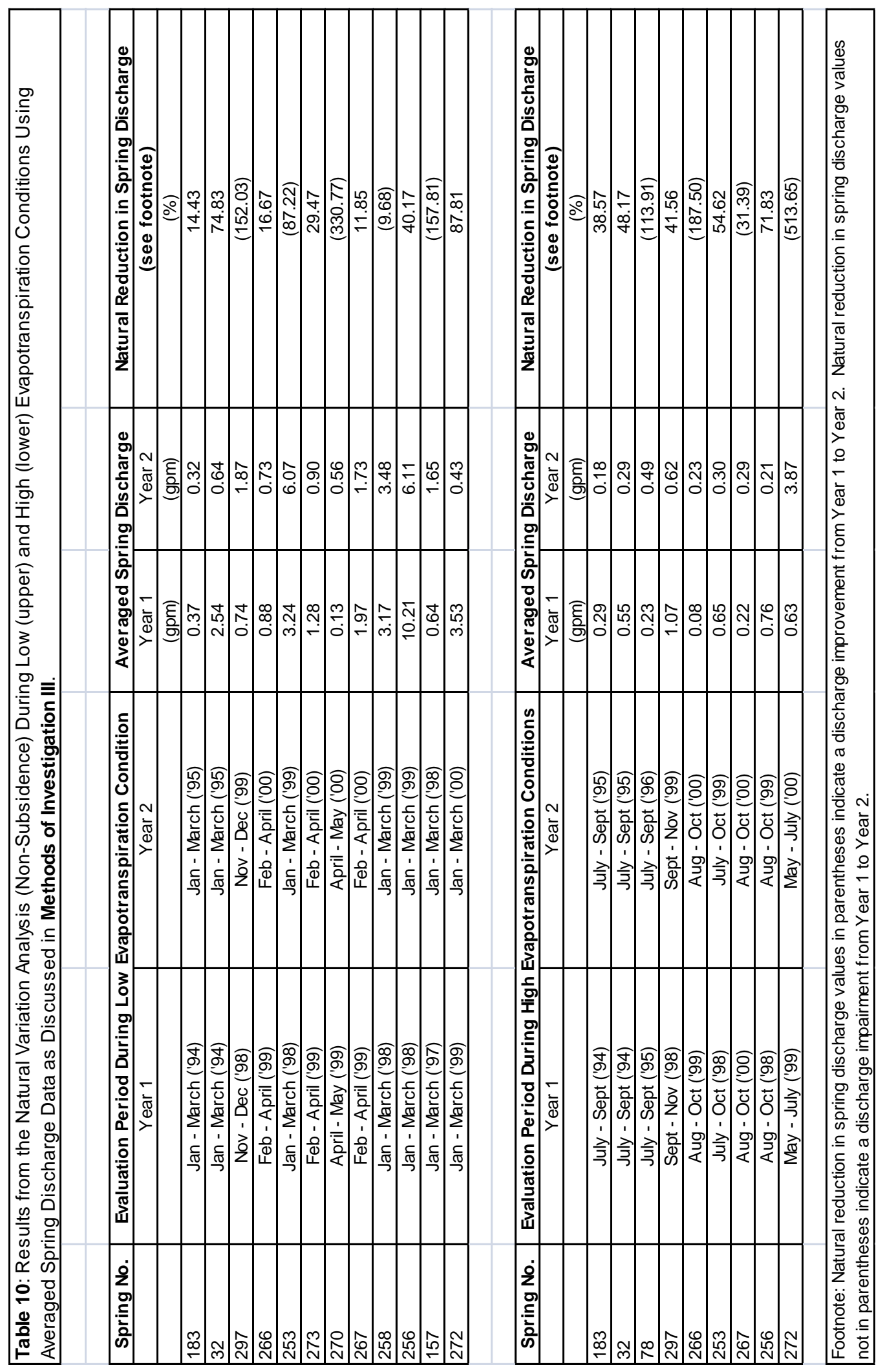




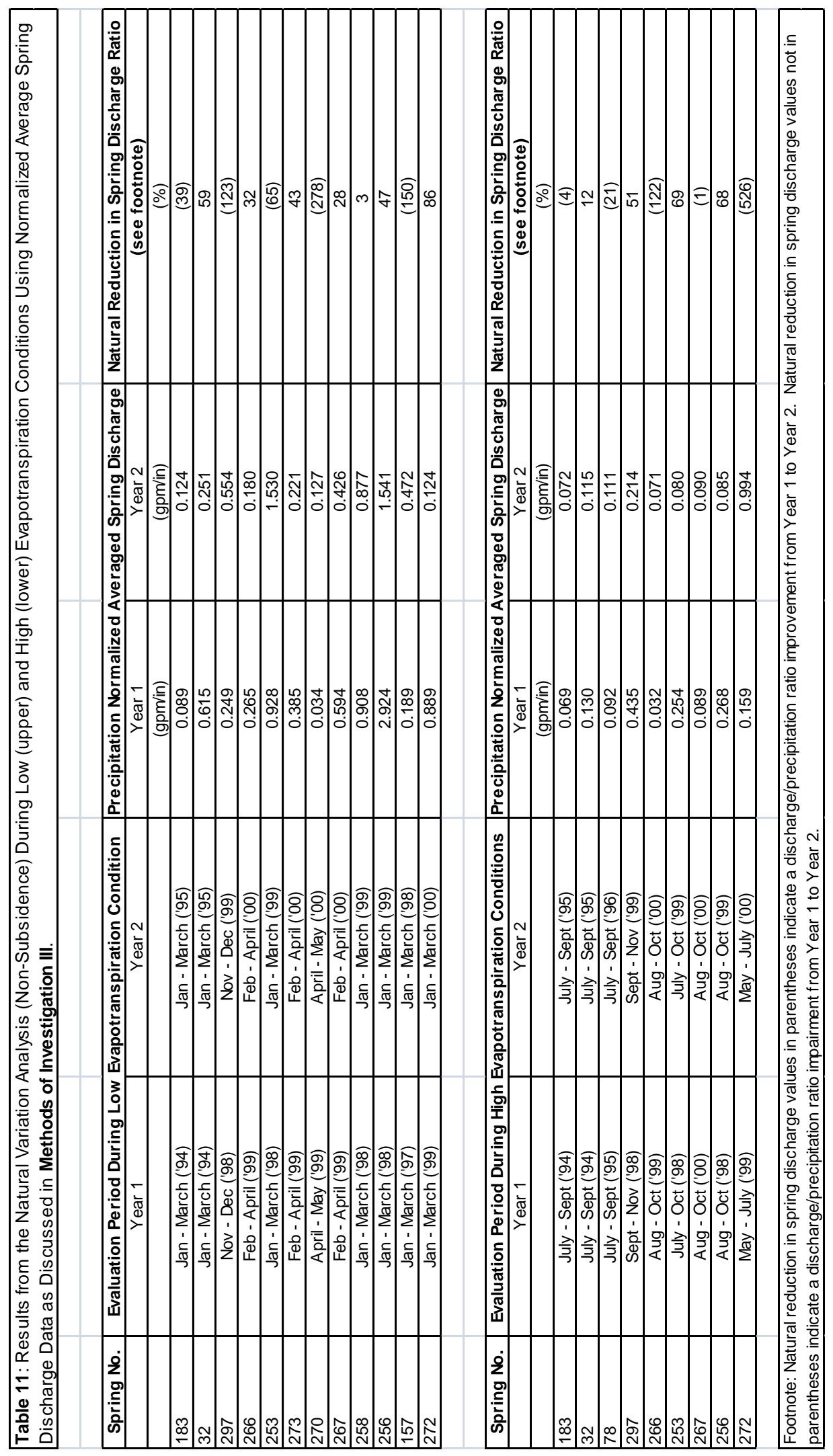




\subsubsection{Reduction Boundary Conditions}

Two general questions were investigated. First, which use of the spring discharge data was more statistically significant and should be used for the remaining statistical examination of hydrologic, geologic, topographic, and mine-specific independent variable data trends during low and high evapotranspiration conditions? Secondly, what are the optimum and absolute values of spring discharge reduction boundaries during low and high evapotranspiration seasonal conditions?

Four spring discharge scenarios were examined through the use of the optimum partition testing technique. The spring discharge scenarios (Table 12) were different combinations of the use of the spring discharge data and seasonal evapotranspiration conditions.

Different partitions (10\% reduction increments) were used to determine the optimum and absolute values of the spring discharge reduction boundaries through the utilization of the contingency table approach (Figure 15).

The optimum spring discharge reduction boundary was determined through the evaluation of each partition that contained at least one spring within each contingency table box (A, B, C, and D). The optimum partition for each scenario was additionally determined as the partition that had the lowest calculated error probability. 


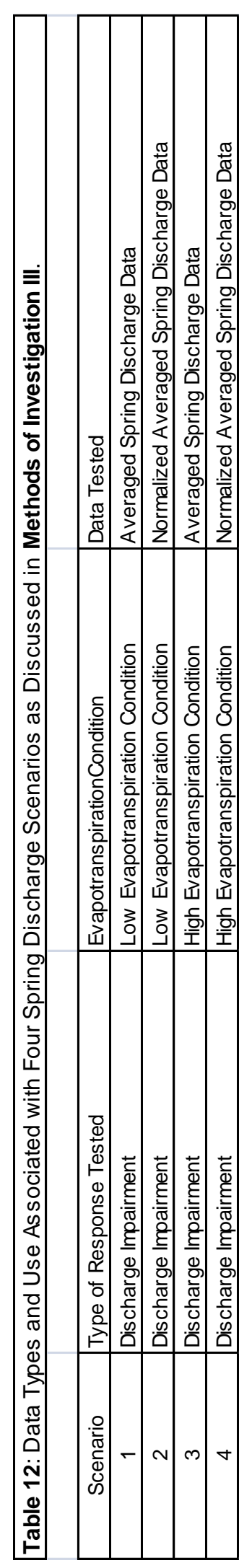




\begin{tabular}{|c|c|c|c|}
\hline \multirow{3}{*}{$\begin{array}{l}\text { Number of Control Springs } \\
\text { Number of Undermined Springs }\end{array}$} & $>/=$ & $<^{\prime} x^{\prime}$ & Totals \\
\hline & $\mathrm{A}$ & B & \multirow{2}{*}{$\begin{array}{l}\mathrm{A}+\mathrm{B} \\
\mathrm{C}+\mathrm{D}\end{array}$} \\
\hline & $\mathrm{C}$ & D & \\
\hline
\end{tabular}

where,

' $\mathrm{x}$ ' is the partition percentage (reduction in spring discharge)

$\mathrm{A}$ is the number of control springs that had natural changes to spring discharge $>/=\mathrm{X}$

$\mathrm{B}$ is the number of control springs that had natural changes to spring discharge $<\mathrm{x}$

$\mathrm{C}$ is the number of undermined springs that had changes to spring discharge $>/=\mathrm{X}$

$\mathrm{D}$ is the number of undermined springs that had changes to spring discharge $<\mathrm{x}$

Figure 15: 2x2 Contingency Table Test Used for the Natural Variation Analysis Associated with Investigation III.

The absolute spring discharge reduction boundary was determined as the partition with the maximum naturally occurring change in spring discharge.

The use of averaged spring discharge data and precipitation normalized averaged spring discharge data resulted in different partitions associated with the optimum and absolute values of the spring discharge reduction boundaries during low and high seasonal evapotranspiration conditions. The following rationale was used to determine which partitions would be used to decipher between naturally occurring changes in spring discharge and mining-induced changes to spring discharge during low and high evapotranspiration conditions.

The following results are from the optimum partition tests used to determine the optimum reduction boundary (Table 13). 
Table 13: Results from the Optimum Partition Tests Used to Determine the Optimum Reduction Boundaries as Discussed in Methods of Investigation III.

\begin{tabular}{|c|c|c|c|c|c|c|c|c|c|c|}
\hline \multirow{12}{*}{ 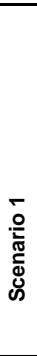 } & $\mathrm{x}^{\prime}$ & A & $B$ & $C$ & $\mathrm{D}$ & $\mathrm{n}$ & $C /(C+D) * 100$ & $A /(A+B) * 100$ & $(A+D) /(A+B+C+D) * 100$ & $\mathrm{P}_{\text {(error) }}$ \\
\hline & $10 \%$ & 7 & 5 & 54 & 9 & 75 & $86 \%$ & $58 \%$ & $21 \%$ & 0.99277 \\
\hline & $20 \%$ & 4 & 8 & 48 & 15 & 75 & $76 \%$ & $33 \%$ & $25 \%$ & 0.00583 \\
\hline & $30 \%$ & 3 & 9 & 48 & 15 & 75 & $76 \%$ & $25 \%$ & $24 \%$ & 0.00114 \\
\hline & $40 \%$ & 3 & 9 & 44 & 19 & 75 & $70 \%$ & $25 \%$ & $29 \%$ & 0.00487 \\
\hline & $50 \%$ & 2 & 10 & 44 & 19 & 75 & $70 \%$ & $17 \%$ & $28 \%$ & 0.00086 \\
\hline & $55 \%$ & 2 & 10 & 43 & 20 & 75 & $68 \%$ & $17 \%$ & $29 \%$ & 0.00123 \\
\hline & $60 \%$ & 2 & 10 & 40 & 23 & 75 & $63 \%$ & $17 \%$ & $33 \%$ & 0.00338 \\
\hline & $65 \%$ & 2 & 10 & 39 & 24 & 75 & $62 \%$ & $17 \%$ & $35 \%$ & 0.00458 \\
\hline & $70 \%$ & 2 & 10 & 36 & 27 & 75 & $57 \%$ & $17 \%$ & $39 \%$ & 0.01069 \\
\hline & $80 \%$ & 1 & 11 & 35 & 28 & 75 & $56 \%$ & $8 \%$ & $39 \%$ & 0.00246 \\
\hline & $88 \%$ & 0 & 12 & 33 & 30 & 75 & $52 \%$ & $0 \%$ & $40 \%$ & 0.00042 \\
\hline & & & & & & & & & & \\
\hline \multirow{12}{*}{ 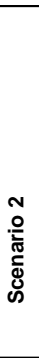 } & $\mathrm{x}^{\prime}$ & A & $\mathrm{B}$ & $\mathrm{C}$ & $\mathrm{D}$ & $\mathrm{n}$ & $\mathrm{C} /(\mathrm{C}+\mathrm{D})$ & $\mathrm{A} /(\mathrm{A}+\mathrm{B})$ & $(\mathrm{A}+\mathrm{D}) /(\mathrm{A}+\mathrm{B}+\mathrm{C}+\mathrm{D}) * 100$ & $\mathrm{P}_{\text {(error) }}$ \\
\hline & $10 \%$ & 6 & 6 & 53 & 10 & 75 & $84 \%$ & $50 \%$ & $21 \%$ & 0.01624 \\
\hline & $20 \%$ & 6 & 6 & 52 & 11 & 75 & $83 \%$ & $50 \%$ & $23 \%$ & 0.02301 \\
\hline & $30 \%$ & 5 & 7 & 49 & 14 & 75 & $78 \%$ & $42 \%$ & $25 \%$ & 0.01684 \\
\hline & $40 \%$ & 4 & 8 & 47 & 16 & 75 & $75 \%$ & $33 \%$ & $27 \%$ & 0.00818 \\
\hline & $50 \%$ & 2 & 10 & 43 & 20 & 75 & $68 \%$ & $17 \%$ & $29 \%$ & 0.00124 \\
\hline & $55 \%$ & 2 & 10 & 41 & 22 & 75 & $65 \%$ & $17 \%$ & $32 \%$ & 0.00245 \\
\hline & $60 \%$ & 1 & 11 & 40 & 23 & 75 & $63 \%$ & $8 \%$ & $32 \%$ & 0.00047 \\
\hline & $65 \%$ & 1 & 11 & 37 & 26 & 75 & $59 \%$ & $8 \%$ & $36 \%$ & 0.00131 \\
\hline & $70 \%$ & 1 & 11 & 37 & 26 & 75 & $59 \%$ & $8 \%$ & $36 \%$ & 0.00131 \\
\hline & $80 \%$ & 1 & 11 & 35 & 28 & 75 & $56 \%$ & $8 \%$ & $39 \%$ & 0.00246 \\
\hline & $88 \%$ & 0 & 12 & 33 & 30 & 75 & $52 \%$ & $0 \%$ & $40 \%$ & 0.00042 \\
\hline \multirow{12}{*}{ 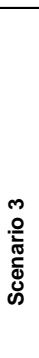 } & $x^{\prime}$ & $A$ & $B$ & C & $\mathrm{D}$ & $\mathrm{n}$ & $\mathrm{C} /(\mathrm{C}+\mathrm{D})$ & $A /(A+B)$ & $(A+D) /(A+B+C+D)^{*} 100$ & $\mathrm{P}_{\text {(error) }}$ \\
\hline & $10 \%$ & 5 & 4 & 49 & 9 & 67 & $84 \%$ & $56 \%$ & $21 \%$ & 0.98943 \\
\hline & $20 \%$ & 5 & 4 & 49 & 9 & 67 & $84 \%$ & $56 \%$ & $21 \%$ & 0.98943 \\
\hline & $30 \%$ & 5 & 4 & 49 & 9 & 67 & $84 \%$ & $56 \%$ & $21 \%$ & 0.98943 \\
\hline & $40 \%$ & 4 & 5 & 49 & 9 & 67 & $84 \%$ & $44 \%$ & $19 \%$ & 0.01547 \\
\hline & $50 \%$ & 2 & 7 & 48 & 10 & 67 & $83 \%$ & $22 \%$ & $18 \%$ & 0.00059 \\
\hline & $55 \%$ & 1 & 8 & 48 & 10 & 67 & $83 \%$ & $11 \%$ & $16 \%$ & $5.13 \times 10^{\wedge}-5$ \\
\hline & $60 \%$ & 1 & 8 & 48 & 10 & 67 & $83 \%$ & $11 \%$ & $16 \%$ & $5.13 \times 10^{\wedge}-5$ \\
\hline & $65 \%$ & 1 & 8 & 48 & 10 & 67 & $83 \%$ & $11 \%$ & $16 \%$ & $5.13 \times 10^{\wedge}-5$ \\
\hline & $70 \%$ & 1 & 8 & 47 & 11 & 67 & $81 \%$ & $11 \%$ & $18 \%$ & $8.70 \times 10^{\wedge}-5$ \\
\hline & $80 \%$ & 0 & 9 & 46 & 12 & 67 & $79 \%$ & $0 \%$ & $18 \%$ & $6.87 \times 10^{\wedge}-6$ \\
\hline & $88 \%$ & 0 & 9 & 44 & 14 & 67 & $76 \%$ & $0 \%$ & $21 \%$ & $1.91 \times 10^{\wedge}-5$ \\
\hline \multirow{12}{*}{ 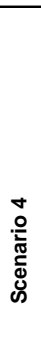 } & $\mathrm{x}^{\prime}$ & $\mathrm{A}$ & $\mathrm{B}$ & $\mathrm{C}$ & $\mathrm{D}$ & $\mathrm{n}$ & $\mathrm{C} /(\mathrm{C}+\mathrm{D})$ & $A /(A+B)$ & $(A+D) /(A+B+C+D)^{*} 100$ & $\mathrm{P}_{\text {(error) }}$ \\
\hline & $10 \%$ & 4 & 5 & 49 & 9 & 67 & $84 \%$ & $44 \%$ & \begin{tabular}{|l|}
$19 \%$ \\
\end{tabular} & 0.01547 \\
\hline & $20 \%$ & 3 & 6 & 49 & 9 & 67 & $84 \%$ & $33 \%$ & $18 \%$ & 0.00279 \\
\hline & $30 \%$ & 3 & 6 & 48 & 10 & 67 & $83 \%$ & $33 \%$ & $19 \%$ & 0.00426 \\
\hline & $40 \%$ & 3 & 6 & 48 & 10 & 67 & $83 \%$ & $33 \%$ & $19 \%$ & 0.00426 \\
\hline & $50 \%$ & 3 & 6 & 48 & 10 & 67 & $83 \%$ & $33 \%$ & $19 \%$ & 0.00426 \\
\hline & $55 \%$ & 2 & 7 & 48 & 10 & 67 & $83 \%$ & $22 \%$ & $18 \%$ & 0.00059 \\
\hline & $60 \%$ & 2 & 7 & 48 & 10 & 67 & $83 \%$ & $22 \%$ & $18 \%$ & 0.00059 \\
\hline & $65 \%$ & 2 & 7 & 48 & 10 & 67 & $83 \%$ & $22 \%$ & $18 \%$ & 0.00059 \\
\hline & $70 \%$ & 0 & 9 & 48 & 10 & 67 & $83 \%$ & $0 \%$ & $15 \%$ & $2.16 \times 10^{\wedge}-6$ \\
\hline & $80 \%$ & 0 & 9 & 46 & 12 & 67 & $79 \%$ & $0 \%$ & $18 \%$ & $6.87 \times 10^{\wedge}-6$ \\
\hline & $88 \%$ & 0 & 9 & 44 & 14 & 67 & $76 \%$ & $0 \%$ & $21 \%$ & $1.91 \times 10^{\wedge}-5$ \\
\hline
\end{tabular}

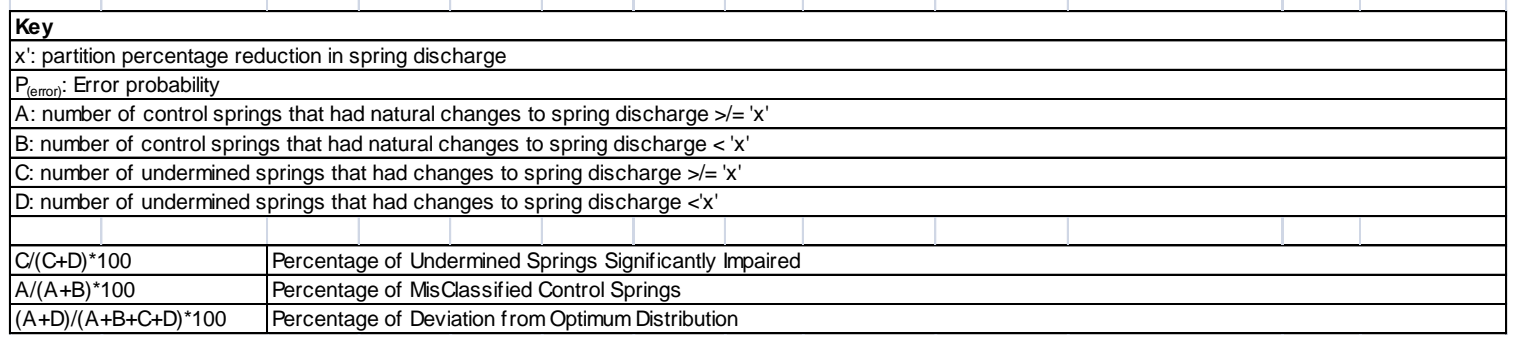


- The use of averaged spring discharge data (scenario 1) during low evapotranspiration conditions resulted in a probability of error less statistically significant (comparatively higher $\mathrm{p}$ ) than the use of precipitation normalized averaged spring discharge data (scenario 2); $\mathrm{p}$ is 0.00086 and 0.00047 , respectively.

- The use of averaged spring discharge data (scenario 3) during high evapotranspiration conditions resulted in a probability of error more statistically significant (comparatively lower $\mathrm{p}$ ) than the use of precipitation normalized averaged spring discharge data (scenario 4); $\mathrm{p}$ is 0.0000513 and 0.00059 , respectively.

- Percent deviation from the optimum distribution, $[(\mathrm{A}+\mathrm{D}) /(\mathrm{A}+\mathrm{B}+\mathrm{C}+\mathrm{D})]^{*} 100$, was less for the averaged spring discharge data than from the precipitation normalized averaged spring discharge data during low and high evapotranspiration conditions; 28 percent to 32 percent and 16 percent to 18 percent, respectively.

Due to the low calculated error probability for both the averaged spring discharge and precipitation normalized averaged spring discharge data, the selected optimum spring discharge reduction boundaries during low and high evapotranspiration conditions were chosen based in part upon percent deviation from the optimum distribution of the data; that is, misclassified control springs (contingency table box A) and misclassified undermined springs (contingency table box D) were zero. Deviation from the optimum distribution was less for the averaged spring discharge data than for the precipitation normalized averaged spring discharge data during both evapotranspiration conditions; therefore, it is perceived that the averaged spring discharge data are slightly more 
significant than the precipitation normalized averaged spring discharge data. This does not assume that precipitation data are not needed to assess spring discharge response to mining-induced subsidence. This is only suggestive that the technique employed for use of the precipitation data is slightly less valuable to this research methodology.

Therefore, the selected optimum spring discharge reduction boundaries (most probable naturally occurring reduction in spring discharge) range from 50 and 60 percent during low and high evapotranspiration conditions (Table 13). The selected absolute spring discharge reduction boundaries (maximum naturally occurring reduction in spring discharge) range from 80 to 88 percent during low and high evapotranspiration conditions (Table 14).

\subsubsection{Spring Discharge Response}

\subsubsection{Optimum Boundary Reduction}

Averaged spring discharge data were used to assess spring discharge response to mininginduced subsidence under the optimum boundary spring discharge reduction percentages statistically derived during low and high seasonal evapotranspiration conditions.

Subsidence-induced spring discharge response was 88 percent impaired and 12 percent unaffected (Table 15). Of the 53 impaired springs, 17 percent were partially impaired during low evapotranspiration conditions but not during high evapotranspiration conditions, 23 percent were partially impaired during high evapotranspiration conditions but not during low evapotranspiration conditions, 21 percent were partially impaired 
Table 14: Results from the Optimum Partition Tests Used to Determine the Absolute Reduction Boundaries as Discussed in Methods of Investigation III.

\begin{tabular}{|c|c|c|c|c|c|c|}
\hline \multirow{4}{*}{} & $\mathrm{X}^{\prime}$ & $\mathrm{A}$ & $\mathrm{B}$ & $\mathrm{C}$ & $\mathrm{D}$ & $\mathrm{n}$ \\
\cline { 2 - 7 } & $10 \%$ & 7 & 5 & 54 & 9 & 75 \\
\cline { 2 - 7 } & $20 \%$ & 4 & 8 & 48 & 15 & 75 \\
\cline { 2 - 7 } & $30 \%$ & 3 & 9 & 48 & 15 & 75 \\
\cline { 2 - 7 } & $40 \%$ & 3 & 9 & 44 & 19 & 75 \\
\cline { 2 - 7 } & $50 \%$ & 2 & 10 & 44 & 19 & 75 \\
\cline { 2 - 7 } & $55 \%$ & 2 & 10 & 43 & 20 & 75 \\
\cline { 2 - 7 } & $60 \%$ & 2 & 10 & 40 & 23 & 75 \\
\cline { 2 - 7 } & $65 \%$ & 2 & 10 & 39 & 24 & 75 \\
\cline { 2 - 7 } & $70 \%$ & 2 & 10 & 36 & 27 & 75 \\
\cline { 2 - 7 } & $80 \%$ & 1 & 11 & 35 & 28 & 75 \\
\cline { 2 - 7 } & $\mathbf{8 8} \%$ & $\mathbf{0}$ & 12 & 33 & 30 & 75 \\
\hline
\end{tabular}

\begin{tabular}{|c|c|c|}
\hline $\mathrm{C} /(\mathrm{C}+\mathrm{D})$ & $\mathrm{A} /(\mathrm{A}+\mathrm{B})$ & $(\mathrm{A}+\mathrm{D}) /(\mathrm{A}+\mathrm{B}+\mathrm{C}+\mathrm{D})^{*} 100$ \\
\hline $86 \%$ & $58 \%$ & $21 \%$ \\
\hline $76 \%$ & $33 \%$ & $25 \%$ \\
\hline $76 \%$ & $25 \%$ & $24 \%$ \\
\hline $70 \%$ & $25 \%$ & $29 \%$ \\
\hline $70 \%$ & $17 \%$ & $28 \%$ \\
\hline $68 \%$ & $17 \%$ & $29 \%$ \\
\hline $63 \%$ & $17 \%$ & $33 \%$ \\
\hline $62 \%$ & $17 \%$ & $35 \%$ \\
\hline $57 \%$ & $17 \%$ & $39 \%$ \\
\hline $56 \%$ & $8 \%$ & $39 \%$ \\
\hline $52 \%$ & $0 \%$ & $40 \%$ \\
\hline
\end{tabular}

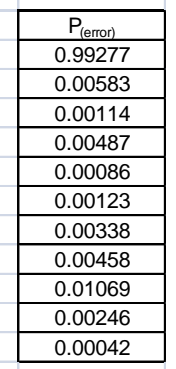

\begin{tabular}{|c|c|c|c|c|c|c|}
\hline \multirow{11}{*}{ 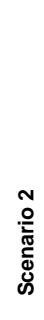 } & $\mathrm{x}^{\prime}$ & A & $B$ & C & $D$ & $\mathrm{n}$ \\
\hline & $10 \%$ & 6 & 6 & 53 & 10 & 75 \\
\hline & $20 \%$ & 6 & 6 & 52 & 11 & 75 \\
\hline & $30 \%$ & 5 & 7 & 49 & 14 & 75 \\
\hline & $40 \%$ & 4 & 8 & 47 & 16 & 75 \\
\hline & $50 \%$ & 2 & 10 & 43 & 20 & 75 \\
\hline & $55 \%$ & 2 & 10 & 41 & 22 & 75 \\
\hline & $60 \%$ & 1 & 11 & 40 & 23 & 75 \\
\hline & $65 \%$ & 1 & 11 & 37 & 26 & 75 \\
\hline & $70 \%$ & 1 & 11 & 37 & 26 & 75 \\
\hline & $80 \%$ & 1 & 11 & 35 & 28 & 75 \\
\hline & $88 \%$ & 0 & 12 & 33 & 30 & 75 \\
\hline
\end{tabular}

\begin{tabular}{|c|c|c|}
\hline $\mathrm{C} /(\mathrm{C}+\mathrm{D})$ & $\mathrm{A} /(\mathrm{A}+\mathrm{B})$ & $(\mathrm{A}+\mathrm{D}) /(\mathrm{A}+\mathrm{B}+\mathrm{C}+\mathrm{D})^{*} 100$ \\
\hline $84 \%$ & $50 \%$ & $21 \%$ \\
\hline $83 \%$ & $50 \%$ & $23 \%$ \\
\hline $78 \%$ & $42 \%$ & $25 \%$ \\
\hline $75 \%$ & $33 \%$ & $27 \%$ \\
\hline $68 \%$ & $17 \%$ & $29 \%$ \\
\hline $65 \%$ & $17 \%$ & $32 \%$ \\
\hline $63 \%$ & $8 \%$ & $32 \%$ \\
\hline $59 \%$ & $8 \%$ & $36 \%$ \\
\hline $59 \%$ & $8 \%$ & $36 \%$ \\
\hline $56 \%$ & $8 \%$ & $39 \%$ \\
\hline $52 \%$ & $0 \%$ & $40 \%$ \\
\hline
\end{tabular}

\begin{tabular}{|c|}
\hline$P_{\text {(error) }}$ \\
\hline 0.01624 \\
\hline 0.02301 \\
\hline 0.01684 \\
\hline 0.00818 \\
\hline 0.00124 \\
\hline 0.00245 \\
\hline 0.00047 \\
\hline 0.00131 \\
\hline 0.00131 \\
\hline 0.00246 \\
\hline 0.00042 \\
\hline
\end{tabular}

\begin{tabular}{|c|c|c|c|c|c|c|}
\hline \multirow{11}{*}{ 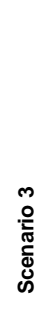 } & $x^{\prime}$ & A & B & C & D & $\mathrm{n}$ \\
\hline & $10 \%$ & 5 & 4 & 49 & 9 & 67 \\
\hline & $20 \%$ & 5 & 4 & 49 & 9 & 67 \\
\hline & $30 \%$ & 5 & 4 & 49 & 9 & 67 \\
\hline & $40 \%$ & 4 & 5 & 49 & 9 & 67 \\
\hline & $50 \%$ & 2 & 7 & 48 & 10 & 67 \\
\hline & $55 \%$ & 1 & 8 & 48 & 10 & 67 \\
\hline & $60 \%$ & 1 & 8 & 48 & 10 & 67 \\
\hline & $65 \%$ & 1 & 8 & 48 & 10 & 67 \\
\hline & $70 \%$ & 1 & 8 & 47 & 11 & 67 \\
\hline & $80 \%$ & 0 & 9 & 46 & 12 & 67 \\
\hline & $88 \%$ & 0 & 9 & 44 & 14 & 67 \\
\hline
\end{tabular}

\begin{tabular}{|c|c|c|}
\hline $\mathrm{C} /(\mathrm{C}+\mathrm{D})$ & $\mathrm{A} /(\mathrm{A}+\mathrm{B})$ & $(\mathrm{A}+\mathrm{D}) /(\mathrm{A}+\mathrm{B}+\mathrm{C}+\mathrm{D})^{*} 100$ \\
\hline $84 \%$ & $56 \%$ & $21 \%$ \\
\hline $84 \%$ & $56 \%$ & $21 \%$ \\
\hline $84 \%$ & $56 \%$ & $21 \%$ \\
\hline $84 \%$ & $44 \%$ & $19 \%$ \\
\hline $83 \%$ & $22 \%$ & $18 \%$ \\
\hline $83 \%$ & $11 \%$ & $16 \%$ \\
\hline $83 \%$ & $11 \%$ & $16 \%$ \\
\hline $83 \%$ & $11 \%$ & $16 \%$ \\
\hline $81 \%$ & $11 \%$ & $18 \%$ \\
\hline $79 \%$ & $0 \%$ & $18 \%$ \\
\hline $76 \%$ & $0 \%$ & $21 \%$ \\
\hline
\end{tabular}

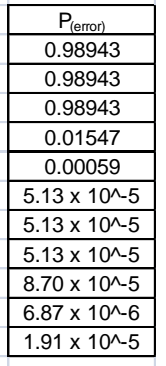

\begin{tabular}{|c|c|c|c|c|c|c|}
\hline \multirow{11}{*}{ 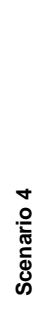 } & $x^{\prime}$ & $A$ & $B$ & C & D & $\mathrm{n}$ \\
\hline & $10 \%$ & 4 & 5 & 49 & 9 & 67 \\
\hline & $20 \%$ & 3 & 6 & 49 & 9 & 67 \\
\hline & $30 \%$ & 3 & 6 & 48 & 10 & 67 \\
\hline & $40 \%$ & 3 & 6 & 48 & 10 & 67 \\
\hline & $50 \%$ & 3 & 6 & 48 & 10 & 67 \\
\hline & $55 \%$ & 2 & 7 & 48 & 10 & 67 \\
\hline & $60 \%$ & 2 & 7 & 48 & 10 & 67 \\
\hline & $65 \%$ & 2 & 7 & 48 & 10 & 67 \\
\hline & $70 \%$ & 0 & 9 & 48 & 10 & 67 \\
\hline & $80 \%$ & 0 & 9 & 46 & 12 & 67 \\
\hline & $88 \%$ & 0 & 9 & 44 & 14 & 67 \\
\hline
\end{tabular}

\begin{tabular}{|c|c|c|}
\hline $\mathrm{C} /(\mathrm{C}+\mathrm{D})$ & $\mathrm{A} /(\mathrm{A}+\mathrm{B})$ & $(\mathrm{A}+\mathrm{D}) /(\mathrm{A}+\mathrm{B}+\mathrm{C}+\mathrm{D})^{*} 100$ \\
\hline $84 \%$ & $44 \%$ & $19 \%$ \\
\hline $84 \%$ & $33 \%$ & $18 \%$ \\
\hline $83 \%$ & $33 \%$ & $19 \%$ \\
\hline $83 \%$ & $33 \%$ & $19 \%$ \\
\hline $83 \%$ & $33 \%$ & $19 \%$ \\
\hline $83 \%$ & $22 \%$ & $18 \%$ \\
\hline $83 \%$ & $22 \%$ & $18 \%$ \\
\hline $83 \%$ & $22 \%$ & $18 \%$ \\
\hline $83 \%$ & $0 \%$ & $15 \%$ \\
\hline $79 \%$ & $0 \%$ & $18 \%$ \\
\hline $76 \%$ & $0 \%$ & $21 \%$ \\
\hline
\end{tabular}

\begin{tabular}{|c|}
\hline$P_{\text {(error) }}$ \\
\hline 0.01547 \\
\hline 0.00279 \\
\hline 0.00426 \\
\hline 0.00426 \\
\hline 0.00426 \\
\hline 0.00059 \\
\hline 0.00059 \\
\hline 0.00059 \\
\hline $2.16 \times 10^{\wedge}-6$ \\
\hline $6.87 \times 10^{\wedge}-6$ \\
\hline $1.91 \times 10^{\wedge}-5$ \\
\hline
\end{tabular}

Key

$x^{\prime}$ : partition percentage reduction in spring discharge

$P_{(\text {error) }}$ : Error probability

A: number of control springs that had natural changes to spring discharge $>/={ }^{\prime} \mathrm{x}$ '

B: number of control springs that had natural changes to spring discharge $<$ ' $x$ '

C: number of undermined springs that had changes to spring discharge $>/=$ ' $x$ '

D: number of undermined springs that had changes to spring discharge $<' x$ '

\begin{tabular}{|l|l}
\hline$C /(C+D)^{*} 100$ & Percentage of Undermined Springs Significantly Impaired
\end{tabular}

\begin{tabular}{|l|l|}
\hline $\mathrm{A} /(\mathrm{A}+\mathrm{B})^{*} 100$ & Percentage of MisClassified Control Springs \\
\hline
\end{tabular}

\begin{tabular}{|l|l}
\hline$(A+D) /(A+B+C+D)^{*} 100$ & Percentage of Deviation from Optimum Distribution
\end{tabular} 
Table 15. Spring Discharge Response to Mining-Induced Subsidence Evaluated at the Optimum Spring Discharge Reduction Boundary During Low and High Evapotranspiration Conditions.

\begin{tabular}{|c|c|c|c|}
\hline Source & Optimum Val & ge Reduction & Spring Discharge Response \\
\hline & Low ET (50\%) & High ET $(60 \%)$ & \\
\hline 33 & 87 & (1) & Impaired During Low Evapotranspiration Conditions \\
\hline 198 & 92 & (23) & Impaired During Low Evapotranspiration Conditions \\
\hline 155 & 100 & 100 & Permanently Impaired \\
\hline 166 & 100 & 100 & Permanently Impaired \\
\hline 167 & 100 & 100 & Permanently Impaired \\
\hline 173 & 100 & 100 & Permanently Impaired \\
\hline 174 & 100 & 100 & Permanently Impaired \\
\hline 177 & 100 & 100 & Permanently Impaired \\
\hline 199 & 100 & 100 & Permanently Impaired \\
\hline 224 & 100 & 100 & Permanently Impaired \\
\hline 249 & 100 & 100 & Permanently Impaired \\
\hline 254 & 100 & 100 & Permanently Impaired \\
\hline 259 & 100 & 100 & Permanently Impaired \\
\hline 263 & 100 & 100 & Permanently Impaired \\
\hline 272 & 100 & 100 & Permanently Impaired \\
\hline 35 & 100 & 100 & Permanently Impaired \\
\hline 36 & 100 & 100 & Permanently Impaired \\
\hline 41 & 100 & 100 & Permanently Impaired \\
\hline 63 & 100 & 100 & Permanently Impaired \\
\hline 64 & 100 & 100 & Permanently Impaired \\
\hline 84 & 100 & 100 & Permanently Impaired \\
\hline 94 & 100 & 100 & Permanently Impaired \\
\hline 269 & $(126)$ & $(61)$ & Unaffected \\
\hline 271 & (133) & $(74)$ & Unaffected \\
\hline 297 & (6) & 10 & Unaffected \\
\hline 268 & (31) & $(118)$ & Unaffected \\
\hline 99A & $(600)$ & 100 & Impaired During High Evapotranspiration Conditions \\
\hline 258 & (149) & 100 & Impaired During High Evapotranspiration Conditions \\
\hline 216 & (338) & 100 & Impaired During High Evapotranspiration Conditions \\
\hline 43 & 2 & 80 & Impaired During High Evapotranspiration Conditions \\
\hline 38 & 13 & 100 & Impaired During High Evapotranspiration Conditions \\
\hline 176 & 17 & 100 & Impaired During High Evapotranspiration Conditions \\
\hline 226 & 20 & 100 & Impaired During High Evapotranspiration Conditions \\
\hline 154 & 18 & & Unaffected \\
\hline 265 & 32 & 100 & Impaired During High Evapotranspiration Conditions \\
\hline 79 & 54 & 100 & Impaired During Low and High Evapotranspiration Conditions \\
\hline 99 & 14 & 100 & Impaired During High Evapotranspiration Conditions \\
\hline 107 & 58 & 85 & Impaired During Low and High Evapotranspiration Conditions \\
\hline 270 & 57 & & Impaired During Low Evapotranspiration Conditions \\
\hline 102 & 39 & 100 & Impaired During High Evapotranspiration Conditions \\
\hline 260 & 58 & & Impaired During Low Evapotranspiration Conditions \\
\hline 267 & 69 & 96 & Impaired During Low and High Evapotranspiration Conditions \\
\hline 97 & 30 & 45 & Unaffected \\
\hline 92 & 67 & & Impaired During Low Evapotranspiration Conditions \\
\hline 106 & 74 & 100 & Impaired During Low and High Evapotranspiration Conditions \\
\hline 93 & 68 & 100 & Impaired During Low and High Evapotranspiration Conditions \\
\hline 171 & 91 & & Impaired During Low Evapotranspiration Conditions \\
\hline 175 & 62 & 100 & Impaired During Low and High Evapotranspiration Conditions \\
\hline 274 & 94 & 100 & Impaired During Low and High Evapotranspiration Conditions \\
\hline 102A & 88 & 99 & Impaired During Low and High Evapotranspiration Conditions \\
\hline 273 & 95 & & Impaired During Low Evapotranspiration Conditions \\
\hline 256 & 98 & 88 & Impaired During Low and High Evapotranspiration Conditions \\
\hline 169 & 98 & 65 & Impaired During Low and High Evapotranspiration Conditions \\
\hline 91 & 97 & & Impaired During Low Evapotranspiration Conditions \\
\hline 90 & 99 & 100 & Impaired During Low and High Evapotranspiration Conditions \\
\hline 152 & 100 & 100 & Permanently Impaired \\
\hline 39 & 100 & & Impaired During Low Evapotranspiration Conditions \\
\hline 165 & & $(64)$ & Unaffected \\
\hline 101 & & 98 & Impaired During High Evapotranspiration Conditions \\
\hline 83 & & 100 & Impaired During High Evapotranspiration Conditions \\
\hline
\end{tabular}

Footnote: spring discharge reduction values in parentheses indicate a discharge/precipitation ratio improvement from Year 1 to Year 2. Spring discharge reduction values not in parentheses indicate a discharge/precipitation ratio impairment from Year 1 to Year 2. 
during both low and high evapotranspiration conditions, and 39 percent were permanently impaired through the duration of the post-mine monitoring program.

\subsubsection{Absolute Boundary Reduction}

Averaged spring discharge data were used to assess spring discharge response to mininginduced subsidence under the absolute boundary reduction percentages statistically derived during low and high seasonal evapotranspiration conditions. Subsidence-induced spring discharge response was 80 percent impaired and 20 percent unaffected (Table 16).

Of the 48 impaired springs, 10 percent were partially impaired during low evapotranspiration conditions but not during high evapotranspiration conditions, 40 percent were partially impaired during high evapotranspiration conditions but not during low evapotranspiration conditions, 6 percent were partially impaired during both low and high evapotranspiration conditions, and 44 percent were permanently impaired through the duration of the post-mine monitoring program.

\subsubsection{Spring Discharge Response Statistical Examination (Median Value)}

The following results from the Chi square contingency and Fisher exact probability statistical examination of spring discharge response are provided in Tables 17 and 18, respectively. These results are listed according to evapotranspiration condition and spring discharge reduction boundary. The hydrologic, geologic, topographic, and mine- 
Table 16. Spring Discharge Response to Mining-Induced Subsidence Evaluated at the Absolute Spring Discharge Reduction Boundary During Low and High Evapotranspiration Conditions.

\begin{tabular}{|c|c|c|c|}
\hline Source & Absolute Va & ge Reduction & Spring Discharge Response \\
\hline & Low ET $(88 \%)$ & High ET (80\%) & \\
\hline 33 & 87 & $(1)$ & Unaffected \\
\hline 198 & 92 & (23) & Impaired During Low Evapotranspiration Conditions \\
\hline 155 & 100 & 100 & Permanently Impaired \\
\hline 166 & 100 & 100 & Permanently Impaired \\
\hline 167 & 100 & 100 & Permanently Impaired \\
\hline 173 & 100 & 100 & Permanently Impaired \\
\hline 174 & 100 & 100 & Permanently Impaired \\
\hline 177 & 100 & 100 & Permanently Impaired \\
\hline 199 & 100 & 100 & Permanently Impaired \\
\hline 224 & 100 & 100 & Permanently Impaired \\
\hline 249 & 100 & 100 & Permanently Impaired \\
\hline 254 & 100 & 100 & Permanently Impaired \\
\hline 259 & 100 & 100 & Permanently Impaired \\
\hline 263 & 100 & 100 & Permanently Impaired \\
\hline 272 & 100 & 100 & Permanently Impaired \\
\hline 35 & 100 & 100 & Permanently Impaired \\
\hline 36 & 100 & 100 & Permanently Impaired \\
\hline 41 & 100 & 100 & Permanently Impaired \\
\hline 63 & 100 & 100 & Permanently Impaired \\
\hline 64 & 100 & 100 & Permanently Impaired \\
\hline 84 & 100 & 100 & Permanently Impaired \\
\hline 94 & 100 & 100 & Permanently Impaired \\
\hline 269 & $(126)$ & $(61)$ & Unaffected \\
\hline 271 & (133) & $(74)$ & Unaffected \\
\hline 297 & (6) & 10 & Unaffected \\
\hline 268 & (31) & $(118)$ & Unaffected \\
\hline 99A & $(600)$ & 100 & Impaired During High Evapotranspiration Conditions \\
\hline 258 & (149) & 100 & Impaired During High Evapotranspiration Conditions \\
\hline 216 & (338) & 100 & Impaired During High Evapotranspiration Conditions \\
\hline 43 & 2 & 80 & Unaffected \\
\hline 38 & 13 & 100 & Impaired During High Evapotranspiration Conditions \\
\hline 176 & 17 & 100 & Impaired During High Evapotranspiration Conditions \\
\hline 226 & 20 & 100 & Impaired During High Evapotranspiration Conditions \\
\hline 154 & 18 & & Unaffected \\
\hline 265 & 32 & 100 & Impaired During High Evapotranspiration Conditions \\
\hline 79 & 54 & 100 & Impaired During High Evapotranspiration Conditions \\
\hline 99 & 14 & 100 & Impaired During High Evapotranspiration Conditions \\
\hline 107 & 58 & 85 & Impaired During High Evapotranspiration Conditions \\
\hline 270 & 57 & & Unaffected \\
\hline 102 & 39 & 100 & Impaired During High Evapotranspiration Conditions \\
\hline 260 & 58 & & Unaffected \\
\hline 267 & 69 & 96 & Impaired During High Evapotranspiration Conditions \\
\hline 97 & 30 & 45 & Unaffected \\
\hline 92 & 67 & & Unaffected \\
\hline 106 & 74 & 100 & Impaired During High Evapotranspiration Conditions \\
\hline 93 & 68 & 100 & Impaired During High Evapotranspiration Conditions \\
\hline 171 & 91 & & Impaired During Low Evapotranspiration Conditions \\
\hline 175 & 62 & 100 & Impaired During High Evapotranspiration Conditions \\
\hline 274 & 94 & 100 & Impaired During Low and High Evapotranspiration Conditions \\
\hline 102A & 88 & 99 & Impaired During High Evapotranspiration Conditions \\
\hline 273 & 95 & & Impaired During Low Evapotranspiration Conditions \\
\hline 256 & 98 & 88 & Impaired During Low and High Evapotranspiration Conditions \\
\hline 169 & 98 & 65 & Impaired During Low Evapotranspiration Conditions \\
\hline 91 & 97 & & Impaired During Low Evapotranspiration Conditions \\
\hline 90 & 99 & 100 & Impaired During Low and High Evapotranspiration Conditions \\
\hline 152 & 100 & 100 & Permanently Impaired \\
\hline 39 & 100 & & Impaired During High Evapotranspiration Conditions \\
\hline 165 & & $(64)$ & Unaffected \\
\hline 101 & & 98 & Impaired During High Evapotranspiration Conditions \\
\hline 83 & & 100 & Impaired During High Evapotranspiration Conditions \\
\hline
\end{tabular}

Footnote: spring discharge reduction values in parentheses indicate a discharge/precipitation ratio improvement from Year 1 to Year 2. Spring discharge reduction values not in parentheses indicate a discharge/precipitation ratio impairment from Year 1 to Year 2. 


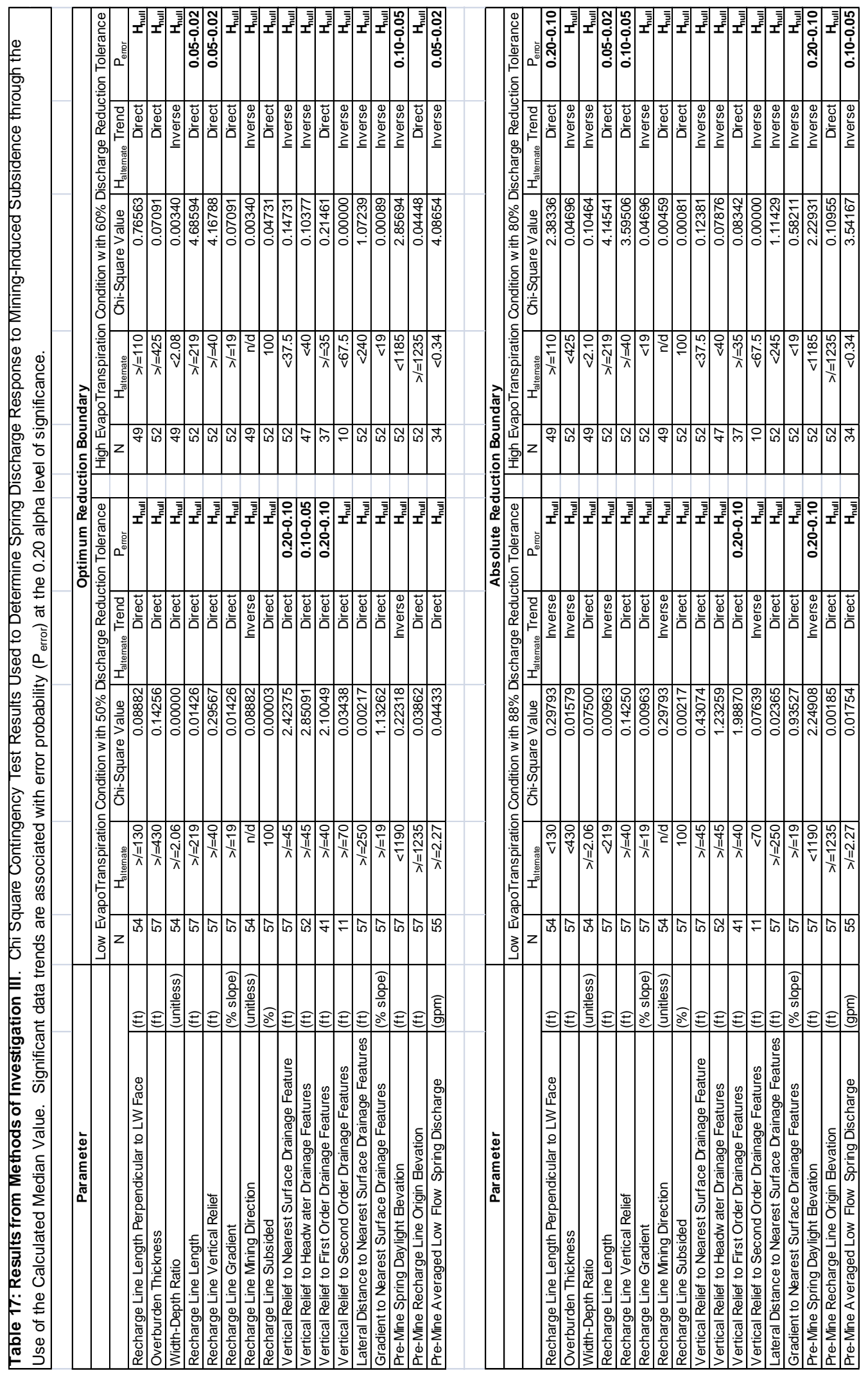




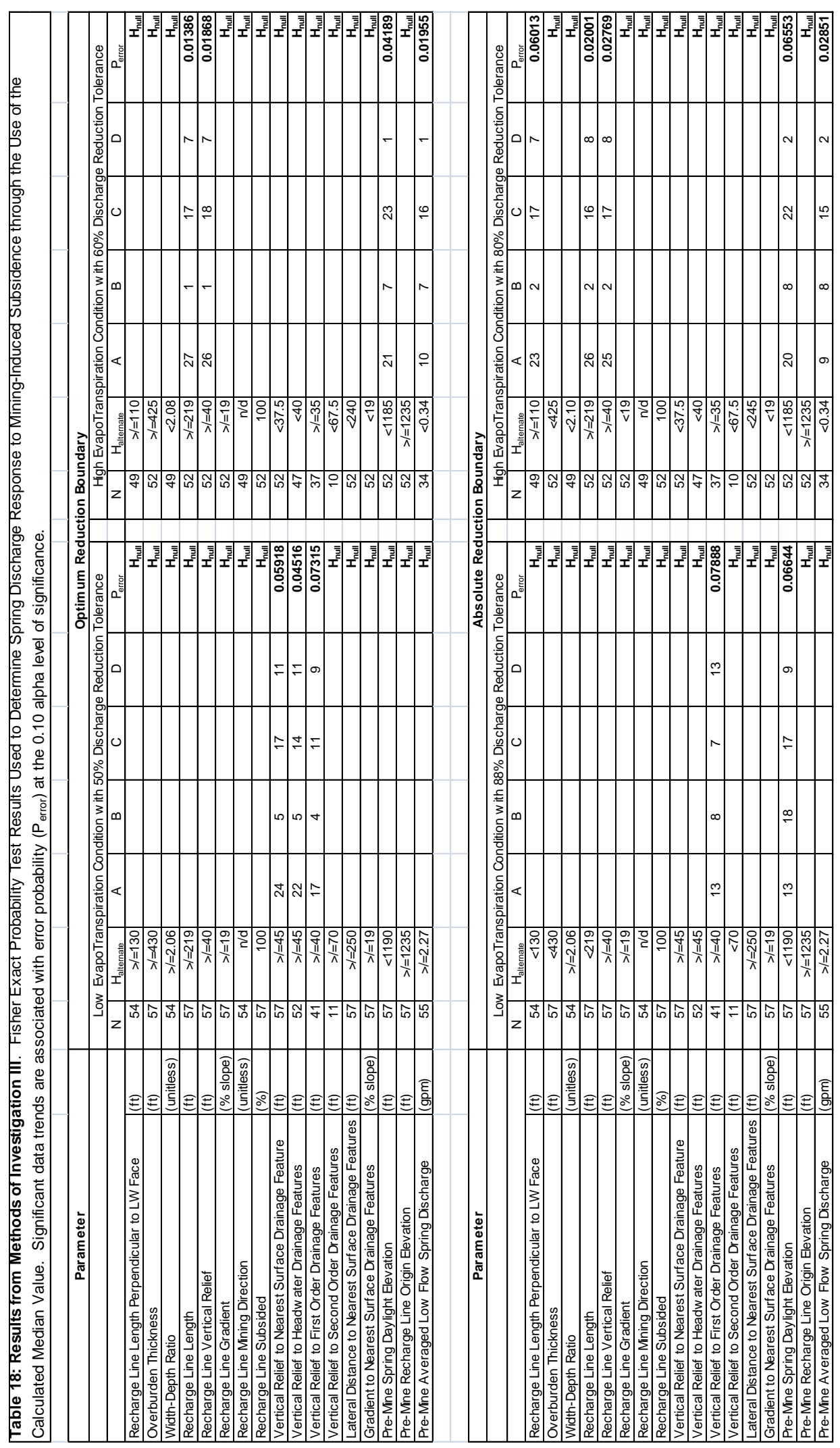


specific independent variables were examined for statistically significant data trends through the use of the calculated independent variable median values and median contingency table tests (Figure 16). Refer to Appendix E for figures illustrating acceptance of the significant alternative hypotheses and data tables used for calculating Fisher exact error probabilities at the 0.10 alpha level of significance. Two or more springs plotted at the same position (spring discharge change and independent variable value) are not deciphered in the Appendix E independent variable-specific figures; consult the Appendix E independent variable-specific tables for information regarding this scenario.

$\begin{aligned} & \text { Spring Discharge } \\ & \text { Spring Frequency for }>/=\text { Median Independent Variable Value } \\ & \text { Spring Frequency for }<\text { Median Independent Variable Value }\end{aligned}$
Totals
where,
A is the number of undermined springs $>/=$ the calculated independent variable median
value and $>/=$ the spring discharge reduction boundary condition
B is the number of undermined springs $>/=$ the calculated independent variable median
value and $<$ the spring discharge reduction boundary condition




\subsubsection{Low Evapotranspiration Condition - Optimum Reduction Boundary}

Nonparametric statistical tests resulted in acceptance of the alternative hypothesis for vertical relief to nearest surface drainage features, vertical relief to headwater surface drainage (first and second order) features, and vertical relief to first order surface drainage features. The significant alternative hypothesis statements are as follows:

- Spring discharge impairment is associated with vertical relief to nearest surface drainage features greater than or equal to the calculated median value of 45 feet (Appendix E_fig_1 and E_tab_1); +/-5ft.

- Spring discharge impairment is associated with vertical relief to headwater surface drainage (first and second order) features greater than or equal to the calculated median value of 45 feet (Appendix E_fig_2 and E_tab_2); +/- 5ft.

- Spring discharge impairment is associated with vertical relief to first order surface drainage features greater than or equal to the calculated median value of 40 feet (Appendix E_fig_3 and E_tab_3); +/-5ft.

The use of Chi square contingency tests resulted in calculated error probabilities of 0.20$0.10,0.10-0.05$, and $0.20-0.10$, respectively, for the above data trends (Table 17). The use of Fisher exact probability tests resulted in calculated error probabilities of 0.05918 , 0.04516 , and 0.07315 , respectively (Table 18 ). The remaining alternative hypotheses examined for the topographic and mine independent variables were rejected by the Chi square contingency and Fisher exact probability tests at the 0.20 and 0.10 alpha probability levels, respectively. 
Based upon the statistical results, the use of vertical relief to nearest surface drainage features, vertical relief to headwater surface drainage features, and vertical relief to first order surface drainage features, resulted in 94 percent, 95 percent, and 92 percent degree of confidence that a significant data trend exists, as determined from the complement of alpha, for these respective independent variables.

\subsubsection{Low Evapotranspiration Condition - Absolute Reduction Boundary}

Nonparametric statistical tests resulted in acceptance of the alternative hypothesis for vertical relief to first order surface drainage features and spring daylight elevation. The significant alternative hypothesis statements are as follows:

- Spring discharge impairment is associated with vertical relief to first order surface drainage features greater than or equal to the calculated median value of 40 feet (Appendix E_fig_4 and E_tab_4); +/- 5ft.

- Spring discharge impairment is associated with pre-mining spring daylight elevation less than the calculated median value of 1190 feet msl (Appendix E_fig_5 and E_tab_5); +/- 5ft.

The use of Chi square contingency tests resulted in calculated error probabilities of 0.200.10 and $0.20-0.10$, respectively, for the above data trends (Table 17). The use of Fisher exact probability tests resulted in calculated error probabilities of 0.07888 and 0.06644 , respectively (Table 18). The remaining alternative hypotheses examined for the topographic and mine independent variables were rejected by the Chi square contingency 
and Fisher exact probability tests at the 0.20 and 0.10 alpha probability levels, respectively.

Based upon the statistical results, the use of vertical relief to first order surface drainage features, gradient to nearest surface drainage features, and pre-mining spring daylight elevation resulted in 92 percent and 93 percent degree of confidence that a significant data trend exists, as determined from the complement of alpha, for these respective independent variables.

\subsubsection{High Evapotranspiration Condition - Optimum Reduction Boundary}

Nonparametric statistical tests resulted in acceptance of the alternative hypothesis for recharge line length, recharge line vertical relief, spring daylight elevation, and pre-mine average low flow discharge. The significant alternative hypothesis statements are as follows:

- Spring discharge impairment is associated with recharge line length greater than or equal to the calculated median value of 219 feet (Appendix E_fig_6 and E_tab_6); +/- 10ft.

- Spring discharge impairment is associated with recharge line vertical relief greater than or equal to the calculated median value of 40 feet (Appendix E_fig_7 and E_tab_7); +/- 5ft.

- Spring discharge impairment is associated with pre-mining spring daylight elevation less than the calculated median value of 1185 feet msl (Appendix E_fig_8 and E_tab_8); +/- 5ft. 
- Spring discharge impairment is associated with pre-mine average low flow discharge less than the calculated median value of 0.34 gpm (Appendix E_fig_9 and E_tab_9).

The use of Chi square contingency tests resulted in calculated error probabilities of 0.05 $0.02,0.05-0.02,0.10-0.05$, and $0.05-0.02$, respectively, for the above data trends (Table 17). The use of Fisher exact probability tests resulted in calculated error probabilities of $0.01386,0.01868,0.04189$, and 0.01955 , respectively (Table 18 ). The remaining alternative hypotheses examined for the topographic and mine independent variables were rejected by the Chi square contingency and Fisher exact probability tests, at the 0.20 and 0.10 alpha probability levels, respectively.

Based upon the statistical results, the use of recharge line length, recharge line vertical relief, recharge line gradient, pre-mining spring daylight elevation, and pre-mine average low flow discharge resulted in 99 percent, 98 percent, 96 percent, and 98 percent degree of confidence that a significant data trend exists, as determined from the complement of alpha, for these respective independent variables.

\subsubsection{High Evapotranspiration Condition - Absolute Reduction Boundary}

Nonparametric statistical tests resulted in acceptance of the alternative hypothesis for the recharge line length component perpendicular to longwall panel face, recharge line length, recharge line vertical relief, spring daylight elevations, and pre-mine average low flow discharges. The significant alternative hypothesis statements are as follows: 
- $\quad$ Spring discharge impairment is associated with the recharge line length component perpendicular to longwall panel face greater than or equal to the calculated median value of 110 feet (Appendix E_fig_10 and E_tab_10); +/-10ft.

- Spring discharge impairment is associated with recharge line length greater than or equal to the calculated median value of 219 feet (Appendix E_fig_11 and E_tab_11); +/- 10ft.

- Spring discharge impairment is associated with recharge line vertical relief greater than or equal to the calculated median value of 40 feet (Appendix E_fig_12 and E_tab_12); +/- 5ft.

- $\quad$ Spring discharge impairment is associated with pre-mining spring daylight elevation less than the calculated median value of 1185 feet msl (Appendix E_fig_13 and E_tab_13); +/- 5ft.

- Spring discharge impairment is associated with pre-mine average low flow discharge less than the calculated median value of 0.34 gpm (Appendix E_fig_14 and E_tab_14).

The use of Chi square contingency tests resulted in calculated error probabilities of 0.20$0.10,0.05-0.02,0.10-0.05,0.20-0.10$, and $0.10-0.05$, respectively, for the above data trends (Table 17). The use of Fisher exact probability tests resulted in calculated error probabilities of $0.06013,0.02001,0.02769,0.06553$, and 0.02851 , respectively (Table 18). The remaining alternative hypotheses examined for the topographic and mine independent variables were rejected by the Chi square contingency and Fisher exact probability tests, at the 0.20 and 0.10 alpha probability levels, respectively. 
Based upon the statistical results, the use of recharge line length component perpendicular to longwall panel face, recharge line length, recharge line vertical relief, pre-mining spring daylight elevation, and pre-mine average low flow discharge resulted in 94 percent, 98 percent, 97 percent, 93 percent, and 97 percent degree of confidence that a significant data trend exists, as determined from the complement of alpha, for these respective independent variables.

\subsubsection{Degree of Spring Discharge Response Statistical Examination (Median Value)}

The following results from the Chi square contingency and Fisher exact probability statistical examination for the degree of spring discharge response are provided in Tables 19 and 20, respectively. These results are listed according to evapotranspiration condition and spring discharge reduction boundary. The hydrologic, geologic, topographic, and mine-specific independent variables were examined for statistically significant data trends through the use of the calculated independent variable median values and median contingency table tests (Figure 17). Refer to Appendix F for figures illustrating acceptance of the significant alternative hypotheses and data tables used for calculating Fisher exact error probabilities at the 0.10 alpha level of significance. Two or more springs plotted at the same position (spring discharge change and independent variable value) are not deciphered in the Appendix F independent variable-specific figures; consult the Appendix F independent variable-specific tables for information regarding this scenario. 


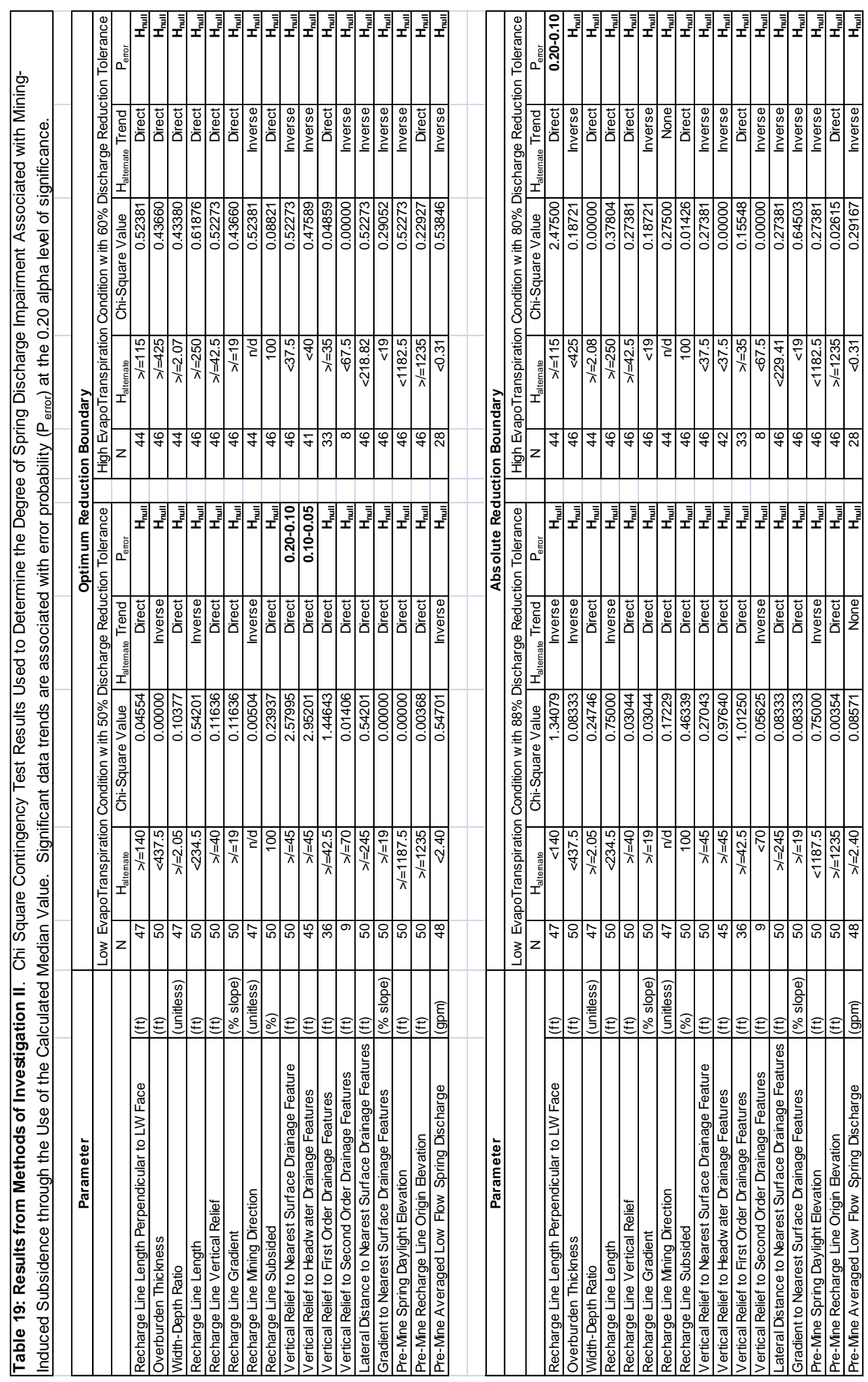




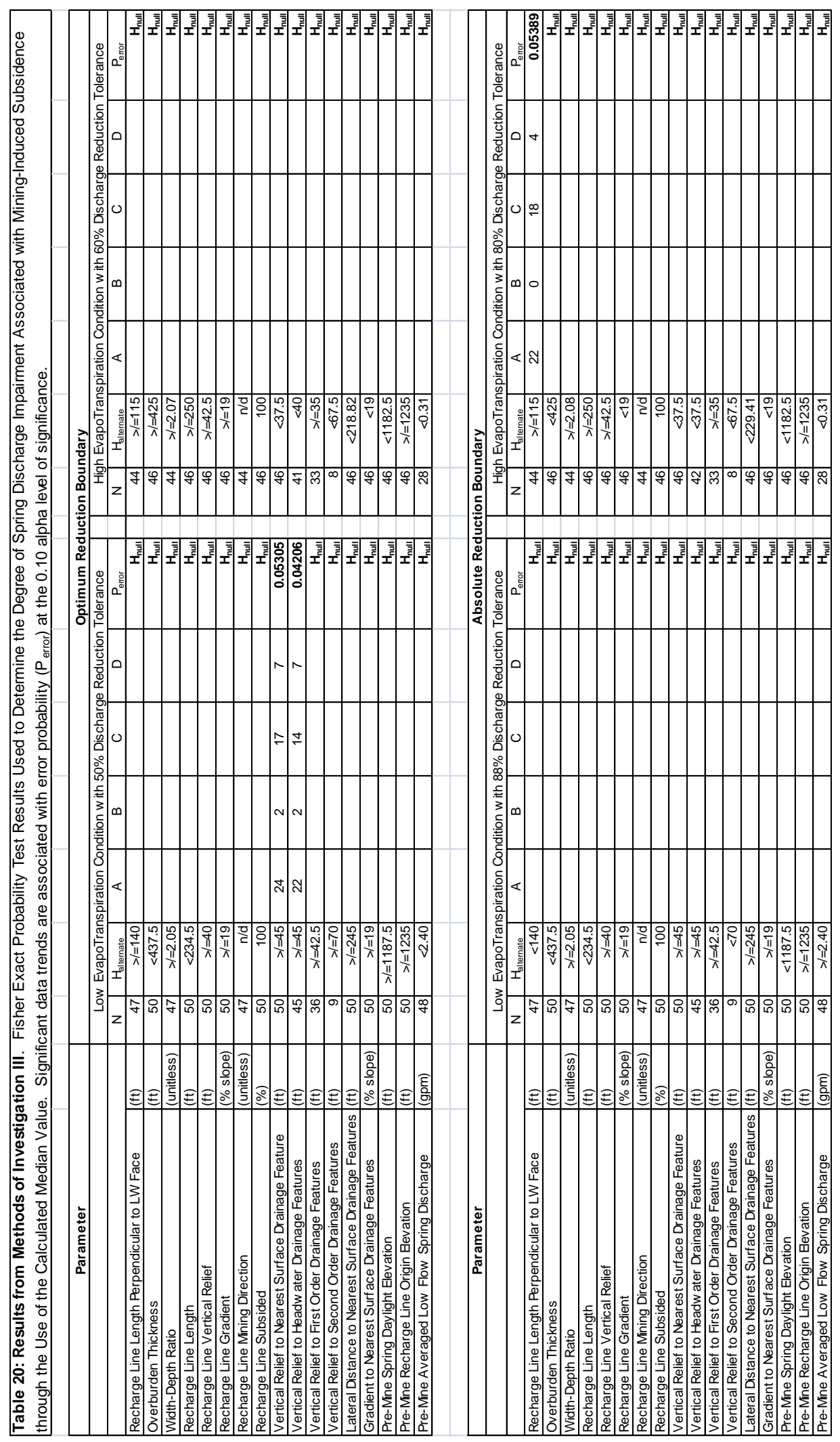




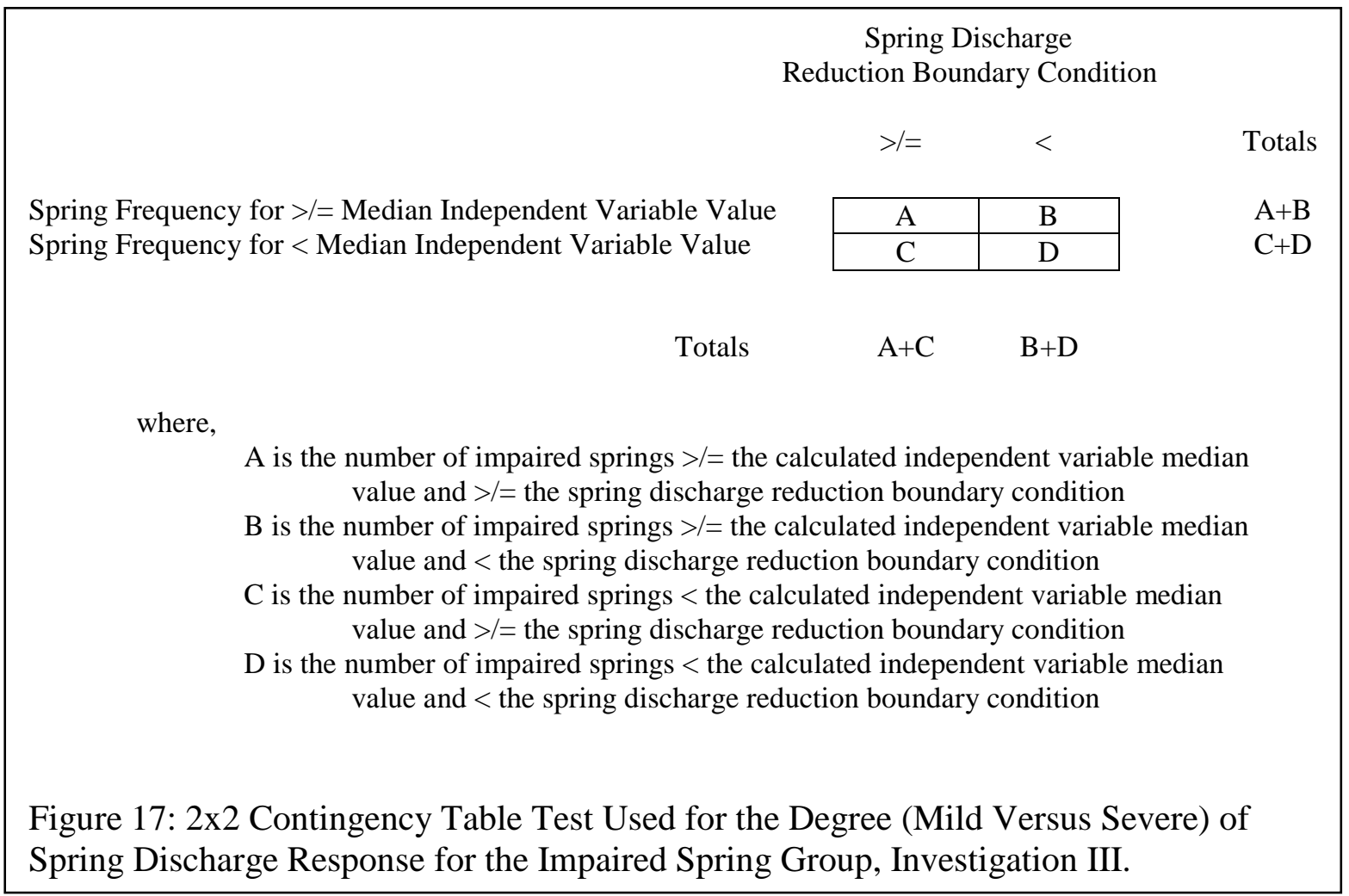

\subsubsection{Low Evapotranspiration Condition - Optimum Reduction Boundary}

Nonparametric statistical tests resulted in acceptance of the alternative hypothesis for vertical relief to nearest surface drainage features and vertical relief to headwater surface drainage (first and second order) features. The significant alternative hypothesis statements are as follows:

- Spring discharge impairment is associated with vertical relief to nearest surface drainage features greater than or equal to the calculated median value of 45 feet (Appendix F_fig_1 and F_tab_1); +/- 5ft. 
- Spring discharge impairment is associated with vertical relief to headwater surface drainage (first and second order) features greater than or equal to the calculated median value of 45 feet (Appendix F_fig_2 and F_tab_2); +/- 5ft.

The use of Chi square contingency tests resulted in calculated error probabilities of 0.200.10 , and 0.10-0.05, respectively, for the above data trends (Table 19). The use of Fisher exact probability tests resulted in calculated error probabilities of 0.05305 and 0.04206 , respectively (Table 20). The remaining alternative hypotheses examined for the topographic and mine independent variables were rejected by the Chi square contingency and Fisher exact probability tests, at the 0.20 and 0.10 alpha probability levels, respectively.

Based upon the statistical results, the use of vertical relief to nearest surface drainage features and vertical relief to headwater surface drainage features resulted in 95 percent and 96 percent degree of confidence that a significant data trend exists, as determined from the complement of alpha, for these respective independent variables.

\subsubsection{Low Evapotranspiration Condition - Absolute Reduction Boundary}

Nonparametric statistical tests resulted in rejection of all the alternative hypotheses; therefore, there are no significant statistical relationships between the degree of spring impairment and the independent variables during low evapotranspiration conditions when evaluated at the absolute reduction boundary. 


\subsubsection{High Evapotranspiration Condition - Optimum Reduction Boundary}

Nonparametric statistical tests resulted in rejection of all the alternative hypotheses, therefore, there are no significant statistical relationships between the degree of spring impairment and the independent variables during high evapotranspiration conditions when evaluated at the optimum reduction boundary.

\subsubsection{High Evapotranspiration Condition - Absolute Reduction Boundary}

Nonparametric statistical tests resulted in acceptance of the alternative hypothesis for the recharge line length component perpendicular to longwall panel face. The significant alternative hypothesis statement is as follows:

- Spring discharge impairment is associated with the recharge line length component perpendicular to longwall panel face greater than or equal to the calculated median value of 115 feet (Appendix F_fig_3 and F_tab_3); +/- 10ft.

The use of the Chi square contingency test resulted in a calculated error probability of 0.20-0.10, for this data trend (Table 19). The use of the Fisher exact probability test resulted in a calculated error probability of 0.05389 (Table 20). The remaining alternative hypotheses examined for the topographic and mine independent variables were rejected by the Chi square contingency and Fisher exact probability tests, at the 0.20 and 0.10 alpha probability levels, respectively. 
Based upon the statistical results, the use of recharge line length component perpendicular to longwall panel face resulted in a 95 percent degree of confidence that a significant data trend exists, as determined from the complement of alpha, for this independent variable. 


\subsection{INVESTIGATION IV}

\subsection{Methods of Investigation IV}

The previous investigations have evaluated the hydrologic, geologic, topographic, and mine-specific independent variables for association with spring discharge impairment through the use of the calculated variable median values. The methodology of Investigation IV uses interpreted best-fit partitioning values in place of the calculated median values. These interpreted best-fit values were determined through shifting the boundary condition of the independent variable from the median value in order to minimize the probability of error through optimizing the distribution of the spring discharge responses among the group data classes of the $2 \times 2$ contingency statistical tests. The best-fit partition value tests are more representative of data trends for spring discharge associated with the variables than data trends determined from the median value tests.

\subsection{Results of Investigation IV}

\subsubsection{Spring Discharge Response Statistical Examination (Interpreted Best Fit Value)}

The following results from the Chi square contingency and Fisher exact probability statistical examinations of spring discharge response trends are provided in Tables 21 and 22 , respectively. These results are listed according to evapotranspiration condition and spring discharge reduction boundary. The hydrologic, geologic, topographic, and minespecific independent variables were examined for statistical significance through the use 


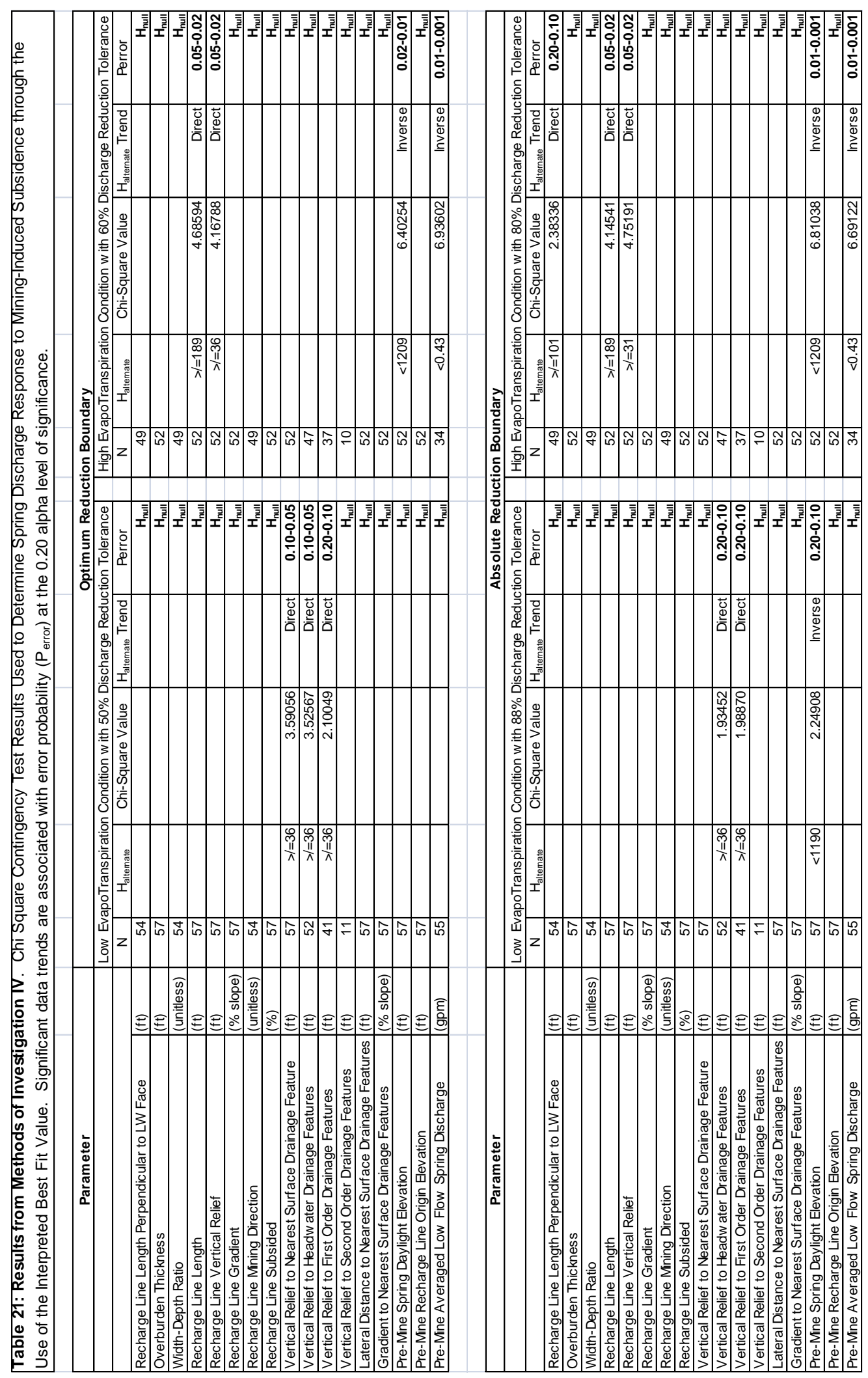




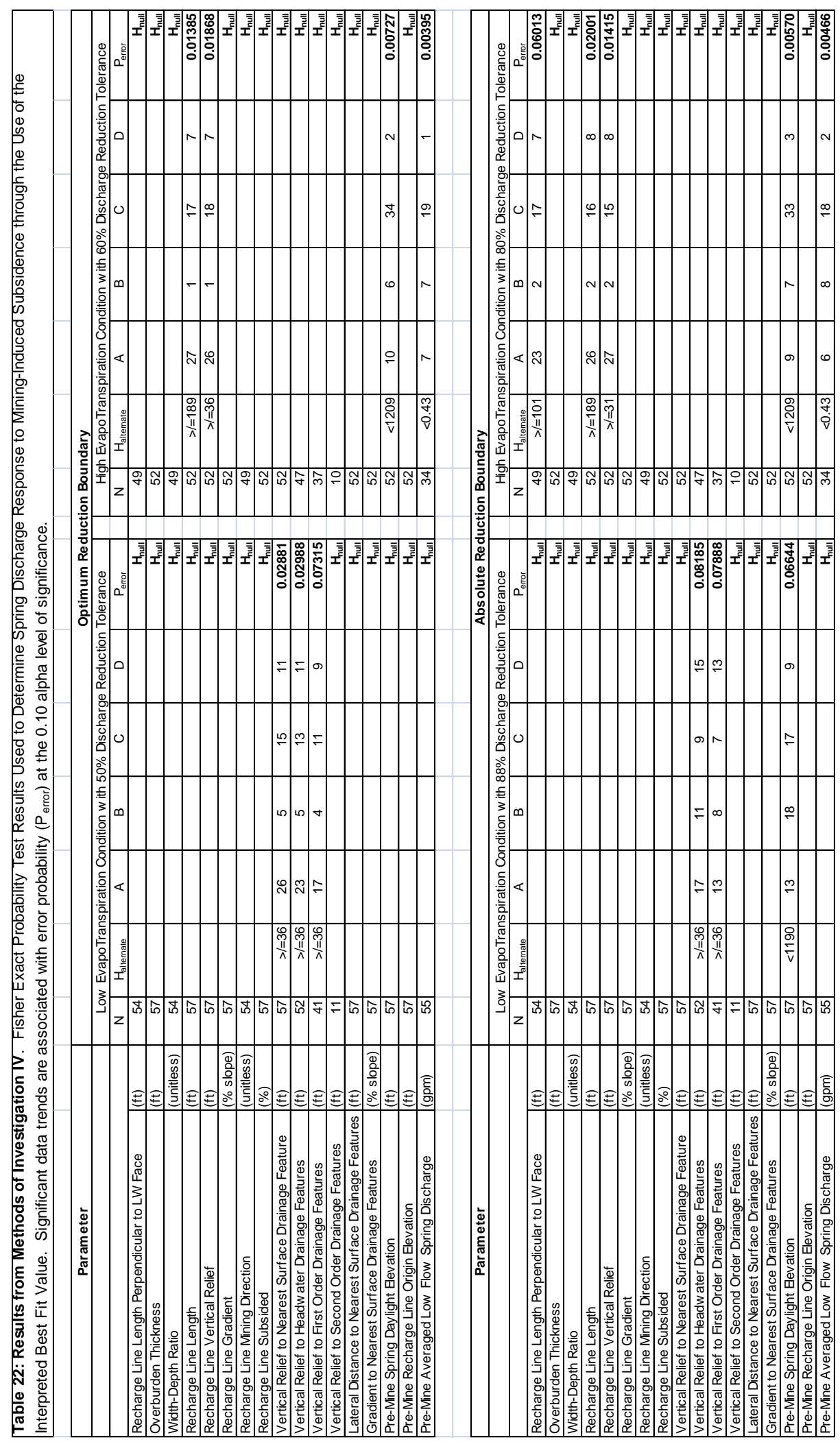


of the interpreted best-fit values and contingency table tests (Figure 18). Refer to Appendix $G$ for figures illustrating acceptance of the significant alternative hypotheses and data tables used for calculating Fisher exact error probabilities at the 0.10 alpha level of significance. Two or more springs plotted at the same position (spring discharge change and independent variable value) are not deciphered in the Appendix G independent variable-specific figures; consult the Appendix G independent variablespecific tables for information regarding this scenario.

$\begin{aligned} & \text { Spring Frequency for }>/=\text { Interpreted Best Fit Value } \\ & \text { Spring Frequency for }<\text { Interpreted Best Fit Value }\end{aligned}$
Totals
where,
A is the number of undermined springs $>/=$ the interpreted best fit value and $>/=$ the
spring discharge reduction boundary condition
B is the number of undermined springs $>/=$ the interpreted best fit value and $<$ the
spring discharge reduction boundary condition
$\mathrm{C}$ is the number of undermined springs $<$ the interpreted best fit value and $>/=$ the
spring discharge reduction boundary condition
$\mathrm{D}$ is the number of undermined springs $<$ the interpreted best fit value and $<$ the
spring discharge reduction boundary condition




\subsubsection{Low Evapotranspiration Condition - Optimum Reduction Boundary}

Nonparametric statistical tests resulted in acceptance of the alternative hypothesis for vertical relief to nearest surface drainage features, vertical relief to headwater surface drainage (first and second order) features, and vertical relief to first order surface drainage features. The significant alternative hypothesis statements are as follows:

- Spring discharge impairment is associated with vertical relief to nearest surface drainage features greater than or equal to the interpreted best fit value of 36 feet (Appendix G_fig_1 and G_tab_1); +/- 5ft.

- Spring discharge impairment is associated with vertical relief to headwater surface drainage (first and second order) features greater than or equal to the interpreted best fit value of 36 feet (Appendix G_fig_2 and G_tab_2); +/- 5ft.

- Spring discharge impairment is associated with vertical relief to first order surface drainage features greater than or equal to the interpreted best fit value of 36 feet (Appendix G_fig_3 and G_tab_3); +/- 5ft.

The use of Chi square contingency tests resulted in calculated error probabilities of 0.10$0.05,0.10-0.05$, and $0.20-0.10$, respectively, for the above data trends (Table 21). The use of Fisher exact probability tests resulted in calculated error probabilities of 0.02881 , 0.02988 , and 0.07315 , respectively (Table 22 ). The remaining alternative hypotheses examined for the topographic and mine independent variables were rejected by the Chi square contingency and Fisher exact probability tests, at the 0.20 and 0.10 alpha probability levels, respectively.

Based upon the statistical results, the use of vertical relief to nearest surface drainage features, vertical relief to headwater surface drainage features and vertical relief to first 
order surface drainage features resulted in 97 percent, 97 percent, and 93 percent degree of confidence that a significant data trend exists, as determined from the complement of alpha, for these respective independent variables.

\subsubsection{Low Evapotranspiration Condition - Absolute Reduction Boundary}

Nonparametric statistical tests resulted in acceptance of the alternative hypothesis for vertical relief to headwater surface drainage (first and second order) features, vertical relief to first order surface drainage features, and spring daylight elevation. The significant alternative hypothesis statements are as follows:

- Spring discharge impairment is associated with vertical relief to headwater surface drainage (first and second order) features greater than or equal to the interpreted best fit value of 36 feet (Appendix G_fig_4 and G_tab_4); +/- 5ft.

- Spring discharge impairment is associated with vertical relief to first order surface drainage features greater than or equal to the interpreted best fit value of 36 feet (Appendix G_fig_5 and G_tab_5); +/-5ft.

- Spring discharge impairment is associated with pre-mining spring daylight elevation less than the interpreted best fit value of 1190 feet msl (Appendix G_fig_6 and G_tab_6); +/- 5ft.

The use of Chi square contingency tests resulted in calculated error probabilities of 0.20$0.10,0.20-0.10$, and $0.20-0.10$, respectively, for the above data trends (Table 21). The use of Fisher exact probability tests resulted in calculated error probabilities of 0.08185 , 0.07888 , and 0.06644 , respectively (Table 22). The remaining alternative hypotheses examined for the topographic and mine independent variables were rejected by the Chi 
square contingency and Fisher exact probability tests, at the 0.20 and 0.10 alpha probability levels, respectively.

Based upon the statistical results, the use of vertical relief to headwater surface drainage features, vertical relief to first order surface drainage features, and pre-mining spring daylight elevation resulted in 92 percent, 92 percent, and 93 percent degree of confidence that a significant data trend exists, as determined from the complement of alpha, for these respective independent variables.

\subsubsection{High Evapotranspiration Condition - Optimum Reduction Boundary}

Nonparametric statistical tests resulted in acceptance of the alternative hypothesis for recharge line length, recharge line vertical relief, spring daylight elevation, and pre-mine average low flow discharge. The significant alternative hypothesis statements are as follows:

- Spring discharge impairment is associated with recharge line length greater than or equal to the interpreted best fit value of 189 feet (Appendix G_fig_7 and G_tab_7); +/- 10ft.

- Spring discharge impairment is associated with recharge line vertical relief greater than or equal to the interpreted best fit value of 36 feet (Appendix G_fig_8 and G_tab_8); +/-5ft.

- Spring discharge impairment is associated with pre-mining spring daylight elevation less than the interpreted best fit value of 1209 feet msl (Appendix G_fig_9 and G_tab_9); +/- 5ft. 
- Spring discharge impairment is associated with pre-mine average low flow discharge less than the interpreted best fit value of 0.43 gpm (Appendix G_fig_10 and $G_{-}$tab_10).

The use of Chi square contingency tests resulted in calculated error probabilities of 0.05 $0.02,0.05-0.02,0.02-0.01$, and $0.01-0.001$, respectively, for the above data trends (Table 21). The use of Fisher exact probability tests resulted in calculated error probabilities of $0.01385,0.01868,0.00727$, and 0.00395 , respectively (Table 22). The remaining alternative hypotheses examined for the topographic and mine independent variables were rejected by the Chi square contingency and Fisher exact probability tests, at the 0.20 and 0.10 alpha probability levels, respectively.

Based upon the statistical results, the use of recharge line length, recharge line vertical relief, recharge line gradient, pre-mining spring daylight elevation, and pre-mine average low flow discharge resulted in 99 percent, 98 percent, 99 percent, and 99 percent degree of confidence that a significant data trend exists, as determined from the complement of alpha, for these respective independent variables.

\subsubsection{High Evapotranspiration Condition - Absolute Reduction Boundary}

Nonparametric statistical tests resulted in acceptance of the alternative hypothesis for the recharge line length component perpendicular to longwall panel face, recharge line length, recharge line vertical relief, spring daylight elevation, and pre-mine average low flow discharge. The significant alternative hypothesis statements are as follows. 
- $\quad$ Spring discharge impairment is associated with the recharge line length component perpendicular to longwall panel face greater than or equal to the interpreted best fit value of 101 feet (Appendix G_fig_11 and G_tab_11); +/- 10ft.

- Spring discharge impairment is associated with recharge line length greater than or equal to the interpreted best fit value of 189 feet (Appendix G_fig_12 and G_tab_12); +/- 10ft.

- Spring discharge impairment is associated with recharge line vertical relief greater than or equal to the interpreted best fit value of 31 feet (Appendix G_fig_13 and G_tab_13); +/- 5ft.

- Spring discharge impairment is associated with pre-mining spring daylight elevation less than the interpreted best fit value of 1209 feet msl (Appendix G_fig_14 and G_tab_14); +/- 5ft.

- Spring discharge impairment is associated with pre-mine average low flow discharge less than the interpreted best fit value of $0.43 \mathrm{gpm}$ (Appendix G_fig_15 and $G_{-}$tab_15).

The use of Chi square contingency tests resulted in calculated error probabilities of 0.20$0.10,0.05-0.02,0.05-0.02,0.01-0.001$, and 0.01-0.001, respectively, for the above data trends (Table 21). The use of Fisher exact probability tests resulted in calculated error probabilities of $0.06013,0.02001,0.01415,0.00570$, and 0.00466 , respectively (Table 22). The remaining alternative hypotheses examined for the topographic and mine independent variables were rejected by the Chi square contingency and Fisher exact probability tests, at the 0.20 and 0.10 alpha probability levels, respectively. 
Based upon the statistical results, the use of recharge line length component perpendicular to longwall panel face, recharge line length, recharge line vertical relief, pre-mining spring daylight elevation, and pre-mine average low flow discharge resulted in 94 percent, 98 percent, 99 percent, 99 percent, and 99 percent degree of confidence that a significant data trend exists, as determined from the complement of alpha, for these respective independent variables.

\subsubsection{Degree of Spring Discharge Response Statistical Examination (Interpreted Best Fit}

\section{$\underline{\text { Value) }}$}

The following results from the Chi square contingency and Fisher exact probability statistical examinations for the degree of spring discharge response trends are provided in Tables 23 and 24, respectively. These results are listed according to evapotranspiration condition and spring discharge reduction boundary type. The hydrologic, geologic, topographic, and mine-specific independent variables were examined for statistical significance through the use of the interpreted best-fit values and contingency table tests (Figure 19). Refer to Appendix $\mathrm{H}$ for figures illustrating acceptance of the significant alternative hypotheses and data tables used for calculating Fisher exact error probabilities at the 0.10 alpha level of significance. Two or more springs plotted at the same position (spring discharge change and independent variable value) are not deciphered in the Appendix $\mathrm{H}$ independent variable-specific figures; consult the Appendix $\mathrm{H}$ independent variable-specific tables for information regarding this scenario. 


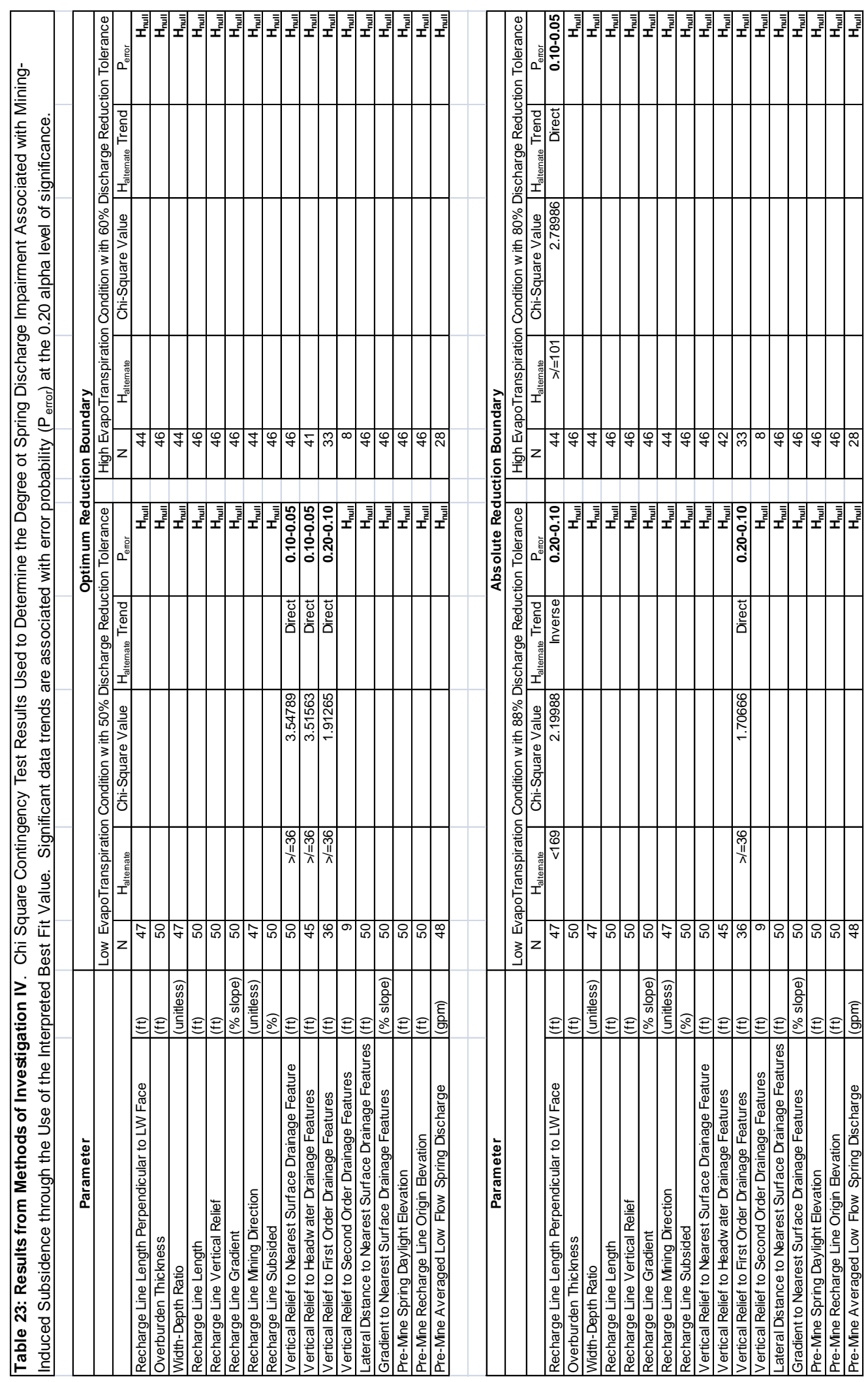




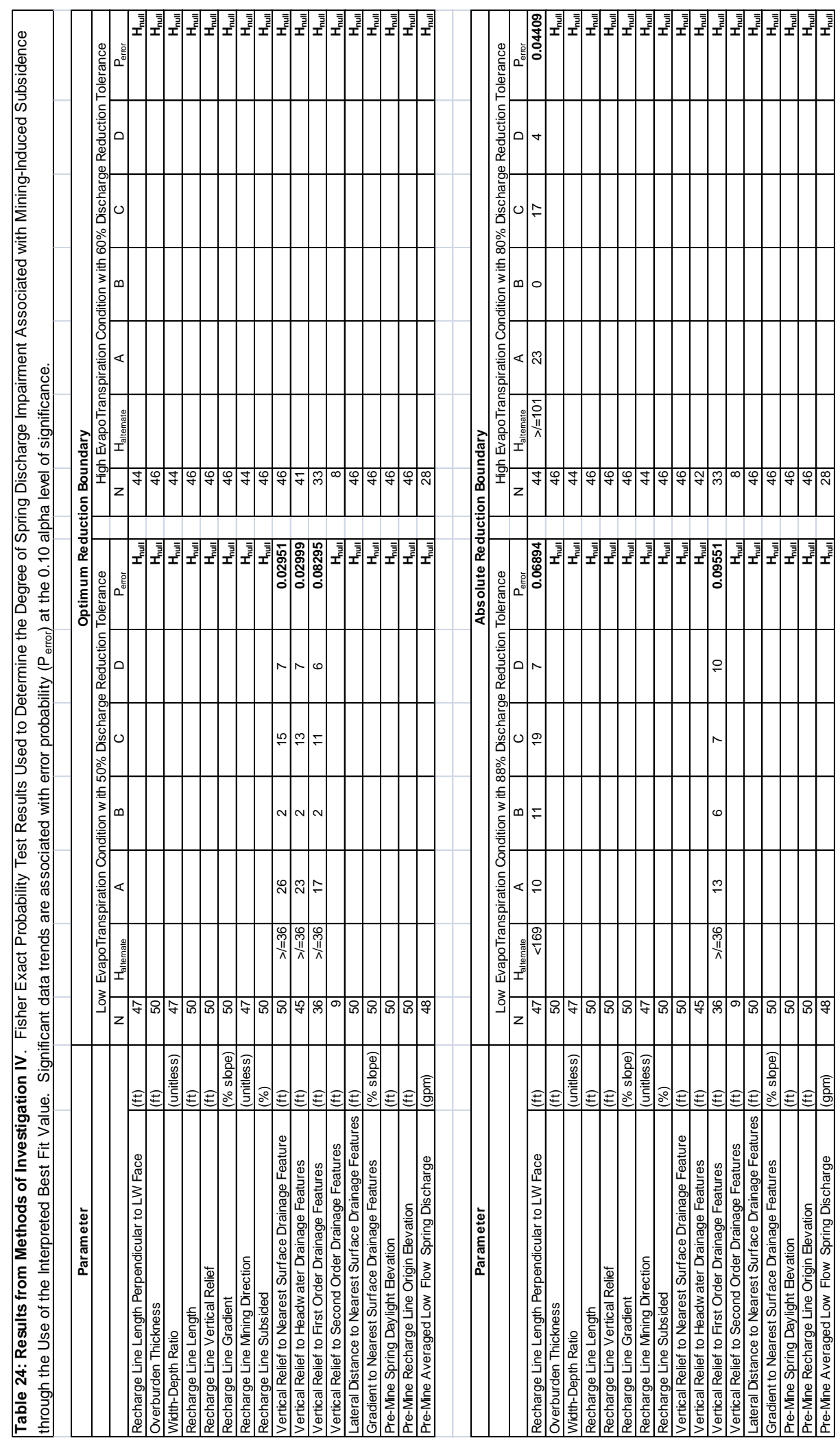




\begin{tabular}{|c|c|c|c|}
\hline \multicolumn{4}{|c|}{$\begin{array}{c}\text { Spring Discharge } \\
\text { Reduction Boundary Condition }\end{array}$} \\
\hline \multirow{3}{*}{$\begin{array}{l}\text { Spring Frequency for }>/=\text { Interpreted Best Fit Value } \\
\text { Spring Frequency for }<\text { Interpreted Best Fit Value }\end{array}$} & $>1=$ & $<$ & Totals \\
\hline & $\mathrm{A}$ & $B$ & \multirow{2}{*}{$\begin{array}{l}\mathrm{A}+\mathrm{B} \\
\mathrm{C}+\mathrm{D}\end{array}$} \\
\hline & $\mathrm{C}$ & $\mathrm{D}$ & \\
\hline Totals & $\mathrm{A}+\mathrm{C}$ & $B+D$ & \\
\hline \multicolumn{4}{|c|}{$\begin{array}{c}\text { A is the number of impaired springs }>/=\text { the interpreted best fit value and }>/=\text { the } \\
\text { spring discharge reduction boundary condition } \\
\text { B is the number of impaired springs }>/=\text { the interpreted best fit value and }<\text { the } \\
\text { spring discharge reduction boundary condition } \\
\text { C is the number of impaired springs }<\text { the interpreted best fit value and }>/=\text { the } \\
\text { spring discharge reduction boundary condition } \\
\text { D is the number of impaired springs }<\text { the interpreted best fit value and }<\text { the } \\
\text { spring discharge reduction boundary condition }\end{array}$} \\
\hline \multicolumn{4}{|c|}{$\begin{array}{l}\text { Figure 19: 2x2 Contingency Table Test Used for the Degree (Mild Versus Severe) of } \\
\text { Spring Discharge Response for the Impaired Spring Group, Investigation IV. }\end{array}$} \\
\hline
\end{tabular}

\subsubsection{Low Evapotranspiration Condition - Optimum Reduction Boundary}

Nonparametric statistical tests resulted in acceptance of the alternative hypothesis for vertical relief to nearest surface drainage features, vertical relief to headwater surface drainage (first and second order) features, and vertical relief to first order surface drainage features. The significant alternative hypothesis statements are as follows:

- Spring discharge impairment is associated with vertical relief to nearest surface drainage features greater than or equal to the interpreted best fit value of 36 feet (Appendix H_fig_1 and H_tab_1); +/- $5 \mathrm{ft}$. 
- Spring discharge impairment is associated with vertical relief to headwater surface drainage (first and second order) features greater than or equal to the interpreted best fit value of 36 feet (Appendix H_fig_2 and H_tab_2); +/- 5ft.

- Spring discharge impairment is associated with vertical relief to first order surface drainage features greater than or equal to the interpreted best fit value of 36 feet (Appendix H_fig_3 and H_tab_3); +/-5ft.

The use of Chi square contingency tests resulted in calculated error probabilities of 0.100.05, 0.10-0.05, and 0.20-0.10, respectively, for the above data trends (Table 23). The use of Fisher exact probability tests resulted in calculated error probabilities of 0.02951 , 0.02999, and 0.08295, respectively (Table 24). The remaining alternative hypotheses examined for the topographic and mine independent variables were rejected by the Chi square contingency and Fisher exact probability tests, at the 0.20 and 0.10 alpha probability levels, respectively.

Based upon the statistical results, the use of vertical relief to nearest surface drainage features, vertical relief to headwater surface drainage features, and vertical relief to first order surface drainage features resulted in 97 percent, 97 percent and 92 percent degree of confidence that a significant data trend exists, as determined from the complement of alpha, for these respective independent variables.

\subsubsection{Low Evapotranspiration Condition - Absolute Reduction Boundary}

Nonparametric statistical tests resulted in acceptance of the alternative hypothesis for the recharge line length component perpendicular to longwall panel face and vertical relief to 
first order surface drainage features. The significant alternative hypothesis statements are as follows:

- Spring discharge impairment is associated with the recharge line length component perpendicular to longwall panel face less than the interpreted best fit value of 169 feet (Appendix H_fig_4 and H_tab_4); +/- 10ft.

- Spring discharge impairment is associated with vertical relief to first order surface drainage features greater than or equal to the interpreted best fit value of 36 feet (Appendix H_fig_5 and H_tab_5); +/-5ft.

The use of Chi square contingency tests resulted in calculated error probabilities of 0.200.10 and $0.20-0.10$, respectively, for the above data trends (Table 23). The use of Fisher exact probability tests resulted in calculated error probabilities of 0.06894 and 0.09551 , respectively (Table 24). The remaining alternative hypotheses examined for the topographic and mine independent variables were rejected by the Chi square contingency and Fisher exact probability tests, at the 0.20 and 0.10 alpha probability levels, respectively.

Based upon the statistical results, the use of recharge line length component perpendicular to longwall panel face and vertical relief to first order surface drainage features resulted in 93 percent and 90 percent degree of confidence that a significant data trend exists, as determined from the complement of alpha, for these respective independent variables. 


\subsubsection{High Evapotranspiration Condition - Optimum Reduction Boundary}

Nonparametric statistical tests resulted in rejection of all the alternative hypotheses, therefore, there are no significant statistical relationships between the degree of spring impairment and the independent variables during high evapotranspiration conditions when evaluated at the optimum reduction boundary.

\subsubsection{High Evapotranspiration Condition - Absolute Reduction Boundary}

Nonparametric statistical tests resulted in acceptance of the alternative hypothesis for the recharge line length component perpendicular to longwall panel face. The significant alternative hypothesis statement is as follows:

- Spring discharge impairment is associated with the recharge line length component perpendicular to longwall panel face greater than or equal to the interpreted best fit value of 101 feet (Appendix H_fig_6 and H_tab_6); +/-10ft.

The use of the Chi square contingency test resulted in a calculated error probability of 0.10-0.05, for this data trend (Table 23). The use of the Fisher exact probability test resulted in a calculated error probability of 0.04409 (Table 24). The remaining alternative hypotheses examined for the topographic and mine independent variables were rejected by the Chi square contingency and Fisher exact probability tests, at the 0.20 and 0.10 alpha probability levels, respectively. 
Based upon the statistical results, the use of recharge line length component perpendicular to longwall panel face resulted in 96 percent degree of confidence that a significant data trend exists, as determined from the complement of alpha, for this independent variable. 


\subsection{CONCLUSIONS}

The methodology used for Investigation IV is the most discriminating of the four investigations of the study, in terms of mine-subsidence impacts on spring discharge. This research is a case study for one mine site, and therefore is limited in terms of its applicability to other mine sites, until additional research projects with similar objectives are conducted at other mine locations within the northern Appalachian Coal Basin.

The following conclusions are drawn from the results of Investigation IV and are offered for use to assist in the prediction of mining-induced changes to spring discharge within the research study area. Precision errors, related to the statistical noise and measurement techniques inherent to the research data, are assumed to have negligible impacts on observed statistical data trends.

1. Approximately 40 percent of springs were permanently (for at least 12 months) impaired within the research study area through the post-mine monitoring program. The remaining 60 percent of springs were either unaffected or only seasonally impaired.

2. The following conclusions are related to spring discharge impairment data trends identified for the data set studied during low evapotranspiration seasonal conditions (December through May). These data trends are associated with bedrock stratigraphy and the different mechanical deformation responses to mining-induced subsidence inherent to the formations. Specifically: 
a. Springs that were greater than 36 vertical feet $(+/-5 \mathrm{ft})$ from the nearest surface drainage feature (stream channel) had a higher probability to experience some degree of flow impairment during low evapotranspiration conditions. This is the strongest low evapotranspiration statistical data trend.

b. Springs that daylighted at an elevation of $1190 \mathrm{ft}(+/-5 \mathrm{ft})$ amsl or less had a higher probability to experience some degree of flow impairment during low evapotranspiration conditions.

3. The following conclusions are related to spring discharge impairment data trends identified for the data set studied during high evapotranspiration seasonal conditions (June through November). These data trends are associated with an inverse relationship between hydraulic gradient and hydraulic conductivity; higher hydraulic gradients were directly related to longer recharge line lengths and greater vertical reliefs but inversely related to pre-mining, averaged, low-flow spring discharge. In addition, spring recharge was more susceptible to mininginduced subsidence during high evapotranspiration seasonal conditions than for low evapotranspiration seasonal conditions. Specifically:

a. Springs with recharge line length greater than 189 linear feet $(+/-10 \mathrm{ft})$ had a higher probability to experience some degree of flow impairment during high evapotranspiration conditions. 
b. Springs with recharge line vertical relief greater than 36 vertical feet (+/$5 \mathrm{ft}$ ) had a higher probability to experience some degree of flow impairment during high evapotranspiration conditions.

c. Springs that daylighted at an elevation of $1209 \mathrm{ft}(+/-5 \mathrm{ft})$ amsl or less had a higher probability to experience some degree of flow impairment during high evapotranspiration conditions.

d. Springs with pre-mine average low flow discharge of less than $0.43 \mathrm{gpm}$ $(+/-10 \%)$ had a higher probability to experience some degree of flow impairment during high evapotranspiration conditions. This is the strongest high evapotranspiration statistical data trend. 


\subsection{DISCUSSION AND THEORY}

The objectives of this research were, essentially, to determine what magnitude of spring discharge reduction constitutes mining-induced spring discharge impairment and what are the underlying factors, independent variables, associated with springs that induce such impairments.

The statistical examination of hydrologic, geologic, topographic, and mine-specific independent variables was conducted to determine what critical intrinsic values most strongly associate with spring discharge impairment. The independent variables were examined during low (December through May) and high (June through November) evapotranspiration conditions for both their calculated median values and interpreted best fit boundary values. These best fit boundary values were interpreted in an effort to identify the boundary value associated with the lowest probability of error for the trend with spring discharge.

The spring types encountered within the research study area are assumed to be contact springs and fracture-controlled springs. The spring discharge responses to mininginduced subsidence are associated with the natural setting conditions of these springs; springs form at the intersection of fractures and/or at the boundary of aquifers (like sandstone) with underlying confining layers (like shale) and ground surface. Confining layers deform through ductile mechanics and have a greater probability for healing of subsidence fractures through natural attenuation processes. 
If vertical hydraulic conductivity of the confining layer increases through minesubsidence fracturing, the perched ground water could drain vertically downward until it encounters another underlying confining layer. Springs located at lower elevations sometimes increase in discharge after the subsidence event. New post-mining springs typically change positions to lower elevations that are often laterally different than the pre-mining springs. It is theorized that the ground water within perched aquifers affected by mine subsidence is reporting to lower perched aquifers and/or the regional water table.

This theory is supported through the results of this research and collection of anecdotal information from surface property owners. Eleven of the 77 springs researched had higher average discharge during the post-mining monitoring period than during the premining monitoring period. During the field work component of this research, 15 new post-mining spring discharge locations were reported by surface property owners.

\subsection{Independent Variable Analysis}

The methodologies used for Investigations I through IV yielded results related to which independent variables were and were not associated with mining-induced spring discharge impairment (Table 25). The following independent variables are associated with mining-induced spring discharge impairment.

- Spring recharge line length component perpendicular to longwall panel face

- Spring recharge line length 


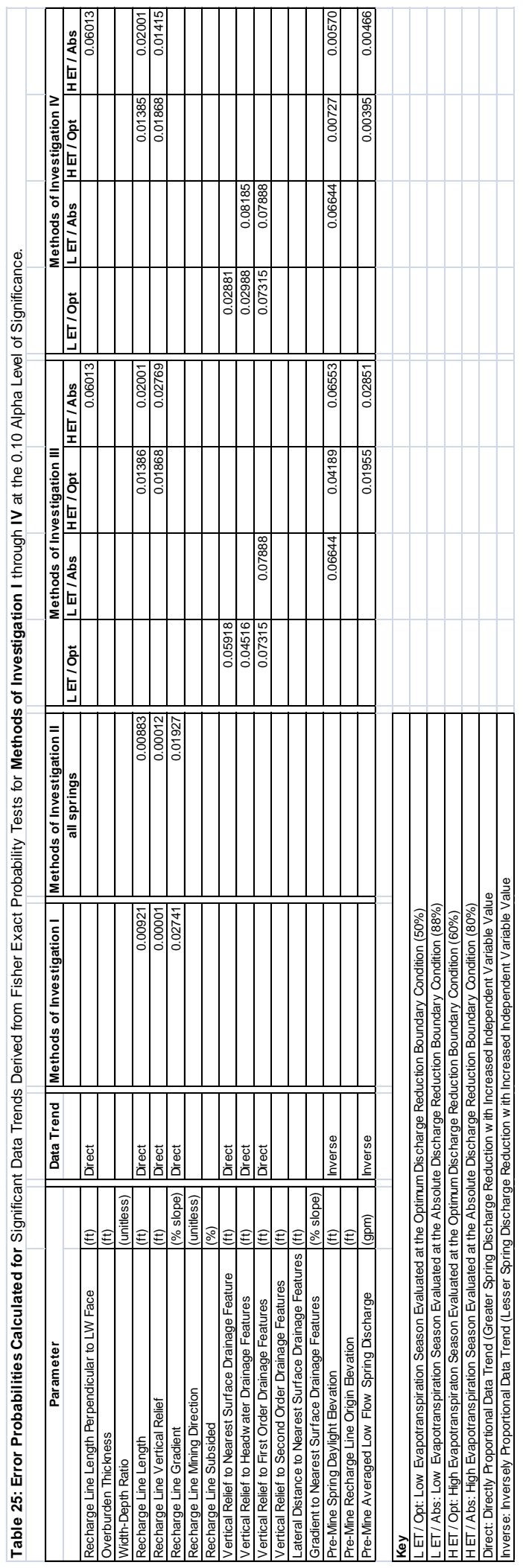


- Spring recharge line vertical relief

- Spring recharge line gradient

- Spring vertical relief to nearest surface drainage feature

- Spring vertical relief to first and second order surface drainage features

- Spring vertical relief to first order surface drainage features

- Pre-mine spring daylight elevation

- Pre-mine averaged low flow spring discharge

It is conjectured by the author that spring discharge impairment is controlled by two factors - bedrock stratigraphy and spring recharge. Bedrock stratigraphy is associated with spring discharge impairment during both low and high evapotranspiration seasonal conditions, and spring recharge is associated with spring discharge impairment during high evapotranspiration seasonal conditions.

\subsubsection{Bedrock Stratigraphy}

It is surmised by the author that pre-mining spring daylight elevations are associated with spring discharge impairment due to stratigraphic control; however, data needs to be collected to further support this speculation. This research did not evaluate stratigraphy, stratigraphic dip, or lineaments. Spring locations, and spring discharge mining responses, are widely distributed throughout the research study area. It is presumed that localized features, such as specific rock units and structures (such as lineaments) may be associated with specific spring discharge mining responses. 
Springs that daylight lower in elevation are more susceptible to mining-induced subsidence. The assumptions associated with this variable are related to either the overburden strata movement zones or changes in stratigraphy. Overburden thickness is not a statistically significant independent variable. The uppermost surface fracture zone according to mine-subsidence theory is assumed to be involved with spring discharge response.

In addition to the spring discharge impairment association with daylight elevation, spring proximity to the nearest surface drainage feature (stream channel) is statistically significant. A spring's pre-mining proximity to the nearest surface drainage feature, as described within section 4.2.2 and 8.1.4.2, is equal to the shortest horizontal and vertical distance discharge water from a spring would travel on ground surface to the nearest surface drainage feature.

The vertical relief and lateral distance to the nearest surface drainage feature are directly proportional (Figure 20), that is, the greater the horizontal distance a spring is from a stream channel, the greater the vertical relief. Springs further from surface drainage features have greater vertical reliefs, such as springs that daylight within the mid- to upper hillside locations. Springs closer to surface drainage features have lower vertical reliefs, such as springs that daylight within the lower valley walls. 


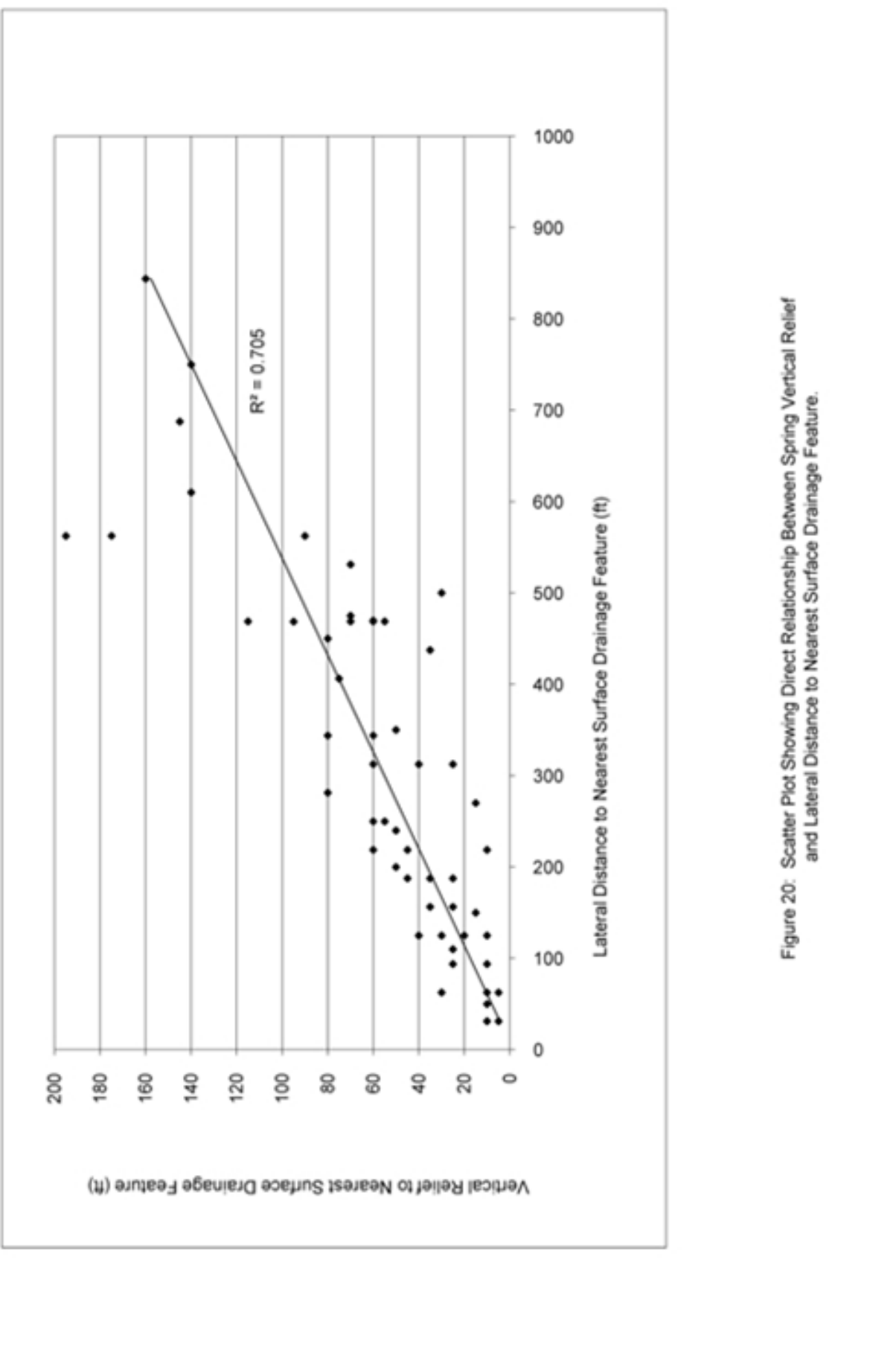


Spring discharge impairment is associated with greater vertical relief; therefore springs located further laterally from and up slope from surface drainage features (stream channel) are more susceptible to mining-induced spring discharge impairment. Nearsurface fracturing from mining-induced subsidence probably influences spring response to mining.

Spring discharge impairment is not associated with overburden thickness. Therefore, it is postulated that spring discharge impairment is associated with different mechanical deformation responses to stress-relief fracturing and surface zone fracturing inherent to the formations of the bedrock stratigraphy within the research study area. More specifically, it is speculated that spring discharge impairment is associated with formations that respond to mining-induced subsidence through tensile deformation means, as opposed to formations that deform through ductile means.

\subsubsection{Spring Recharge}

The spring recharge line, as described within sections 4.2.1 and 8.1.4.1, is a conceptual analog to the topographic subsurface drainage and recharge basin of a spring. The recharge line concept assumes that ground water flows down-slope along the steepest hydraulic gradient (Fetter, 2001), essentially perpendicular to ground surface topographic elevation contours. The length and vertical relief of the spring recharge line are directly proportional (Figure 21); longer recharge lines typically have greater vertical reliefs. It is 

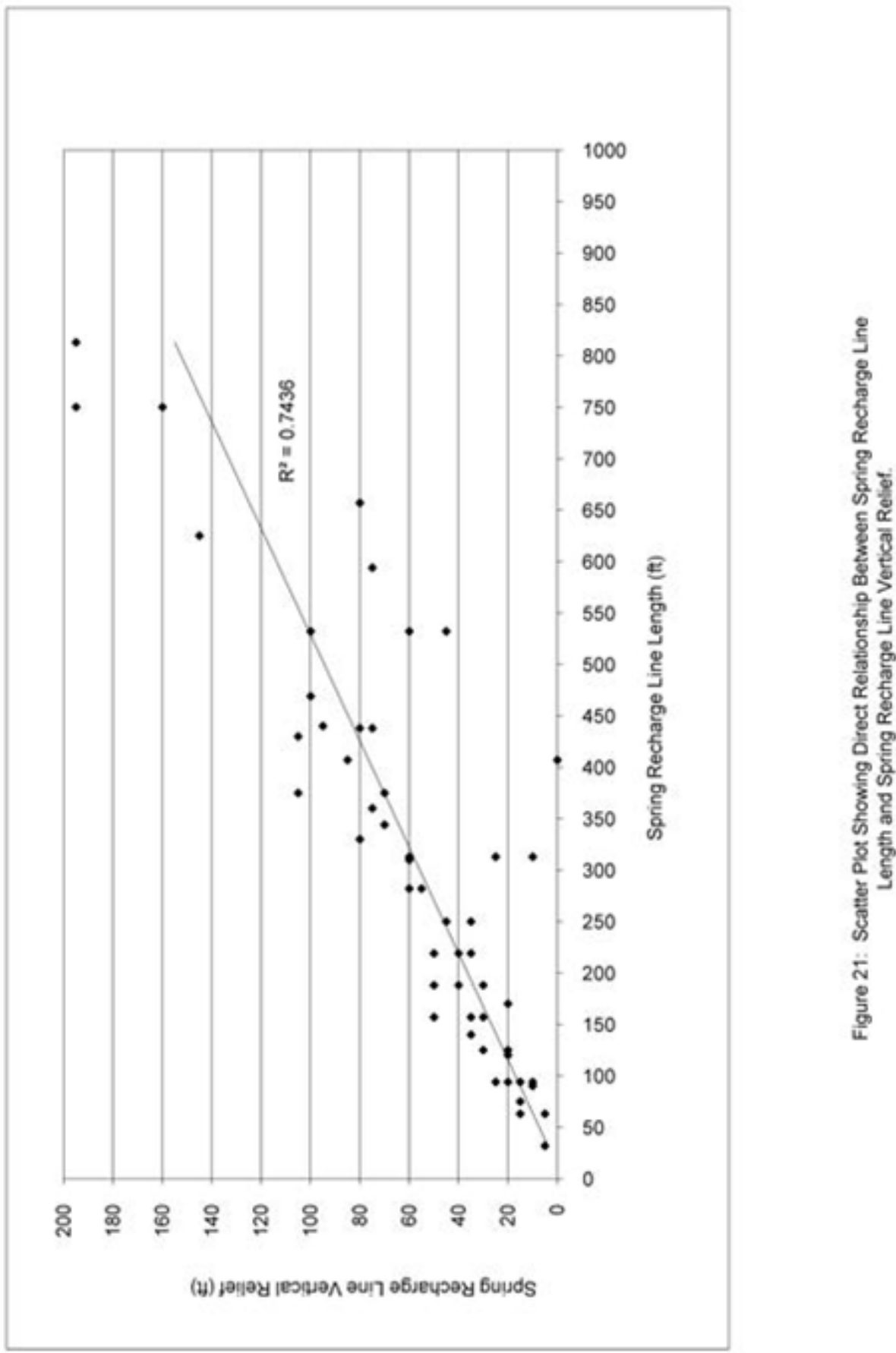
assumed that greater spring recharge line length and vertical relief are associated with higher hydraulic gradients, that is, higher gradients contain longer lengths and greater vertical reliefs. Therefore, direct relationships exist among the length, vertical relief, and gradient of the recharge line.

It is also hypothesized that aquifers with high ground water gradients are associated with low hydraulic conductivity (Fetter, 2001), therefore, higher recharge line gradients are inversely related to hydraulic conductivity. Hydraulic conductivity should be directly related to pre-mine averaged low flow spring discharge; that is, an aquifer with low hydraulic conductivity will transmit low spring discharge. Therefore, springs with low pre-mine averaged spring discharge should be associated with aquifers with low hydraulic conductivity, which are associated with higher recharge line hydraulic gradients, longer recharge line lengths, and greater recharge line vertical reliefs. Therefore, lower hydraulic conductivity of shallow rock strata, supplying water to springs, could cause springs to be more susceptible to the greater subsidence-induced dewatering observed for springs with longer, steeper, and greater relief recharge lines. These recharge lines could provide greater opportunity for mining-induced fractures to negatively impact the spring recharge basins through increased vertical hydraulic conductivity.

This speculation is supported by the length component of the recharge line perpendicular to longwall panel face. This recharge line length component is an analog measure of the 
relative amount of time that would have elapsed across a mined longwall panel subsidence event. Greater amounts of time, or longer recharge line length components, increase the opportunity for the formation of mining-induced fractures, or enlargement of the apertures of existing fractures, to intercept ground water from spring recharge basins through the influence of increased vertical hydraulic conductivity.

In addition, springs have lower discharges during high evapotranspiration conditions than during low evapotranspiration conditions; averaged spring discharge during high and low evapotranspiration conditions were $1.56 \mathrm{gpm}$ and $8.97 \mathrm{gpm}$, respectively. Spring discharge response to mining-induced subsidence is therefore more noticeable during high evapotranspiration conditions than during low evapotranspiration conditions and a greater susceptibility exists for spring discharge impairment during high evapotranspiration conditions. 


\subsection{RECOMMENDATIONS}

The natural variation analysis resulted in the determination of two spring discharge reduction boundaries; absolute and optimum. These spring discharge reduction boundaries were evaluated during both the low and high evapotranspiration conditions; however, the spring discharge reduction boundaries were not evaluated specifically during periods of precipitation deficit or surplus due to a lack of enough pre-mine spring discharge data.

It is recommended that further investigation into the natural variation analysis be conducted in a manner to account for meteorological influence. It is suggested that premine spring discharge data be evaluated at different departures from normal precipitation to determine if pre-mine spring discharge variation exists. It is assumed that greater departures from normal precipitation would yield greater variation in pre-mine spring discharge. Spring discharge reduction boundaries could then be used to determine spring discharge responses more specific to the precipitation deficit or surplus across the subsidence events.

Knowledge of natural variation in spring discharge across subsidence events (before versus after mining) is significant in determining if a spring discharge impairment occurred, as well as if seasonal evapotranspiration conditions and precipitation are influential in concluding if a spring supply was affected by mining-induced subsidence. It is recommended that naturally-occurring changes in spring discharge be identified for 
prior to declaring if a mining-induced environmental effect has occurred. Therefore, it is recommended by the author that a more sophisticated approach, with a greater degree of data discrimination, be used for hydrologic impairment analysis.

In addition, 11 of the 77 springs had higher average discharge during the post-mine monitoring period than during the pre-mine monitoring period. During the field work component of this research, 15 new post-mine spring discharge locations were reported by surface property owners. It is recommended that further investigation into post-mine "new" spring discharge locations and improved (increased) spring discharge locations be evaluated to determine if independent variables specific to those springs could be used for probable hydrologic consequence reports or for assistance to locate post-mine water replacement supplies. 


\subsection{REFERENCES}

Berryhill, H.L., 1963. Geology and Coal Resources of __*,_*. _ * Geological Survey Professional Paper, 113 p.

Borchers, J.W., and Wyrick, G.G., 1981. Application of Stress-Relief Fracturing Concepts for Monitoring the Effects of Surface Mining on Groundwater in Appalachian Plateau Valleys, U.S. Geological Survey, Symposium on Surface Mining Hydrology, Sedimentology, and Reclamation, 443-449 p.

Carver, L.S., and H.W. Rauch, 1994. Hydrogeologic Effects of Subsidence at a Longwall Mine in the Pittsburgh Coal Seam; in Proceedings of the Thirteenth Annual Conference on Ground Control in Mining, College of Mineral and Energy Resources, West Virginia University, Morgantown, West Virginia, 249-263 p.

Cifelli, R.C., and H.W. Rauch, 1986. Dewatering Effects from Selected Underground Coal Mines in North-Central West Virginia; in Proceedings of the Second Workshop on Surface Subsidence Due to Underground Mining, College of Mineral and Energy Resources, West Virginia University, Morgantown, West Virginia, 249-263 p.

Coe, C.J., and Stowe, S.M., 1984. Evaluating the Impact of Longwall Coal Mining on the Hydrologic Balance; in Proceedings of the Conference on the Impact of Mining on Ground Water, National Water Well Association, Dublin, Ohio, 348-359 p.

Dixon, D.Y., and H.W. Rauch, 1988, Study of Quantitative Ground Water Impacts from Longwall Mine Subsidence; in Proceedings of the Seventh International Conference on Ground Control in Mining, College of Mineral and Energy Resources, West Virginia University, Morgantown, West Virginia, 321-335 p.

Dixon, D.Y., and H.W. Rauch, 1990, The Impact of Three Longwall Coal Mines on Streamflow in the Appalachian Coalfield; in Proceedings of the Ninth International Conference on Ground Control in Mining, College of Mineral and Energy Resources, West Virginia University, Morgantown, West Virginia, 169-182 p.

Donohue, T.D.A., and Parizek, R.R., 1994. Evaluation of the Long Term Impact on Domestic and Farm Groundwater Supplies under Pennsylvania Longwall Mining Conditions; in Proceedings of the Third International Conference on the Abatement of Acidic Drainage, Pittsburgh, Pennsylvania, 180-188 p.

Elsworth, D. and Liu, J., 1995. The Impact of Deep Mining on an Overlying Aquifer in Western Pennsylvania, Ground Water Monitoring Review, Vol. 3, No. 5, 786-793 p. 
Fetter, C.W., 2001. Applied Hydrogeology, Fourth Edition, Prentice-Hall, Upper Saddle River, New Jersey, 598 p.

Fiscor, S., 2008. Underground Coal Operators Install Several New Longwall Mining Systems. Coal Age, Vol. 113, No. 2, 28-29 p.

Freme, F., 2008. Energy Information Administration [online]. U.S. Coal Supply and Demand: 2007 Review. Available at: http://www.eia.doe.gov/cneaf/coal. [Accessed 03 Sept 2008].

Hill, J.G. and Price, D.R., 1983. The Impact of Deep Mining on an Overlying Aquifer in Western Pennsylvania, Ground Water Monitoring Review, Vol. 3, No. 1, 1138-1143 p.

Kendorski, F.S., 2001. Effects of High-Extraction Coal Mining on Surface and Ground Waters; in Proceedings of the Twelfth Conference on Ground Control in Mining, 412$423 \mathrm{p}$.

Leavitt, B.R., and Gibbens, J.F., 1992. Effects of Longwall Coal Mining on Rural Water Supplies and Stress Relief Fracture Flow Systems; in Proceedings of the Third Workshop on Subsurface Subsidence Due to Underground Mining, College of Mineral and Energy Resources, West Virginia University, Morgantown, West Virginia, 228-234 p.

Matetic, R.J., Trevits, M.A., and Swinehart, T., 1991. A Case Study of Longwall Mining and Near-Surface Hydrological Response; in Proceedings of the American Mining Congress Coal Convention, Pittsburgh, Pennsylvania, 11 p.

Matetic, R.J., and Trevits, M.A., 1992. Hydrologic Variations Due to Longwall Mining: in Proceedings of the Third Workshop on Surface Subsidence Due to Underground Mining, College of Mineral and Energy Resources, West Virginia University, Morgantown, West Virginia, 204-213 p.

Owili-Eger, A.S.C., and Johnson, K.L., 1987. Hydrogeological Environment of Full Extraction Mining; in Proceedings of the Longwall USA Exhibition and Conference, Pittsburgh, Pennsylvania, 9 p.

Parizek, R.R., and Ramani, R.V., 1995. Longwall Coal Mines Pre-Monitoring and Water Supply Replacement Alternatives; Workshop on Longwall Mining and Rural Water Supplies, Holiday Inn, Pittsburgh South Hills, Pennsylvania, 94 p.

Peng, Syd S., 1992. Surface Subsidence Engineering. Society for Mining, Metallurgy, and Exploration, Inc. 161 p. 
Peng, S.S., and Chiang, H.S., 1984. Longwall Mining. John Wiley and Sons, New York, New York, $450 \mathrm{p}$.

Pennsylvania Department of Environmental Protection (Pa DEP), 1999. The Effects of Subsidence Resulting from Underground Bituminous Coal Mining on Surface Structures and Features and Water Resources (Submitted to Governor Tom Ridge, the General Assembly, and the Citizens Advisory Council).

Rauch, H.W., O’Steen, W.N., Ahnell, G., and Giannatos, D.F., 1984. Predictions for Aquifer Dewatering over Underground Mines in the Pittsburgh, Sewickley, and Upper Freeport Coals of Northern West Virginia; in Proceedings of the Surface Mine Drainage Task Force Symposium, Ramada Inn, Morgantown, West Virginia, 11p.

Rauch, H.W., 1989. A Summary of the Ground Water Impacts from Underground Longwall Mine Subsidence in the North Central Appalachians; in Proceedings of Special Institute on Coal Mine Subsidence, Eastern Mineral Law Foundation, Westin William Penn Hotel, Pittsburgh, Pennsylvania, 201-231 p.

Rossendaal, D.J.V., Brutcher, B.B. Mehnert, J.T.K., and Bauer, R.A., 1990. Overburden Deformation and Hydrologic Changes Due to Longwall Mine Subsidence in Illinois; in Proceedings of the Third Conference on Ground Control Problems in the Illinois Coal Basin, Illinois State Geological Survey, 73-81 p.

Schumacher, S.D., Boone, K.M., and Brown, L.C., 2007. _ * State University Extension Fact Sheet; _* County Water Resources, AEX-480.07. Available at: http://*line.*su.edu/aex-fact/0480 07.html [Accessed 20 Sept 2007].

Siegel, S., 1956. Nonparametric Statistics for the Behavioral Sciences, McGraw-Hill Book Company, New York, New York, 249 p.

Stoner, J.D., 1983. Probable Hydrologic Effects of Subsurface Mining, Ground Water Monitoring Review, Vol. 3, No. 1, 128-137 p.

Tieman, G.E., and Rauch, H.W., 1987. Study of Dewatering Effects at an Underground Longwall Mine Site in the Pittsburgh Seam of the Northern Appalachian Coalfield; in Proceedings of the U.S. Bureau of Mines Technology Transfer Seminar, Information Circular 9137, U.S. Bureau of Mines, Pittsburgh, Pennsylvania, 72-89 p.

Trevits, M.A., and Matetic, R.J., 1991. A Study of the Relationship Between Saturated Zone Response and Longwall Mining-Induced Ground Strain; in Proceedings of the Fifth National Outdoor Action Conference, Las Vegas, Nevada, National Water Well Association, 1101-1109 p. 
Walker, J.S., Green, J.B., and Trevits, M.A., 1986. A Case Study of Water Level Fluctuations Over a Series of Longwall Panels in the Northern Appalachian Coal Region; in Proceedings of the Second Workshop on Surface Subsidence Due to Underground Mining, West Virginia University, Morgantown, West Virginia, 264-269 p.

Walker, J.S., 1988. Case Study of the Effects of Longwall Mining Induced Subsidence on Shallow Ground Water Sources in the Northern Appalachian Coal Field, U.S. Bureau of Mines Report of Investigations, 9198, Pittsburgh, Pennsylvania, 17 p.

Footnote: * denotes location of research study area and would jeopardize the terms of anonymity. 


\subsection{APPENDIX}

APPENDIX A: Spring Discharge Hydrographs Used to Assess Spring Discharge

Response to Mining-Induced Subsidence as Discussed in Methods of Investigation I 


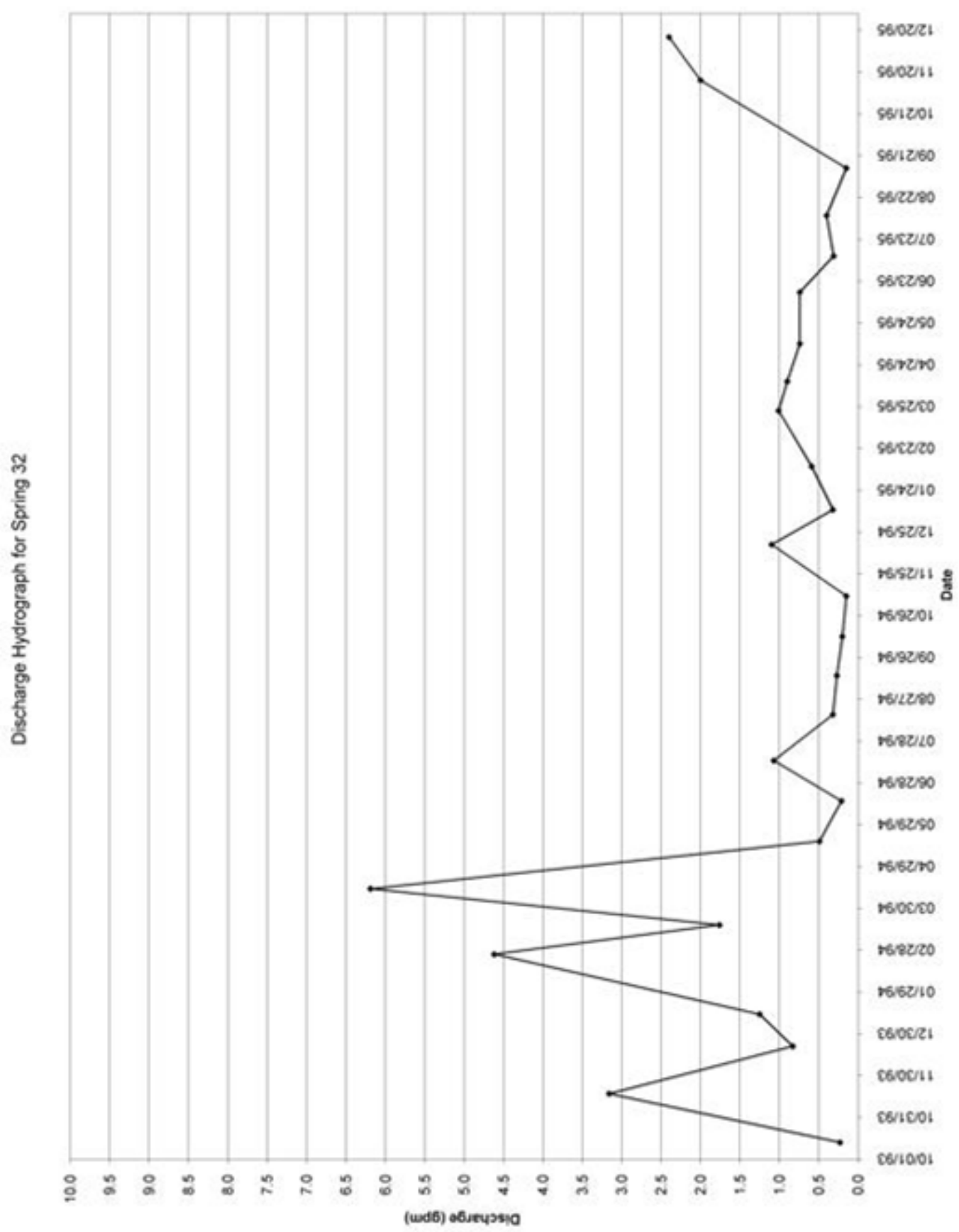




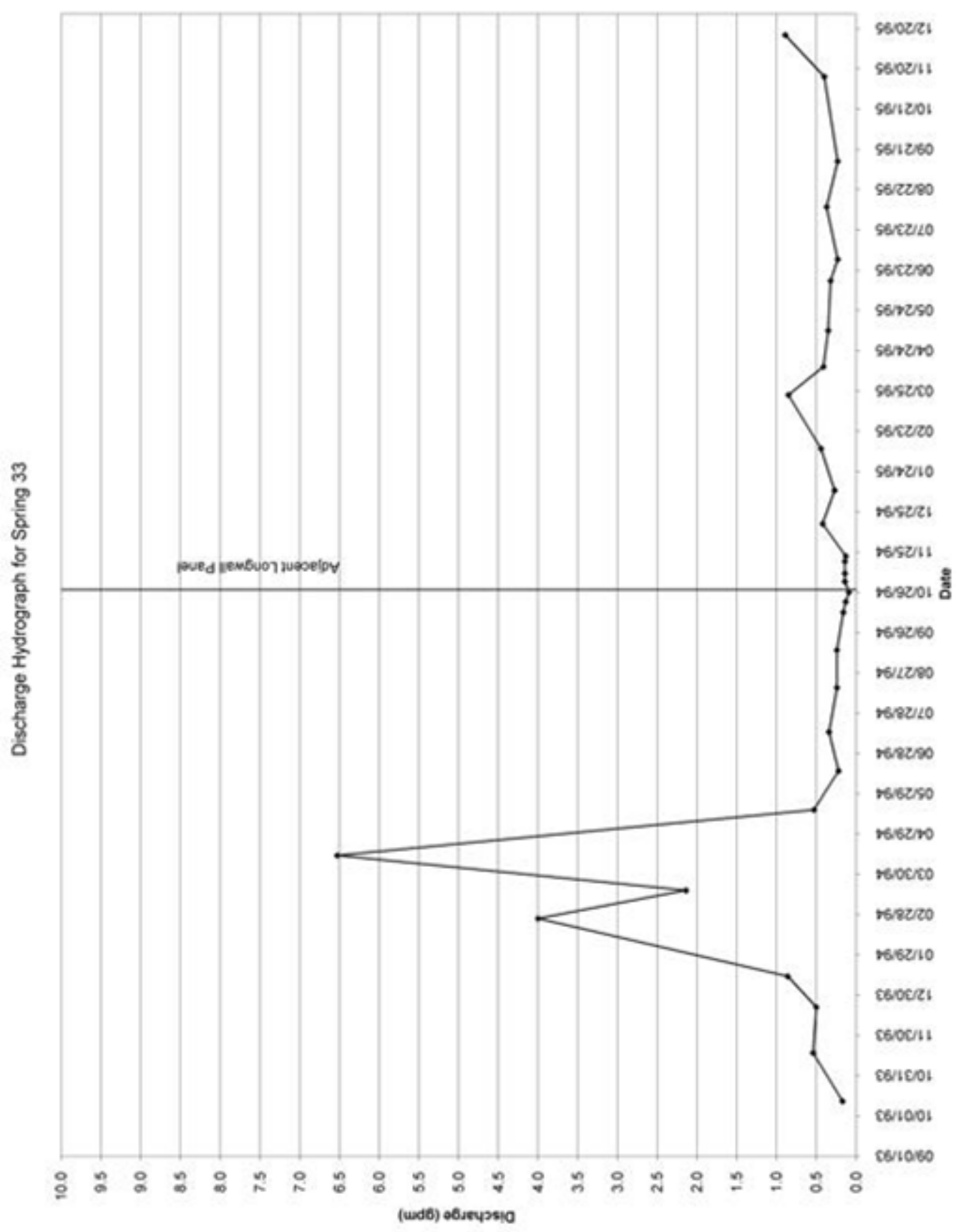




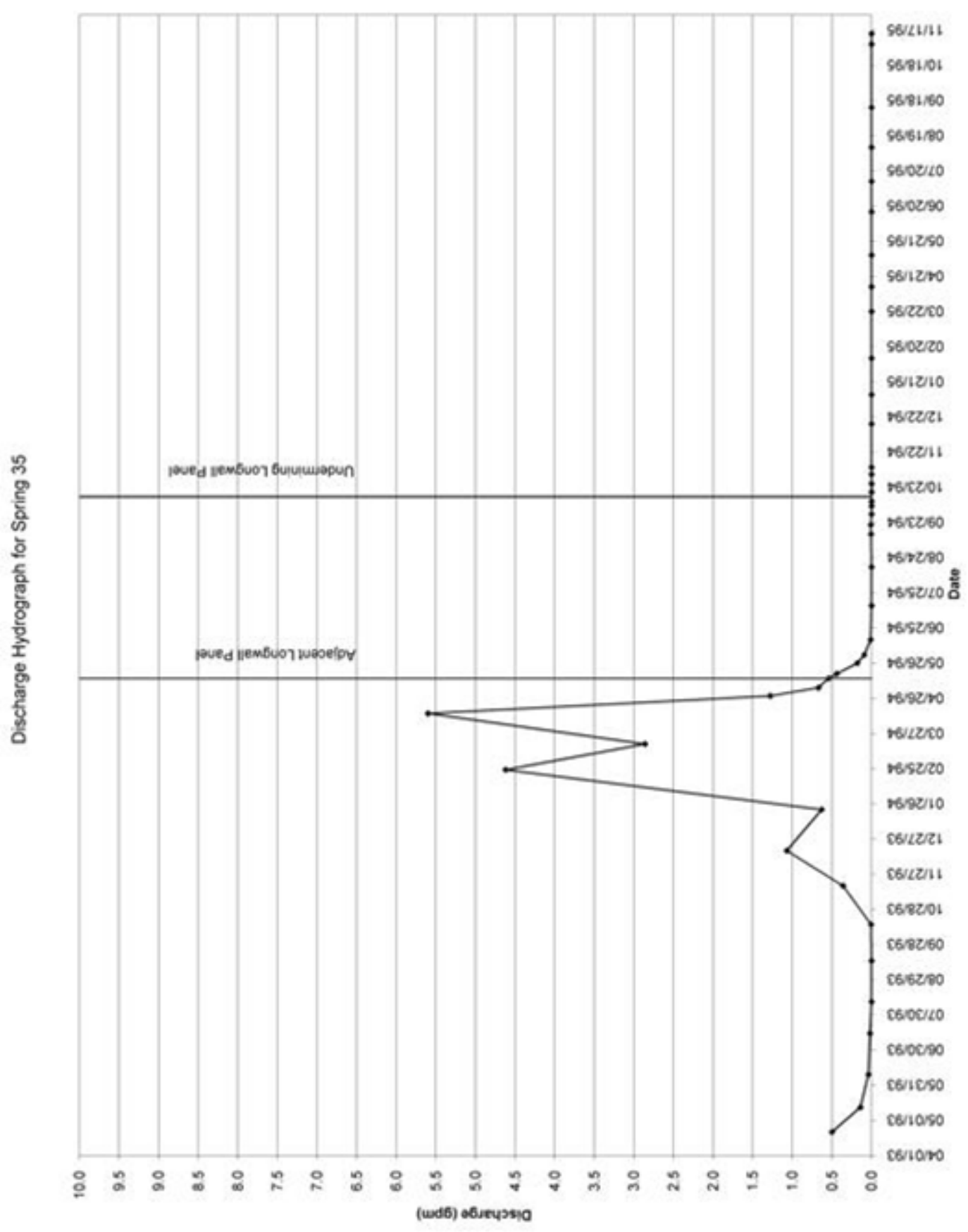




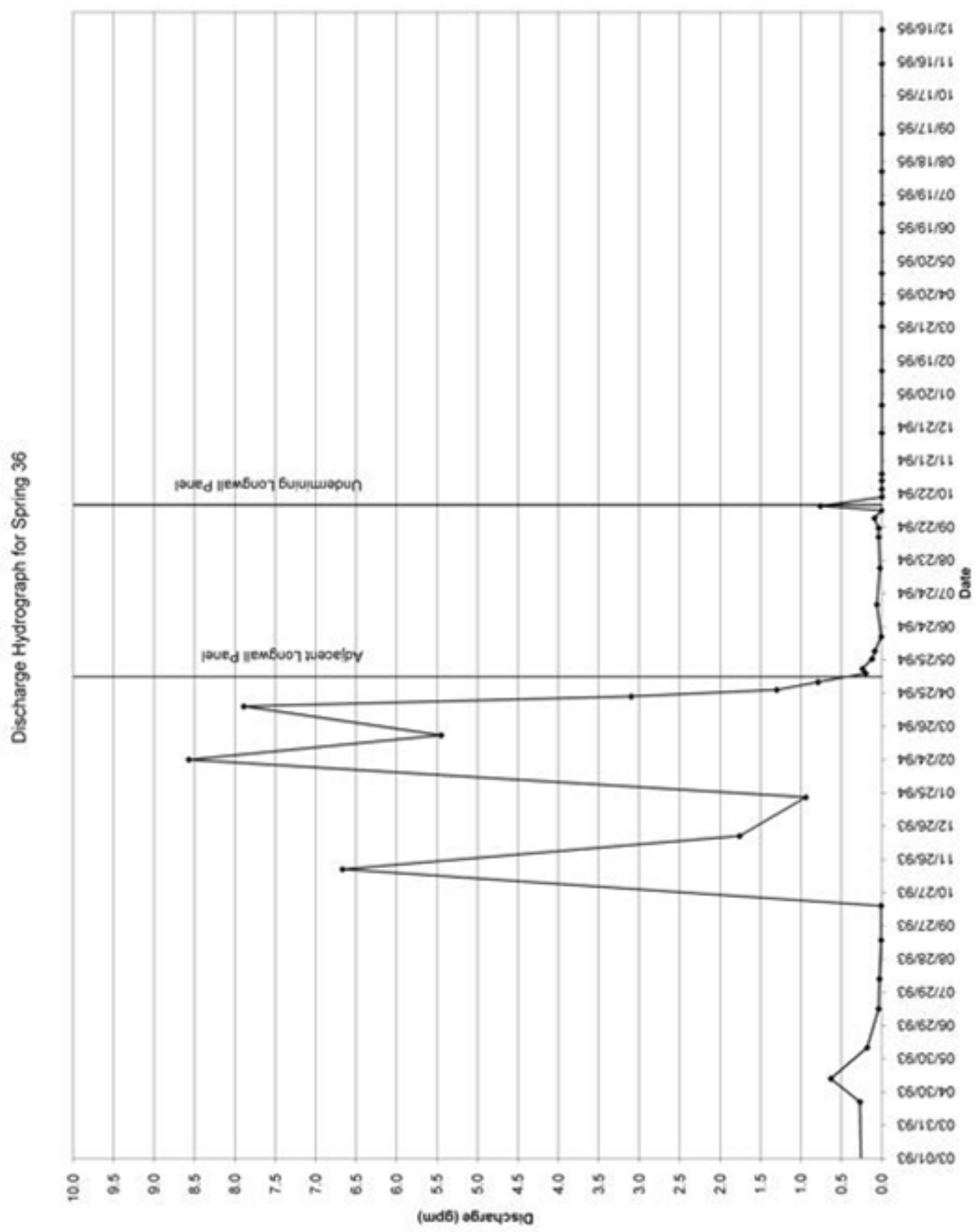




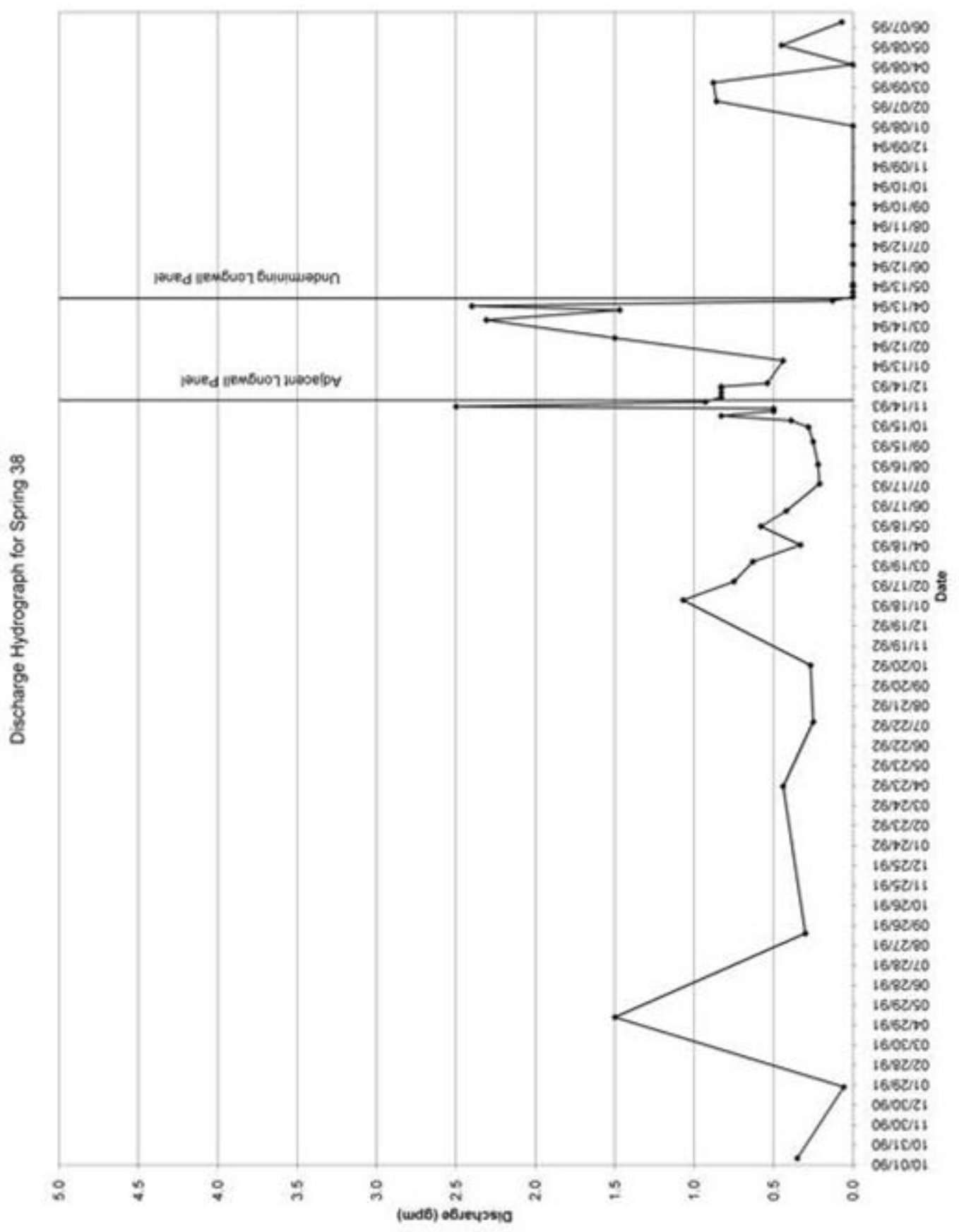

138 


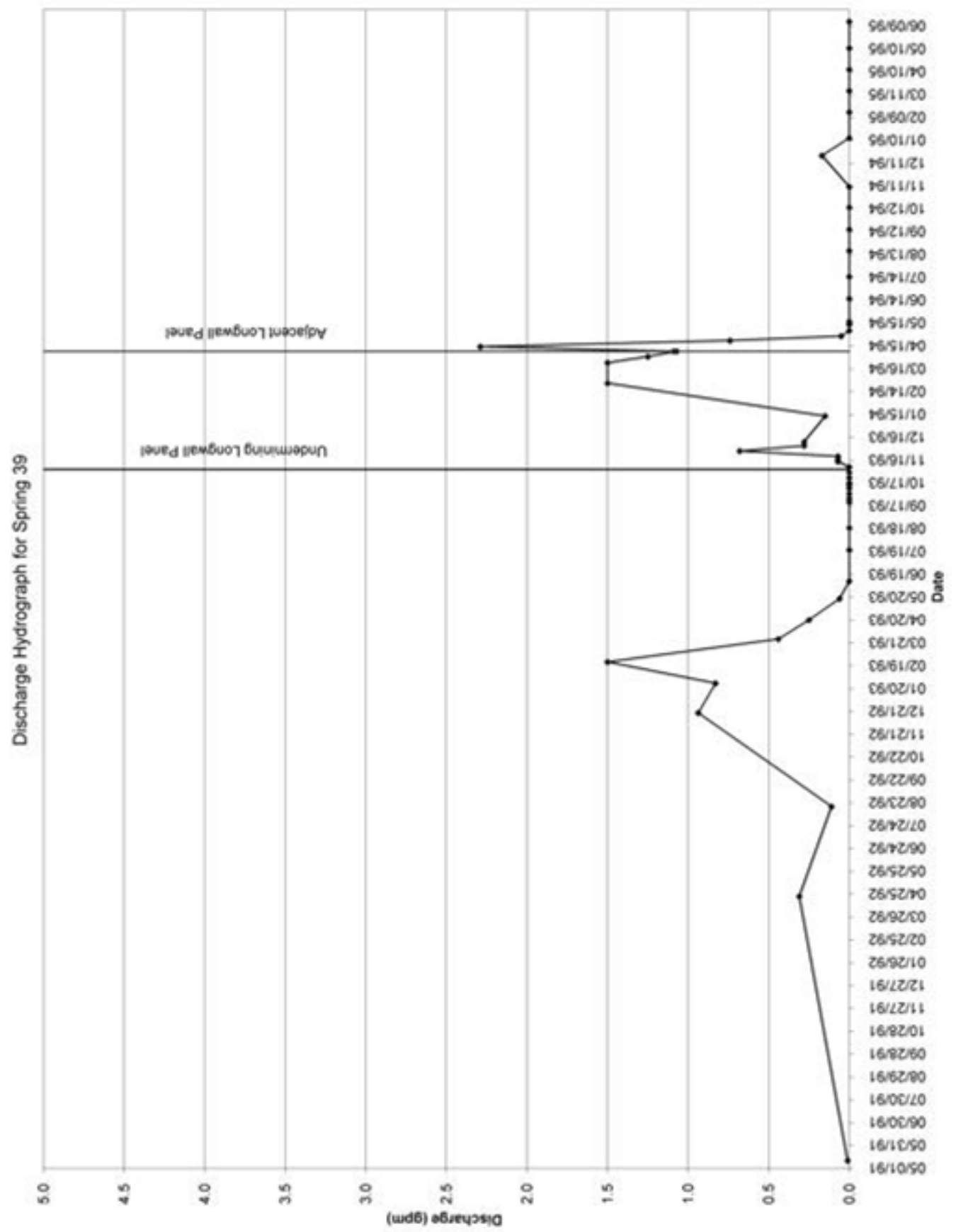




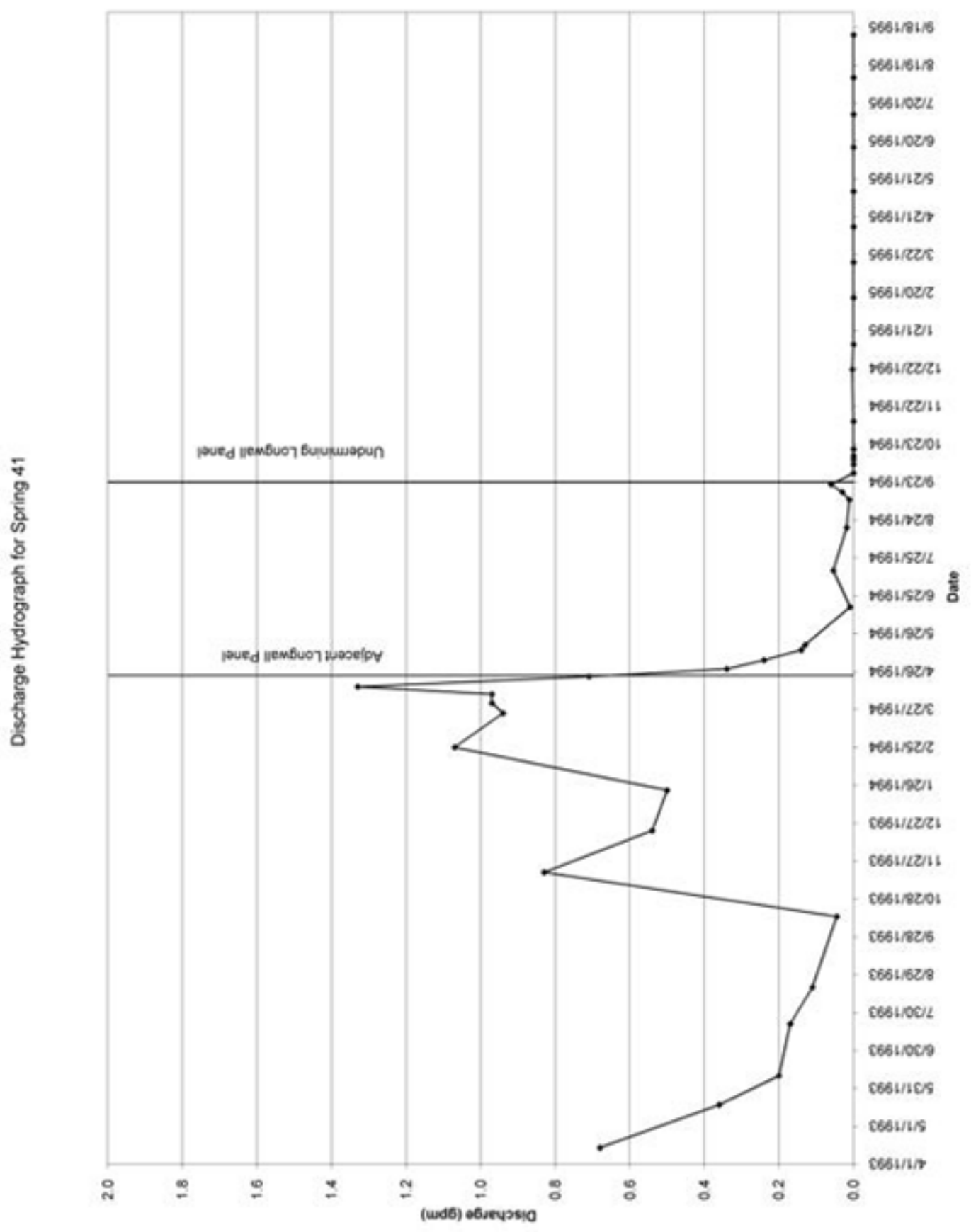




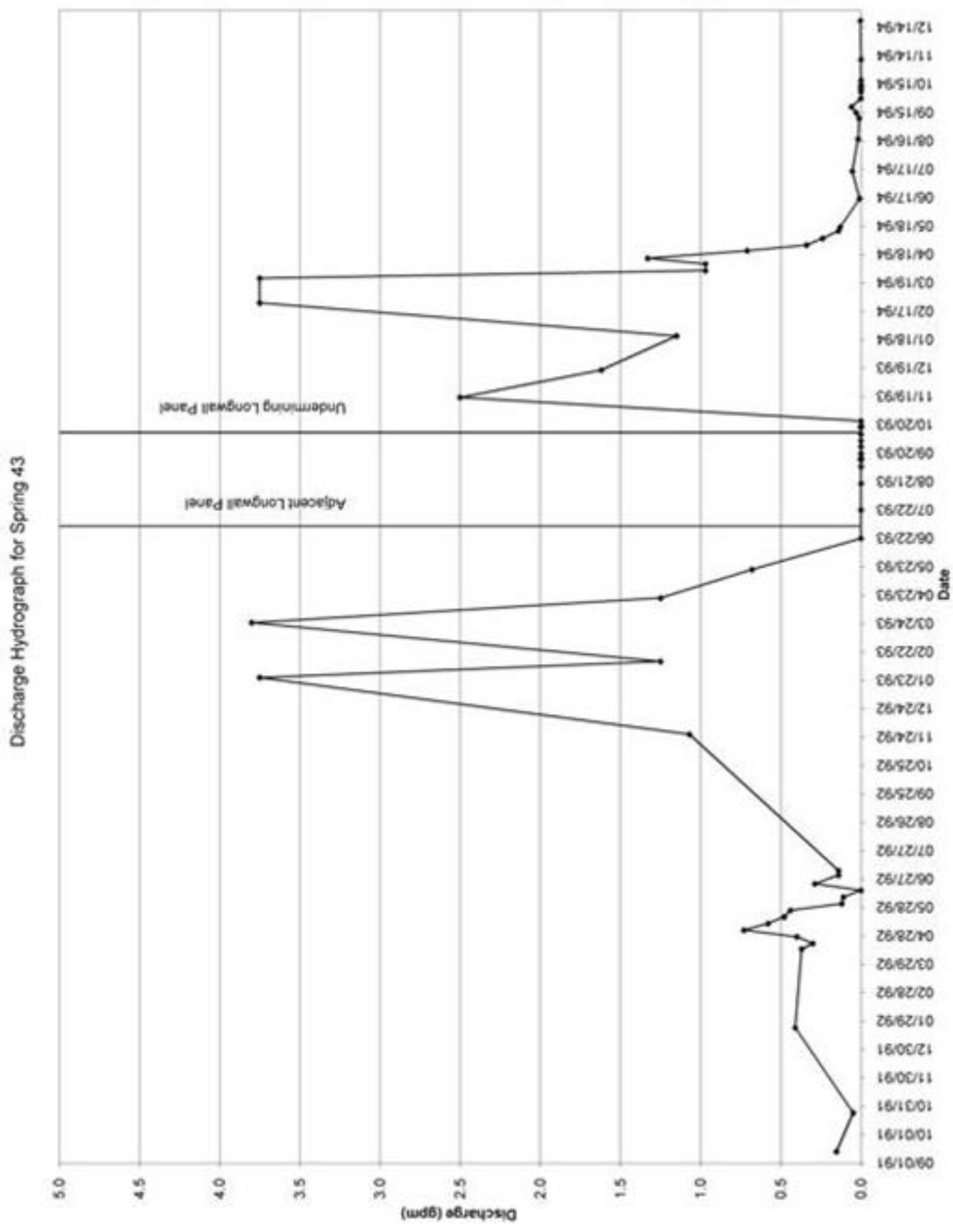




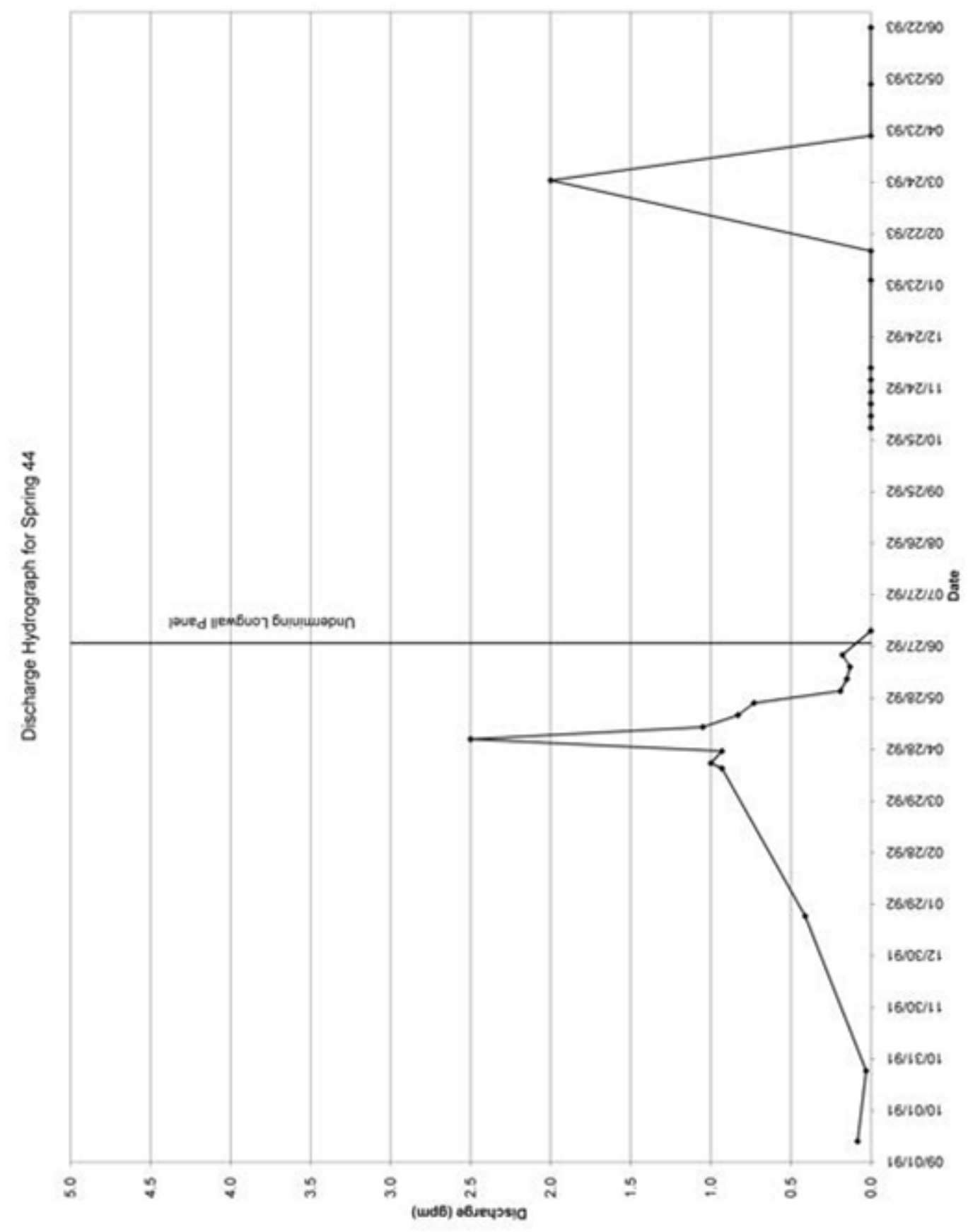




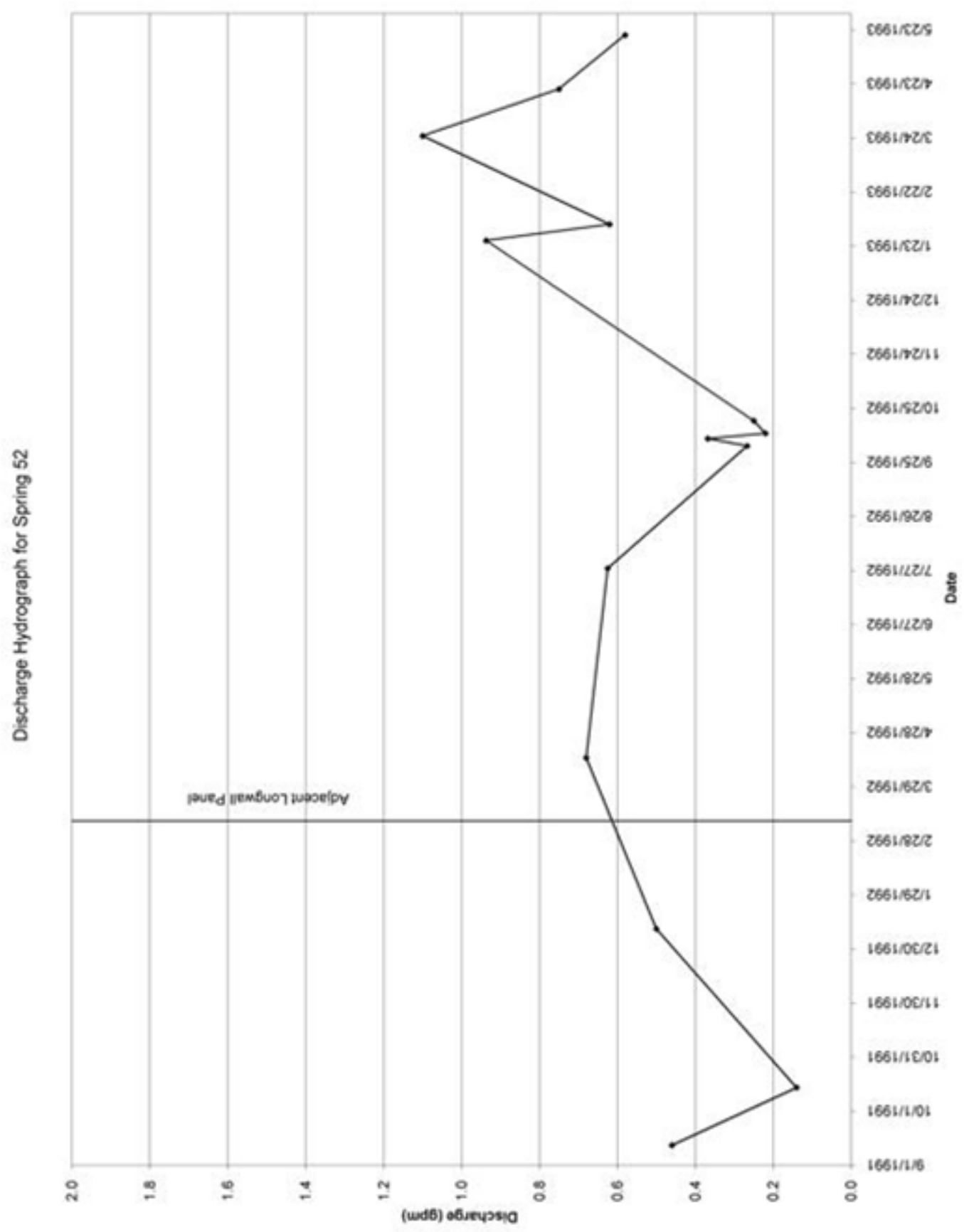




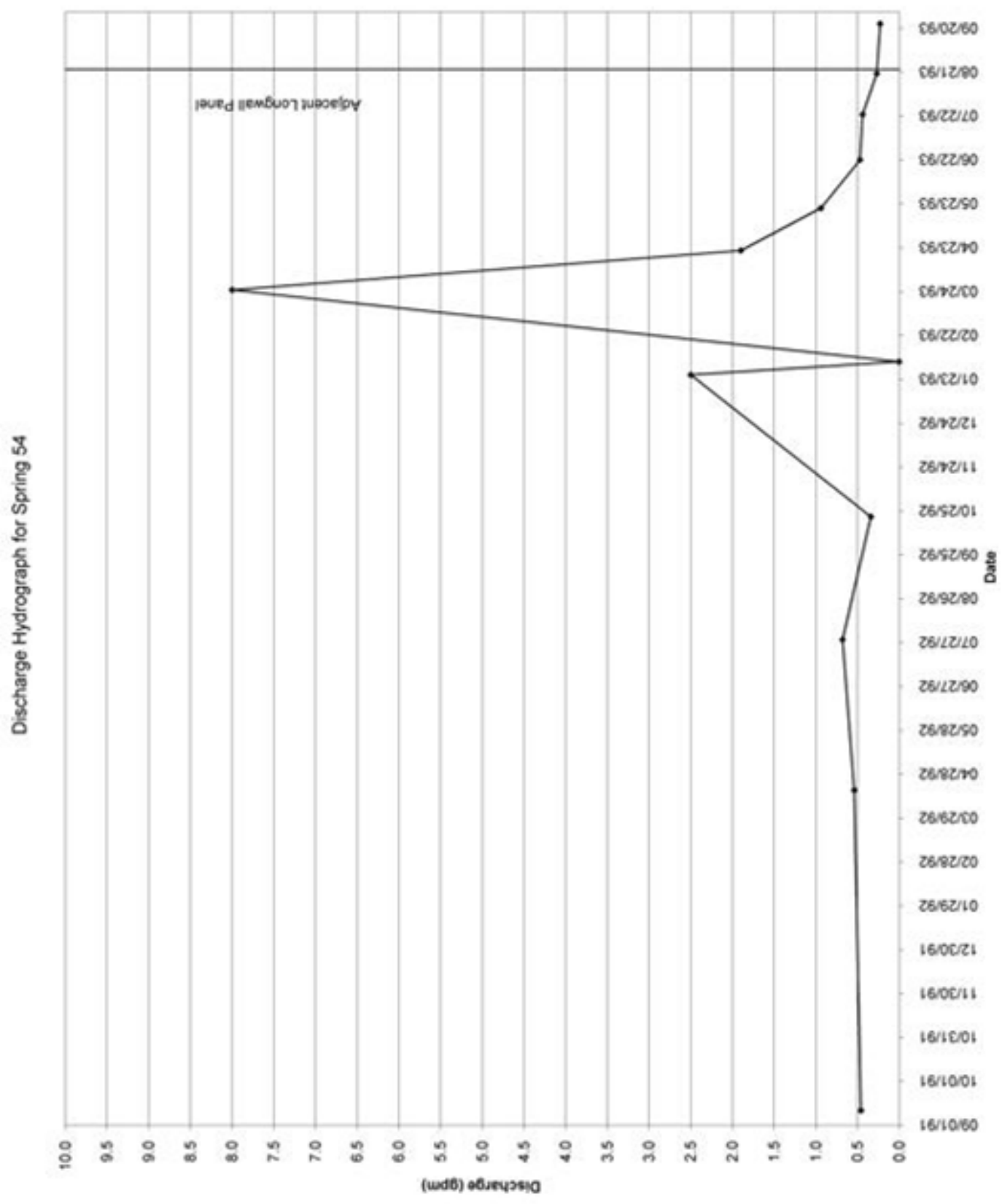




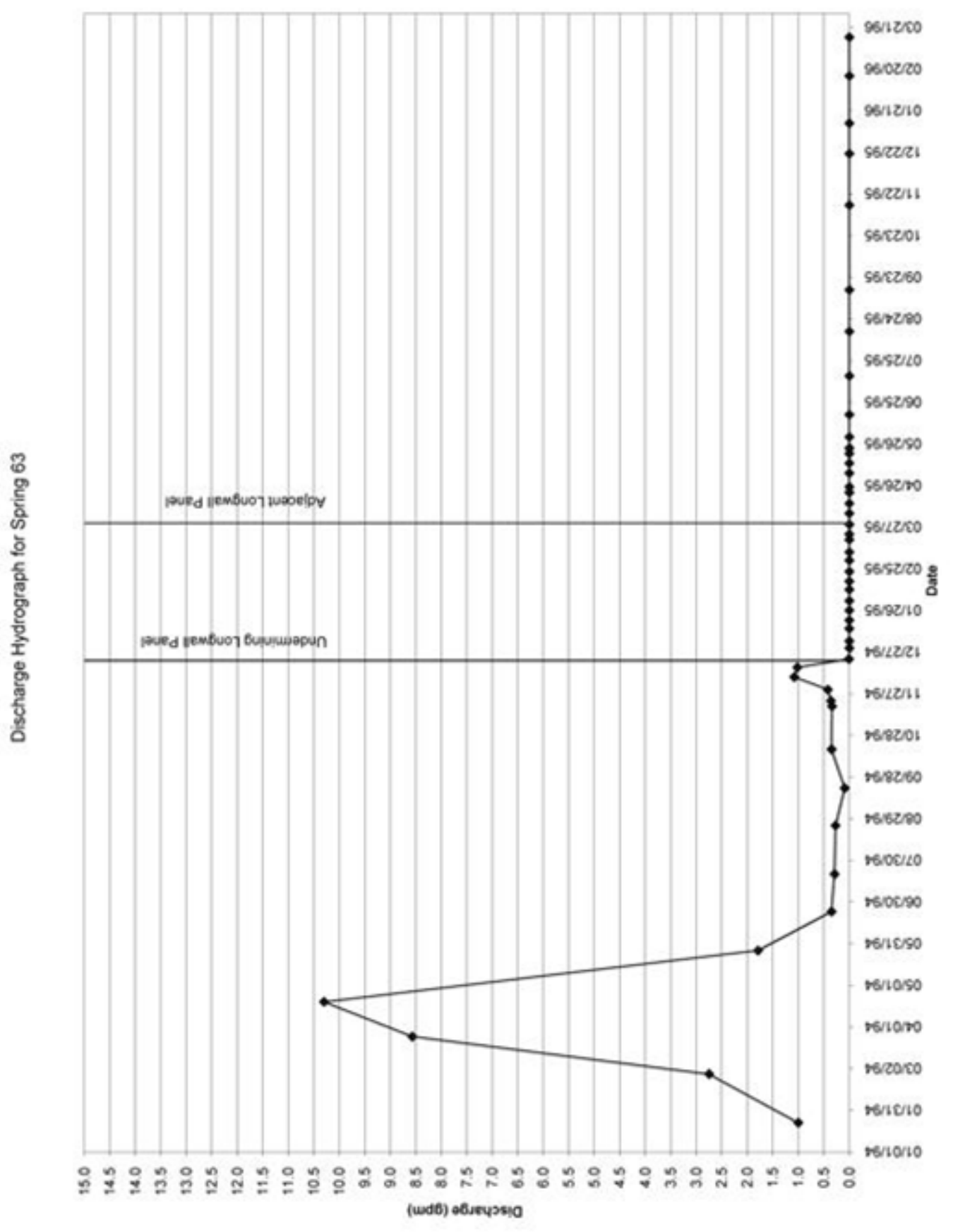




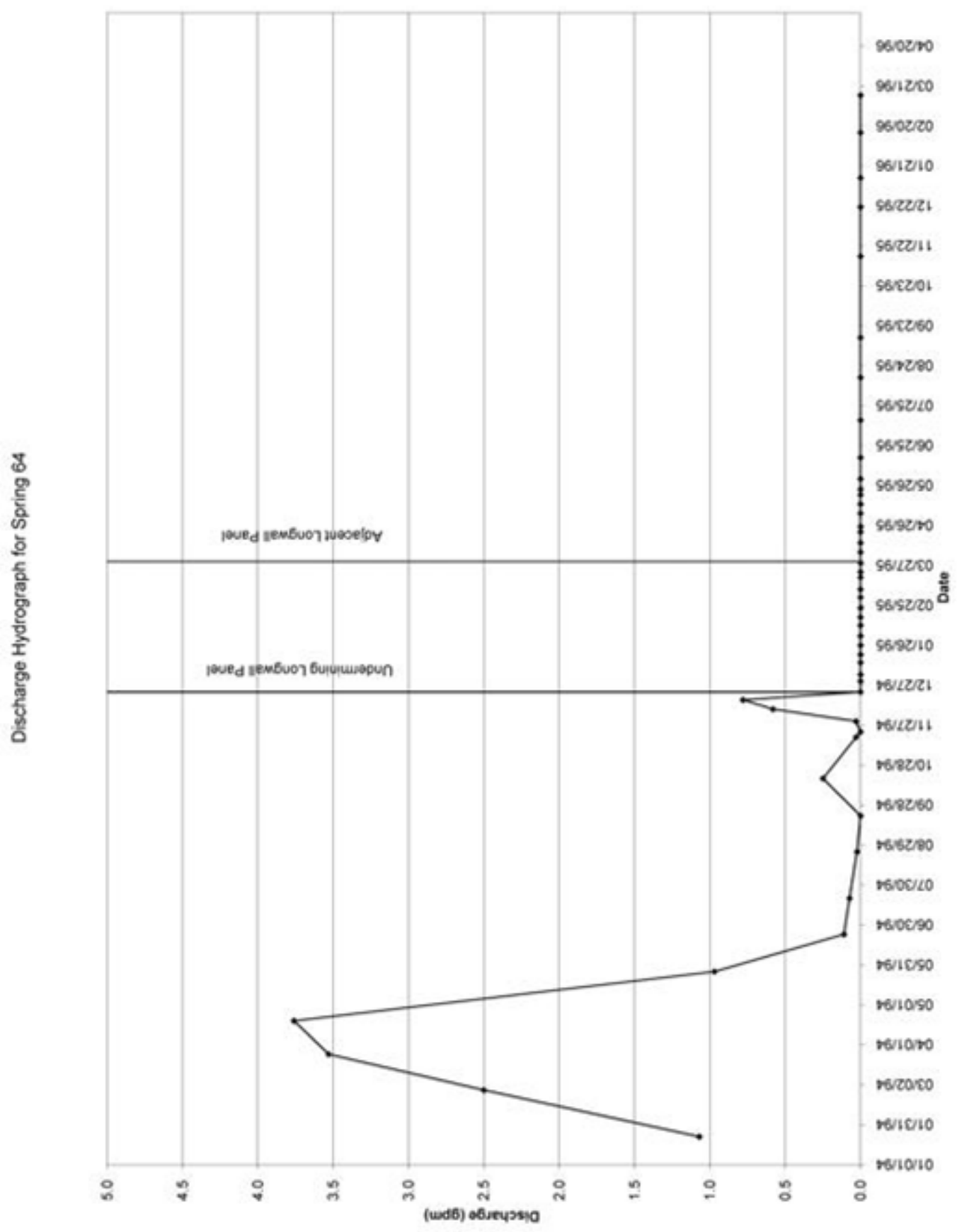




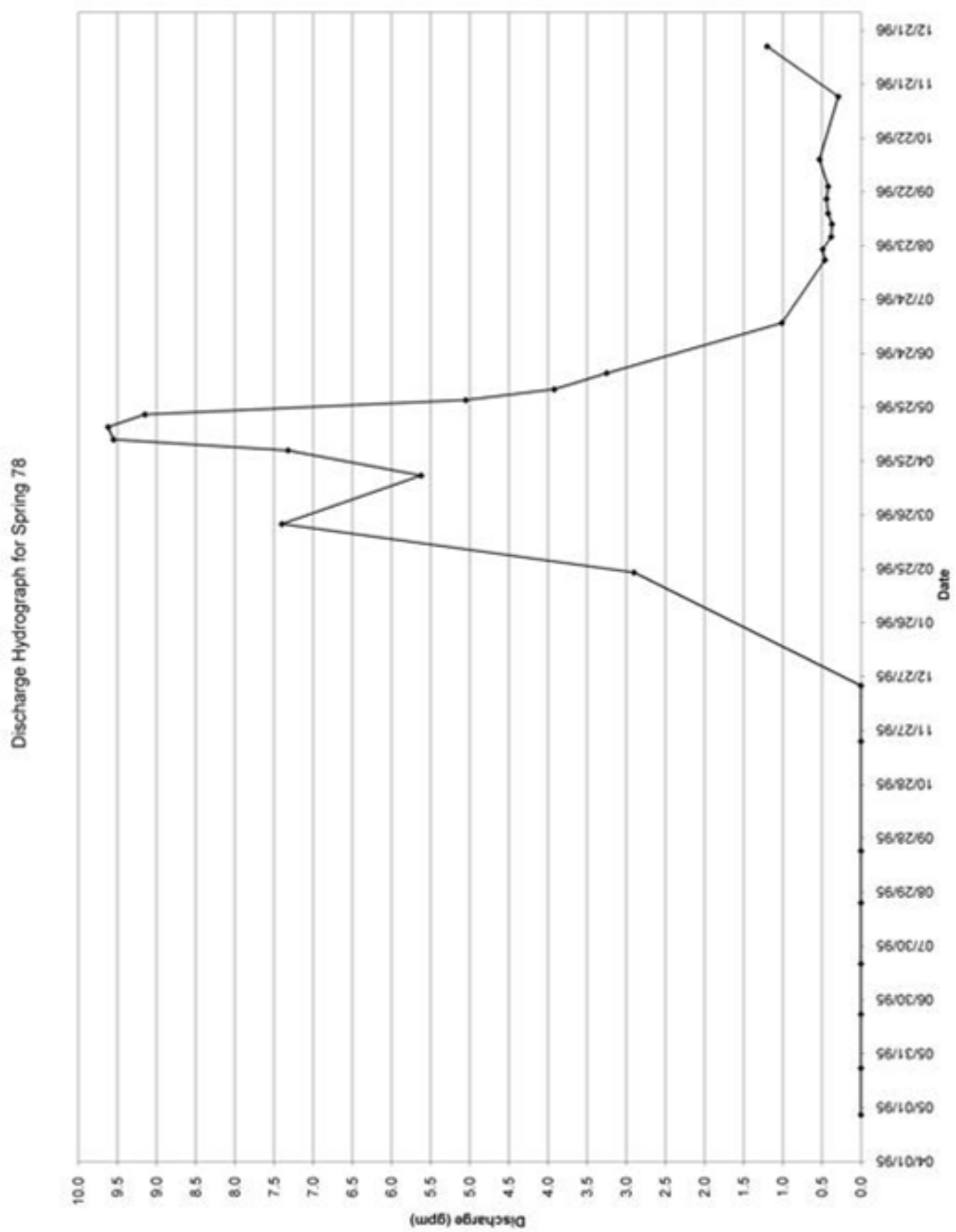




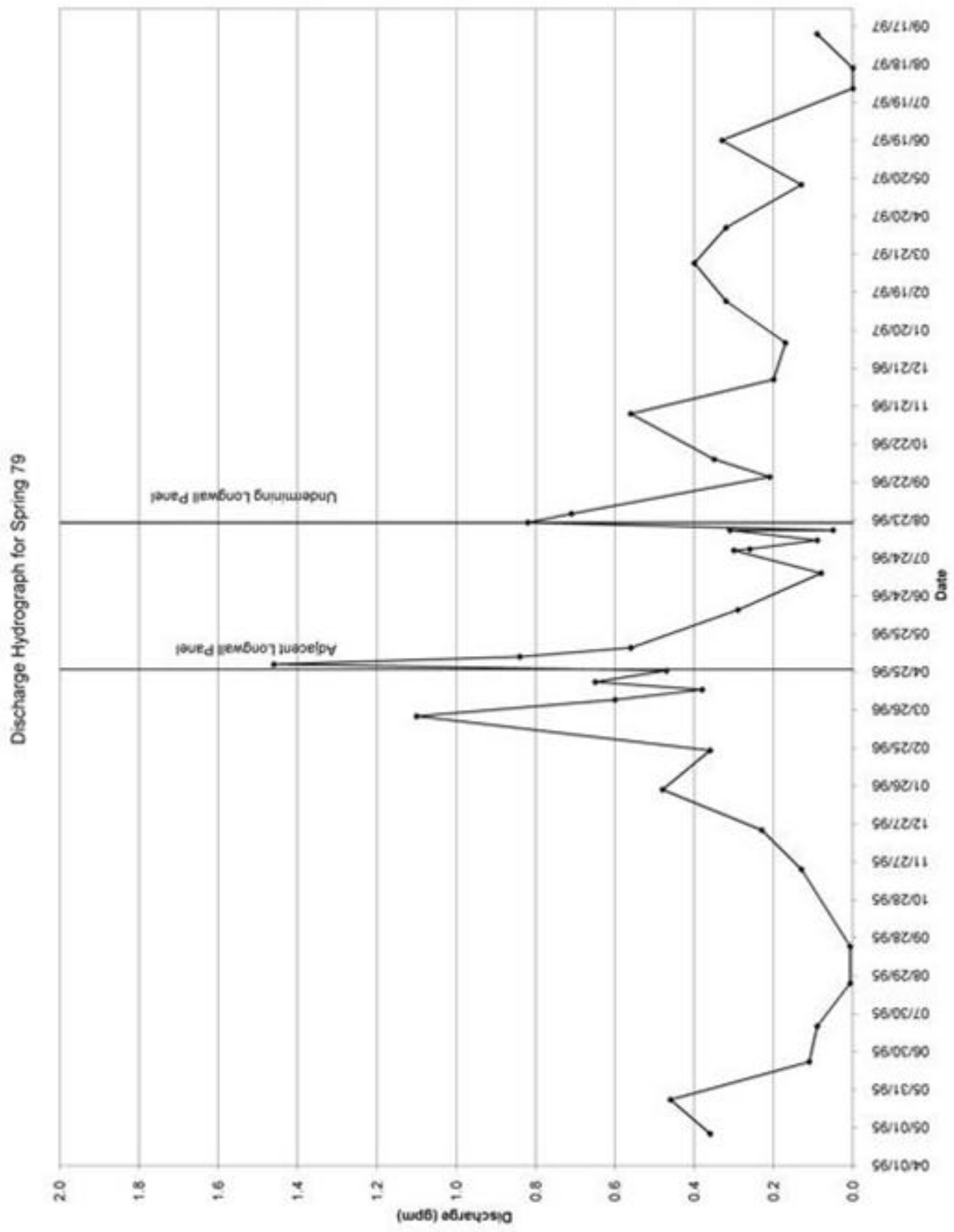




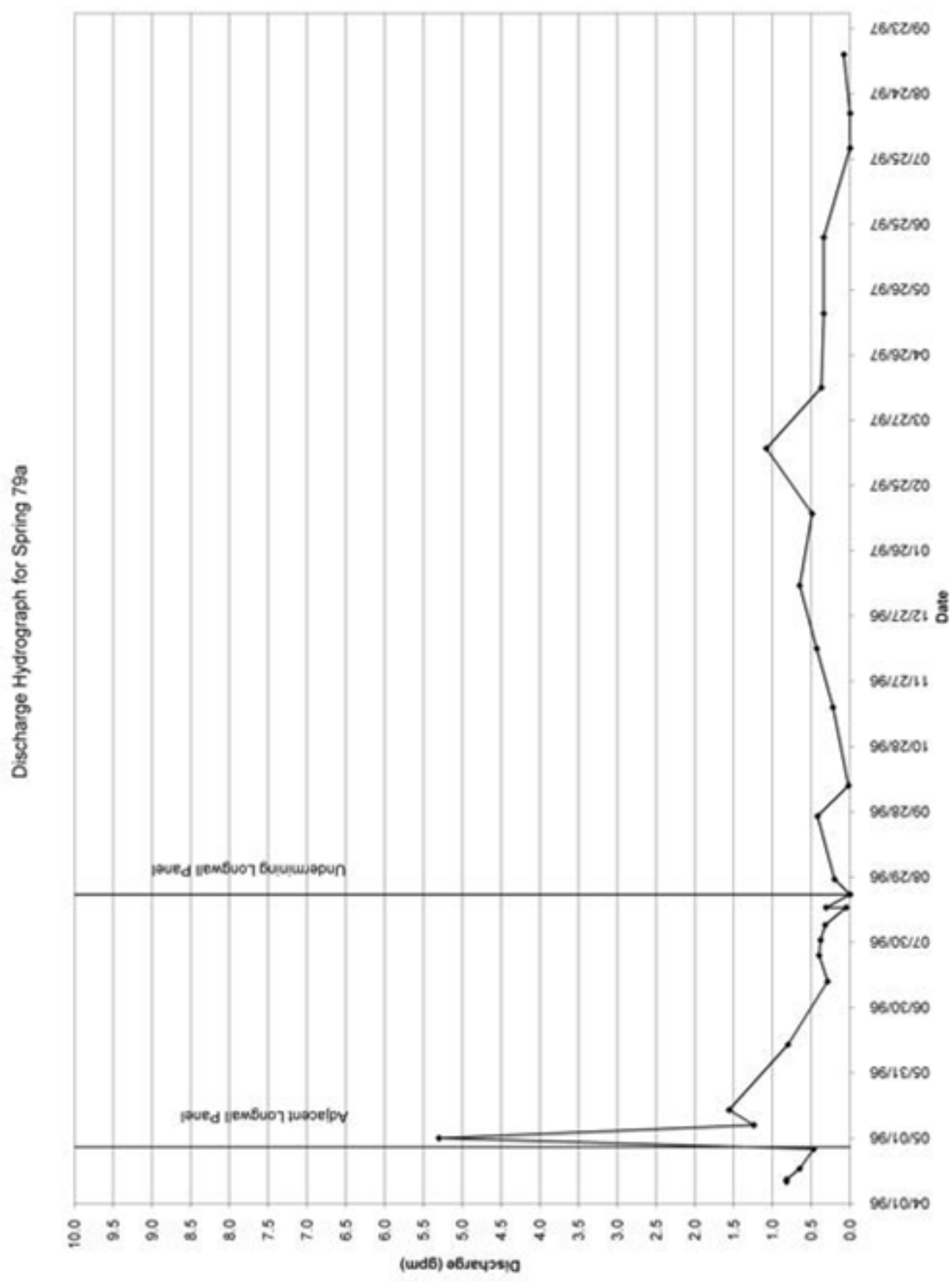




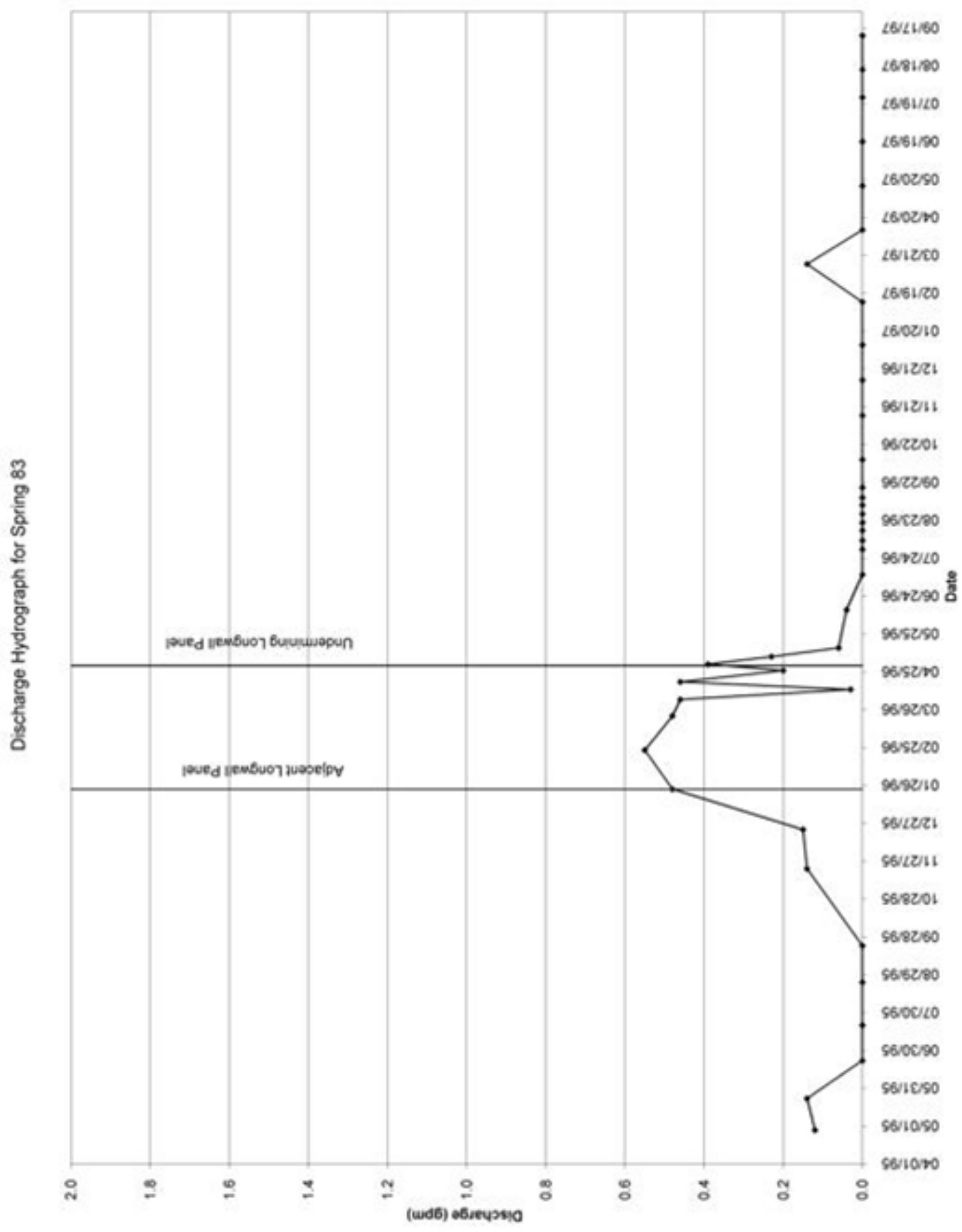




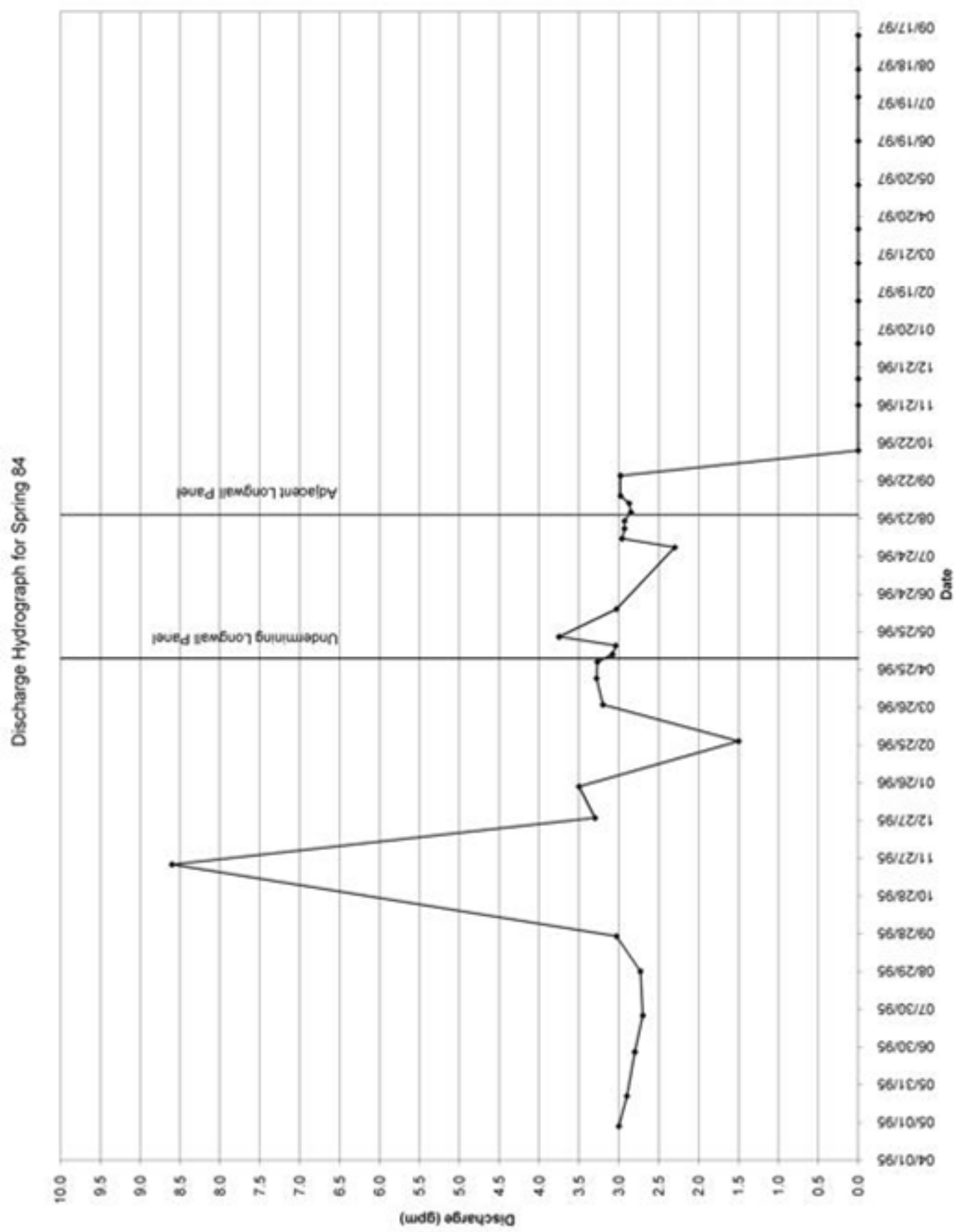




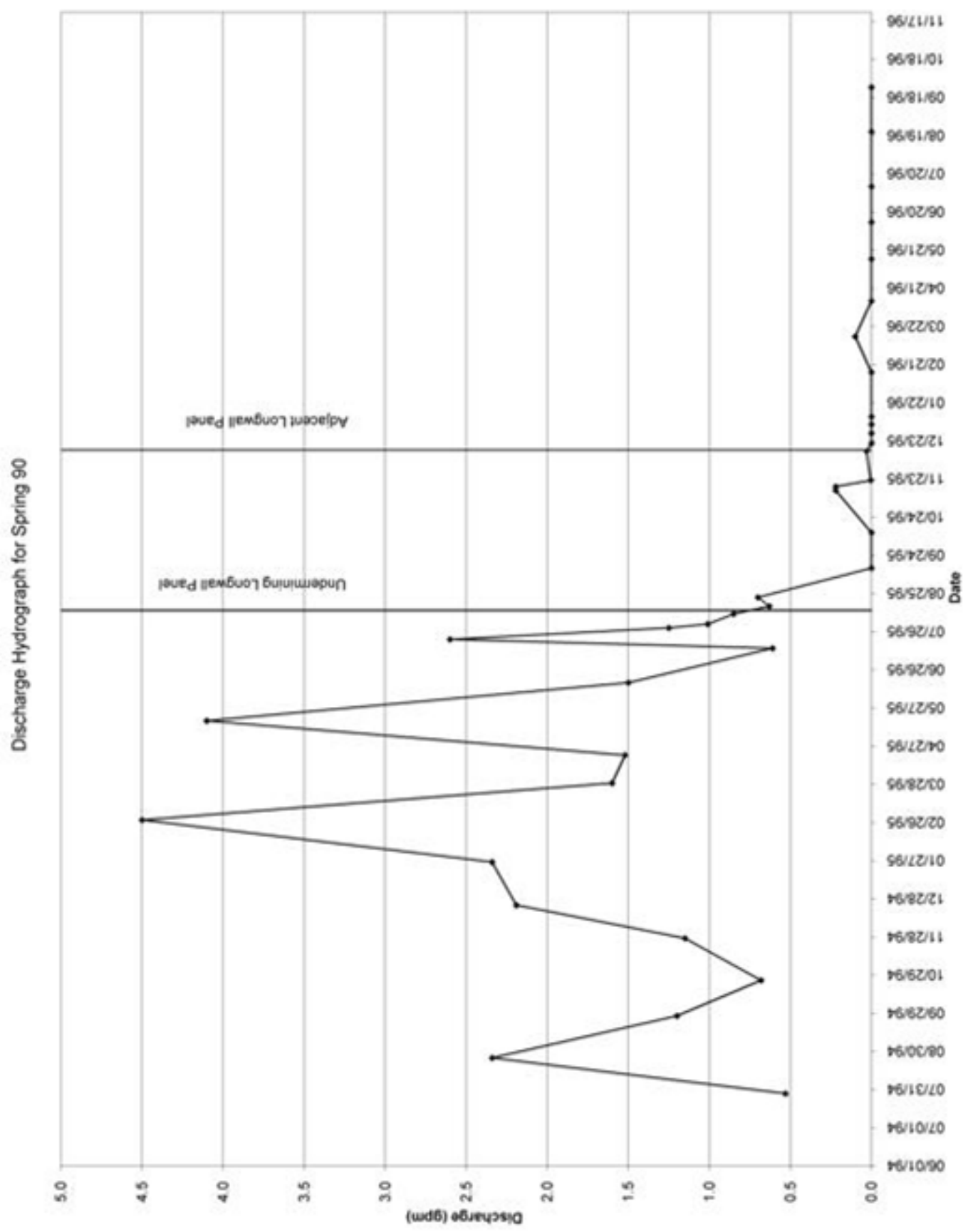




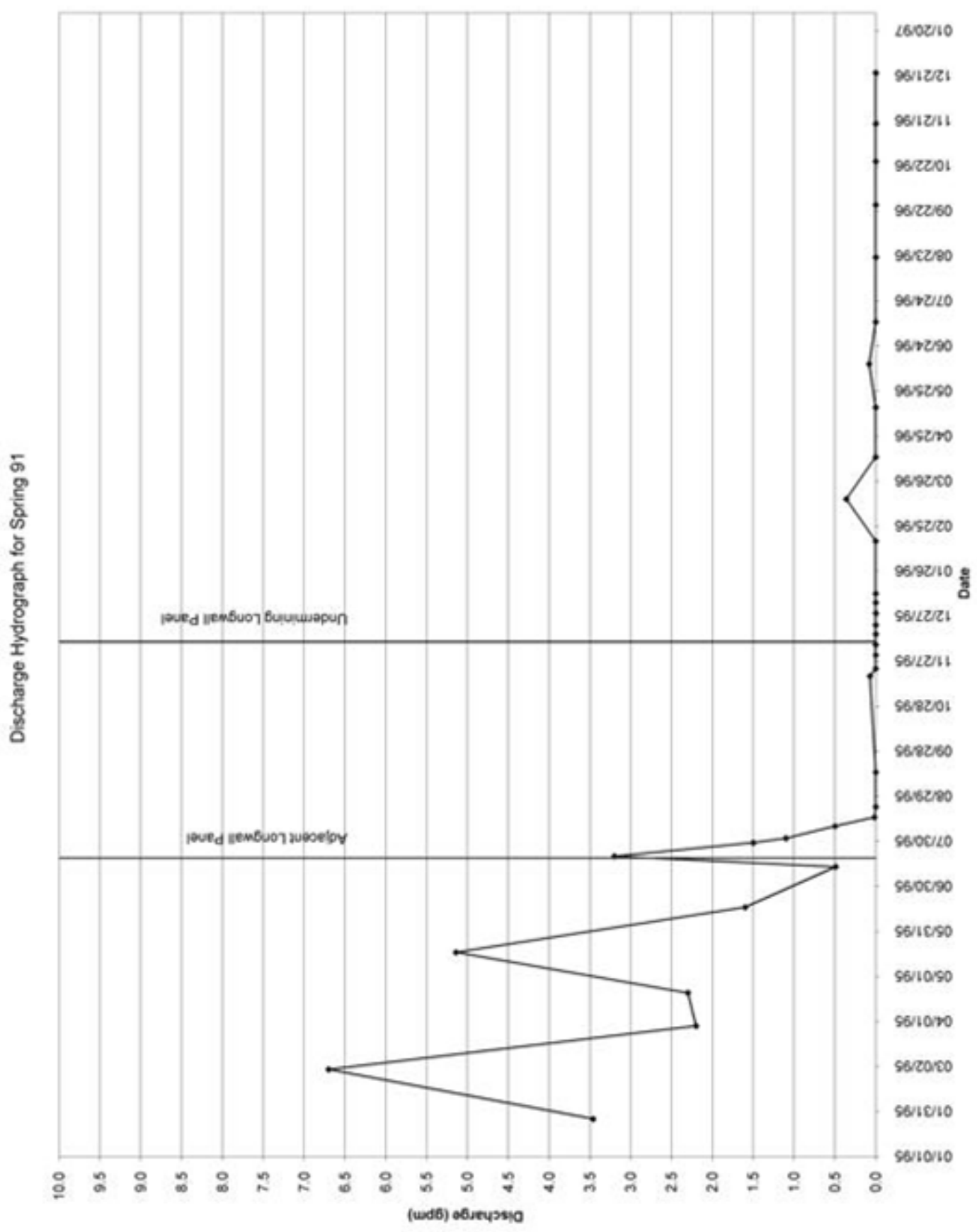




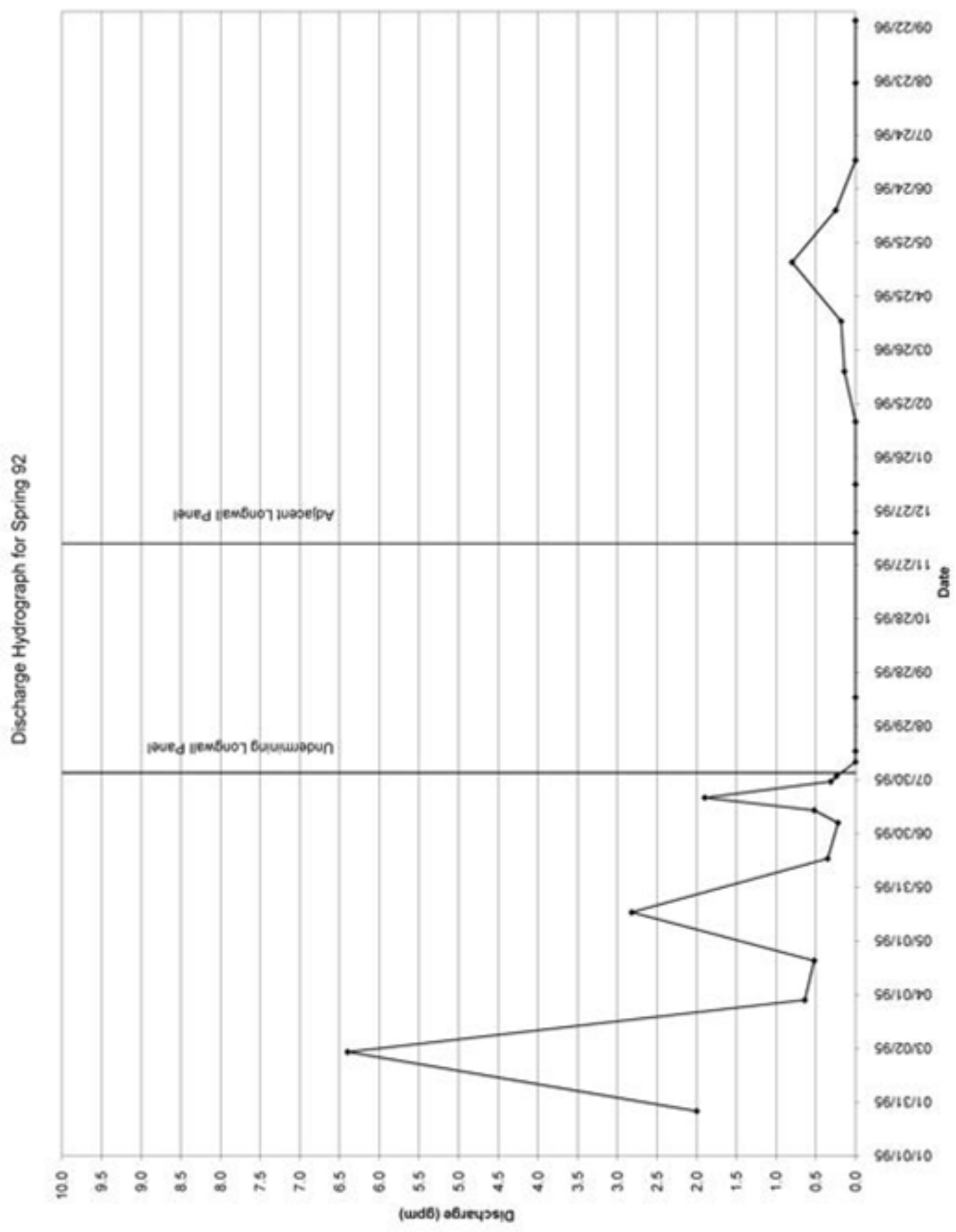




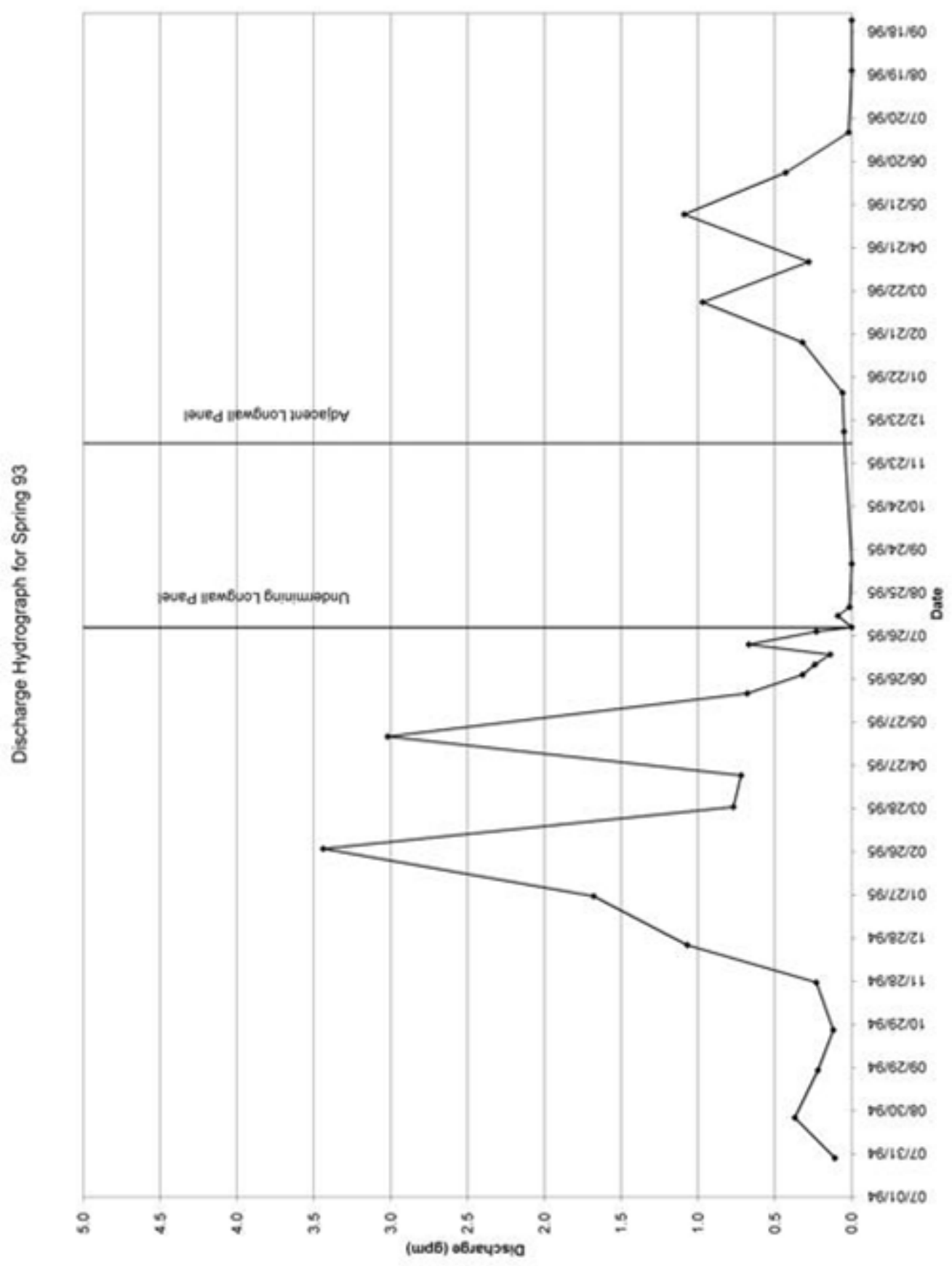




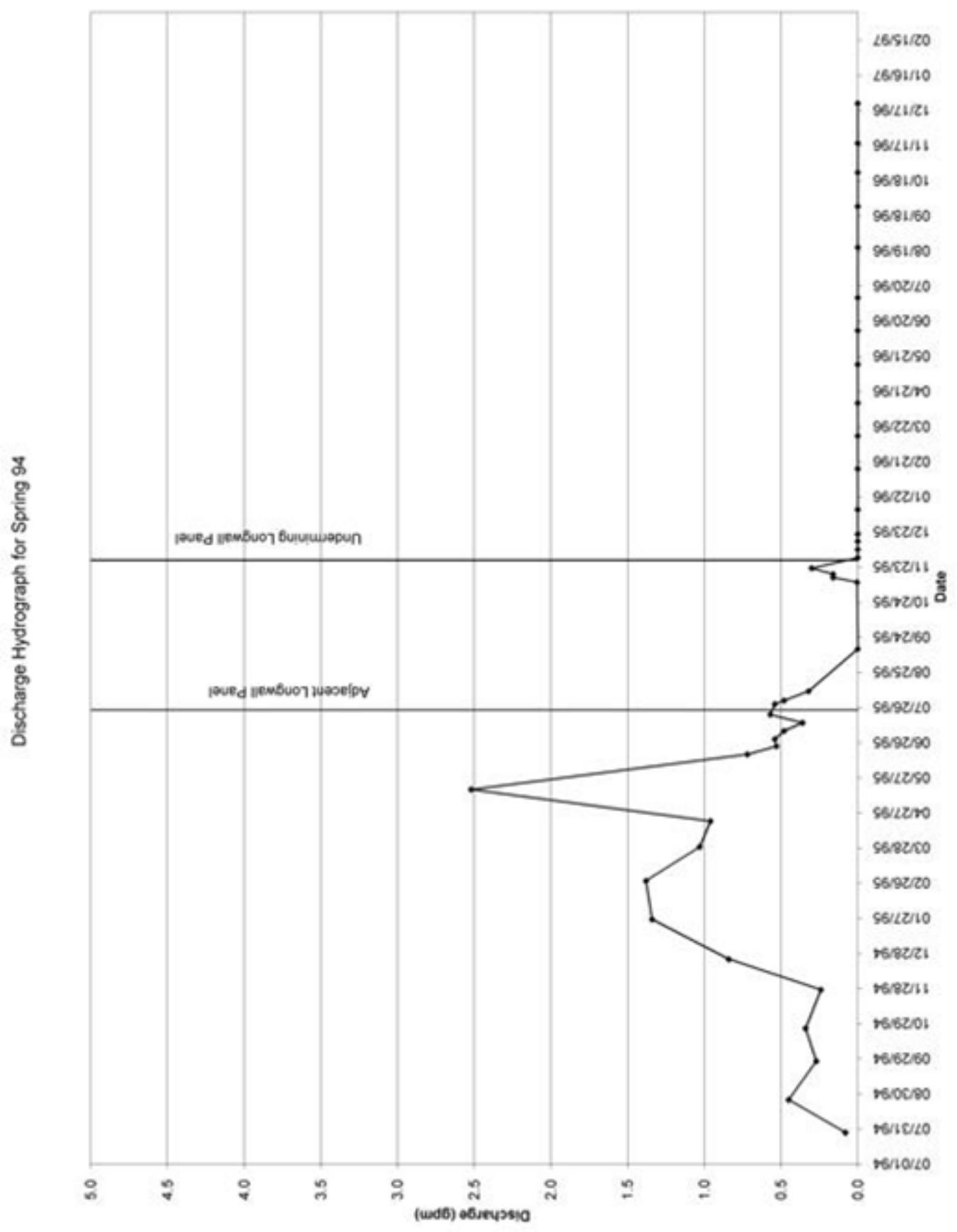




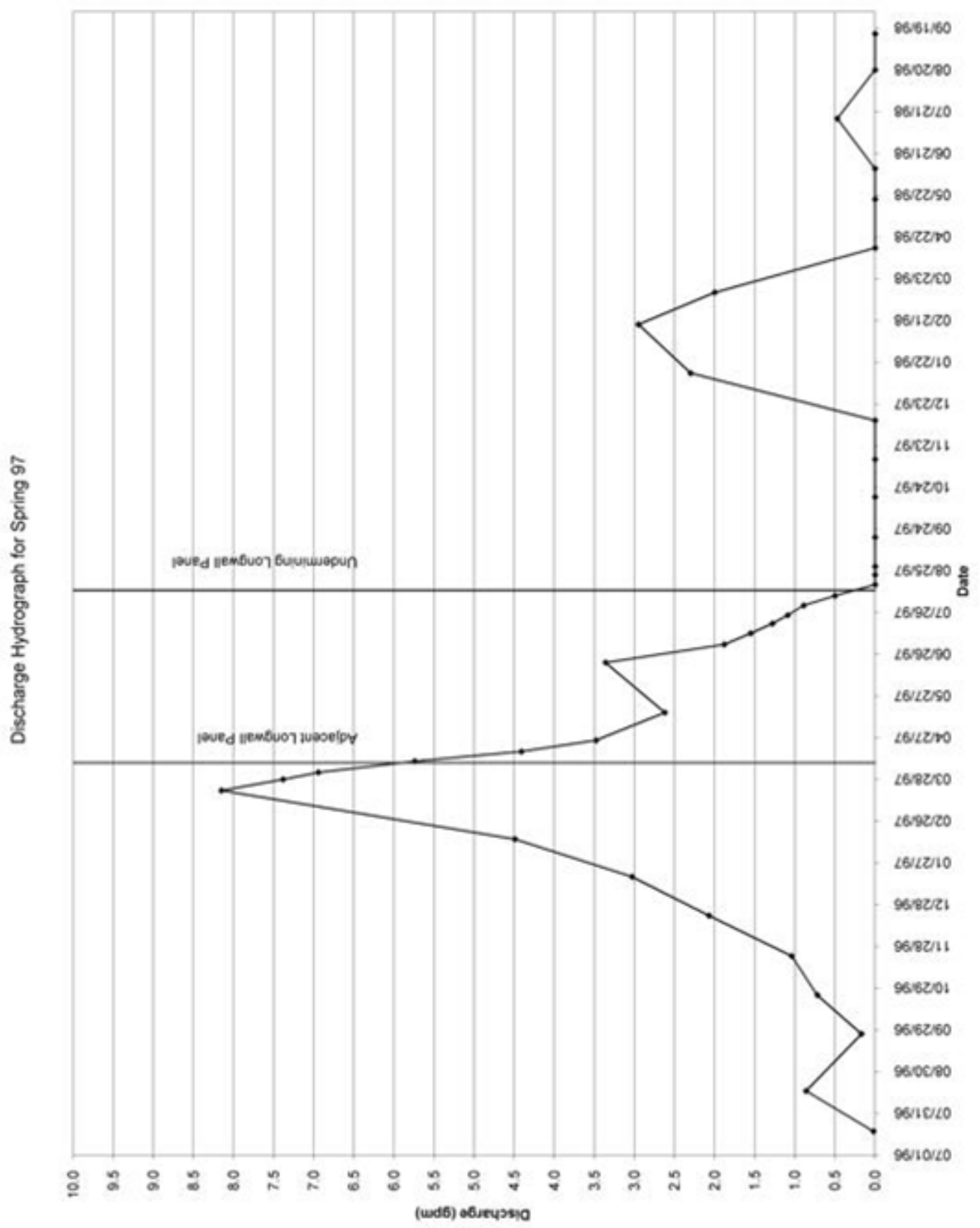




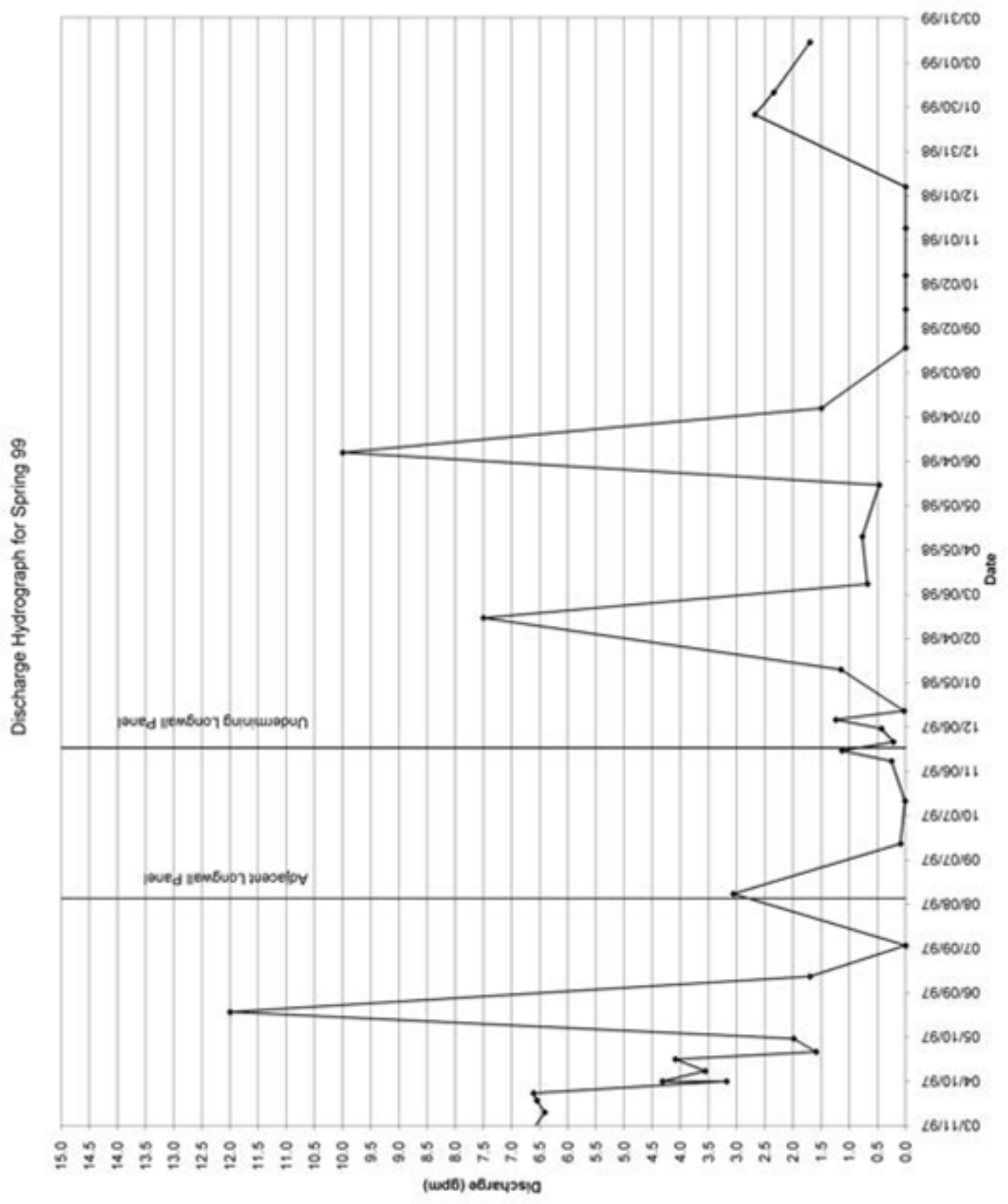




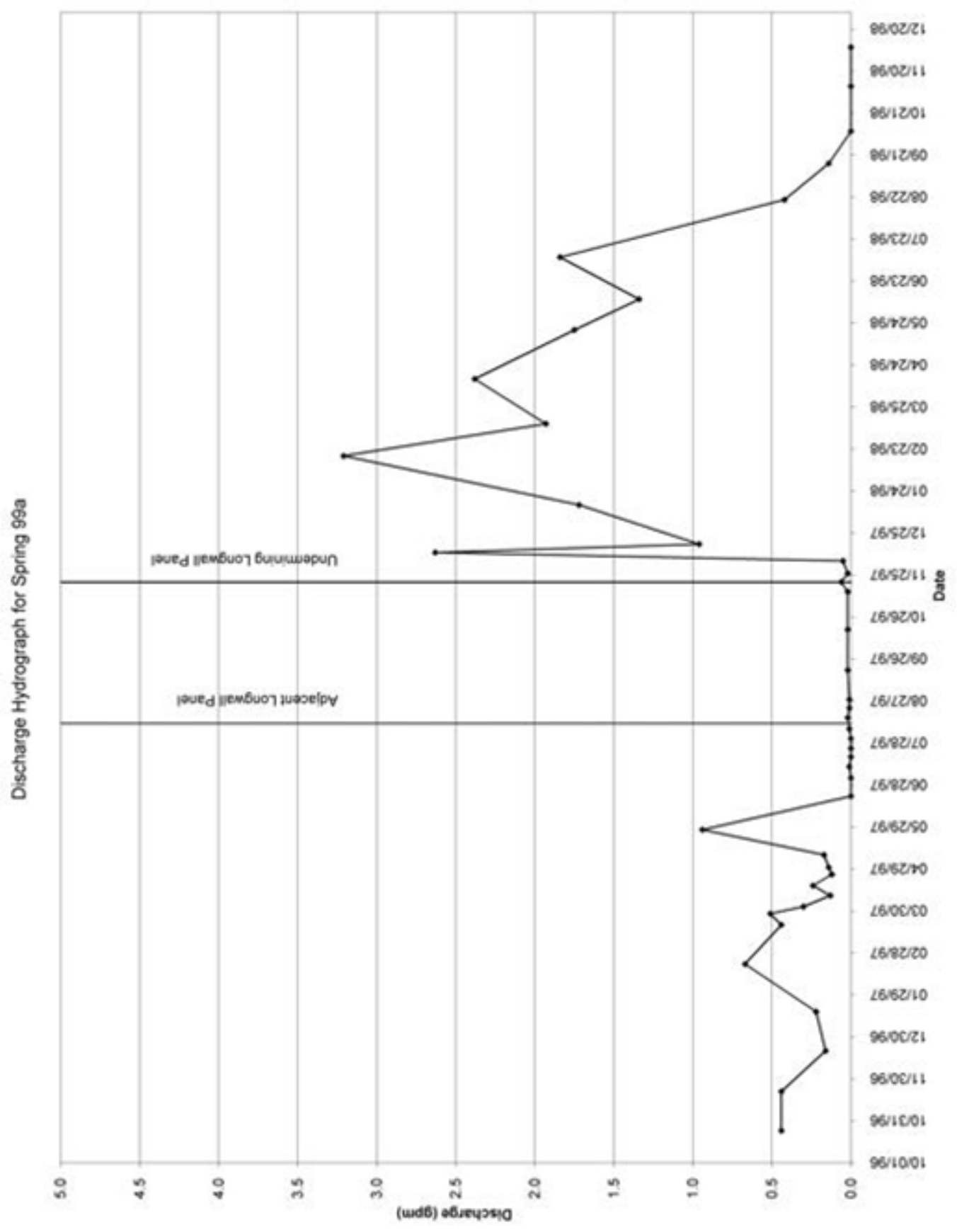




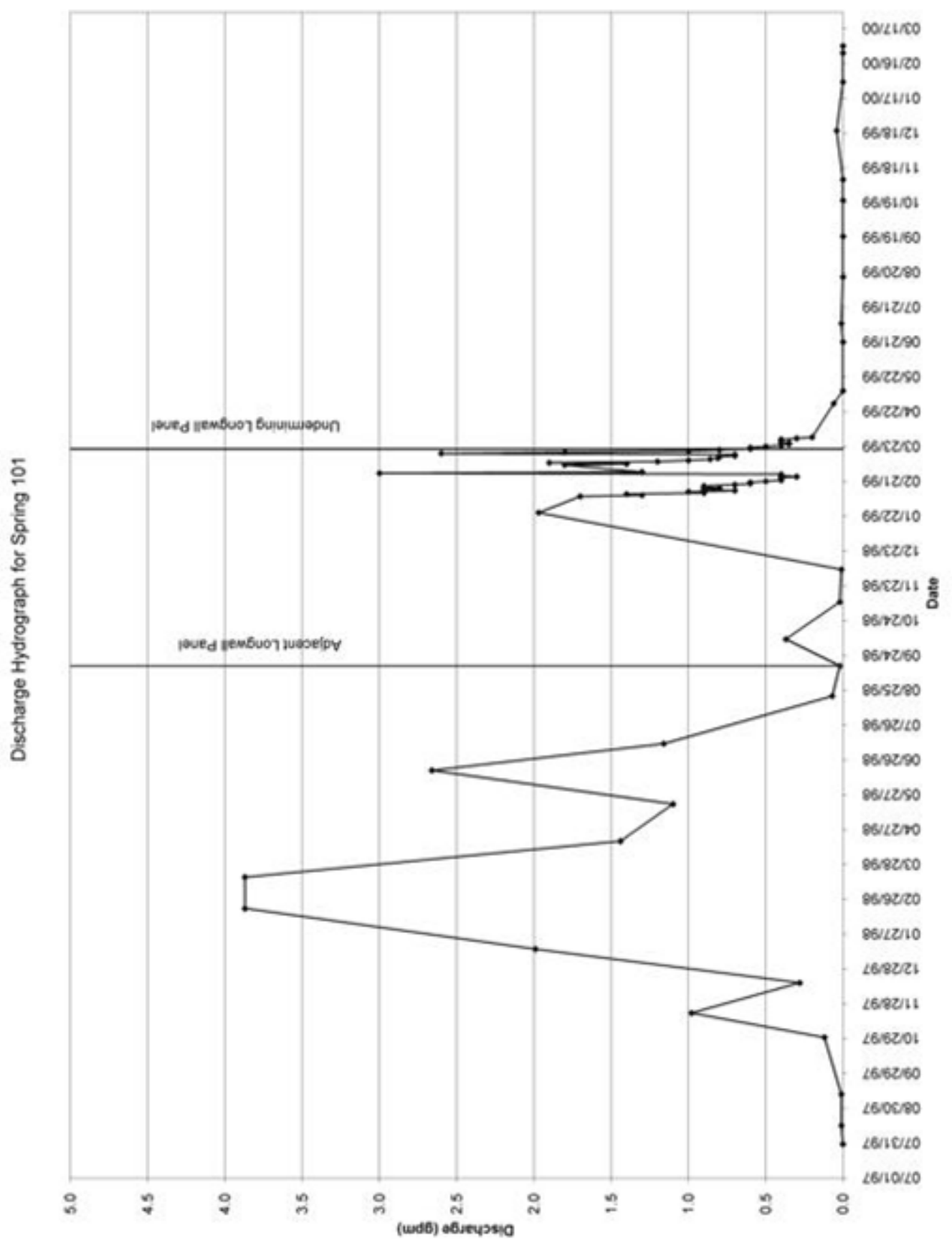




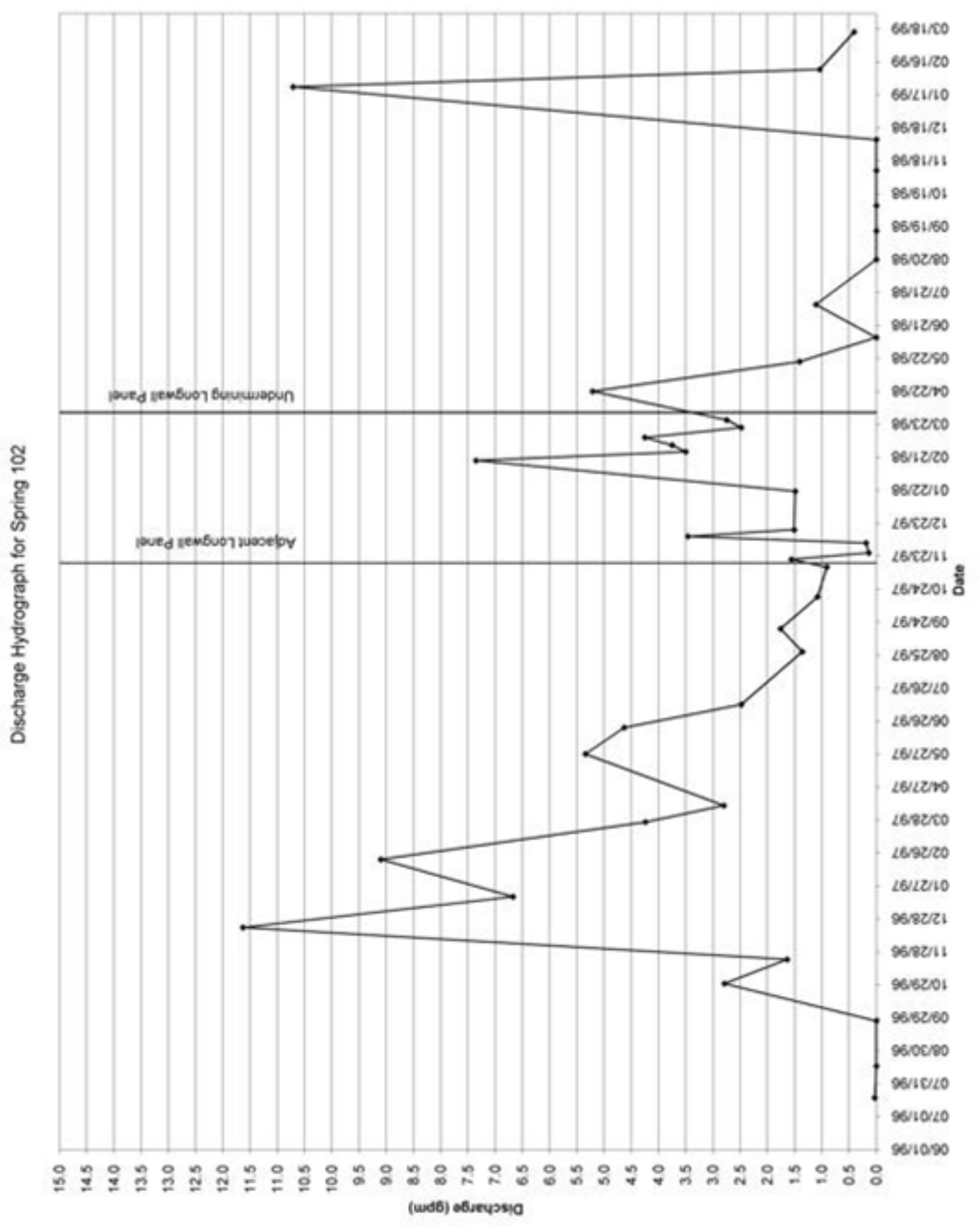




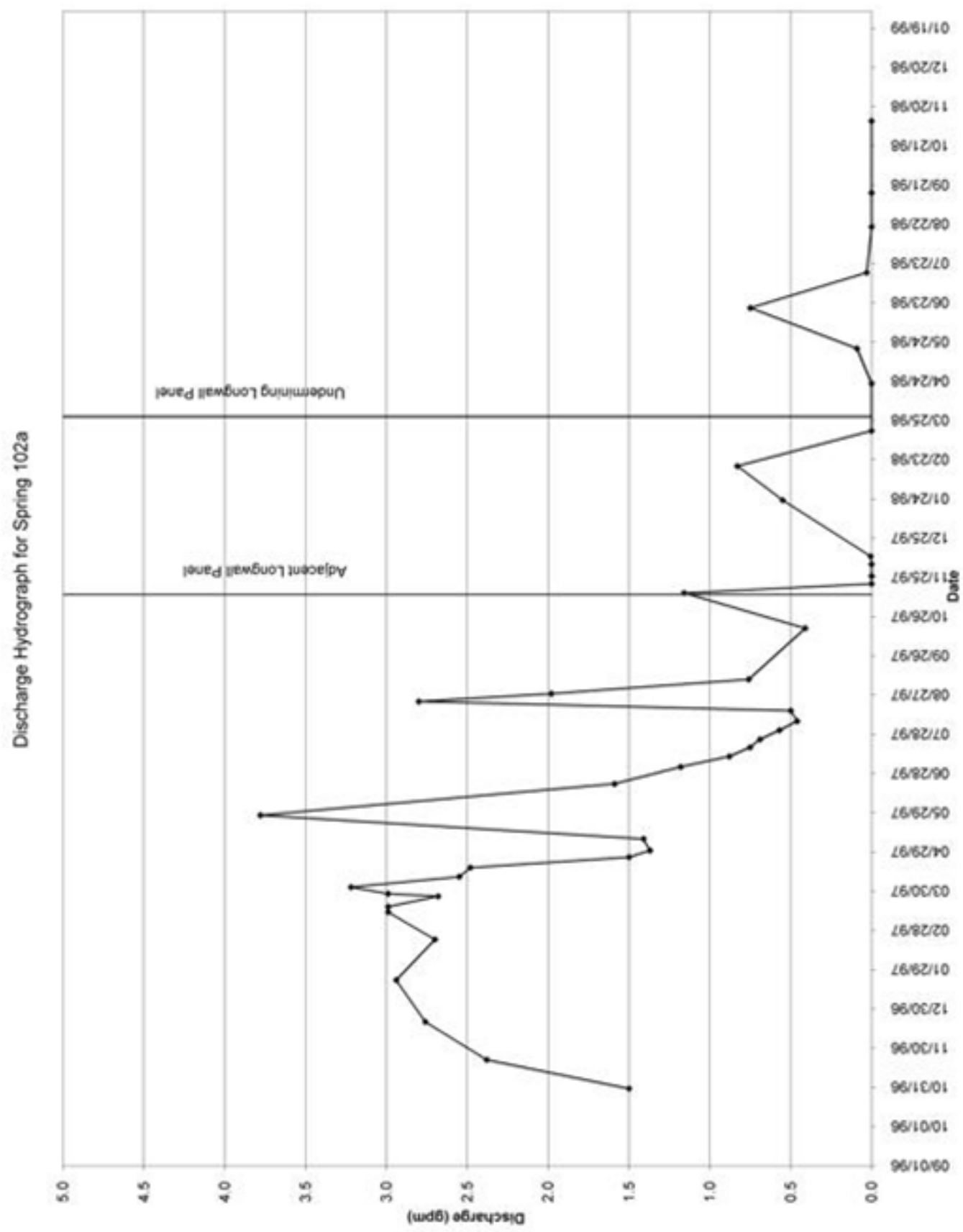




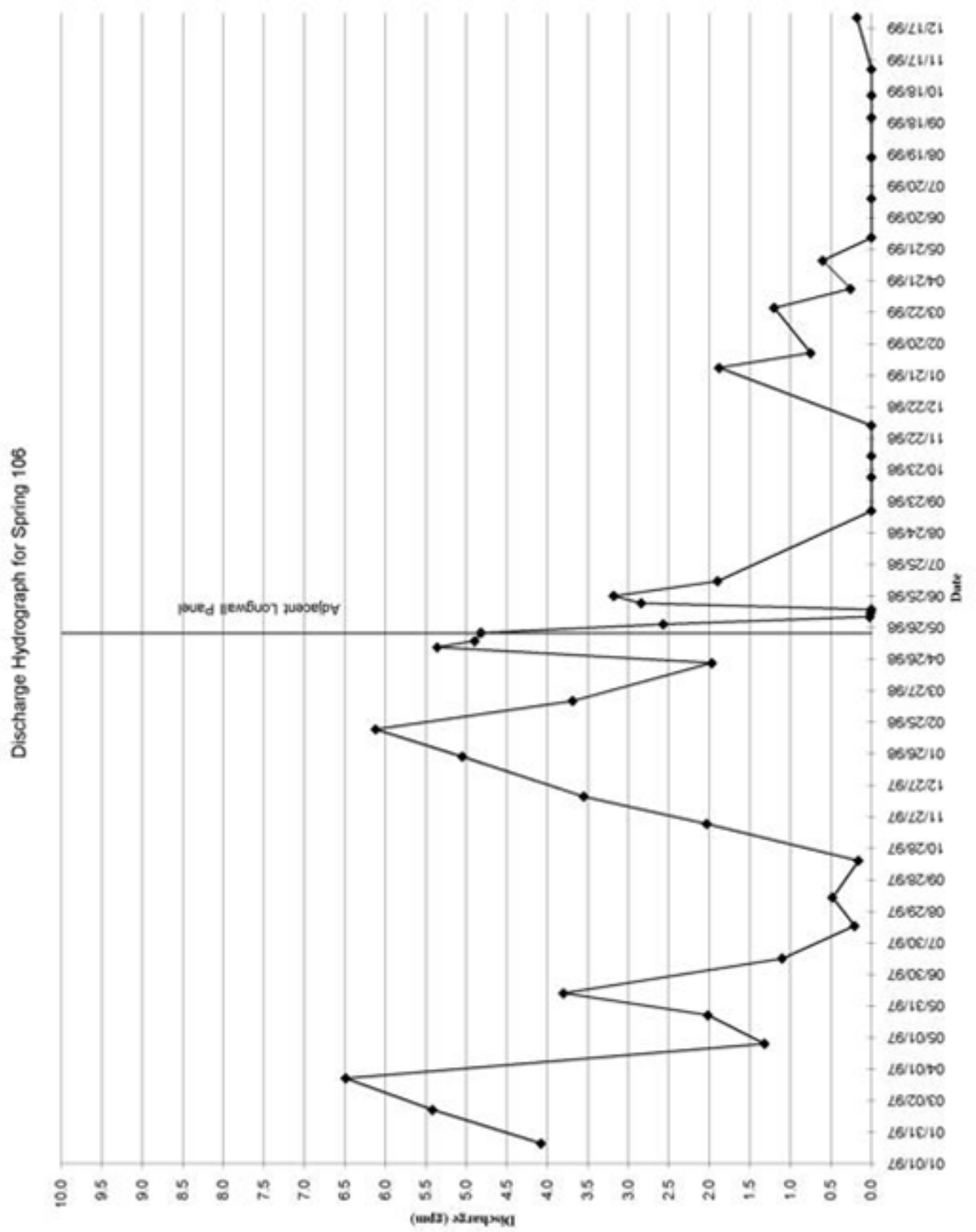




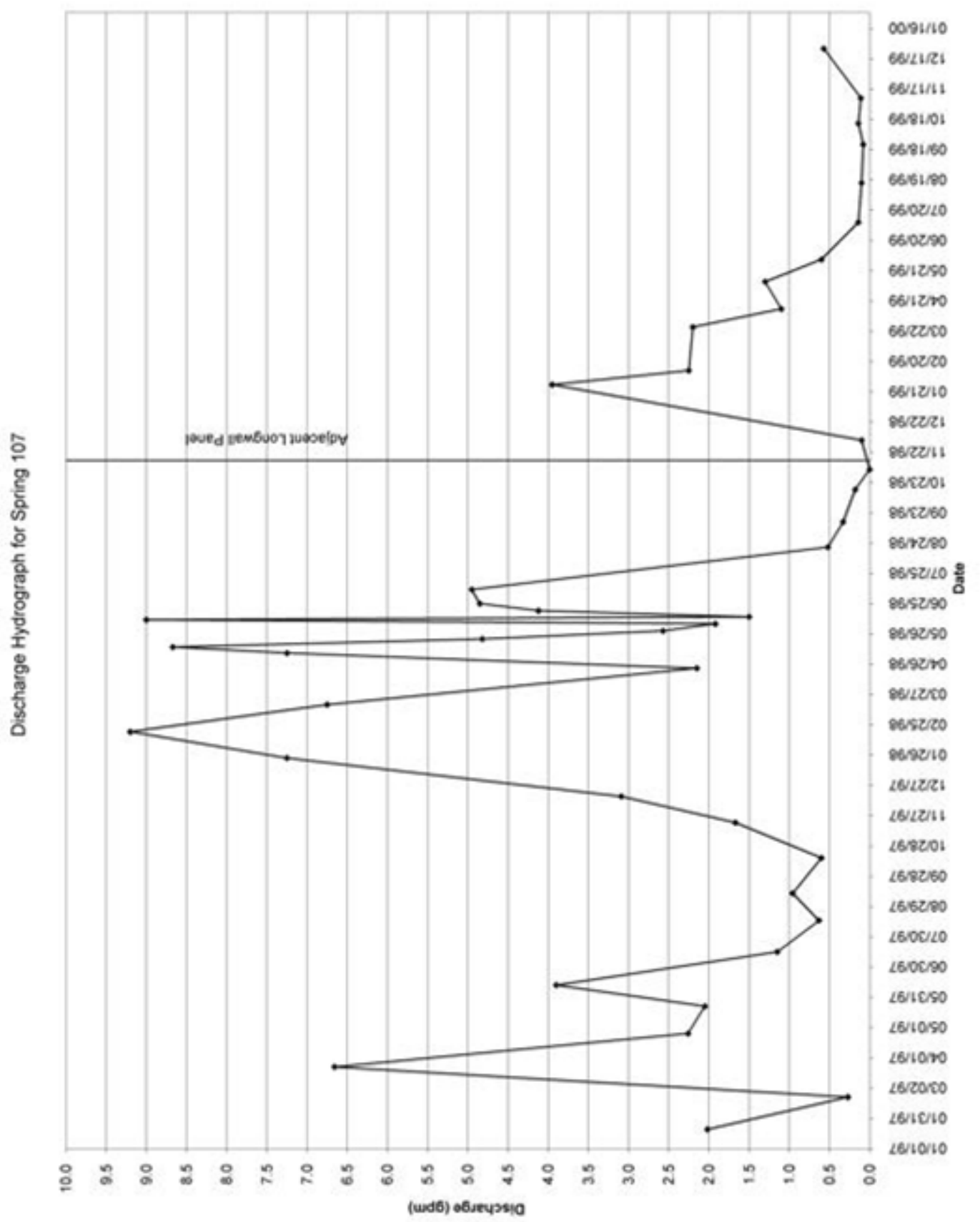




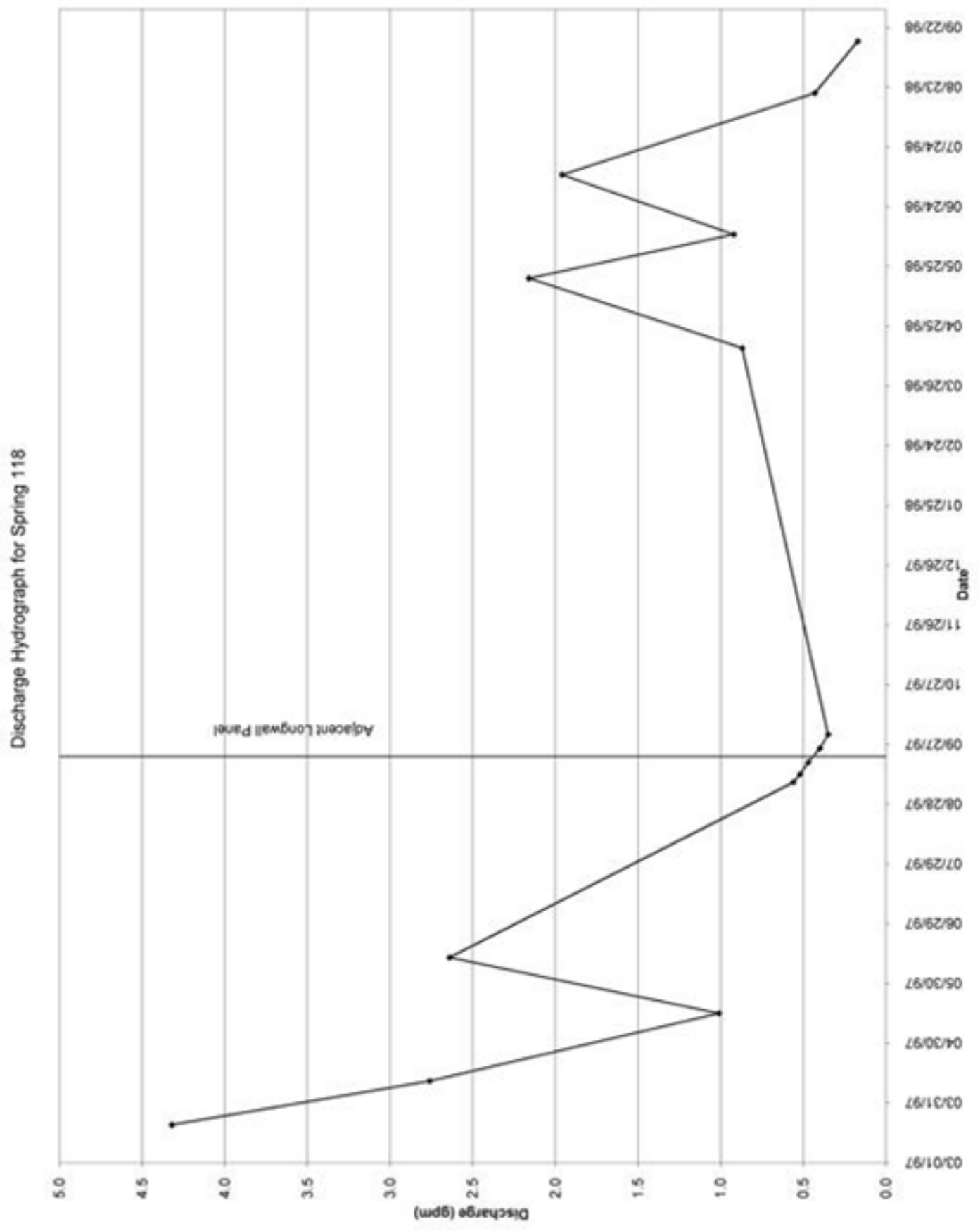




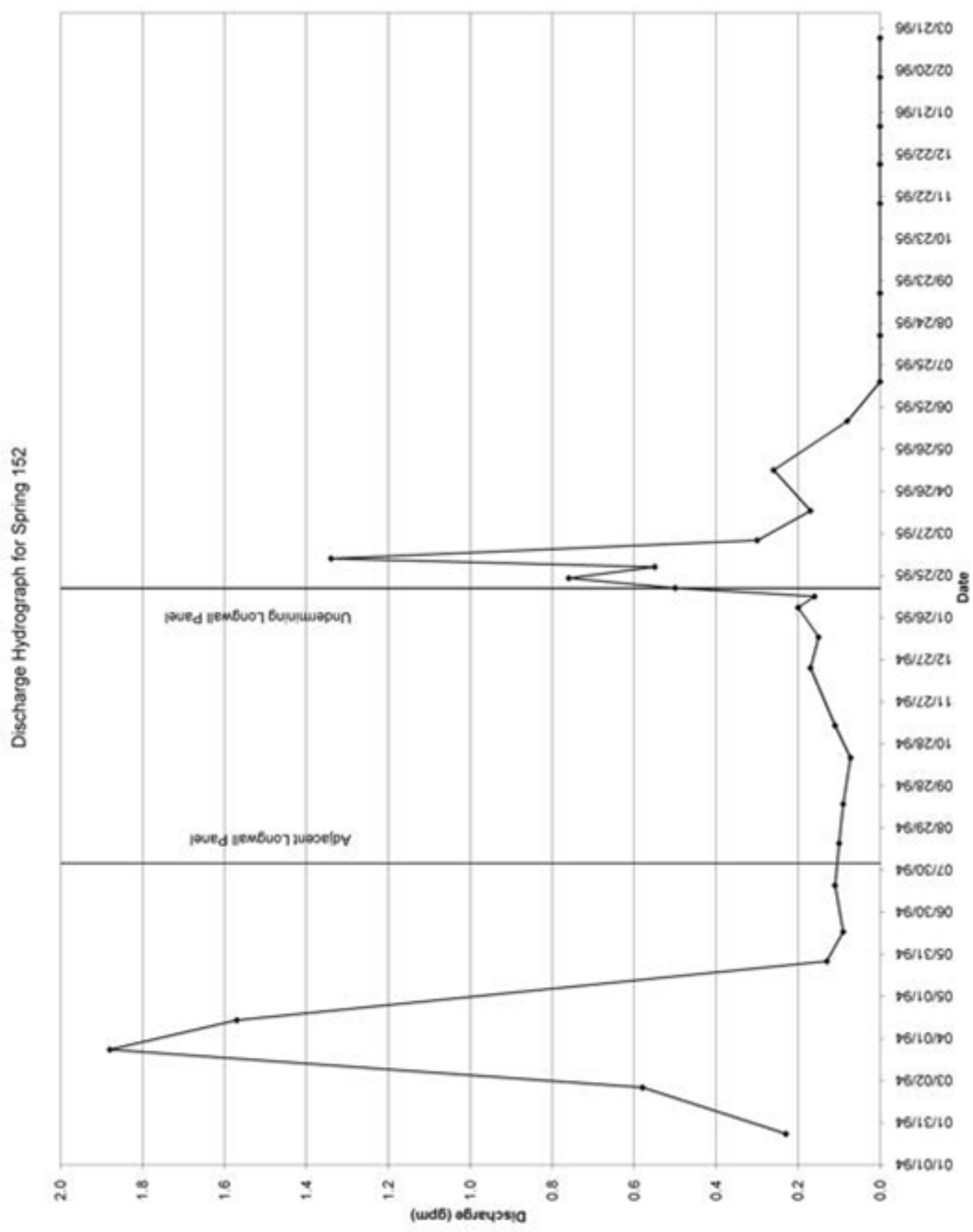

166 


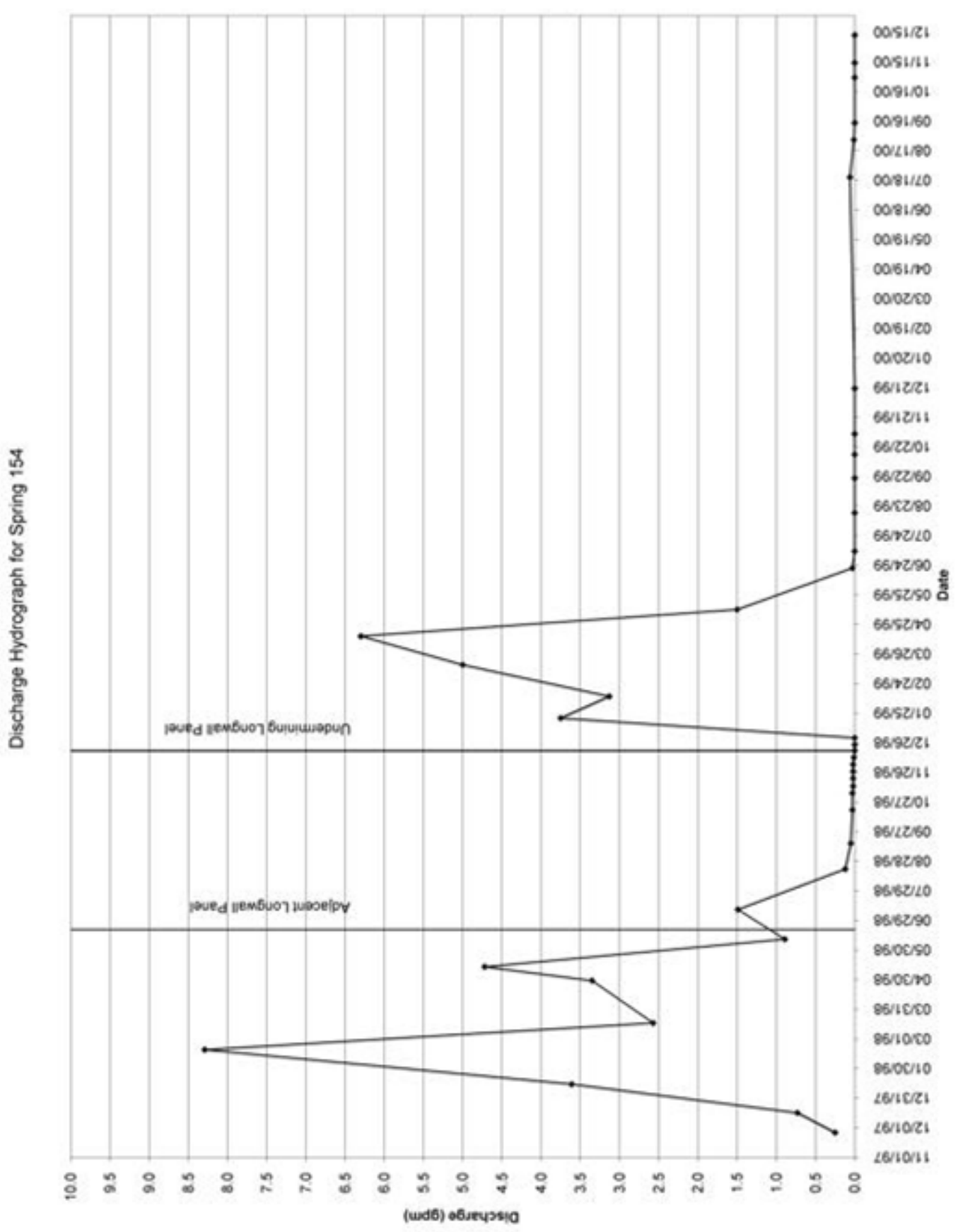




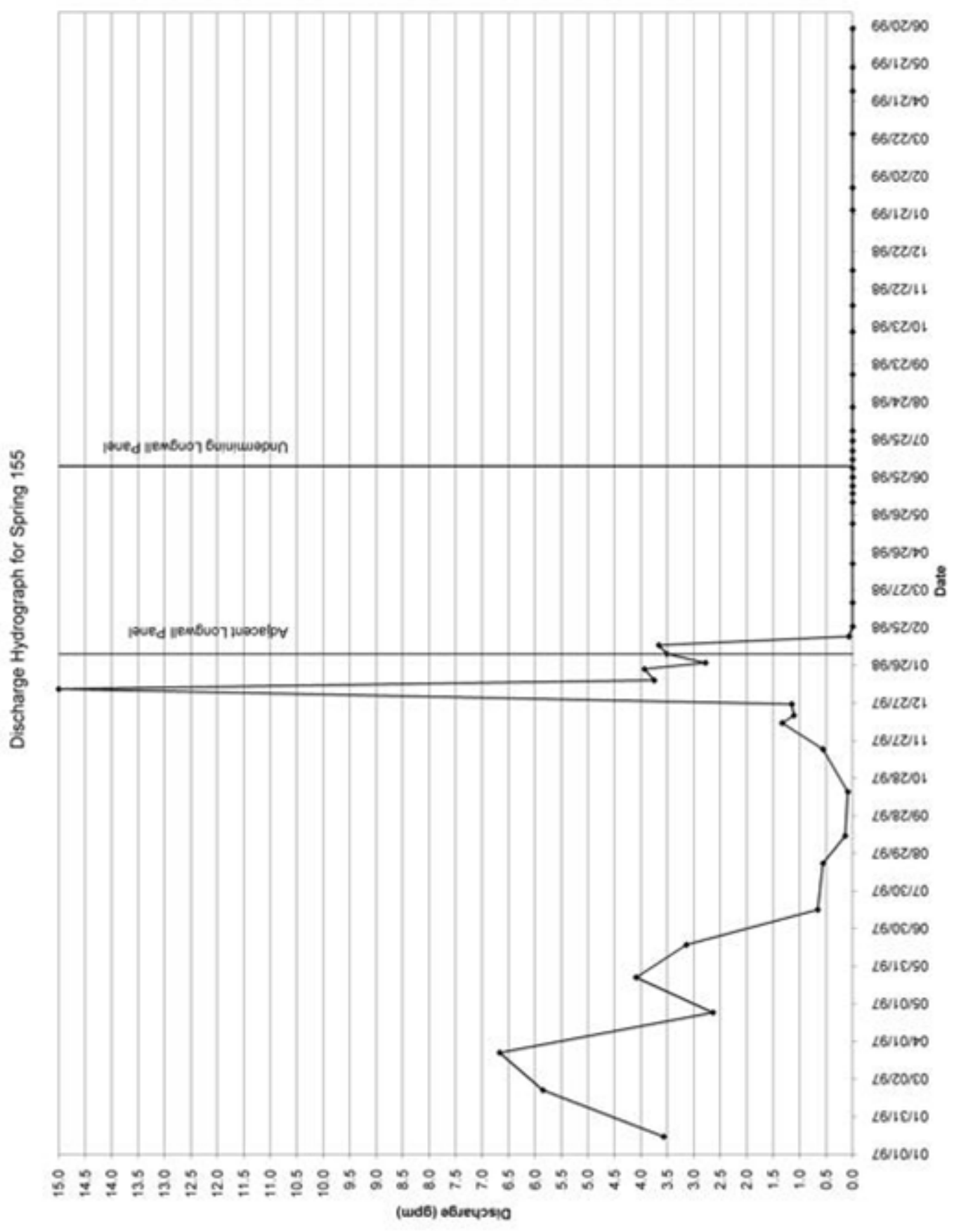




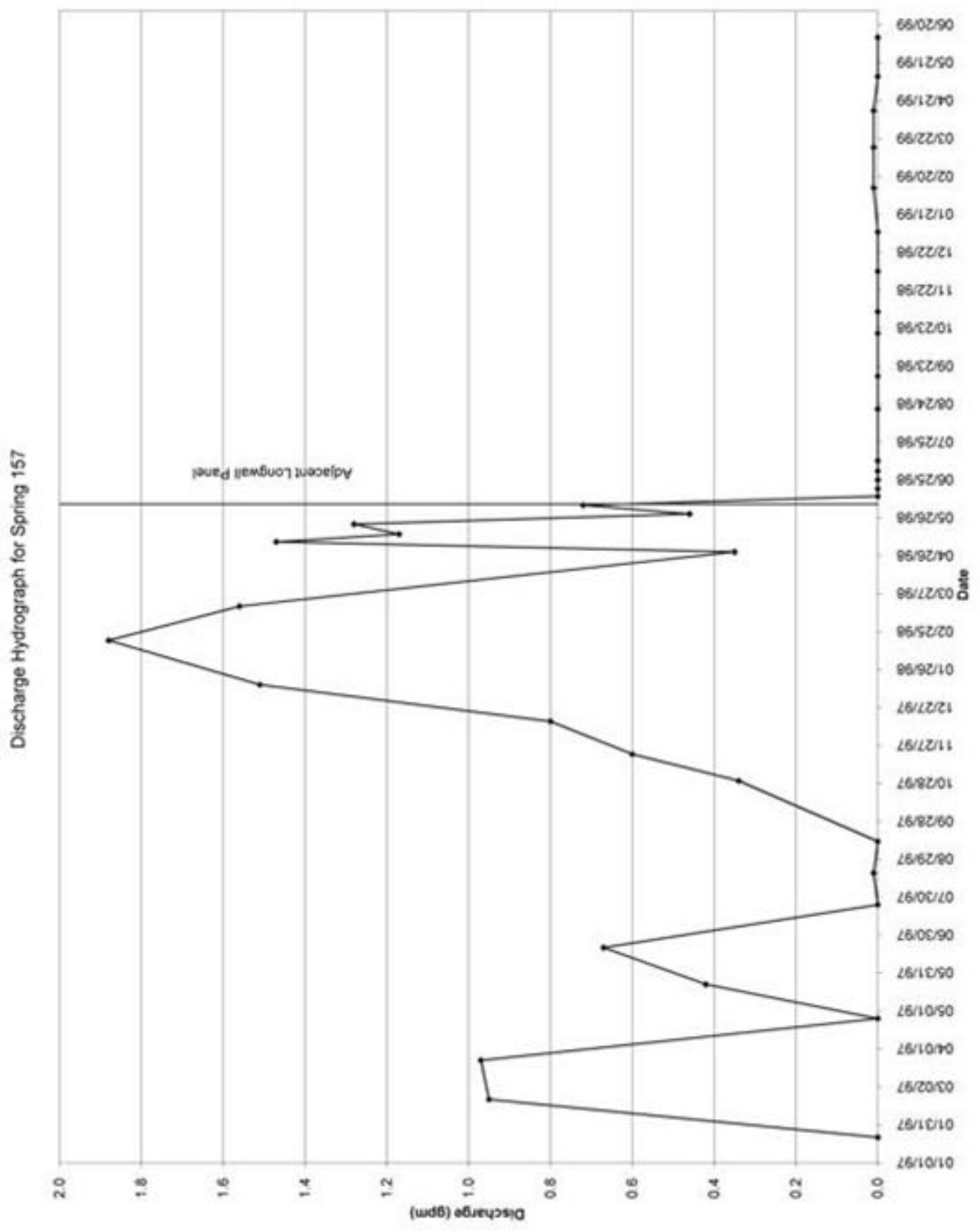




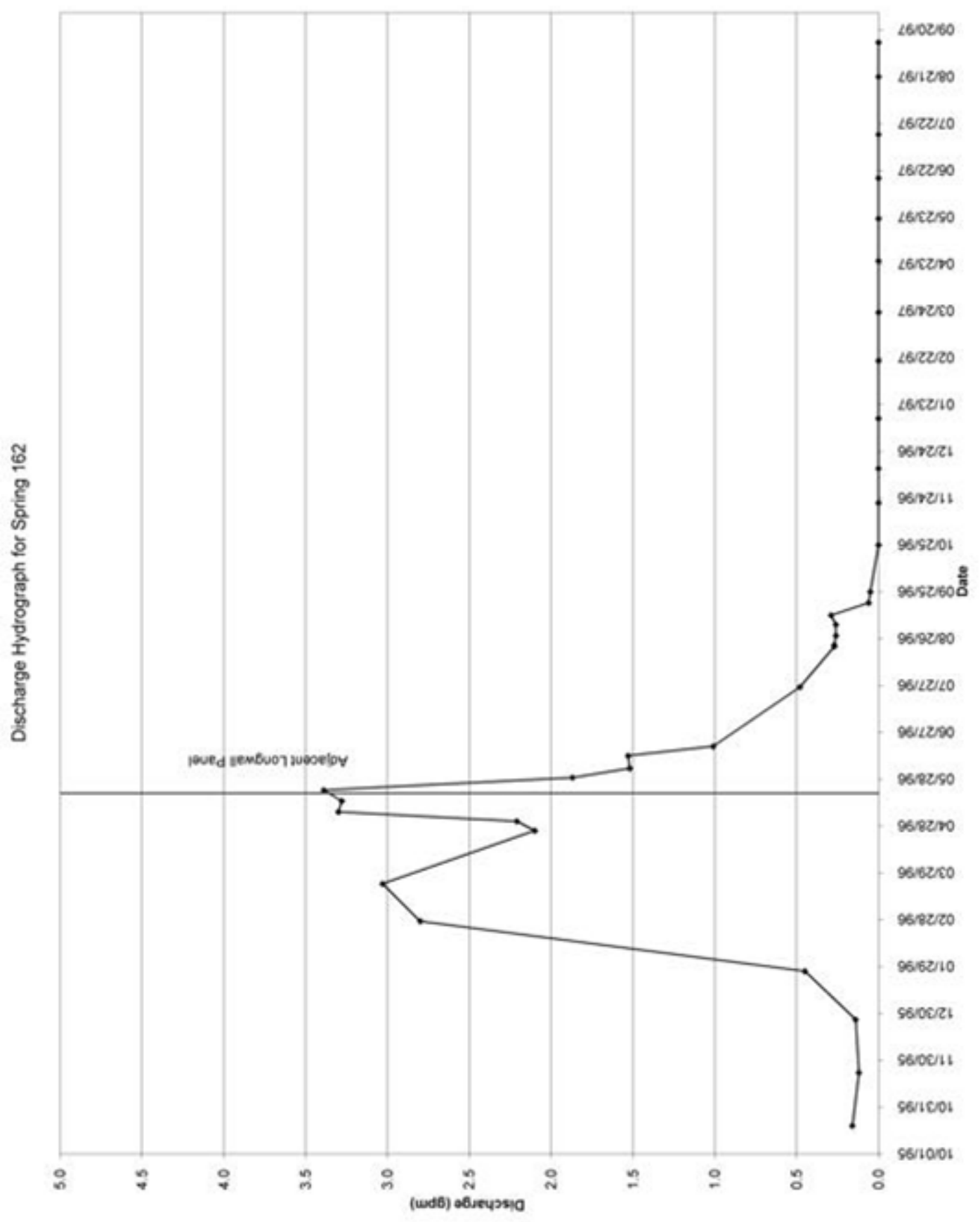




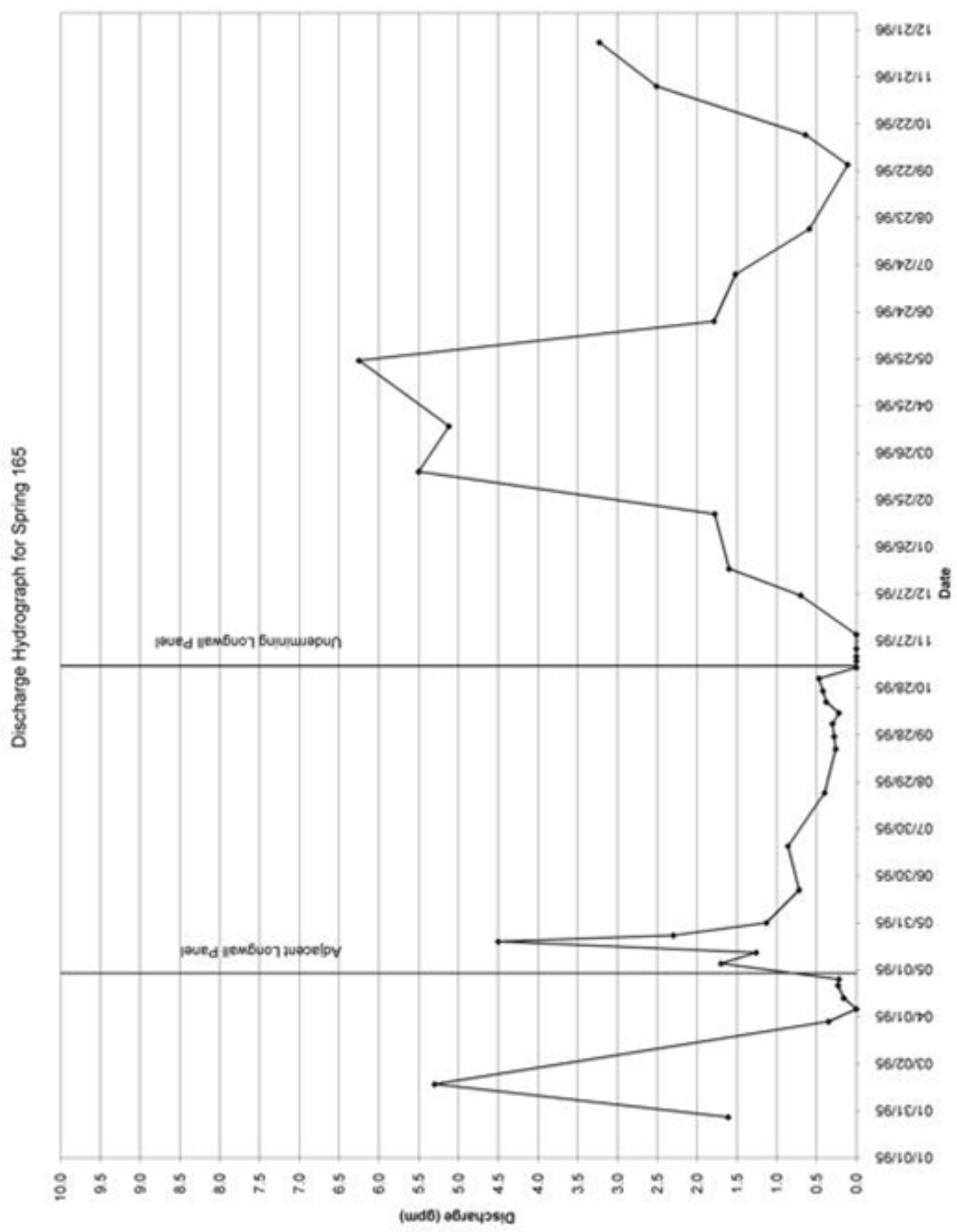




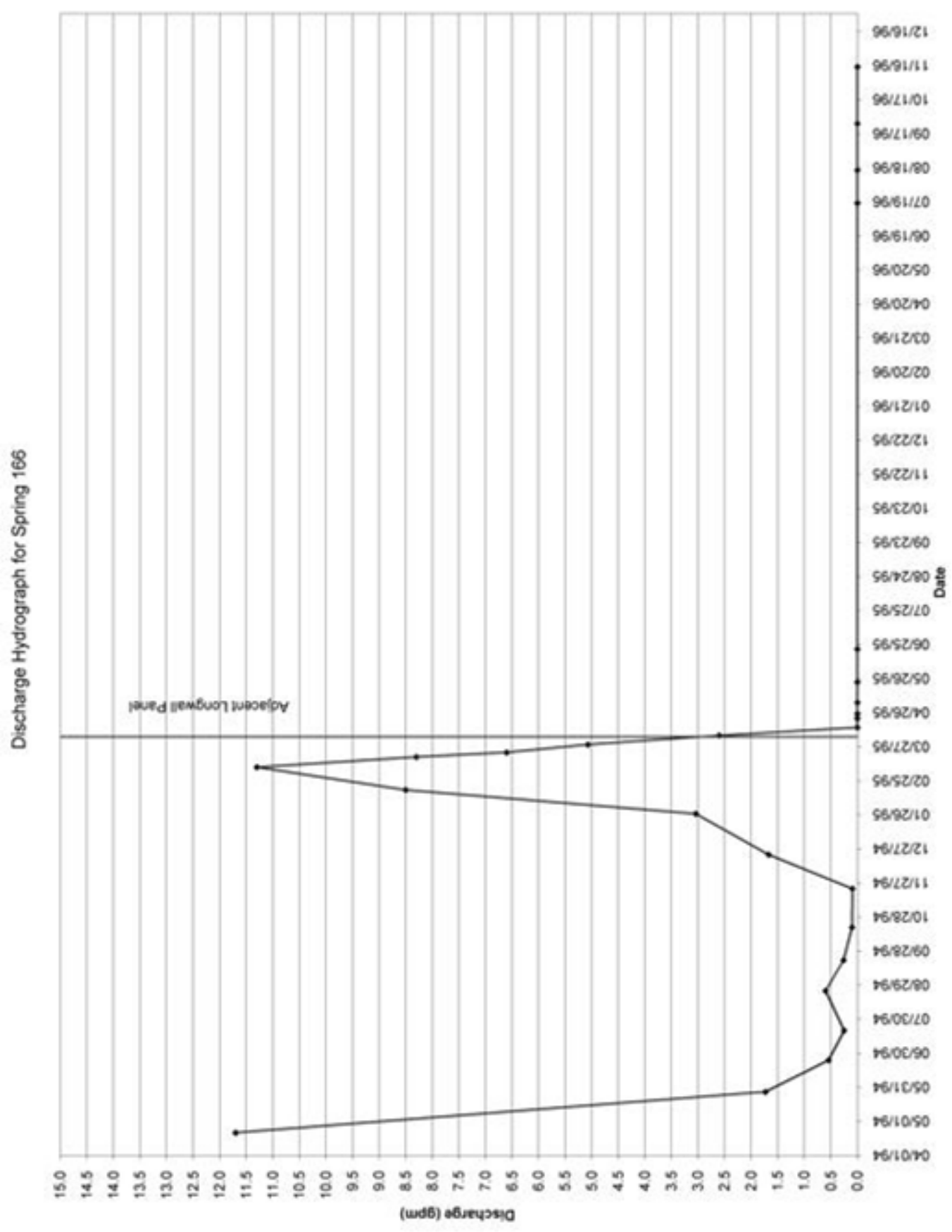




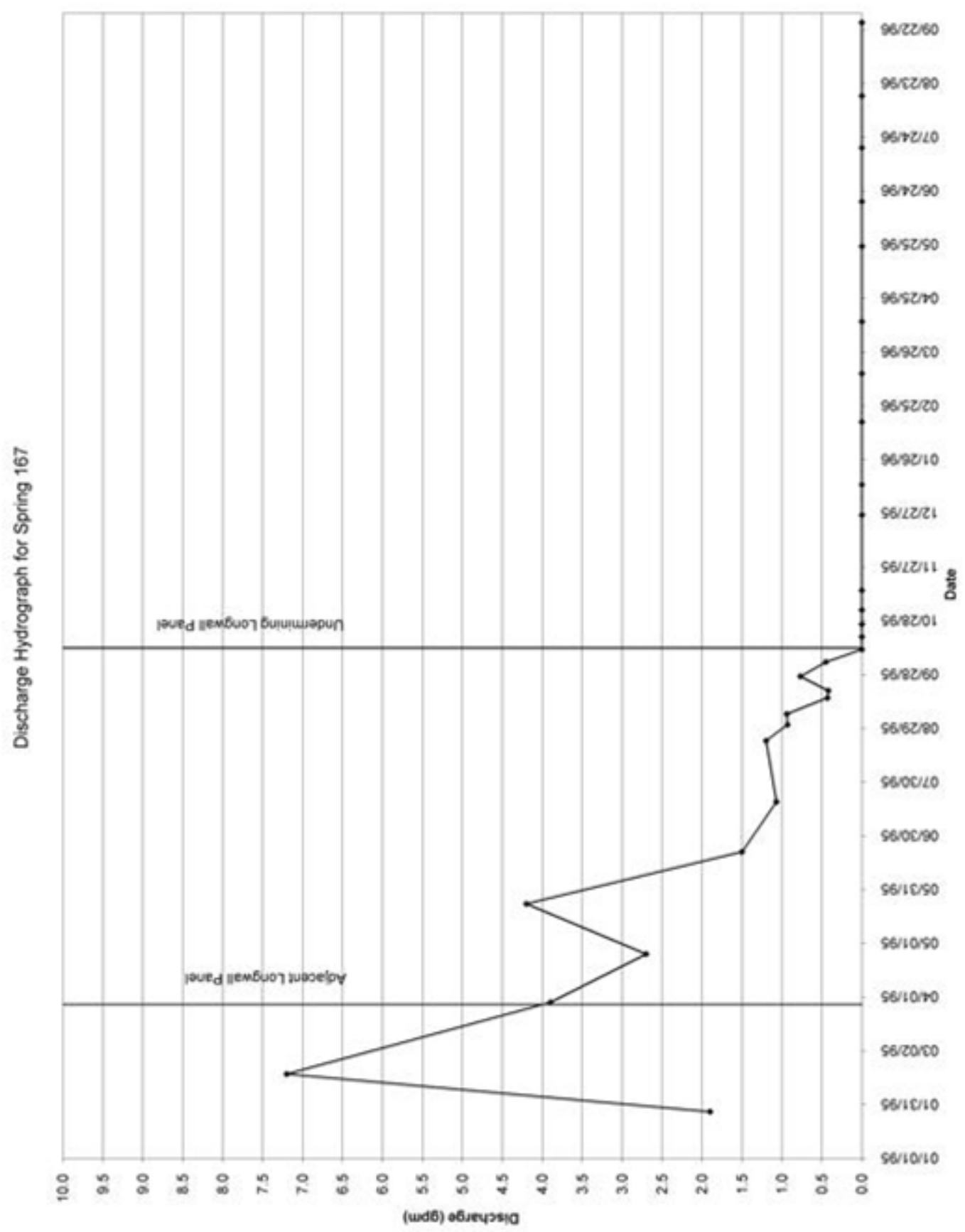




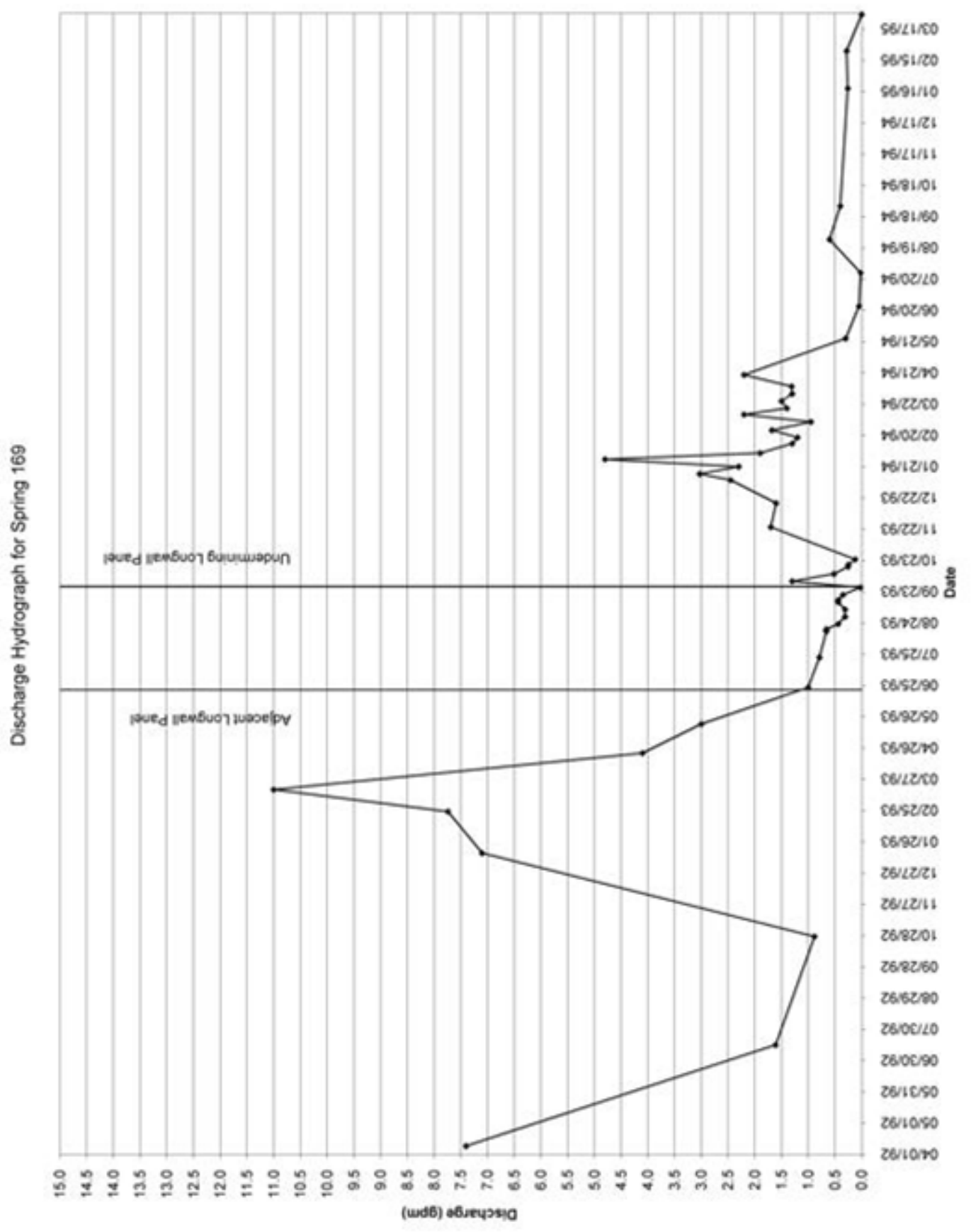




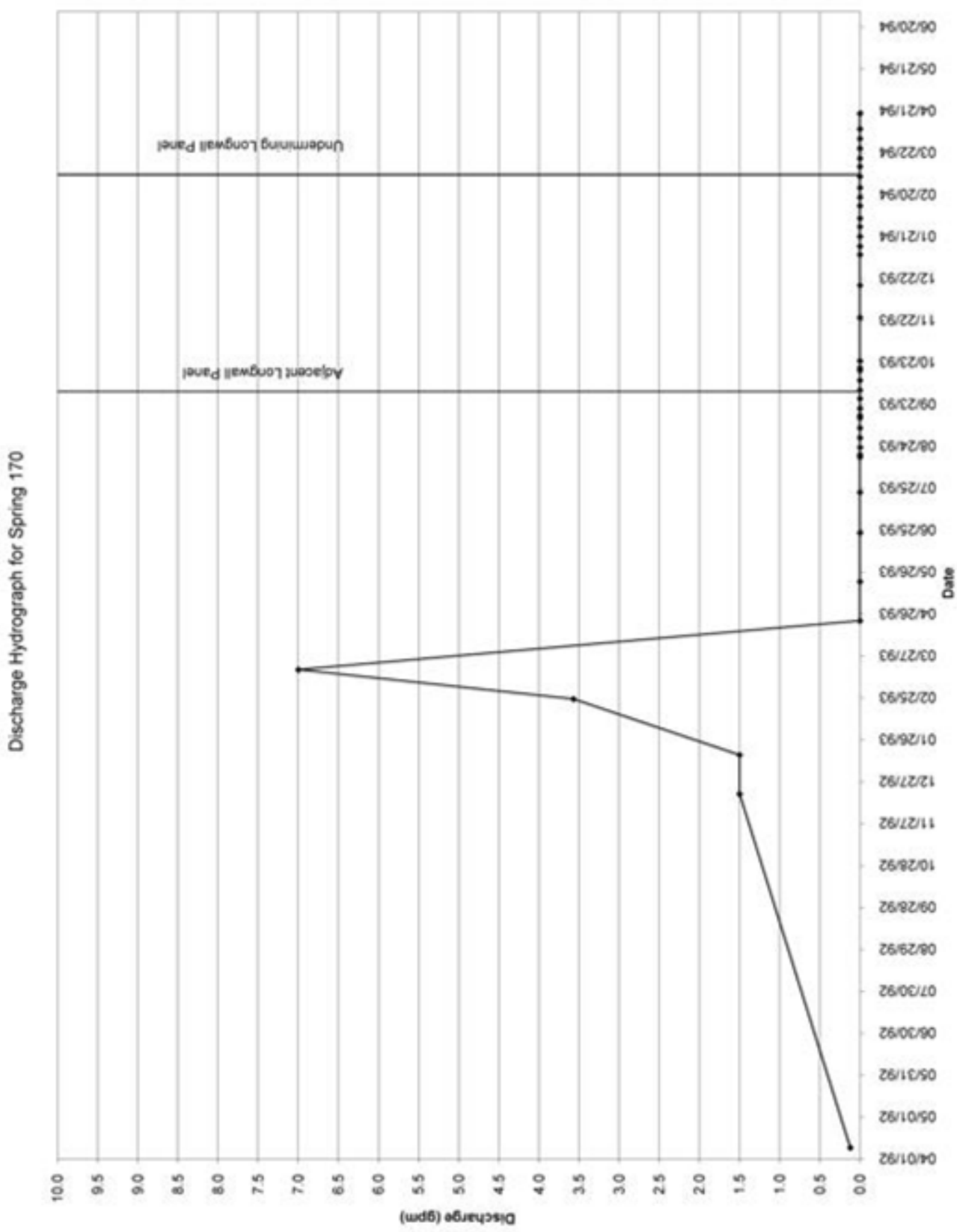




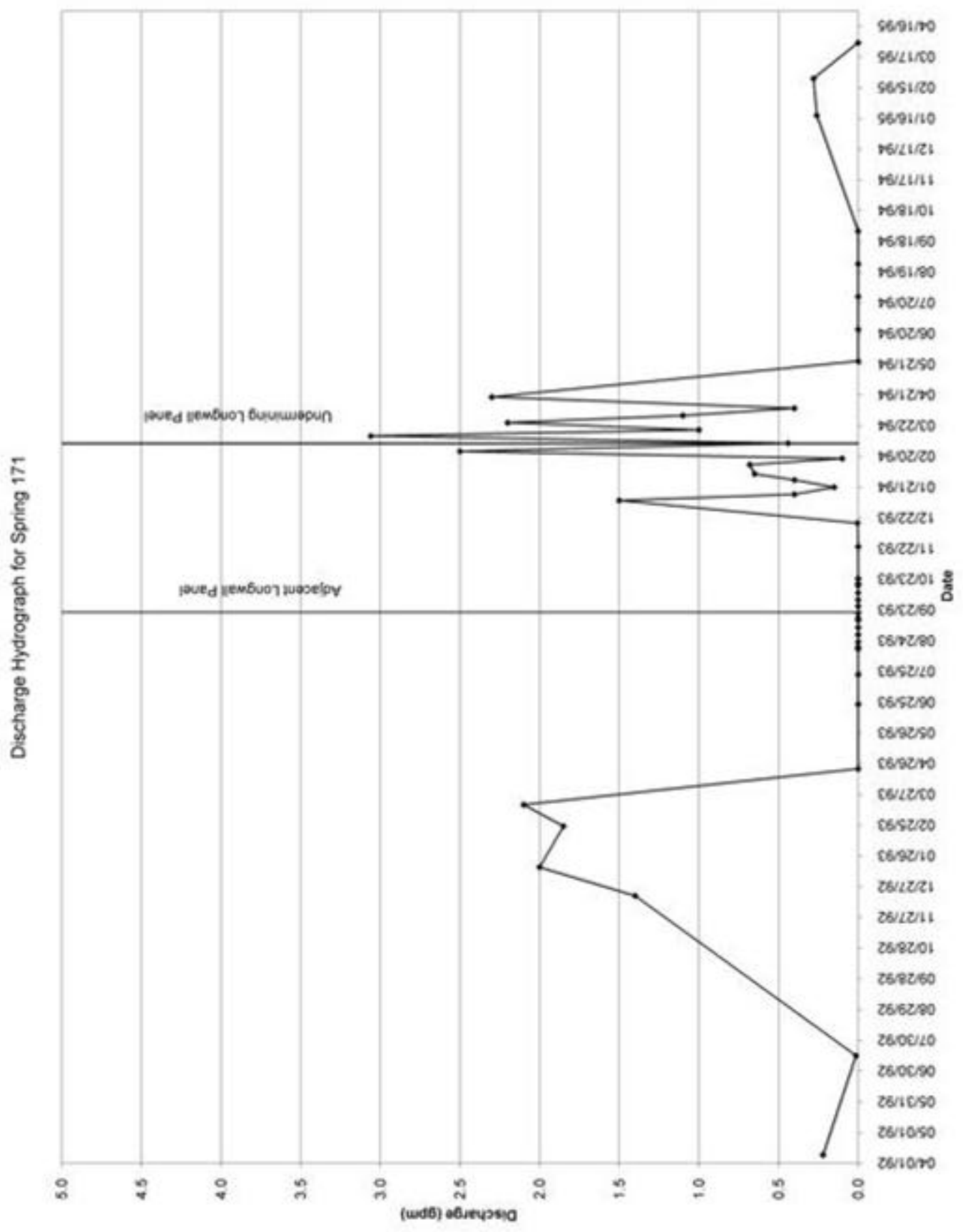




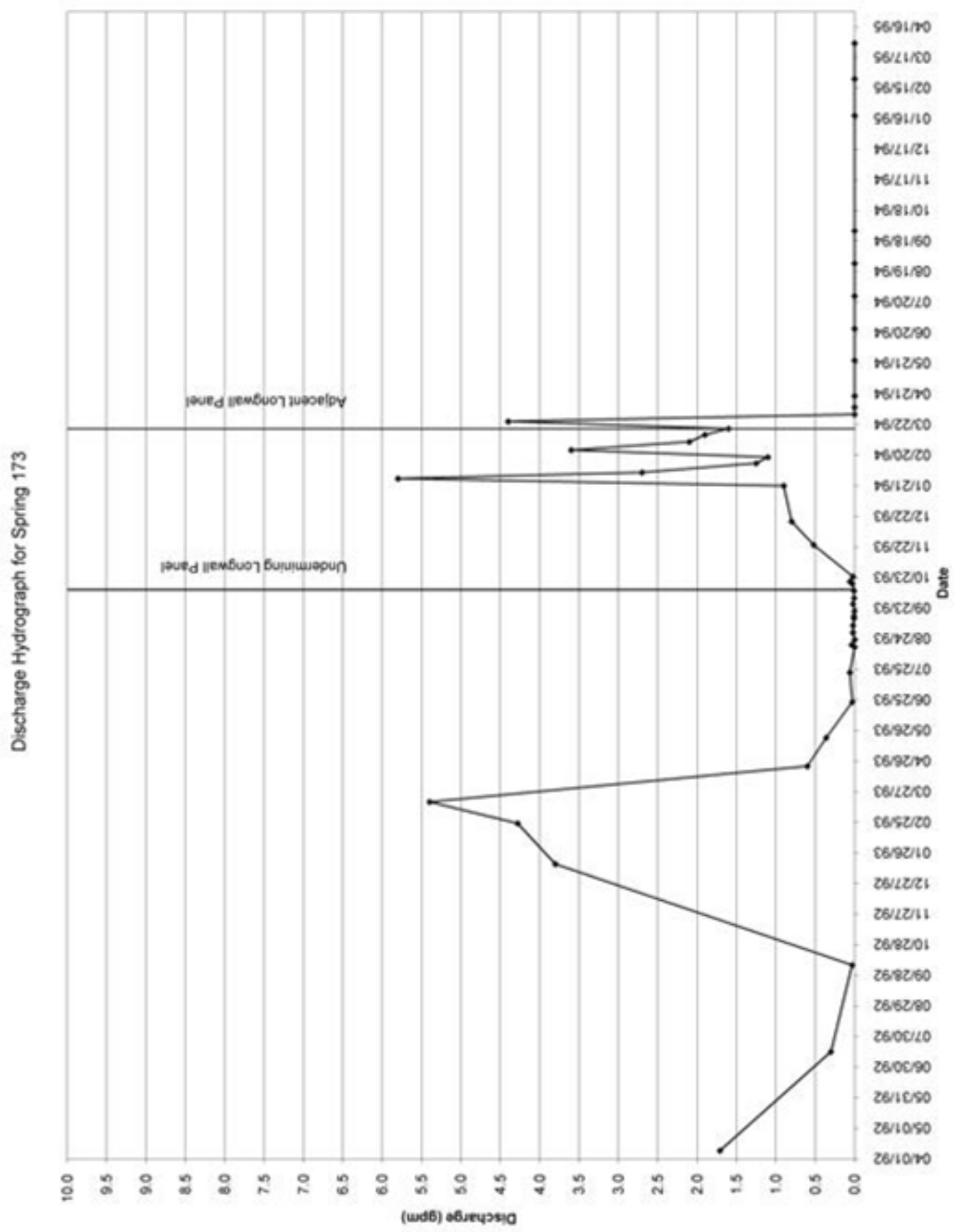




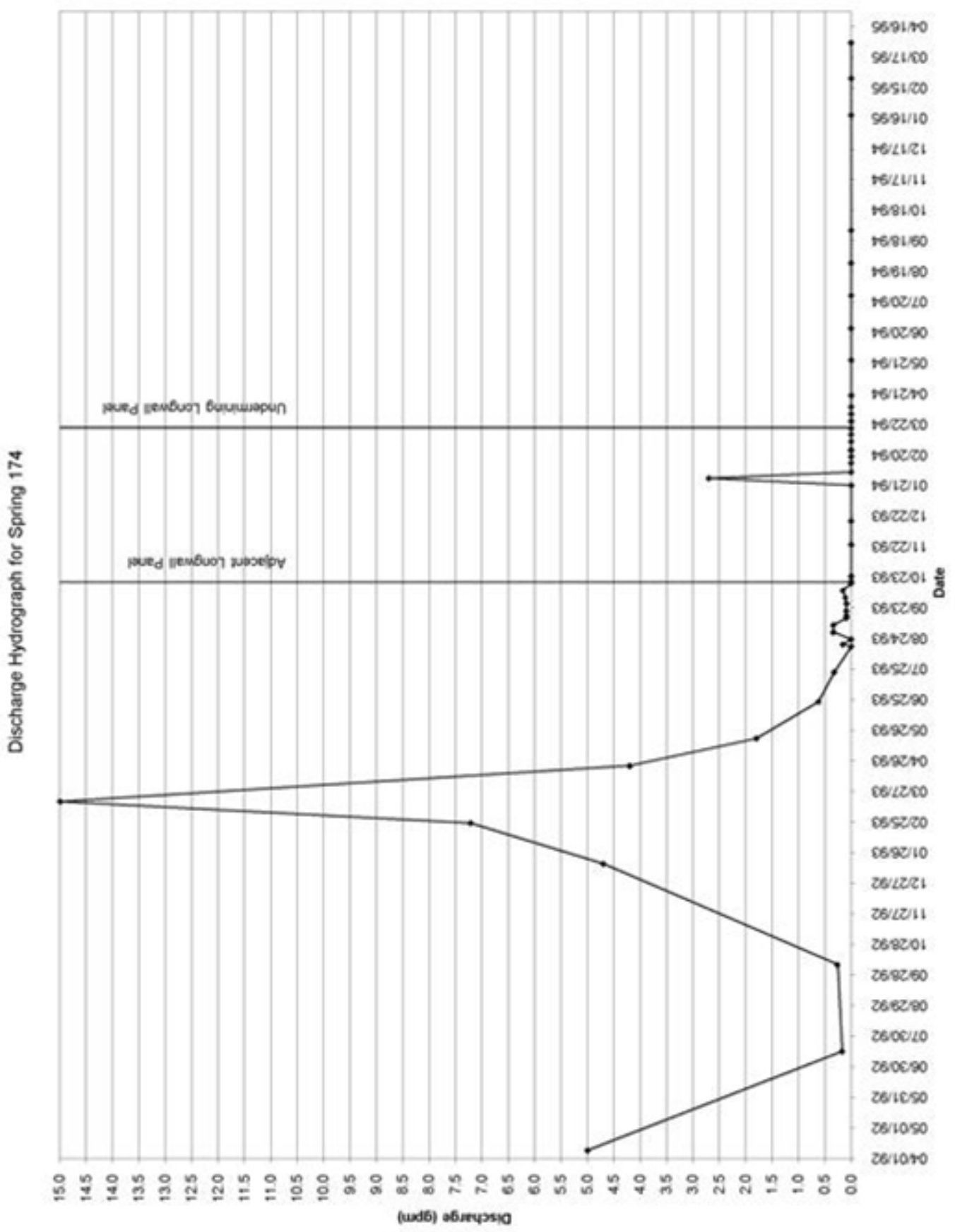




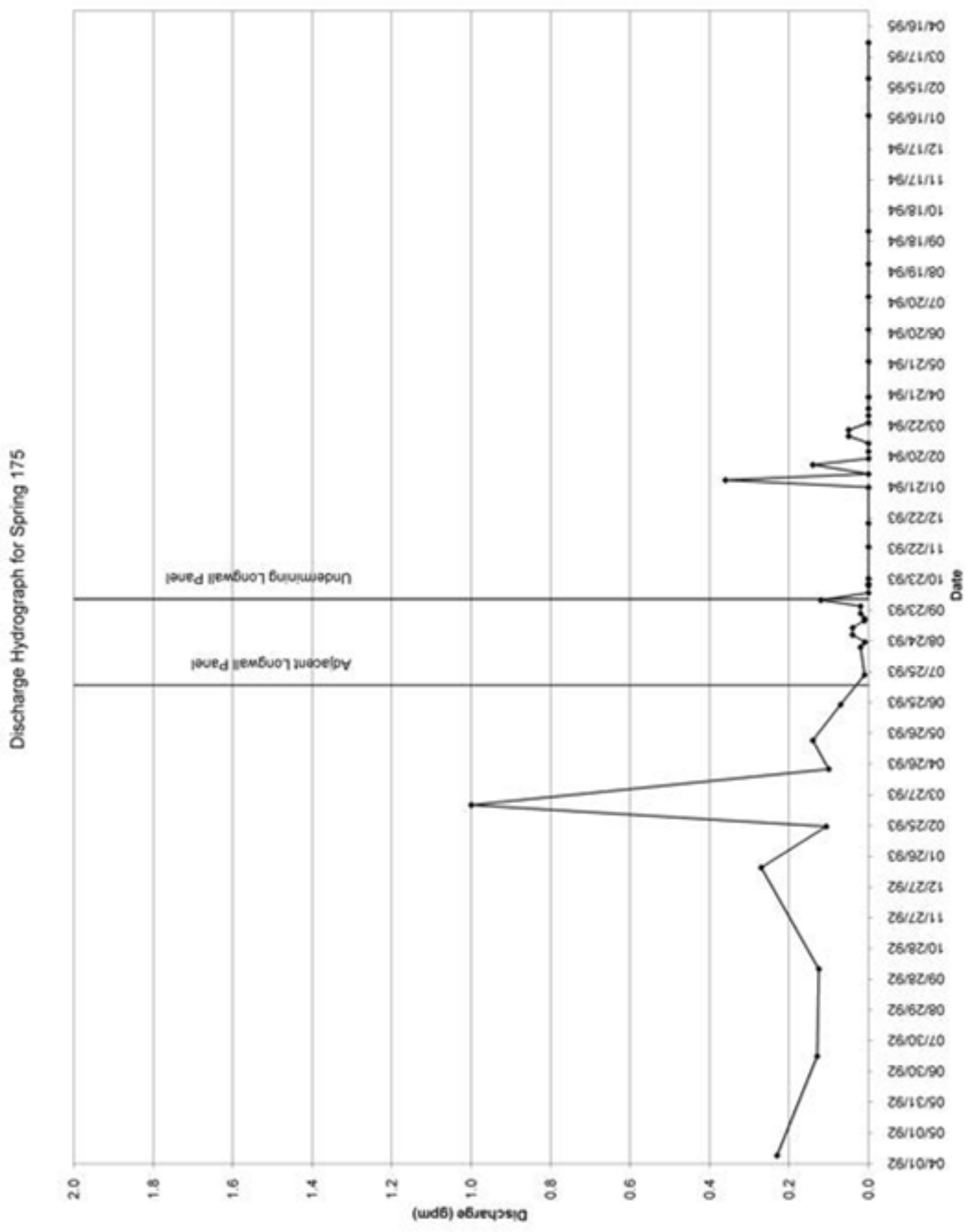




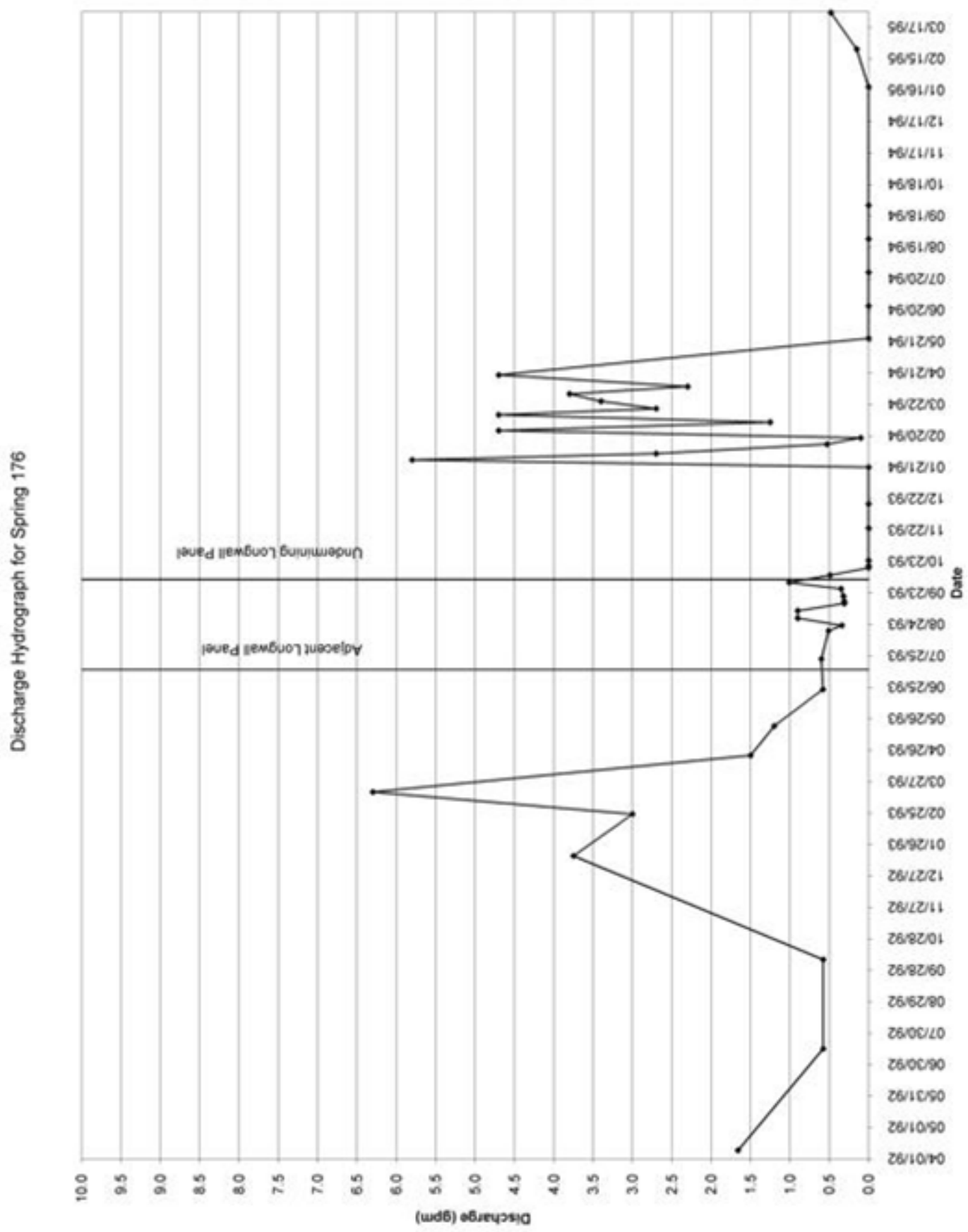




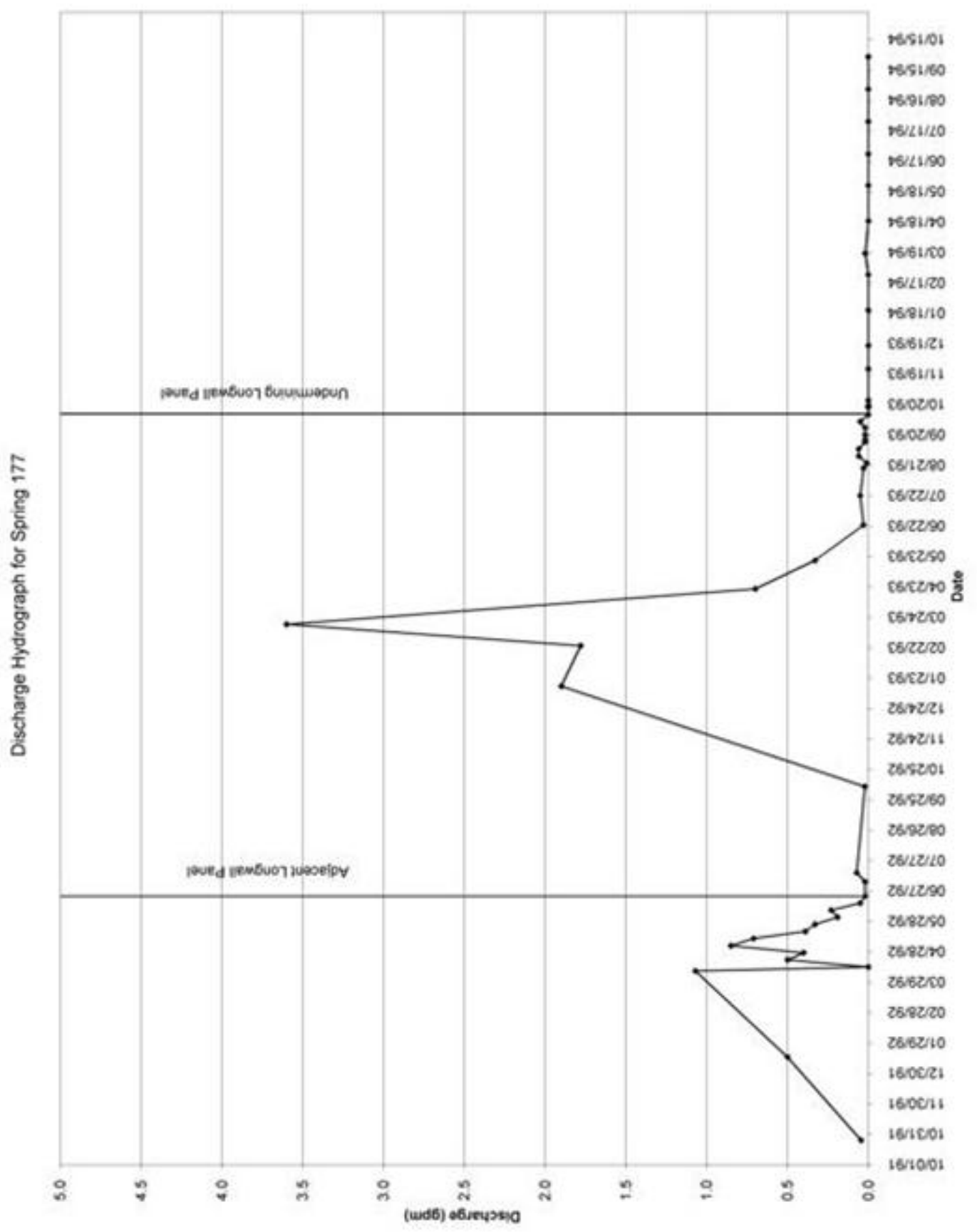




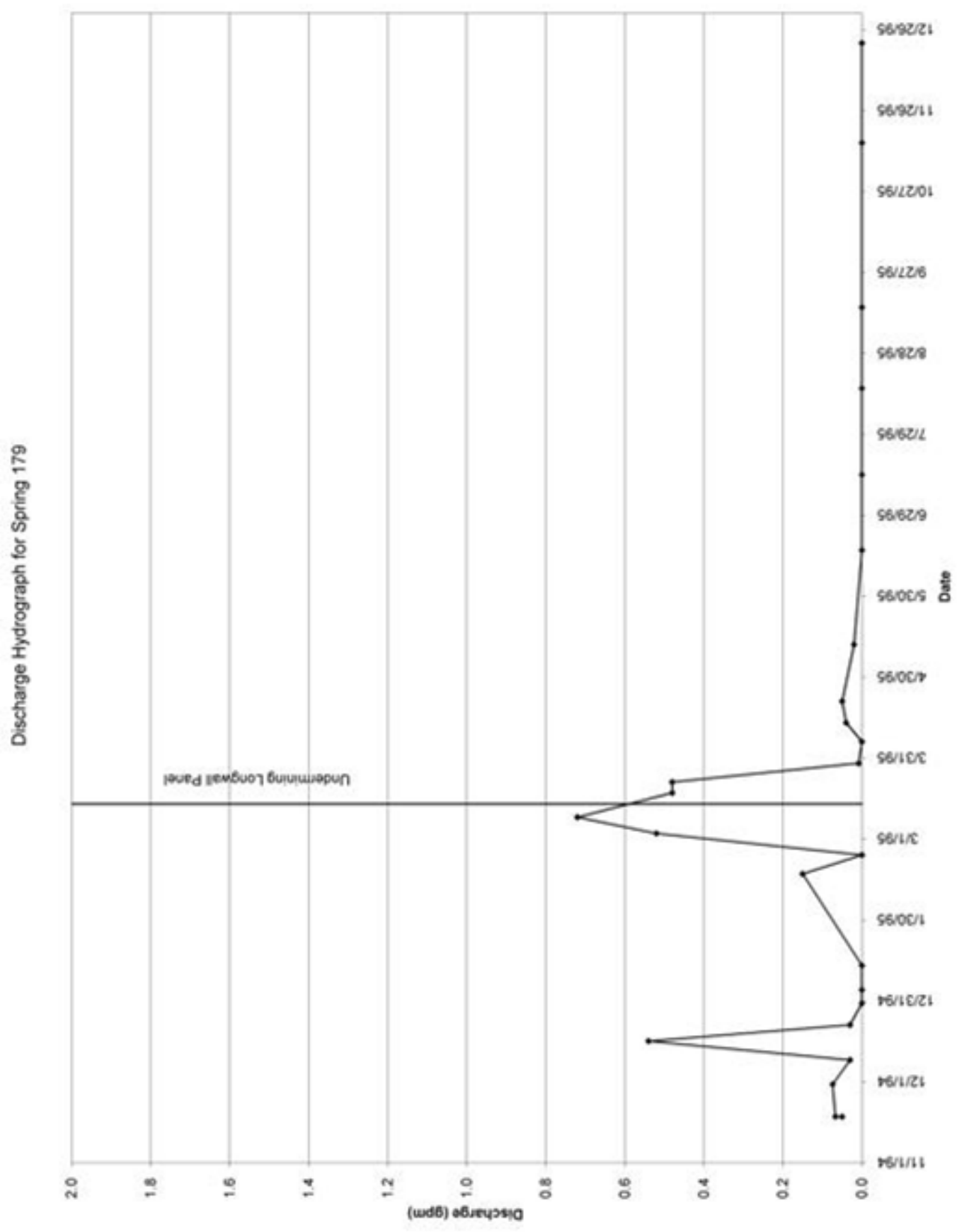




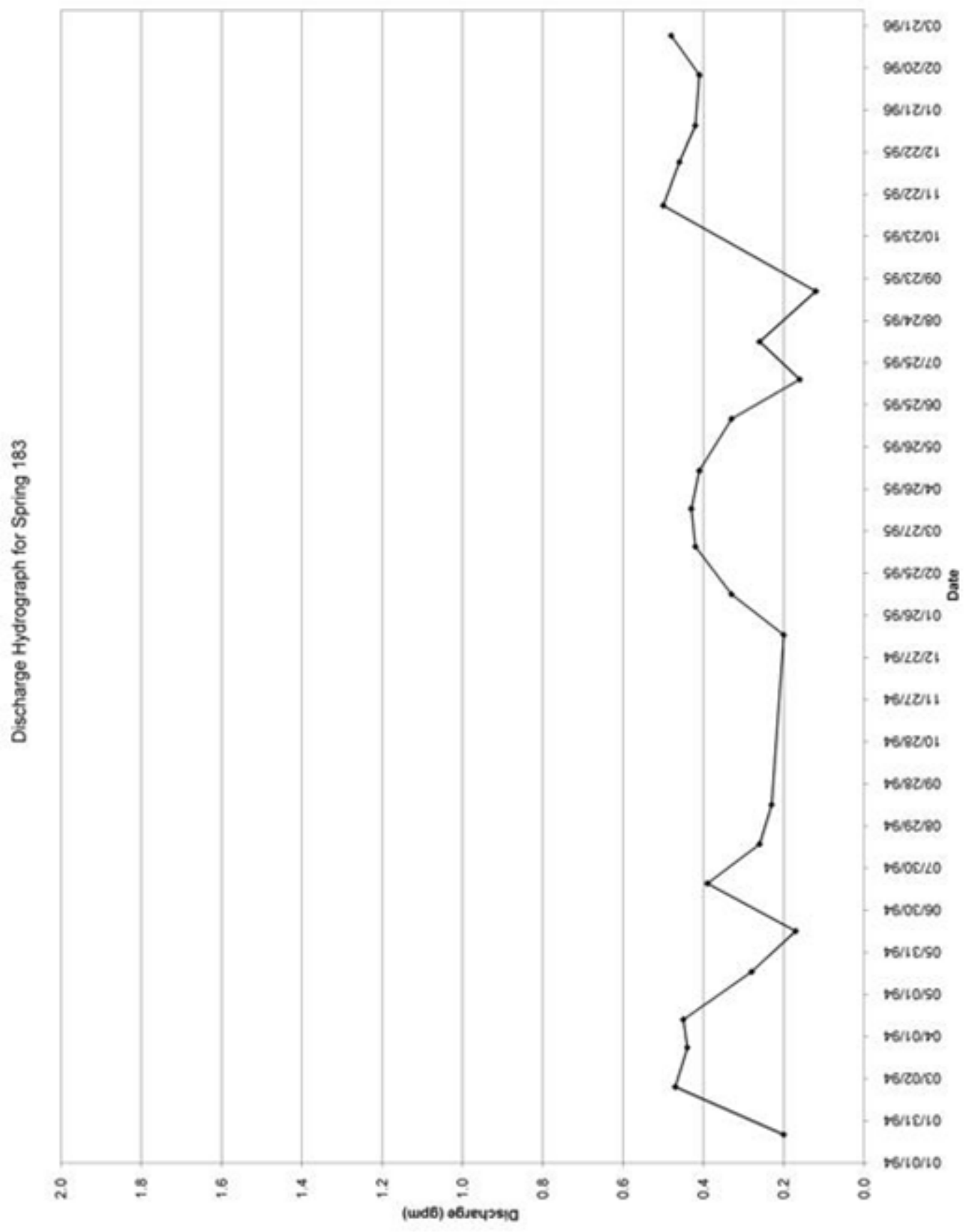




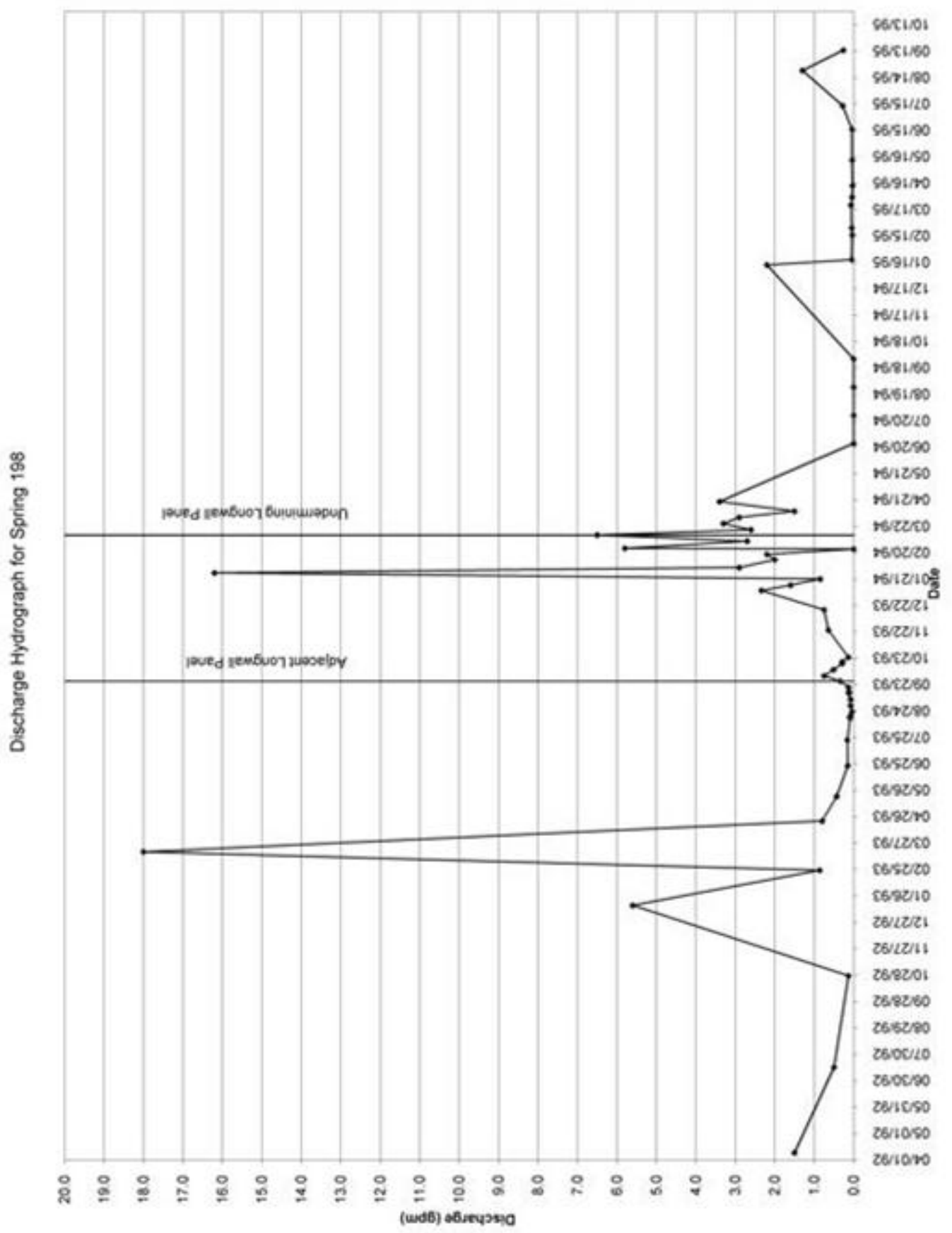




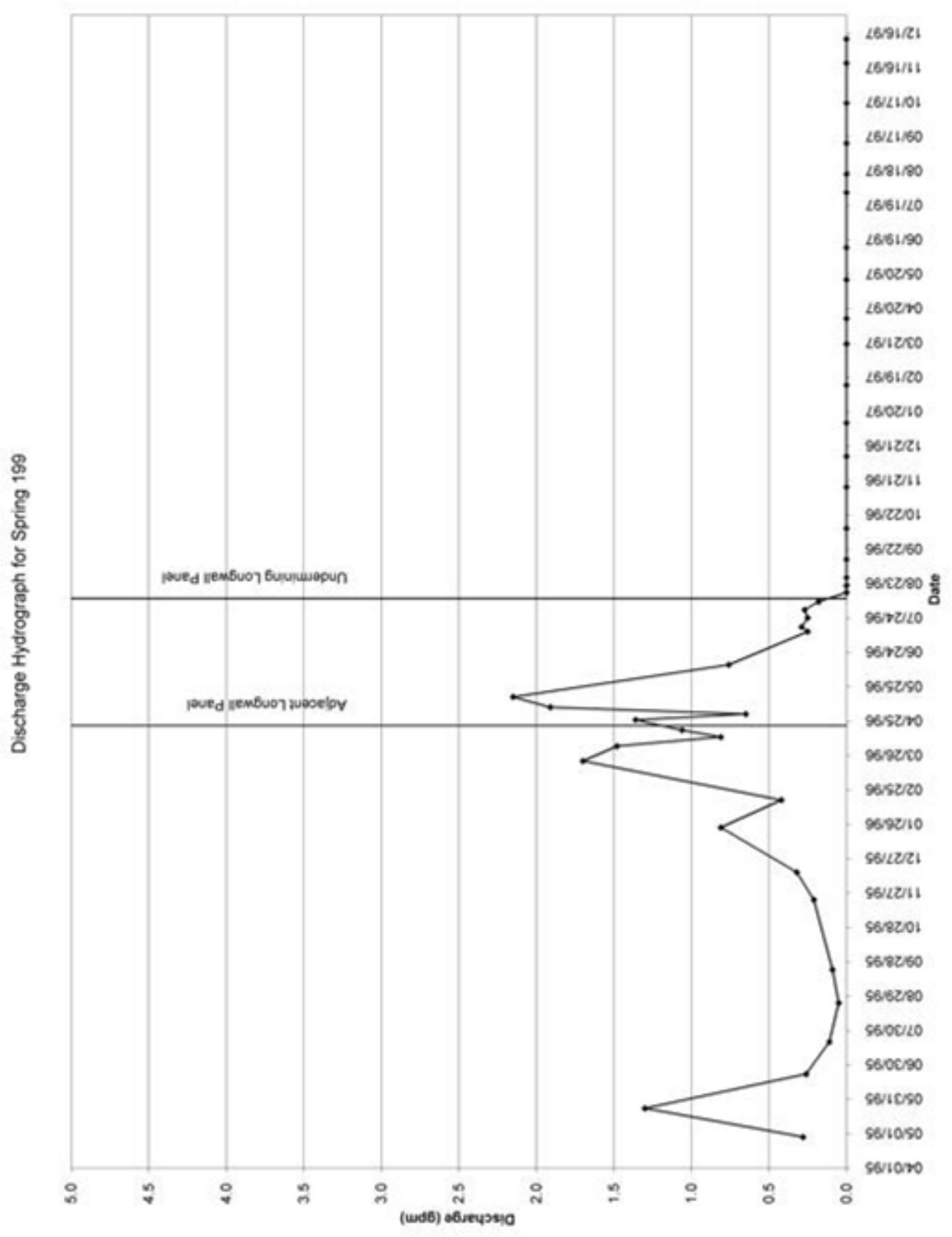




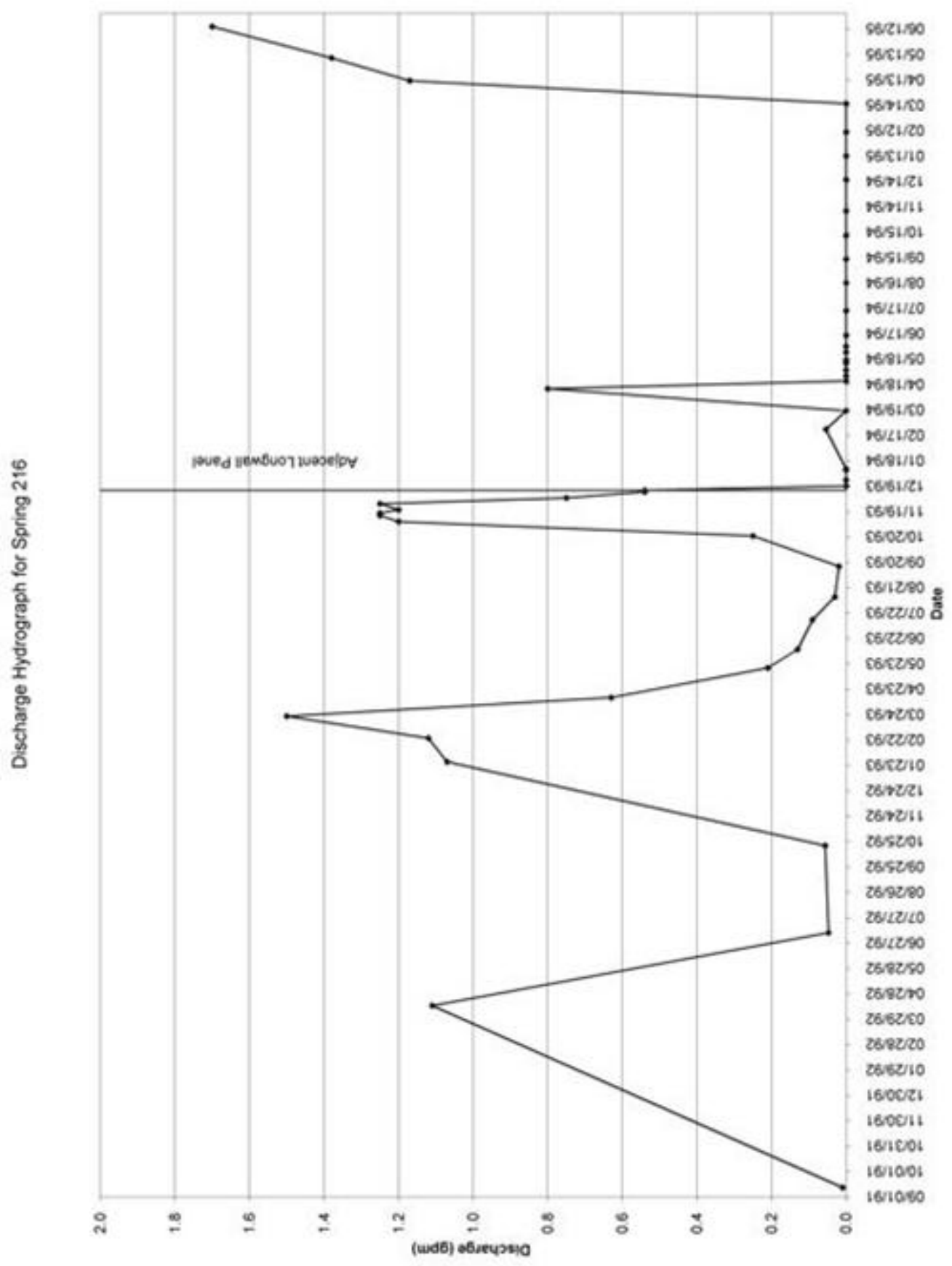




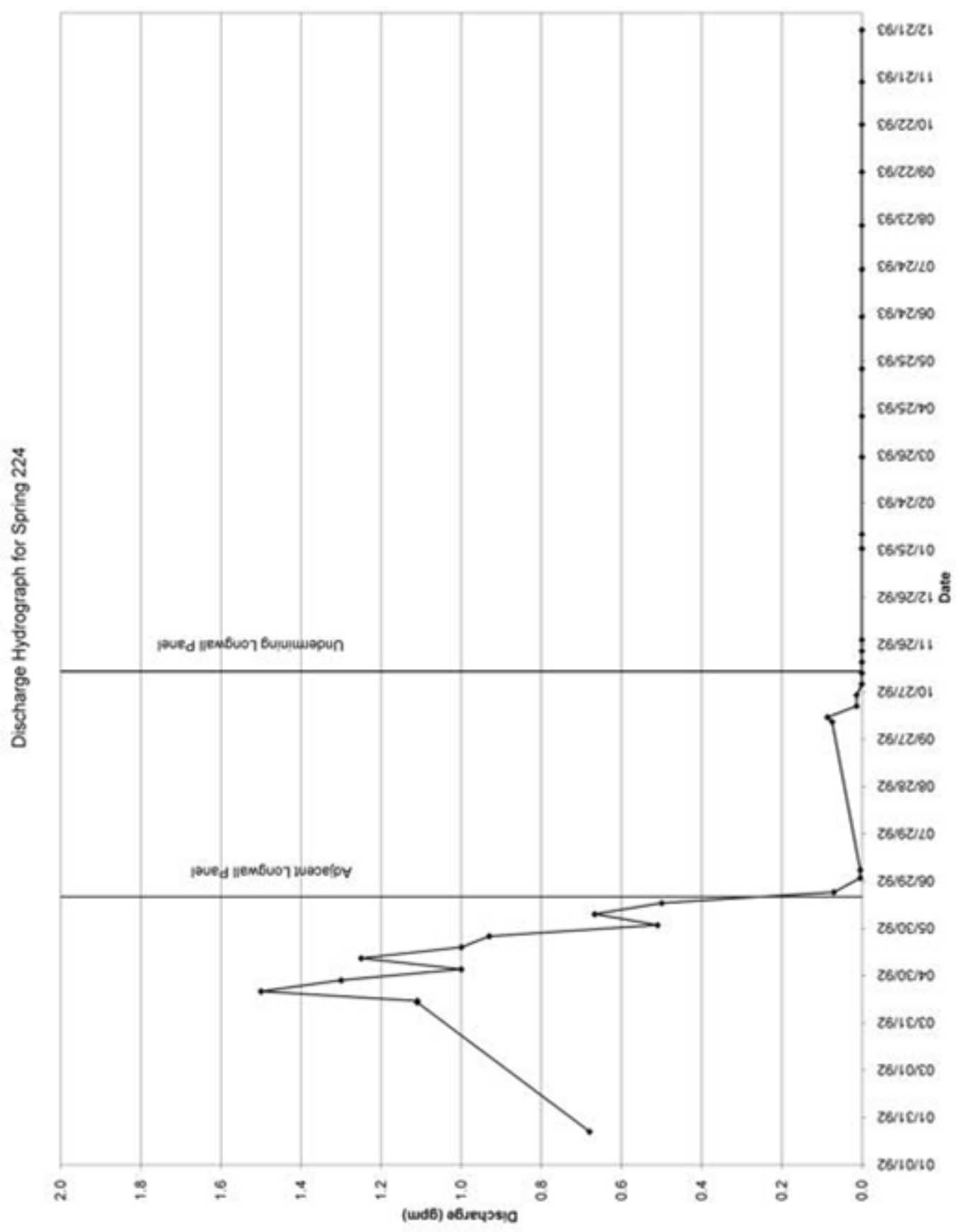




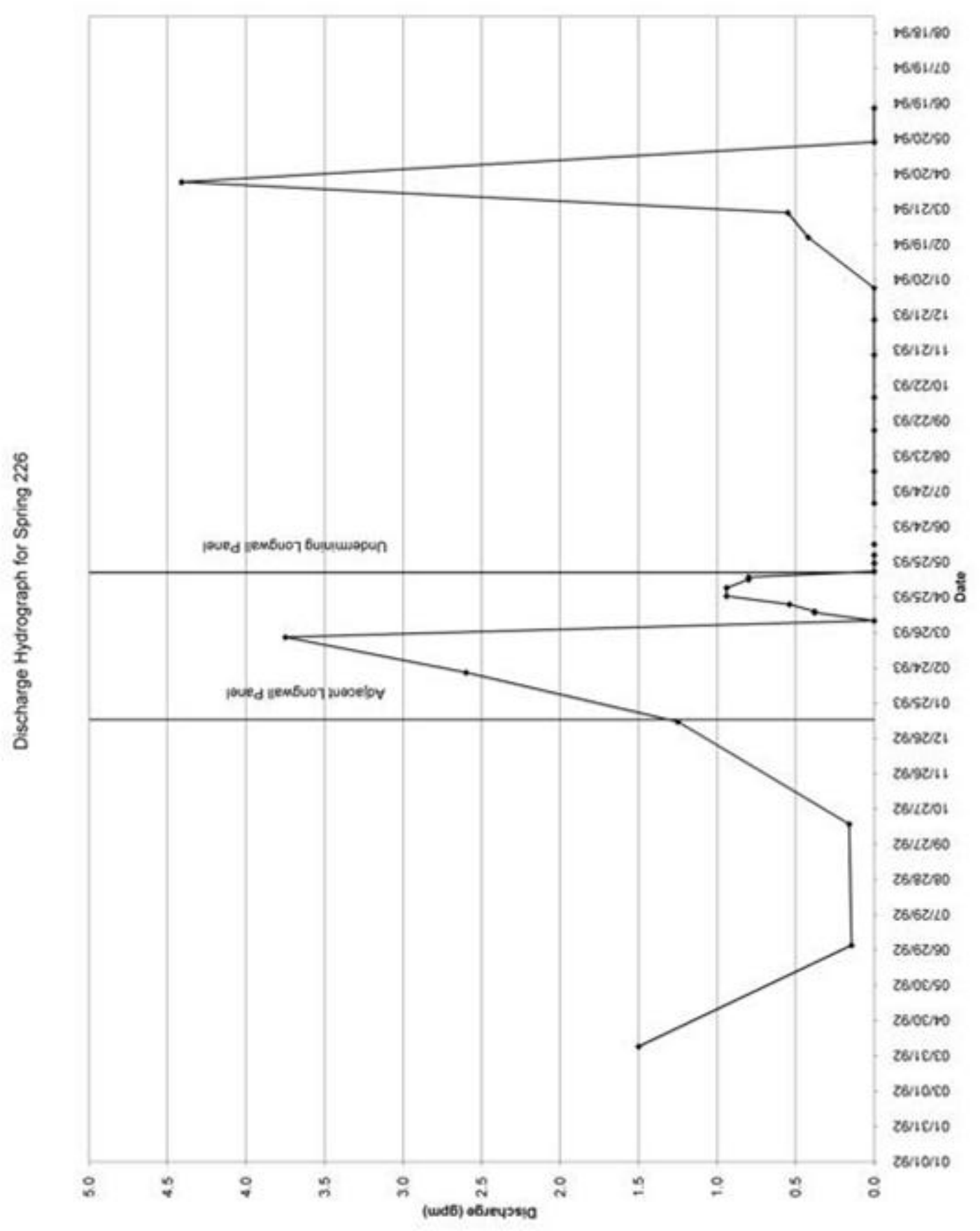




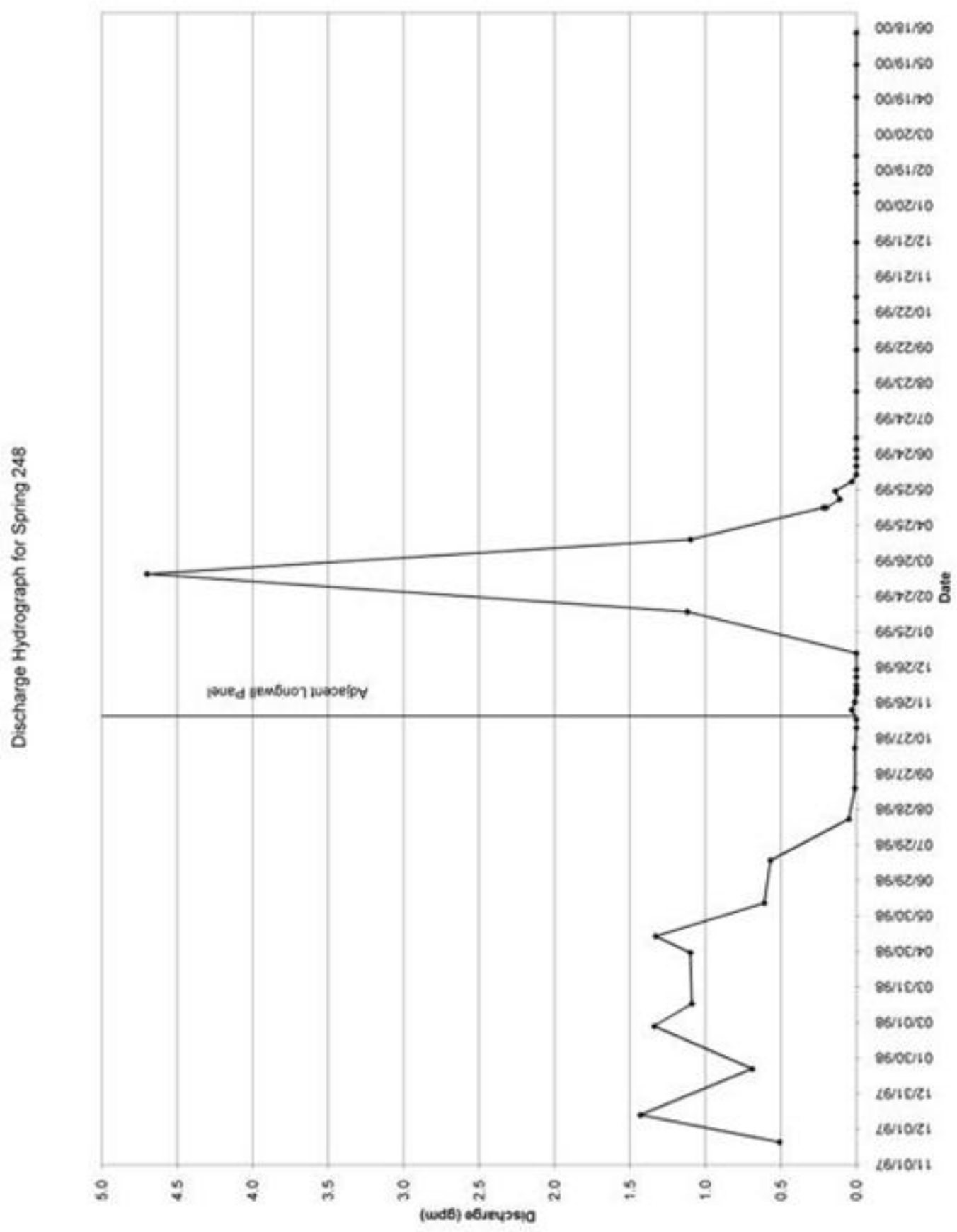




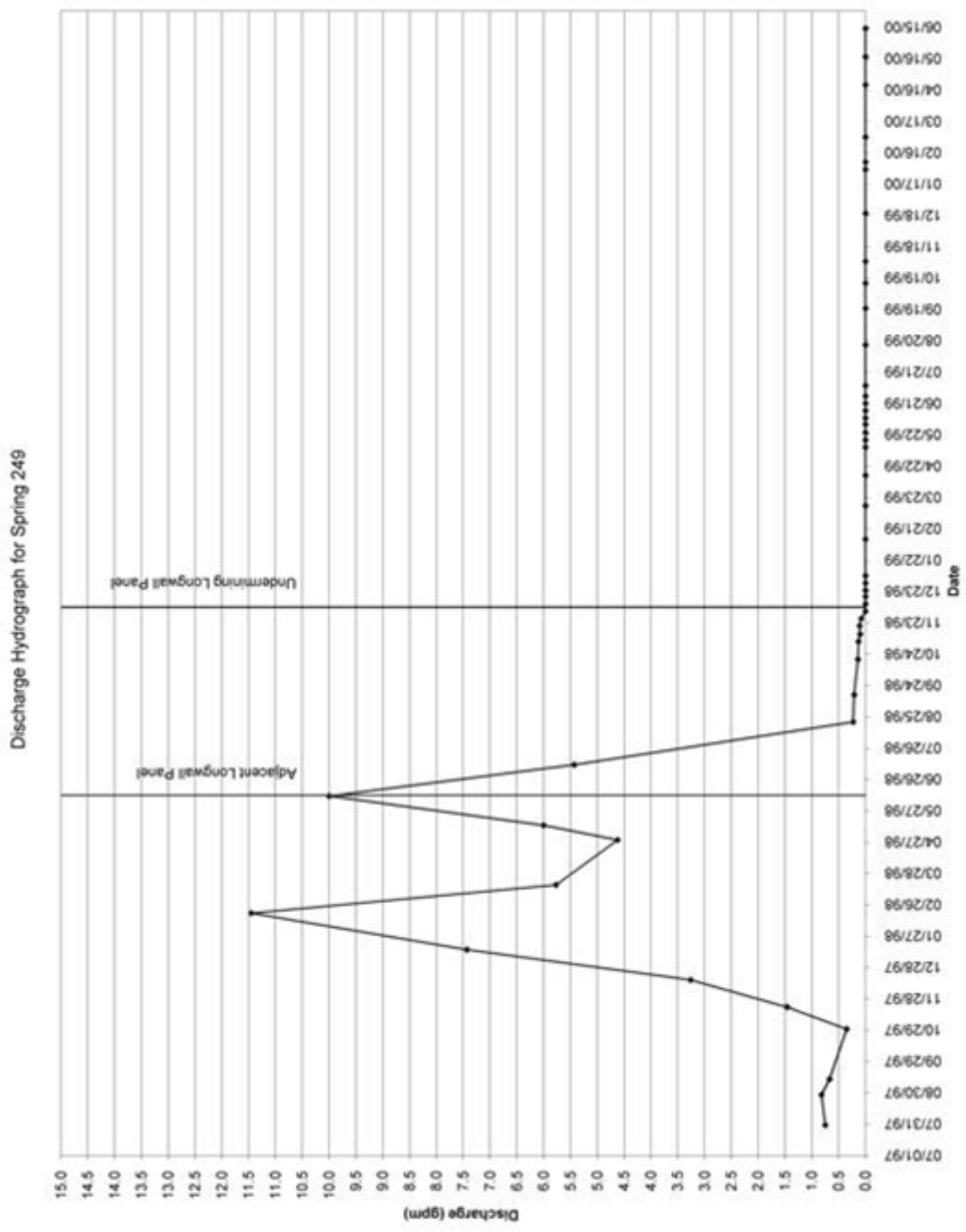




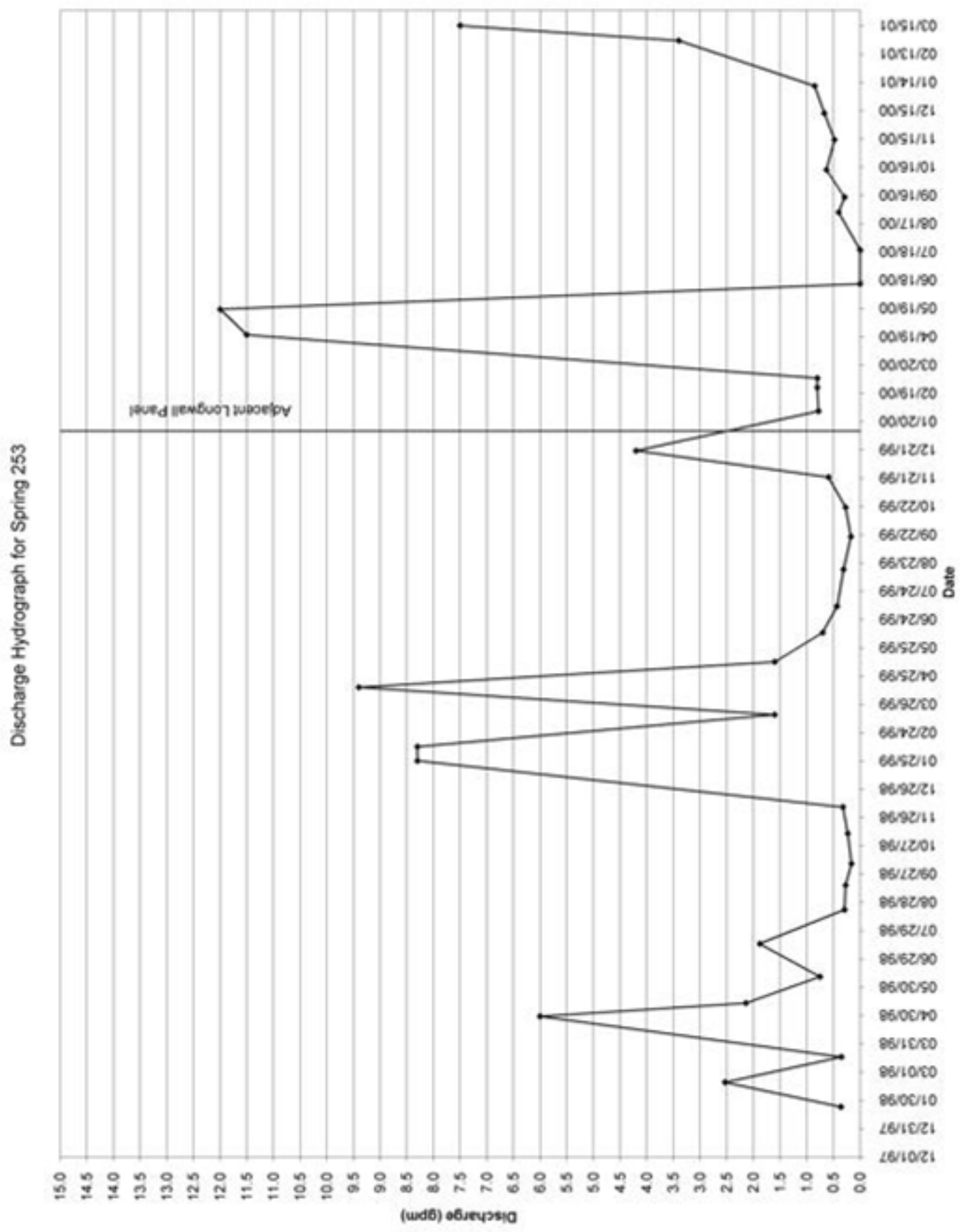




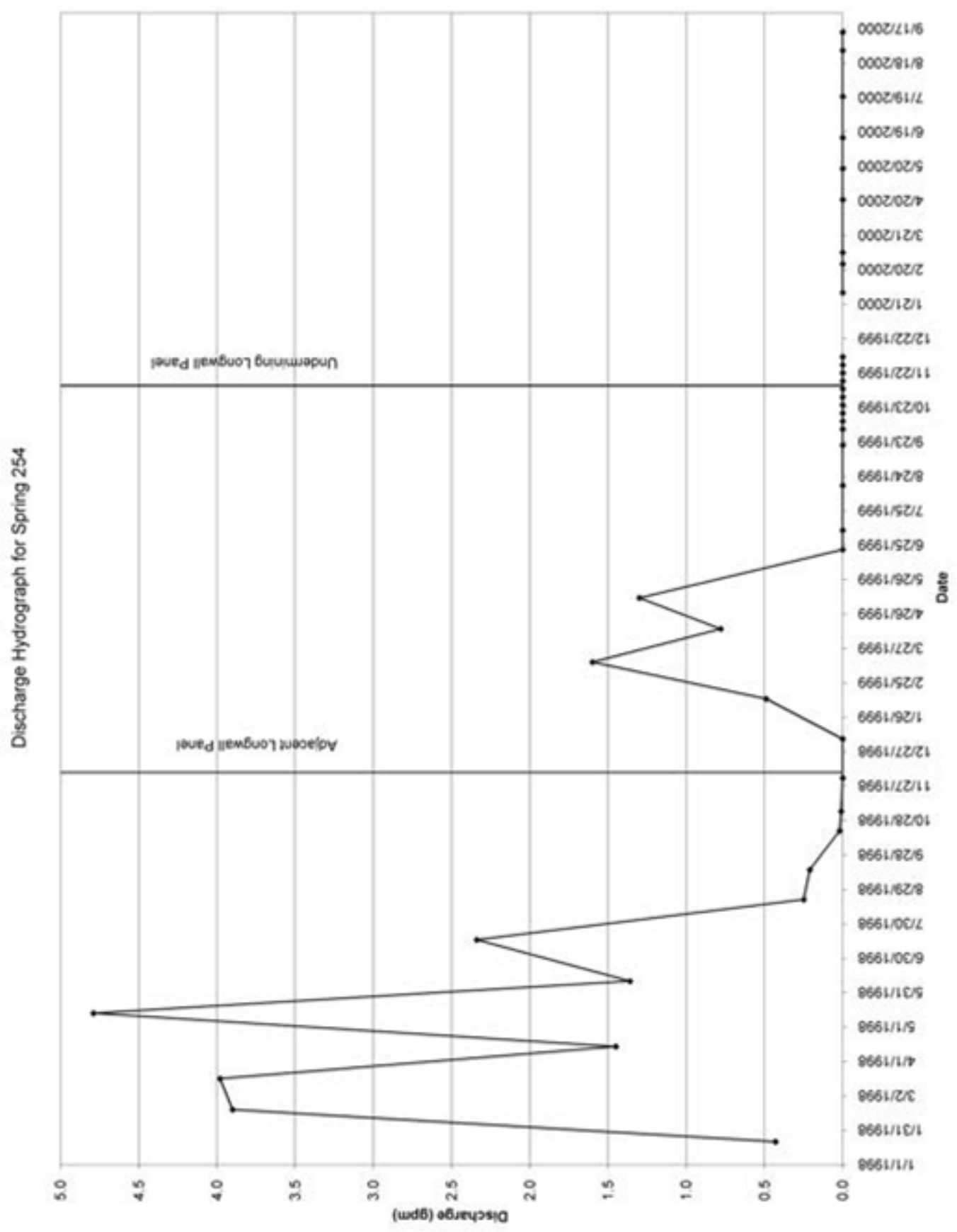




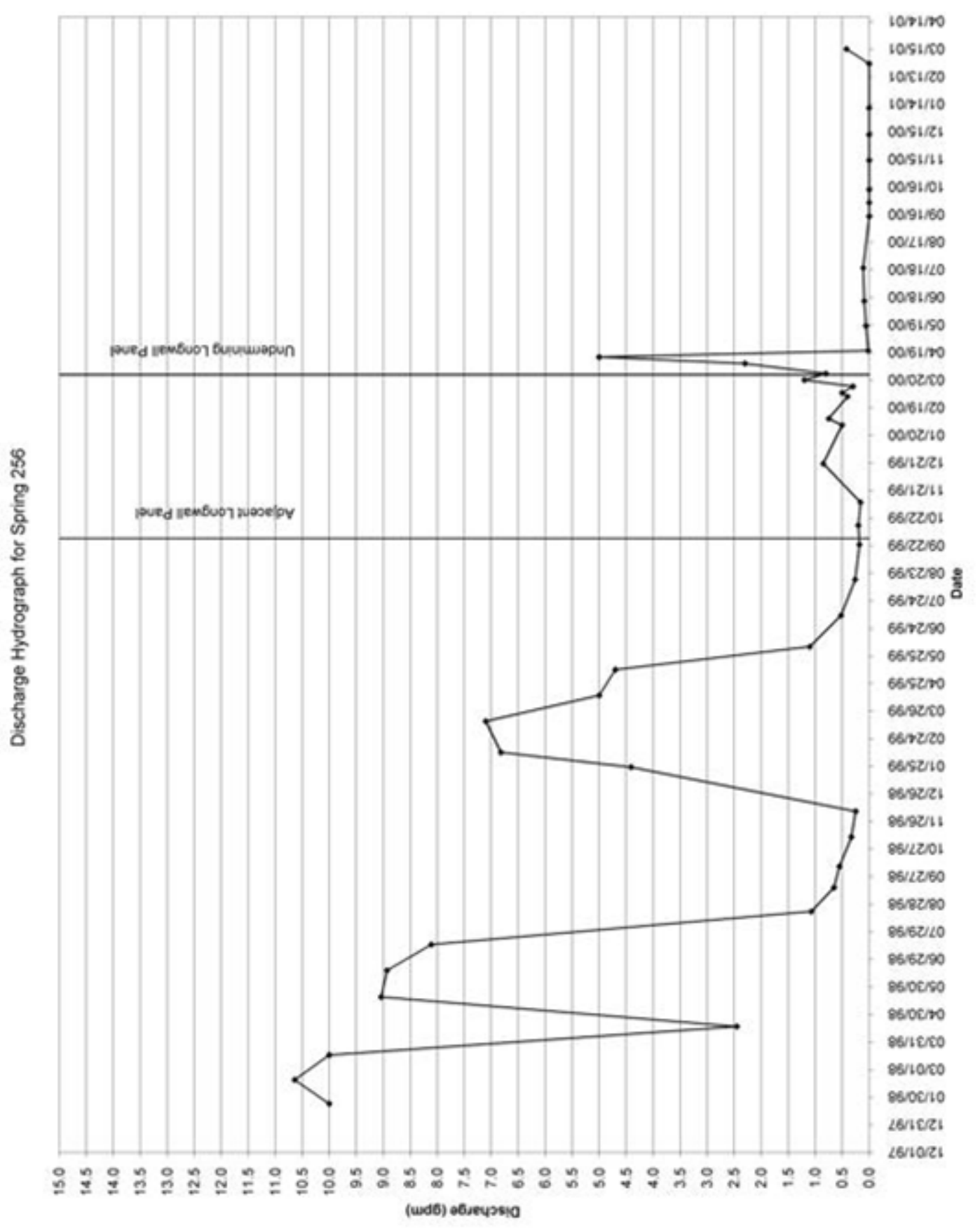




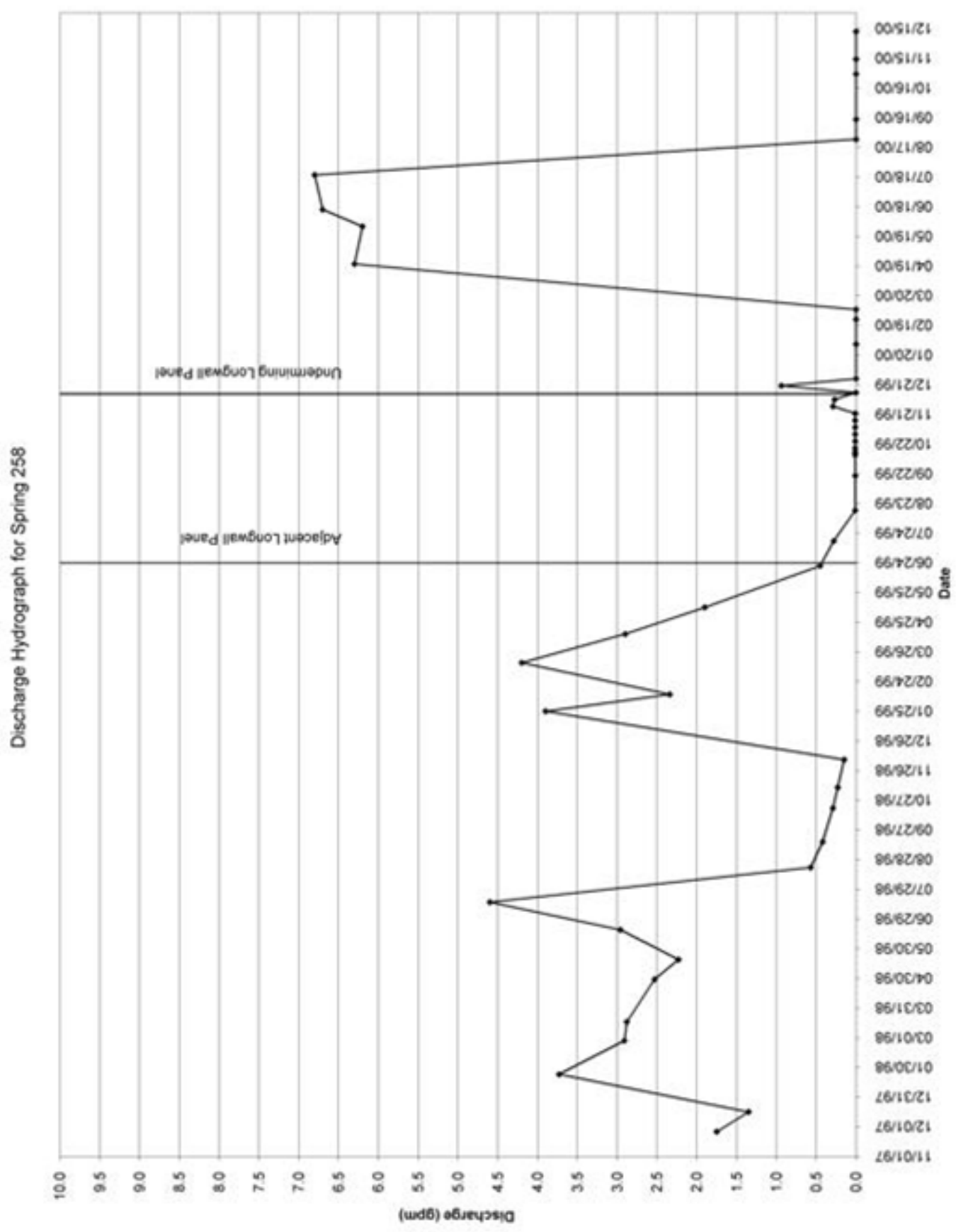




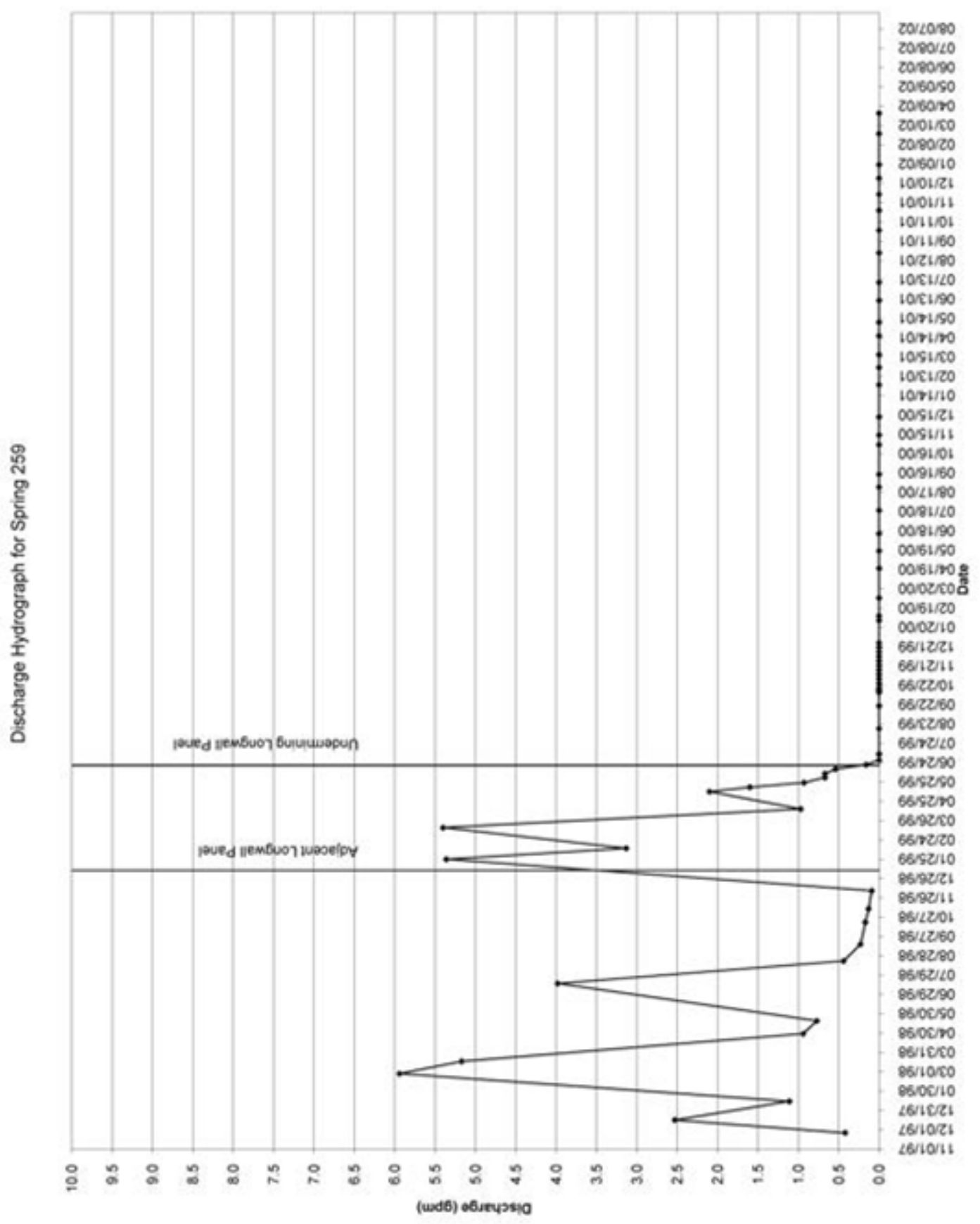




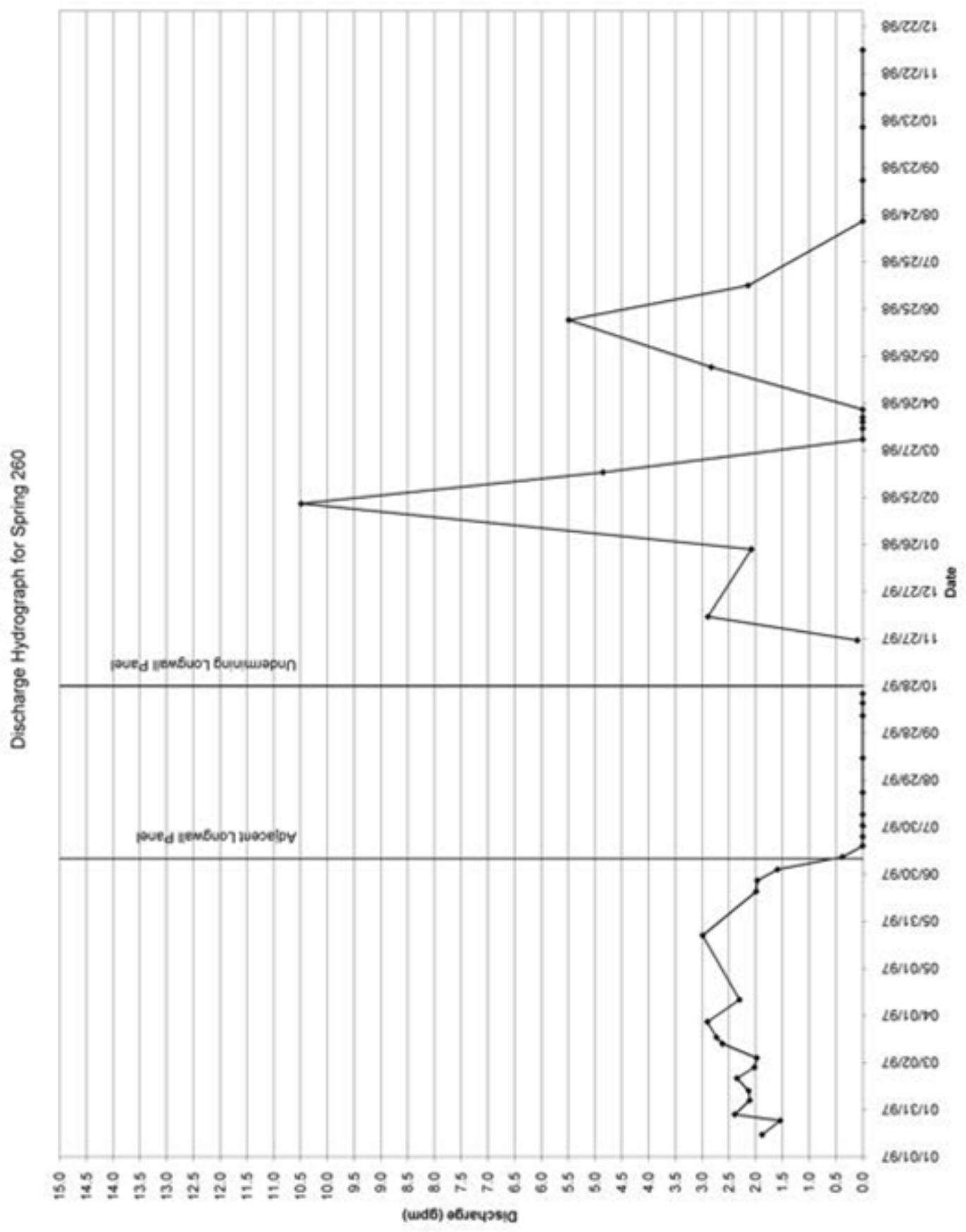




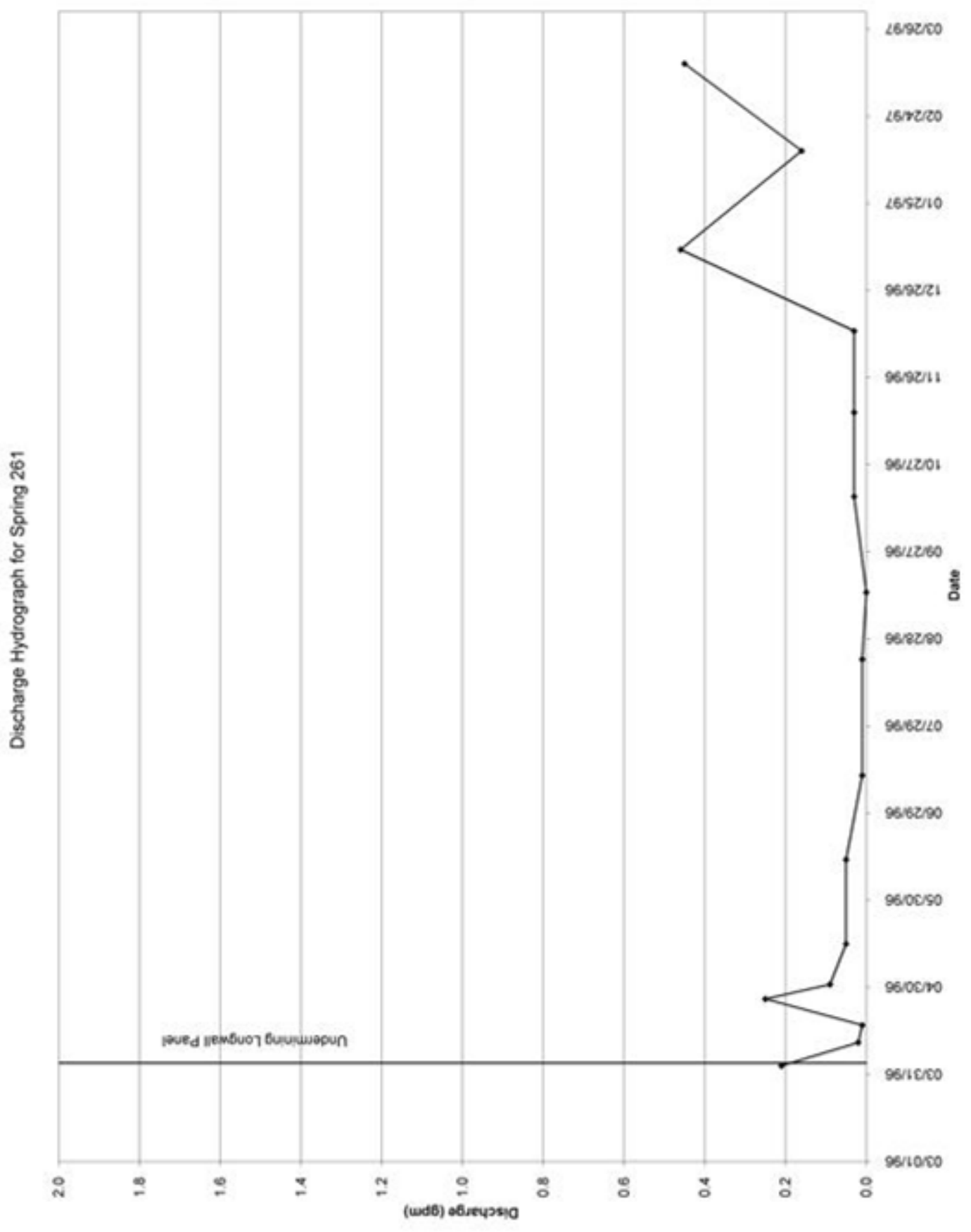




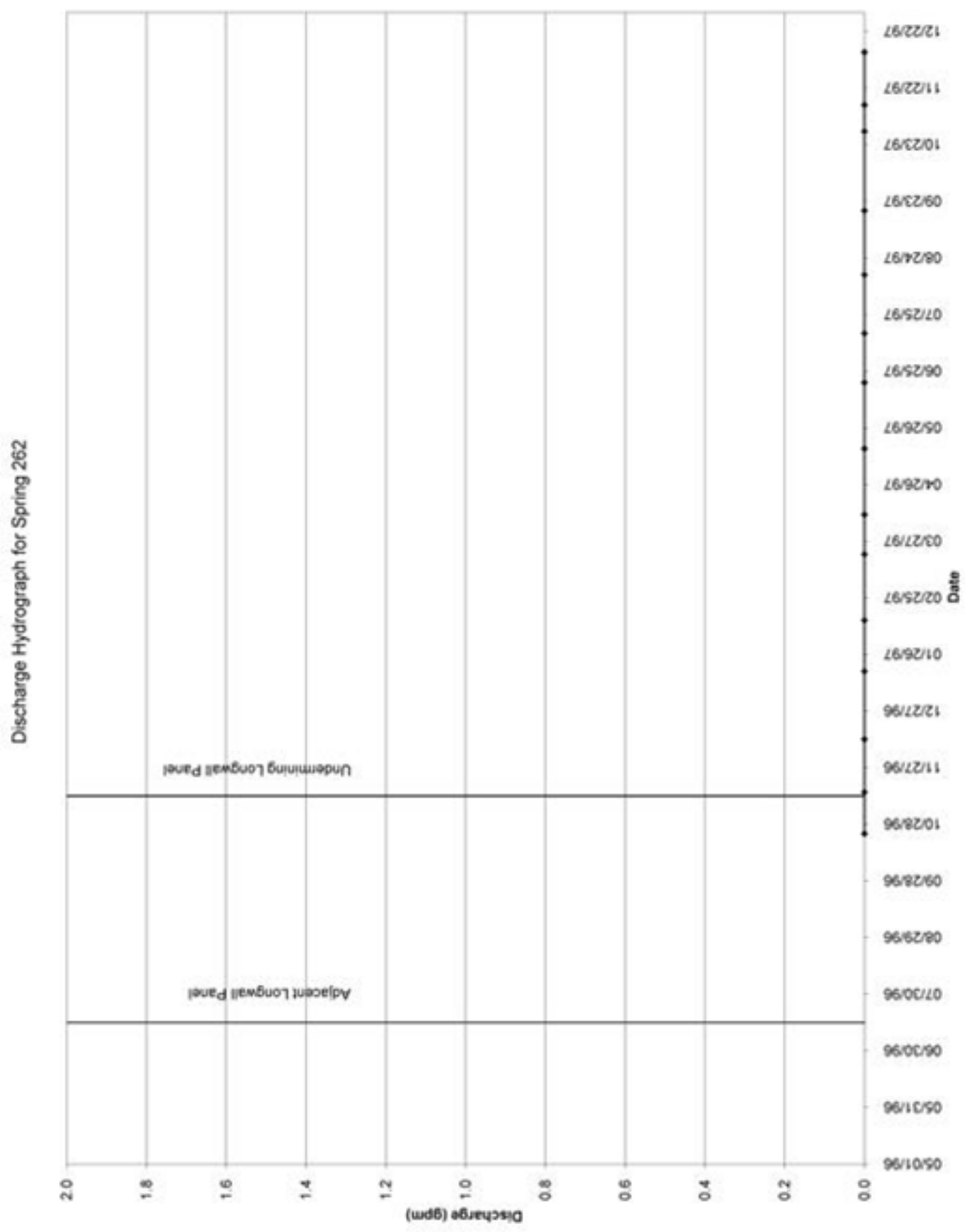




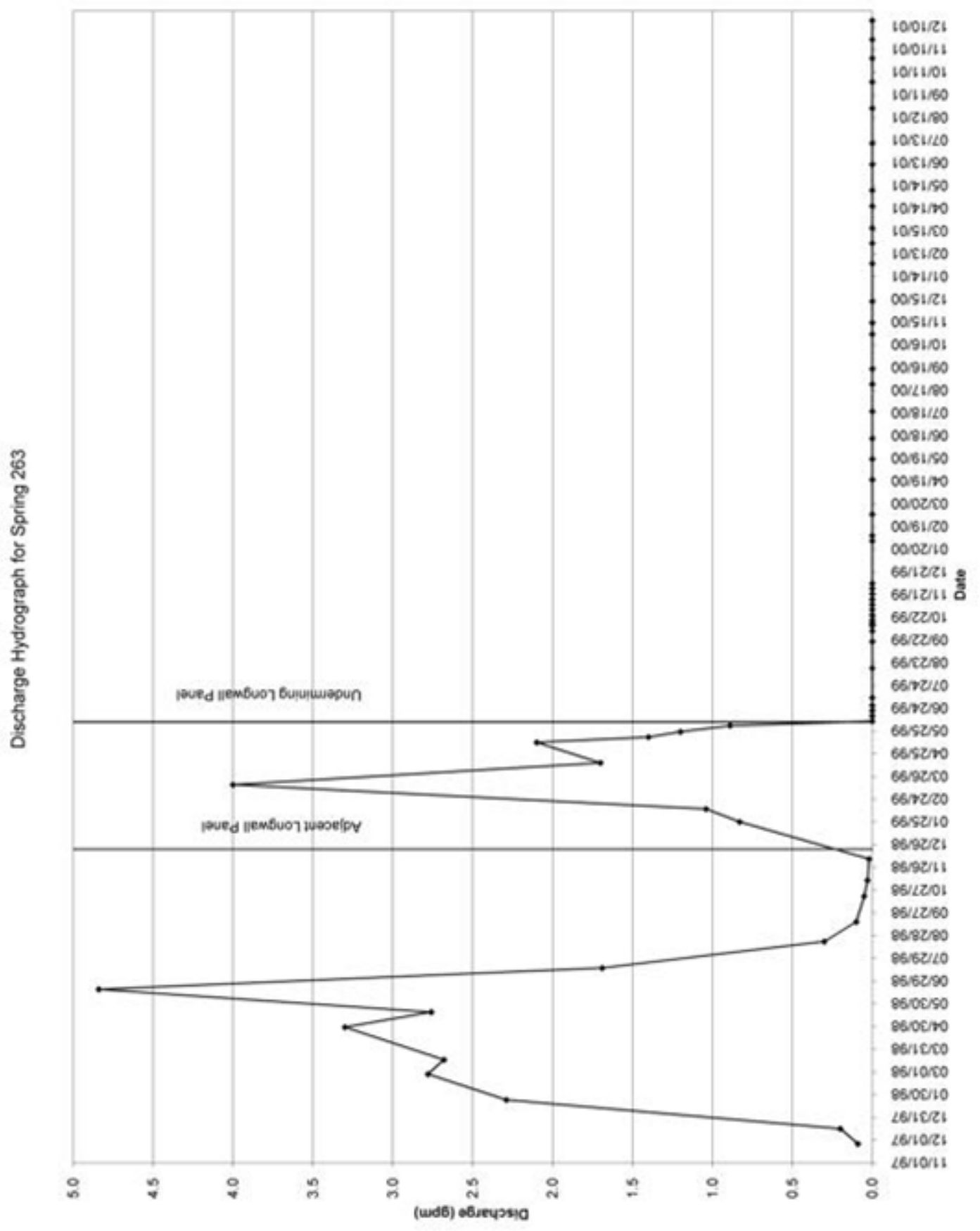




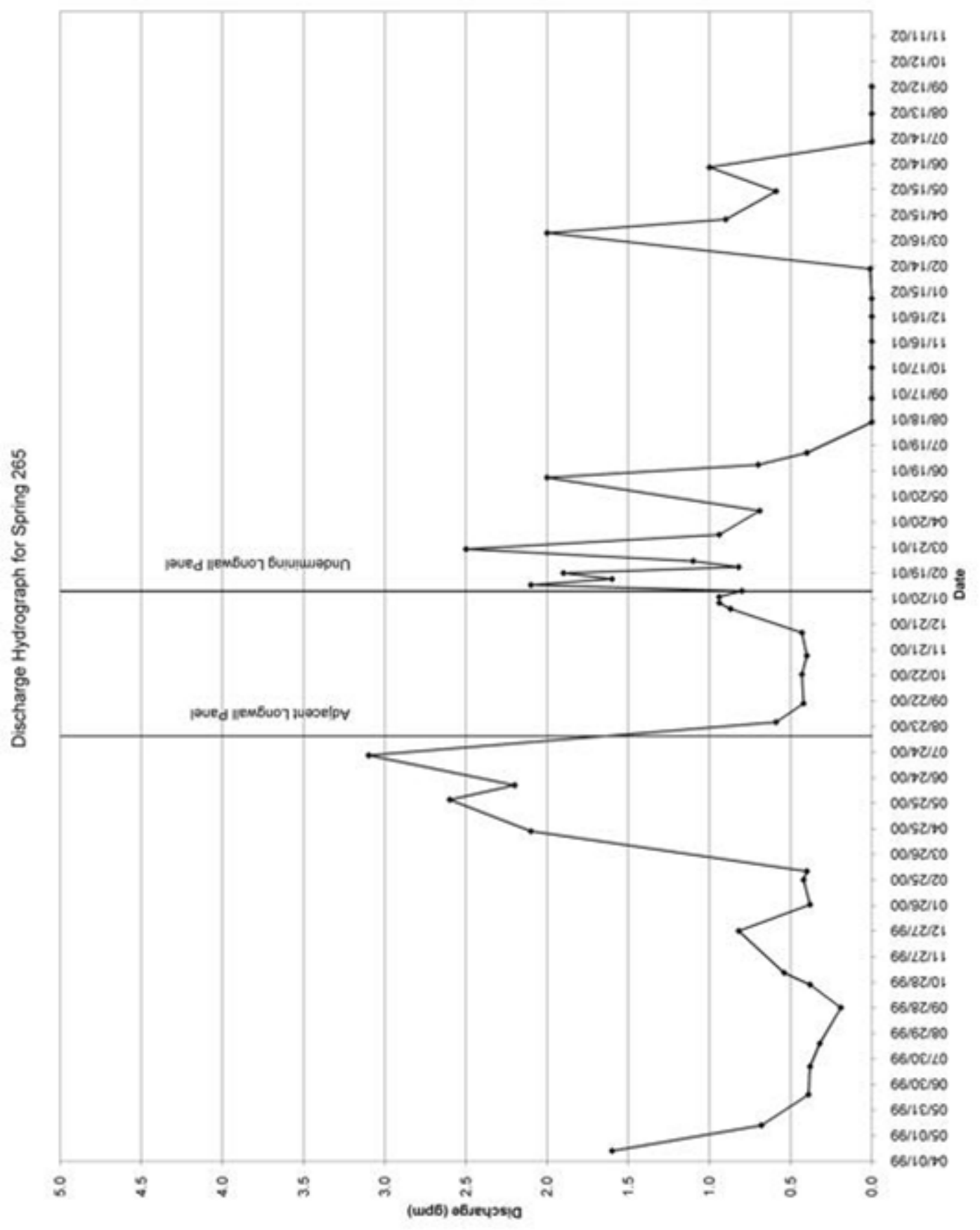




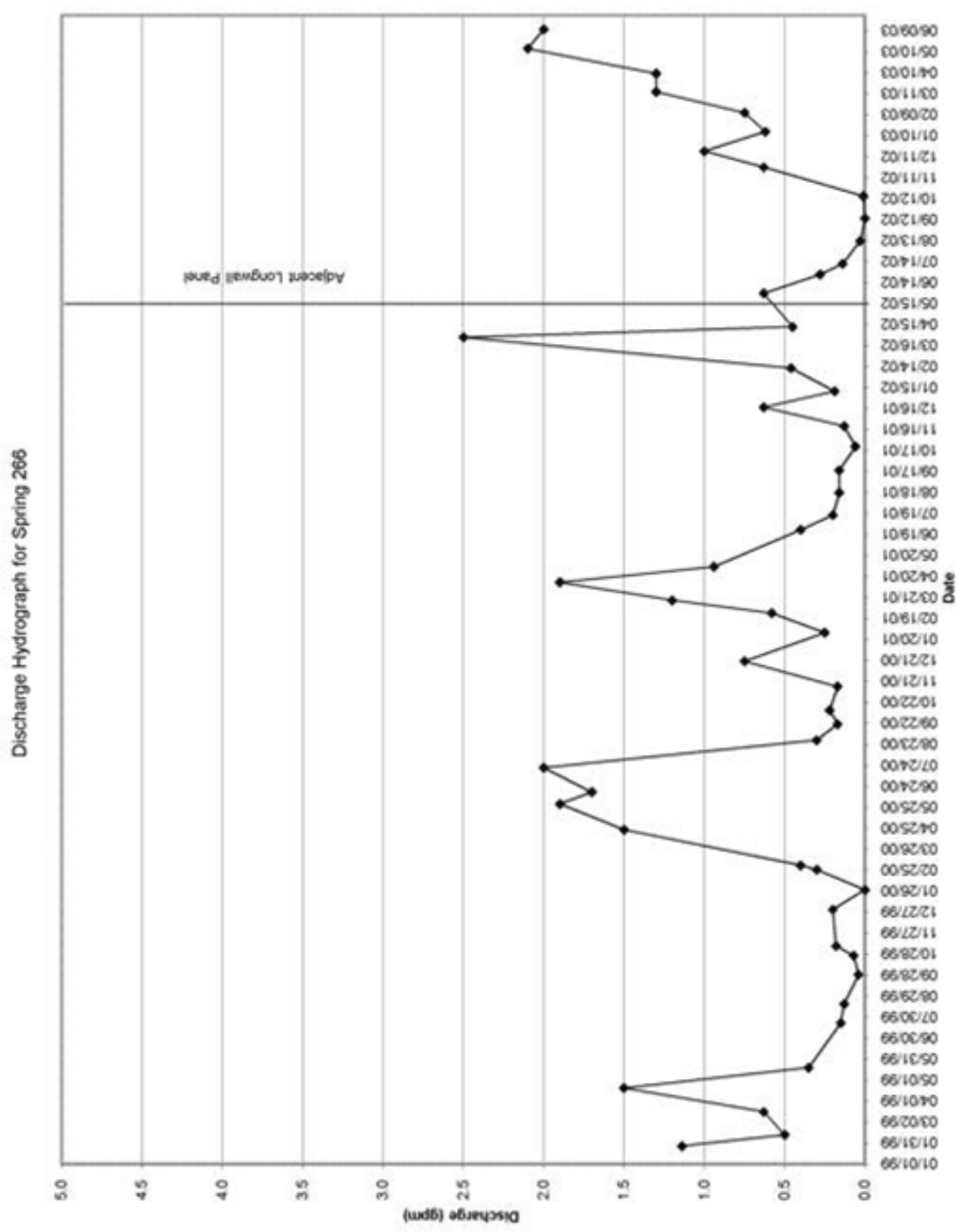




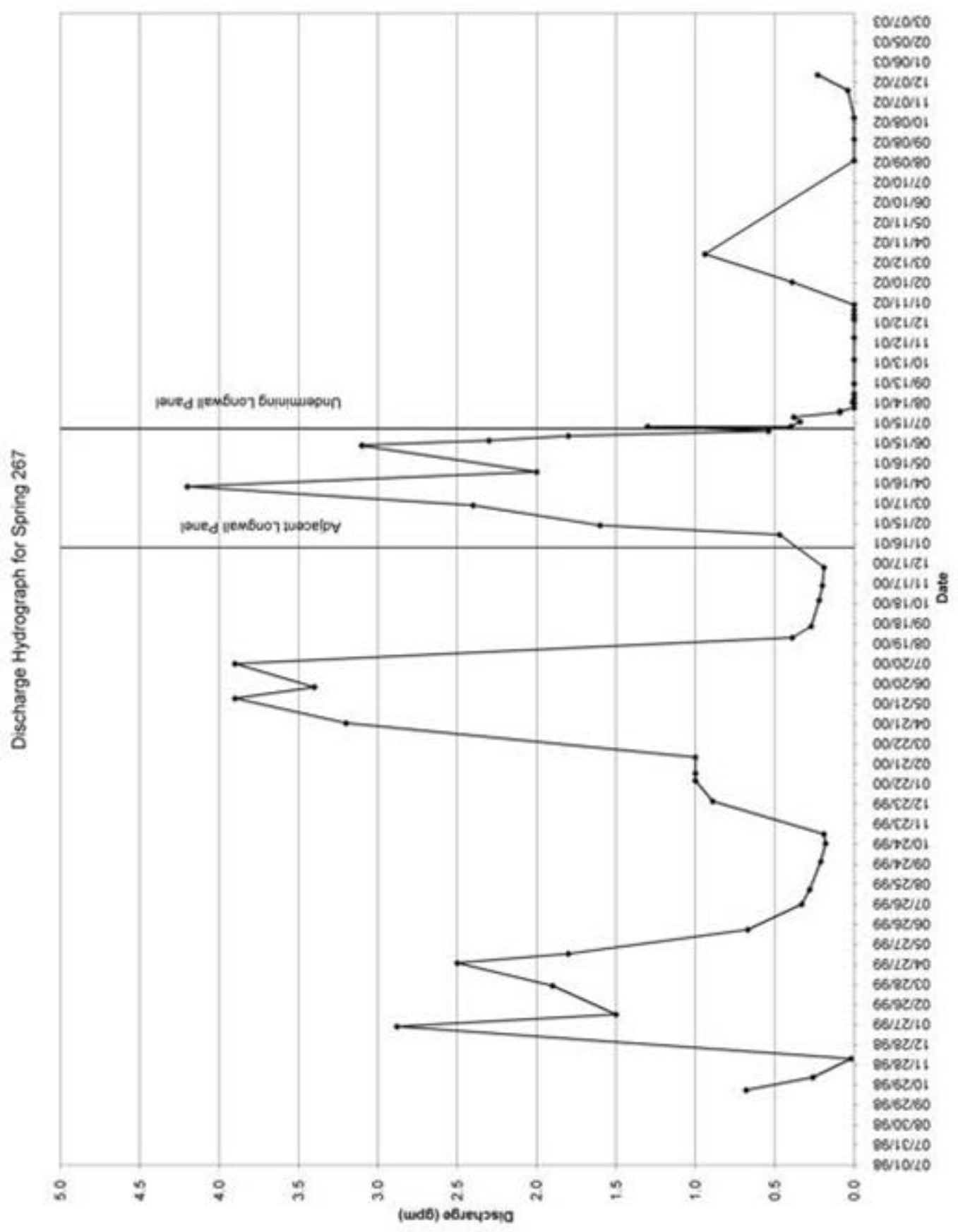




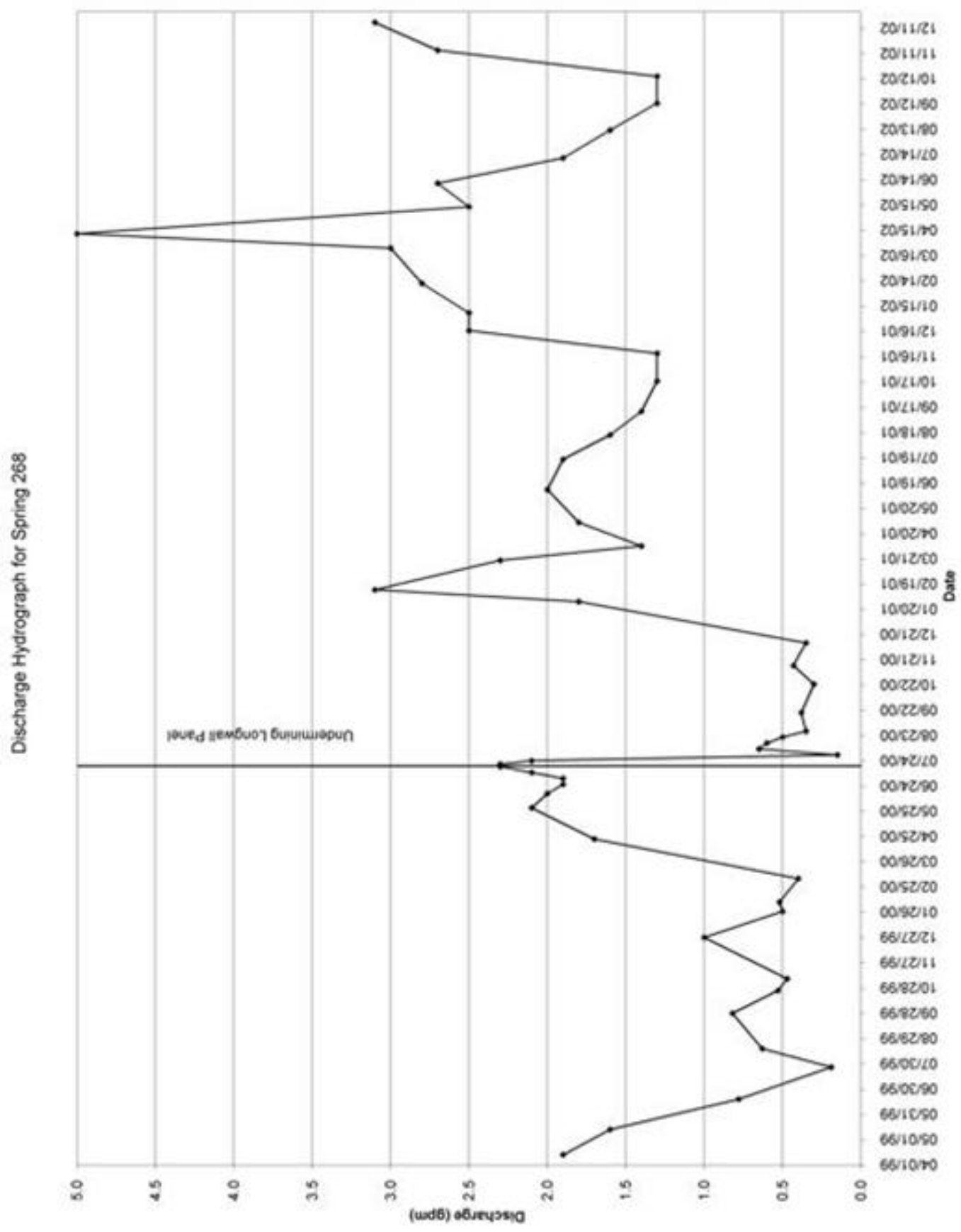




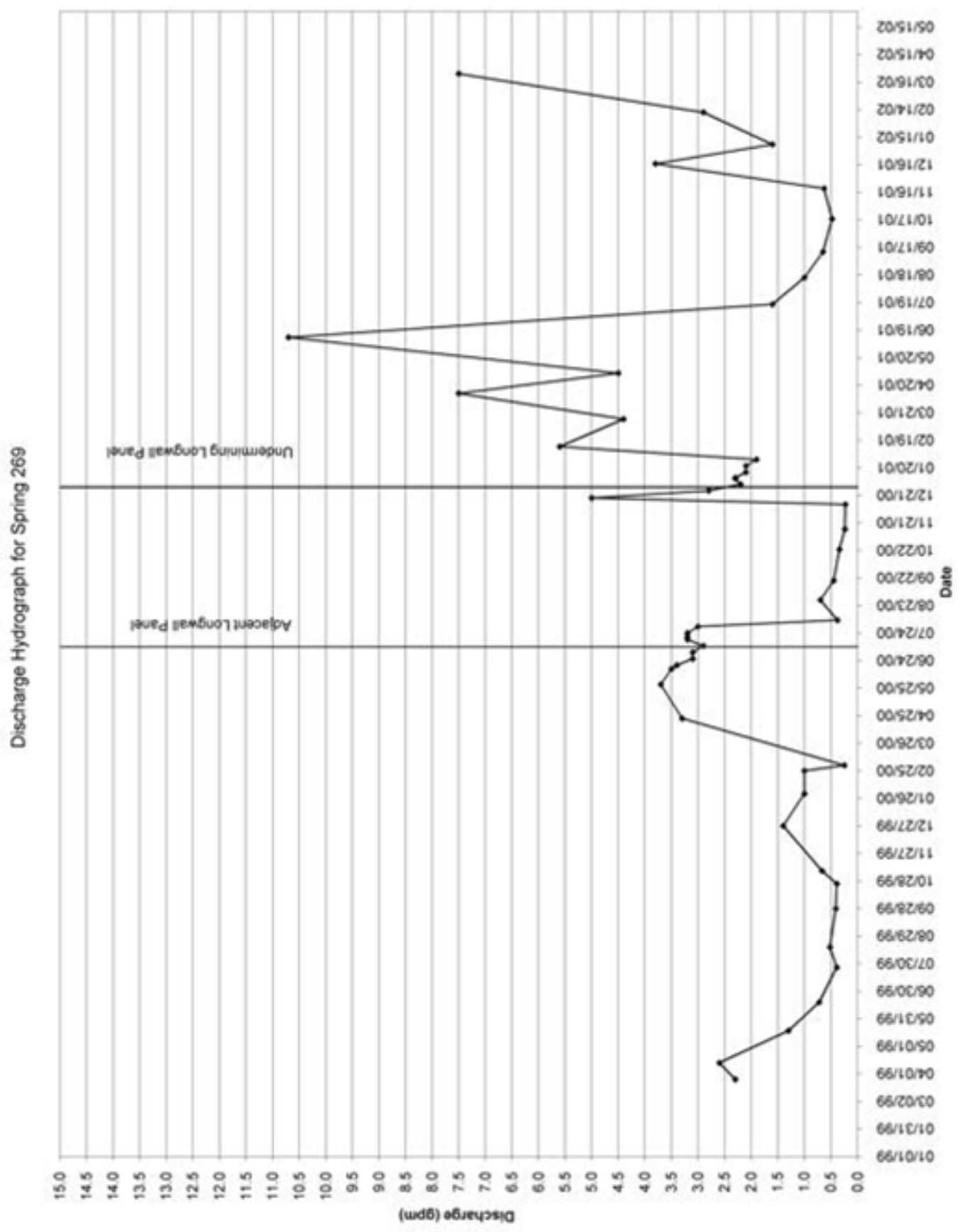




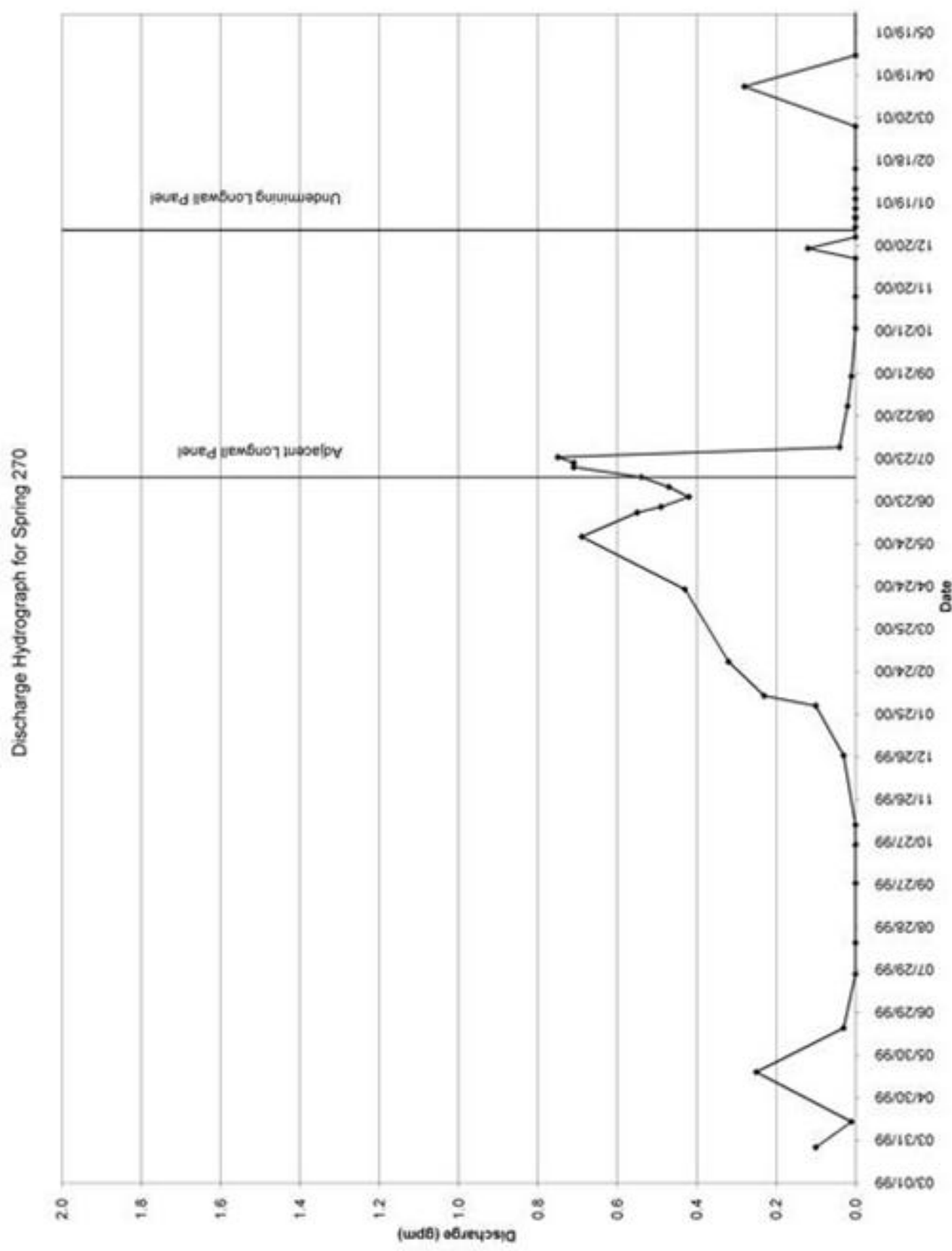




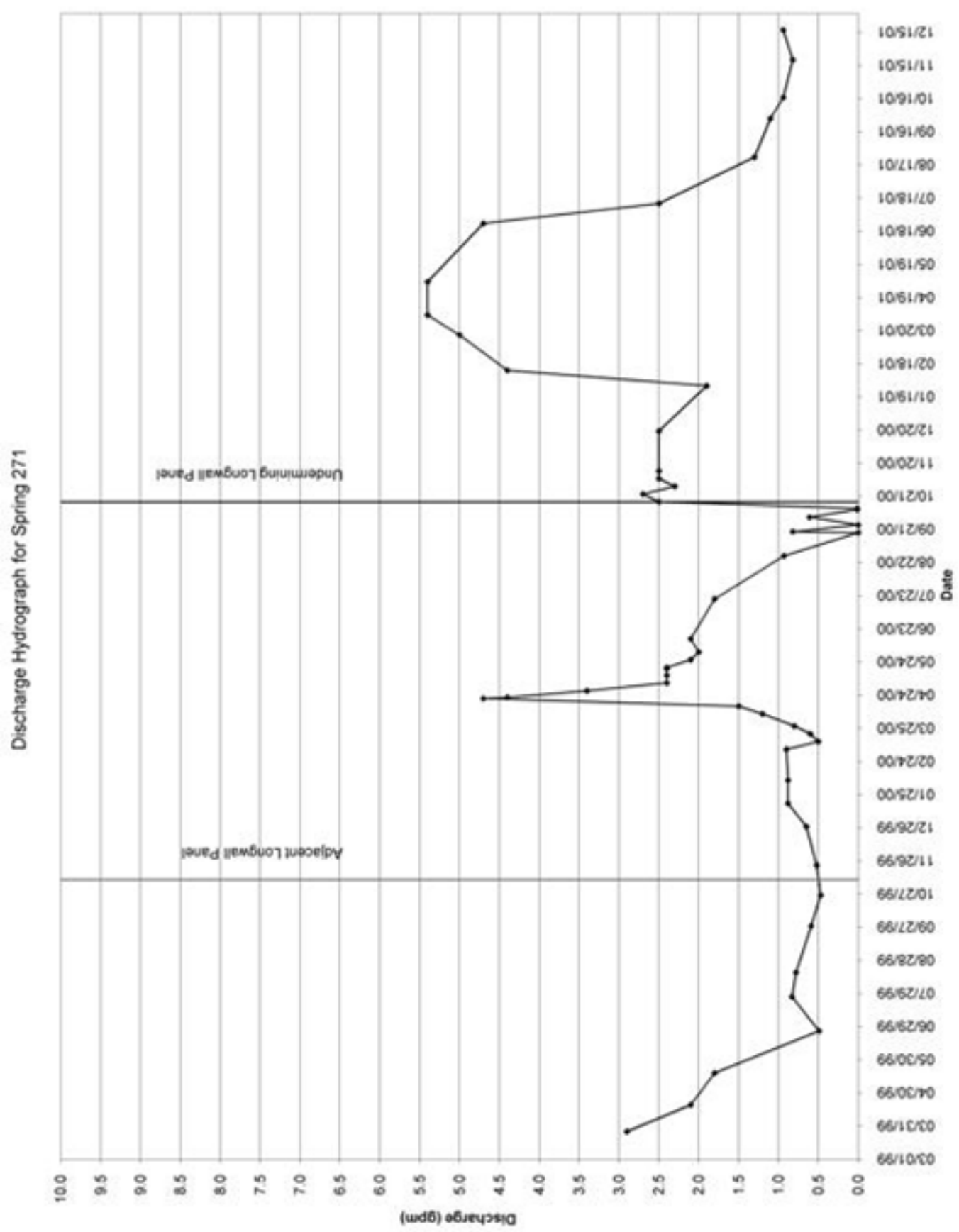




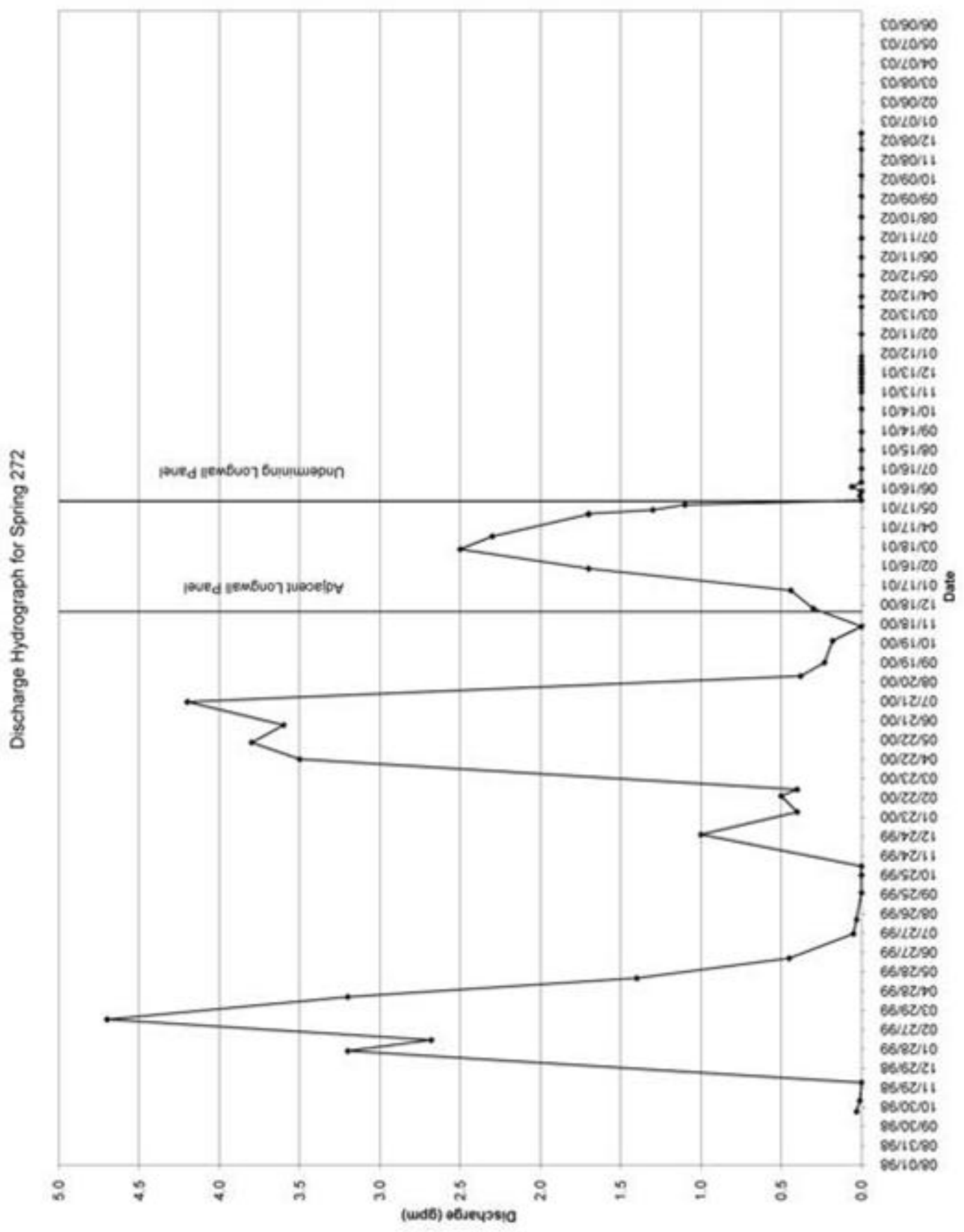




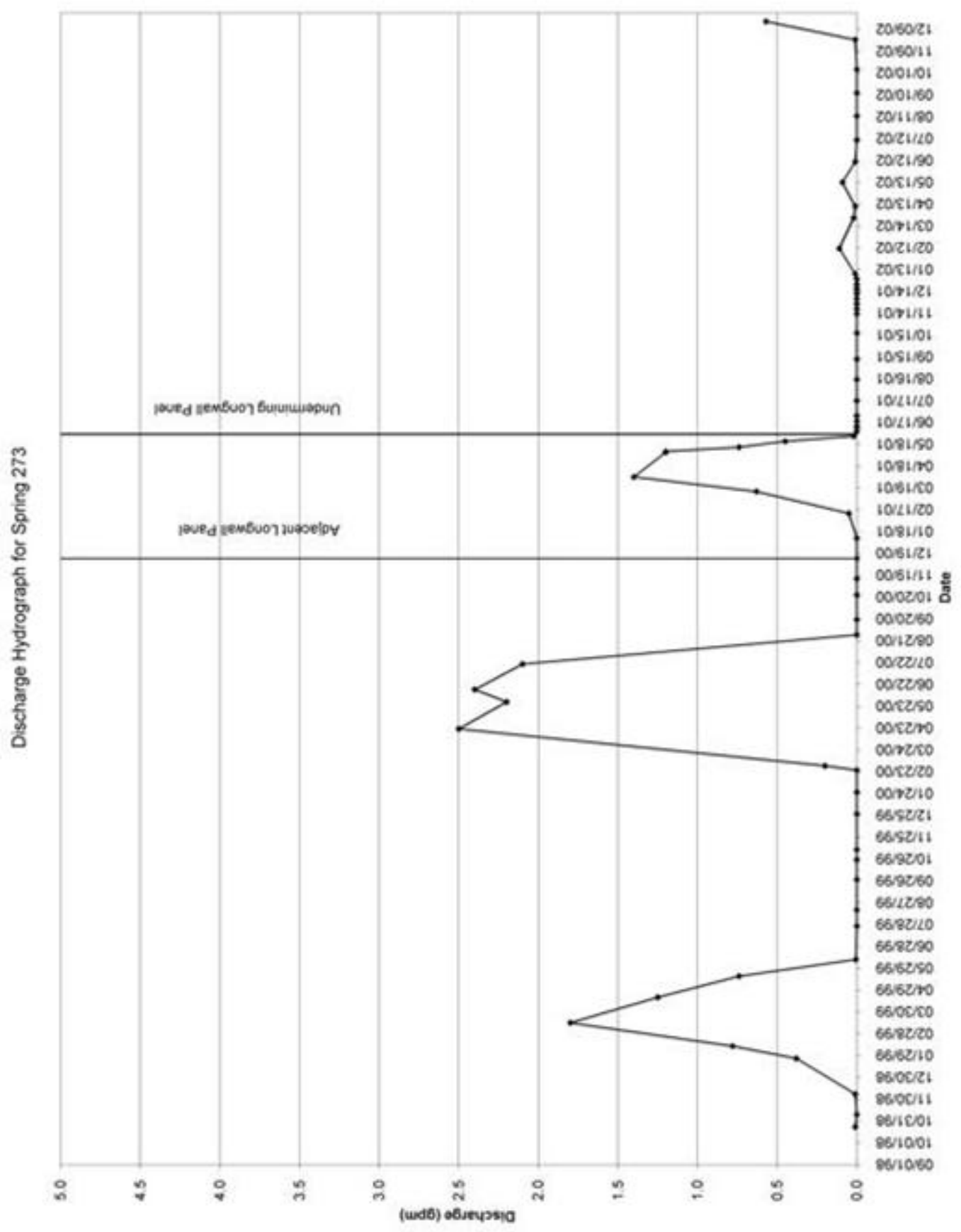




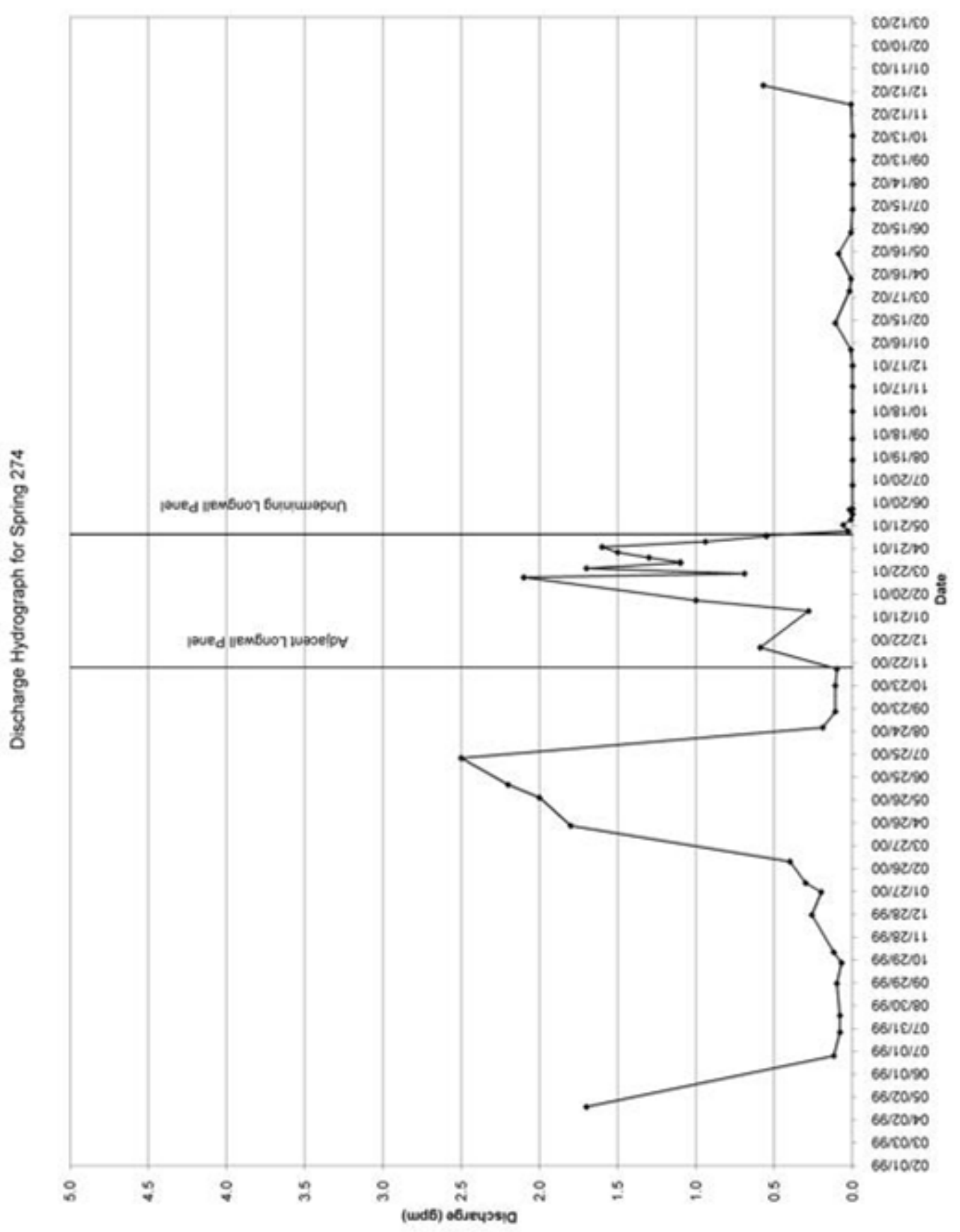




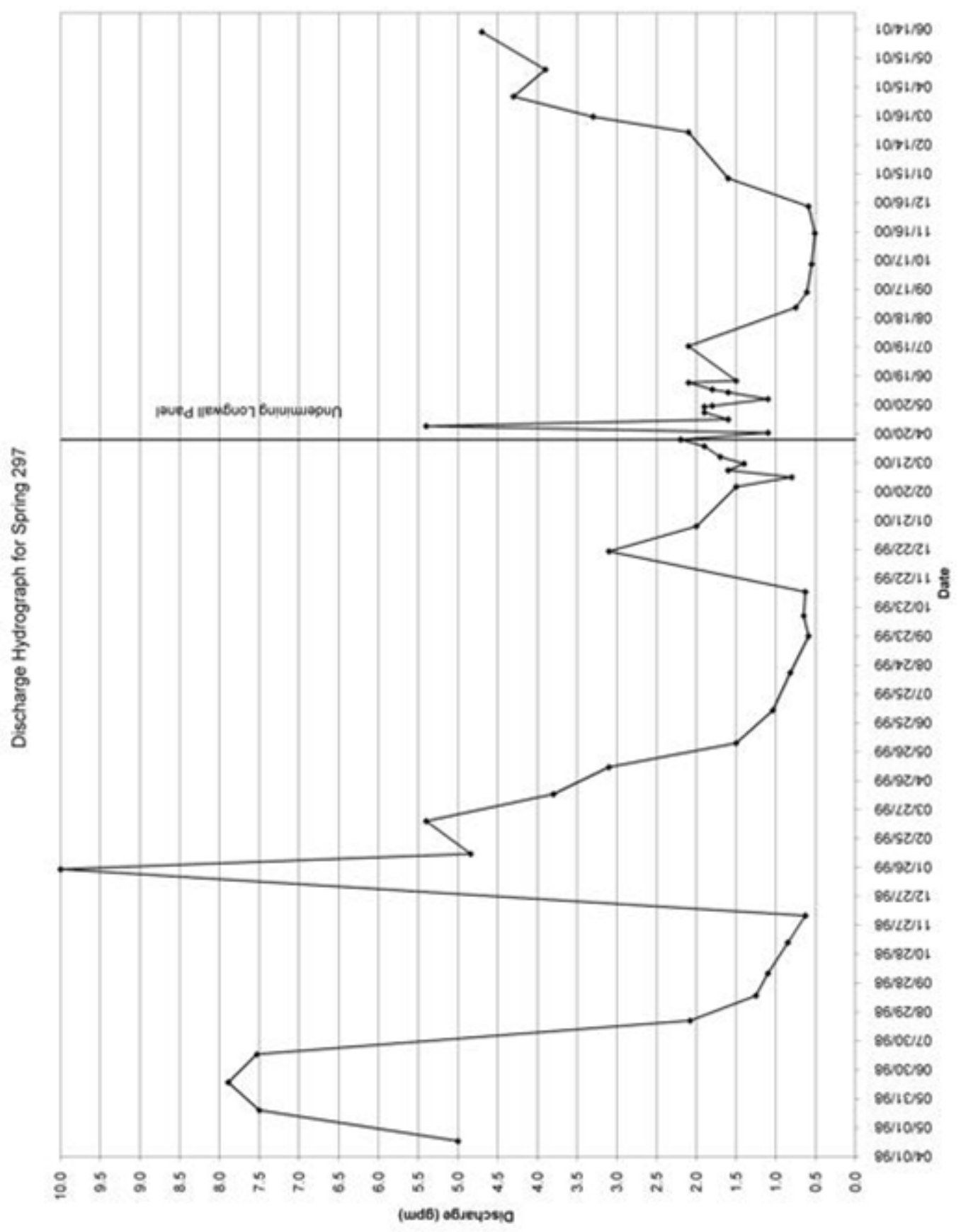


APPENDIX B: Quantitative Data Related to the Hydrologic, Geologic, Topographic, and Mine-Specific Variables Discussed in Methods of Investigation I 


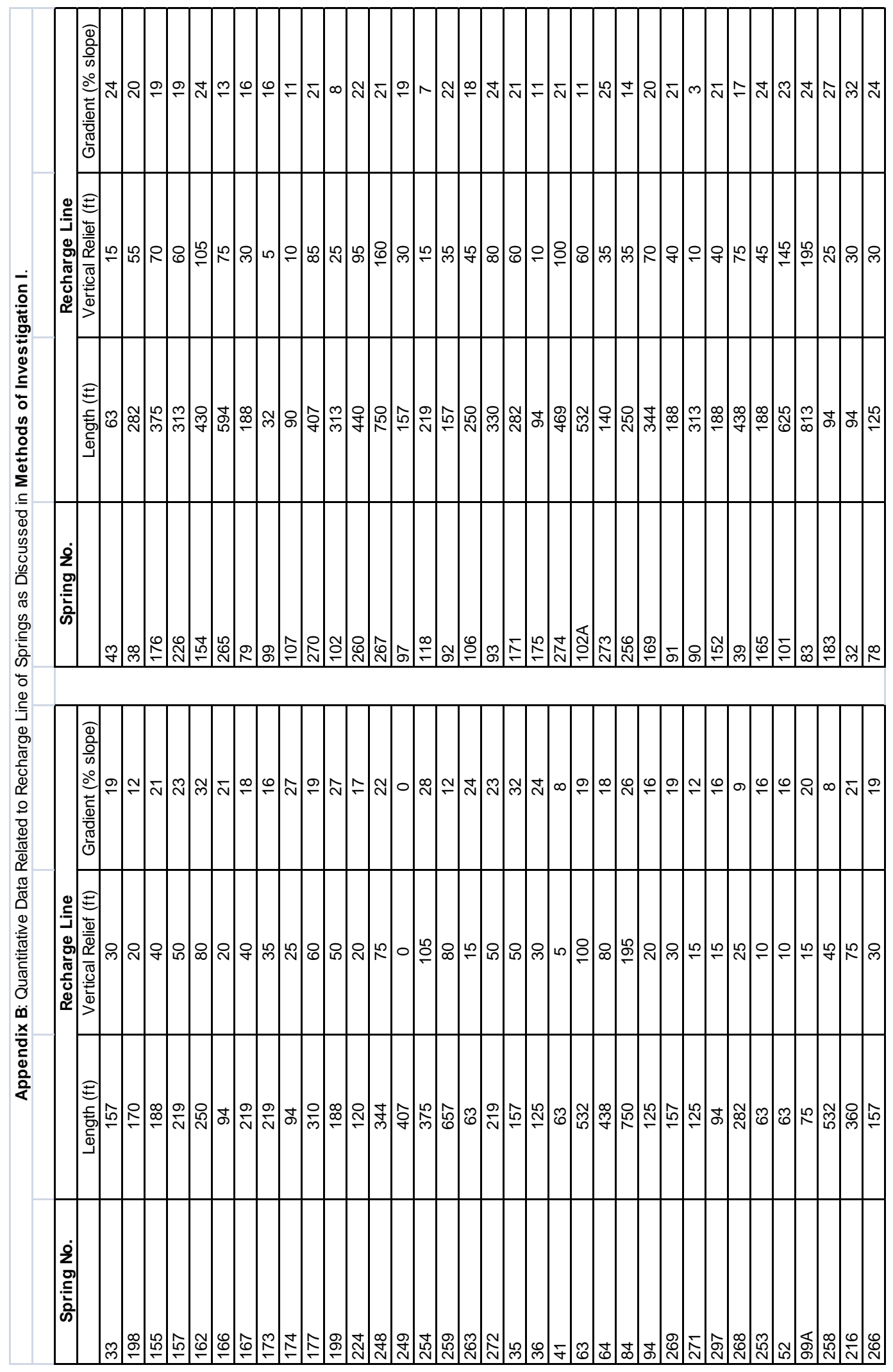




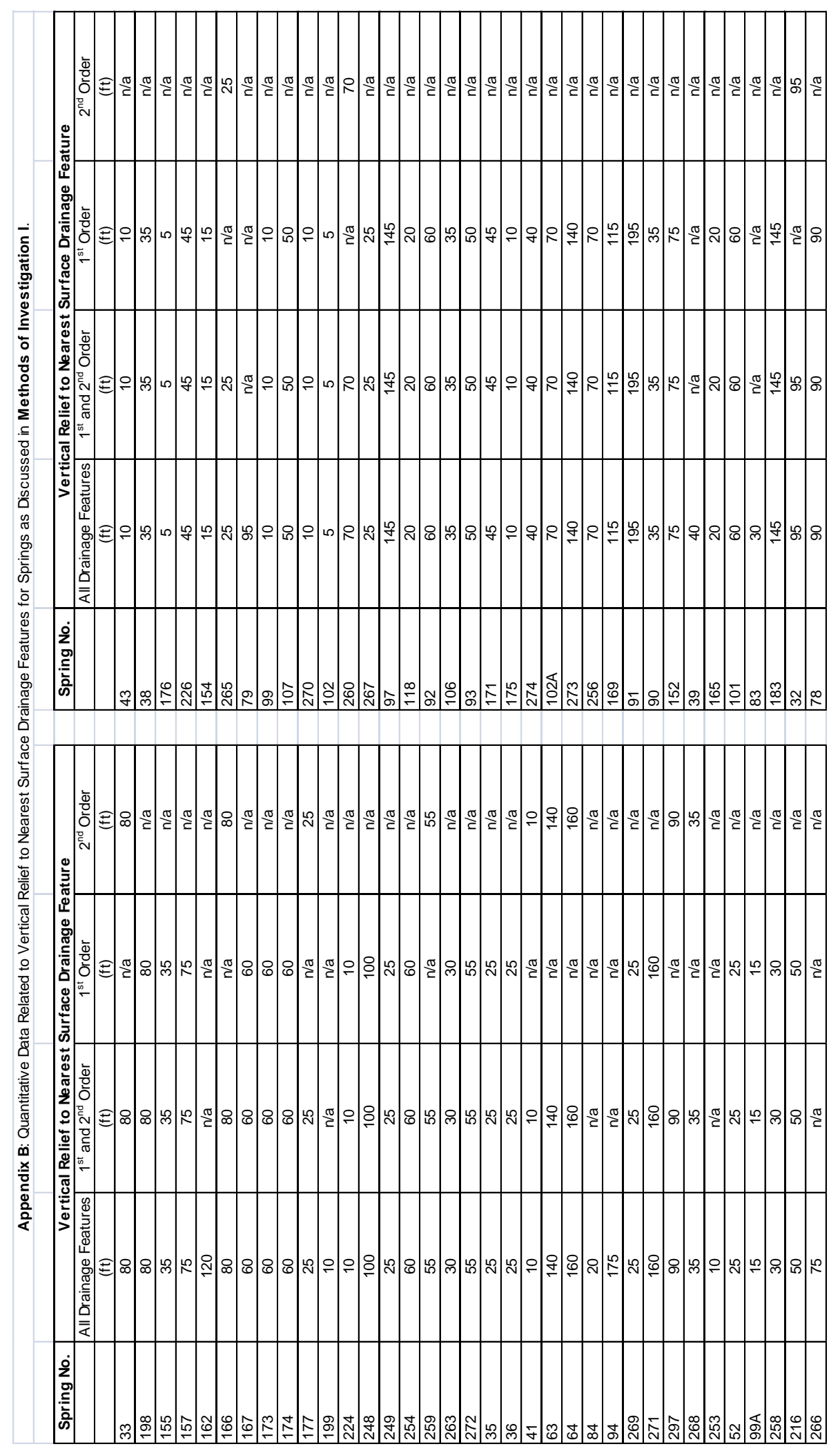




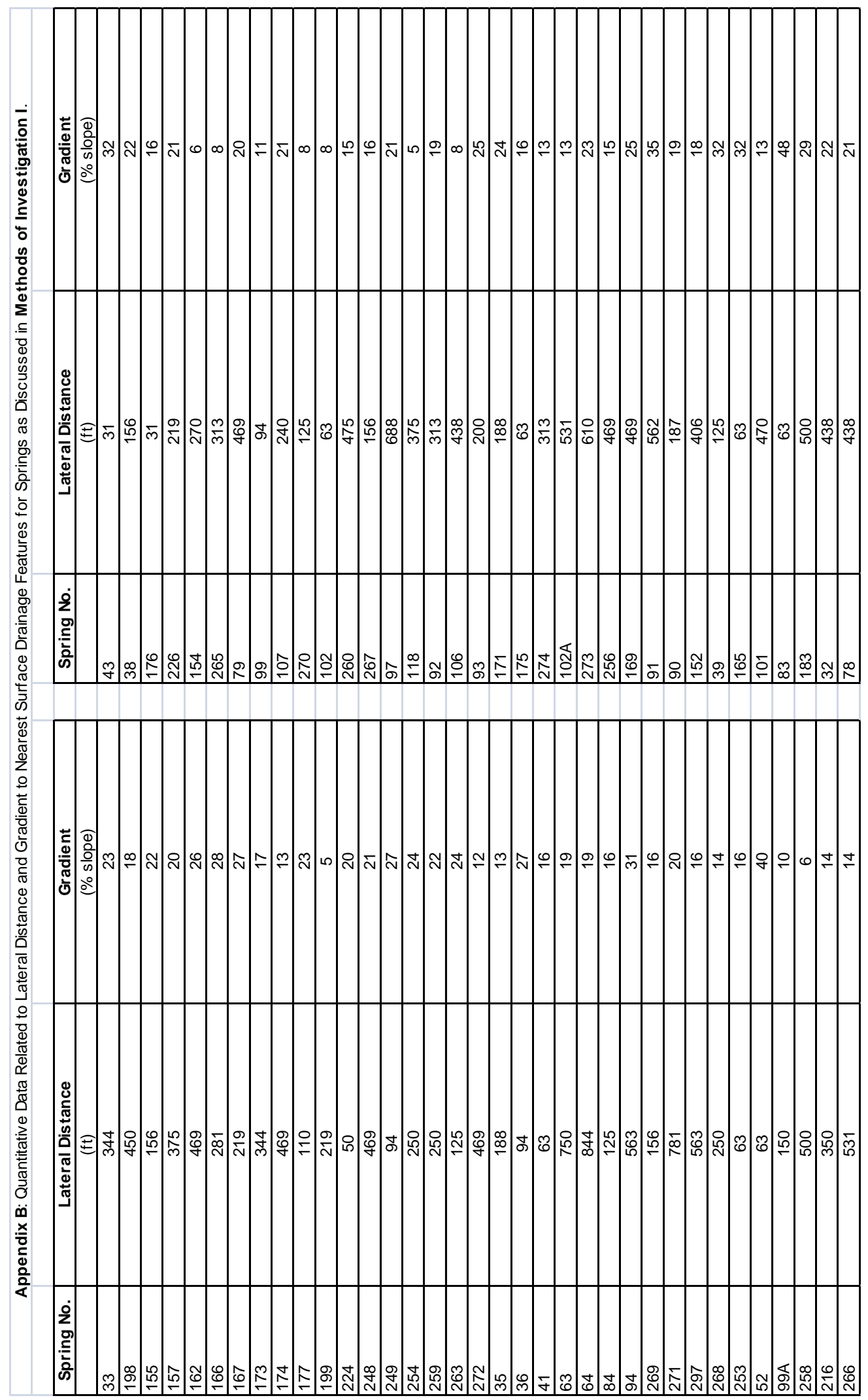




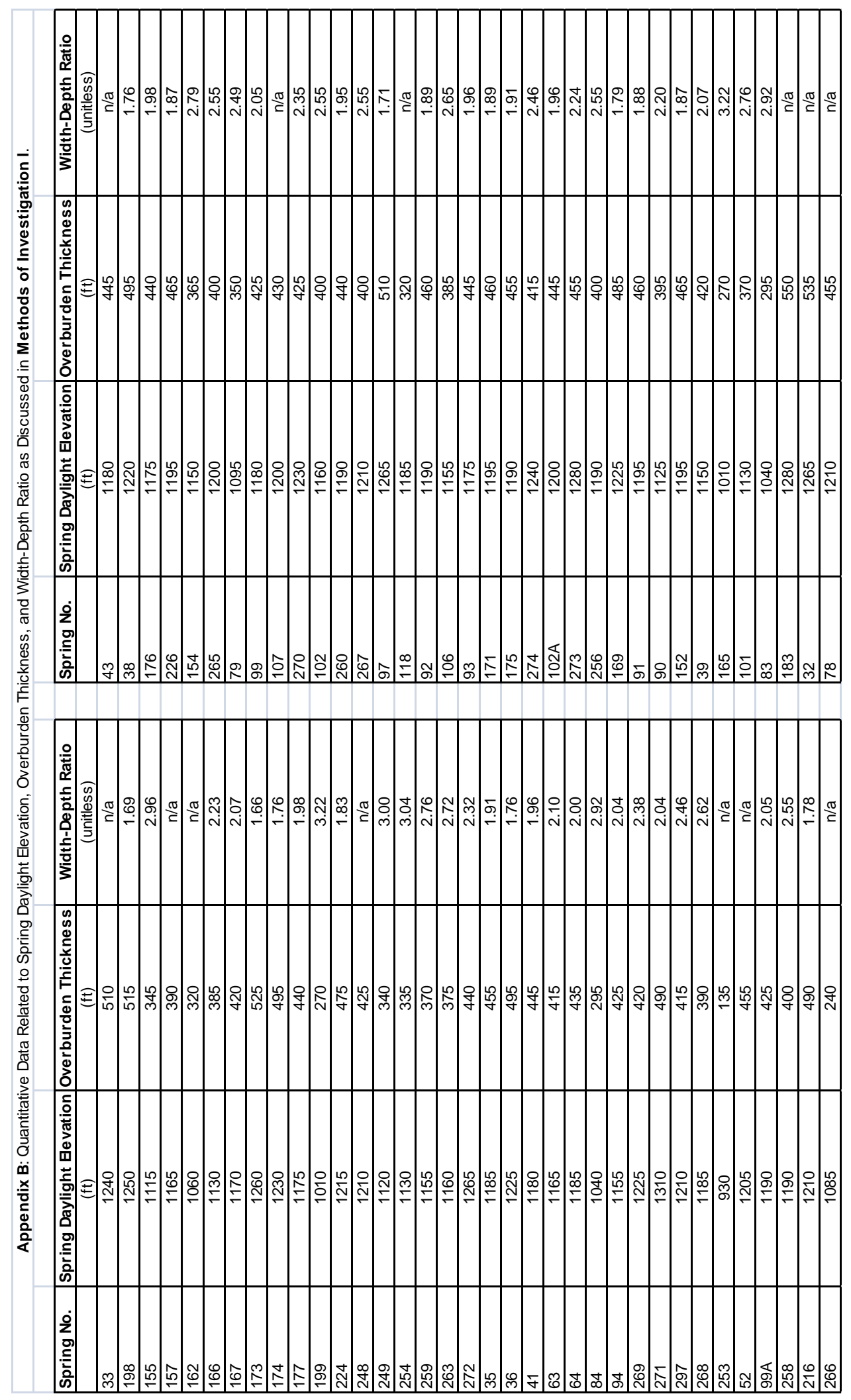




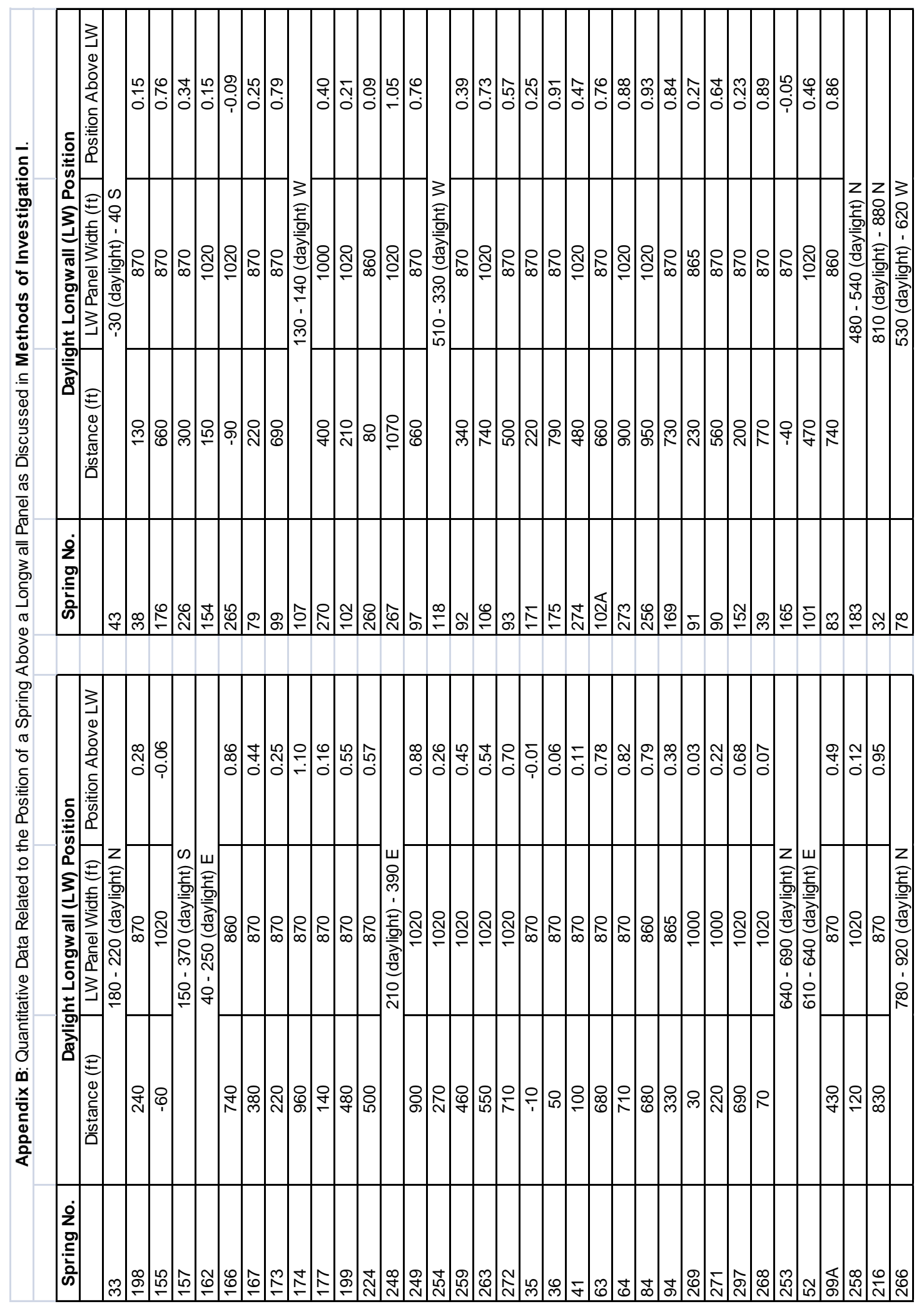


APPENDIX C: Quantitative Data Related to the Additional Hydrologic, Geologic, Topographic, and Mine-Specific Variables Discussed in Methods of Investigation III 


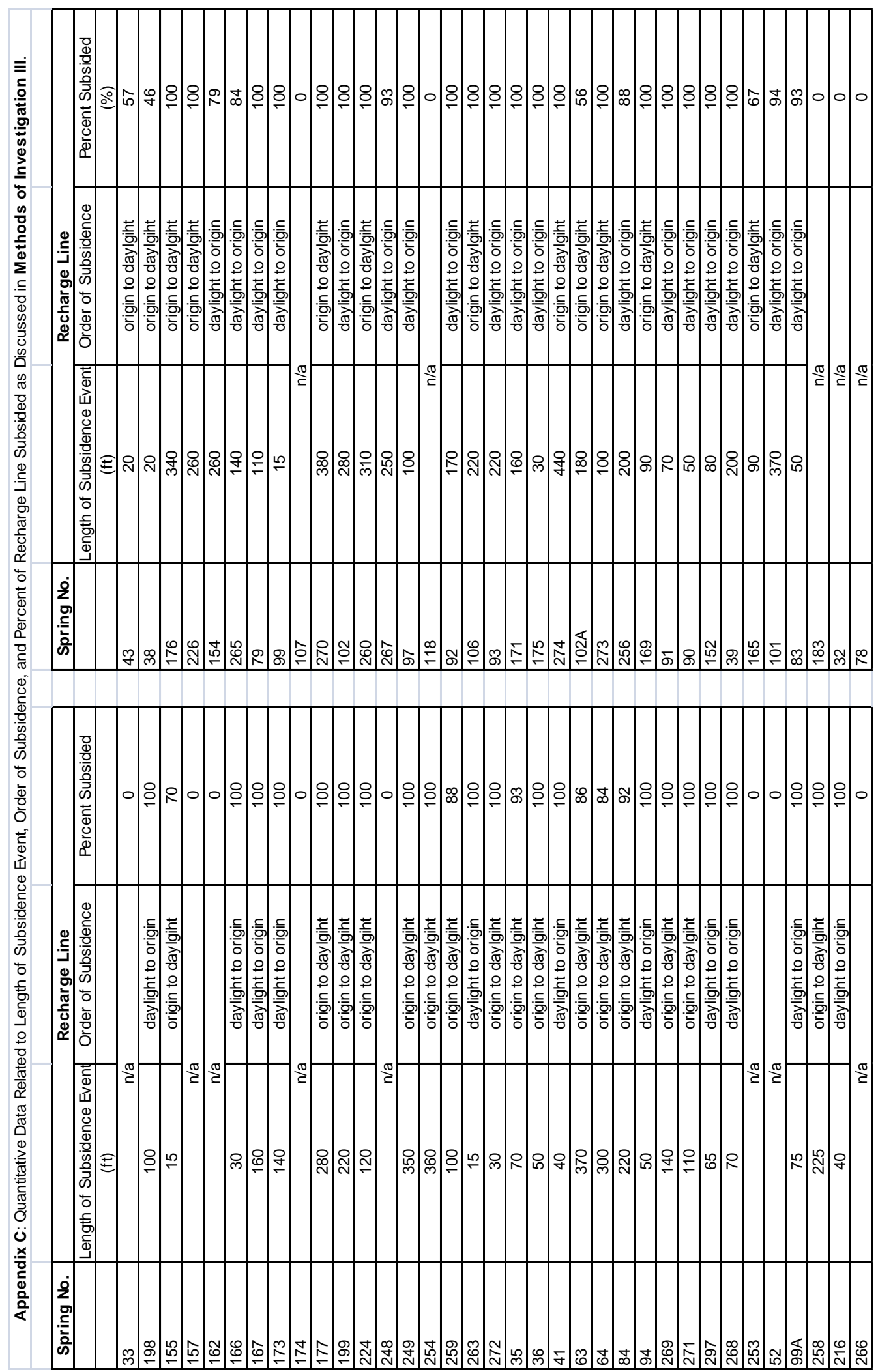




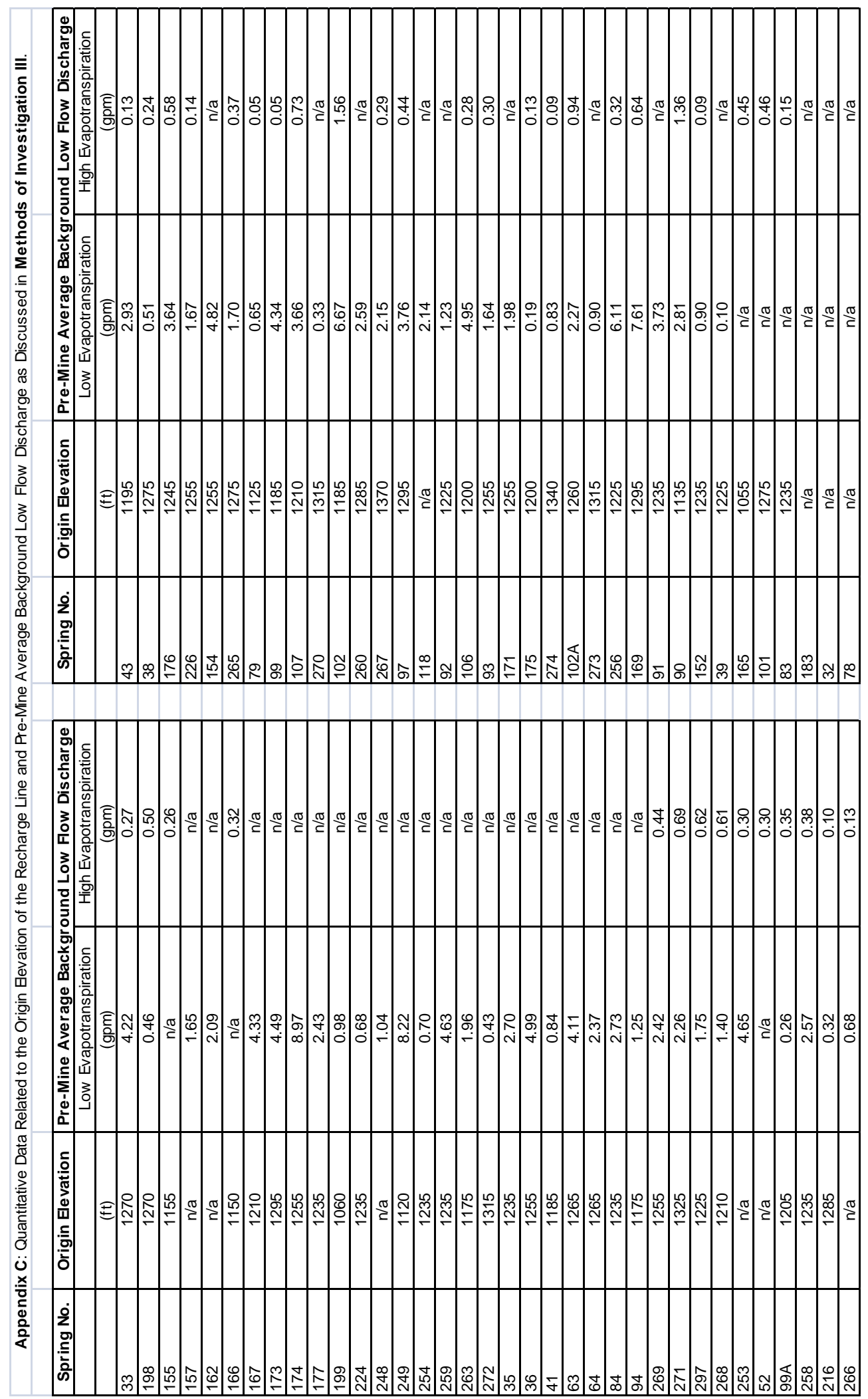


APPENDIX D: Data Used to Calculate Changes to Spring Discharge Across Subsidence Events During Low and High Evapotranspiration Conditions as Discussed in Methods of Investigation III 
Results for Changes to Spring Discharge Across a Subsidence Event Using Averaged Spring Discharge Data During Low Evapotranspiration Conditions as Discussed in Methods of Investigation III.

\begin{tabular}{|c|c|c|c|c|c|}
\hline \multirow[t]{2}{*}{ Spring No. } & \multicolumn{2}{|c|}{ Evaluation Period During Low Evapotranspiration Condition } & \multicolumn{2}{|c|}{ Averaged Spring Discharge } & \multirow{2}{*}{\begin{tabular}{|c|} 
Natural Reduction in Spring Discharge \\
(see footnote) \\
\end{tabular}} \\
\hline & Year 1 & Year 2 & Year 1 & Year 2 & \\
\hline & & & (gpm) & (gpm) & $(\%)$ \\
\hline 33 & Feb - April ('94) & Feb - April ('95) & 4.22 & 0.57 & 87 \\
\hline 198 & April - June ('93) & April - June ('95) & 0.46 & 0.04 & 92 \\
\hline 157 & Jan - March ('98) & Jan - March ('99) & 1.65 & 0.00 & 100 \\
\hline 162 & Jan - March ('96) & Jan - March ('97) & 2.09 & 0.00 & 100 \\
\hline 167 & Jan - March ('95) & Jan - March ('96) & 4.33 & 0.00 & 100 \\
\hline 173 & Jan - March ('93) & Jan - March ('95) & 4.49 & 0.00 & 100 \\
\hline 174 & Jan - March ('93) & Jan - March ('95) & 8.97 & 0.00 & 100 \\
\hline 177 & Jan - March ('93) & Jan - March ('94) & 2.43 & 0.00 & 100 \\
\hline 199 & Jan - March ('96) & Jan - March ('97) & 0.98 & 0.00 & 100 \\
\hline 224 & Jan - March ('92) & Jan - March ('93) & 0.68 & 0.00 & 100 \\
\hline 248 & Jan - March ('98) & Jan - March ('00) & 1.04 & 0.00 & 100 \\
\hline 249 & Jan - March ('98) & Jan - March ('99) & 8.22 & 0.00 & 100 \\
\hline 254 & Jan - March ('99) & Jan - March ('00) & 0.70 & 0.00 & 100 \\
\hline 259 & Jan - March ('99) & Jan - March ('00) & 4.63 & 0.00 & 100 \\
\hline 263 & Jan - March ('99) & Jan - March ('00) & 1.96 & 0.00 & 100 \\
\hline 272 & Jan - March ('00) & Jan - March ('02) & 0.43 & 0.00 & 100 \\
\hline 35 & Jan - March ('94) & Jan - March ('95) & 2.70 & 0.00 & 100 \\
\hline 36 & Jan - March ('94) & Jan - March ('95) & 4.99 & 0.00 & 100 \\
\hline 41 & Jan - March ('94) & Jan - March ('95) & 0.84 & 0.00 & 100 \\
\hline 63 & Jan - March ('94) & Jan - March ('95) & 4.11 & 0.00 & 100 \\
\hline 64 & Jan - March ('94) & Jan - March ('95) & 2.37 & 0.00 & 100 \\
\hline 84 & Jan - March ('96) & Jan - March ('97) & 2.73 & 0.00 & 100 \\
\hline 94 & Jan - March ('95) & Jan - March ('96) & 1.25 & 0.00 & 100 \\
\hline 269 & March - May ('00) & March - May ('01) & 2.42 & 5.46 & (126) \\
\hline 271 & March - May ('99) & March - May ('01) & 2.26 & 5.26 & (133) \\
\hline 297 & Jan - Feb ('00) & Jan - Feb ('01) & 1.75 & 1.85 & (6) \\
\hline 268 & March - May ('00) & March - May (01) & 1.40 & 1.83 & (31) \\
\hline 253 & Jan - March ('98, '99) & Jan - March ('01) & 4.65 & 3.92 & 16 \\
\hline $99 \mathrm{~A}$ & April - June ('97) & April - June ('98) & 0.26 & 1.82 & $(600)$ \\
\hline 258 & April - June ('98) & April - June ('00) & 2.57 & 6.40 & $(149)$ \\
\hline 216 & April - June ('93) & April - June ('95) & 0.32 & 1.42 & (338) \\
\hline 266 & Jan - March ('01) & Jan - March ('03) & 0.68 & 0.89 & $(32)$ \\
\hline 43 & Jan - March ('93) & Jan - March ('94) & 2.93 & 2.88 & 2 \\
\hline 38 & March - May ('93) & March - May ('95) & 0.51 & 0.45 & 13 \\
\hline 176 & Jan - March ('93) & Jan - March ('94) & 3.64 & 3.01 & 17 \\
\hline 226 & Jan - April ('93) & Jan - April ('94) & 1.67 & 1.35 & 20 \\
\hline 154 & Jan - March ('98) & Jan - March ('99) & 4.82 & 3.96 & 18 \\
\hline 265 & March - May ('00) & March - May ('02) & 1.70 & 1.16 & 32 \\
\hline 79 & Jan - March ('96) & Jan - March ('97) & 0.65 & 0.30 & 54 \\
\hline 99 & April - June ('97) & April - June ('98) & 4.34 & 3.75 & 14 \\
\hline 107 & March - May ('97) & March - May ('99) & 3.66 & 1.53 & 58 \\
\hline 270 & Feb - April ('00) & Feb - April ('01) & 0.33 & 0.14 & 57 \\
\hline 102 & Jan - March ('97) & Jan - March ('99) & 6.67 & 4.05 & 39 \\
\hline 260 & March - May ('97) & March - May ('98) & 2.59 & 1.10 & 58 \\
\hline 267 & Feb - April ('00) & Feb - April ('02) & 2.15 & 0.67 & 69 \\
\hline 97 & Jan - Feb ('97) & Jan - Feb ('98) & 3.76 & 2.63 & 30 \\
\hline 118 & April - June ('97) & April - June ('98) & 2.14 & 1.32 & 38 \\
\hline 92 & April - June ('95) & April - June ('96) & 1.23 & 0.41 & 67 \\
\hline 106 & Jan - March ('98) & Jan - March ('99) & 4.95 & 1.28 & 74 \\
\hline 93 & Feb - April ('95) & Feb - April ('96) & 1.64 & 0.52 & 68 \\
\hline 171 & Jan - March ('93) & Jan - March ('95) & 1.98 & 0.18 & 91 \\
\hline 175 & Jan - Feb ('93) & July - Sept ('92) & 0.19 & 0.07 & 62 \\
\hline 274 & Feb - April ('00) & Feb - April ('02) & 0.83 & 0.05 & 94 \\
\hline $102 \mathrm{~A}$ & April - June ('97) & April - June ('98) & 2.27 & 0.28 & 88 \\
\hline 273 & Feb - April ('00) & Feb - April ('02) & 0.90 & 0.05 & 95 \\
\hline 256 & Jan - March ('99) & Jan - March ('01) & 6.11 & 0.14 & 98 \\
\hline 169 & Feb - April ('93) & Feb - April ('95) & 7.61 & 0.14 & 98 \\
\hline 91 & Feb - April ('95) & Feb - April ('96) & 3.73 & 0.12 & 97 \\
\hline 90 & Jan - March ('95) & Jan - March ('96) & 2.81 & 0.03 & 99 \\
\hline 152 & Jan - March ('94) & Jan - March ('96) & 0.90 & 0.00 & 100 \\
\hline 39 & April - June ('93) & April - June ('95) & 0.10 & 0.00 & 100 \\
\hline
\end{tabular}

Footnote: Natural reduction in spring discharge values in parentheses indicate a discharge improvement from Year 1 to Year 2. Natural reduction in spring discharge values not in parentheses indicate a discharge impairment from Year 1 to Year 2. 
Results for Changes to Spring Discharge Across a Subsidence Event Using Averaged Spring Discharge Data During High Evapotranspiration Conditions as Discussed in Methods of Investigation III.

\begin{tabular}{|c|c|c|c|c|c|}
\hline \multirow[t]{2}{*}{ Spring No. } & \multicolumn{2}{|c|}{ Evaluation Period During High Evapotranspiration Condition } & \multicolumn{2}{|c|}{ Averaged Spring Discharge } & \multirow{2}{*}{\begin{tabular}{|c|} 
Natural Reduction in Spring Discharge \\
(see footnote) \\
\end{tabular}} \\
\hline & Year 1 & Year 2 & Year 1 & Year 2 & \\
\hline & & & (gpm) & (gpm) & $(\%)$ \\
\hline 33 & July - Sept ('94) & July - Sept ('95) & 0.27 & 0.28 & $(1)$ \\
\hline 198 & July - Sept ('92) & July - Sept ('95) & 0.50 & 0.61 & (23) \\
\hline 155 & Aug - Oct ('97) & Aug - Oct ('98) & 0.26 & 0.00 & 100 \\
\hline 166 & Aug - Oct ('94) & Aug - Oct ('96) & 0.32 & 0.00 & 100 \\
\hline 269 & Aug - Oct ('99) & Aug - Oct ('01) & 0.44 & 0.71 & $(61)$ \\
\hline 271 & Aug - Sept ('99) & Aug - Sept ('01) & 0.69 & 1.20 & (74) \\
\hline 297 & Sept - Nov ('99) & Sept - Nov ('00) & 0.62 & 0.56 & 10 \\
\hline 268 & Sept - Nov ('99) & Sept - Nov ('01) & 0.61 & 1.33 & (118) \\
\hline 253 & July - Oct ('99) & July - Oct ('00) & 0.30 & 0.32 & $(7)$ \\
\hline 52 & Sept - Oct ('91) & Sept - Oct ('92) & 0.30 & 0.28 & 8 \\
\hline $99 \mathrm{~A}$ & Oct - Dec ('96) & Oct - Dec ('98) & 0.35 & 0.00 & 100 \\
\hline 258 & Aug - Nov ('98) & Aug - Nov ('00) & 0.38 & 0.00 & 100 \\
\hline 216 & Aug - Oct ('93) & Aug - Oct ('94) & 0.10 & 0.00 & 100 \\
\hline 266 & Aug - Oct ('01) & Aug - Oct ('02) & 0.13 & 0.01 & 92 \\
\hline 43 & June - Aug ('92) & June - Aug ('94) & 0.13 & 0.03 & 80 \\
\hline 38 & Aug - Sept ('93) & Aug - Sept ('94) & 0.24 & 0.00 & 100 \\
\hline 176 & July - Aug ('92) & July - Aug ('94) & 0.58 & 0.00 & 100 \\
\hline 226 & June - Aug ('92) & June - Aug ('93) & 0.14 & 0.00 & 100 \\
\hline 265 & Sept - Nov ('99) & Sept - Nov ('01) & 0.37 & 0.00 & 100 \\
\hline 79 & July - Aug ('95) & July - Aug ('97) & 0.05 & 0.00 & 100 \\
\hline 99 & Sept - Oct ('97) & Sept - Oct ('98) & 0.05 & 0.00 & 100 \\
\hline 107 & Aug - Oct ('97) & Aug - Oct ('99) & 0.73 & 0.11 & 85 \\
\hline 102 & Aug - Sept ('97) & Aug - Sept ('98) & 1.56 & 0.00 & 100 \\
\hline 267 & Aug - Oct ('00) & Aug - Oct ('01) & 0.29 & 0.01 & 96 \\
\hline 97 & July - Aug ('96) & July - Aug ('98) & 0.44 & 0.24 & 45 \\
\hline 106 & Aug - Oct ('97) & Aug - Oct ('99) & 0.28 & 0.00 & 100 \\
\hline 93 & Aug - Sept ('94) & Aug - Sept ('96) & 0.30 & 0.00 & 100 \\
\hline 175 & Jan - Feb ('94) & July - Sept ('94) & 0.13 & 0.00 & 100 \\
\hline 274 & July - Sept ('99) & July - Sept ('02) & 0.09 & 0.00 & 100 \\
\hline $102 \mathrm{~A}$ & July - Oct ('97) & July - Oct ('98) & 0.94 & 0.01 & 99 \\
\hline 256 & July - Sept ('99) & July - Sept ('00) & 0.32 & 0.04 & 88 \\
\hline 169 & June - Aug ('93) & June - Aug ('94) & 0.64 & 0.22 & 65 \\
\hline 90 & July - Sept ('94) & July - Sept ('96) & 1.36 & 0.00 & 100 \\
\hline 152 & Aug - Oct ('94) & Aug - Oct ('95) & 0.09 & 0.00 & 100 \\
\hline 165 & July - Sept ('95) & July - Sept ('96) & 0.45 & 0.74 & (64) \\
\hline 101 & Oct - Dec ('97) & Oct - Dec ('99) & 0.46 & 0.01 & 98 \\
\hline 83 & Nov - Dec ('95) & Nov - Dec ('96) & 0.15 & 0.00 & 100 \\
\hline
\end{tabular}

Footnote: Natural reduction in spring discharge values in parentheses indicate a discharge improvement from Year 1 to Year 2. Natural reduction in spring discharge values not in parentheses indicate a discharge impairment from Year 1 to Year 2. 


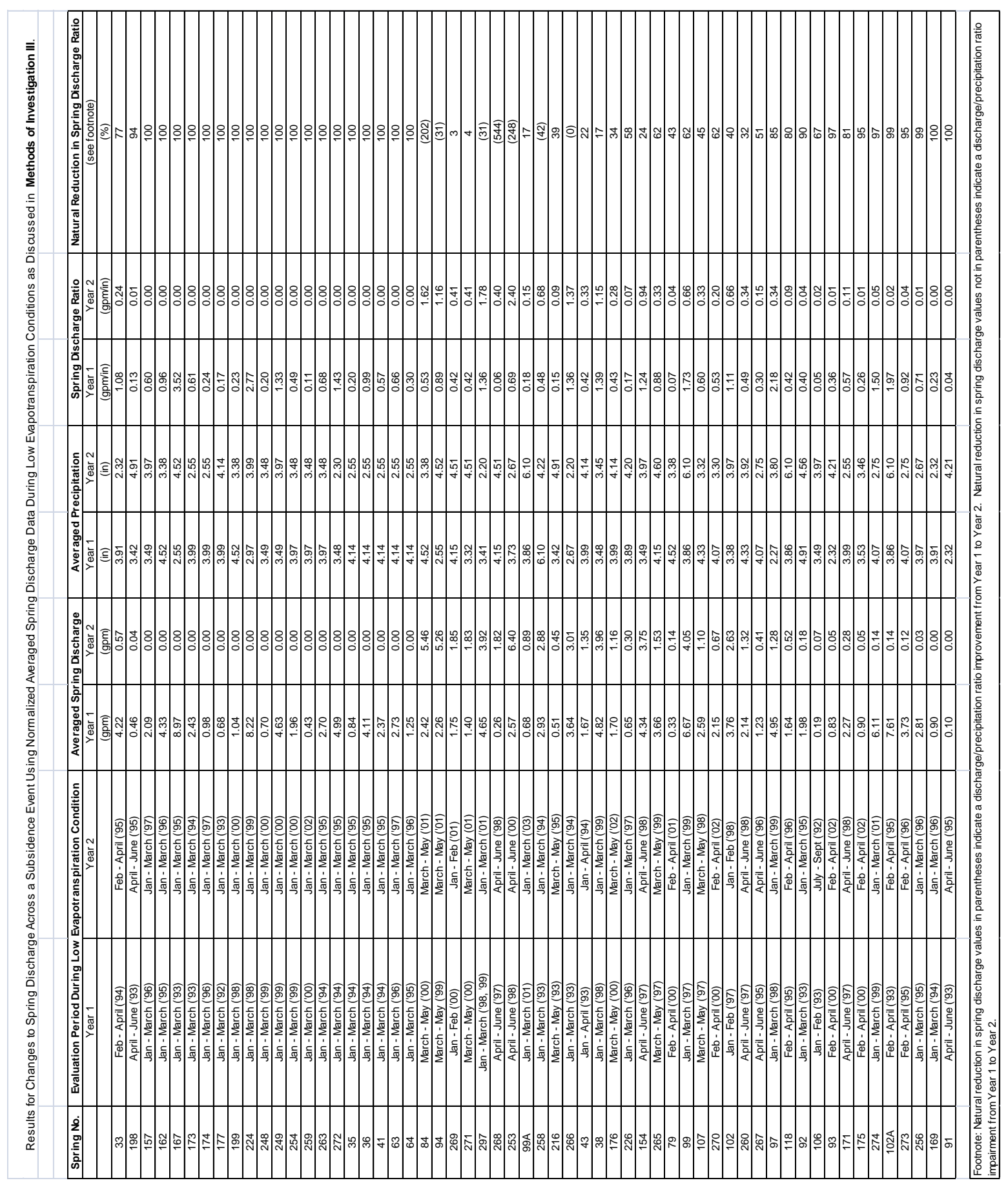




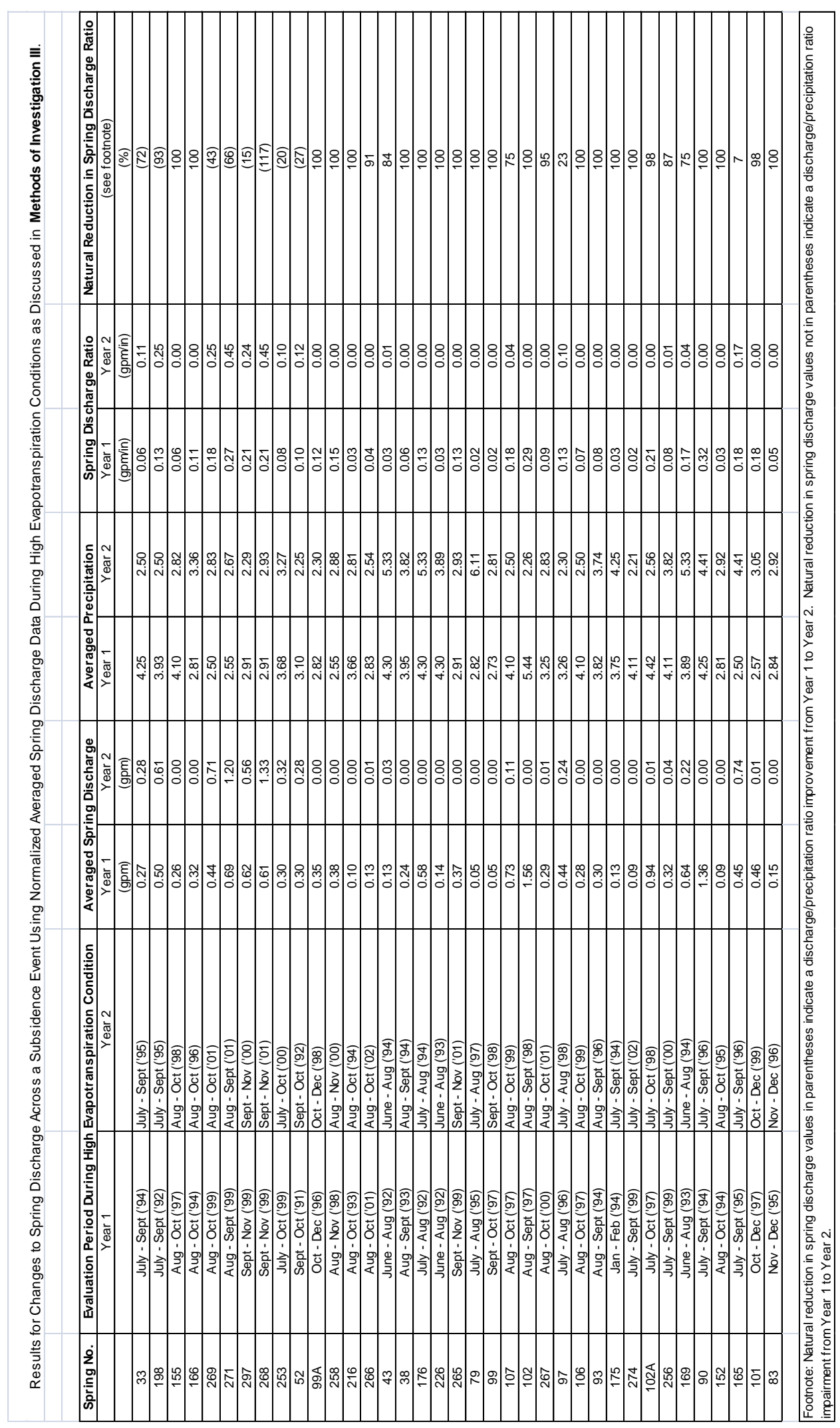


APPENDIX E: Figures Illustrating the Statistically Significant Variables Identified from the Spring Discharge Response to Mining-Induced Subsidence Analysis through the Use of the Calculated Median Values as Discussed in Results of Investigation III 
Appendix E_tab_1: Data Used to Determine the Statistical Significance of the Spring Vertical Relief to Nearest Surface Drainage Feature Data Trend at the Optimum Discharge Reduction Boundary During Low Evapotranspiration Conditions.

\begin{tabular}{|c|c|c|c|c|}
\hline \multirow[t]{2}{*}{ Spring No. } & \multirow{2}{*}{$\begin{array}{c}\text { Optimum Discharge Reduction Boundary } \\
\text { Low ET }(50 \%)\end{array}$} & \multicolumn{3}{|c|}{ Spring Vertical Relief to Nearest Surface Drainage Feature (ft) } \\
\hline & & All & $>1=50 \%$ & $<50 \%$ \\
\hline 33 & 87 & 80 & 80 & $\mathrm{n} / \mathrm{a}$ \\
\hline 198 & 92 & 80 & 80 & $\mathrm{n} / \mathrm{a}$ \\
\hline 155 & 100 & 35 & 35 & $\mathrm{n} / \mathrm{a}$ \\
\hline 166 & 100 & 80 & 80 & $\mathrm{n} / \mathrm{a}$ \\
\hline 167 & 100 & 60 & 60 & $\mathrm{n} / \mathrm{a}$ \\
\hline 173 & 100 & 60 & 60 & $\mathrm{n} / \mathrm{a}$ \\
\hline 174 & 100 & 60 & 60 & $\mathrm{n} / \mathrm{a}$ \\
\hline 177 & 100 & 25 & 25 & $\mathrm{n} / \mathrm{a}$ \\
\hline 199 & 100 & 10 & 10 & $\mathrm{n} / \mathrm{a}$ \\
\hline 224 & 100 & 10 & 10 & $\mathrm{n} / \mathrm{a}$ \\
\hline 249 & 100 & 25 & 25 & $\mathrm{n} / \mathrm{a}$ \\
\hline 254 & 100 & 60 & 60 & $\mathrm{n} / \mathrm{a}$ \\
\hline 259 & 100 & 55 & 55 & $\mathrm{n} / \mathrm{a}$ \\
\hline 263 & 100 & 30 & 30 & $\mathrm{n} / \mathrm{a}$ \\
\hline 272 & 100 & 55 & 55 & $\mathrm{n} / \mathrm{a}$ \\
\hline 35 & 100 & 25 & 25 & $\mathrm{n} / \mathrm{a}$ \\
\hline 36 & 100 & 25 & 25 & $\mathrm{n} / \mathrm{a}$ \\
\hline 41 & 100 & 10 & 10 & $\mathrm{n} / \mathrm{a}$ \\
\hline 63 & 100 & 140 & 140 & $\mathrm{n} / \mathrm{a}$ \\
\hline 64 & 100 & 160 & 160 & $\mathrm{n} / \mathrm{a}$ \\
\hline 84 & 100 & 20 & 20 & $\mathrm{n} / \mathrm{a}$ \\
\hline 94 & 100 & 175 & 175 & $\mathrm{n} / \mathrm{a}$ \\
\hline 269 & (126) & 25 & $\mathrm{n} / \mathrm{a}$ & 25 \\
\hline 271 & (133) & 160 & $\mathrm{n} / \mathrm{a}$ & 160 \\
\hline 297 & (6) & 90 & $\mathrm{n} / \mathrm{a}$ & 90 \\
\hline 268 & (31) & 35 & $\mathrm{n} / \mathrm{a}$ & 35 \\
\hline $99 \mathrm{~A}$ & $(600)$ & 15 & $\mathrm{n} / \mathrm{a}$ & 15 \\
\hline 258 & (149) & 30 & $\mathrm{n} / \mathrm{a}$ & 30 \\
\hline 216 & (338) & 50 & $\mathrm{n} / \mathrm{a}$ & 50 \\
\hline 43 & 2 & 10 & $\mathrm{n} / \mathrm{a}$ & 10 \\
\hline 38 & 13 & 35 & $\mathrm{n} / \mathrm{a}$ & 35 \\
\hline 176 & 17 & 5 & $\mathrm{n} / \mathrm{a}$ & 5 \\
\hline 226 & 20 & 45 & $\mathrm{n} / \mathrm{a}$ & 45 \\
\hline 154 & 18 & 15 & $\mathrm{n} / \mathrm{a}$ & 15 \\
\hline 265 & 32 & 25 & $\mathrm{n} / \mathrm{a}$ & 25 \\
\hline 79 & 54 & 95 & 95 & $\mathrm{n} / \mathrm{a}$ \\
\hline 99 & 14 & 10 & $\mathrm{n} / \mathrm{a}$ & 10 \\
\hline 107 & 58 & 50 & 50 & $\mathrm{n} / \mathrm{a}$ \\
\hline 270 & 57 & 10 & 10 & $\mathrm{n} / \mathrm{a}$ \\
\hline 102 & 39 & 5 & $\mathrm{n} / \mathrm{a}$ & 5 \\
\hline 260 & 58 & 70 & 70 & $\mathrm{n} / \mathrm{a}$ \\
\hline 267 & 69 & 25 & 25 & $\mathrm{n} / \mathrm{a}$ \\
\hline 97 & 30 & 145 & $\mathrm{n} / \mathrm{a}$ & 145 \\
\hline 92 & 67 & 60 & 60 & $\mathrm{n} / \mathrm{a}$ \\
\hline 106 & 74 & 35 & 35 & $\mathrm{n} / \mathrm{a}$ \\
\hline 93 & 68 & 50 & 50 & $\mathrm{n} / \mathrm{a}$ \\
\hline 171 & 91 & 45 & 45 & $\mathrm{n} / \mathrm{a}$ \\
\hline 175 & 62 & 10 & 10 & $\mathrm{n} / \mathrm{a}$ \\
\hline 274 & 94 & 40 & 40 & $\mathrm{n} / \mathrm{a}$ \\
\hline $102 \mathrm{~A}$ & 88 & 70 & 70 & $\mathrm{n} / \mathrm{a}$ \\
\hline 273 & 95 & 140 & 140 & $\mathrm{n} / \mathrm{a}$ \\
\hline 256 & 98 & 70 & 70 & $\mathrm{n} / \mathrm{a}$ \\
\hline 169 & 98 & 115 & 115 & $\mathrm{n} / \mathrm{a}$ \\
\hline 91 & 97 & 195 & 195 & $\mathrm{n} / \mathrm{a}$ \\
\hline 90 & 99 & 35 & 35 & $\mathrm{n} / \mathrm{a}$ \\
\hline 152 & 100 & 75 & 75 & $\mathrm{n} / \mathrm{a}$ \\
\hline 39 & 100 & 40 & 40 & $\mathrm{n} / \mathrm{a}$ \\
\hline \multicolumn{5}{|l|}{165} \\
\hline \multicolumn{5}{|l|}{101} \\
\hline \multicolumn{5}{|l|}{83} \\
\hline \multicolumn{2}{|l|}{$\mathrm{n}$} & 57 & & \\
\hline \multicolumn{2}{|c|}{ Median Value } & 45 & & \\
\hline \multicolumn{2}{|c|}{ (A) \# of Undermined Springs $>/=$ Median Value $w />/=50 \%$ Discharge Reduction } & & 24 & \\
\hline \multicolumn{2}{|c|}{ (B) \# of Undermined Springs $>/=$ Median Value $w /<50 \%$ Discharge Reduction } & & & 5 \\
\hline \multicolumn{2}{|c|}{ (C) \# of Undermined Springs $<$ Median Value $w />/=50 \%$ Discharge Reduction } & & 17 & \\
\hline (D) \# of Undermined Spring & dian Value $w /<50 \%$ Discharge Reduction & & & 11 \\
\hline Absolute Value (AD-BC) & & 179 & & \\
\hline Chi Square Value at 1 Degr & Freedom & 2.42375 & & \\
\hline Error Probability as Derived & Chi Square Contingency Test & $0.20-0.10$ & & \\
\hline Error Probability as Derived & Fisher Exact Probability Test & 0.05918 & & \\
\hline
\end{tabular}




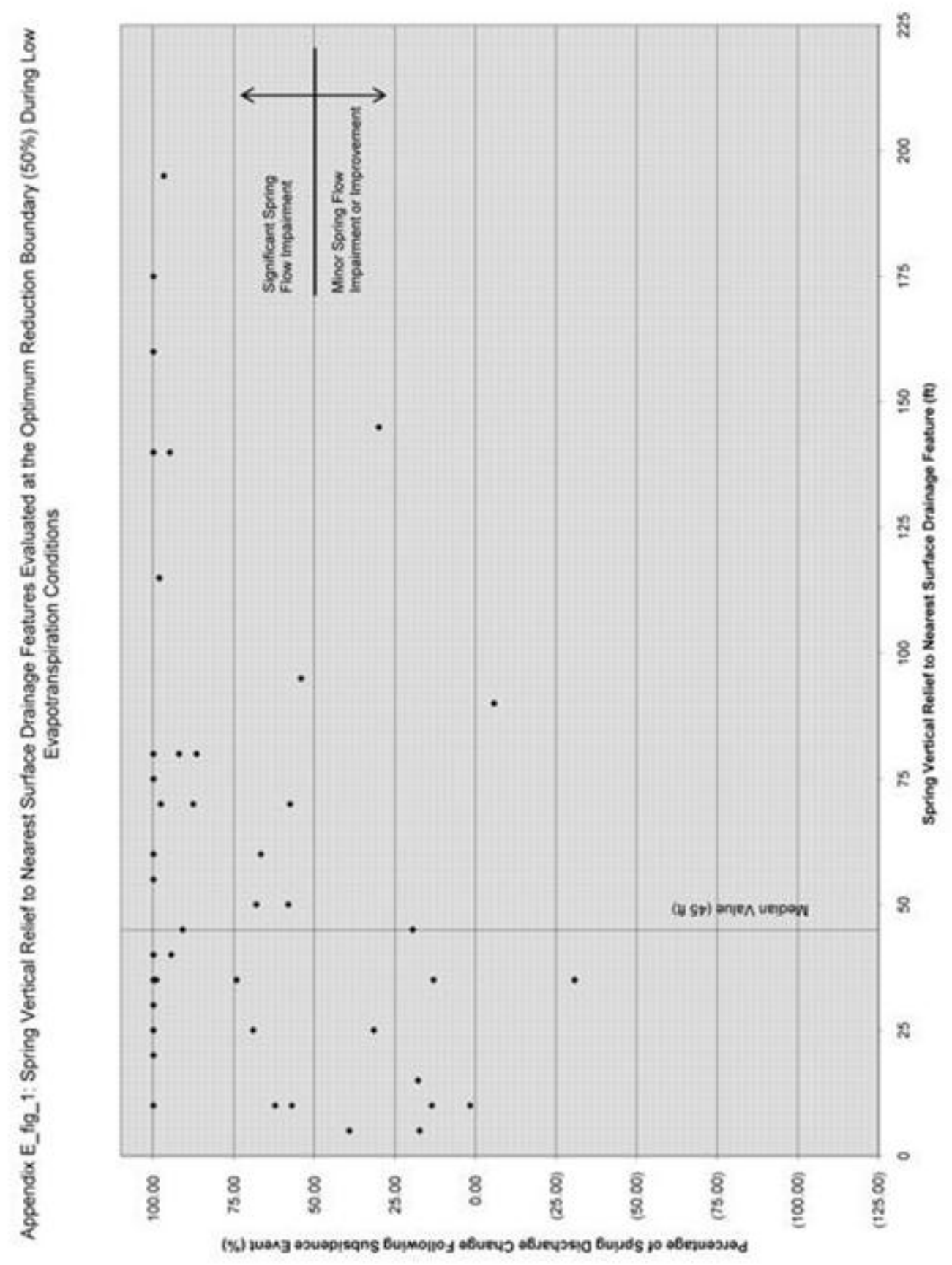


Appendix E_tab_2: Data Used to Determine the Statistical Significance of the Spring Vertical Relief to Headw ater, First and Second Order, Surface Drainage Feature Data Trend at the Optimum Discharge Reduction Boundary During Low Evapotranspiration Conditions.

\begin{tabular}{|c|c|c|c|c|}
\hline Spring No. & Optimum Discharge Reduction Boundary & Spring V & adw ater $\mathrm{S}$ & ure $(\mathrm{ft})$ \\
\hline & Low ET $(50 \%)$ & All & $>/=50 \%$ & $<50 \%$ \\
\hline 33 & 87 & 80 & 80 & $\mathrm{n} / \mathrm{a}$ \\
\hline 198 & 92 & 80 & 80 & $\mathrm{n} / \mathrm{a}$ \\
\hline 155 & 100 & 35 & 35 & $\mathrm{n} / \mathrm{a}$ \\
\hline 166 & 100 & 80 & 80 & $\mathrm{n} / \mathrm{a}$ \\
\hline 167 & 100 & 60 & 60 & $\mathrm{n} / \mathrm{a}$ \\
\hline 173 & 100 & 60 & 60 & $\mathrm{n} / \mathrm{a}$ \\
\hline 174 & 100 & 60 & 60 & $\mathrm{n} / \mathrm{a}$ \\
\hline 177 & 100 & 25 & 25 & $\mathrm{n} / \mathrm{a}$ \\
\hline 199 & & & & \\
\hline 224 & 100 & 10 & 10 & $\mathrm{n} / \mathrm{a}$ \\
\hline 249 & 100 & 25 & 25 & $\mathrm{n} / \mathrm{a}$ \\
\hline 254 & 100 & 60 & 60 & $\mathrm{n} / \mathrm{a}$ \\
\hline 259 & 100 & 55 & 55 & $\mathrm{n} / \mathrm{a}$ \\
\hline 263 & 100 & 30 & 30 & $\mathrm{n} / \mathrm{a}$ \\
\hline \begin{tabular}{|l|}
272 \\
\end{tabular} & 100 & 55 & 55 & $\mathrm{n} / \mathrm{a}$ \\
\hline 35 & 100 & 25 & 25 & $\mathrm{n} / \mathrm{a}$ \\
\hline 36 & 100 & 25 & 25 & $\mathrm{n} / \mathrm{a}$ \\
\hline 41 & 100 & 10 & 10 & $\mathrm{n} / \mathrm{a}$ \\
\hline 63 & 100 & 140 & 140 & $\mathrm{n} / \mathrm{a}$ \\
\hline 64 & 100 & 160 & 160 & $\mathrm{n} / \mathrm{a}$ \\
\hline 84 & & & & \\
\hline 94 & & & & \\
\hline 269 & (126) & 25 & $\mathrm{n} / \mathrm{a}$ & 25 \\
\hline 271 & (133) & 160 & $\mathrm{n} / \mathrm{a}$ & 160 \\
\hline 297 & (6) & 90 & $\mathrm{n} / \mathrm{a}$ & 90 \\
\hline 268 & (31) & 35 & $\mathrm{n} / \mathrm{a}$ & 35 \\
\hline 99A & $(600)$ & 15 & $\mathrm{n} / \mathrm{a}$ & 15 \\
\hline 258 & (149) & 30 & $\mathrm{n} / \mathrm{a}$ & 30 \\
\hline 216 & (338) & 50 & $\mathrm{n} / \mathrm{a}$ & 50 \\
\hline 43 & 2 & 10 & $\mathrm{n} / \mathrm{a}$ & 10 \\
\hline 38 & 13 & 35 & $\mathrm{n} / \mathrm{a}$ & 35 \\
\hline 176 & 17 & 5 & $\mathrm{n} / \mathrm{a}$ & 5 \\
\hline 226 & 20 & 45 & $\mathrm{n} / \mathrm{a}$ & 45 \\
\hline 154 & 18 & 15 & $\mathrm{n} / \mathrm{a}$ & 15 \\
\hline 265 & 32 & 25 & $\mathrm{n} / \mathrm{a}$ & 25 \\
\hline 79 & & & & \\
\hline 99 & 14 & 10 & $\mathrm{n} / \mathrm{a}$ & 10 \\
\hline 107 & 58 & 50 & 50 & $\mathrm{n} / \mathrm{a}$ \\
\hline 270 & 57 & 10 & 10 & $\mathrm{n} / \mathrm{a}$ \\
\hline 102 & 39 & 5 & $\mathrm{n} / \mathrm{a}$ & 5 \\
\hline 260 & 58 & 70 & 70 & $\mathrm{n} / \mathrm{a}$ \\
\hline 267 & 69 & 25 & 25 & $\mathrm{n} / \mathrm{a}$ \\
\hline 97 & 30 & 145 & $\mathrm{n} / \mathrm{a}$ & 145 \\
\hline \begin{tabular}{|l|}
92 \\
\end{tabular} & 67 & 60 & 60 & $\mathrm{n} / \mathrm{a}$ \\
\hline 106 & 74 & 35 & 35 & $\mathrm{n} / \mathrm{a}$ \\
\hline 93 & 68 & 50 & 50 & $\mathrm{n} / \mathrm{a}$ \\
\hline 171 & 91 & 45 & 45 & $\mathrm{n} / \mathrm{a}$ \\
\hline 175 & 62 & 10 & 10 & $\mathrm{n} / \mathrm{a}$ \\
\hline 274 & 94 & 40 & 40 & $\mathrm{n} / \mathrm{a}$ \\
\hline $102 \mathrm{~A}$ & 88 & 70 & 70 & $\mathrm{n} / \mathrm{a}$ \\
\hline 273 & 95 & 140 & 140 & $\mathrm{n} / \mathrm{a}$ \\
\hline 256 & 98 & 70 & 70 & $\mathrm{n} / \mathrm{a}$ \\
\hline 169 & 98 & 115 & 115 & $\mathrm{n} / \mathrm{a}$ \\
\hline 91 & 97 & 195 & 195 & $\mathrm{n} / \mathrm{a}$ \\
\hline 90 & 99 & 35 & 35 & $\mathrm{n} / \mathrm{a}$ \\
\hline 152 & 100 & 75 & 75 & $\mathrm{n} / \mathrm{a}$ \\
\hline 39 & & & & \\
\hline 165 & & & & \\
\hline 101 & & & & \\
\hline 83 & & & & \\
\hline $\mathrm{n}$ & & 52 & & \\
\hline Median Value & & 45 & & \\
\hline (A) \# of Undermined Sprin & Median Value $w />/=50 \%$ Discharge Reduction & & 22 & \\
\hline (B) \# of Undermined Sprin & Median Value $\mathrm{w} /<50 \%$ Discharge Reduction & & & 5 \\
\hline (C) \# of Undermined Spring & edian Value $\mathrm{w} />/=50 \%$ Discharge Reduction & & 14 & \\
\hline (D) \# of Undermined Sprin & edian Value $w /<50 \%$ Discharge Reduction & & & 11 \\
\hline Absolute Value (AD-BC) & & 172 & & \\
\hline Chi Square Value at $1 \mathrm{Deg}$ & Freedom & 2.85091 & & \\
\hline Error Probability as Derive & Chi Square Contingency Test & $0.10-0.05$ & & \\
\hline Error Probability as Derive & Fisher Exact Probability Test & 0.04516 & & \\
\hline
\end{tabular}




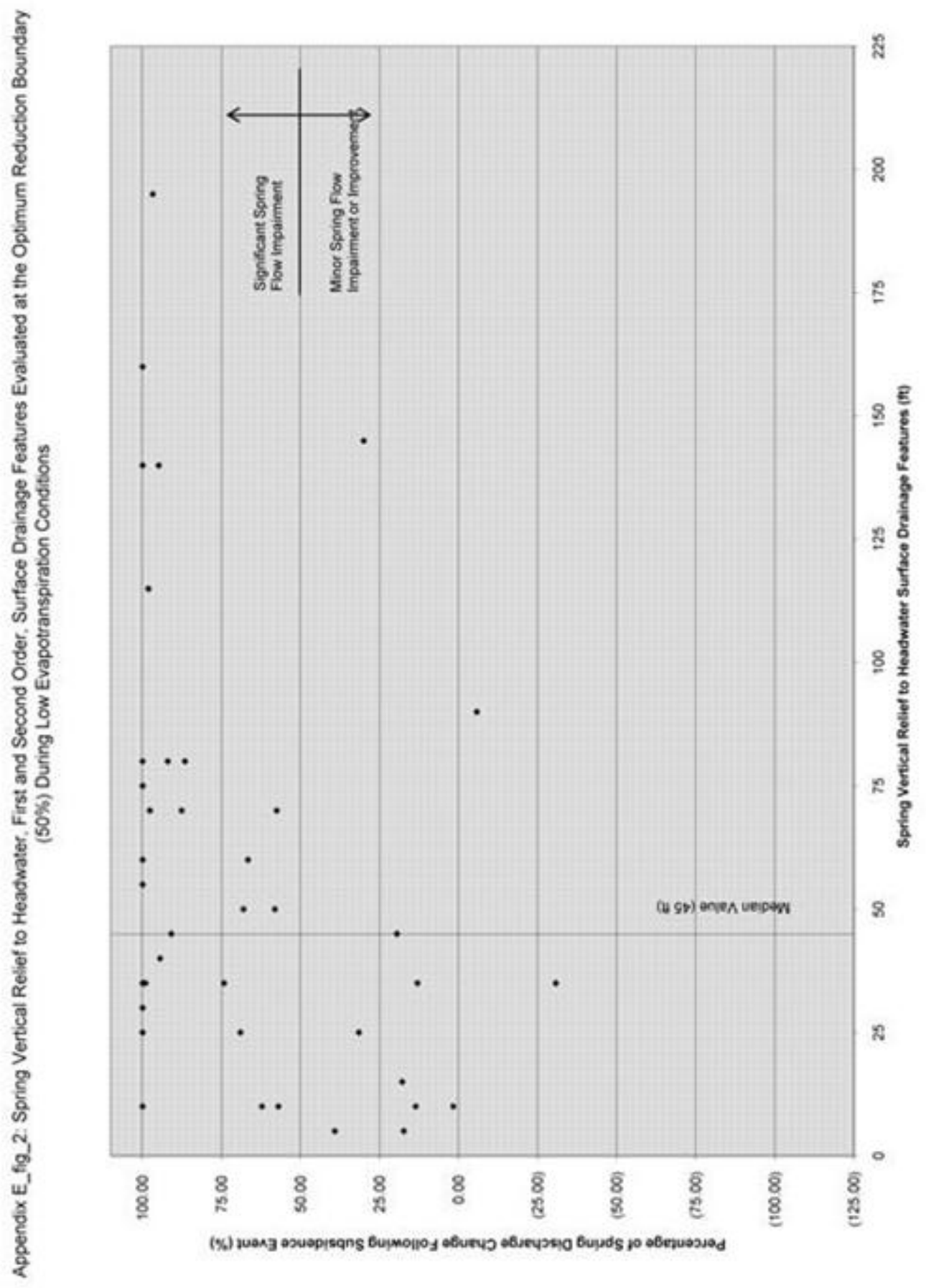


Appendix E_tab_3: Data Used to Determine the Statistical Significance of the Spring Vertical Relief to First Order Surface Drainage Feature Data Trend at the Optimum Discharge Reduction Boundary During Low Evapotranspiration Conditions.

\begin{tabular}{|c|c|c|c|c|}
\hline \multirow[t]{2}{*}{ Spring No. } & \multirow{2}{*}{$\begin{array}{c}\text { Optimum Discharge Reduction Boundary } \\
\text { Low ET }(50 \%) \\
\end{array}$} & \multicolumn{3}{|c|}{ Spring Vertical Relief to First Order Surface Drainage Feature (ft) } \\
\hline & & All & $>l=50 \%$ & $<50 \%$ \\
\hline \multicolumn{5}{|l|}{33} \\
\hline 198 & 92 & 80 & 80 & $\mathrm{n} / \mathrm{a}$ \\
\hline 155 & 100 & 35 & 35 & $\mathrm{n} / \mathrm{a}$ \\
\hline \multicolumn{5}{|l|}{166} \\
\hline 167 & 100 & 60 & 60 & $\mathrm{n} / \mathrm{a}$ \\
\hline 173 & 100 & 60 & 60 & $\mathrm{n} / \mathrm{a}$ \\
\hline 174 & 100 & 60 & 60 & $\mathrm{n} / \mathrm{a}$ \\
\hline \multicolumn{5}{|l|}{177} \\
\hline \multicolumn{5}{|l|}{199} \\
\hline 224 & 100 & 10 & 10 & $\mathrm{n} / \mathrm{a}$ \\
\hline 249 & 100 & 25 & 25 & $\mathrm{n} / \mathrm{a}$ \\
\hline 254 & 100 & 60 & 60 & $\mathrm{n} / \mathrm{a}$ \\
\hline \multicolumn{5}{|l|}{259} \\
\hline 263 & 100 & 30 & 30 & $\mathrm{n} / \mathrm{a}$ \\
\hline 272 & 100 & 55 & 55 & $\mathrm{n} / \mathrm{a}$ \\
\hline 35 & 100 & 25 & 25 & $\mathrm{n} / \mathrm{a}$ \\
\hline 36 & 100 & 25 & 25 & $\mathrm{n} / \mathrm{a}$ \\
\hline \multicolumn{5}{|l|}{41} \\
\hline \multicolumn{5}{|l|}{63} \\
\hline \multicolumn{5}{|l|}{64} \\
\hline 84 & & & & \\
\hline 94 & & & & \\
\hline 269 & (126) & 25 & $\mathrm{n} / \mathrm{a}$ & 25 \\
\hline 271 & (133) & 160 & $\mathrm{n} / \mathrm{a}$ & 160 \\
\hline 297 & & & & \\
\hline 268 & & & & \\
\hline 99A & $(600)$ & 15 & $\mathrm{n} / \mathrm{a}$ & 15 \\
\hline 258 & (149) & 30 & $\mathrm{n} / \mathrm{a}$ & 30 \\
\hline 216 & (338) & 50 & $\mathrm{n} / \mathrm{a}$ & 50 \\
\hline 43 & 2 & 10 & $\mathrm{n} / \mathrm{a}$ & 10 \\
\hline 38 & 13 & 35 & $\mathrm{n} / \mathrm{a}$ & 35 \\
\hline 176 & 17 & 5 & $\mathrm{n} / \mathrm{a}$ & 5 \\
\hline 226 & 20 & 45 & $\mathrm{n} / \mathrm{a}$ & 45 \\
\hline 154 & 18 & 15 & $\mathrm{n} / \mathrm{a}$ & 15 \\
\hline 265 & & & & \\
\hline 79 & & & & \\
\hline 99 & 14 & 10 & $\mathrm{n} / \mathrm{a}$ & 10 \\
\hline 107 & 58 & 50 & 50 & $\mathrm{n} / \mathrm{a}$ \\
\hline 270 & 57 & 10 & 10 & $\mathrm{n} / \mathrm{a}$ \\
\hline 102 & 39 & 5 & $\mathrm{n} / \mathrm{a}$ & 5 \\
\hline 260 & & & & \\
\hline 267 & 69 & 25 & 25 & $\mathrm{n} / \mathrm{a}$ \\
\hline 97 & 30 & 145 & $\mathrm{n} / \mathrm{a}$ & 145 \\
\hline 92 & 67 & 60 & 60 & $\mathrm{n} / \mathrm{a}$ \\
\hline 106 & 74 & 35 & 35 & $\mathrm{n} / \mathrm{a}$ \\
\hline 93 & 68 & 50 & 50 & $\mathrm{n} / \mathrm{a}$ \\
\hline 171 & 91 & 45 & 45 & $\mathrm{n} / \mathrm{a}$ \\
\hline 175 & 62 & 10 & 10 & $\mathrm{n} / \mathrm{a}$ \\
\hline 274 & 94 & 40 & 40 & $\mathrm{n} / \mathrm{a}$ \\
\hline $102 \mathrm{~A}$ & 88 & 70 & 70 & $\mathrm{n} / \mathrm{a}$ \\
\hline 273 & 95 & 140 & 140 & $\mathrm{n} / \mathrm{a}$ \\
\hline 256 & 98 & 70 & 70 & $\mathrm{n} / \mathrm{a}$ \\
\hline 169 & 98 & 115 & 115 & $\mathrm{n} / \mathrm{a}$ \\
\hline 91 & 97 & 195 & 195 & $\mathrm{n} / \mathrm{a}$ \\
\hline 90 & 99 & 35 & 35 & $\mathrm{n} / \mathrm{a}$ \\
\hline 152 & 100 & 75 & 75 & $\mathrm{n} / \mathrm{a}$ \\
\hline 39 & & & & \\
\hline 165 & & & & \\
\hline 101 & & & & \\
\hline 83 & & & & \\
\hline $\mathrm{n}$ & & 41 & & \\
\hline Median Value & & 40 & & \\
\hline (A) \# of Undermined Sprin & Median Value $\mathrm{w} />/=50 \%$ Discharge Reduction & & 17 & \\
\hline (B) \# of Undermined Spring & Median Value $\mathrm{w} /<50 \%$ Discharge Reduction & & & 4 \\
\hline (C) \# of Undermined Spring & edian Value $\mathrm{w} />/=50 \%$ Discharge Reduction & & 11 & \\
\hline (D) \# of Undermined Sprin & edian Value w $/<50 \%$ Discharge Reduction & & & 9 \\
\hline Absolute Value (AD-BC) & & 109 & & \\
\hline Chi Square Value at $1 \mathrm{Deg}$ & Freedom & 2.10049 & & \\
\hline Error Probability as Derive & Chi Square Contingency Test & $0.20-0.10$ & & \\
\hline Error Probability as Derive & Fisher Exact Probability Test & 0.07315 & & \\
\hline
\end{tabular}




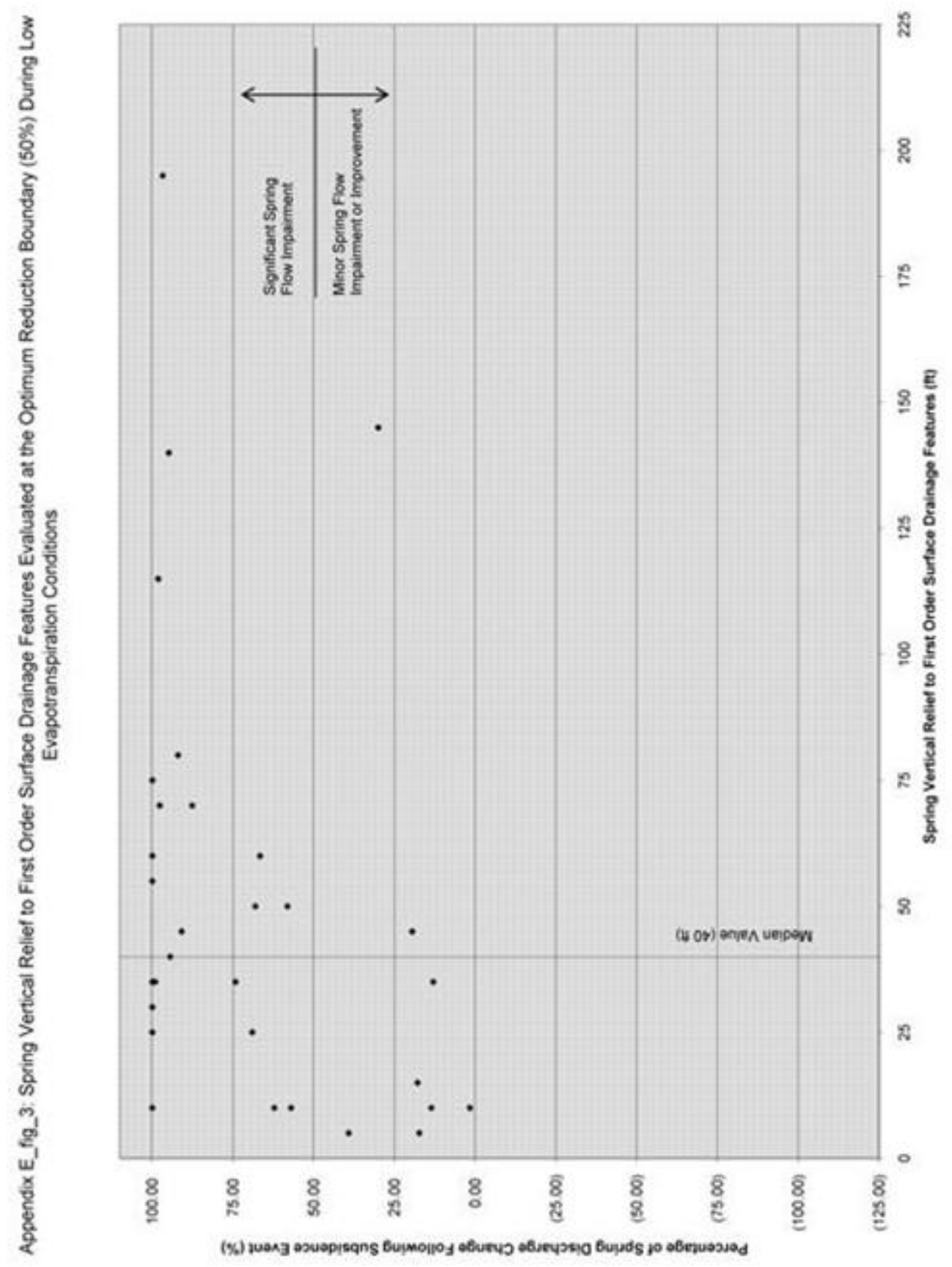


Appendix E_tab_4: Data Used to Determine the Statistical Significance of the Spring Vertical Relief to First Order Surface Drainage Feature Data Trend at the Absolute Discharge Reduction Boundary During Low Evapotranspiration Conditions.

\begin{tabular}{|c|c|c|c|c|}
\hline \multirow[t]{2}{*}{ Spring No. } & \multirow{2}{*}{$\begin{array}{c}\text { Absolute Discharge Reduction Boundary } \\
\text { Low ET }(88 \%)\end{array}$} & \multicolumn{3}{|c|}{ Spring Vertical Relief to First Order Surface Drainage Feature (ft) } \\
\hline & & All & $>1=88 \%$ & $<88 \%$ \\
\hline \multicolumn{5}{|l|}{33} \\
\hline 198 & 92 & 80 & 80 & $\mathrm{n} / \mathrm{a}$ \\
\hline 155 & 100 & 35 & 35 & $\mathrm{n} / \mathrm{a}$ \\
\hline \multicolumn{5}{|l|}{166} \\
\hline 167 & 100 & 60 & 60 & $\mathrm{n} / \mathrm{a}$ \\
\hline 173 & 100 & 60 & 60 & $\mathrm{n} / \mathrm{a}$ \\
\hline 174 & 100 & 60 & 60 & $\mathrm{n} / \mathrm{a}$ \\
\hline \multicolumn{5}{|l|}{177} \\
\hline \multicolumn{5}{|l|}{199} \\
\hline 224 & 100 & 10 & 10 & $\mathrm{n} / \mathrm{a}$ \\
\hline 249 & 100 & 25 & 25 & $\mathrm{n} / \mathrm{a}$ \\
\hline 254 & 100 & 60 & 60 & $\mathrm{n} / \mathrm{a}$ \\
\hline \multicolumn{5}{|l|}{259} \\
\hline 263 & 100 & 30 & 30 & $\mathrm{n} / \mathrm{a}$ \\
\hline 272 & 100 & 55 & 55 & $\mathrm{n} / \mathrm{a}$ \\
\hline 35 & 100 & 25 & 25 & $\mathrm{n} / \mathrm{a}$ \\
\hline 36 & 100 & 25 & 25 & $\mathrm{n} / \mathrm{a}$ \\
\hline \multicolumn{5}{|l|}{41} \\
\hline \multicolumn{5}{|l|}{63} \\
\hline \multicolumn{5}{|l|}{64} \\
\hline 84 & & & & \\
\hline 94 & & & & \\
\hline 269 & (126) & 25 & $\mathrm{n} / \mathrm{a}$ & 25 \\
\hline 271 & (133) & 160 & $\mathrm{n} / \mathrm{a}$ & 160 \\
\hline 297 & & & & \\
\hline 268 & & & & \\
\hline 99A & $(600)$ & 15 & $\mathrm{n} / \mathrm{a}$ & 15 \\
\hline 258 & (149) & 30 & $\mathrm{n} / \mathrm{a}$ & 30 \\
\hline 216 & (338) & 50 & $\mathrm{n} / \mathrm{a}$ & 50 \\
\hline 43 & 2 & 10 & $\mathrm{n} / \mathrm{a}$ & 10 \\
\hline 38 & 13 & 35 & $\mathrm{n} / \mathrm{a}$ & 35 \\
\hline 176 & 17 & 5 & $\mathrm{n} / \mathrm{a}$ & 5 \\
\hline 226 & 20 & 45 & $\mathrm{n} / \mathrm{a}$ & 45 \\
\hline 154 & 18 & 15 & $\mathrm{n} / \mathrm{a}$ & 15 \\
\hline 265 & & & & \\
\hline 79 & & & & \\
\hline 99 & 14 & 10 & $\mathrm{n} / \mathrm{a}$ & 10 \\
\hline 107 & 58 & 50 & $\mathrm{n} / \mathrm{a}$ & 50 \\
\hline 270 & 57 & 10 & $\mathrm{n} / \mathrm{a}$ & 10 \\
\hline 102 & 39 & 5 & $\mathrm{n} / \mathrm{a}$ & 5 \\
\hline 260 & & & & \\
\hline 267 & 69 & 25 & $\mathrm{n} / \mathrm{a}$ & 25 \\
\hline 97 & 30 & 145 & $\mathrm{n} / \mathrm{a}$ & 145 \\
\hline 92 & 67 & 60 & $\mathrm{n} / \mathrm{a}$ & 60 \\
\hline 106 & 74 & 35 & $\mathrm{n} / \mathrm{a}$ & 35 \\
\hline 93 & 68 & 50 & $\mathrm{n} / \mathrm{a}$ & 50 \\
\hline 171 & 91 & 45 & 45 & $\mathrm{n} / \mathrm{a}$ \\
\hline 175 & 62 & 10 & $\mathrm{n} / \mathrm{a}$ & 10 \\
\hline 274 & 94 & 40 & 40 & $n / a$ \\
\hline 102A & 88 & 70 & $\mathrm{n} / \mathrm{a}$ & 70 \\
\hline 273 & 95 & 140 & 140 & $n / a$ \\
\hline 256 & 98 & 70 & 70 & $\mathrm{n} / \mathrm{a}$ \\
\hline 169 & 98 & 115 & 115 & $n / a$ \\
\hline 91 & 97 & 195 & 195 & $\mathrm{n} / \mathrm{a}$ \\
\hline 90 & 99 & 35 & 35 & $\mathrm{n} / \mathrm{a}$ \\
\hline 152 & 100 & 75 & 75 & $n / a$ \\
\hline 39 & & & & \\
\hline 165 & & & & \\
\hline 101 & & & & \\
\hline 83 & & & & \\
\hline $\mathrm{n}$ & & 41 & & \\
\hline Median Value & & 40 & & \\
\hline (A) \# of Undermined Spri & Median Value $\mathrm{w} />/=50 \%$ Discharge Reduction & & 13 & \\
\hline (B) \# of Undermined Spri & Median Value $\mathrm{w} /<50 \%$ Discharge Reduction & & & 8 \\
\hline (C) \# of Undermined Spri & edian Value $\mathrm{w} />/=50 \%$ Discharge Reduction & & 7 & \\
\hline (D) \# of Undermined Spri & edian Value w $/<50 \%$ Discharge Reduction & & & 13 \\
\hline Absolute Value (AD-BC) & & 113 & & \\
\hline Chi Square Value at $1 \mathrm{De}$ & Freedom & 1.98870 & & \\
\hline Error Probability as Deriv & Chi Square Contingency Test & $0.20-0.10$ & & \\
\hline Error Probability as Deriv & Fisher Exact Probability Test & 0.07888 & & \\
\hline
\end{tabular}




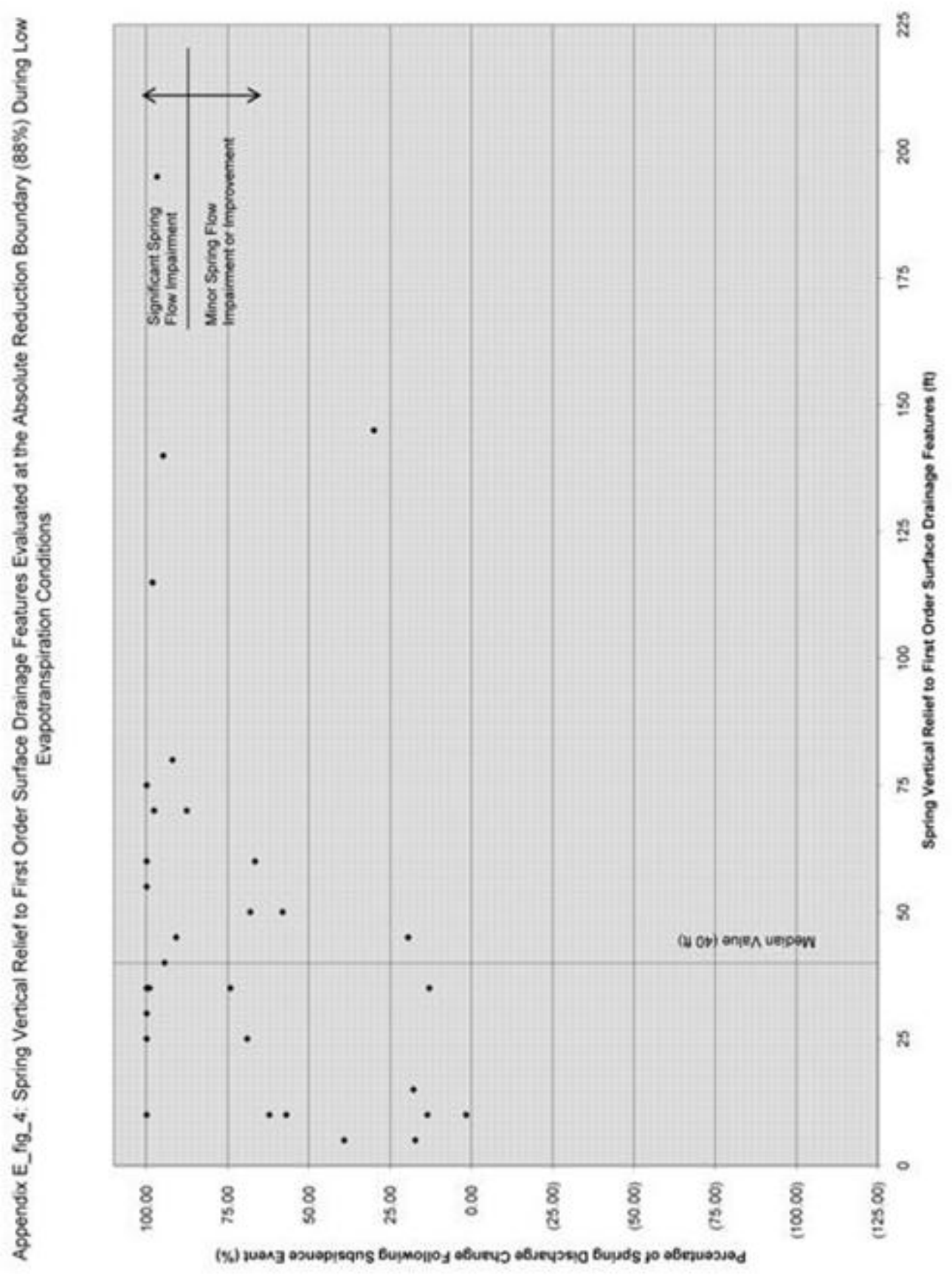


Appendix E_tab_5: Data Used to Determine the Statistical Significance of the Spring Daylight Elevation Data Trend at the Absolute Discharge Reduction Boundary During Low Evapotranspiration Conditions.

\begin{tabular}{|c|c|c|c|c|}
\hline Spring No. & Absolute Discharge Reduction Boundary & \multicolumn{3}{|c|}{ Spring Daylight Elevation (ft amsl) } \\
\hline & Low ET (88\%) & All & $>1=88 \%$ & $<88 \%$ \\
\hline 33 & 87 & 1240 & $\mathrm{n} / \mathrm{a}$ & 1240 \\
\hline 198 & 92 & 1250 & 1250 & $\mathrm{n} / \mathrm{a}$ \\
\hline 155 & 100 & 1115 & 1115 & $\mathrm{n} / \mathrm{a}$ \\
\hline 166 & 100 & 1130 & 1130 & $\mathrm{n} / \mathrm{a}$ \\
\hline 167 & 100 & 1170 & 1170 & $\mathrm{n} / \mathrm{a}$ \\
\hline 173 & 100 & 1260 & 1260 & $\mathrm{n} / \mathrm{a}$ \\
\hline 174 & 100 & 1230 & 1230 & $\mathrm{n} / \mathrm{a}$ \\
\hline 177 & 100 & 1175 & 1175 & $\mathrm{n} / \mathrm{a}$ \\
\hline 199 & 100 & 1010 & 1010 & $\mathrm{n} / \mathrm{a}$ \\
\hline 224 & 100 & 1215 & 1215 & $\mathrm{n} / \mathrm{a}$ \\
\hline 249 & 100 & 1120 & 1120 & $\mathrm{n} / \mathrm{a}$ \\
\hline 254 & 100 & 1130 & 1130 & $\mathrm{n} / \mathrm{a}$ \\
\hline 259 & 100 & 1155 & 1155 & $\mathrm{n} / \mathrm{a}$ \\
\hline 263 & 100 & 1160 & 1160 & $\mathrm{n} / \mathrm{a}$ \\
\hline 272 & 100 & 1265 & 1265 & $\mathrm{n} / \mathrm{a}$ \\
\hline 35 & 100 & 1185 & 1185 & $\mathrm{n} / \mathrm{a}$ \\
\hline 36 & 100 & 1225 & 1225 & $\mathrm{n} / \mathrm{a}$ \\
\hline 41 & 100 & 1180 & 1180 & $\mathrm{n} / \mathrm{a}$ \\
\hline 63 & 100 & 1165 & 1165 & $\mathrm{n} / \mathrm{a}$ \\
\hline 64 & 100 & 1185 & 1185 & $\mathrm{n} / \mathrm{a}$ \\
\hline 84 & 100 & 1040 & 1040 & $\mathrm{n} / \mathrm{a}$ \\
\hline 94 & 100 & 1155 & 1155 & $\mathrm{n} / \mathrm{a}$ \\
\hline 269 & (126) & 1225 & $\mathrm{n} / \mathrm{a}$ & 1225 \\
\hline 271 & (133) & 1310 & $\mathrm{n} / \mathrm{a}$ & 1310 \\
\hline 297 & (6) & 1210 & $\mathrm{n} / \mathrm{a}$ & 1210 \\
\hline 268 & (31) & 1185 & $\mathrm{n} / \mathrm{a}$ & 1185 \\
\hline $99 \mathrm{~A}$ & $(600)$ & 1190 & $\mathrm{n} / \mathrm{a}$ & 1190 \\
\hline 258 & (149) & 1190 & $\mathrm{n} / \mathrm{a}$ & 1190 \\
\hline 216 & (338) & 1210 & $\mathrm{n} / \mathrm{a}$ & 1210 \\
\hline 43 & 2 & 1180 & $\mathrm{n} / \mathrm{a}$ & 1180 \\
\hline 38 & 13 & 1220 & $\mathrm{n} / \mathrm{a}$ & 1220 \\
\hline 176 & 17 & 1175 & $\mathrm{n} / \mathrm{a}$ & 1175 \\
\hline 226 & 20 & 1195 & $\mathrm{n} / \mathrm{a}$ & 1195 \\
\hline 154 & 18 & 1150 & $\mathrm{n} / \mathrm{a}$ & 1150 \\
\hline 265 & 32 & 1200 & $\mathrm{n} / \mathrm{a}$ & 1200 \\
\hline 79 & 54 & 1095 & $\mathrm{n} / \mathrm{a}$ & 1095 \\
\hline 99 & 14 & 1180 & $\mathrm{n} / \mathrm{a}$ & 1180 \\
\hline 107 & 58 & 1200 & $\mathrm{n} / \mathrm{a}$ & 1200 \\
\hline 270 & 57 & 1230 & $\mathrm{n} / \mathrm{a}$ & 1230 \\
\hline 102 & 39 & 1160 & $\mathrm{n} / \mathrm{a}$ & 1160 \\
\hline 260 & 58 & 1190 & $\mathrm{n} / \mathrm{a}$ & 1190 \\
\hline 267 & 69 & 1210 & $\mathrm{n} / \mathrm{a}$ & 1210 \\
\hline 97 & 30 & 1265 & $\mathrm{n} / \mathrm{a}$ & 1265 \\
\hline 92 & 67 & 1190 & $\mathrm{n} / \mathrm{a}$ & 1190 \\
\hline 106 & 74 & 1155 & $\mathrm{n} / \mathrm{a}$ & 1155 \\
\hline 93 & 68 & 1175 & $\mathrm{n} / \mathrm{a}$ & 1175 \\
\hline 171 & 91 & 1195 & 1195 & $\mathrm{n} / \mathrm{a}$ \\
\hline 175 & 62 & 1190 & $\mathrm{n} / \mathrm{a}$ & 1190 \\
\hline 274 & 94 & 1240 & 1240 & $\mathrm{n} / \mathrm{a}$ \\
\hline 102A & 88 & 1200 & $\mathrm{n} / \mathrm{a}$ & 1200 \\
\hline 273 & 95 & 1280 & 1280 & $\mathrm{n} / \mathrm{a}$ \\
\hline 256 & 98 & 1190 & 1190 & $\mathrm{n} / \mathrm{a}$ \\
\hline 169 & 98 & 1225 & 1225 & $\mathrm{n} / \mathrm{a}$ \\
\hline 91 & 97 & 1195 & 1195 & $\mathrm{n} / \mathrm{a}$ \\
\hline 90 & 99 & 1125 & 1125 & $\mathrm{n} / \mathrm{a}$ \\
\hline 152 & 100 & 1195 & 1195 & $\mathrm{n} / \mathrm{a}$ \\
\hline 39 & 100 & 1150 & 1150 & $\mathrm{n} / \mathrm{a}$ \\
\hline \multicolumn{5}{|l|}{165} \\
\hline \multicolumn{5}{|l|}{101} \\
\hline \multicolumn{5}{|l|}{83} \\
\hline \multicolumn{2}{|l|}{$\mathrm{n}$} & 57 & & \\
\hline \multicolumn{2}{|c|}{ Median Value } & 1190 & & \\
\hline \multicolumn{2}{|c|}{ (A) \# of Undermined Springs $>/=$ Median Value $w />/=50 \%$ Discharge Reduction } & & 13 & \\
\hline \multicolumn{2}{|c|}{ (B) \# of Undermined Springs $>/=$ Median Value $w /<50 \%$ Discharge Reduction } & & & 18 \\
\hline \multicolumn{2}{|c|}{ (C) \# of Undermined Springs < Median Value w $/>/=50 \%$ Discharge Reduction } & & 17 & \\
\hline \multicolumn{2}{|c|}{ (D) \# of Undermined Springs < Median Value w $/<50 \%$ Discharge Reduction } & & & 9 \\
\hline \multicolumn{2}{|c|}{ Absolute Value (AD-BC) } & 189 & & \\
\hline Chi Square Value at 1 Degr & Freedom & 2.24908 & & \\
\hline Error Probability as Derived & Chi Square Contingency Test & $0.20-0.10$ & & \\
\hline Error Probability as Derived & Fisher Exact Probability Test & 0.06644 & & \\
\hline
\end{tabular}




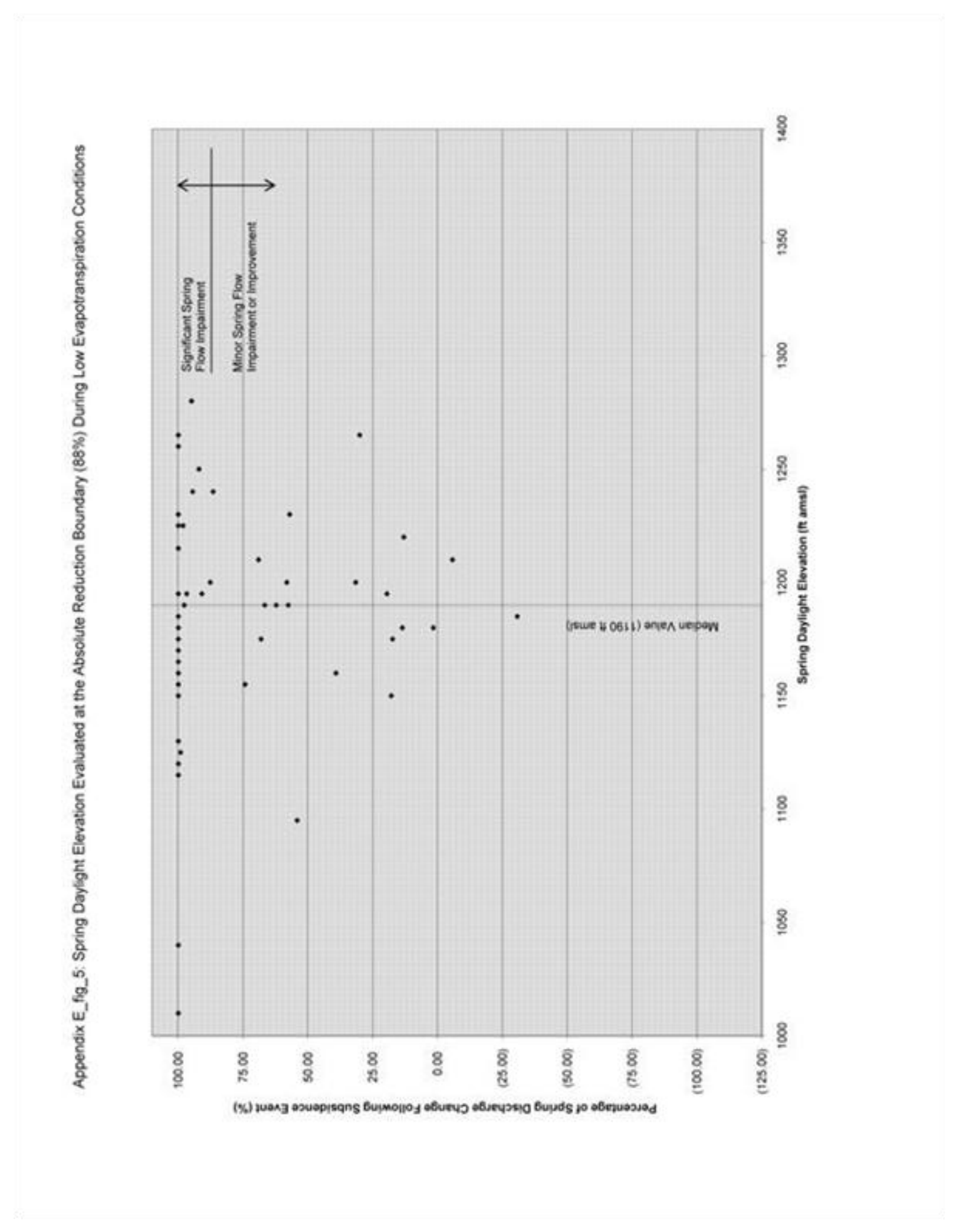


Appendix E_tab_6: Data Used to Determine the Statistical Significance of the Spring Recharge Line Length Data Trend at the Optimum Discharge Reduction Boundary During High Evapotranspiration Conditions.

\begin{tabular}{|c|c|c|c|c|}
\hline Spring No. & Optimum Discharge Reduction Boundary & & harge Line & \\
\hline & High ET (60\%) & All & $>/=60 \%$ & $<60 \%$ \\
\hline 33 & (1) & 157 & $\mathrm{n} / \mathrm{a}$ & 157 \\
\hline 198 & (23) & 170 & $\mathrm{n} / \mathrm{a}$ & 170 \\
\hline 155 & 100 & 188 & 188 & $\mathrm{n} / \mathrm{a}$ \\
\hline 166 & 100 & 94 & 94 & $\mathrm{n} / \mathrm{a}$ \\
\hline 167 & 100 & 219 & 219 & $\mathrm{n} / \mathrm{a}$ \\
\hline 173 & 100 & 219 & 219 & $\mathrm{n} / \mathrm{a}$ \\
\hline 174 & 100 & 94 & 94 & $\mathrm{n} / \mathrm{a}$ \\
\hline 177 & 100 & 310 & 310 & $\mathrm{n} / \mathrm{a}$ \\
\hline 199 & 100 & 188 & 188 & $\mathrm{n} / \mathrm{a}$ \\
\hline 224 & 100 & 120 & 120 & $\mathrm{n} / \mathrm{a}$ \\
\hline 249 & 100 & 407 & 407 & $\mathrm{n} / \mathrm{a}$ \\
\hline 254 & 100 & 375 & 375 & $\mathrm{n} / \mathrm{a}$ \\
\hline 259 & 100 & 657 & 657 & $\mathrm{n} / \mathrm{a}$ \\
\hline 263 & 100 & 63 & 63 & $\mathrm{n} / \mathrm{a}$ \\
\hline 272 & 100 & 219 & 219 & $\mathrm{n} / \mathrm{a}$ \\
\hline 35 & 100 & 157 & 157 & $\mathrm{n} / \mathrm{a}$ \\
\hline 36 & 100 & 125 & 125 & $\mathrm{n} / \mathrm{a}$ \\
\hline 41 & 100 & 63 & 63 & $\mathrm{n} / \mathrm{a}$ \\
\hline 63 & 100 & 532 & 532 & $\mathrm{n} / \mathrm{a}$ \\
\hline 64 & 100 & 438 & 438 & $\mathrm{n} / \mathrm{a}$ \\
\hline 84 & 100 & 750 & 750 & $\mathrm{n} / \mathrm{a}$ \\
\hline 94 & 100 & 125 & 125 & $\mathrm{n} / \mathrm{a}$ \\
\hline 269 & (61) & 157 & $\mathrm{n} / \mathrm{a}$ & 157 \\
\hline 271 & (74) & 125 & $\mathrm{n} / \mathrm{a}$ & 125 \\
\hline 297 & 10 & 94 & $\mathrm{n} / \mathrm{a}$ & 94 \\
\hline 268 & (118) & 282 & $\mathrm{n} / \mathrm{a}$ & 282 \\
\hline 99A & 100 & 75 & 75 & $\mathrm{n} / \mathrm{a}$ \\
\hline 258 & 100 & 532 & 532 & $\mathrm{n} / \mathrm{a}$ \\
\hline 216 & 100 & 360 & 360 & $\mathrm{n} / \mathrm{a}$ \\
\hline 43 & 80 & 63 & 63 & $\mathrm{n} / \mathrm{a}$ \\
\hline 38 & 100 & 282 & 282 & $\mathrm{n} / \mathrm{a}$ \\
\hline 176 & 100 & 375 & 375 & $\mathrm{n} / \mathrm{a}$ \\
\hline 226 & 100 & 313 & 313 & $\mathrm{n} / \mathrm{a}$ \\
\hline 154 & & & & \\
\hline 265 & 100 & 594 & 594 & $\mathrm{n} / \mathrm{a}$ \\
\hline 79 & 100 & 188 & 188 & $\mathrm{n} / \mathrm{a}$ \\
\hline 99 & 100 & 32 & 32 & $\mathrm{n} / \mathrm{a}$ \\
\hline 107 & 85 & 90 & 90 & $\mathrm{n} / \mathrm{a}$ \\
\hline 270 & & & & \\
\hline 102 & 100 & 313 & 313 & $\mathrm{n} / \mathrm{a}$ \\
\hline 260 & & & & \\
\hline 267 & 96 & 750 & 750 & $\mathrm{n} / \mathrm{a}$ \\
\hline 97 & 45 & 157 & $\mathrm{n} / \mathrm{a}$ & 157 \\
\hline 92 & & & & \\
\hline 106 & 100 & 250 & 250 & $n / a$ \\
\hline 93 & 100 & 330 & 330 & $\mathrm{n} / \mathrm{a}$ \\
\hline 171 & & & & \\
\hline 175 & 100 & 94 & 94 & $\mathrm{n} / \mathrm{a}$ \\
\hline 274 & 100 & 469 & 469 & $\mathrm{n} / \mathrm{a}$ \\
\hline $102 A$ & 99 & 532 & 532 & $\mathrm{n} / \mathrm{a}$ \\
\hline 273 & & & & \\
\hline 256 & 88 & 250 & 250 & $\mathrm{n} / \mathrm{a}$ \\
\hline 169 & 65 & 344 & 344 & $\mathrm{n} / \mathrm{a}$ \\
\hline 91 & & & & \\
\hline 90 & 100 & 313 & 313 & $\mathrm{n} / \mathrm{a}$ \\
\hline 152 & 100 & 188 & 188 & $\mathrm{n} / \mathrm{a}$ \\
\hline 39 & & & & \\
\hline 165 & (64) & 188 & $\mathrm{n} / \mathrm{a}$ & 188 \\
\hline 101 & 98 & 625 & 625 & $\mathrm{n} / \mathrm{a}$ \\
\hline 83 & 100 & 813 & 813 & $\mathrm{n} / \mathrm{a}$ \\
\hline $\mathrm{n}$ & & 52 & & \\
\hline Median Value & & 219 & & \\
\hline (A) \# of Undermined Spri & Median Value w $/>/=50 \%$ Discharge Reduction & & 27 & \\
\hline (B) \# of Undermined Spri & ledian Value w $/<50 \%$ Discharge Reduction & & & 1 \\
\hline (C) \# of Undermined Spri & dian Value $w />/=50 \%$ Discharge Reduction & & 17 & \\
\hline (D) \# of Undermined Spri & dian Value $\mathrm{w} /<50 \%$ Discharge Reduction & & & 7 \\
\hline Absolute Value (AD-BC) & & 172 & & \\
\hline Chi Square Value at $1 \mathrm{De}$ & reedom & 4.68594 & & \\
\hline Error Probability as Deriv & Chi Square Contingency Test & $0.05-0.02$ & & \\
\hline Error Probability as Deriv & isher Exact Probability Test & 0.01386 & & \\
\hline
\end{tabular}




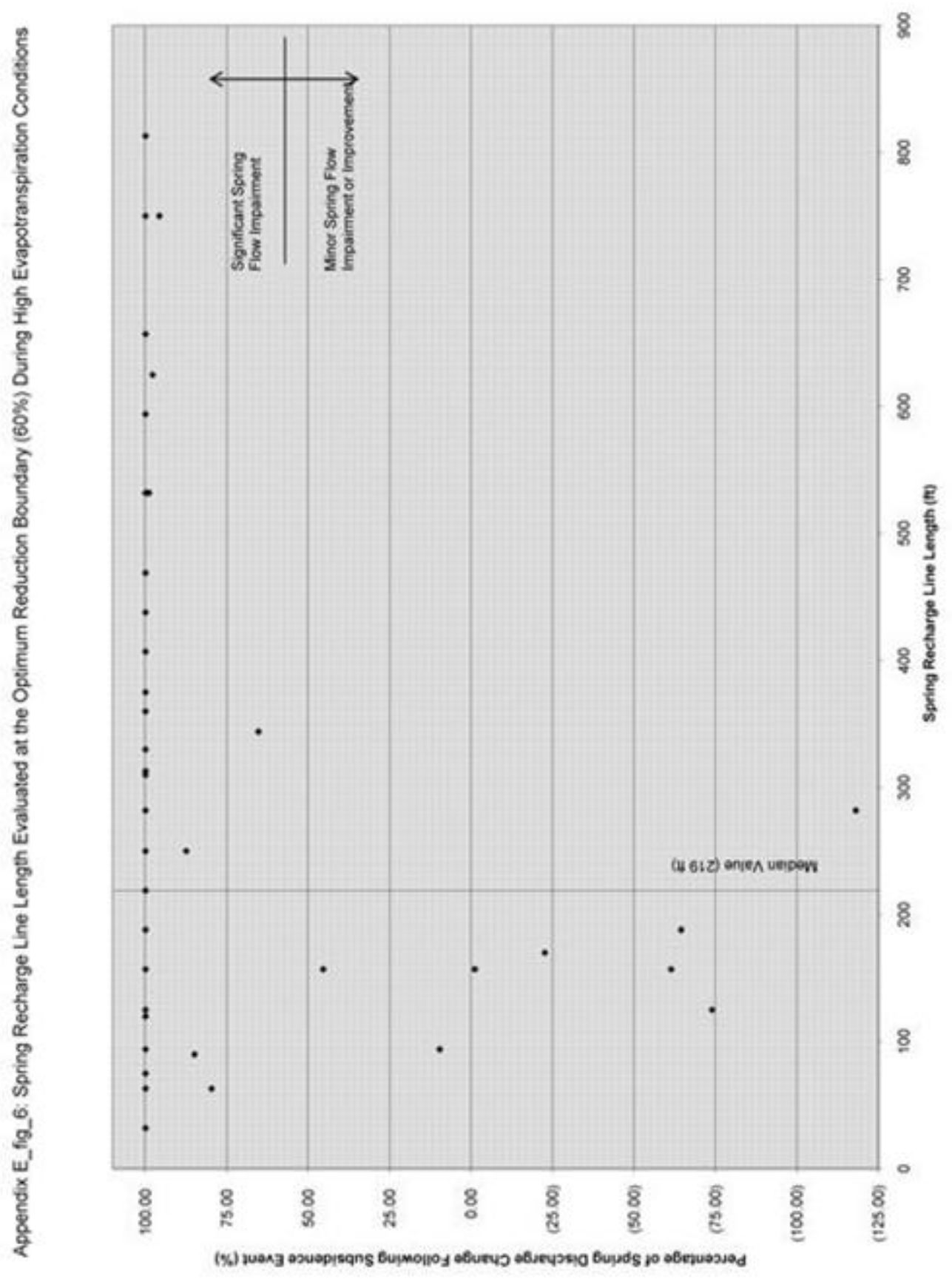


Appendix E_tab_7: Data Used to Determine the Statistical Significance of the Spring Recharge Line Vertical Relief Data Trend at the Optimum Discharge Reduction Boundary During High Evapotranspiration Conditions.

\begin{tabular}{|c|c|c|c|c|}
\hline Spring No. & Optimum Discharge Reduction Boundary & & ge Line $V_{e}$ & \\
\hline & High ET $(60 \%)$ & All & $>/=60 \%$ & $<60 \%$ \\
\hline 33 & $(1)$ & 30 & $\mathrm{n} / \mathrm{a}$ & 30 \\
\hline 198 & $(23)$ & 20 & $\mathrm{n} / \mathrm{a}$ & 20 \\
\hline 155 & 100 & 40 & 40 & $\mathrm{n} / \mathrm{a}$ \\
\hline 166 & 100 & 20 & 20 & $\mathrm{n} / \mathrm{a}$ \\
\hline 167 & 100 & 40 & 40 & $\mathrm{n} / \mathrm{a}$ \\
\hline 173 & 100 & 35 & 35 & $\mathrm{n} / \mathrm{a}$ \\
\hline 174 & 100 & 25 & 25 & $\mathrm{n} / \mathrm{a}$ \\
\hline 177 & 100 & 60 & 60 & $\mathrm{n} / \mathrm{a}$ \\
\hline 199 & 100 & 50 & 50 & $\mathrm{n} / \mathrm{a}$ \\
\hline 224 & 100 & 20 & 20 & $\mathrm{n} / \mathrm{a}$ \\
\hline 249 & 100 & 0 & 0 & $\mathrm{n} / \mathrm{a}$ \\
\hline 254 & 100 & 105 & 105 & $\mathrm{n} / \mathrm{a}$ \\
\hline 259 & 100 & 80 & 80 & $\mathrm{n} / \mathrm{a}$ \\
\hline 263 & 100 & 15 & 15 & $\mathrm{n} / \mathrm{a}$ \\
\hline 272 & 100 & 50 & 50 & $\mathrm{n} / \mathrm{a}$ \\
\hline \begin{tabular}{|l|}
35 \\
\end{tabular} & 100 & 50 & 50 & $\mathrm{n} / \mathrm{a}$ \\
\hline 36 & 100 & 30 & 30 & $\mathrm{n} / \mathrm{a}$ \\
\hline \begin{tabular}{|l|}
41 \\
\end{tabular} & 100 & 5 & 5 & $\mathrm{n} / \mathrm{a}$ \\
\hline 63 & 100 & 100 & 100 & $\mathrm{n} / \mathrm{a}$ \\
\hline \begin{tabular}{|l|}
64 \\
\end{tabular} & 100 & 80 & 80 & $\mathrm{n} / \mathrm{a}$ \\
\hline 84 & 100 & 195 & 195 & $\mathrm{n} / \mathrm{a}$ \\
\hline 94 & 100 & 20 & 20 & $\mathrm{n} / \mathrm{a}$ \\
\hline 269 & (61) & 30 & $\mathrm{n} / \mathrm{a}$ & 30 \\
\hline \begin{tabular}{|l|}
271 \\
\end{tabular} & (74) & 15 & $\mathrm{n} / \mathrm{a}$ & 15 \\
\hline \begin{tabular}{|l|}
297 \\
\end{tabular} & 10 & 15 & $\mathrm{n} / \mathrm{a}$ & 15 \\
\hline 268 & (118) & 25 & $\mathrm{n} / \mathrm{a}$ & 25 \\
\hline $99 \mathrm{~A}$ & 100 & 15 & 15 & $\mathrm{n} / \mathrm{a}$ \\
\hline 258 & 100 & 45 & 45 & $\mathrm{n} / \mathrm{a}$ \\
\hline 216 & 100 & 75 & 75 & $\mathrm{n} / \mathrm{a}$ \\
\hline \begin{tabular}{|l|}
43 \\
\end{tabular} & 80 & 15 & 15 & $\mathrm{n} / \mathrm{a}$ \\
\hline 38 & 100 & 55 & 55 & $\mathrm{n} / \mathrm{a}$ \\
\hline 176 & 100 & 70 & 70 & $\mathrm{n} / \mathrm{a}$ \\
\hline 226 & 100 & 60 & 60 & $\mathrm{n} / \mathrm{a}$ \\
\hline 154 & & & & \\
\hline 265 & 100 & 75 & 75 & $\mathrm{n} / \mathrm{a}$ \\
\hline 79 & 100 & 30 & 30 & $\mathrm{n} / \mathrm{a}$ \\
\hline 99 & 100 & 5 & 5 & $\mathrm{n} / \mathrm{a}$ \\
\hline \begin{tabular}{|l}
107 \\
\end{tabular} & 85 & 10 & 10 & $\mathrm{n} / \mathrm{a}$ \\
\hline 270 & & & & \\
\hline 102 & 100 & 25 & 25 & $\mathrm{n} / \mathrm{a}$ \\
\hline 260 & & & & \\
\hline 267 & 96 & 160 & 160 & $\mathrm{n} / \mathrm{a}$ \\
\hline \begin{tabular}{|l|}
97 \\
\end{tabular} & 45 & 30 & $\mathrm{n} / \mathrm{a}$ & 30 \\
\hline \begin{tabular}{|l|}
92 \\
\end{tabular} & & & & \\
\hline 106 & 100 & 45 & 45 & $\mathrm{n} / \mathrm{a}$ \\
\hline \begin{tabular}{|l|}
93 \\
\end{tabular} & 100 & 80 & 80 & $\mathrm{n} / \mathrm{a}$ \\
\hline \begin{tabular}{|l|}
171 \\
\end{tabular} & & & & \\
\hline 175 & 100 & 10 & 10 & $\mathrm{n} / \mathrm{a}$ \\
\hline \begin{tabular}{|l|}
274 \\
\end{tabular} & 100 & 100 & 100 & $\mathrm{n} / \mathrm{a}$ \\
\hline 102A & 99 & 60 & 60 & $\mathrm{n} / \mathrm{a}$ \\
\hline 273 & & & & \\
\hline 256 & 88 & 35 & 35 & $\mathrm{n} / \mathrm{a}$ \\
\hline \begin{tabular}{|l|}
169 \\
\end{tabular} & 65 & 70 & 70 & $\mathrm{n} / \mathrm{a}$ \\
\hline 91 & & & & \\
\hline \begin{tabular}{|l|}
90 \\
\end{tabular} & 100 & 10 & 10 & $\mathrm{n} / \mathrm{a}$ \\
\hline 152 & 100 & 40 & 40 & $\mathrm{n} / \mathrm{a}$ \\
\hline 39 & & & & \\
\hline 165 & (64) & 45 & $\mathrm{n} / \mathrm{a}$ & 45 \\
\hline \begin{tabular}{|l|}
101 \\
\end{tabular} & 98 & 145 & 145 & $\mathrm{n} / \mathrm{a}$ \\
\hline 83 & 100 & 195 & 195 & $\mathrm{n} / \mathrm{a}$ \\
\hline $\mathrm{n}$ & & 52 & & \\
\hline Median Value & & 40 & & \\
\hline (A) \# of Undermined Spri & Median Value $w />/=50 \%$ Discharge Reduction & & 26 & \\
\hline (B) \# of Undermined Spri & Median Value w $/<50 \%$ Discharge Reduction & & & 1 \\
\hline (C) \# of Undermined Spri & dian Value $w />/=50 \%$ Discharge Reduction & & 18 & \\
\hline (D) \# of Undermined Spri & edian Value $w /<50 \%$ Discharge Reduction & & & 7 \\
\hline Absolute Value (AD-BC) & & 164 & & \\
\hline Chi Square Value at $1 \mathrm{De}$ & Freedom & 4.16788 & & \\
\hline Eror Probability as Deriv & Chi Square Contingency Test & $0.05-0.02$ & & \\
\hline Error Probability as Deriv & Fisher Exact Probability Test & 0.01868 & & \\
\hline
\end{tabular}




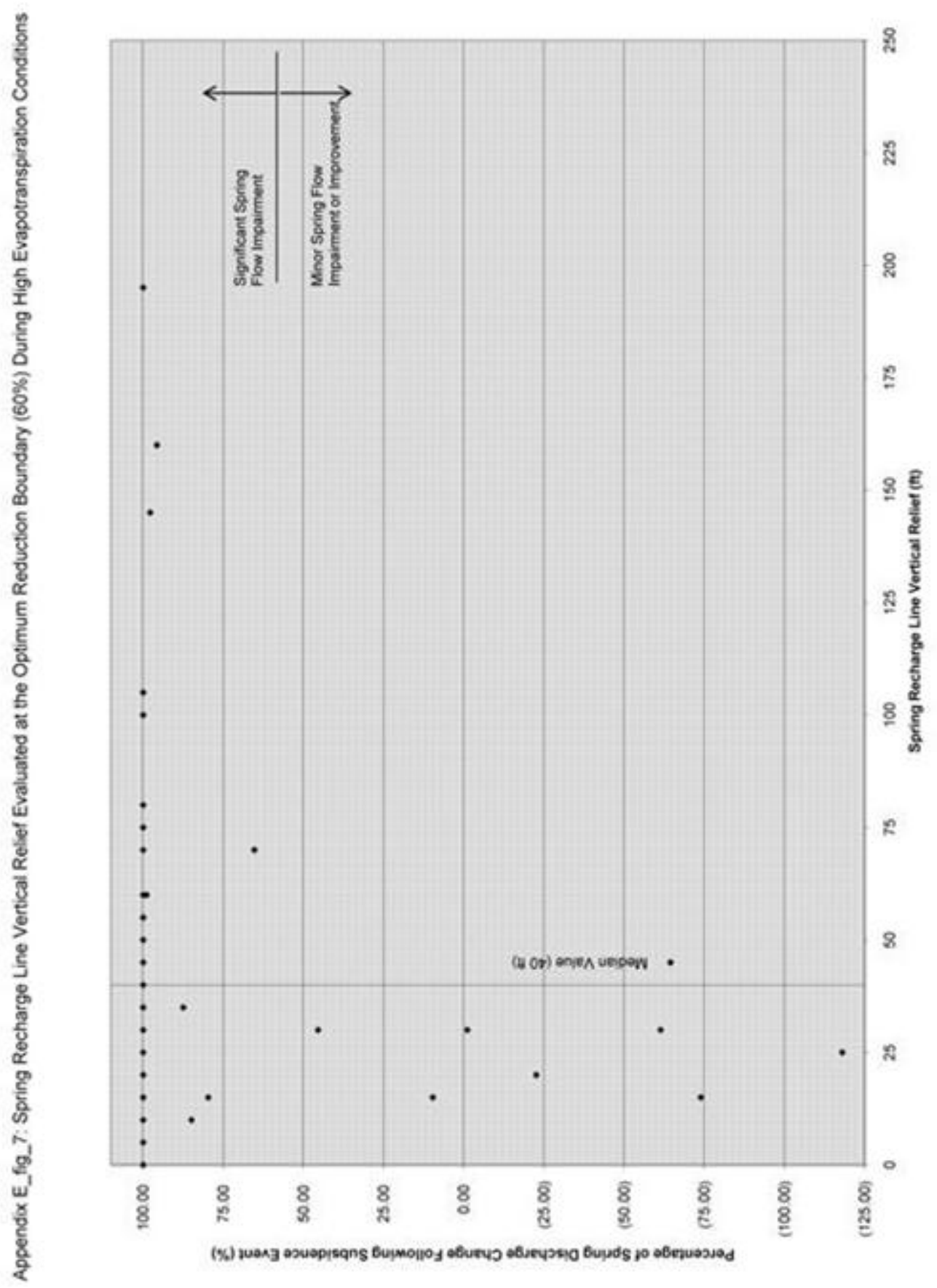


Appendix E_tab_8: Data Used to Determine the Statistical Significance of the Spring Daylight Elevation Data Trend at the Optimum Discharge Reduction Boundary During High Evapotranspiration Conditions.

\begin{tabular}{|c|c|c|c|c|}
\hline \multirow[t]{2}{*}{ Spring No. } & \multirow{2}{*}{$\begin{array}{c}\text { Optimum Discharge Reduction Boundary } \\
\text { High ET }(60 \%) \\
\end{array}$} & \multicolumn{3}{|c|}{ Spring Daylight Elevation (ft amsl) } \\
\hline & & All & $>l=60 \%$ & $<60 \%$ \\
\hline 33 & $(1)$ & 1240 & $\mathrm{n} / \mathrm{a}$ & 1240 \\
\hline 198 & (23) & 1250 & $\mathrm{n} / \mathrm{a}$ & 1250 \\
\hline 155 & 100 & 1115 & 1115 & $\mathrm{n} / \mathrm{a}$ \\
\hline 166 & 100 & 1130 & 1130 & $\mathrm{n} / \mathrm{a}$ \\
\hline 167 & 100 & 1170 & 1170 & $\mathrm{n} / \mathrm{a}$ \\
\hline 173 & 100 & 1260 & 1260 & $\mathrm{n} / \mathrm{a}$ \\
\hline 174 & 100 & 1230 & 1230 & $\mathrm{n} / \mathrm{a}$ \\
\hline 177 & 100 & 1175 & 1175 & $\mathrm{n} / \mathrm{a}$ \\
\hline 199 & 100 & 1010 & 1010 & $\mathrm{n} / \mathrm{a}$ \\
\hline 224 & 100 & 1215 & 1215 & $\mathrm{n} / \mathrm{a}$ \\
\hline 249 & 100 & 1120 & 1120 & $\mathrm{n} / \mathrm{a}$ \\
\hline 254 & 100 & 1130 & 1130 & $\mathrm{n} / \mathrm{a}$ \\
\hline 259 & 100 & 1155 & 1155 & $\mathrm{n} / \mathrm{a}$ \\
\hline 263 & 100 & 1160 & 1160 & $\mathrm{n} / \mathrm{a}$ \\
\hline 272 & 100 & 1265 & 1265 & $\mathrm{n} / \mathrm{a}$ \\
\hline 35 & 100 & 1185 & 1185 & $\mathrm{n} / \mathrm{a}$ \\
\hline 36 & 100 & 1225 & 1225 & $\mathrm{n} / \mathrm{a}$ \\
\hline 41 & 100 & 1180 & 1180 & $\mathrm{n} / \mathrm{a}$ \\
\hline 63 & 100 & 1165 & 1165 & $\mathrm{n} / \mathrm{a}$ \\
\hline 64 & 100 & 1185 & 1185 & $\mathrm{n} / \mathrm{a}$ \\
\hline 84 & 100 & 1040 & 1040 & $\mathrm{n} / \mathrm{a}$ \\
\hline 94 & 100 & 1155 & 1155 & $\mathrm{n} / \mathrm{a}$ \\
\hline 269 & (61) & 1225 & $\mathrm{n} / \mathrm{a}$ & 1225 \\
\hline 271 & (74) & 1310 & $\mathrm{n} / \mathrm{a}$ & 1310 \\
\hline 297 & 10 & 1210 & $\mathrm{n} / \mathrm{a}$ & 1210 \\
\hline 268 & (118) & 1185 & $\mathrm{n} / \mathrm{a}$ & 1185 \\
\hline 99A & 100 & 1190 & 1190 & $\mathrm{n} / \mathrm{a}$ \\
\hline 258 & 100 & 1190 & 1190 & $\mathrm{n} / \mathrm{a}$ \\
\hline 216 & 100 & 1210 & 1210 & $\mathrm{n} / \mathrm{a}$ \\
\hline 43 & 80 & 1180 & 1180 & $\mathrm{n} / \mathrm{a}$ \\
\hline 38 & 100 & 1220 & 1220 & $\mathrm{n} / \mathrm{a}$ \\
\hline 176 & 100 & 1175 & 1175 & $\mathrm{n} / \mathrm{a}$ \\
\hline 226 & 100 & 1195 & 1195 & $\mathrm{n} / \mathrm{a}$ \\
\hline \multicolumn{5}{|l|}{154} \\
\hline 265 & 100 & 1200 & 1200 & $\mathrm{n} / \mathrm{a}$ \\
\hline 79 & 100 & 1095 & 1095 & $\mathrm{n} / \mathrm{a}$ \\
\hline 99 & 100 & 1180 & 1180 & $\mathrm{n} / \mathrm{a}$ \\
\hline 107 & 85 & 1200 & 1200 & $\mathrm{n} / \mathrm{a}$ \\
\hline \multicolumn{5}{|l|}{270} \\
\hline 102 & 100 & 1160 & 1160 & $\mathrm{n} / \mathrm{a}$ \\
\hline \multicolumn{5}{|l|}{260} \\
\hline 267 & 96 & 1210 & 1210 & $\mathrm{n} / \mathrm{a}$ \\
\hline 97 & 45 & 1265 & $\mathrm{n} / \mathrm{a}$ & 1265 \\
\hline \multicolumn{5}{|l|}{92} \\
\hline 106 & 100 & 1155 & 1155 & $\mathrm{n} / \mathrm{a}$ \\
\hline 93 & 100 & 1175 & 1175 & $\mathrm{n} / \mathrm{a}$ \\
\hline \multicolumn{5}{|l|}{171} \\
\hline 175 & 100 & 1190 & 1190 & $\mathrm{n} / \mathrm{a}$ \\
\hline 274 & 100 & 1240 & 1240 & $\mathrm{n} / \mathrm{a}$ \\
\hline 102A & 99 & 1200 & 1200 & $\mathrm{n} / \mathrm{a}$ \\
\hline \multicolumn{5}{|l|}{273} \\
\hline 256 & 88 & 1190 & 1190 & $\mathrm{n} / \mathrm{a}$ \\
\hline 169 & 65 & 1225 & 1225 & $\mathrm{n} / \mathrm{a}$ \\
\hline \multicolumn{5}{|l|}{91} \\
\hline 90 & 100 & 1125 & 1125 & $\mathrm{n} / \mathrm{a}$ \\
\hline 152 & 100 & 1195 & 1195 & $\mathrm{n} / \mathrm{a}$ \\
\hline \multicolumn{5}{|l|}{39} \\
\hline 165 & (64) & 1010 & $\mathrm{n} / \mathrm{a}$ & 1010 \\
\hline 101 & 98 & 1130 & 1130 & $\mathrm{n} / \mathrm{a}$ \\
\hline 83 & 100 & 1040 & 1040 & $\mathrm{n} / \mathrm{a}$ \\
\hline $\mathrm{n}$ & & 52 & & \\
\hline Median Value & & 1185 & & \\
\hline (A) \# of Undermined Spr & Median Value $w />/=50 \%$ Discharge Reduction & & 21 & \\
\hline (B) \# of Undermined Spr & Median Value $\mathrm{w} /<50 \%$ Discharge Reduction & & & 7 \\
\hline (C) \# of Undermined Spr & edian Value $\mathrm{w} />/=50 \%$ Discharge Reduction & & 23 & \\
\hline (D) \# of Undermined Spr & edian Value w $/<50 \%$ Discharge Reduction & & & 1 \\
\hline Absolute Value (AD-BC) & & 140 & & \\
\hline Chi Square Value at $1 \mathrm{D}$ & Freedom & 2.85694 & & \\
\hline Error Probability as Deriv & Chi Square Contingency Test & $0.10-0.05$ & & \\
\hline Error Probability as Deriv & Fisher Exact Probability Test & 0.04189 & & \\
\hline
\end{tabular}




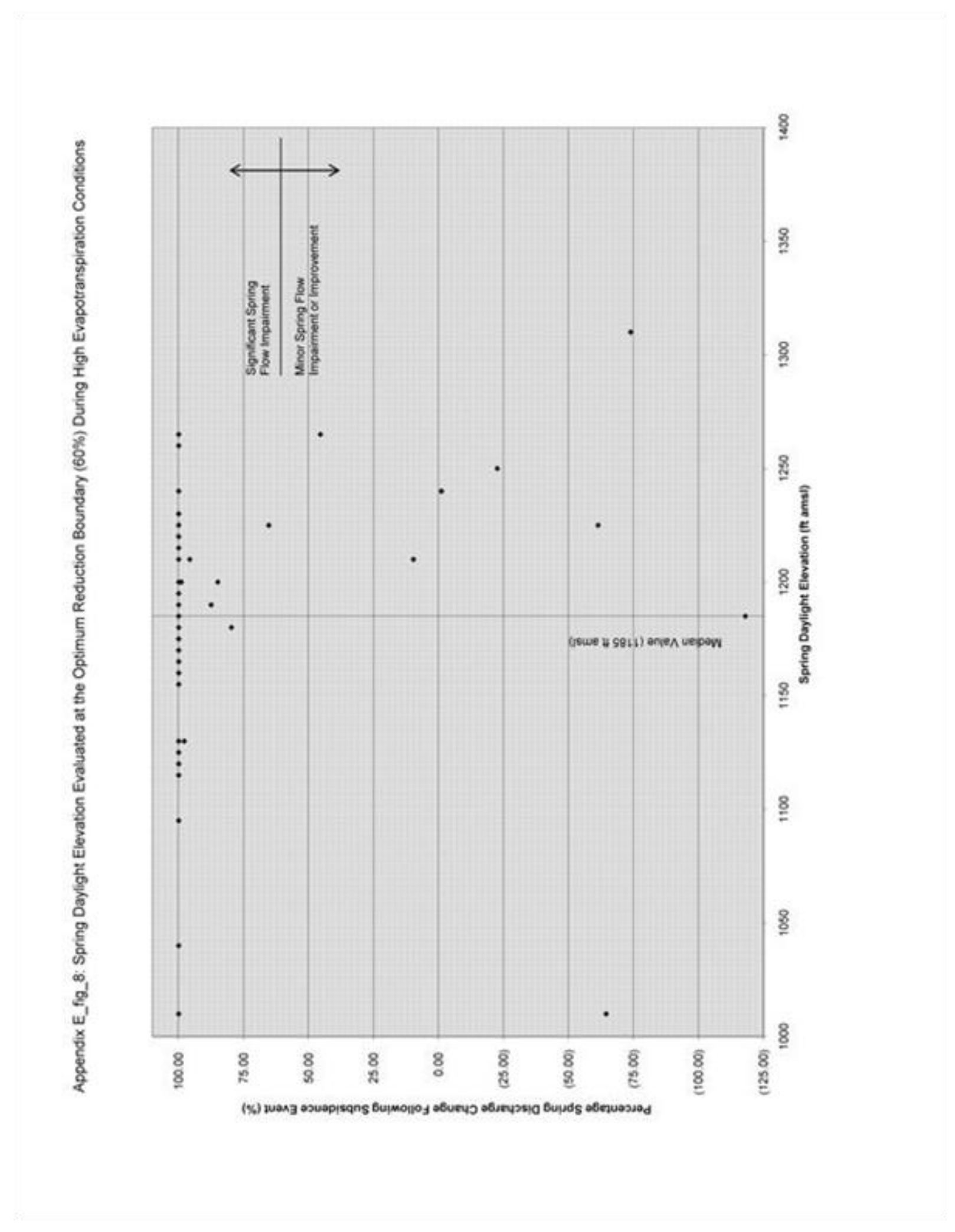


Appendix E_tab_9: Data Used to Determine the Statistical Significance of the Pre-Mine Averaged Low Flow Spring Discharge Data Trend at the Optimum Discharge Reduction Boundary During High Evapotranspiration Conditions.

\begin{tabular}{|c|c|c|c|c|}
\hline \multirow[t]{2}{*}{ Spring No. } & \multirow{2}{*}{$\begin{array}{c}\text { Optimum Discharge Reduction Boundary } \\
\text { High ET }(60 \%)\end{array}$} & \multicolumn{3}{|c|}{ Pre-Mine Averaged Low Flow Spring Discharge (gpm) } \\
\hline & & All & $>/=60 \%$ & $<60 \%$ \\
\hline 33 & $(1)$ & 0.27 & $\mathrm{n} / \mathrm{a}$ & 0.27 \\
\hline 198 & $(23)$ & 0.50 & $\mathrm{n} / \mathrm{a}$ & 0.50 \\
\hline 155 & 100 & 0.26 & 0.26 & $\mathrm{n} / \mathrm{a}$ \\
\hline 166 & 100 & 0.32 & 0.32 & $\mathrm{n} / \mathrm{a}$ \\
\hline \multicolumn{5}{|l|}{167} \\
\hline \multicolumn{5}{|l|}{173} \\
\hline \multicolumn{5}{|l|}{174} \\
\hline \multicolumn{5}{|l|}{177} \\
\hline \multicolumn{5}{|l|}{199} \\
\hline \multicolumn{5}{|l|}{224} \\
\hline \multicolumn{5}{|l|}{249} \\
\hline \multicolumn{5}{|l|}{254} \\
\hline 259 & & & & \\
\hline 263 & & & & \\
\hline 272 & & & & \\
\hline 35 & & & & \\
\hline 36 & & & & \\
\hline 41 & & & & \\
\hline 63 & & & & \\
\hline 64 & & & & \\
\hline 84 & & & & \\
\hline 94 & & & & \\
\hline 269 & $(61)$ & 0.44 & $\mathrm{n} / \mathrm{a}$ & 0.44 \\
\hline 271 & (74) & 0.69 & $\mathrm{n} / \mathrm{a}$ & 0.69 \\
\hline 297 & 10 & 0.62 & $\mathrm{n} / \mathrm{a}$ & 0.62 \\
\hline 268 & $(118)$ & 0.61 & $\mathrm{n} / \mathrm{a}$ & 0.61 \\
\hline 99A & 100 & 0.35 & 0.35 & $\mathrm{n} / \mathrm{a}$ \\
\hline 258 & 100 & 0.38 & 0.38 & $\mathrm{n} / \mathrm{a}$ \\
\hline 216 & 100 & 0.10 & 0.10 & $\mathrm{n} / \mathrm{a}$ \\
\hline 43 & 80 & 0.13 & 0.13 & $\mathrm{n} / \mathrm{a}$ \\
\hline 38 & 100 & 0.24 & 0.24 & $\mathrm{n} / \mathrm{a}$ \\
\hline 176 & 100 & 0.58 & 0.58 & $\mathrm{n} / \mathrm{a}$ \\
\hline 226 & 100 & 0.14 & 0.14 & $\mathrm{n} / \mathrm{a}$ \\
\hline 154 & & & & \\
\hline 265 & 100 & 0.37 & 0.37 & $\mathrm{n} / \mathrm{a}$ \\
\hline 79 & 100 & 0.05 & 0.05 & $\mathrm{n} / \mathrm{a}$ \\
\hline 99 & 100 & 0.05 & 0.05 & $\mathrm{n} / \mathrm{a}$ \\
\hline 107 & 85 & 0.73 & 0.73 & $\mathrm{n} / \mathrm{a}$ \\
\hline 270 & & & & \\
\hline 102 & 100 & 1.56 & 1.56 & $\mathrm{n} / \mathrm{a}$ \\
\hline 260 & & & & \\
\hline 267 & 96 & 0.29 & 0.29 & $\mathrm{n} / \mathrm{a}$ \\
\hline 97 & 45 & 0.44 & $\mathrm{n} / \mathrm{a}$ & 0.44 \\
\hline 92 & & & & \\
\hline 106 & 100 & 0.28 & 0.28 & $\mathrm{n} / \mathrm{a}$ \\
\hline 93 & 100 & 0.30 & 0.30 & $\mathrm{n} / \mathrm{a}$ \\
\hline 171 & & & & \\
\hline 175 & 100 & 0.13 & 0.13 & $\mathrm{n} / \mathrm{a}$ \\
\hline 274 & 100 & 0.09 & 0.09 & $\mathrm{n} / \mathrm{a}$ \\
\hline 102A & 99 & 0.94 & 0.94 & $\mathrm{n} / \mathrm{a}$ \\
\hline 273 & & & & \\
\hline 256 & 88 & 0.32 & 0.32 & $\mathrm{n} / \mathrm{a}$ \\
\hline 169 & 65 & 0.64 & 0.64 & $\mathrm{n} / \mathrm{a}$ \\
\hline 91 & & & & \\
\hline 90 & 100 & 1.36 & 1.36 & $\mathrm{n} / \mathrm{a}$ \\
\hline 152 & 100 & 0.09 & 0.09 & $\mathrm{n} / \mathrm{a}$ \\
\hline 39 & & & & \\
\hline 165 & $(64)$ & 0.45 & $\mathrm{n} / \mathrm{a}$ & 0.45 \\
\hline 101 & 98 & 0.46 & 0.46 & $\mathrm{n} / \mathrm{a}$ \\
\hline 83 & 100 & 0.15 & 0.15 & $\mathrm{n} / \mathrm{a}$ \\
\hline$n$ & & 34 & & \\
\hline Median Value & & 0.34 & & \\
\hline (A) \# of Undermined Sprin & Median Value $w />/=50 \%$ Discharge Reduction & & 10 & \\
\hline (B) \# of Undermined Sprin & Median Value w/ <50\% Discharge Reduction & & & 7 \\
\hline (C) \# of Undermined Sprin & dian Value $w />/=50 \%$ Discharge Reduction & & 16 & \\
\hline (D) \# of Undermined Sprin & dian Value $w /<50 \%$ Discharge Reduction & & & 1 \\
\hline Absolute Value (AD-BC) & & 102 & & \\
\hline Chi Square Value at $1 \mathrm{Deg}$ & reedom & 4.08654 & & \\
\hline Error Probability as Derive & Chi Square Contingency Test & $0.05-0.02$ & & \\
\hline Error Probability as Derive & isher Exact Probability Test & 0.01955 & & \\
\hline
\end{tabular}




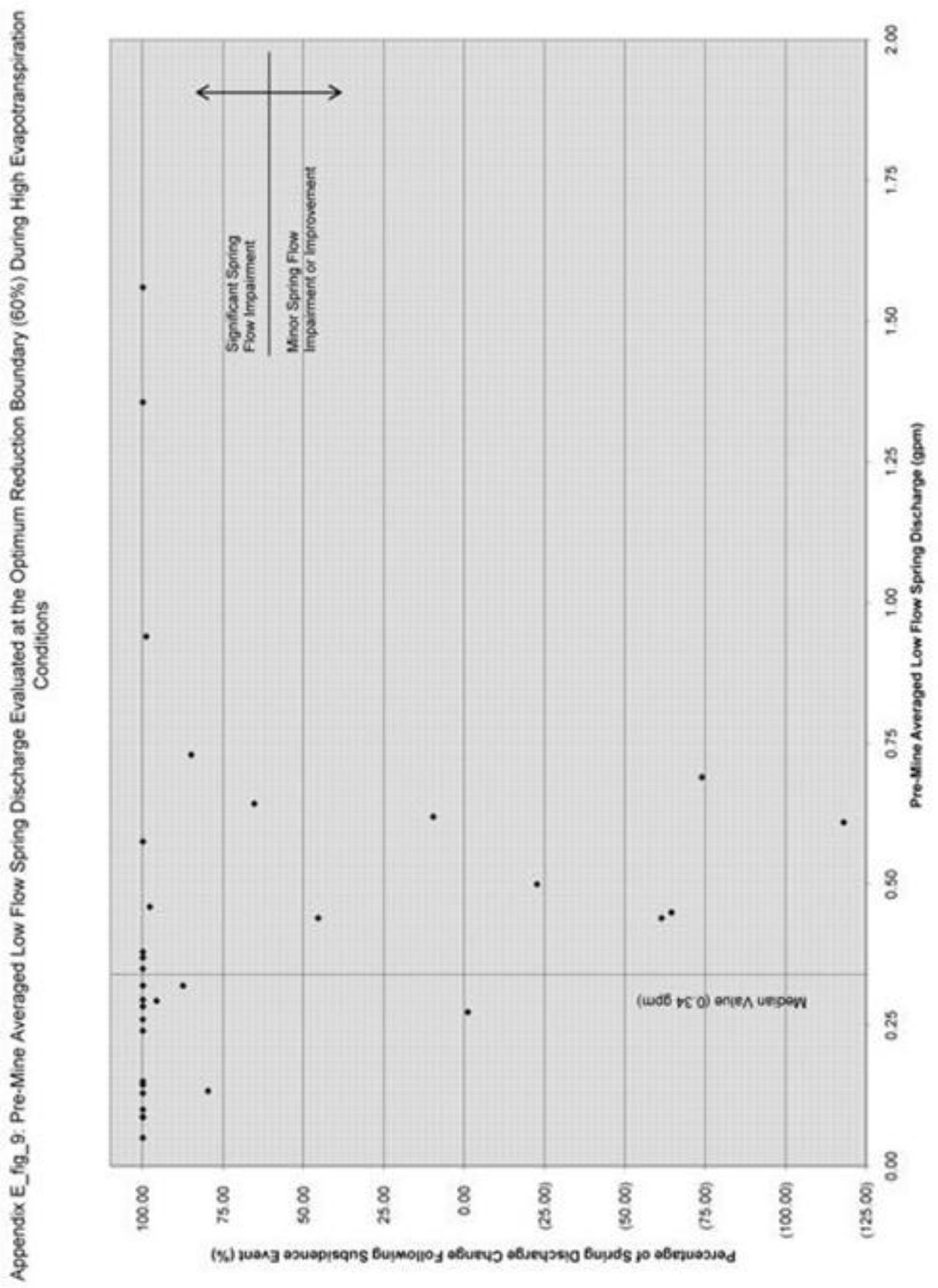


Appendix E_tab_10: Data Used to Determine the Statistical Significance of the Spring Recharge Line Length Component Perpendicular to Longw all Face Data Trend at the Absolute Discharge Reduction Boundary During High Evapotranspiration Conditions.

\begin{tabular}{|c|c|c|c|c|}
\hline \multirow[t]{2}{*}{ Spring No. } & \multirow{2}{*}{$\begin{array}{c}\text { Absolute Discharge Reduction Boundary } \\
\text { High ET }(80 \%)\end{array}$} & \multicolumn{3}{|c|}{ Spring Recharge Line Length Component Perpendicular to Longw all Face (ft) } \\
\hline & & All & $>1=80 \%$ & $<80 \%$ \\
\hline \multicolumn{5}{|l|}{33} \\
\hline 198 & (23) & 100 & $\mathrm{n} / \mathrm{a}$ & 100 \\
\hline 155 & 100 & 15 & 15 & $\mathrm{n} / \mathrm{a}$ \\
\hline 166 & 100 & 30 & 30 & $\mathrm{n} / \mathrm{a}$ \\
\hline 167 & 100 & 160 & 160 & $\mathrm{n} / \mathrm{a}$ \\
\hline 173 & 100 & 140 & 140 & $\mathrm{n} / \mathrm{a}$ \\
\hline \multicolumn{5}{|l|}{174} \\
\hline 177 & 100 & 280 & 280 & $\mathrm{n} / \mathrm{a}$ \\
\hline 199 & 100 & 220 & 220 & $\mathrm{n} / \mathrm{a}$ \\
\hline 224 & 100 & 120 & 120 & $\mathrm{n} / \mathrm{a}$ \\
\hline 249 & 100 & 350 & 350 & $\mathrm{n} / \mathrm{a}$ \\
\hline 254 & 100 & 360 & 360 & $\mathrm{n} / \mathrm{a}$ \\
\hline 259 & 100 & 100 & 100 & $\mathrm{n} / \mathrm{a}$ \\
\hline 263 & 100 & 15 & 15 & $\mathrm{n} / \mathrm{a}$ \\
\hline 272 & 100 & 30 & 30 & $\mathrm{n} / \mathrm{a}$ \\
\hline 35 & 100 & 70 & 70 & $\mathrm{n} / \mathrm{a}$ \\
\hline 36 & 100 & 50 & 50 & $\mathrm{n} / \mathrm{a}$ \\
\hline 41 & 100 & 40 & 40 & $\mathrm{n} / \mathrm{a}$ \\
\hline 63 & 100 & 370 & 370 & $\mathrm{n} / \mathrm{a}$ \\
\hline 64 & 100 & 300 & 300 & $\mathrm{n} / \mathrm{a}$ \\
\hline 84 & 100 & 220 & 220 & $\mathrm{n} / \mathrm{a}$ \\
\hline 94 & 100 & 50 & 50 & $\mathrm{n} / \mathrm{a}$ \\
\hline 269 & (61) & 140 & $\mathrm{n} / \mathrm{a}$ & 140 \\
\hline 271 & (74) & 110 & $\mathrm{n} / \mathrm{a}$ & 110 \\
\hline 297 & 10 & 65 & $\mathrm{n} / \mathrm{a}$ & 65 \\
\hline 268 & (118) & 70 & $\mathrm{n} / \mathrm{a}$ & 70 \\
\hline 99A & 100 & 75 & 75 & $\mathrm{n} / \mathrm{a}$ \\
\hline 258 & 100 & 225 & 225 & $\mathrm{n} / \mathrm{a}$ \\
\hline 216 & 100 & 40 & 40 & $\mathrm{n} / \mathrm{a}$ \\
\hline 43 & 80 & 20 & $\mathrm{n} / \mathrm{a}$ & 20 \\
\hline 38 & 100 & 20 & 20 & $\mathrm{n} / \mathrm{a}$ \\
\hline 176 & 100 & 340 & 340 & $\mathrm{n} / \mathrm{a}$ \\
\hline 226 & 100 & 260 & 260 & $\mathrm{n} / \mathrm{a}$ \\
\hline \multicolumn{5}{|l|}{154} \\
\hline 265 & 100 & 140 & 140 & $\mathrm{n} / \mathrm{a}$ \\
\hline 79 & 100 & 110 & 110 & $\mathrm{n} / \mathrm{a}$ \\
\hline 99 & 100 & 15 & 15 & $\mathrm{n} / \mathrm{a}$ \\
\hline \multicolumn{5}{|l|}{107} \\
\hline \multicolumn{5}{|l|}{270} \\
\hline 102 & 100 & 280 & 280 & $\mathrm{n} / \mathrm{a}$ \\
\hline \multicolumn{5}{|l|}{260} \\
\hline 267 & 96 & 250 & 250 & $\mathrm{n} / \mathrm{a}$ \\
\hline 97 & 45 & 100 & $\mathrm{n} / \mathrm{a}$ & 100 \\
\hline \multicolumn{5}{|l|}{92} \\
\hline 106 & 100 & 220 & 220 & $\mathrm{n} / \mathrm{a}$ \\
\hline 93 & 100 & 220 & 220 & $\mathrm{n} / \mathrm{a}$ \\
\hline \multicolumn{5}{|l|}{171} \\
\hline 175 & 100 & 30 & 30 & $\mathrm{n} / \mathrm{a}$ \\
\hline 274 & 100 & 440 & 440 & $\mathrm{n} / \mathrm{a}$ \\
\hline 102A & 99 & 180 & 180 & $\mathrm{n} / \mathrm{a}$ \\
\hline 273 & & & & \\
\hline 256 & 88 & 200 & 200 & $\mathrm{n} / \mathrm{a}$ \\
\hline 169 & 65 & 90 & $\mathrm{n} / \mathrm{a}$ & 90 \\
\hline 91 & & & & \\
\hline 90 & 100 & 50 & 50 & $\mathrm{n} / \mathrm{a}$ \\
\hline 152 & 100 & 80 & 80 & $\mathrm{n} / \mathrm{a}$ \\
\hline 39 & & & & \\
\hline 165 & (64) & 90 & $\mathrm{n} / \mathrm{a}$ & 90 \\
\hline 101 & 98 & 370 & 370 & $\mathrm{n} / \mathrm{a}$ \\
\hline 83 & 100 & 50 & 50 & $\mathrm{n} / \mathrm{a}$ \\
\hline $\mathrm{n}$ & & 49 & & \\
\hline Median Value & & 110 & & \\
\hline (A) \# of Undermined Spr & Median Value $\mathrm{w} />/=50 \%$ Discharge Reduction & & 23 & \\
\hline (B) \# of Undermined Spr & Median Value $\mathrm{w} /<50 \%$ Discharge Reduction & & & 2 \\
\hline (C) \# of Undermined Spr & ledian Value $\mathrm{w} />/=50 \%$ Discharge Reduction & & 17 & \\
\hline (D) \# of Undermined Spr & ledian Value w/ $<50 \%$ Discharge Reduction & & & 7 \\
\hline Absolute Value (AD-BC) & & 127 & & \\
\hline Chi Square Value at $1 \mathrm{De}$ & Freedom & 2.38336 & & \\
\hline Error Probability as Deriv & Chi Square Contingency Test & $0.20-0.10$ & & \\
\hline Error Probability as Deriv & Fisher Exact Probability Test & 0.06013 & & \\
\hline
\end{tabular}




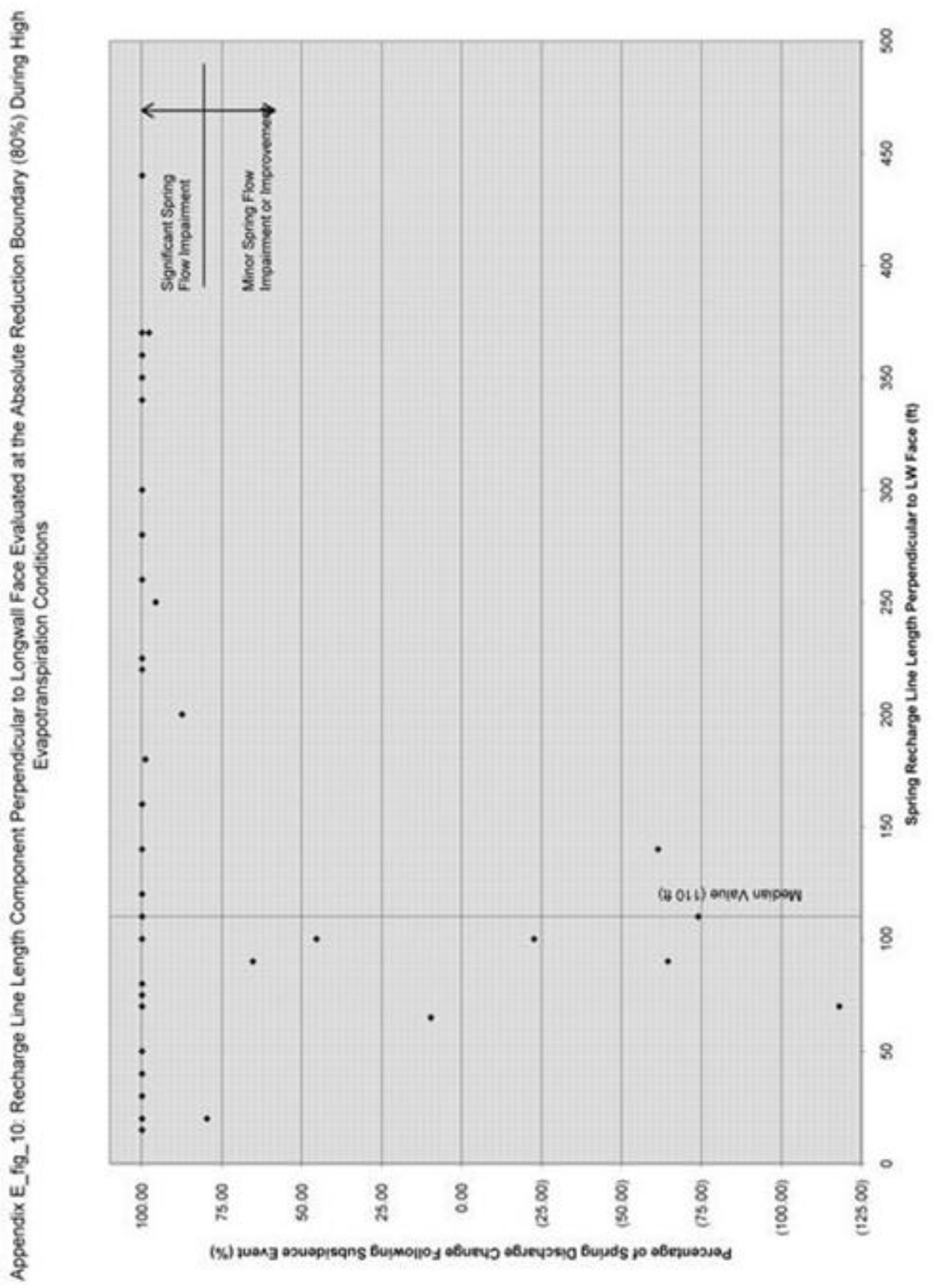


Appendix E_tab_11: Data Used to Determine the Statistical Significance of the Spring Recharge Line Length Data Trend at the Absolute Discharge Reduction Boundary During High Evapotranspiration Conditions.

\begin{tabular}{|c|c|c|c|c|}
\hline \multirow[t]{2}{*}{ Spring No. } & \multirow{2}{*}{$\begin{array}{c}\text { Absolute Discharge Reduction Boundary } \\
\text { High ET }(80 \%)\end{array}$} & \multicolumn{3}{|c|}{ Spring Recharge Line Length (ft) } \\
\hline & & All & $>/=80 \%$ & $<80 \%$ \\
\hline 33 & $(1)$ & 157 & $\mathrm{n} / \mathrm{a}$ & 157 \\
\hline 198 & (23) & 170 & $\mathrm{n} / \mathrm{a}$ & 170 \\
\hline 155 & 100 & 188 & 188 & $\mathrm{n} / \mathrm{a}$ \\
\hline 166 & 100 & 94 & 94 & $\mathrm{n} / \mathrm{a}$ \\
\hline 167 & 100 & 219 & 219 & $\mathrm{n} / \mathrm{a}$ \\
\hline 173 & 100 & 219 & 219 & $\mathrm{n} / \mathrm{a}$ \\
\hline 174 & 100 & 94 & 94 & $\mathrm{n} / \mathrm{a}$ \\
\hline 177 & 100 & 310 & 310 & $\mathrm{n} / \mathrm{a}$ \\
\hline 199 & 100 & 188 & 188 & $\mathrm{n} / \mathrm{a}$ \\
\hline 224 & 100 & 120 & 120 & $\mathrm{n} / \mathrm{a}$ \\
\hline 249 & 100 & 407 & 407 & $\mathrm{n} / \mathrm{a}$ \\
\hline 254 & 100 & 375 & 375 & $\mathrm{n} / \mathrm{a}$ \\
\hline 259 & 100 & 657 & 657 & $\mathrm{n} / \mathrm{a}$ \\
\hline 263 & 100 & 63 & 63 & $\mathrm{n} / \mathrm{a}$ \\
\hline 272 & 100 & 219 & 219 & $\mathrm{n} / \mathrm{a}$ \\
\hline 35 & 100 & 157 & 157 & $\mathrm{n} / \mathrm{a}$ \\
\hline 36 & 100 & 125 & 125 & $\mathrm{n} / \mathrm{a}$ \\
\hline 41 & 100 & 63 & 63 & $\mathrm{n} / \mathrm{a}$ \\
\hline 63 & 100 & 532 & 532 & $\mathrm{n} / \mathrm{a}$ \\
\hline 64 & 100 & 438 & 438 & $\mathrm{n} / \mathrm{a}$ \\
\hline 84 & 100 & 750 & 750 & $\mathrm{n} / \mathrm{a}$ \\
\hline 94 & 100 & 125 & 125 & $\mathrm{n} / \mathrm{a}$ \\
\hline 269 & (61) & 157 & $\mathrm{n} / \mathrm{a}$ & 157 \\
\hline 271 & (74) & 125 & $\mathrm{n} / \mathrm{a}$ & 125 \\
\hline 297 & 10 & 94 & $\mathrm{n} / \mathrm{a}$ & 94 \\
\hline 268 & (118) & 282 & $\mathrm{n} / \mathrm{a}$ & 282 \\
\hline 99A & 100 & 75 & 75 & $\mathrm{n} / \mathrm{a}$ \\
\hline 258 & 100 & 532 & 532 & $\mathrm{n} / \mathrm{a}$ \\
\hline 216 & 100 & 360 & 360 & $\mathrm{n} / \mathrm{a}$ \\
\hline 43 & 80 & 63 & $\mathrm{n} / \mathrm{a}$ & 63 \\
\hline 38 & 100 & 282 & 282 & $\mathrm{n} / \mathrm{a}$ \\
\hline 176 & 100 & 375 & 375 & $\mathrm{n} / \mathrm{a}$ \\
\hline 226 & 100 & 313 & 313 & $\mathrm{n} / \mathrm{a}$ \\
\hline \multicolumn{5}{|l|}{154} \\
\hline 265 & 100 & 594 & 594 & $\mathrm{n} / \mathrm{a}$ \\
\hline 79 & 100 & 188 & 188 & $\mathrm{n} / \mathrm{a}$ \\
\hline 99 & 100 & 32 & 32 & $\mathrm{n} / \mathrm{a}$ \\
\hline 107 & 85 & 90 & 90 & $\mathrm{n} / \mathrm{a}$ \\
\hline \multicolumn{5}{|l|}{270} \\
\hline 102 & 100 & 313 & 313 & $\mathrm{n} / \mathrm{a}$ \\
\hline \multicolumn{5}{|l|}{260} \\
\hline 267 & 96 & 750 & 750 & $\mathrm{n} / \mathrm{a}$ \\
\hline 97 & 45 & 157 & $\mathrm{n} / \mathrm{a}$ & 157 \\
\hline \multicolumn{5}{|l|}{92} \\
\hline 106 & 100 & 250 & 250 & $\mathrm{n} / \mathrm{a}$ \\
\hline 93 & 100 & 330 & 330 & $\mathrm{n} / \mathrm{a}$ \\
\hline \multicolumn{5}{|l|}{171} \\
\hline 175 & 100 & 94 & 94 & $\mathrm{n} / \mathrm{a}$ \\
\hline 274 & 100 & 469 & 469 & $\mathrm{n} / \mathrm{a}$ \\
\hline 102A & 99 & 532 & 532 & $\mathrm{n} / \mathrm{a}$ \\
\hline \multicolumn{5}{|l|}{273} \\
\hline 256 & 88 & 250 & 250 & $\mathrm{n} / \mathrm{a}$ \\
\hline 169 & 65 & 344 & $\mathrm{n} / \mathrm{a}$ & 344 \\
\hline \multicolumn{5}{|l|}{91} \\
\hline 90 & 100 & 313 & 313 & $\mathrm{n} / \mathrm{a}$ \\
\hline 152 & 100 & 188 & 188 & $\mathrm{n} / \mathrm{a}$ \\
\hline \multicolumn{5}{|l|}{39} \\
\hline 165 & (64) & 188 & $\mathrm{n} / \mathrm{a}$ & 188 \\
\hline 101 & 98 & 625 & 625 & $\mathrm{n} / \mathrm{a}$ \\
\hline 83 & 100 & 813 & 813 & $\mathrm{n} / \mathrm{a}$ \\
\hline $\mathrm{n}$ & & 52 & & \\
\hline Median Value & & 219 & & \\
\hline (A) \# of Undermined Spri & Median Value $\mathrm{w} />/=50 \%$ Discharge Reduction & & 26 & \\
\hline (B) \# of Undermined Sprir & Median Value $\mathrm{w} /<50 \%$ Discharge Reduction & & & 2 \\
\hline (C) \# of Undermined Sprir & edian Value $\mathrm{w} />/=50 \%$ Discharge Reduction & & 16 & \\
\hline (D) \# of Undermined Sprit & edian Value w/ < 50\% Discharge Reduction & & & 8 \\
\hline Absolute Value (AD-BC) & & 176 & & \\
\hline Chi Square Value at $1 \mathrm{De}$ & Freedom & 4.14541 & & \\
\hline Error Probability as Deriv & Chi Square Contingency Test & $0.05-0.02$ & & \\
\hline Error Probability as Deriv & Fisher Exact Probability Test & 0.02001 & & \\
\hline
\end{tabular}




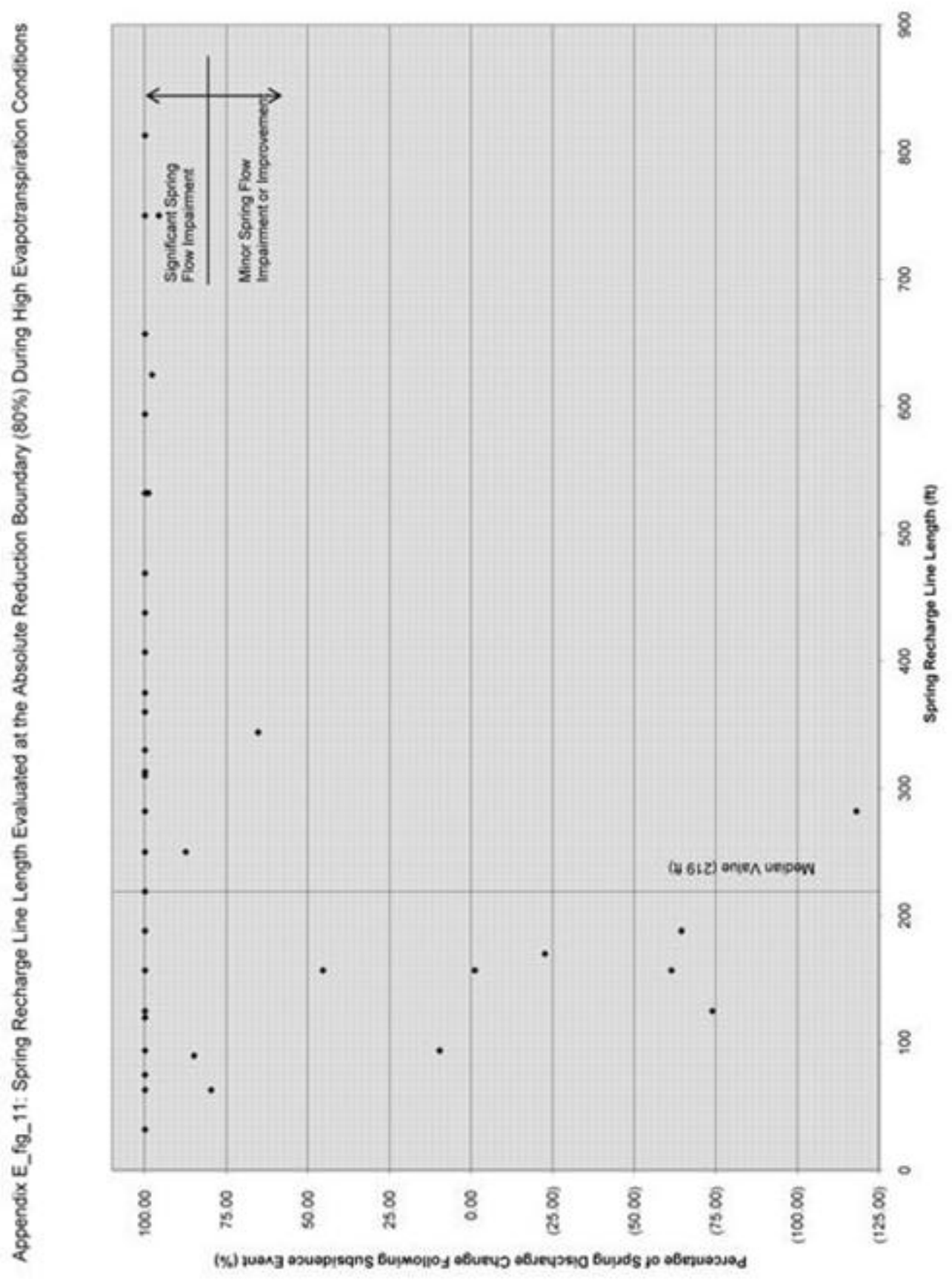


Appendix E_tab_12: Data Used to Determine the Statistical Significance of the Spring Recharge Line Vertical Relief Data Trend at the Absolute Discharge Reduction Boundary During High Evapotranspiration Conditions.

\begin{tabular}{|c|c|c|c|c|}
\hline Spring No. & Absolute Discharge Reduction Boundary & & ge Line Ve & \\
\hline & High ET (80\%) & All & $>1=80 \%$ & $<80 \%$ \\
\hline 33 & (1) & 30 & $\mathrm{n} / \mathrm{a}$ & 30 \\
\hline 198 & (23) & 20 & $\mathrm{n} / \mathrm{a}$ & 20 \\
\hline 155 & 100 & 40 & 40 & $\mathrm{n} / \mathrm{a}$ \\
\hline 166 & 100 & 20 & 20 & $\mathrm{n} / \mathrm{a}$ \\
\hline 167 & 100 & 40 & 40 & $\mathrm{n} / \mathrm{a}$ \\
\hline 173 & 100 & 35 & 35 & $\mathrm{n} / \mathrm{a}$ \\
\hline 174 & 100 & 25 & 25 & $\mathrm{n} / \mathrm{a}$ \\
\hline 177 & 100 & 60 & 60 & $\mathrm{n} / \mathrm{a}$ \\
\hline 199 & 100 & 50 & 50 & $\mathrm{n} / \mathrm{a}$ \\
\hline 224 & 100 & 20 & 20 & $\mathrm{n} / \mathrm{a}$ \\
\hline 249 & 100 & 0 & 0 & $\mathrm{n} / \mathrm{a}$ \\
\hline 254 & 100 & 105 & 105 & $\mathrm{n} / \mathrm{a}$ \\
\hline 259 & 100 & 80 & 80 & $\mathrm{n} / \mathrm{a}$ \\
\hline 263 & 100 & 15 & 15 & $\mathrm{n} / \mathrm{a}$ \\
\hline 272 & 100 & 50 & 50 & $\mathrm{n} / \mathrm{a}$ \\
\hline 35 & 100 & 50 & 50 & $n / a$ \\
\hline 36 & 100 & 30 & 30 & $\mathrm{n} / \mathrm{a}$ \\
\hline 41 & 100 & 5 & 5 & $\mathrm{n} / \mathrm{a}$ \\
\hline 63 & 100 & 100 & 100 & $\mathrm{n} / \mathrm{a}$ \\
\hline 64 & 100 & 80 & 80 & $\mathrm{n} / \mathrm{a}$ \\
\hline 84 & 100 & 195 & 195 & $n / a$ \\
\hline 94 & 100 & 20 & 20 & $\mathrm{n} / \mathrm{a}$ \\
\hline 269 & (61) & 30 & $\mathrm{n} / \mathrm{a}$ & 30 \\
\hline 271 & (74) & 15 & $\mathrm{n} / \mathrm{a}$ & 15 \\
\hline 297 & 10 & 15 & $\mathrm{n} / \mathrm{a}$ & 15 \\
\hline 268 & (118) & 25 & $\mathrm{n} / \mathrm{a}$ & 25 \\
\hline 99A & 100 & 15 & 15 & $\mathrm{n} / \mathrm{a}$ \\
\hline 258 & 100 & 45 & 45 & $\mathrm{n} / \mathrm{a}$ \\
\hline 216 & 100 & 75 & 75 & $n / a$ \\
\hline 43 & 80 & 15 & $\mathrm{n} / \mathrm{a}$ & 15 \\
\hline 38 & 100 & 55 & 55 & $\mathrm{n} / \mathrm{a}$ \\
\hline 176 & 100 & 70 & 70 & $\mathrm{n} / \mathrm{a}$ \\
\hline 226 & 100 & 60 & 60 & $\mathrm{n} / \mathrm{a}$ \\
\hline 154 & & & & \\
\hline 265 & 100 & 75 & 75 & $\mathrm{n} / \mathrm{a}$ \\
\hline 79 & 100 & 30 & 30 & $n / a$ \\
\hline 99 & 100 & 5 & 5 & $\mathrm{n} / \mathrm{a}$ \\
\hline 107 & 85 & 10 & 10 & $\mathrm{n} / \mathrm{a}$ \\
\hline 270 & & & & \\
\hline 102 & 100 & 25 & 25 & $\mathrm{n} / \mathrm{a}$ \\
\hline 260 & & & & \\
\hline 267 & 96 & 160 & 160 & $\mathrm{n} / \mathrm{a}$ \\
\hline 97 & 45 & 30 & $\mathrm{n} / \mathrm{a}$ & 30 \\
\hline 92 & & & & \\
\hline 106 & 100 & 45 & 45 & $\mathrm{n} / \mathrm{a}$ \\
\hline 93 & 100 & 80 & 80 & $\mathrm{n} / \mathrm{a}$ \\
\hline 171 & & & & \\
\hline 175 & 100 & 10 & 10 & $\mathrm{n} / \mathrm{a}$ \\
\hline 274 & 100 & 100 & 100 & $n / a$ \\
\hline 102A & 99 & 60 & 60 & $\mathrm{n} / \mathrm{a}$ \\
\hline 273 & & & & \\
\hline 256 & 88 & 35 & 35 & $\mathrm{n} / \mathrm{a}$ \\
\hline 169 & 65 & 70 & $\mathrm{n} / \mathrm{a}$ & 70 \\
\hline 91 & & & & \\
\hline 90 & 100 & 10 & 10 & $\mathrm{n} / \mathrm{a}$ \\
\hline 152 & 100 & 40 & 40 & $\mathrm{n} / \mathrm{a}$ \\
\hline 39 & & & & \\
\hline 165 & (64) & 45 & $\mathrm{n} / \mathrm{a}$ & 45 \\
\hline 101 & 98 & 145 & 145 & $\mathrm{n} / \mathrm{a}$ \\
\hline 83 & 100 & 195 & 195 & $\mathrm{n} / \mathrm{a}$ \\
\hline$n$ & & 52 & & \\
\hline Median Value & & 40 & & \\
\hline (A) \# of Undermined Spri & Median Value $\mathrm{w} />/=50 \%$ Discharge Reduction & & 25 & \\
\hline (B) \# of Undermined Spri & Median Value $\mathrm{w} /<50 \%$ Discharge Reduction & & & 2 \\
\hline (C) \# of Undermined Spri & dian Value $\mathrm{w} />/=50 \%$ Discharge Reduction & & 17 & \\
\hline (D) \# of Undermined Spri & dian Value $w /<50 \%$ Discharge Reduction & & & 8 \\
\hline Absolute Value (AD-BC) & & 166 & & \\
\hline Chi Square Value at $1 \mathrm{De}$ & Freedom & 3.59506 & & \\
\hline Error Probability as Deriv & Chi Square Contingency Test & $0.10-0.05$ & & \\
\hline Error Probability as Deriv & isher Exact Probability Test & 0.02769 & & \\
\hline
\end{tabular}




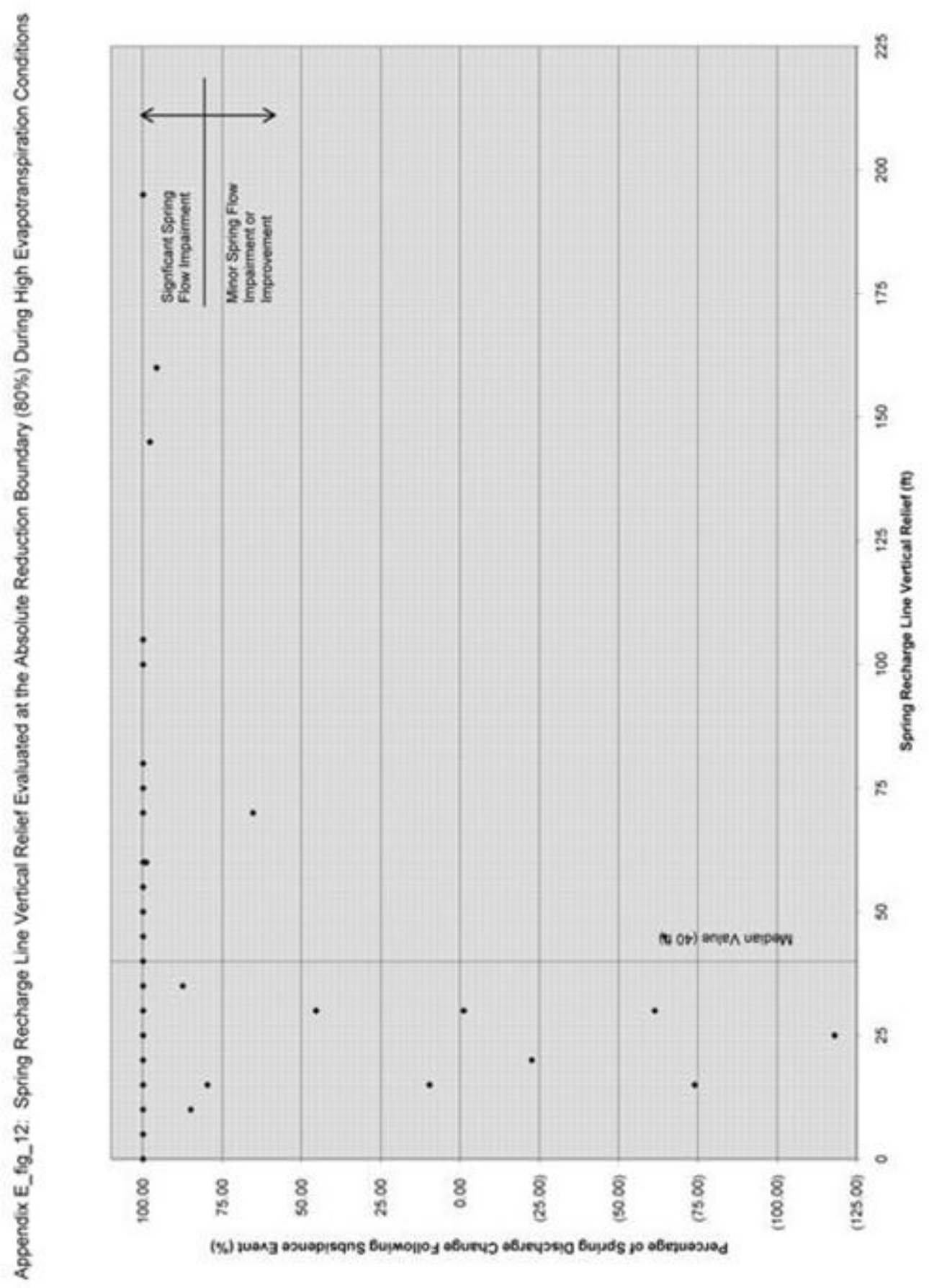


Appendix E_tab_13: Data Used to Determine the Statistical Significance of the Spring Daylight Elevation Data Trend at the Absolute Discharge Reduction Boundary During High Evapotranspiration Conditions.

\begin{tabular}{|c|c|c|c|c|}
\hline \multirow[t]{2}{*}{ Spring No. } & \multirow{2}{*}{$\begin{array}{c}\text { Absolute Discharge Reduction Boundary } \\
\text { High ET }(80 \%) \\
\end{array}$} & \multicolumn{3}{|c|}{ Spring Daylight Elevation (ft amsl) } \\
\hline & & All & $>l=80 \%$ & $<80 \%$ \\
\hline 33 & $(1)$ & 1240 & $\mathrm{n} / \mathrm{a}$ & 1240 \\
\hline 198 & (23) & 1250 & $\mathrm{n} / \mathrm{a}$ & 1250 \\
\hline 155 & 100 & 1115 & 1115 & $\mathrm{n} / \mathrm{a}$ \\
\hline 166 & 100 & 1130 & 1130 & $\mathrm{n} / \mathrm{a}$ \\
\hline 167 & 100 & 1170 & 1170 & $\mathrm{n} / \mathrm{a}$ \\
\hline 173 & 100 & 1260 & 1260 & $\mathrm{n} / \mathrm{a}$ \\
\hline 174 & 100 & 1230 & 1230 & $\mathrm{n} / \mathrm{a}$ \\
\hline 177 & 100 & 1175 & 1175 & $\mathrm{n} / \mathrm{a}$ \\
\hline 199 & 100 & 1010 & 1010 & $\mathrm{n} / \mathrm{a}$ \\
\hline 224 & 100 & 1215 & 1215 & $\mathrm{n} / \mathrm{a}$ \\
\hline 249 & 100 & 1120 & 1120 & $\mathrm{n} / \mathrm{a}$ \\
\hline 254 & 100 & 1130 & 1130 & $\mathrm{n} / \mathrm{a}$ \\
\hline 259 & 100 & 1155 & 1155 & $\mathrm{n} / \mathrm{a}$ \\
\hline 263 & 100 & 1160 & 1160 & $\mathrm{n} / \mathrm{a}$ \\
\hline 272 & 100 & 1265 & 1265 & $\mathrm{n} / \mathrm{a}$ \\
\hline 35 & 100 & 1185 & 1185 & $\mathrm{n} / \mathrm{a}$ \\
\hline 36 & 100 & 1225 & 1225 & $\mathrm{n} / \mathrm{a}$ \\
\hline 41 & 100 & 1180 & 1180 & $\mathrm{n} / \mathrm{a}$ \\
\hline 63 & 100 & 1165 & 1165 & $\mathrm{n} / \mathrm{a}$ \\
\hline 64 & 100 & 1185 & 1185 & $\mathrm{n} / \mathrm{a}$ \\
\hline 84 & 100 & 1040 & 1040 & $\mathrm{n} / \mathrm{a}$ \\
\hline 94 & 100 & 1155 & 1155 & $\mathrm{n} / \mathrm{a}$ \\
\hline 269 & (61) & 1225 & $\mathrm{n} / \mathrm{a}$ & 1225 \\
\hline 271 & (74) & 1310 & $\mathrm{n} / \mathrm{a}$ & 1310 \\
\hline 297 & 10 & 1210 & $\mathrm{n} / \mathrm{a}$ & 1210 \\
\hline 268 & (118) & 1185 & $\mathrm{n} / \mathrm{a}$ & 1185 \\
\hline 99A & 100 & 1190 & 1190 & $\mathrm{n} / \mathrm{a}$ \\
\hline 258 & 100 & 1190 & 1190 & $\mathrm{n} / \mathrm{a}$ \\
\hline 216 & 100 & 1210 & 1210 & $\mathrm{n} / \mathrm{a}$ \\
\hline 43 & 80 & 1180 & $\mathrm{n} / \mathrm{a}$ & 1180 \\
\hline 38 & 100 & 1220 & 1220 & $\mathrm{n} / \mathrm{a}$ \\
\hline 176 & 100 & 1175 & 1175 & $\mathrm{n} / \mathrm{a}$ \\
\hline 226 & 100 & 1195 & 1195 & $\mathrm{n} / \mathrm{a}$ \\
\hline \multicolumn{5}{|l|}{154} \\
\hline 265 & 100 & 1200 & 1200 & $\mathrm{n} / \mathrm{a}$ \\
\hline 79 & 100 & 1095 & 1095 & $\mathrm{n} / \mathrm{a}$ \\
\hline 99 & 100 & 1180 & 1180 & $\mathrm{n} / \mathrm{a}$ \\
\hline 107 & 85 & 1200 & 1200 & $\mathrm{n} / \mathrm{a}$ \\
\hline \multicolumn{5}{|l|}{270} \\
\hline 102 & 100 & 1160 & 1160 & $\mathrm{n} / \mathrm{a}$ \\
\hline \multicolumn{5}{|l|}{260} \\
\hline 267 & 96 & 1210 & 1210 & $\mathrm{n} / \mathrm{a}$ \\
\hline 97 & 45 & 1265 & $\mathrm{n} / \mathrm{a}$ & 1265 \\
\hline \multicolumn{5}{|l|}{92} \\
\hline 106 & 100 & 1155 & 1155 & $\mathrm{n} / \mathrm{a}$ \\
\hline 93 & 100 & 1175 & 1175 & $\mathrm{n} / \mathrm{a}$ \\
\hline \multicolumn{5}{|l|}{171} \\
\hline 175 & 100 & 1190 & 1190 & $\mathrm{n} / \mathrm{a}$ \\
\hline 274 & 100 & 1240 & 1240 & $\mathrm{n} / \mathrm{a}$ \\
\hline 102A & 99 & 1200 & 1200 & $\mathrm{n} / \mathrm{a}$ \\
\hline \multicolumn{5}{|l|}{273} \\
\hline 256 & 88 & 1190 & 1190 & $\mathrm{n} / \mathrm{a}$ \\
\hline 169 & 65 & 1225 & $\mathrm{n} / \mathrm{a}$ & 1225 \\
\hline \multicolumn{5}{|l|}{91} \\
\hline 90 & 100 & 1125 & 1125 & $\mathrm{n} / \mathrm{a}$ \\
\hline 152 & 100 & 1195 & 1195 & $\mathrm{n} / \mathrm{a}$ \\
\hline \multicolumn{5}{|l|}{39} \\
\hline 165 & (64) & 1010 & $\mathrm{n} / \mathrm{a}$ & 1010 \\
\hline 101 & 98 & 1130 & 1130 & $\mathrm{n} / \mathrm{a}$ \\
\hline 83 & 100 & 1040 & 1040 & $\mathrm{n} / \mathrm{a}$ \\
\hline $\mathrm{n}$ & & 52 & & \\
\hline Median Value & & 1185 & & \\
\hline (A) \# of Undermined Spr & Median Value $w />/=50 \%$ Discharge Reduction & & 20 & \\
\hline (B) \# of Undermined Spr & Median Value $\mathrm{w} /<50 \%$ Discharge Reduction & & & 8 \\
\hline (C) \# of Undermined Spr & edian Value $\mathrm{w} />/=50 \%$ Discharge Reduction & & 22 & \\
\hline (D) \# of Undermined Spr & edian Value w $/<50 \%$ Discharge Reduction & & & 2 \\
\hline Absolute Value (AD-BC) & & 136 & & \\
\hline Chi Square Value at $1 \mathrm{D}$ & Freedom & 2.22931 & & \\
\hline Error Probability as Deriv & Chi Square Contingency Test & $0.20-0.10$ & & \\
\hline Error Probability as Deriv & Fisher Exact Probability Test & 0.06553 & & \\
\hline
\end{tabular}




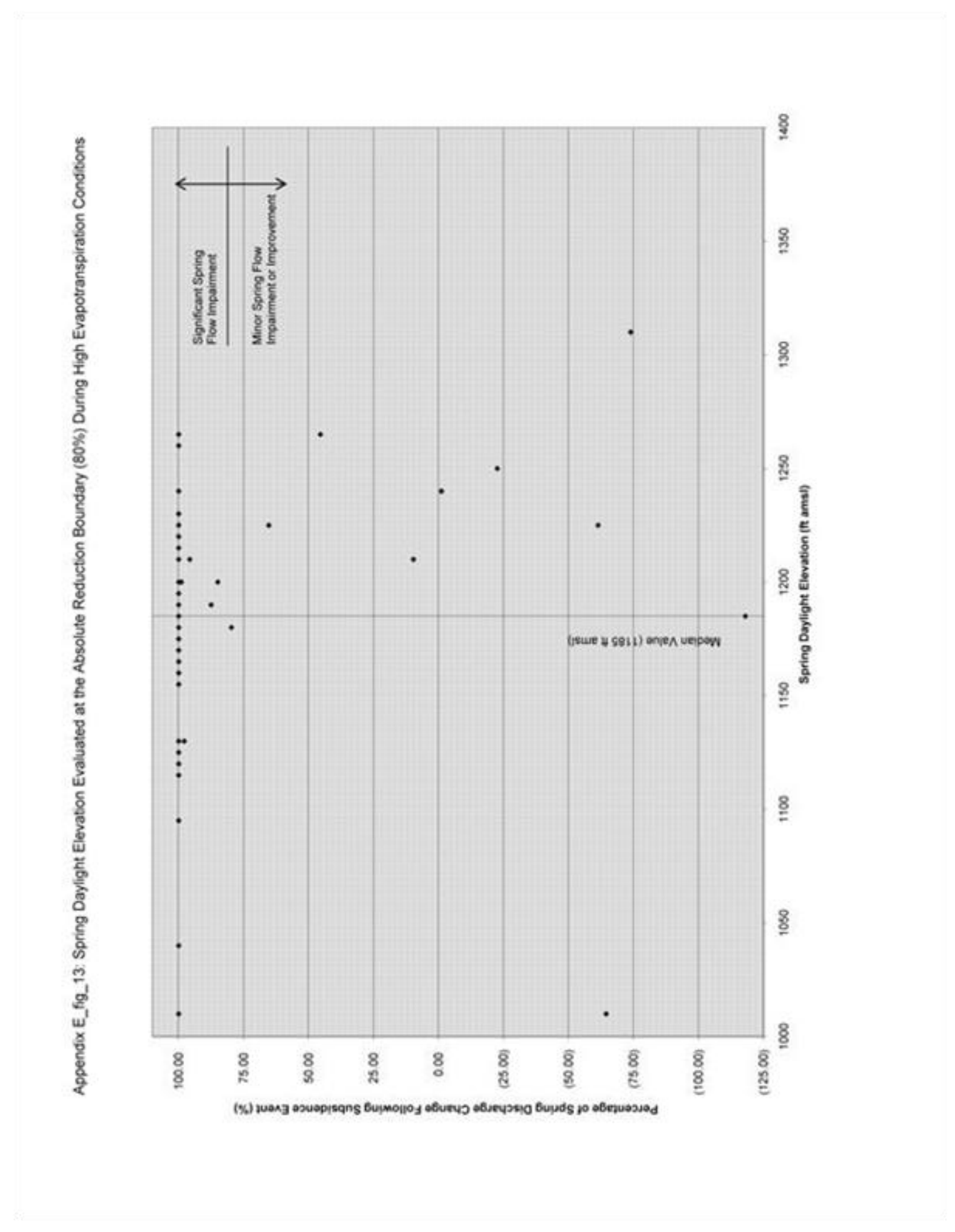


Appendix E_tab_14: Data Used to Determine the Statistical Significance of the Pre-Mine Averaged Low Flow Spring Discharge Data Trend at the Absolute Discharge Reduction Boundary During High Evapotranspiration Conditions.

\begin{tabular}{|c|c|c|c|c|}
\hline \multirow[t]{2}{*}{ Spring No. } & \multirow{2}{*}{$\begin{array}{c}\text { Absolute Discharge Reduction Boundary } \\
\text { High ET }(80 \%) \\
\end{array}$} & \multicolumn{3}{|c|}{ Pre-Mine Averaged Low Flow Spring Discharge (gpm) } \\
\hline & & All & $>1=80 \%$ & $<80 \%$ \\
\hline 33 & $(1)$ & 0.27 & $\mathrm{n} / \mathrm{a}$ & 0.27 \\
\hline 198 & $(23)$ & 0.50 & $\mathrm{n} / \mathrm{a}$ & 0.50 \\
\hline 155 & 100 & 0.26 & 0.26 & $\mathrm{n} / \mathrm{a}$ \\
\hline 166 & 100 & 0.32 & 0.32 & $\mathrm{n} / \mathrm{a}$ \\
\hline \multicolumn{5}{|l|}{167} \\
\hline \multicolumn{5}{|l|}{173} \\
\hline \multicolumn{5}{|l|}{174} \\
\hline \multicolumn{5}{|l|}{177} \\
\hline \multicolumn{5}{|l|}{199} \\
\hline \multicolumn{5}{|l|}{224} \\
\hline \multicolumn{5}{|l|}{249} \\
\hline \multicolumn{5}{|l|}{254} \\
\hline 259 & & & & \\
\hline 263 & & & & \\
\hline 272 & & & & \\
\hline 35 & & & & \\
\hline 36 & & & & \\
\hline 41 & & & & \\
\hline 63 & & & & \\
\hline 64 & & & & \\
\hline 84 & & & & \\
\hline 94 & & & & \\
\hline 269 & (61) & 0.44 & $\mathrm{n} / \mathrm{a}$ & 0.44 \\
\hline 271 & (74) & 0.69 & $\mathrm{n} / \mathrm{a}$ & 0.69 \\
\hline 297 & 10 & 0.62 & $\mathrm{n} / \mathrm{a}$ & 0.62 \\
\hline 268 & (118) & 0.61 & $\mathrm{n} / \mathrm{a}$ & 0.61 \\
\hline $99 \mathrm{~A}$ & 100 & 0.35 & 0.35 & $\mathrm{n} / \mathrm{a}$ \\
\hline 258 & 100 & 0.38 & 0.38 & $\mathrm{n} / \mathrm{a}$ \\
\hline 216 & 100 & 0.10 & 0.10 & $\mathrm{n} / \mathrm{a}$ \\
\hline 43 & 80 & 0.13 & $\mathrm{n} / \mathrm{a}$ & 0.13 \\
\hline 38 & 100 & 0.24 & 0.24 & $\mathrm{n} / \mathrm{a}$ \\
\hline 176 & 100 & 0.58 & 0.58 & $\mathrm{n} / \mathrm{a}$ \\
\hline 226 & 100 & 0.14 & 0.14 & $\mathrm{n} / \mathrm{a}$ \\
\hline 154 & & & & \\
\hline 265 & 100 & 0.37 & 0.37 & $\mathrm{n} / \mathrm{a}$ \\
\hline 79 & 100 & 0.05 & 0.05 & $\mathrm{n} / \mathrm{a}$ \\
\hline 99 & 100 & 0.05 & 0.05 & $\mathrm{n} / \mathrm{a}$ \\
\hline 107 & 85 & 0.73 & 0.73 & $\mathrm{n} / \mathrm{a}$ \\
\hline 270 & & & & \\
\hline 102 & 100 & 1.56 & 1.56 & $\mathrm{n} / \mathrm{a}$ \\
\hline 260 & & & & \\
\hline 267 & 96 & 0.29 & 0.29 & $\mathrm{n} / \mathrm{a}$ \\
\hline 97 & 45 & 0.44 & $\mathrm{n} / \mathrm{a}$ & 0.44 \\
\hline 92 & & & & \\
\hline 106 & 100 & 0.28 & 0.28 & $\mathrm{n} / \mathrm{a}$ \\
\hline 93 & 100 & 0.30 & 0.30 & $\mathrm{n} / \mathrm{a}$ \\
\hline 171 & & & & \\
\hline 175 & 100 & 0.13 & 0.13 & $\mathrm{n} / \mathrm{a}$ \\
\hline 274 & 100 & 0.09 & 0.09 & $\mathrm{n} / \mathrm{a}$ \\
\hline $102 \mathrm{~A}$ & 99 & 0.94 & 0.94 & $\mathrm{n} / \mathrm{a}$ \\
\hline 273 & & & & \\
\hline 256 & 88 & 0.32 & 0.32 & $\mathrm{n} / \mathrm{a}$ \\
\hline 169 & 65 & 0.64 & $\mathrm{n} / \mathrm{a}$ & 0.64 \\
\hline 91 & & & & \\
\hline 90 & 100 & 1.36 & 1.36 & $\mathrm{n} / \mathrm{a}$ \\
\hline 152 & 100 & 0.09 & 0.09 & $\mathrm{n} / \mathrm{a}$ \\
\hline 39 & & & & \\
\hline 165 & $(64)$ & 0.45 & $\mathrm{n} / \mathrm{a}$ & 0.45 \\
\hline 101 & 98 & 0.46 & 0.46 & $\mathrm{n} / \mathrm{a}$ \\
\hline 83 & 100 & 0.15 & 0.15 & $\mathrm{n} / \mathrm{a}$ \\
\hline$n$ & & 34 & & \\
\hline Median Value & & 0.34 & & \\
\hline (A) \# of Undermined Spri & Median Value $w />/=50 \%$ Discharge Reduction & & 9 & \\
\hline (B) \# of Undermined Spri & Median Value w $/<50 \%$ Discharge Reduction & & & 8 \\
\hline (C) \# of Undermined Spri & edian Value $\mathrm{w} />/=50 \%$ Discharge Reduction & & 15 & \\
\hline (D) \# of Undermined Spri & dian Value $w /<50 \%$ Discharge Reduction & & & 2 \\
\hline Absolute Value (AD-BC) & & 102 & & \\
\hline Chi Square Value at $1 \mathrm{De}$ & Freedom & 3.54167 & & \\
\hline Error Probability as Deriv & Chi Square Contingency Test & $0.10-0.05$ & & \\
\hline Error Probability as Deriv & Fisher Exact Probability Test & 0.02851 & & \\
\hline
\end{tabular}




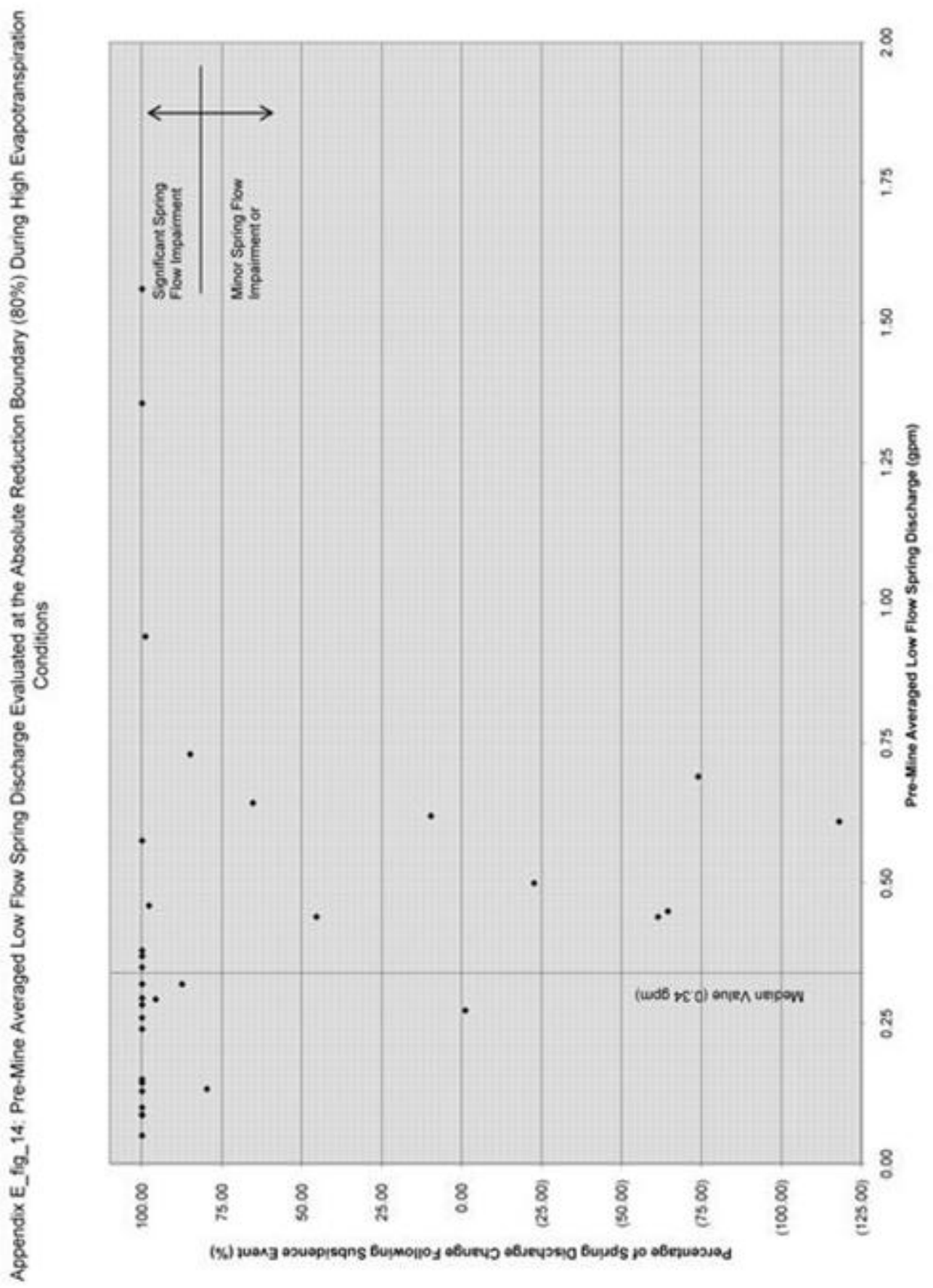


APPENDIX F: Figures Illustrating the Statistically Significant Variables Identified from the Degree of Spring Discharge Impairment to Mining-Induced Subsidence Analysis through the Use of the Calculated Median Values as Discussed in Results of Investigation III 
Appendix F_tab_1: Data Used to Determine the Statistical Significance of the Spring Vertical Relief to Nearest Surface Drainage Feature Data Trend at the Optimum Discharge Reduction Boundary During Low Evapotranspiration Conditions.

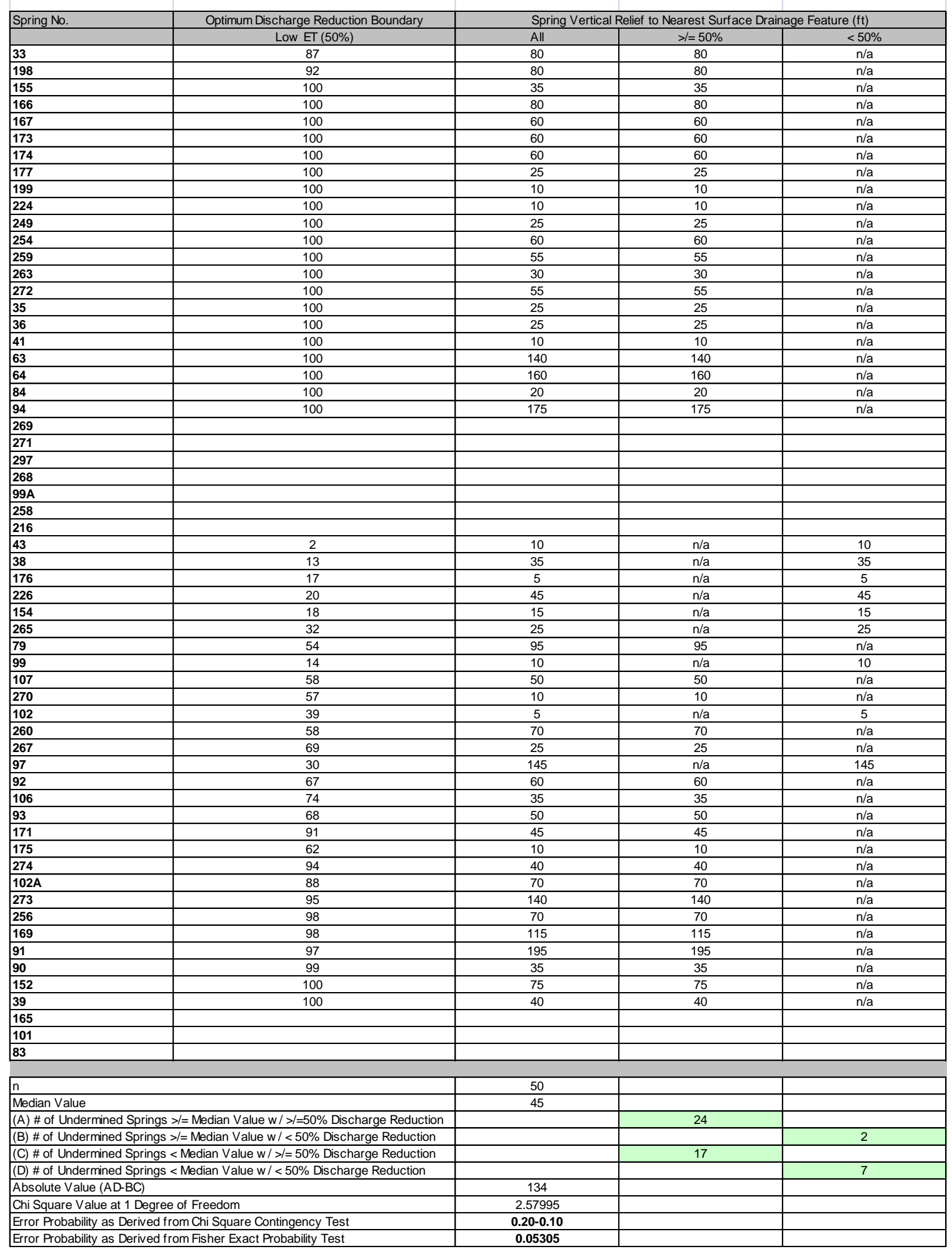




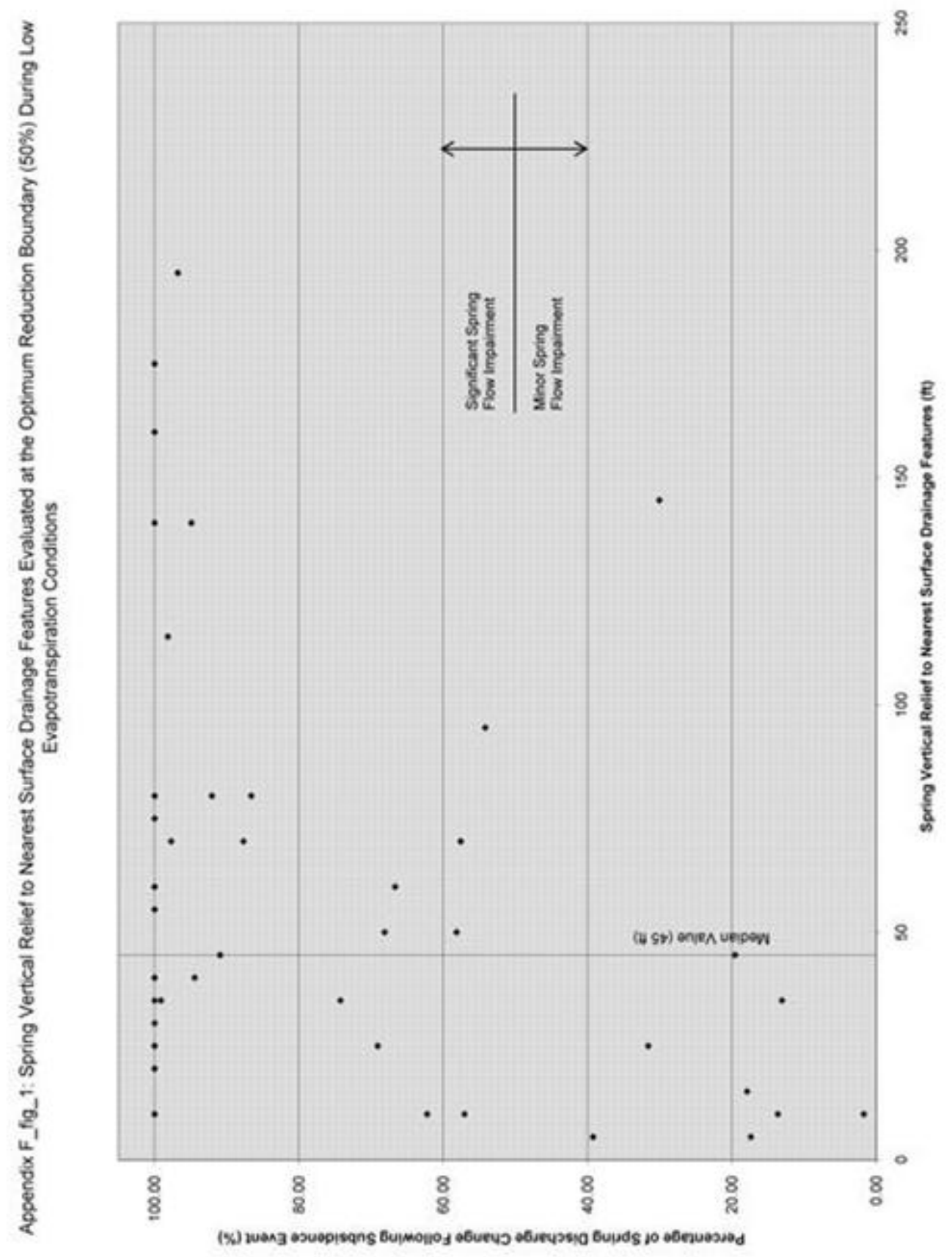


Appendix F_tab_2: Data Used to Determine the Statistical Significance of the Spring Vertical Relief to Headw ater, First and Second Order, Surface Drainage Feature Data Trend at the Optimum Discharge Reduction Boundary During Low Evapotranspiration Conditions.

\begin{tabular}{|c|c|c|c|c|}
\hline Spring No. & Optimum Discharge Reduction Boundary & Spring V & adw ater $\mathrm{S}$ & ure $(\mathrm{ft})$ \\
\hline & Low ET $(50 \%)$ & All & $>/=50 \%$ & $<50 \%$ \\
\hline 33 & 87 & 80 & 80 & $\mathrm{n} / \mathrm{a}$ \\
\hline 198 & 92 & 80 & 80 & $\mathrm{n} / \mathrm{a}$ \\
\hline 155 & 100 & 35 & 35 & $\mathrm{n} / \mathrm{a}$ \\
\hline 166 & 100 & 80 & 80 & $\mathrm{n} / \mathrm{a}$ \\
\hline 167 & 100 & 60 & 60 & $\mathrm{n} / \mathrm{a}$ \\
\hline 173 & 100 & 60 & 60 & $\mathrm{n} / \mathrm{a}$ \\
\hline 174 & 100 & 60 & 60 & $\mathrm{n} / \mathrm{a}$ \\
\hline 177 & 100 & 25 & 25 & $\mathrm{n} / \mathrm{a}$ \\
\hline 199 & & & & \\
\hline 224 & 100 & 10 & 10 & $\mathrm{n} / \mathrm{a}$ \\
\hline 249 & 100 & 25 & 25 & $\mathrm{n} / \mathrm{a}$ \\
\hline 254 & 100 & 60 & 60 & $\mathrm{n} / \mathrm{a}$ \\
\hline 259 & 100 & 55 & 55 & $\mathrm{n} / \mathrm{a}$ \\
\hline 263 & 100 & 30 & 30 & $\mathrm{n} / \mathrm{a}$ \\
\hline 272 & 100 & 55 & 55 & $\mathrm{n} / \mathrm{a}$ \\
\hline 35 & 100 & 25 & 25 & $\mathrm{n} / \mathrm{a}$ \\
\hline 36 & 100 & 25 & 25 & $\mathrm{n} / \mathrm{a}$ \\
\hline 41 & 100 & 10 & 10 & $\mathrm{n} / \mathrm{a}$ \\
\hline 63 & 100 & 140 & 140 & $\mathrm{n} / \mathrm{a}$ \\
\hline 64 & 100 & 160 & 160 & $\mathrm{n} / \mathrm{a}$ \\
\hline 84 & & & & \\
\hline 94 & & & & \\
\hline 269 & & & & \\
\hline 271 & & & & \\
\hline 297 & & & & \\
\hline 268 & & & & \\
\hline 99A & & & & \\
\hline 258 & & & & \\
\hline 216 & & & & \\
\hline 43 & 2 & 10 & $\mathrm{n} / \mathrm{a}$ & 10 \\
\hline 38 & 13 & 35 & $\mathrm{n} / \mathrm{a}$ & 35 \\
\hline 176 & 17 & 5 & $\mathrm{n} / \mathrm{a}$ & 5 \\
\hline 226 & 20 & 45 & $\mathrm{n} / \mathrm{a}$ & 45 \\
\hline 154 & 18 & 15 & $\mathrm{n} / \mathrm{a}$ & 15 \\
\hline 265 & 32 & 25 & $\mathrm{n} / \mathrm{a}$ & 25 \\
\hline 79 & & & & \\
\hline 99 & 14 & 10 & $\mathrm{n} / \mathrm{a}$ & 10 \\
\hline 107 & 58 & 50 & 50 & $\mathrm{n} / \mathrm{a}$ \\
\hline 270 & 57 & 10 & 10 & $\mathrm{n} / \mathrm{a}$ \\
\hline 102 & 39 & 5 & $\mathrm{n} / \mathrm{a}$ & 5 \\
\hline 260 & 58 & 70 & 70 & $\mathrm{n} / \mathrm{a}$ \\
\hline 267 & 69 & 25 & 25 & $\mathrm{n} / \mathrm{a}$ \\
\hline 97 & 30 & 145 & $\mathrm{n} / \mathrm{a}$ & 145 \\
\hline \begin{tabular}{|l|}
92 \\
\end{tabular} & 67 & 60 & 60 & $\mathrm{n} / \mathrm{a}$ \\
\hline 106 & 74 & 35 & 35 & $\mathrm{n} / \mathrm{a}$ \\
\hline 93 & 68 & 50 & 50 & $\mathrm{n} / \mathrm{a}$ \\
\hline 171 & 91 & 45 & 45 & $\mathrm{n} / \mathrm{a}$ \\
\hline 175 & 62 & 10 & 10 & $\mathrm{n} / \mathrm{a}$ \\
\hline 274 & 94 & 40 & 40 & $\mathrm{n} / \mathrm{a}$ \\
\hline $102 \mathrm{~A}$ & 88 & 70 & 70 & $\mathrm{n} / \mathrm{a}$ \\
\hline 273 & 95 & 140 & 140 & $\mathrm{n} / \mathrm{a}$ \\
\hline 256 & 98 & 70 & 70 & $\mathrm{n} / \mathrm{a}$ \\
\hline 169 & 98 & 115 & 115 & $\mathrm{n} / \mathrm{a}$ \\
\hline 91 & 97 & 195 & 195 & $\mathrm{n} / \mathrm{a}$ \\
\hline 90 & 99 & 35 & 35 & $\mathrm{n} / \mathrm{a}$ \\
\hline 152 & 100 & 75 & 75 & $\mathrm{n} / \mathrm{a}$ \\
\hline 39 & & & & \\
\hline 165 & & & & \\
\hline 101 & & & & \\
\hline 83 & & & & \\
\hline $\mathrm{n}$ & & 45 & & \\
\hline Median Value & & 45 & & \\
\hline (A) \# of Undermined Sprin & Median Value $w />/=50 \%$ Discharge Reduction & & 22 & \\
\hline (B) \# of Undermined Sprin & Median Value $\mathrm{w} /<50 \%$ Discharge Reduction & & & 2 \\
\hline (C) \# of Undermined Sprin & edian Value $\mathrm{w} />/=50 \%$ Discharge Reduction & & 14 & \\
\hline (D) \# of Undermined Sprin & edian Value $w /<50 \%$ Discharge Reduction & & & 7 \\
\hline Absolute Value (AD-BC) & & 126 & & \\
\hline Chi Square Value at 1 Deg & Freedom & 2.95201 & & \\
\hline Error Probability as Derive & Chi Square Contingency Test & $0.10-0.05$ & & \\
\hline Error Probability as Derive & Fisher Exact Probability Test & 0.04206 & & \\
\hline
\end{tabular}




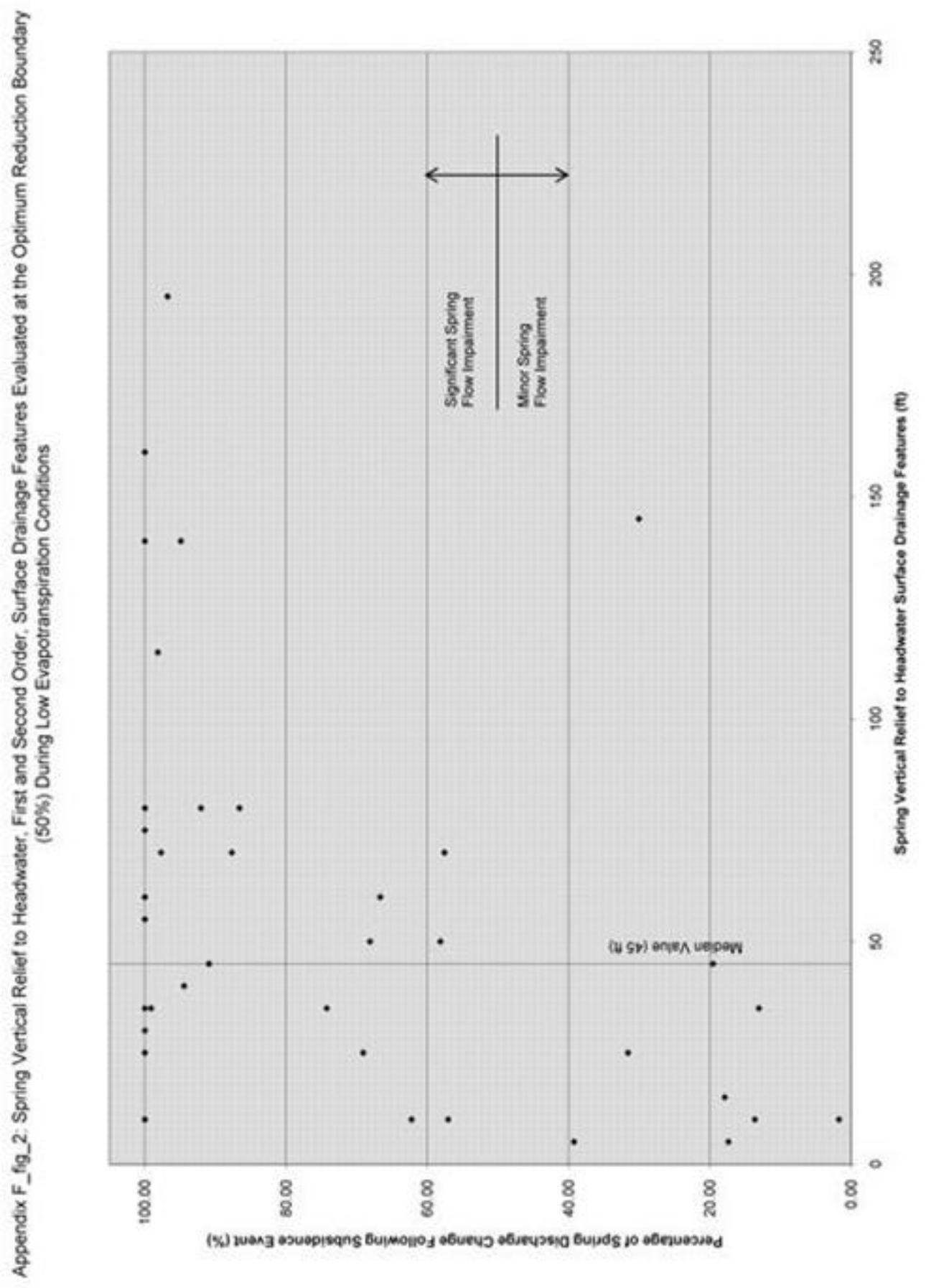


Appendix F_tab_3: Data Used to Determine the Statistical Significance of the Spring Recharge Line Length Component Perpendicular to Longw all Face Data Trend at the Absolute Discharge Reduction Boundary During High Evapotranspiration Conditions.

\begin{tabular}{|c|c|c|c|c|}
\hline Spring No. & Optimum Discharge Reduction Boundary & Spring Rechar & mponent $\mathrm{Pe}$ & $v$ all Face $(\mathrm{ft})$ \\
\hline & High ET (80\%) & All & $>1=80 \%$ & $<80 \%$ \\
\hline 33 & & & & \\
\hline 198 & & & & \\
\hline 155 & 100 & 15 & 15 & $\mathrm{n} / \mathrm{a}$ \\
\hline 166 & 100 & 30 & 30 & $\mathrm{n} / \mathrm{a}$ \\
\hline 167 & 100 & 160 & 160 & $\mathrm{n} / \mathrm{a}$ \\
\hline 173 & 100 & 140 & 140 & $\mathrm{n} / \mathrm{a}$ \\
\hline 174 & & & & \\
\hline 177 & 100 & 280 & 280 & $\mathrm{n} / \mathrm{a}$ \\
\hline 199 & 100 & 220 & 220 & $\mathrm{n} / \mathrm{a}$ \\
\hline 224 & 100 & 120 & 120 & $\mathrm{n} / \mathrm{a}$ \\
\hline 249 & 100 & 350 & 350 & $\mathrm{n} / \mathrm{a}$ \\
\hline 254 & 100 & 360 & 360 & $\mathrm{n} / \mathrm{a}$ \\
\hline 259 & 100 & 100 & 100 & $\mathrm{n} / \mathrm{a}$ \\
\hline 263 & 100 & 15 & 15 & $\mathrm{n} / \mathrm{a}$ \\
\hline 272 & 100 & 30 & 30 & $\mathrm{n} / \mathrm{a}$ \\
\hline 35 & 100 & 70 & 70 & $\mathrm{n} / \mathrm{a}$ \\
\hline 36 & 100 & 50 & 50 & $\mathrm{n} / \mathrm{a}$ \\
\hline 41 & 100 & 40 & 40 & $\mathrm{n} / \mathrm{a}$ \\
\hline 63 & 100 & 370 & 370 & $\mathrm{n} / \mathrm{a}$ \\
\hline 64 & 100 & 300 & 300 & $\mathrm{n} / \mathrm{a}$ \\
\hline 84 & 100 & 220 & 220 & $\mathrm{n} / \mathrm{a}$ \\
\hline 94 & 100 & 50 & 50 & $\mathrm{n} / \mathrm{a}$ \\
\hline 269 & & & & \\
\hline 271 & & & & \\
\hline 297 & 10 & 65 & $\mathrm{n} / \mathrm{a}$ & 65 \\
\hline 268 & & & & \\
\hline 99A & 100 & 75 & 75 & $\mathrm{n} / \mathrm{a}$ \\
\hline 258 & 100 & 225 & 225 & $\mathrm{n} / \mathrm{a}$ \\
\hline 216 & 100 & 40 & 40 & $\mathrm{n} / \mathrm{a}$ \\
\hline 43 & 80 & 20 & $\mathrm{n} / \mathrm{a}$ & 20 \\
\hline 38 & 100 & 20 & 20 & $\mathrm{n} / \mathrm{a}$ \\
\hline 176 & 100 & 340 & 340 & $\mathrm{n} / \mathrm{a}$ \\
\hline 226 & 100 & 260 & 260 & $\mathrm{n} / \mathrm{a}$ \\
\hline 154 & & & & \\
\hline 265 & 100 & 140 & 140 & $\mathrm{n} / \mathrm{a}$ \\
\hline 79 & 100 & 110 & 110 & $\mathrm{n} / \mathrm{a}$ \\
\hline 99 & 100 & 15 & 15 & $\mathrm{n} / \mathrm{a}$ \\
\hline 107 & & & & \\
\hline 270 & & & & \\
\hline 102 & 100 & 280 & 280 & $\mathrm{n} / \mathrm{a}$ \\
\hline 260 & & & & \\
\hline 267 & 96 & 250 & 250 & $\mathrm{n} / \mathrm{a}$ \\
\hline 97 & 45 & 100 & $\mathrm{n} / \mathrm{a}$ & 100 \\
\hline 92 & & & & \\
\hline 106 & 100 & 220 & 220 & $\mathrm{n} / \mathrm{a}$ \\
\hline 93 & 100 & 220 & 220 & $\mathrm{n} / \mathrm{a}$ \\
\hline 171 & & & & \\
\hline 175 & 100 & 30 & 30 & $\mathrm{n} / \mathrm{a}$ \\
\hline 274 & 100 & 440 & 440 & $\mathrm{n} / \mathrm{a}$ \\
\hline 102A & 99 & 180 & 180 & $\mathrm{n} / \mathrm{a}$ \\
\hline 273 & & & & \\
\hline 256 & 88 & 200 & 200 & $\mathrm{n} / \mathrm{a}$ \\
\hline 169 & 65 & 90 & $\mathrm{n} / \mathrm{a}$ & 90 \\
\hline 91 & & & & \\
\hline 90 & 100 & 50 & 50 & $\mathrm{n} / \mathrm{a}$ \\
\hline 152 & 100 & 80 & 80 & $\mathrm{n} / \mathrm{a}$ \\
\hline 39 & & & & \\
\hline 165 & & & & \\
\hline \begin{tabular}{|l|}
101 \\
\end{tabular} & 98 & 370 & 370 & $\mathrm{n} / \mathrm{a}$ \\
\hline 83 & 100 & 50 & 50 & $\mathrm{n} / \mathrm{a}$ \\
\hline $\mathrm{n}$ & & 44 & & \\
\hline Median Value & & 115 & & \\
\hline (A) \# of Undermined Spr & Median Value $w />/=50 \%$ Discharge Reduction & & 22 & \\
\hline (B) \# of Undermined Spr & Median Value $\mathrm{w} /<50 \%$ Discharge Reduction & & & 0 \\
\hline (C) \# of Undermined Spr & edian Value $\mathrm{w} />/=50 \%$ Discharge Reduction & & 18 & \\
\hline (D) \# of Undermined Spr & edian Value $w /<50 \%$ Discharge Reduction & & & 4 \\
\hline Absolute Value (AD-BC) & & 88 & & \\
\hline Chi Square Value at $1 \mathrm{De}$ & Freedom & 2.47500 & & \\
\hline Error Probability as Deriv & Chi Square Contingency Test & $0.20-0.10$ & & \\
\hline Error Probability as Deriv & Fisher Exact Probability Test & 0.05389 & & \\
\hline
\end{tabular}




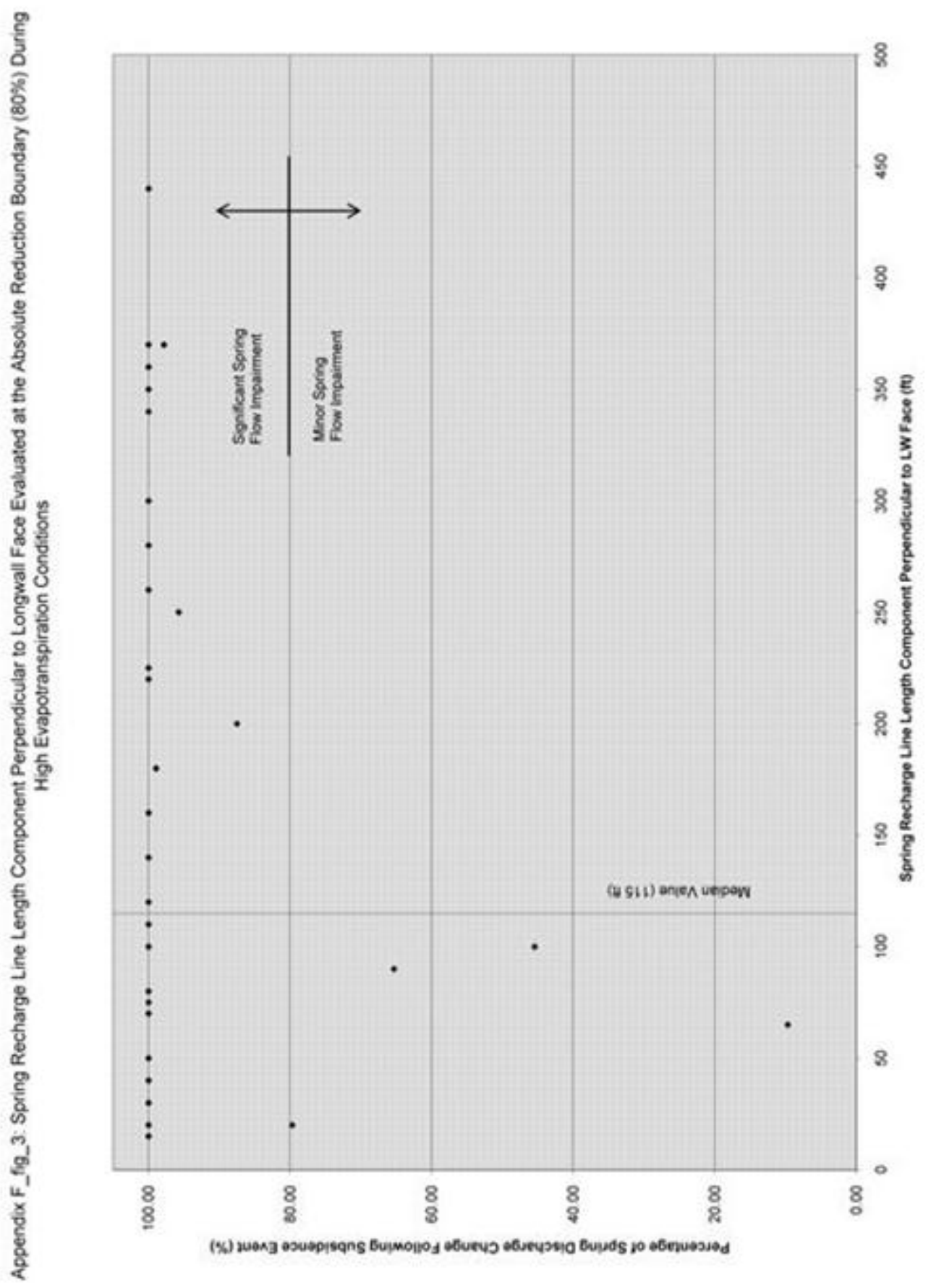


APPENDIX G: Figures Illustrating the Statistically Significant Variables Identified from the Spring Discharge Response to Mining-Induced Subsidence Analysis through the Use of the Interpreted Best Fit Values as Discussed in Results of Investigation IV 
Appendix G_tab_1: Data Used to Determine the Statistical Significance of the Spring Vertical Relief to Nearest Surface Drainage Feature Data Trend at the Optimum Discharge Reduction Boundary During Low Evapotranspiration Conditions.

\begin{tabular}{|c|c|c|c|c|}
\hline \multirow[t]{2}{*}{ Spring No. } & \multirow{2}{*}{$\begin{array}{c}\text { Optimum Discharge Reduction Boundary } \\
\text { Low ET }(50 \%)\end{array}$} & \multicolumn{3}{|c|}{ Spring Vertical Relief to Nearest Surface Drainage Feature (ft) } \\
\hline & & All & $>1=50 \%$ & $<50 \%$ \\
\hline 33 & 87 & 80 & 80 & $\mathrm{n} / \mathrm{a}$ \\
\hline 198 & 92 & 80 & 80 & $\mathrm{n} / \mathrm{a}$ \\
\hline 155 & 100 & 35 & 35 & $\mathrm{n} / \mathrm{a}$ \\
\hline 166 & 100 & 80 & 80 & $\mathrm{n} / \mathrm{a}$ \\
\hline 167 & 100 & 60 & 60 & $\mathrm{n} / \mathrm{a}$ \\
\hline 173 & 100 & 60 & 60 & $\mathrm{n} / \mathrm{a}$ \\
\hline 174 & 100 & 60 & 60 & $\mathrm{n} / \mathrm{a}$ \\
\hline 177 & 100 & 25 & 25 & $\mathrm{n} / \mathrm{a}$ \\
\hline 199 & 100 & 10 & 10 & $\mathrm{n} / \mathrm{a}$ \\
\hline 224 & 100 & 10 & 10 & $\mathrm{n} / \mathrm{a}$ \\
\hline 249 & 100 & 25 & 25 & $\mathrm{n} / \mathrm{a}$ \\
\hline 254 & 100 & 60 & 60 & $n / a$ \\
\hline 259 & 100 & 55 & 55 & $\mathrm{n} / \mathrm{a}$ \\
\hline 263 & 100 & 30 & 30 & $\mathrm{n} / \mathrm{a}$ \\
\hline 272 & 100 & 55 & 55 & $\mathrm{n} / \mathrm{a}$ \\
\hline 35 & 100 & 25 & 25 & $\mathrm{n} / \mathrm{a}$ \\
\hline 36 & 100 & 25 & 25 & $\mathrm{n} / \mathrm{a}$ \\
\hline 41 & 100 & 10 & 10 & $\mathrm{n} / \mathrm{a}$ \\
\hline 63 & 100 & 140 & 140 & $\mathrm{n} / \mathrm{a}$ \\
\hline 64 & 100 & 160 & 160 & $\mathrm{n} / \mathrm{a}$ \\
\hline 84 & 100 & 20 & 20 & $\mathrm{n} / \mathrm{a}$ \\
\hline 94 & 100 & 175 & 175 & $\mathrm{n} / \mathrm{a}$ \\
\hline 269 & (126) & 25 & $\mathrm{n} / \mathrm{a}$ & 25 \\
\hline 271 & (133) & 160 & $\mathrm{n} / \mathrm{a}$ & 160 \\
\hline 297 & (6) & 90 & $\mathrm{n} / \mathrm{a}$ & 90 \\
\hline 268 & (31) & 35 & $\mathrm{n} / \mathrm{a}$ & 35 \\
\hline 99A & $(600)$ & 15 & $\mathrm{n} / \mathrm{a}$ & 15 \\
\hline 258 & (149) & 30 & $\mathrm{n} / \mathrm{a}$ & 30 \\
\hline 216 & (338) & 50 & $\mathrm{n} / \mathrm{a}$ & 50 \\
\hline 43 & 2 & 10 & $\mathrm{n} / \mathrm{a}$ & 10 \\
\hline 38 & 13 & 35 & $\mathrm{n} / \mathrm{a}$ & 35 \\
\hline 176 & 17 & 5 & $\mathrm{n} / \mathrm{a}$ & 5 \\
\hline 226 & 20 & 45 & $n / a$ & 45 \\
\hline 154 & 18 & 15 & $n / a$ & 15 \\
\hline 265 & 32 & 25 & $n / a$ & 25 \\
\hline 79 & 54 & 95 & 95 & $\mathrm{n} / \mathrm{a}$ \\
\hline 99 & 14 & 10 & $\mathrm{n} / \mathrm{a}$ & 10 \\
\hline 107 & 58 & 50 & 50 & $\mathrm{n} / \mathrm{a}$ \\
\hline 270 & 57 & 10 & 10 & $\mathrm{n} / \mathrm{a}$ \\
\hline 102 & 39 & 5 & $\mathrm{n} / \mathrm{a}$ & 5 \\
\hline 260 & 58 & 70 & 70 & $\mathrm{n} / \mathrm{a}$ \\
\hline 267 & 69 & 25 & 25 & $\mathrm{n} / \mathrm{a}$ \\
\hline 97 & 30 & 145 & $\mathrm{n} / \mathrm{a}$ & 145 \\
\hline 92 & 67 & 60 & 60 & $\mathrm{n} / \mathrm{a}$ \\
\hline 106 & 74 & 35 & 35 & $\mathrm{n} / \mathrm{a}$ \\
\hline 93 & 68 & 50 & 50 & $\mathrm{n} / \mathrm{a}$ \\
\hline 171 & 91 & 45 & 45 & $\mathrm{n} / \mathrm{a}$ \\
\hline 175 & 62 & 10 & 10 & $n / a$ \\
\hline 274 & 94 & 40 & 40 & $n / a$ \\
\hline 102A & 88 & 70 & 70 & $\mathrm{n} / \mathrm{a}$ \\
\hline 273 & 95 & 140 & 140 & $\mathrm{n} / \mathrm{a}$ \\
\hline 256 & 98 & 70 & 70 & $\mathrm{n} / \mathrm{a}$ \\
\hline 169 & 98 & 115 & 115 & $\mathrm{n} / \mathrm{a}$ \\
\hline 91 & 97 & 195 & 195 & $\mathrm{n} / \mathrm{a}$ \\
\hline 90 & 99 & 35 & 35 & $\mathrm{n} / \mathrm{a}$ \\
\hline 152 & 100 & 75 & 75 & $n / a$ \\
\hline 39 & 100 & 40 & 40 & $\mathrm{n} / \mathrm{a}$ \\
\hline \multicolumn{5}{|l|}{165} \\
\hline \multicolumn{5}{|l|}{101} \\
\hline \multicolumn{5}{|l|}{83} \\
\hline \multicolumn{2}{|l|}{$\mathrm{n}$} & 57 & & \\
\hline \multicolumn{2}{|l|}{ Median Value } & 45 & & \\
\hline \multicolumn{2}{|c|}{ Interpreted Best Fit Value } & 36 & & \\
\hline \multicolumn{2}{|c|}{ (A) \# of Undermined Springs $>/=$ Best Fit Value $w />/=50 \%$ Discharge Reduction } & & 26 & \\
\hline (B) \# of Undermined Spring & est Fit Value $\mathrm{w} /<50 \%$ Discharge Reduction & & & 5 \\
\hline (C) \# of Undermined Spring & st Fit Value w/ $>/=50 \%$ Discharge Reduction & & 15 & \\
\hline (D) \# of Undermined Spring & st Fit Value $w /<50 \%$ Discharge Reduction & & & 11 \\
\hline Absolute Value (AD-BC) & & 211 & & \\
\hline Chi Square Value at 1 Degr & reedom & 3.59056 & & \\
\hline Error Probability as Derived & Chi Square Contingency Test & $0.10-0.05$ & & \\
\hline Error Probability as Derived & isher Exact Probability Test & 0.02881 & & \\
\hline
\end{tabular}




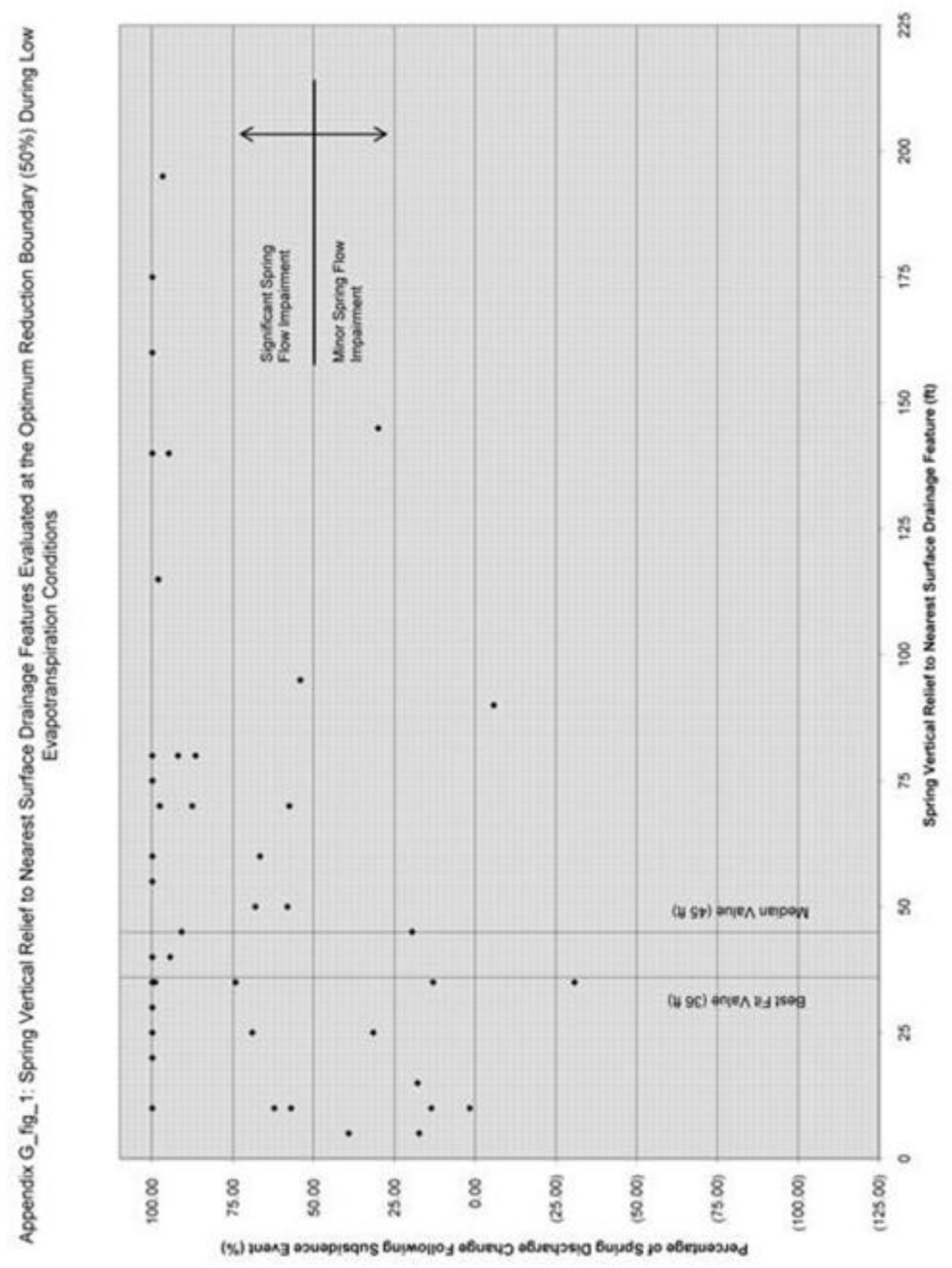


Appendix G_tab_2: Data Used to Determine the Statistical Significance of the Spring Vertical Relief to Headw ater, First and Second Order, Surface Drainage Feature Data Trend at the Optimum Discharge Reduction Boundary During Low Evapotranspiration Conditions.

\begin{tabular}{|c|c|c|c|c|}
\hline \multirow[t]{2}{*}{ Spring No. } & \multirow{2}{*}{$\begin{array}{c}\text { Optimum Discharge Reduction Boundary } \\
\text { Low ET }(50 \%)\end{array}$} & \multicolumn{3}{|c|}{ Spring Vertical Relief to Headw ater Surface Drainage Features (ft) } \\
\hline & & All & $>/=50 \%$ & $<50 \%$ \\
\hline 33 & 87 & 80 & 80 & $\mathrm{n} / \mathrm{a}$ \\
\hline 198 & 92 & 80 & 80 & $\mathrm{n} / \mathrm{a}$ \\
\hline 155 & 100 & 35 & 35 & $\mathrm{n} / \mathrm{a}$ \\
\hline 166 & 100 & 80 & 80 & $\mathrm{n} / \mathrm{a}$ \\
\hline 167 & 100 & 60 & 60 & $\mathrm{n} / \mathrm{a}$ \\
\hline 173 & 100 & 60 & 60 & $\mathrm{n} / \mathrm{a}$ \\
\hline 174 & 100 & 60 & 60 & $\mathrm{n} / \mathrm{a}$ \\
\hline 177 & 100 & 25 & 25 & $\mathrm{n} / \mathrm{a}$ \\
\hline \multicolumn{5}{|l|}{199} \\
\hline 224 & 100 & 10 & 10 & $\mathrm{n} / \mathrm{a}$ \\
\hline 249 & 100 & 25 & 25 & $\mathrm{n} / \mathrm{a}$ \\
\hline 254 & 100 & 60 & 60 & $\mathrm{n} / \mathrm{a}$ \\
\hline 259 & 100 & 55 & 55 & $\mathrm{n} / \mathrm{a}$ \\
\hline 263 & 100 & 30 & 30 & $\mathrm{n} / \mathrm{a}$ \\
\hline 272 & 100 & 55 & 55 & $\mathrm{n} / \mathrm{a}$ \\
\hline 35 & 100 & 25 & 25 & $\mathrm{n} / \mathrm{a}$ \\
\hline 36 & 100 & 25 & 25 & $\mathrm{n} / \mathrm{a}$ \\
\hline 41 & 100 & 10 & 10 & $\mathrm{n} / \mathrm{a}$ \\
\hline 63 & 100 & 140 & 140 & $\mathrm{n} / \mathrm{a}$ \\
\hline 64 & 100 & 160 & 160 & $\mathrm{n} / \mathrm{a}$ \\
\hline \multicolumn{5}{|l|}{84} \\
\hline \multicolumn{5}{|l|}{94} \\
\hline 269 & (126) & 25 & $\mathrm{n} / \mathrm{a}$ & 25 \\
\hline 271 & (133) & 160 & $\mathrm{n} / \mathrm{a}$ & 160 \\
\hline 297 & (6) & 90 & $\mathrm{n} / \mathrm{a}$ & 90 \\
\hline 268 & (31) & 35 & $\mathrm{n} / \mathrm{a}$ & 35 \\
\hline 99A & $(600)$ & 15 & $\mathrm{n} / \mathrm{a}$ & 15 \\
\hline 258 & (149) & 30 & $\mathrm{n} / \mathrm{a}$ & 30 \\
\hline 216 & (338) & 50 & $\mathrm{n} / \mathrm{a}$ & 50 \\
\hline 43 & 2 & 10 & $\mathrm{n} / \mathrm{a}$ & 10 \\
\hline 38 & 13 & 35 & $\mathrm{n} / \mathrm{a}$ & 35 \\
\hline 176 & 17 & 5 & $\mathrm{n} / \mathrm{a}$ & 5 \\
\hline 226 & 20 & 45 & $\mathrm{n} / \mathrm{a}$ & 45 \\
\hline 154 & 18 & 15 & $\mathrm{n} / \mathrm{a}$ & 15 \\
\hline 265 & 32 & 25 & $\mathrm{n} / \mathrm{a}$ & 25 \\
\hline \multicolumn{5}{|l|}{79} \\
\hline 99 & 14 & 10 & $\mathrm{n} / \mathrm{a}$ & 10 \\
\hline 107 & 58 & 50 & 50 & $\mathrm{n} / \mathrm{a}$ \\
\hline 270 & 57 & 10 & 10 & $\mathrm{n} / \mathrm{a}$ \\
\hline \begin{tabular}{|l|}
102 \\
\end{tabular} & 39 & 5 & $\mathrm{n} / \mathrm{a}$ & 5 \\
\hline 260 & 58 & 70 & 70 & $\mathrm{n} / \mathrm{a}$ \\
\hline 267 & 69 & 25 & 25 & $\mathrm{n} / \mathrm{a}$ \\
\hline 97 & 30 & 145 & $\mathrm{n} / \mathrm{a}$ & 145 \\
\hline 92 & 67 & 60 & 60 & $\mathrm{n} / \mathrm{a}$ \\
\hline 106 & 74 & 35 & 35 & $\mathrm{n} / \mathrm{a}$ \\
\hline 93 & 68 & 50 & 50 & $\mathrm{n} / \mathrm{a}$ \\
\hline 171 & 91 & 45 & 45 & $\mathrm{n} / \mathrm{a}$ \\
\hline 175 & 62 & 10 & 10 & $\mathrm{n} / \mathrm{a}$ \\
\hline 274 & 94 & 40 & 40 & $\mathrm{n} / \mathrm{a}$ \\
\hline 102A & 88 & 70 & 70 & $\mathrm{n} / \mathrm{a}$ \\
\hline 273 & 95 & 140 & 140 & $\mathrm{n} / \mathrm{a}$ \\
\hline 256 & 98 & 70 & 70 & $\mathrm{n} / \mathrm{a}$ \\
\hline 169 & 98 & 115 & 115 & $\mathrm{n} / \mathrm{a}$ \\
\hline 91 & 97 & 195 & 195 & $\mathrm{n} / \mathrm{a}$ \\
\hline 90 & 99 & 35 & 35 & $\mathrm{n} / \mathrm{a}$ \\
\hline 152 & 100 & 75 & 75 & $\mathrm{n} / \mathrm{a}$ \\
\hline \multicolumn{5}{|l|}{39} \\
\hline \multicolumn{5}{|l|}{165} \\
\hline \multicolumn{5}{|l|}{101} \\
\hline 83 & & & & \\
\hline $\mathrm{n}$ & & 52 & & \\
\hline Median Value & & 45 & & \\
\hline Interpreted Best Fit Value & & 36 & & \\
\hline (A) \# of Undermined Spring & Best Fit Value $w />/=50 \%$ Discharge Reduction & & 23 & \\
\hline (B) \# of Undermined Spring & Best Fit Value w $/<50 \%$ Discharge Reduction & & & 5 \\
\hline (C) \# of Undermined Spring & est Fit Value $\mathrm{w} />/=50 \%$ Discharge Reduction & & 13 & \\
\hline (D) \# of Undermined Spring & est Fit Value w $/<50 \%$ Discharge Reduction & & & 11 \\
\hline Absolute Value (AD-BC) & & 188 & & \\
\hline Chi Square Value at 1 Degr & Freedom & 3.52567 & & \\
\hline Error Probability as Derived & Chi Square Contingency Test & $0.10-0.05$ & & \\
\hline \begin{tabular}{|l} 
Eror Probability as Derived \\
\end{tabular} & Fisher Exact Probability Test & 0.02988 & & \\
\hline
\end{tabular}




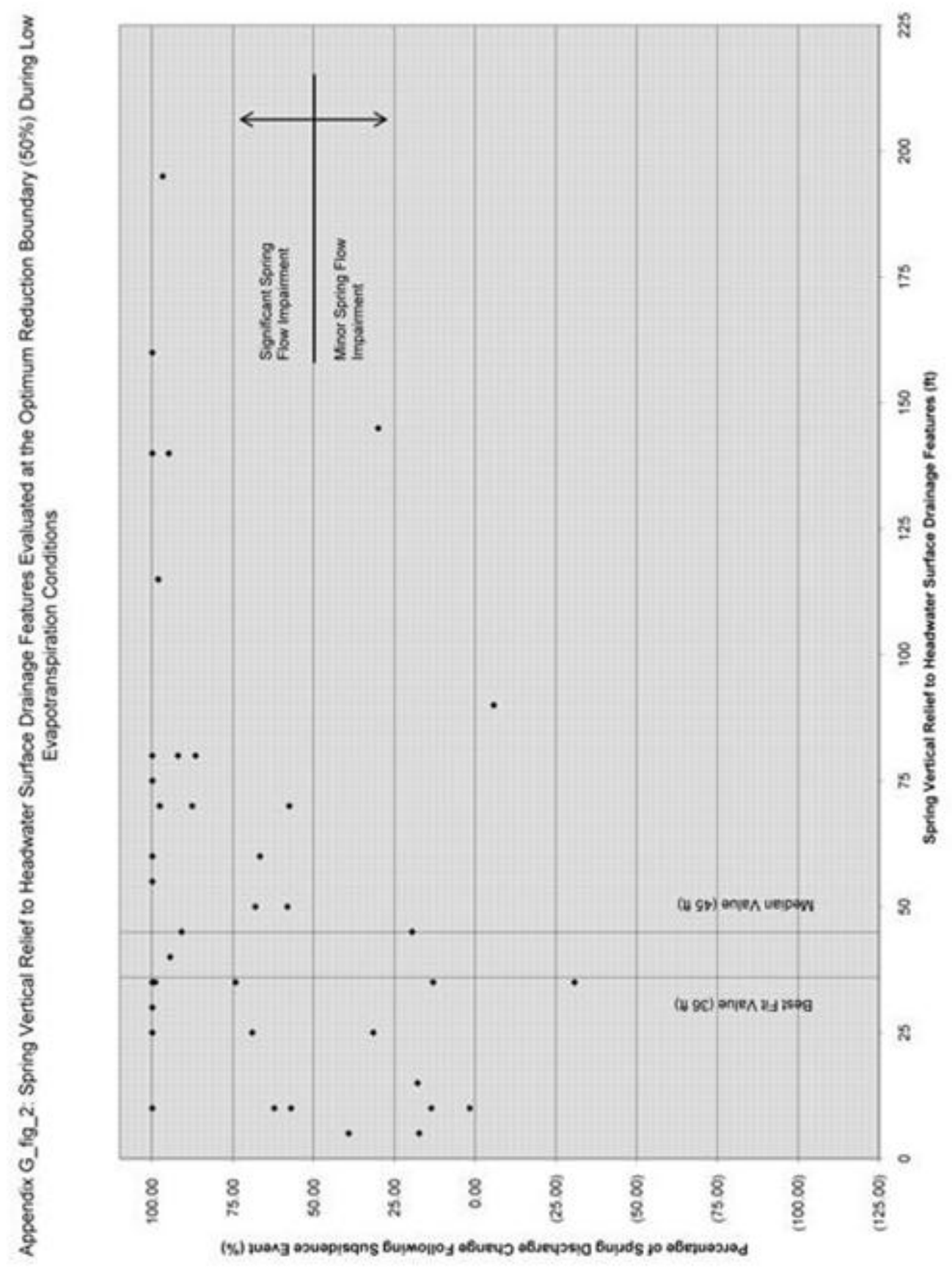


Appendix G_tab_3: Data Used to Determine the Statistical Significance of the Spring Vertical Relief to First Order Surface Drainage Feature Data Trend at the Optimum Discharge Reduction Boundary During Low Evapotranspiration Conditions.

\begin{tabular}{|c|c|c|c|c|}
\hline \multirow[t]{2}{*}{ Spring No. } & \multirow{2}{*}{$\begin{array}{c}\text { Optimum Discharge Reduction Boundary } \\
\text { Low ET }(50 \%)\end{array}$} & \multicolumn{3}{|c|}{ Spring Vertical Relief to First Order Surface Drainage Features ( $\mathrm{ft}$ ) } \\
\hline & & All & $>1=50 \%$ & $<50 \%$ \\
\hline \multicolumn{5}{|l|}{33} \\
\hline 198 & 92 & 80 & 80 & $\mathrm{n} / \mathrm{a}$ \\
\hline 155 & 100 & 35 & 35 & $n / a$ \\
\hline \multicolumn{5}{|l|}{166} \\
\hline 167 & 100 & 60 & 60 & $\mathrm{n} / \mathrm{a}$ \\
\hline 173 & 100 & 60 & 60 & $\mathrm{n} / \mathrm{a}$ \\
\hline 174 & 100 & 60 & 60 & $\mathrm{n} / \mathrm{a}$ \\
\hline \multicolumn{5}{|l|}{177} \\
\hline \multicolumn{5}{|l|}{199} \\
\hline 224 & 100 & 10 & 10 & $\mathrm{n} / \mathrm{a}$ \\
\hline 249 & 100 & 25 & 25 & $\mathrm{n} / \mathrm{a}$ \\
\hline 254 & 100 & 60 & 60 & $\mathrm{n} / \mathrm{a}$ \\
\hline \multicolumn{5}{|l|}{259} \\
\hline 263 & 100 & 30 & 30 & $\mathrm{n} / \mathrm{a}$ \\
\hline 272 & 100 & 55 & 55 & $\mathrm{n} / \mathrm{a}$ \\
\hline 35 & 100 & 25 & 25 & $\mathrm{n} / \mathrm{a}$ \\
\hline 36 & 100 & 25 & 25 & $\mathrm{n} / \mathrm{a}$ \\
\hline \multicolumn{5}{|l|}{41} \\
\hline \multicolumn{5}{|l|}{63} \\
\hline 64 & & & & \\
\hline 84 & & & & \\
\hline 94 & & & & \\
\hline 269 & (126) & 25 & $\mathrm{n} / \mathrm{a}$ & 25 \\
\hline 271 & (133) & 160 & $\mathrm{n} / \mathrm{a}$ & 160 \\
\hline 297 & & & & \\
\hline 268 & & & & \\
\hline $99 \mathrm{~A}$ & $(600)$ & 15 & $\mathrm{n} / \mathrm{a}$ & 15 \\
\hline 258 & (149) & 30 & $\mathrm{n} / \mathrm{a}$ & 30 \\
\hline 216 & (338) & 50 & $\mathrm{n} / \mathrm{a}$ & 50 \\
\hline 43 & 2 & 10 & $\mathrm{n} / \mathrm{a}$ & 10 \\
\hline 38 & 13 & 35 & $\mathrm{n} / \mathrm{a}$ & 35 \\
\hline 176 & 17 & 5 & $\mathrm{n} / \mathrm{a}$ & 5 \\
\hline 226 & 20 & 45 & $\mathrm{n} / \mathrm{a}$ & 45 \\
\hline 154 & 18 & 15 & $\mathrm{n} / \mathrm{a}$ & 15 \\
\hline 265 & & & & \\
\hline 79 & & & & \\
\hline 99 & 14 & 10 & $\mathrm{n} / \mathrm{a}$ & 10 \\
\hline 107 & 58 & 50 & 50 & $\mathrm{n} / \mathrm{a}$ \\
\hline 270 & 57 & 10 & 10 & $\mathrm{n} / \mathrm{a}$ \\
\hline 102 & 39 & 5 & $\mathrm{n} / \mathrm{a}$ & 5 \\
\hline 260 & & & & \\
\hline 267 & 69 & 25 & 25 & $\mathrm{n} / \mathrm{a}$ \\
\hline 97 & 30 & 145 & $\mathrm{n} / \mathrm{a}$ & 145 \\
\hline 92 & 67 & 60 & 60 & $\mathrm{n} / \mathrm{a}$ \\
\hline 106 & 74 & 35 & 35 & $\mathrm{n} / \mathrm{a}$ \\
\hline 93 & 68 & 50 & 50 & $\mathrm{n} / \mathrm{a}$ \\
\hline 171 & 91 & 45 & 45 & $\mathrm{n} / \mathrm{a}$ \\
\hline 175 & 62 & 10 & 10 & $\mathrm{n} / \mathrm{a}$ \\
\hline 274 & 94 & 40 & 40 & $\mathrm{n} / \mathrm{a}$ \\
\hline $102 \mathrm{~A}$ & 88 & 70 & 70 & $\mathrm{n} / \mathrm{a}$ \\
\hline 273 & 95 & 140 & 140 & $\mathrm{n} / \mathrm{a}$ \\
\hline 256 & 98 & 70 & 70 & $\mathrm{n} / \mathrm{a}$ \\
\hline 169 & 98 & 115 & 115 & $\mathrm{n} / \mathrm{a}$ \\
\hline 91 & 97 & 195 & 195 & $\mathrm{n} / \mathrm{a}$ \\
\hline 90 & 99 & 35 & 35 & $\mathrm{n} / \mathrm{a}$ \\
\hline 152 & 100 & 75 & 75 & $\mathrm{n} / \mathrm{a}$ \\
\hline 39 & & & & \\
\hline 165 & & & & \\
\hline 101 & & & & \\
\hline 83 & & & & \\
\hline $\mathrm{n}$ & & 41 & & \\
\hline Median Value & & 40 & & \\
\hline Interpreted Best Fit Value & & 36 & & \\
\hline (A) \# of Undermined Spring & Best Fit Value $\mathrm{w} />/=50 \%$ Discharge Reduction & & 17 & \\
\hline (B) \# of Undermined Spring & Best Fit Value w $/<50 \%$ Discharge Reduction & & & 4 \\
\hline (C) \# of Undermined Spring & st Fit Value $w />/=50 \%$ Discharge Reduction & & 11 & \\
\hline (D) \# of Undermined Spring & st Fit Value w/ <50\% Discharge Reduction & & & 9 \\
\hline Absolute Value (AD-BC) & & 109 & & \\
\hline Chi Square Value at 1 Degr & Freedom & 2.10049 & & \\
\hline Error Probability as Derived & Chi Square Contingency Test & $0.20-0.10$ & & \\
\hline Error Probability as Derived & Fisher Exact Probability Test & 0.07315 & & \\
\hline
\end{tabular}




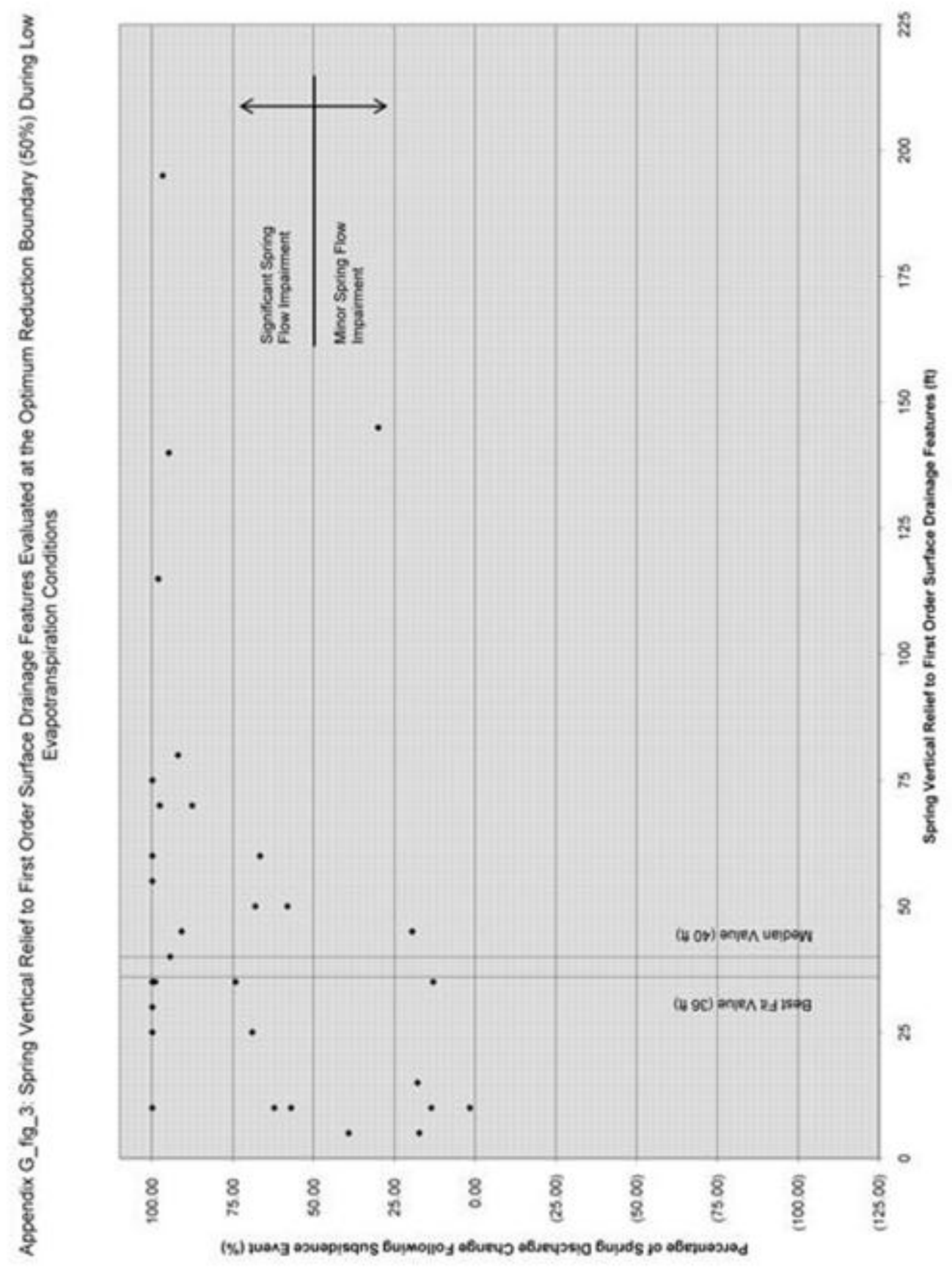


Appendix G_tab_4: Data Used to Determine the Statistical Significance of the Spring Vertical Relief to Headw ater, First and Second Order, Surface Drainage Feature Data Trend at the Absolute Discharge Reduction Boundary During Low Evapotranspiration Conditions.

\begin{tabular}{|c|c|c|c|c|}
\hline \multirow[t]{2}{*}{ Spring No. } & \multirow{2}{*}{$\begin{array}{c}\text { Absolute Discharge Reduction Boundary } \\
\text { Low ET }(88 \%)\end{array}$} & \multicolumn{3}{|c|}{ Spring Vertical Relief to Headw ater Surface Drainage Features (ft) } \\
\hline & & All & $>1=88 \%$ & $<88 \%$ \\
\hline 33 & 87 & 80 & $\mathrm{n} / \mathrm{a}$ & 80 \\
\hline 198 & 92 & 80 & 80 & $\mathrm{n} / \mathrm{a}$ \\
\hline 155 & 100 & 35 & 35 & $\mathrm{n} / \mathrm{a}$ \\
\hline 166 & 100 & 80 & 80 & $\mathrm{n} / \mathrm{a}$ \\
\hline 167 & 100 & 60 & 60 & $\mathrm{n} / \mathrm{a}$ \\
\hline 173 & 100 & 60 & 60 & $\mathrm{n} / \mathrm{a}$ \\
\hline 174 & 100 & 60 & 60 & $\mathrm{n} / \mathrm{a}$ \\
\hline 177 & 100 & 25 & 25 & $\mathrm{n} / \mathrm{a}$ \\
\hline \multicolumn{5}{|l|}{199} \\
\hline 224 & 100 & 10 & 10 & $\mathrm{n} / \mathrm{a}$ \\
\hline 249 & 100 & 25 & 25 & $\mathrm{n} / \mathrm{a}$ \\
\hline 254 & 100 & 60 & 60 & $\mathrm{n} / \mathrm{a}$ \\
\hline 259 & 100 & 55 & 55 & $\mathrm{n} / \mathrm{a}$ \\
\hline 263 & 100 & 30 & 30 & $\mathrm{n} / \mathrm{a}$ \\
\hline 272 & 100 & 55 & 55 & $\mathrm{n} / \mathrm{a}$ \\
\hline 35 & 100 & 25 & 25 & $\mathrm{n} / \mathrm{a}$ \\
\hline 36 & 100 & 25 & 25 & $\mathrm{n} / \mathrm{a}$ \\
\hline 41 & 100 & 10 & 10 & $\mathrm{n} / \mathrm{a}$ \\
\hline 63 & 100 & 140 & 140 & $\mathrm{n} / \mathrm{a}$ \\
\hline 64 & 100 & 160 & 160 & $\mathrm{n} / \mathrm{a}$ \\
\hline \multicolumn{5}{|l|}{84} \\
\hline \multicolumn{5}{|l|}{94} \\
\hline 269 & (126) & 25 & $\mathrm{n} / \mathrm{a}$ & 25 \\
\hline 271 & (133) & 160 & $\mathrm{n} / \mathrm{a}$ & 160 \\
\hline 297 & (6) & 90 & $\mathrm{n} / \mathrm{a}$ & 90 \\
\hline 268 & (31) & 35 & $\mathrm{n} / \mathrm{a}$ & 35 \\
\hline 99A & $(600)$ & 15 & $n / a$ & 15 \\
\hline 258 & (149) & 30 & $\mathrm{n} / \mathrm{a}$ & 30 \\
\hline 216 & (338) & 50 & $\mathrm{n} / \mathrm{a}$ & 50 \\
\hline 43 & 2 & 10 & $n / a$ & 10 \\
\hline 38 & 13 & 35 & $\mathrm{n} / \mathrm{a}$ & 35 \\
\hline 176 & 17 & 5 & $\mathrm{n} / \mathrm{a}$ & 5 \\
\hline 226 & 20 & 45 & $\mathrm{n} / \mathrm{a}$ & 45 \\
\hline 154 & 18 & 15 & $\mathrm{n} / \mathrm{a}$ & 15 \\
\hline 265 & 32 & 25 & $\mathrm{n} / \mathrm{a}$ & 25 \\
\hline \multicolumn{5}{|l|}{79} \\
\hline 99 & 14 & 10 & $\mathrm{n} / \mathrm{a}$ & 10 \\
\hline 107 & 58 & 50 & $\mathrm{n} / \mathrm{a}$ & 50 \\
\hline 270 & 57 & 10 & $\mathrm{n} / \mathrm{a}$ & 10 \\
\hline 102 & 39 & 5 & $\mathrm{n} / \mathrm{a}$ & 5 \\
\hline 260 & 58 & 70 & $\mathrm{n} / \mathrm{a}$ & 70 \\
\hline 267 & 69 & 25 & $\mathrm{n} / \mathrm{a}$ & 25 \\
\hline 97 & 30 & 145 & $\mathrm{n} / \mathrm{a}$ & 145 \\
\hline 92 & 67 & 60 & $\mathrm{n} / \mathrm{a}$ & 60 \\
\hline 106 & 74 & 35 & $\mathrm{n} / \mathrm{a}$ & 35 \\
\hline 93 & 68 & 50 & $\mathrm{n} / \mathrm{a}$ & 50 \\
\hline 171 & 91 & 45 & 45 & $\mathrm{n} / \mathrm{a}$ \\
\hline 175 & 62 & 10 & $\mathrm{n} / \mathrm{a}$ & 10 \\
\hline 274 & 94 & 40 & 40 & $\mathrm{n} / \mathrm{a}$ \\
\hline 102A & 88 & 70 & $\mathrm{n} / \mathrm{a}$ & 70 \\
\hline 273 & 95 & 140 & 140 & $\mathrm{n} / \mathrm{a}$ \\
\hline 256 & 98 & 70 & 70 & $\mathrm{n} / \mathrm{a}$ \\
\hline 169 & 98 & 115 & 115 & $\mathrm{n} / \mathrm{a}$ \\
\hline 91 & 97 & 195 & 195 & $\mathrm{n} / \mathrm{a}$ \\
\hline 90 & 99 & 35 & 35 & $\mathrm{n} / \mathrm{a}$ \\
\hline 152 & 100 & 75 & 75 & $\mathrm{n} / \mathrm{a}$ \\
\hline \multicolumn{5}{|l|}{\begin{tabular}{|l|}
39 \\
\end{tabular}} \\
\hline \multicolumn{5}{|l|}{165} \\
\hline \multicolumn{5}{|l|}{101} \\
\hline 83 & & & & \\
\hline$n$ & & 52 & & \\
\hline Median Value & & 45 & & \\
\hline Interpreted Best Fit Value & & 36 & & \\
\hline (A) \# of Undermined Springs & 3est Fit Value $w />/=50 \%$ Discharge Reduction & & 17 & \\
\hline (B) \# of Undermined Springs & Best Fit Value w $/<50 \%$ Discharge Reduction & & & 11 \\
\hline (C) \# of Undermined Springs & st Fit Value $w />/=50 \%$ Discharge Reduction & & 9 & \\
\hline (D) \# of Undermined Springs & st Fit Value $w /<50 \%$ Discharge Reduction & & & 15 \\
\hline Absolute Value (AD-BC) & & 156 & & \\
\hline Chi Square Value at 1 Degre & reedom & 1.93452 & & \\
\hline Error Probability as Derived & Chi Square Contingency Test & $0.20-0.10$ & & \\
\hline Error Probability as Derived & isher Exact Probability Test & 0.08185 & & \\
\hline
\end{tabular}




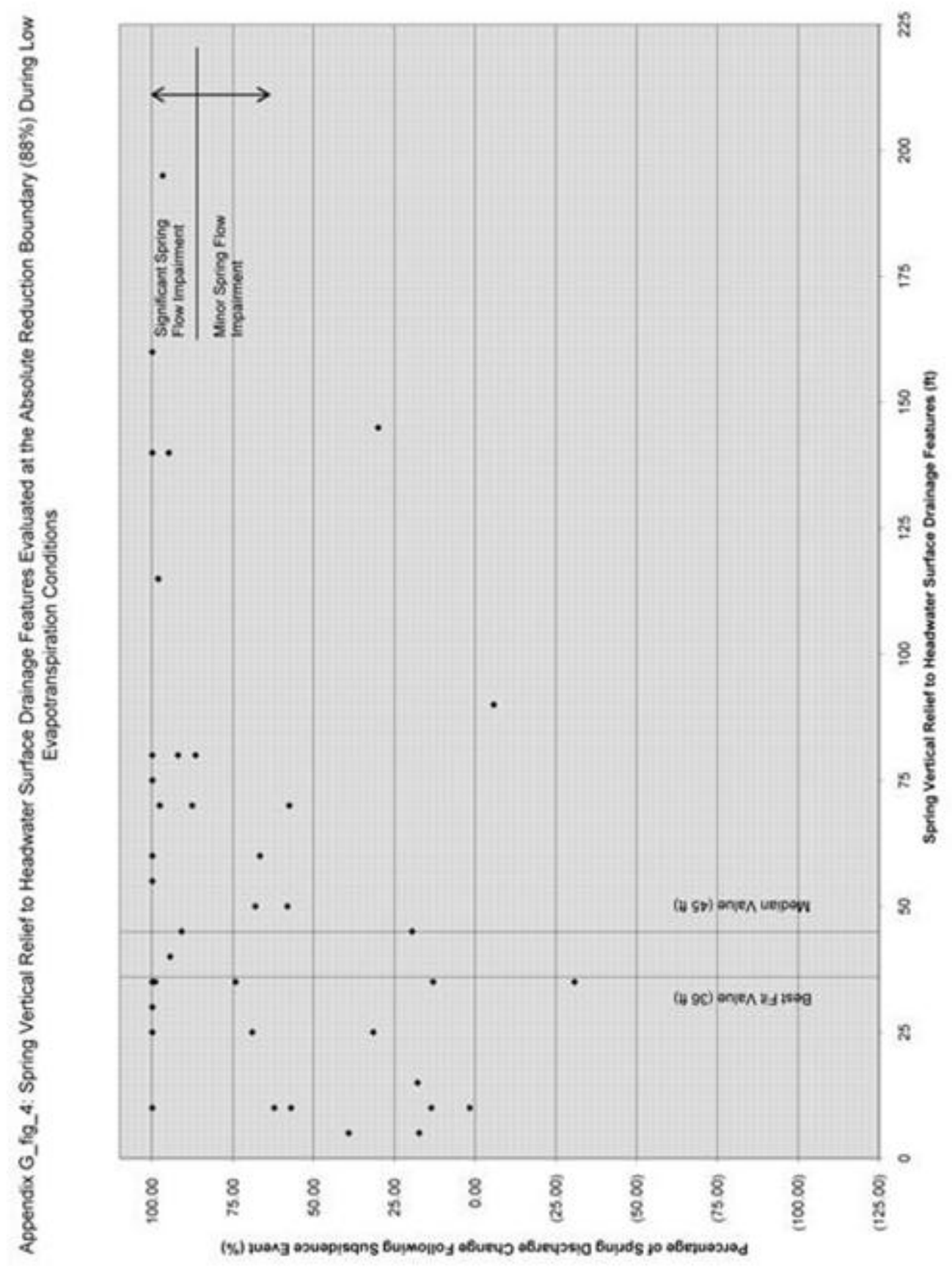


Appendix G_tab_5: Data Used to Determine the Statistical Significance of the Spring Vertical Relief to First Order Surface Drainage Feature Data Trend at the Absolute Discharge Reduction Boundary During Low Evapotranspiration Conditions.

\begin{tabular}{|c|c|c|c|c|}
\hline \multirow[t]{2}{*}{ Spring No. } & \multirow{2}{*}{$\begin{array}{c}\text { Absolute Discharge Reduction Boundary } \\
\text { Low ET }(88 \%)\end{array}$} & \multicolumn{3}{|c|}{ Spring Vertical Relief to First Order Surface Drainage Features ( $\mathrm{ft}$ ) } \\
\hline & & All & $>1=88 \%$ & $<88 \%$ \\
\hline \multicolumn{5}{|l|}{33} \\
\hline 198 & 92 & 80 & 80 & $\mathrm{n} / \mathrm{a}$ \\
\hline 155 & 100 & 35 & 35 & $n / a$ \\
\hline \multicolumn{5}{|l|}{166} \\
\hline 167 & 100 & 60 & 60 & $\mathrm{n} / \mathrm{a}$ \\
\hline 173 & 100 & 60 & 60 & $\mathrm{n} / \mathrm{a}$ \\
\hline 174 & 100 & 60 & 60 & $\mathrm{n} / \mathrm{a}$ \\
\hline \multicolumn{5}{|l|}{177} \\
\hline \multicolumn{5}{|l|}{199} \\
\hline 224 & 100 & 10 & 10 & $\mathrm{n} / \mathrm{a}$ \\
\hline 249 & 100 & 25 & 25 & $\mathrm{n} / \mathrm{a}$ \\
\hline 254 & 100 & 60 & 60 & $\mathrm{n} / \mathrm{a}$ \\
\hline \multicolumn{5}{|l|}{259} \\
\hline 263 & 100 & 30 & 30 & $\mathrm{n} / \mathrm{a}$ \\
\hline 272 & 100 & 55 & 55 & $\mathrm{n} / \mathrm{a}$ \\
\hline 35 & 100 & 25 & 25 & $\mathrm{n} / \mathrm{a}$ \\
\hline 36 & 100 & 25 & 25 & $\mathrm{n} / \mathrm{a}$ \\
\hline \multicolumn{5}{|l|}{41} \\
\hline \multicolumn{5}{|l|}{63} \\
\hline 64 & & & & \\
\hline 84 & & & & \\
\hline 94 & & & & \\
\hline 269 & (126) & 25 & $\mathrm{n} / \mathrm{a}$ & 25 \\
\hline 271 & (133) & 160 & $\mathrm{n} / \mathrm{a}$ & 160 \\
\hline 297 & & & & \\
\hline 268 & & & & \\
\hline $99 \mathrm{~A}$ & $(600)$ & 15 & $\mathrm{n} / \mathrm{a}$ & 15 \\
\hline 258 & (149) & 30 & $\mathrm{n} / \mathrm{a}$ & 30 \\
\hline 216 & (338) & 50 & $\mathrm{n} / \mathrm{a}$ & 50 \\
\hline 43 & 2 & 10 & $\mathrm{n} / \mathrm{a}$ & 10 \\
\hline 38 & 13 & 35 & $\mathrm{n} / \mathrm{a}$ & 35 \\
\hline 176 & 17 & 5 & $\mathrm{n} / \mathrm{a}$ & 5 \\
\hline 226 & 20 & 45 & $\mathrm{n} / \mathrm{a}$ & 45 \\
\hline 154 & 18 & 15 & $\mathrm{n} / \mathrm{a}$ & 15 \\
\hline 265 & & & & \\
\hline 79 & & & & \\
\hline 99 & 14 & 10 & $\mathrm{n} / \mathrm{a}$ & 10 \\
\hline 107 & 58 & 50 & $\mathrm{n} / \mathrm{a}$ & 50 \\
\hline 270 & 57 & 10 & $\mathrm{n} / \mathrm{a}$ & 10 \\
\hline 102 & 39 & 5 & $\mathrm{n} / \mathrm{a}$ & 5 \\
\hline 260 & & & & \\
\hline 267 & 69 & 25 & $\mathrm{n} / \mathrm{a}$ & 25 \\
\hline 97 & 30 & 145 & $\mathrm{n} / \mathrm{a}$ & 145 \\
\hline 92 & 67 & 60 & $\mathrm{n} / \mathrm{a}$ & 60 \\
\hline 106 & 74 & 35 & $\mathrm{n} / \mathrm{a}$ & 35 \\
\hline 93 & 68 & 50 & $\mathrm{n} / \mathrm{a}$ & 50 \\
\hline 171 & 91 & 45 & 45 & $\mathrm{n} / \mathrm{a}$ \\
\hline 175 & 62 & 10 & $\mathrm{n} / \mathrm{a}$ & 10 \\
\hline 274 & 94 & 40 & 40 & $\mathrm{n} / \mathrm{a}$ \\
\hline $102 \mathrm{~A}$ & 88 & 70 & $\mathrm{n} / \mathrm{a}$ & 70 \\
\hline 273 & 95 & 140 & 140 & $\mathrm{n} / \mathrm{a}$ \\
\hline 256 & 98 & 70 & 70 & $\mathrm{n} / \mathrm{a}$ \\
\hline 169 & 98 & 115 & 115 & $\mathrm{n} / \mathrm{a}$ \\
\hline 91 & 97 & 195 & 195 & $\mathrm{n} / \mathrm{a}$ \\
\hline 90 & 99 & 35 & 35 & $\mathrm{n} / \mathrm{a}$ \\
\hline 152 & 100 & 75 & 75 & $\mathrm{n} / \mathrm{a}$ \\
\hline 39 & & & & \\
\hline 165 & & & & \\
\hline 101 & & & & \\
\hline 83 & & & & \\
\hline $\mathrm{n}$ & & 41 & & \\
\hline Median Value & & 40 & & \\
\hline Interpreted Best Fit Value & & 36 & & \\
\hline (A) \# of Undermined Spring & Best Fit Value $\mathrm{w} />/=50 \%$ Discharge Reduction & & 13 & \\
\hline (B) \# of Undermined Spring & Best Fit Value w $/<50 \%$ Discharge Reduction & & & 8 \\
\hline (C) \# of Undermined Spring & st Fit Value $w />/=50 \%$ Discharge Reduction & & 7 & \\
\hline (D) \# of Undermined Spring & st Fit Value w/ <50\% Discharge Reduction & & & 13 \\
\hline Absolute Value (AD-BC) & & 113 & & \\
\hline Chi Square Value at 1 Degr & Freedom & 1.98870 & & \\
\hline Error Probability as Derived & Chi Square Contingency Test & $0.20-0.10$ & & \\
\hline Error Probability as Derived & Fisher Exact Probability Test & 0.07888 & & \\
\hline
\end{tabular}




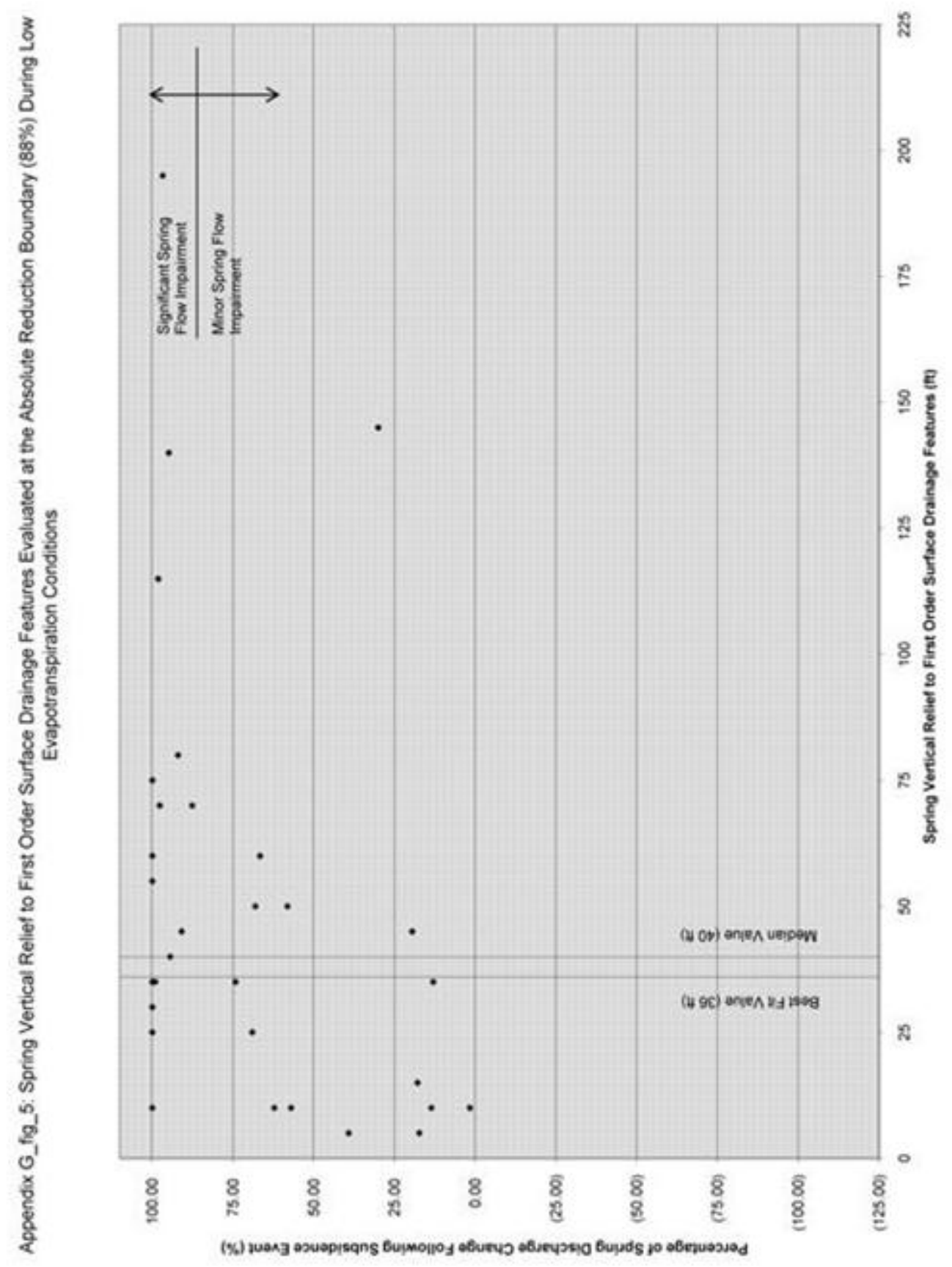


Appendix G_tab_6: Data Used to Determine the Statistical Significance of the Spring Daylight Elevation Data Trend at the Absolute Discharge Reduction Boundary During Low Evapotranspiration Conditions.

\begin{tabular}{|c|c|c|c|c|}
\hline \multirow[t]{2}{*}{ Spring No. } & \multirow{2}{*}{$\begin{array}{c}\text { Absolute Discharge Reduction Boundary } \\
\text { Low ET }(88 \%)\end{array}$} & \multicolumn{3}{|c|}{ Spring Daylight Elevation (ft amsl) } \\
\hline & & All & $>1=88 \%$ & $<88 \%$ \\
\hline 33 & 87 & 1240 & $\mathrm{n} / \mathrm{a}$ & 1240 \\
\hline 198 & 92 & 1250 & 1250 & $\mathrm{n} / \mathrm{a}$ \\
\hline 155 & 100 & 1115 & 1115 & $\mathrm{n} / \mathrm{a}$ \\
\hline 166 & 100 & 1130 & 1130 & $\mathrm{n} / \mathrm{a}$ \\
\hline 167 & 100 & 1170 & 1170 & $\mathrm{n} / \mathrm{a}$ \\
\hline 173 & 100 & 1260 & 1260 & $\mathrm{n} / \mathrm{a}$ \\
\hline 174 & 100 & 1230 & 1230 & $\mathrm{n} / \mathrm{a}$ \\
\hline 177 & 100 & 1175 & 1175 & $\mathrm{n} / \mathrm{a}$ \\
\hline 199 & 100 & 1010 & 1010 & $\mathrm{n} / \mathrm{a}$ \\
\hline 224 & 100 & 1215 & 1215 & $\mathrm{n} / \mathrm{a}$ \\
\hline 249 & 100 & 1120 & 1120 & $\mathrm{n} / \mathrm{a}$ \\
\hline 254 & 100 & 1130 & 1130 & $\mathrm{n} / \mathrm{a}$ \\
\hline 259 & 100 & 1155 & 1155 & $\mathrm{n} / \mathrm{a}$ \\
\hline 263 & 100 & 1160 & 1160 & $\mathrm{n} / \mathrm{a}$ \\
\hline 272 & 100 & 1265 & 1265 & $\mathrm{n} / \mathrm{a}$ \\
\hline 35 & 100 & 1185 & 1185 & $\mathrm{n} / \mathrm{a}$ \\
\hline 36 & 100 & 1225 & 1225 & $\mathrm{n} / \mathrm{a}$ \\
\hline 41 & 100 & 1180 & 1180 & $\mathrm{n} / \mathrm{a}$ \\
\hline 63 & 100 & 1165 & 1165 & $\mathrm{n} / \mathrm{a}$ \\
\hline 64 & 100 & 1185 & 1185 & $\mathrm{n} / \mathrm{a}$ \\
\hline 84 & 100 & 1040 & 1040 & $\mathrm{n} / \mathrm{a}$ \\
\hline 94 & 100 & 1155 & 1155 & $\mathrm{n} / \mathrm{a}$ \\
\hline 269 & (126) & 1225 & $\mathrm{n} / \mathrm{a}$ & 1225 \\
\hline 271 & (133) & 1310 & $\mathrm{n} / \mathrm{a}$ & 1310 \\
\hline 297 & (6) & 1210 & $\mathrm{n} / \mathrm{a}$ & 1210 \\
\hline 268 & (31) & 1185 & $\mathrm{n} / \mathrm{a}$ & 1185 \\
\hline 99A & $(600)$ & 1190 & $\mathrm{n} / \mathrm{a}$ & 1190 \\
\hline 258 & (149) & 1190 & $\mathrm{n} / \mathrm{a}$ & 1190 \\
\hline 216 & (338) & 1210 & $\mathrm{n} / \mathrm{a}$ & 1210 \\
\hline 43 & 2 & 1180 & $\mathrm{n} / \mathrm{a}$ & 1180 \\
\hline 38 & 13 & 1220 & $\mathrm{n} / \mathrm{a}$ & 1220 \\
\hline 176 & 17 & 1175 & $\mathrm{n} / \mathrm{a}$ & 1175 \\
\hline 226 & 20 & 1195 & $n / a$ & 1195 \\
\hline 154 & 18 & 1150 & $n / a$ & 1150 \\
\hline 265 & 32 & 1200 & $n / a$ & 1200 \\
\hline 79 & 54 & 1095 & $\mathrm{n} / \mathrm{a}$ & 1095 \\
\hline 99 & 14 & 1180 & $\mathrm{n} / \mathrm{a}$ & 1180 \\
\hline 107 & 58 & 1200 & $\mathrm{n} / \mathrm{a}$ & 1200 \\
\hline 270 & 57 & 1230 & $\mathrm{n} / \mathrm{a}$ & 1230 \\
\hline 102 & 39 & 1160 & $\mathrm{n} / \mathrm{a}$ & 1160 \\
\hline 260 & 58 & 1190 & $\mathrm{n} / \mathrm{a}$ & 1190 \\
\hline 267 & 69 & 1210 & $\mathrm{n} / \mathrm{a}$ & 1210 \\
\hline 97 & 30 & 1265 & $\mathrm{n} / \mathrm{a}$ & 1265 \\
\hline 92 & 67 & 1190 & $\mathrm{n} / \mathrm{a}$ & 1190 \\
\hline 106 & 74 & 1155 & $\mathrm{n} / \mathrm{a}$ & 1155 \\
\hline 93 & 68 & 1175 & $\mathrm{n} / \mathrm{a}$ & 1175 \\
\hline 171 & 91 & 1195 & 1195 & $\mathrm{n} / \mathrm{a}$ \\
\hline 175 & 62 & 1190 & $\mathrm{n} / \mathrm{a}$ & 1190 \\
\hline 274 & 94 & 1240 & 1240 & $\mathrm{n} / \mathrm{a}$ \\
\hline 102A & 88 & 1200 & $\mathrm{n} / \mathrm{a}$ & 1200 \\
\hline 273 & 95 & 1280 & 1280 & $\mathrm{n} / \mathrm{a}$ \\
\hline 256 & 98 & 1190 & 1190 & $\mathrm{n} / \mathrm{a}$ \\
\hline 169 & 98 & 1225 & 1225 & $\mathrm{n} / \mathrm{a}$ \\
\hline 91 & 97 & 1195 & 1195 & $\mathrm{n} / \mathrm{a}$ \\
\hline 90 & 99 & 1125 & 1125 & $\mathrm{n} / \mathrm{a}$ \\
\hline 152 & 100 & 1195 & 1195 & $n / a$ \\
\hline 39 & 100 & 1150 & 1150 & $\mathrm{n} / \mathrm{a}$ \\
\hline \multicolumn{5}{|l|}{165} \\
\hline \multicolumn{5}{|l|}{101} \\
\hline \multicolumn{5}{|l|}{83} \\
\hline \multicolumn{2}{|l|}{$\mathrm{n}$} & 57 & & \\
\hline \multicolumn{2}{|l|}{ Median Value } & 1190 & & \\
\hline \multicolumn{2}{|c|}{ Interpreted Best Fit Value } & 1190 & & \\
\hline \multicolumn{2}{|c|}{ (A) \# of Undermined Springs $>/=$ Best Fit Value $w />/=50 \%$ Discharge Reduction } & & 13 & \\
\hline (B) \# of Undermined Spring & Best Fit Value $w /<50 \%$ Discharge Reduction & & & 18 \\
\hline (C) \# of Undermined Spring & st Fit Value $\mathrm{w} />/=50 \%$ Discharge Reduction & & 17 & \\
\hline (D) \# of Undermined Spring & st Fit Value w $/<50 \%$ Discharge Reduction & & & 9 \\
\hline Absolute Value (AD-BC) & & 189 & & \\
\hline Chi Square Value at 1 Degr & Freedom & 2.24908 & & \\
\hline Error Probability as Derived & Chi Square Contingency Test & $0.20-0.10$ & & \\
\hline Error Probability as Derived & Fisher Exact Probability Test & 0.06644 & & \\
\hline
\end{tabular}




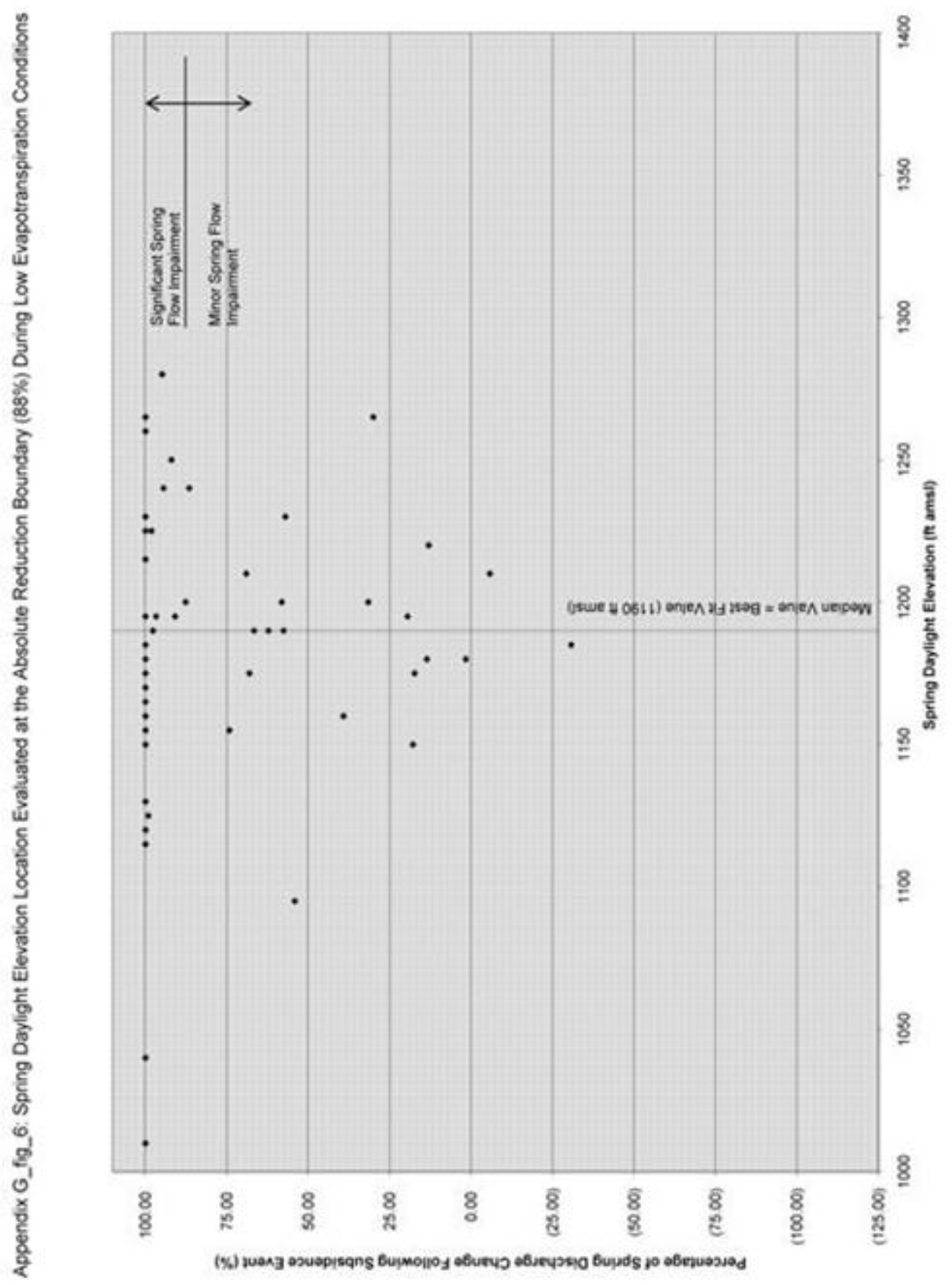


Appendix G_tab_7: Data Used to Determine the Statistical Significance of the Spring Recharge Line Length Data Trend at the Optimum Discharge Reduction Boundary During High Evapotranspiration Conditions.

\begin{tabular}{|c|c|c|c|c|}
\hline \multirow[t]{2}{*}{ Spring No. } & \multirow{2}{*}{$\begin{array}{c}\text { Optimum Discharge Reduction Boundary } \\
\text { High ET }(60 \%)\end{array}$} & \multicolumn{3}{|c|}{ Spring Recharge Line Length (ft) } \\
\hline & & All & $>1=60 \%$ & $<60 \%$ \\
\hline 33 & $(1)$ & 157 & $\mathrm{n} / \mathrm{a}$ & 157 \\
\hline 198 & (23) & 170 & $\mathrm{n} / \mathrm{a}$ & 170 \\
\hline 155 & 100 & 188 & 188 & $\mathrm{n} / \mathrm{a}$ \\
\hline 166 & 100 & 94 & 94 & $\mathrm{n} / \mathrm{a}$ \\
\hline 167 & 100 & 219 & 219 & $n / a$ \\
\hline 173 & 100 & 219 & 219 & $\mathrm{n} / \mathrm{a}$ \\
\hline 174 & 100 & 94 & 94 & $\mathrm{n} / \mathrm{a}$ \\
\hline 177 & 100 & 310 & 310 & $n / a$ \\
\hline 199 & 100 & 188 & 188 & $n / a$ \\
\hline 224 & 100 & 120 & 120 & $n / a$ \\
\hline 249 & 100 & 407 & 407 & $\mathrm{n} / \mathrm{a}$ \\
\hline 254 & 100 & 375 & 375 & $\mathrm{n} / \mathrm{a}$ \\
\hline 259 & 100 & 657 & 657 & $n / a$ \\
\hline 263 & 100 & 63 & 63 & $n / a$ \\
\hline 272 & 100 & 219 & 219 & $\mathrm{n} / \mathrm{a}$ \\
\hline 35 & 100 & 157 & 157 & $n / a$ \\
\hline 36 & 100 & 125 & 125 & $n / a$ \\
\hline 41 & 100 & 63 & 63 & $n / a$ \\
\hline 63 & 100 & 532 & 532 & $n / a$ \\
\hline 64 & 100 & 438 & 438 & $n / a$ \\
\hline 84 & 100 & 750 & 750 & $n / a$ \\
\hline 94 & 100 & 125 & 125 & $n / a$ \\
\hline 269 & (61) & 157 & $\mathrm{n} / \mathrm{a}$ & 157 \\
\hline 271 & (74) & 125 & $n / a$ & 125 \\
\hline 297 & 10 & 94 & $n / a$ & 94 \\
\hline 268 & (118) & 282 & $n / a$ & 282 \\
\hline $99 A$ & 100 & 75 & 75 & $n / a$ \\
\hline 258 & 100 & 532 & 532 & $n / a$ \\
\hline 216 & 100 & 360 & 360 & $n / a$ \\
\hline 43 & 80 & 63 & 63 & $n / a$ \\
\hline 38 & 100 & 282 & 282 & $n / a$ \\
\hline 176 & 100 & 375 & 375 & $\mathrm{n} / \mathrm{a}$ \\
\hline 226 & 100 & 313 & 313 & $n / a$ \\
\hline \multicolumn{5}{|l|}{154} \\
\hline 265 & 100 & 594 & 594 & $\mathrm{n} / \mathrm{a}$ \\
\hline 79 & 100 & 188 & 188 & $n / a$ \\
\hline 99 & 100 & 32 & 32 & $n / a$ \\
\hline 107 & 85 & 90 & 90 & $n / a$ \\
\hline \multicolumn{5}{|l|}{270} \\
\hline 102 & 100 & 313 & 313 & $\mathrm{n} / \mathrm{a}$ \\
\hline \multicolumn{5}{|l|}{260} \\
\hline 267 & 96 & 750 & 750 & $\mathrm{n} / \mathrm{a}$ \\
\hline 97 & 45 & 157 & $\mathrm{n} / \mathrm{a}$ & 157 \\
\hline \multicolumn{5}{|l|}{92} \\
\hline 106 & 100 & 250 & 250 & $\mathrm{n} / \mathrm{a}$ \\
\hline 93 & 100 & 330 & 330 & $\mathrm{n} / \mathrm{a}$ \\
\hline \multicolumn{5}{|l|}{171} \\
\hline 175 & 100 & 94 & 94 & $n / a$ \\
\hline 274 & 100 & 469 & 469 & $n / a$ \\
\hline 102A & 99 & 532 & 532 & $\mathrm{n} / \mathrm{a}$ \\
\hline \multicolumn{5}{|l|}{273} \\
\hline 256 & 88 & 250 & 250 & $\mathrm{n} / \mathrm{a}$ \\
\hline 169 & 65 & 344 & 344 & $\mathrm{n} / \mathrm{a}$ \\
\hline \multicolumn{5}{|l|}{91} \\
\hline 90 & 100 & 313 & 313 & $n / a$ \\
\hline 152 & 100 & 188 & 188 & $\mathrm{n} / \mathrm{a}$ \\
\hline 39 & & & & \\
\hline 165 & (64) & 188 & $\mathrm{n} / \mathrm{a}$ & 188 \\
\hline 101 & 98 & 625 & 625 & $\mathrm{n} / \mathrm{a}$ \\
\hline 83 & 100 & 813 & 813 & $\mathrm{n} / \mathrm{a}$ \\
\hline $\mathrm{n}$ & & 52 & & \\
\hline Median Value & & 219 & & \\
\hline Interpreted Best Fit Value & & 189 & & \\
\hline (A) \# of Undermined Spring & Best Fit Value $w />/=50 \%$ Discharge Reduction & & 27 & \\
\hline (B) \# of Undermined Spring & Best Fit Value w $/<50 \%$ Discharge Reduction & & & 1 \\
\hline (C) \# of Undermined Spring & st Fit Value $w />/=50 \%$ Discharge Reduction & & 17 & \\
\hline (D) \# of Undermined Spring & st Fit Value $w /<50 \%$ Discharge Reduction & & & 7 \\
\hline Absolute Value (AD-BC) & & 172 & & \\
\hline Chi Square Value at 1 Degr & Freedom & 4.68594 & & \\
\hline Error Probability as Derived & Chi Square Contingency Test & $0.05-0.02$ & & \\
\hline Error Probability as Derived & Fisher Exact Probability Test & 0.01385 & & \\
\hline
\end{tabular}




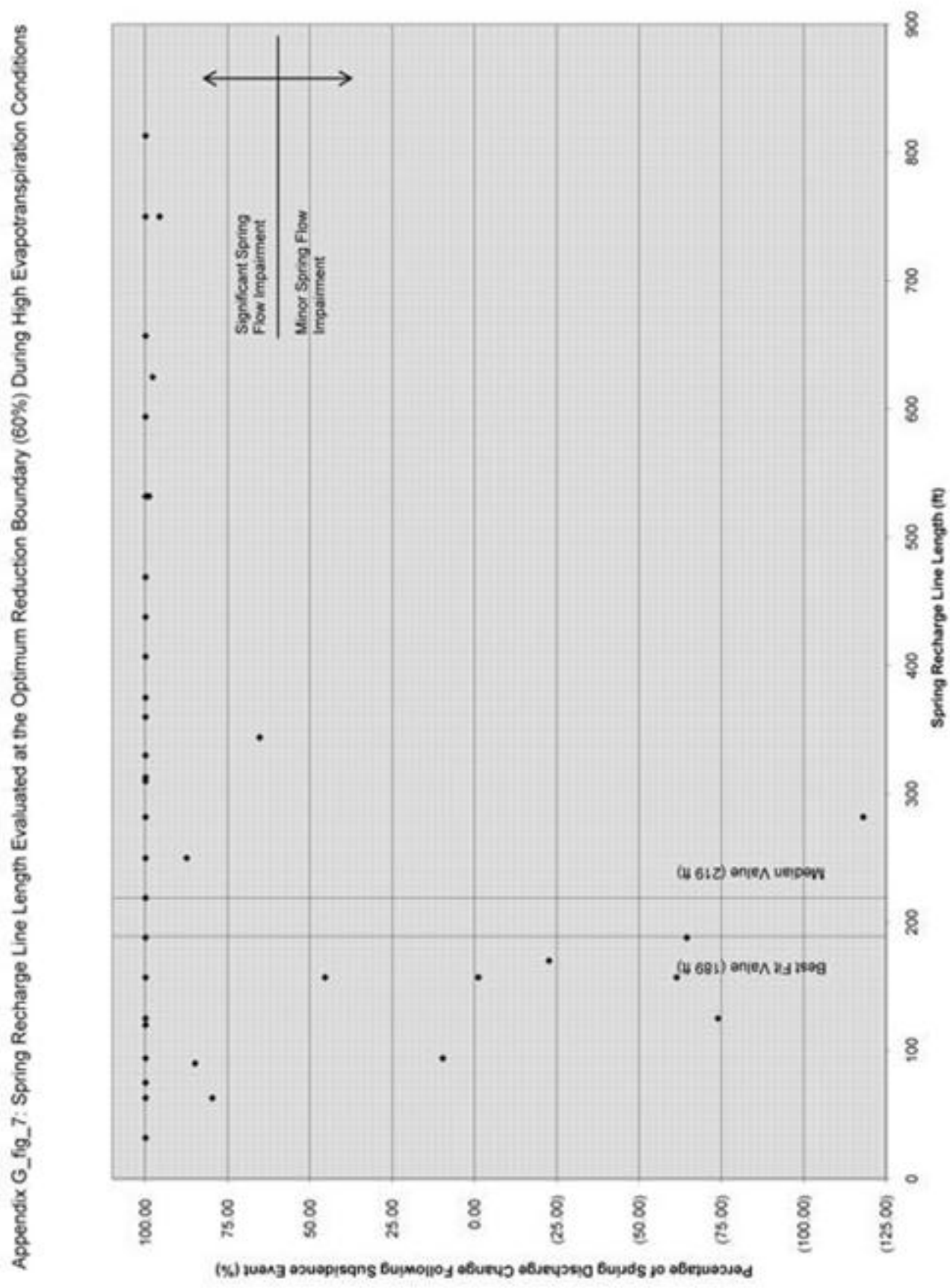


Appendix G_tab_8: Data Used to Determine the Statistical Significance of the Spring Recharge Line Vertical Relief Data Trend at the Optimum Discharge Reduction Boundary During High Evapotranspiration Conditions.

\begin{tabular}{|c|c|c|c|c|}
\hline Spring No. & Optimum Discharge Reduction Boundary & & ge Line Ve & \\
\hline & High ET $(60 \%)$ & All & $>l=60 \%$ & $<60 \%$ \\
\hline 33 & (1) & 30 & $\mathrm{n} / \mathrm{a}$ & 30 \\
\hline 198 & $(23)$ & 20 & $\mathrm{n} / \mathrm{a}$ & 20 \\
\hline 155 & 100 & 40 & 40 & $\mathrm{n} / \mathrm{a}$ \\
\hline 166 & 100 & 20 & 20 & $\mathrm{n} / \mathrm{a}$ \\
\hline 167 & 100 & 40 & 40 & $\mathrm{n} / \mathrm{a}$ \\
\hline 173 & 100 & 35 & 35 & $\mathrm{n} / \mathrm{a}$ \\
\hline 174 & 100 & 25 & 25 & $\mathrm{n} / \mathrm{a}$ \\
\hline 177 & 100 & 60 & 60 & $\mathrm{n} / \mathrm{a}$ \\
\hline 199 & 100 & 50 & 50 & $\mathrm{n} / \mathrm{a}$ \\
\hline 224 & 100 & 20 & 20 & $\mathrm{n} / \mathrm{a}$ \\
\hline 249 & 100 & 0 & 0 & $\mathrm{n} / \mathrm{a}$ \\
\hline 254 & 100 & 105 & 105 & $\mathrm{n} / \mathrm{a}$ \\
\hline 259 & 100 & 80 & 80 & $\mathrm{n} / \mathrm{a}$ \\
\hline 263 & 100 & 15 & 15 & $\mathrm{n} / \mathrm{a}$ \\
\hline 272 & 100 & 50 & 50 & $\mathrm{n} / \mathrm{a}$ \\
\hline 35 & 100 & 50 & 50 & $\mathrm{n} / \mathrm{a}$ \\
\hline 36 & 100 & 30 & 30 & $\mathrm{n} / \mathrm{a}$ \\
\hline 41 & 100 & 5 & 5 & $\mathrm{n} / \mathrm{a}$ \\
\hline 63 & 100 & 100 & 100 & $\mathrm{n} / \mathrm{a}$ \\
\hline 64 & 100 & 80 & 80 & $\mathrm{n} / \mathrm{a}$ \\
\hline 84 & 100 & 195 & 195 & $\mathrm{n} / \mathrm{a}$ \\
\hline 94 & 100 & 20 & 20 & $\mathrm{n} / \mathrm{a}$ \\
\hline 269 & (61) & 30 & $\mathrm{n} / \mathrm{a}$ & 30 \\
\hline 271 & (74) & 15 & $\mathrm{n} / \mathrm{a}$ & 15 \\
\hline 297 & 10 & 15 & $\mathrm{n} / \mathrm{a}$ & 15 \\
\hline 268 & (118) & 25 & $\mathrm{n} / \mathrm{a}$ & 25 \\
\hline $99 \mathrm{~A}$ & 100 & 15 & 15 & $\mathrm{n} / \mathrm{a}$ \\
\hline 258 & 100 & 45 & 45 & $\mathrm{n} / \mathrm{a}$ \\
\hline 216 & 100 & 75 & 75 & $\mathrm{n} / \mathrm{a}$ \\
\hline 43 & 80 & 15 & 15 & $\mathrm{n} / \mathrm{a}$ \\
\hline 38 & 100 & 55 & 55 & $\mathrm{n} / \mathrm{a}$ \\
\hline 176 & 100 & 70 & 70 & $\mathrm{n} / \mathrm{a}$ \\
\hline 226 & 100 & 60 & 60 & $\mathrm{n} / \mathrm{a}$ \\
\hline 154 & & & & \\
\hline 265 & 100 & 75 & 75 & $\mathrm{n} / \mathrm{a}$ \\
\hline 79 & 100 & 30 & 30 & $\mathrm{n} / \mathrm{a}$ \\
\hline 99 & 100 & 5 & 5 & $\mathrm{n} / \mathrm{a}$ \\
\hline 107 & 85 & 10 & 10 & $\mathrm{n} / \mathrm{a}$ \\
\hline 270 & & & & \\
\hline 102 & 100 & 25 & 25 & $\mathrm{n} / \mathrm{a}$ \\
\hline 260 & & & & \\
\hline 267 & 96 & 160 & 160 & $\mathrm{n} / \mathrm{a}$ \\
\hline 97 & 45 & 30 & $\mathrm{n} / \mathrm{a}$ & 30 \\
\hline 92 & & & & \\
\hline 106 & 100 & 45 & 45 & $\mathrm{n} / \mathrm{a}$ \\
\hline 93 & 100 & 80 & 80 & $\mathrm{n} / \mathrm{a}$ \\
\hline 171 & & & & \\
\hline 175 & 100 & 10 & 10 & $\mathrm{n} / \mathrm{a}$ \\
\hline 274 & 100 & 100 & 100 & $\mathrm{n} / \mathrm{a}$ \\
\hline $102 \mathrm{~A}$ & 99 & 60 & 60 & $\mathrm{n} / \mathrm{a}$ \\
\hline 273 & & & & \\
\hline 256 & 88 & 35 & 35 & $\mathrm{n} / \mathrm{a}$ \\
\hline 169 & 65 & 70 & 70 & $\mathrm{n} / \mathrm{a}$ \\
\hline 91 & & & & \\
\hline 90 & 100 & 10 & 10 & $\mathrm{n} / \mathrm{a}$ \\
\hline 152 & 100 & 40 & 40 & $\mathrm{n} / \mathrm{a}$ \\
\hline 39 & & & & \\
\hline 165 & (64) & 45 & $\mathrm{n} / \mathrm{a}$ & 45 \\
\hline 101 & 98 & 145 & 145 & $\mathrm{n} / \mathrm{a}$ \\
\hline 83 & 100 & 195 & 195 & $\mathrm{n} / \mathrm{a}$ \\
\hline $\mathrm{n}$ & & 52 & & \\
\hline Median Value & & 40 & & \\
\hline Interpreted Best Fit Value & & 36 & & \\
\hline (A) \# of Undermined Spring & 3est Fit Value $\mathrm{w} />/=50 \%$ Discharge Reduction & & 26 & \\
\hline (B) \# of Undermined Spring & est Fit Value w / <50\% Discharge Reduction & & & 1 \\
\hline (C) \# of Undermined Spring & st Fit Value w/ $>/=50 \%$ Discharge Reduction & & 18 & \\
\hline (D) \# of Undermined Spring & st Fit Value w/<50\% Discharge Reduction & & & 7 \\
\hline Absolute Value (AD-BC) & & 164 & & \\
\hline Chi Square Value at 1 Degr & reedom & 4.16788 & & \\
\hline Error Probability as Derived & Chi Square Contingency Test & $0.05-0.02$ & & \\
\hline Error Probability as Derived & isher Exact Probability Test & 0.01868 & & \\
\hline
\end{tabular}




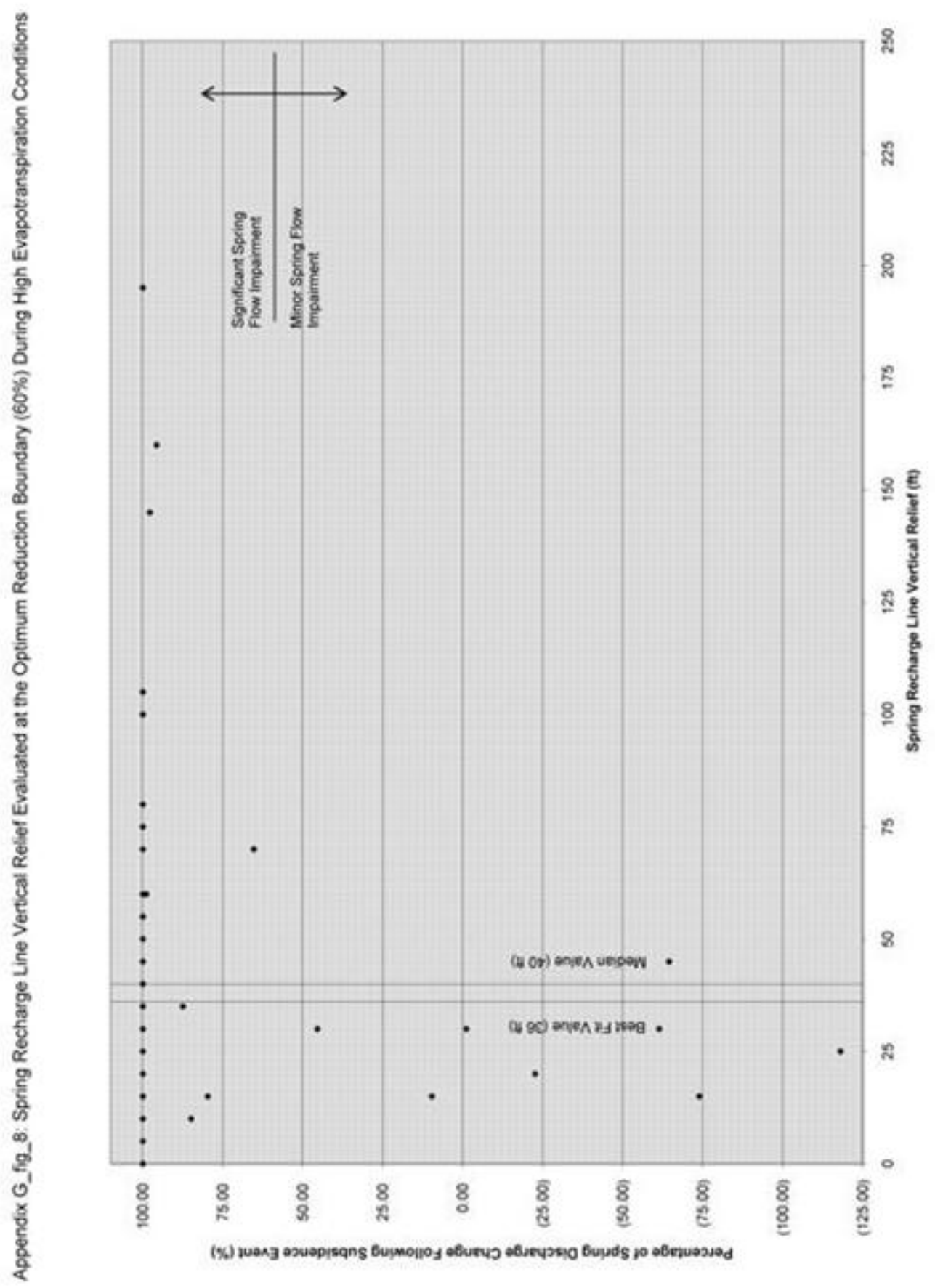


Appendix G_tab_9: Data Used to Determine the Statistical Significance of the Spring Daylight Elevation Data Trend at the Optimum Discharge Reduction Boundary During High Evapotranspiration Conditions.

\begin{tabular}{|c|c|c|c|c|}
\hline Spring No. & Optimum Discharge Reduction Boundary & & light Elevat & \\
\hline & High ET (60\%) & All & $>1=60 \%$ & $<60 \%$ \\
\hline 33 & (1) & 1240 & $\mathrm{n} / \mathrm{a}$ & 1240 \\
\hline 198 & (23) & 1250 & $\mathrm{n} / \mathrm{a}$ & 1250 \\
\hline 155 & 100 & 1115 & 1115 & $\mathrm{n} / \mathrm{a}$ \\
\hline 166 & 100 & 1130 & 1130 & $\mathrm{n} / \mathrm{a}$ \\
\hline 167 & 100 & 1170 & 1170 & $\mathrm{n} / \mathrm{a}$ \\
\hline 173 & 100 & 1260 & 1260 & $\mathrm{n} / \mathrm{a}$ \\
\hline 174 & 100 & 1230 & 1230 & $\mathrm{n} / \mathrm{a}$ \\
\hline 177 & 100 & 1175 & 1175 & $\mathrm{n} / \mathrm{a}$ \\
\hline 199 & 100 & 1010 & 1010 & $\mathrm{n} / \mathrm{a}$ \\
\hline 224 & 100 & 1215 & 1215 & $\mathrm{n} / \mathrm{a}$ \\
\hline 249 & 100 & 1120 & 1120 & $\mathrm{n} / \mathrm{a}$ \\
\hline 254 & 100 & 1130 & 1130 & $\mathrm{n} / \mathrm{a}$ \\
\hline 259 & 100 & 1155 & 1155 & $\mathrm{n} / \mathrm{a}$ \\
\hline 263 & 100 & 1160 & 1160 & $\mathrm{n} / \mathrm{a}$ \\
\hline 272 & 100 & 1265 & 1265 & $\mathrm{n} / \mathrm{a}$ \\
\hline 35 & 100 & 1185 & 1185 & $\mathrm{n} / \mathrm{a}$ \\
\hline 36 & 100 & 1225 & 1225 & $\mathrm{n} / \mathrm{a}$ \\
\hline 41 & 100 & 1180 & 1180 & $\mathrm{n} / \mathrm{a}$ \\
\hline 63 & 100 & 1165 & 1165 & $\mathrm{n} / \mathrm{a}$ \\
\hline 64 & 100 & 1185 & 1185 & $\mathrm{n} / \mathrm{a}$ \\
\hline 84 & 100 & 1040 & 1040 & $\mathrm{n} / \mathrm{a}$ \\
\hline 94 & 100 & 1155 & 1155 & $\mathrm{n} / \mathrm{a}$ \\
\hline 269 & (61) & 1225 & $\mathrm{n} / \mathrm{a}$ & 1225 \\
\hline 271 & (74) & 1310 & $\mathrm{n} / \mathrm{a}$ & 1310 \\
\hline 297 & 10 & 1210 & $\mathrm{n} / \mathrm{a}$ & 1210 \\
\hline 268 & (118) & 1185 & $\mathrm{n} / \mathrm{a}$ & 1185 \\
\hline $99 \mathrm{~A}$ & 100 & 1190 & 1190 & $\mathrm{n} / \mathrm{a}$ \\
\hline 258 & 100 & 1190 & 1190 & $\mathrm{n} / \mathrm{a}$ \\
\hline 216 & 100 & 1210 & 1210 & $\mathrm{n} / \mathrm{a}$ \\
\hline 43 & 80 & 1180 & 1180 & $\mathrm{n} / \mathrm{a}$ \\
\hline 38 & 100 & 1220 & 1220 & $\mathrm{n} / \mathrm{a}$ \\
\hline 176 & 100 & 1175 & 1175 & $\mathrm{n} / \mathrm{a}$ \\
\hline 226 & 100 & 1195 & 1195 & $\mathrm{n} / \mathrm{a}$ \\
\hline 154 & & & & \\
\hline 265 & 100 & 1200 & 1200 & $\mathrm{n} / \mathrm{a}$ \\
\hline 79 & 100 & 1095 & 1095 & $\mathrm{n} / \mathrm{a}$ \\
\hline 99 & 100 & 1180 & 1180 & $\mathrm{n} / \mathrm{a}$ \\
\hline 107 & 85 & 1200 & 1200 & $\mathrm{n} / \mathrm{a}$ \\
\hline 270 & & & & \\
\hline 102 & 100 & 1160 & 1160 & $\mathrm{n} / \mathrm{a}$ \\
\hline 260 & & & & \\
\hline 267 & 96 & 1210 & 1210 & $\mathrm{n} / \mathrm{a}$ \\
\hline 97 & 45 & 1265 & $\mathrm{n} / \mathrm{a}$ & 1265 \\
\hline 92 & & & & \\
\hline 106 & 100 & 1155 & 1155 & $\mathrm{n} / \mathrm{a}$ \\
\hline 93 & 100 & 1175 & 1175 & $\mathrm{n} / \mathrm{a}$ \\
\hline 171 & & & & \\
\hline 175 & 100 & 1190 & 1190 & $\mathrm{n} / \mathrm{a}$ \\
\hline 274 & 100 & 1240 & 1240 & $\mathrm{n} / \mathrm{a}$ \\
\hline $102 \mathrm{~A}$ & 99 & 1200 & 1200 & $\mathrm{n} / \mathrm{a}$ \\
\hline 273 & & & & \\
\hline 256 & 88 & 1190 & 1190 & $\mathrm{n} / \mathrm{a}$ \\
\hline 169 & 65 & 1225 & 1225 & $\mathrm{n} / \mathrm{a}$ \\
\hline 91 & & & & \\
\hline 90 & 100 & 1125 & 1125 & $\mathrm{n} / \mathrm{a}$ \\
\hline 152 & 100 & 1195 & 1195 & $\mathrm{n} / \mathrm{a}$ \\
\hline 39 & & & & \\
\hline 165 & (64) & 1010 & $\mathrm{n} / \mathrm{a}$ & 1010 \\
\hline 101 & 98 & 1130 & 1130 & $\mathrm{n} / \mathrm{a}$ \\
\hline 83 & 100 & 1040 & 1040 & $\mathrm{n} / \mathrm{a}$ \\
\hline $\mathrm{n}$ & & 52 & & \\
\hline Median Value & & 1185 & & \\
\hline Interpreted Best Fit Value & & 1209 & & \\
\hline (A) \# of Undermined Spring & 3est Fit Value $\mathrm{w} />/=50 \%$ Discharge Reduction & & 10 & \\
\hline (B) \# of Undermined Spring & est Fit Value w / <50\% Discharge Reduction & & & 6 \\
\hline (C) \# of Undermined Spring & st Fit Value w/ $>/=50 \%$ Discharge Reduction & & 34 & \\
\hline (D) \# of Undermined Spring & st Fit Value w/<50\% Discharge Reduction & & & 2 \\
\hline Absolute Value (AD-BC) & & 184 & & \\
\hline Chi Square Value at 1 Degr & reedom & 6.40254 & & \\
\hline Error Probability as Derived & Chi Square Contingency Test & $0.02-0.01$ & & \\
\hline Error Probability as Derived & isher Exact Probability Test & 0.00727 & & \\
\hline
\end{tabular}




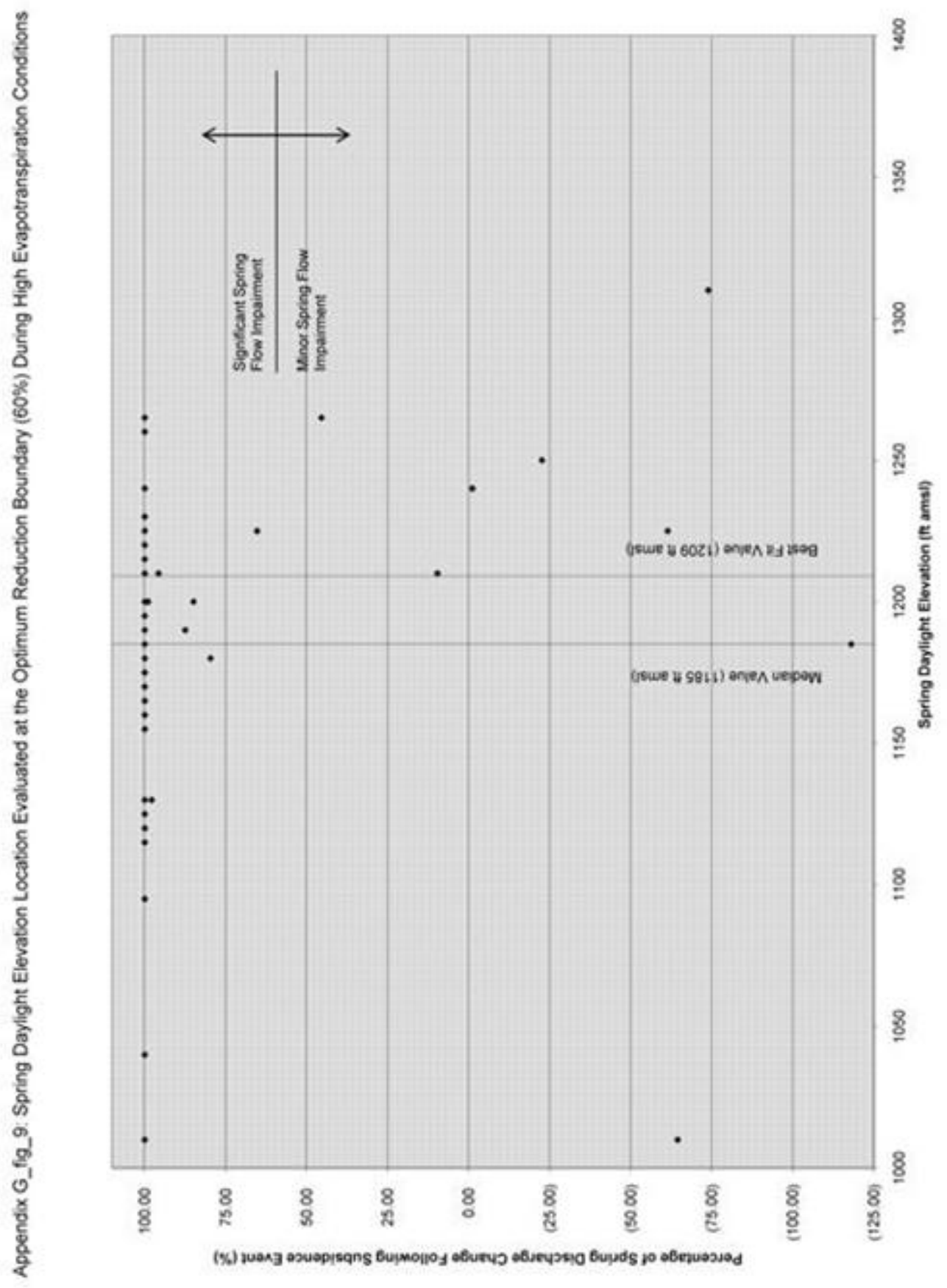


Appendix G_tab_10: Data Used to Determine the Statistical Significance of the Pre-Mine Averaged Low Flow Spring Discharge Data Trend at the Optimum Discharge Reduction Boundary During High Evapotranspiration Conditions.

\begin{tabular}{|c|c|c|c|c|}
\hline \multirow[t]{2}{*}{ Spring No. } & \multirow{2}{*}{$\begin{array}{c}\text { Optimum Discharge Reduction Boundary } \\
\text { High ET }(60 \%) \\
\end{array}$} & \multicolumn{3}{|c|}{ Pre-Mine Averaged Low Flow Spring Discharge (gpm) } \\
\hline & & All & $>1=60 \%$ & $<60 \%$ \\
\hline 33 & $(1)$ & 0.27 & $\mathrm{n} / \mathrm{a}$ & 0.27 \\
\hline 198 & (23) & 0.50 & $\mathrm{n} / \mathrm{a}$ & 0.50 \\
\hline 155 & 100 & 0.26 & 0.26 & $\mathrm{n} / \mathrm{a}$ \\
\hline 166 & 100 & 0.32 & 0.32 & $\mathrm{n} / \mathrm{a}$ \\
\hline \multicolumn{5}{|l|}{167} \\
\hline \multicolumn{5}{|l|}{173} \\
\hline \multicolumn{5}{|l|}{174} \\
\hline \multicolumn{5}{|l|}{177} \\
\hline \multicolumn{5}{|l|}{199} \\
\hline \multicolumn{5}{|l|}{224} \\
\hline \multicolumn{5}{|l|}{249} \\
\hline 254 & & & & \\
\hline 259 & & & & \\
\hline 263 & & & & \\
\hline 272 & & & & \\
\hline 35 & & & & \\
\hline 36 & & & & \\
\hline 41 & & & & \\
\hline 63 & & & & \\
\hline 64 & & & & \\
\hline 84 & & & & \\
\hline 94 & & & & \\
\hline 269 & $(61)$ & 0.44 & $\mathrm{n} / \mathrm{a}$ & 0.44 \\
\hline 271 & (74) & 0.69 & $\mathrm{n} / \mathrm{a}$ & 0.69 \\
\hline 297 & 10 & 0.62 & $\mathrm{n} / \mathrm{a}$ & 0.62 \\
\hline 268 & $(118)$ & 0.61 & $\mathrm{n} / \mathrm{a}$ & 0.61 \\
\hline 99A & 100 & 0.35 & 0.35 & $\mathrm{n} / \mathrm{a}$ \\
\hline 258 & 100 & 0.38 & 0.38 & $\mathrm{n} / \mathrm{a}$ \\
\hline 216 & 100 & 0.10 & 0.10 & $\mathrm{n} / \mathrm{a}$ \\
\hline 43 & 80 & 0.13 & 0.13 & $\mathrm{n} / \mathrm{a}$ \\
\hline 38 & 100 & 0.24 & 0.24 & $\mathrm{n} / \mathrm{a}$ \\
\hline 176 & 100 & 0.58 & 0.58 & $\mathrm{n} / \mathrm{a}$ \\
\hline 226 & 100 & 0.14 & 0.14 & $\mathrm{n} / \mathrm{a}$ \\
\hline 154 & & & & \\
\hline 265 & 100 & 0.37 & 0.37 & $\mathrm{n} / \mathrm{a}$ \\
\hline 79 & 100 & 0.05 & 0.05 & $\mathrm{n} / \mathrm{a}$ \\
\hline 99 & 100 & 0.05 & 0.05 & $\mathrm{n} / \mathrm{a}$ \\
\hline 107 & 85 & 0.73 & 0.73 & $\mathrm{n} / \mathrm{a}$ \\
\hline 270 & & & & \\
\hline 102 & 100 & 1.56 & 1.56 & $\mathrm{n} / \mathrm{a}$ \\
\hline 260 & & & & \\
\hline 267 & 96 & 0.29 & 0.29 & $\mathrm{n} / \mathrm{a}$ \\
\hline 97 & 45 & 0.44 & $\mathrm{n} / \mathrm{a}$ & 0.44 \\
\hline 92 & & & & \\
\hline 106 & 100 & 0.28 & 0.28 & $\mathrm{n} / \mathrm{a}$ \\
\hline 93 & 100 & 0.30 & 0.30 & $\mathrm{n} / \mathrm{a}$ \\
\hline 171 & & & & \\
\hline 175 & 100 & 0.13 & 0.13 & $n / a$ \\
\hline 274 & 100 & 0.09 & 0.09 & $\mathrm{n} / \mathrm{a}$ \\
\hline 102A & 99 & 0.94 & 0.94 & $\mathrm{n} / \mathrm{a}$ \\
\hline 273 & & & & \\
\hline 256 & 88 & 0.32 & 0.32 & $\mathrm{n} / \mathrm{a}$ \\
\hline 169 & 65 & 0.64 & 0.64 & $\mathrm{n} / \mathrm{a}$ \\
\hline 91 & & & & \\
\hline 90 & 100 & 1.36 & 1.36 & $\mathrm{n} / \mathrm{a}$ \\
\hline 152 & 100 & 0.09 & 0.09 & $\mathrm{n} / \mathrm{a}$ \\
\hline 39 & & & & \\
\hline 165 & $(64)$ & 0.45 & $\mathrm{n} / \mathrm{a}$ & 0.45 \\
\hline 101 & 98 & 0.46 & 0.46 & $\mathrm{n} / \mathrm{a}$ \\
\hline 83 & 100 & 0.15 & 0.15 & $\mathrm{n} / \mathrm{a}$ \\
\hline$n$ & & 34 & & \\
\hline Median Value & & 0.34 & & \\
\hline Interpreted Best Fit Value & & 0.43 & & \\
\hline (A) \# of Undermined Spring & Best Fit Value w $/>/=50 \%$ Discharge Reduction & & 7 & \\
\hline (B) \# of Undermined Springs & Best Fit Value w $/<50 \%$ Discharge Reduction & & & 7 \\
\hline (C) \# of Undermined Springs & est Fit Value w $/>/=50 \%$ Discharge Reduction & & 19 & \\
\hline (D) \# of Undermined Springs & est Fit Value w $/<50 \%$ Discharge Reduction & & & 1 \\
\hline Absolute Value (AD-BC) & & 126 & & \\
\hline Chi Square Value at 1 Degre & Freedom & 6.93602 & & \\
\hline Error Probability as Derived & Chi Square Contingency Test & $0.01-0.001$ & & \\
\hline Error Probability as Derived & Fisher Exact Probability Test & 0.00395 & & \\
\hline
\end{tabular}




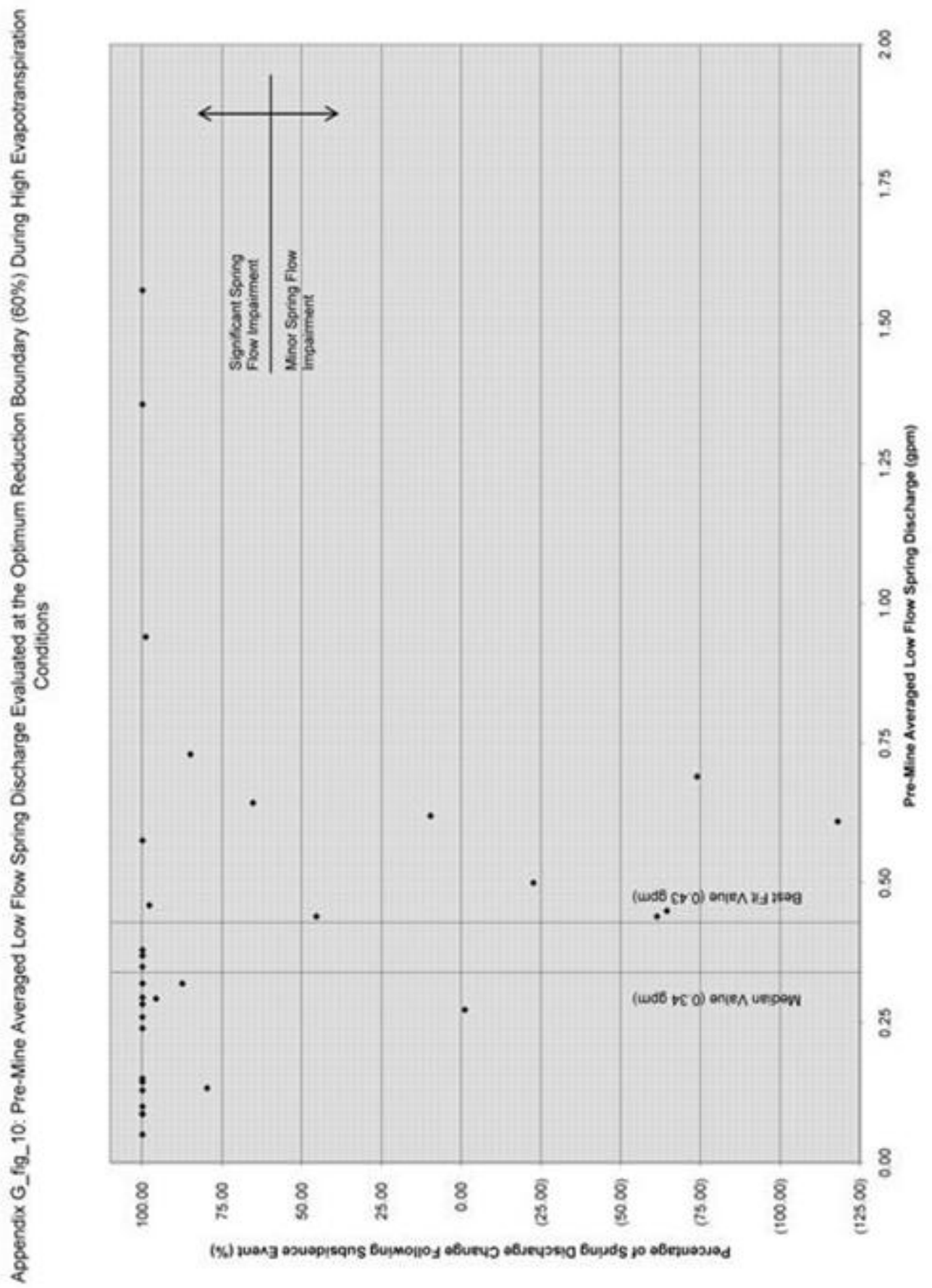


Appendix G_tab_11: Data Used to Determine the Statistical Significance of the Spring Recharge Line Length Component Perpendicular to Longw all Face Data Trend at the Absolute Discharge Reduction Boundary During High Evapotranspiration Conditions.

\begin{tabular}{|c|c|c|c|c|}
\hline Spring No. & Absolute Discharge Reduction Boundary & Spring Rechar & mponent $\mathrm{Pe}$ & $v$ all Face $(\mathrm{ft})$ \\
\hline & High ET $(80 \%)$ & All & $>/=80 \%$ & $<80 \%$ \\
\hline 33 & & & & \\
\hline 198 & (23) & 100 & $\mathrm{n} / \mathrm{a}$ & 100 \\
\hline 155 & 100 & 15 & 15 & $\mathrm{n} / \mathrm{a}$ \\
\hline 166 & 100 & 30 & 30 & $\mathrm{n} / \mathrm{a}$ \\
\hline 167 & 100 & 160 & 160 & $n / a$ \\
\hline 173 & 100 & 140 & 140 & $\mathrm{n} / \mathrm{a}$ \\
\hline 174 & & & & \\
\hline 177 & 100 & 280 & 280 & $\mathrm{n} / \mathrm{a}$ \\
\hline 199 & 100 & 220 & 220 & $\mathrm{n} / \mathrm{a}$ \\
\hline 224 & 100 & 120 & 120 & $\mathrm{n} / \mathrm{a}$ \\
\hline 249 & 100 & 350 & 350 & $\mathrm{n} / \mathrm{a}$ \\
\hline 254 & 100 & 360 & 360 & $\mathrm{n} / \mathrm{a}$ \\
\hline 259 & 100 & 100 & 100 & $\mathrm{n} / \mathrm{a}$ \\
\hline 263 & 100 & 15 & 15 & $\mathrm{n} / \mathrm{a}$ \\
\hline 272 & 100 & 30 & 30 & $\mathrm{n} / \mathrm{a}$ \\
\hline 35 & 100 & 70 & 70 & $n / a$ \\
\hline 36 & 100 & 50 & 50 & $\mathrm{n} / \mathrm{a}$ \\
\hline 41 & 100 & 40 & 40 & $\mathrm{n} / \mathrm{a}$ \\
\hline 63 & 100 & 370 & 370 & $\mathrm{n} / \mathrm{a}$ \\
\hline 64 & 100 & 300 & 300 & $\mathrm{n} / \mathrm{a}$ \\
\hline 84 & 100 & 220 & 220 & $\mathrm{n} / \mathrm{a}$ \\
\hline 94 & 100 & 50 & 50 & $\mathrm{n} / \mathrm{a}$ \\
\hline 269 & (61) & 140 & $\mathrm{n} / \mathrm{a}$ & 140 \\
\hline 271 & (74) & 110 & $\mathrm{n} / \mathrm{a}$ & 110 \\
\hline 297 & 10 & 65 & $\mathrm{n} / \mathrm{a}$ & 65 \\
\hline 268 & (118) & 70 & $\mathrm{n} / \mathrm{a}$ & 70 \\
\hline $99 \mathrm{~A}$ & 100 & 75 & 75 & $\mathrm{n} / \mathrm{a}$ \\
\hline 258 & 100 & 225 & 225 & $\mathrm{n} / \mathrm{a}$ \\
\hline 216 & 100 & 40 & 40 & $\mathrm{n} / \mathrm{a}$ \\
\hline 43 & 80 & 20 & $\mathrm{n} / \mathrm{a}$ & 20 \\
\hline 38 & 100 & 20 & 20 & $\mathrm{n} / \mathrm{a}$ \\
\hline 176 & 100 & 340 & 340 & $\mathrm{n} / \mathrm{a}$ \\
\hline 226 & 100 & 260 & 260 & $\mathrm{n} / \mathrm{a}$ \\
\hline 154 & & & & \\
\hline 265 & 100 & 140 & 140 & $n / a$ \\
\hline 79 & 100 & 110 & 110 & $\mathrm{n} / \mathrm{a}$ \\
\hline 99 & 100 & 15 & 15 & $\mathrm{n} / \mathrm{a}$ \\
\hline 107 & & & & \\
\hline 270 & & & & \\
\hline 102 & 100 & 280 & 280 & $\mathrm{n} / \mathrm{a}$ \\
\hline 260 & & & & \\
\hline 267 & 96 & 250 & 250 & $\mathrm{n} / \mathrm{a}$ \\
\hline 97 & 45 & 100 & $\mathrm{n} / \mathrm{a}$ & 100 \\
\hline 92 & & & & \\
\hline 106 & 100 & 220 & 220 & $\mathrm{n} / \mathrm{a}$ \\
\hline 93 & 100 & 220 & 220 & $\mathrm{n} / \mathrm{a}$ \\
\hline 171 & & & & \\
\hline 175 & 100 & 30 & 30 & $\mathrm{n} / \mathrm{a}$ \\
\hline 274 & 100 & 440 & 440 & $\mathrm{n} / \mathrm{a}$ \\
\hline 102A & 99 & 180 & 180 & $\mathrm{n} / \mathrm{a}$ \\
\hline 273 & & & & \\
\hline 256 & 88 & 200 & 200 & $\mathrm{n} / \mathrm{a}$ \\
\hline 169 & 65 & 90 & $\mathrm{n} / \mathrm{a}$ & 90 \\
\hline 91 & & & & \\
\hline 90 & 100 & 50 & 50 & $\mathrm{n} / \mathrm{a}$ \\
\hline 152 & 100 & 80 & 80 & $\mathrm{n} / \mathrm{a}$ \\
\hline 39 & & & & \\
\hline 165 & (64) & 90 & $\mathrm{n} / \mathrm{a}$ & 90 \\
\hline 101 & 98 & 370 & 370 & $\mathrm{n} / \mathrm{a}$ \\
\hline 83 & 100 & 50 & 50 & $\mathrm{n} / \mathrm{a}$ \\
\hline$n$ & & 49 & & \\
\hline Median Value & & 110 & & \\
\hline Interpreted Best Fit Value & & 101 & & \\
\hline (A) \# of Undermined Spring & 3est Fit Value $w />/=50 \%$ Discharge Reduction & & 23 & \\
\hline (B) \# of Undermined Springs & Best Fit Value w $/<50 \%$ Discharge Reduction & & & 2 \\
\hline (C) \# of Undermined Springs & st Fit Value $w />/=50 \%$ Discharge Reduction & & 17 & \\
\hline (D) \# of Undermined Springs & st Fit Value $w /<50 \%$ Discharge Reduction & & & 7 \\
\hline Absolute Value (AD-BC) & & 127 & & \\
\hline Chi Square Value at 1 Degre & reedom & 2.38336 & & \\
\hline Error Probability as Derived & Chi Square Contingency Test & $0.20-0.10$ & & \\
\hline Error Probability as Derived & isher Exact Probability Test & 0.06013 & & \\
\hline
\end{tabular}




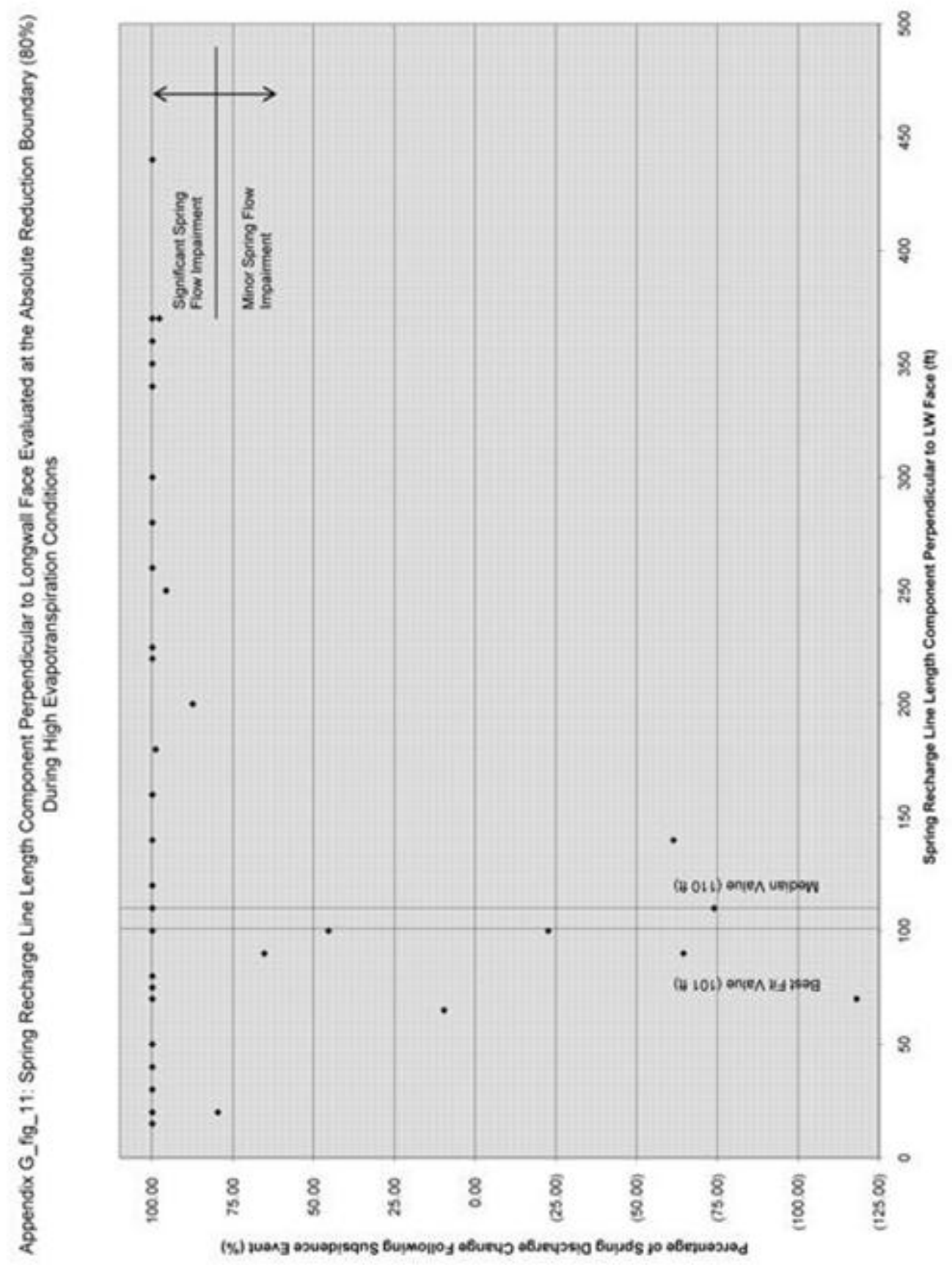


Appendix G_tab_12: Data Used to Determine the Statistical Significance of the Spring Recharge Line Length Data Trend at the Absolute Discharge Reduction Boundary During High Evapotranspiration Conditions.

\begin{tabular}{|c|c|c|c|c|}
\hline \multirow[t]{2}{*}{ Spring No. } & \multirow{2}{*}{$\begin{array}{c}\text { Absolute Discharge Reduction Boundary } \\
\text { High ET }(80 \%)\end{array}$} & \multicolumn{3}{|c|}{ Spring Recharge Line Length (ft) } \\
\hline & & All & $>l=80 \%$ & $<80 \%$ \\
\hline 33 & (1) & 157 & $\mathrm{n} / \mathrm{a}$ & 157 \\
\hline 198 & (23) & 170 & $\mathrm{n} / \mathrm{a}$ & 170 \\
\hline 155 & 100 & 188 & 188 & $\mathrm{n} / \mathrm{a}$ \\
\hline 166 & 100 & 94 & 94 & $\mathrm{n} / \mathrm{a}$ \\
\hline 167 & 100 & 219 & 219 & $\mathrm{n} / \mathrm{a}$ \\
\hline 173 & 100 & 219 & 219 & $\mathrm{n} / \mathrm{a}$ \\
\hline 174 & 100 & 94 & 94 & $\mathrm{n} / \mathrm{a}$ \\
\hline 177 & 100 & 310 & 310 & $\mathrm{n} / \mathrm{a}$ \\
\hline 199 & 100 & 188 & 188 & $\mathrm{n} / \mathrm{a}$ \\
\hline 224 & 100 & 120 & 120 & $\mathrm{n} / \mathrm{a}$ \\
\hline 249 & 100 & 407 & 407 & $\mathrm{n} / \mathrm{a}$ \\
\hline 254 & 100 & 375 & 375 & $\mathrm{n} / \mathrm{a}$ \\
\hline 259 & 100 & 657 & 657 & $\mathrm{n} / \mathrm{a}$ \\
\hline 263 & 100 & 63 & 63 & $\mathrm{n} / \mathrm{a}$ \\
\hline 272 & 100 & 219 & 219 & $\mathrm{n} / \mathrm{a}$ \\
\hline 35 & 100 & 157 & 157 & $\mathrm{n} / \mathrm{a}$ \\
\hline 36 & 100 & 125 & 125 & $\mathrm{n} / \mathrm{a}$ \\
\hline 41 & 100 & 63 & 63 & $\mathrm{n} / \mathrm{a}$ \\
\hline 63 & 100 & 532 & 532 & $\mathrm{n} / \mathrm{a}$ \\
\hline 64 & 100 & 438 & 438 & $\mathrm{n} / \mathrm{a}$ \\
\hline 84 & 100 & 750 & 750 & $\mathrm{n} / \mathrm{a}$ \\
\hline 94 & 100 & 125 & 125 & $\mathrm{n} / \mathrm{a}$ \\
\hline 269 & (61) & 157 & $\mathrm{n} / \mathrm{a}$ & 157 \\
\hline 271 & (74) & 125 & $\mathrm{n} / \mathrm{a}$ & 125 \\
\hline 297 & 10 & 94 & $\mathrm{n} / \mathrm{a}$ & 94 \\
\hline 268 & (118) & 282 & $\mathrm{n} / \mathrm{a}$ & 282 \\
\hline $99 \mathrm{~A}$ & 100 & 75 & 75 & $\mathrm{n} / \mathrm{a}$ \\
\hline 258 & 100 & 532 & 532 & $\mathrm{n} / \mathrm{a}$ \\
\hline 216 & 100 & 360 & 360 & $\mathrm{n} / \mathrm{a}$ \\
\hline 43 & 80 & 63 & $\mathrm{n} / \mathrm{a}$ & 63 \\
\hline 38 & 100 & 282 & 282 & $\mathrm{n} / \mathrm{a}$ \\
\hline 176 & 100 & 375 & 375 & $\mathrm{n} / \mathrm{a}$ \\
\hline 226 & 100 & 313 & 313 & $\mathrm{n} / \mathrm{a}$ \\
\hline \multicolumn{5}{|l|}{154} \\
\hline 265 & 100 & 594 & 594 & $\mathrm{n} / \mathrm{a}$ \\
\hline 79 & 100 & 188 & 188 & $\mathrm{n} / \mathrm{a}$ \\
\hline 99 & 100 & 32 & 32 & $\mathrm{n} / \mathrm{a}$ \\
\hline 107 & 85 & 90 & 90 & $\mathrm{n} / \mathrm{a}$ \\
\hline \multicolumn{5}{|l|}{270} \\
\hline 102 & 100 & 313 & 313 & $\mathrm{n} / \mathrm{a}$ \\
\hline \multicolumn{5}{|l|}{260} \\
\hline 267 & 96 & 750 & 750 & $\mathrm{n} / \mathrm{a}$ \\
\hline 97 & 45 & 157 & $\mathrm{n} / \mathrm{a}$ & 157 \\
\hline \multicolumn{5}{|l|}{92} \\
\hline 106 & 100 & 250 & 250 & $\mathrm{n} / \mathrm{a}$ \\
\hline 93 & 100 & 330 & 330 & $\mathrm{n} / \mathrm{a}$ \\
\hline \multicolumn{5}{|l|}{171} \\
\hline 175 & 100 & 94 & 94 & $\mathrm{n} / \mathrm{a}$ \\
\hline 274 & 100 & 469 & 469 & $\mathrm{n} / \mathrm{a}$ \\
\hline $102 \mathrm{~A}$ & 99 & 532 & 532 & $\mathrm{n} / \mathrm{a}$ \\
\hline \multicolumn{5}{|l|}{273} \\
\hline 256 & 88 & 250 & 250 & $\mathrm{n} / \mathrm{a}$ \\
\hline 169 & 65 & 344 & $\mathrm{n} / \mathrm{a}$ & 344 \\
\hline \multicolumn{5}{|l|}{91} \\
\hline 90 & 100 & 313 & 313 & $\mathrm{n} / \mathrm{a}$ \\
\hline 152 & 100 & 188 & 188 & $\mathrm{n} / \mathrm{a}$ \\
\hline 39 & & & & \\
\hline 165 & (64) & 188 & $\mathrm{n} / \mathrm{a}$ & 188 \\
\hline 101 & 98 & 625 & 625 & $\mathrm{n} / \mathrm{a}$ \\
\hline 83 & 100 & 813 & 813 & $\mathrm{n} / \mathrm{a}$ \\
\hline $\mathrm{n}$ & & 52 & & \\
\hline Median Value & & 219 & & \\
\hline Interpreted Best Fit Value & & 189 & & \\
\hline (A) \# of Undermined Spring & Best Fit Value $\mathrm{w} />/=50 \%$ Discharge Reduction & & 26 & \\
\hline (B) \# of Undermined Spring & Best Fit Value w $/<50 \%$ Discharge Reduction & & & 2 \\
\hline (C) \# of Undermined Spring & st Fit Value $w />/=50 \%$ Discharge Reduction & & 16 & \\
\hline (D) \# of Undermined Spring & st Fit Value w/ < 50\% Discharge Reduction & & & 8 \\
\hline Absolute Value (AD-BC) & & 176 & & \\
\hline Chi Square Value at 1 Degr & Freedom & 4.14541 & & \\
\hline Error Probability as Derived & Chi Square Contingency Test & $0.05-0.02$ & & \\
\hline Error Probability as Derived & Fisher Exact Probability Test & 0.02001 & & \\
\hline
\end{tabular}




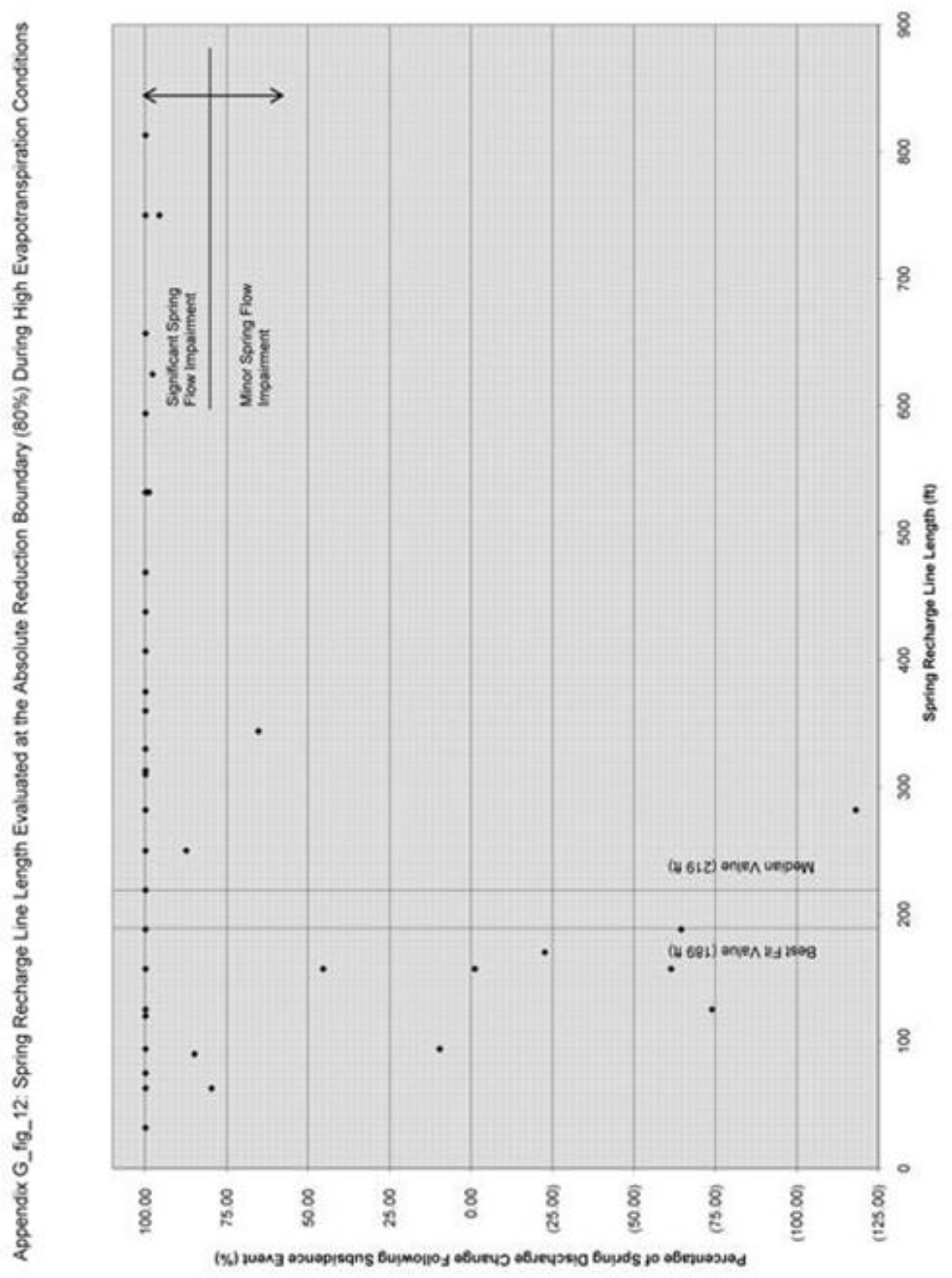


Appendix G_tab_13: Data Used to Determine the Statistical Significance of the Spring Recharge Line Vertical Relief Data Trend at the Absolute Discharge Reduction Boundary During High Evapotranspiration Conditions.

\begin{tabular}{|c|c|c|c|c|}
\hline Spring No. & Absolute Discharge Reduction Boundary & & ge Line Ve & \\
\hline & High ET $(80 \%)$ & All & $>l=80 \%$ & $<80 \%$ \\
\hline 33 & (1) & 30 & $\mathrm{n} / \mathrm{a}$ & 30 \\
\hline 198 & $(23)$ & 20 & $\mathrm{n} / \mathrm{a}$ & 20 \\
\hline 155 & 100 & 40 & 40 & $\mathrm{n} / \mathrm{a}$ \\
\hline 166 & 100 & 20 & 20 & $\mathrm{n} / \mathrm{a}$ \\
\hline 167 & 100 & 40 & 40 & $\mathrm{n} / \mathrm{a}$ \\
\hline 173 & 100 & 35 & 35 & $\mathrm{n} / \mathrm{a}$ \\
\hline 174 & 100 & 25 & 25 & $\mathrm{n} / \mathrm{a}$ \\
\hline 177 & 100 & 60 & 60 & $\mathrm{n} / \mathrm{a}$ \\
\hline 199 & 100 & 50 & 50 & $\mathrm{n} / \mathrm{a}$ \\
\hline 224 & 100 & 20 & 20 & $\mathrm{n} / \mathrm{a}$ \\
\hline 249 & 100 & 0 & 0 & $\mathrm{n} / \mathrm{a}$ \\
\hline 254 & 100 & 105 & 105 & $\mathrm{n} / \mathrm{a}$ \\
\hline 259 & 100 & 80 & 80 & $\mathrm{n} / \mathrm{a}$ \\
\hline 263 & 100 & 15 & 15 & $\mathrm{n} / \mathrm{a}$ \\
\hline 272 & 100 & 50 & 50 & $\mathrm{n} / \mathrm{a}$ \\
\hline 35 & 100 & 50 & 50 & $\mathrm{n} / \mathrm{a}$ \\
\hline 36 & 100 & 30 & 30 & $\mathrm{n} / \mathrm{a}$ \\
\hline 41 & 100 & 5 & 5 & $\mathrm{n} / \mathrm{a}$ \\
\hline 63 & 100 & 100 & 100 & $\mathrm{n} / \mathrm{a}$ \\
\hline 64 & 100 & 80 & 80 & $\mathrm{n} / \mathrm{a}$ \\
\hline 84 & 100 & 195 & 195 & $\mathrm{n} / \mathrm{a}$ \\
\hline 94 & 100 & 20 & 20 & $\mathrm{n} / \mathrm{a}$ \\
\hline 269 & (61) & 30 & $\mathrm{n} / \mathrm{a}$ & 30 \\
\hline 271 & (74) & 15 & $\mathrm{n} / \mathrm{a}$ & 15 \\
\hline 297 & 10 & 15 & $\mathrm{n} / \mathrm{a}$ & 15 \\
\hline 268 & (118) & 25 & $\mathrm{n} / \mathrm{a}$ & 25 \\
\hline $99 \mathrm{~A}$ & 100 & 15 & 15 & $\mathrm{n} / \mathrm{a}$ \\
\hline 258 & 100 & 45 & 45 & $\mathrm{n} / \mathrm{a}$ \\
\hline 216 & 100 & 75 & 75 & $\mathrm{n} / \mathrm{a}$ \\
\hline 43 & 80 & 15 & $\mathrm{n} / \mathrm{a}$ & 15 \\
\hline 38 & 100 & 55 & 55 & $\mathrm{n} / \mathrm{a}$ \\
\hline 176 & 100 & 70 & 70 & $\mathrm{n} / \mathrm{a}$ \\
\hline 226 & 100 & 60 & 60 & $\mathrm{n} / \mathrm{a}$ \\
\hline 154 & & & & \\
\hline 265 & 100 & 75 & 75 & $\mathrm{n} / \mathrm{a}$ \\
\hline 79 & 100 & 30 & 30 & $\mathrm{n} / \mathrm{a}$ \\
\hline 99 & 100 & 5 & 5 & $\mathrm{n} / \mathrm{a}$ \\
\hline 107 & 85 & 10 & 10 & $\mathrm{n} / \mathrm{a}$ \\
\hline 270 & & & & \\
\hline 102 & 100 & 25 & 25 & $\mathrm{n} / \mathrm{a}$ \\
\hline 260 & & & & \\
\hline 267 & 96 & 160 & 160 & $\mathrm{n} / \mathrm{a}$ \\
\hline 97 & 45 & 30 & $\mathrm{n} / \mathrm{a}$ & 30 \\
\hline 92 & & & & \\
\hline 106 & 100 & 45 & 45 & $\mathrm{n} / \mathrm{a}$ \\
\hline 93 & 100 & 80 & 80 & $\mathrm{n} / \mathrm{a}$ \\
\hline 171 & & & & \\
\hline 175 & 100 & 10 & 10 & $\mathrm{n} / \mathrm{a}$ \\
\hline 274 & 100 & 100 & 100 & $\mathrm{n} / \mathrm{a}$ \\
\hline $102 \mathrm{~A}$ & 99 & 60 & 60 & $\mathrm{n} / \mathrm{a}$ \\
\hline 273 & & & & \\
\hline 256 & 88 & 35 & 35 & $\mathrm{n} / \mathrm{a}$ \\
\hline 169 & 65 & 70 & $\mathrm{n} / \mathrm{a}$ & 70 \\
\hline 91 & & & & \\
\hline 90 & 100 & 10 & 10 & $\mathrm{n} / \mathrm{a}$ \\
\hline 152 & 100 & 40 & 40 & $\mathrm{n} / \mathrm{a}$ \\
\hline 39 & & & & \\
\hline 165 & (64) & 45 & $\mathrm{n} / \mathrm{a}$ & 45 \\
\hline 101 & 98 & 145 & 145 & $\mathrm{n} / \mathrm{a}$ \\
\hline 83 & 100 & 195 & 195 & $\mathrm{n} / \mathrm{a}$ \\
\hline $\mathrm{n}$ & & 52 & & \\
\hline Median Value & & 40 & & \\
\hline Interpreted Best Fit Value & & 31 & & \\
\hline (A) \# of Undermined Spring & Best Fit Value $\mathrm{w} />/=50 \%$ Discharge Reduction & & 27 & \\
\hline (B) \# of Undermined Spring & Best Fit Value w $/<50 \%$ Discharge Reduction & & & 2 \\
\hline (C) \# of Undermined Spring & st Fit Value $w />/=50 \%$ Discharge Reduction & & 15 & \\
\hline (D) \# of Undermined Spring & st Fit Value w/ <50\% Discharge Reduction & & & 8 \\
\hline Absolute Value (AD-BC) & & 186 & & \\
\hline Chi Square Value at 1 Degr & Freedom & 4.75191 & & \\
\hline Error Probability as Derived & Chi Square Contingency Test & $0.05-0.02$ & & \\
\hline Error Probability as Derived & Fisher Exact Probability Test & 0.01415 & & \\
\hline
\end{tabular}




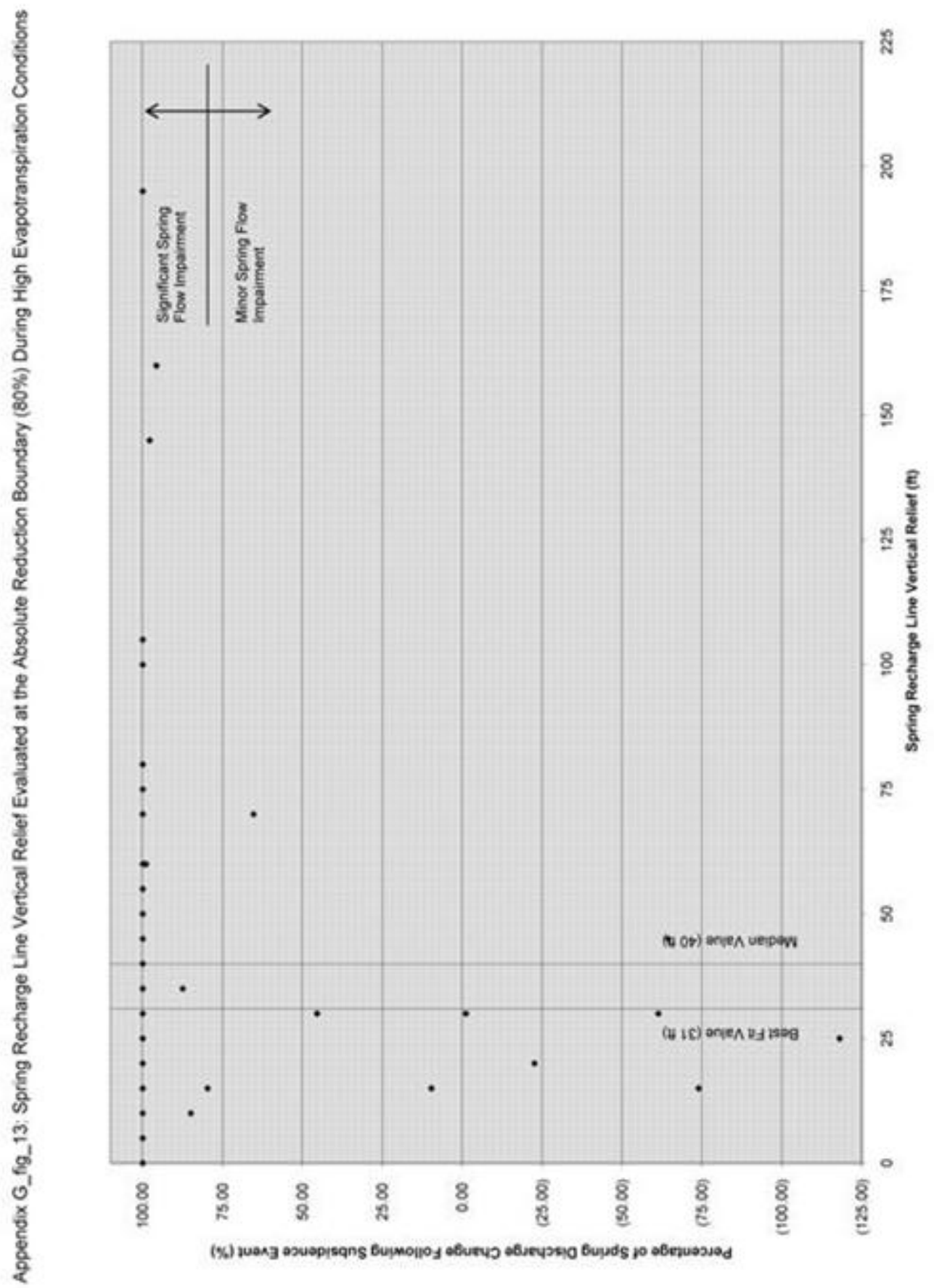


Appendix G_tab_14: Data Used to Determine the Statistical Significance of the Spring Daylight Eevation Data Trend at the Absolute Discharge Reduction Boundary During High Evapotranspiration Conditions.

\begin{tabular}{|c|c|c|c|c|}
\hline Spring No. & Absolute Discharge Reduction Boundary & & light Elevat & \\
\hline & High ET $(80 \%)$ & All & $>1=80 \%$ & $<80 \%$ \\
\hline 33 & (1) & 1240 & $\mathrm{n} / \mathrm{a}$ & 1240 \\
\hline 198 & (23) & 1250 & $\mathrm{n} / \mathrm{a}$ & 1250 \\
\hline 155 & 100 & 1115 & 1115 & $\mathrm{n} / \mathrm{a}$ \\
\hline 166 & 100 & 1130 & 1130 & $\mathrm{n} / \mathrm{a}$ \\
\hline 167 & 100 & 1170 & 1170 & $\mathrm{n} / \mathrm{a}$ \\
\hline 173 & 100 & 1260 & 1260 & $\mathrm{n} / \mathrm{a}$ \\
\hline 174 & 100 & 1230 & 1230 & $\mathrm{n} / \mathrm{a}$ \\
\hline 177 & 100 & 1175 & 1175 & $\mathrm{n} / \mathrm{a}$ \\
\hline 199 & 100 & 1010 & 1010 & $\mathrm{n} / \mathrm{a}$ \\
\hline 224 & 100 & 1215 & 1215 & $\mathrm{n} / \mathrm{a}$ \\
\hline 249 & 100 & 1120 & 1120 & $\mathrm{n} / \mathrm{a}$ \\
\hline 254 & 100 & 1130 & 1130 & $\mathrm{n} / \mathrm{a}$ \\
\hline 259 & 100 & 1155 & 1155 & $\mathrm{n} / \mathrm{a}$ \\
\hline 263 & 100 & 1160 & 1160 & $\mathrm{n} / \mathrm{a}$ \\
\hline 272 & 100 & 1265 & 1265 & $\mathrm{n} / \mathrm{a}$ \\
\hline 35 & 100 & 1185 & 1185 & $\mathrm{n} / \mathrm{a}$ \\
\hline 36 & 100 & 1225 & 1225 & $\mathrm{n} / \mathrm{a}$ \\
\hline 41 & 100 & 1180 & 1180 & $\mathrm{n} / \mathrm{a}$ \\
\hline 63 & 100 & 1165 & 1165 & $\mathrm{n} / \mathrm{a}$ \\
\hline 64 & 100 & 1185 & 1185 & $\mathrm{n} / \mathrm{a}$ \\
\hline 84 & 100 & 1040 & 1040 & $\mathrm{n} / \mathrm{a}$ \\
\hline 94 & 100 & 1155 & 1155 & $\mathrm{n} / \mathrm{a}$ \\
\hline 269 & (61) & 1225 & $\mathrm{n} / \mathrm{a}$ & 1225 \\
\hline 271 & (74) & 1310 & $\mathrm{n} / \mathrm{a}$ & 1310 \\
\hline 297 & 10 & 1210 & $\mathrm{n} / \mathrm{a}$ & 1210 \\
\hline 268 & (118) & 1185 & $\mathrm{n} / \mathrm{a}$ & 1185 \\
\hline $99 \mathrm{~A}$ & 100 & 1190 & 1190 & $\mathrm{n} / \mathrm{a}$ \\
\hline 258 & 100 & 1190 & 1190 & $\mathrm{n} / \mathrm{a}$ \\
\hline 216 & 100 & 1210 & 1210 & $\mathrm{n} / \mathrm{a}$ \\
\hline 43 & 80 & 1180 & $\mathrm{n} / \mathrm{a}$ & 1180 \\
\hline 38 & 100 & 1220 & 1220 & $\mathrm{n} / \mathrm{a}$ \\
\hline 176 & 100 & 1175 & 1175 & $\mathrm{n} / \mathrm{a}$ \\
\hline 226 & 100 & 1195 & 1195 & $\mathrm{n} / \mathrm{a}$ \\
\hline 154 & & & & \\
\hline 265 & 100 & 1200 & 1200 & $\mathrm{n} / \mathrm{a}$ \\
\hline 79 & 100 & 1095 & 1095 & $\mathrm{n} / \mathrm{a}$ \\
\hline 99 & 100 & 1180 & 1180 & $\mathrm{n} / \mathrm{a}$ \\
\hline 107 & 85 & 1200 & 1200 & $\mathrm{n} / \mathrm{a}$ \\
\hline 270 & & & & \\
\hline 102 & 100 & 1160 & 1160 & $\mathrm{n} / \mathrm{a}$ \\
\hline 260 & & & & \\
\hline 267 & 96 & 1210 & 1210 & $\mathrm{n} / \mathrm{a}$ \\
\hline 97 & 45 & 1265 & $\mathrm{n} / \mathrm{a}$ & 1265 \\
\hline 92 & & & & \\
\hline 106 & 100 & 1155 & 1155 & $\mathrm{n} / \mathrm{a}$ \\
\hline 93 & 100 & 1175 & 1175 & $\mathrm{n} / \mathrm{a}$ \\
\hline 171 & & & & \\
\hline 175 & 100 & 1190 & 1190 & $\mathrm{n} / \mathrm{a}$ \\
\hline 274 & 100 & 1240 & 1240 & $\mathrm{n} / \mathrm{a}$ \\
\hline $102 \mathrm{~A}$ & 99 & 1200 & 1200 & $\mathrm{n} / \mathrm{a}$ \\
\hline 273 & & & & \\
\hline 256 & 88 & 1190 & 1190 & $\mathrm{n} / \mathrm{a}$ \\
\hline 169 & 65 & 1225 & $\mathrm{n} / \mathrm{a}$ & 1225 \\
\hline 91 & & & & \\
\hline 90 & 100 & 1125 & 1125 & $\mathrm{n} / \mathrm{a}$ \\
\hline 152 & 100 & 1195 & 1195 & $\mathrm{n} / \mathrm{a}$ \\
\hline 39 & & & & \\
\hline 165 & (64) & 1010 & $\mathrm{n} / \mathrm{a}$ & 1010 \\
\hline 101 & 98 & 1130 & 1130 & $\mathrm{n} / \mathrm{a}$ \\
\hline 83 & 100 & 1040 & 1040 & $\mathrm{n} / \mathrm{a}$ \\
\hline $\mathrm{n}$ & & 52 & & \\
\hline Median Value & & 1185 & & \\
\hline Interpreted Best Fit Value & & 1209 & & \\
\hline (A) \# of Undermined Spring & Best Fit Value $\mathrm{w} />/=50 \%$ Discharge Reduction & & 9 & \\
\hline (B) \# of Undermined Spring & Best Fit Value w $/<50 \%$ Discharge Reduction & & & 7 \\
\hline (C) \# of Undermined Spring & st Fit Value $w />/=50 \%$ Discharge Reduction & & 33 & \\
\hline (D) \# of Undermined Spring & st Fit Value w/ <50\% Discharge Reduction & & & 3 \\
\hline Absolute Value (AD-BC) & & 204 & & \\
\hline Chi Square Value at 1 Degr & Freedom & 6.81038 & & \\
\hline Error Probability as Derived & Chi Square Contingency Test & $0.01-0.001$ & & \\
\hline Error Probability as Derived & Fisher Exact Probability Test & 0.0057 & & \\
\hline
\end{tabular}




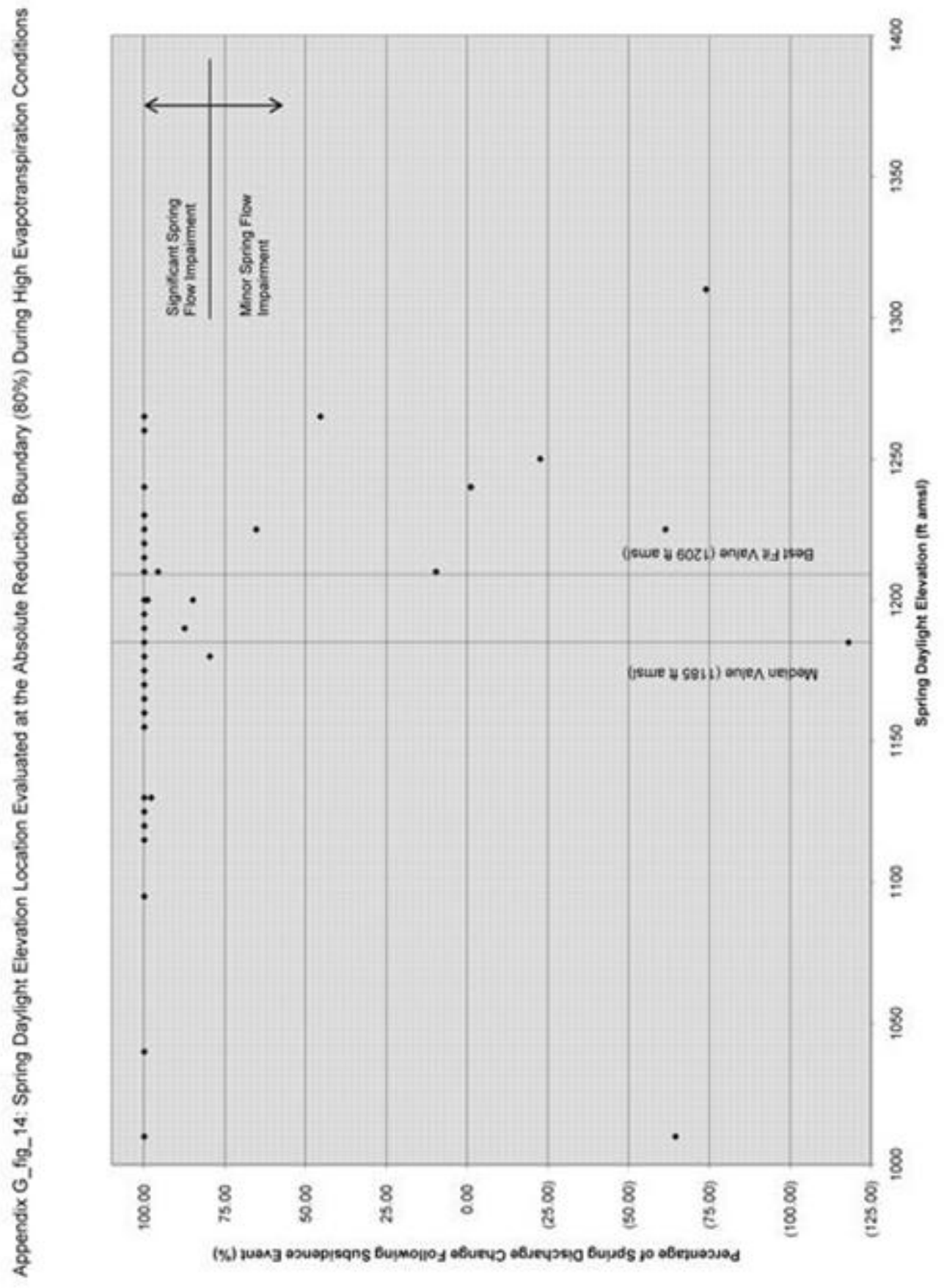


Appendix G_tab_15: Data Used to Determine the Statistical Significance of the Pre-Mine Averaged Low Flow Spring Discharge Data Trend at the Absolute Discharge Reduction Boundary During High Evapotranspiration Conditions.

\begin{tabular}{|c|c|c|c|c|}
\hline \multirow[t]{2}{*}{ Spring No. } & \multirow{2}{*}{$\begin{array}{c}\text { Absolute Discharge Reduction Boundary } \\
\text { High ET }(80 \%)\end{array}$} & \multicolumn{3}{|c|}{ Pre-Mine Averaged Low Flow Spring Discharge (gpm) } \\
\hline & & All & $>1=80 \%$ & $<80 \%$ \\
\hline 33 & $(1)$ & 0.27 & $\mathrm{n} / \mathrm{a}$ & 0.27 \\
\hline 198 & (23) & 0.50 & $\mathrm{n} / \mathrm{a}$ & 0.50 \\
\hline 155 & 100 & 0.26 & 0.26 & $\mathrm{n} / \mathrm{a}$ \\
\hline 166 & 100 & 0.32 & 0.32 & $\mathrm{n} / \mathrm{a}$ \\
\hline \multicolumn{5}{|l|}{167} \\
\hline \multicolumn{5}{|l|}{173} \\
\hline \multicolumn{5}{|l|}{174} \\
\hline \multicolumn{5}{|l|}{177} \\
\hline \multicolumn{5}{|l|}{199} \\
\hline \multicolumn{5}{|l|}{224} \\
\hline \multicolumn{5}{|l|}{249} \\
\hline 254 & & & & \\
\hline 259 & & & & \\
\hline 263 & & & & \\
\hline 272 & & & & \\
\hline 35 & & & & \\
\hline 36 & & & & \\
\hline 41 & & & & \\
\hline 63 & & & & \\
\hline 64 & & & & \\
\hline 84 & & & & \\
\hline 94 & & & & \\
\hline 269 & $(61)$ & 0.44 & $\mathrm{n} / \mathrm{a}$ & 0.44 \\
\hline 271 & (74) & 0.69 & $\mathrm{n} / \mathrm{a}$ & 0.69 \\
\hline 297 & 10 & 0.62 & $\mathrm{n} / \mathrm{a}$ & 0.62 \\
\hline 268 & $(118)$ & 0.61 & $\mathrm{n} / \mathrm{a}$ & 0.61 \\
\hline 99A & 100 & 0.35 & 0.35 & $\mathrm{n} / \mathrm{a}$ \\
\hline 258 & 100 & 0.38 & 0.38 & $\mathrm{n} / \mathrm{a}$ \\
\hline 216 & 100 & 0.10 & 0.10 & $\mathrm{n} / \mathrm{a}$ \\
\hline 43 & 80 & 0.13 & $\mathrm{n} / \mathrm{a}$ & 0.13 \\
\hline 38 & 100 & 0.24 & 0.24 & $\mathrm{n} / \mathrm{a}$ \\
\hline 176 & 100 & 0.58 & 0.58 & $\mathrm{n} / \mathrm{a}$ \\
\hline 226 & 100 & 0.14 & 0.14 & $\mathrm{n} / \mathrm{a}$ \\
\hline 154 & & & & \\
\hline 265 & 100 & 0.37 & 0.37 & $\mathrm{n} / \mathrm{a}$ \\
\hline 79 & 100 & 0.05 & 0.05 & $\mathrm{n} / \mathrm{a}$ \\
\hline 99 & 100 & 0.05 & 0.05 & $\mathrm{n} / \mathrm{a}$ \\
\hline 107 & 85 & 0.73 & 0.73 & $\mathrm{n} / \mathrm{a}$ \\
\hline 270 & & & & \\
\hline 102 & 100 & 1.56 & 1.56 & $\mathrm{n} / \mathrm{a}$ \\
\hline 260 & & & & \\
\hline 267 & 96 & 0.29 & 0.29 & $\mathrm{n} / \mathrm{a}$ \\
\hline 97 & 45 & 0.44 & $\mathrm{n} / \mathrm{a}$ & 0.44 \\
\hline 92 & & & & \\
\hline 106 & 100 & 0.28 & 0.28 & $\mathrm{n} / \mathrm{a}$ \\
\hline 93 & 100 & 0.30 & 0.30 & $\mathrm{n} / \mathrm{a}$ \\
\hline 171 & & & & \\
\hline 175 & 100 & 0.13 & 0.13 & $n / a$ \\
\hline 274 & 100 & 0.09 & 0.09 & $\mathrm{n} / \mathrm{a}$ \\
\hline 102A & 99 & 0.94 & 0.94 & $\mathrm{n} / \mathrm{a}$ \\
\hline 273 & & & & \\
\hline 256 & 88 & 0.32 & 0.32 & $\mathrm{n} / \mathrm{a}$ \\
\hline 169 & 65 & 0.64 & $\mathrm{n} / \mathrm{a}$ & 0.64 \\
\hline 91 & & & & \\
\hline 90 & 100 & 1.36 & 1.36 & $\mathrm{n} / \mathrm{a}$ \\
\hline 152 & 100 & 0.09 & 0.09 & $\mathrm{n} / \mathrm{a}$ \\
\hline 39 & & & & \\
\hline 165 & $(64)$ & 0.45 & $\mathrm{n} / \mathrm{a}$ & 0.45 \\
\hline 101 & 98 & 0.46 & 0.46 & $\mathrm{n} / \mathrm{a}$ \\
\hline 83 & 100 & 0.15 & 0.15 & $\mathrm{n} / \mathrm{a}$ \\
\hline$n$ & & 34 & & \\
\hline Median Value & & 0.34 & & \\
\hline Interpreted Best Fit Value & & 0.43 & & \\
\hline (A) \# of Undermined Spring & Best Fit Value w $/>/=50 \%$ Discharge Reduction & & 6 & \\
\hline (B) \# of Undermined Springs & Best Fit Value w $/<50 \%$ Discharge Reduction & & & 8 \\
\hline (C) \# of Undermined Springs & est Fit Value w $/>/=50 \%$ Discharge Reduction & & 18 & \\
\hline (D) \# of Undermined Springs & est Fit Value w $/<50 \%$ Discharge Reduction & & & 2 \\
\hline Absolute Value (AD-BC) & & 132 & & \\
\hline Chi Square Value at 1 Degre & Freedom & 6.69122 & & \\
\hline Error Probability as Derived & Chi Square Contingency Test & $0.01-0.001$ & & \\
\hline Error Probability as Derived & Fisher Exact Probability Test & 0.00466 & & \\
\hline
\end{tabular}




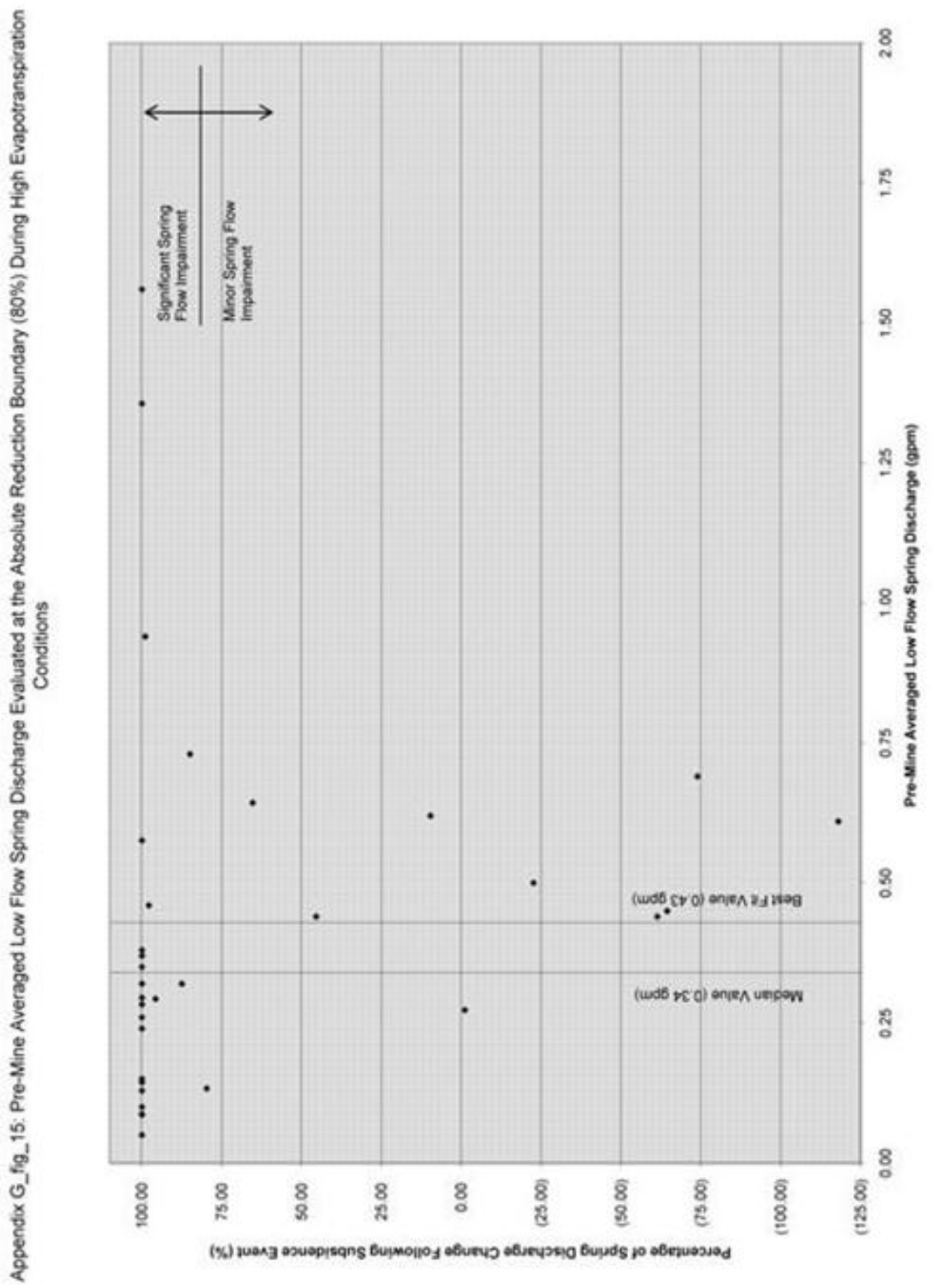


APPENDIX H: Figures Illustrating the Statistically Significant Variables Identified from the Degree of Spring Discharge Impairment to Mining-Induced Subsidence Analysis through the Use of the Interpreted Best Fit Values as Discussed in Results of Investigation IV 
Appendix H_tab_1: Data Used to Determine the Statistical Significance of the Spring Vertical Relief to Nearest Surface Drainage Feature Data Trend at the Optimum Discharge Reduction Boundary During Low Evapotranspiration Conditions.

\begin{tabular}{|c|c|c|c|c|}
\hline \multirow[t]{2}{*}{ Spring No. } & \multirow{2}{*}{$\begin{array}{c}\text { Optimum Discharge Reduction Boundary } \\
\text { Low ET }(50 \%)\end{array}$} & \multicolumn{3}{|c|}{ Spring Vertical Relief to Nearest Surface Drainage Feature (ft) } \\
\hline & & All & $>>=50 \%$ & $<50 \%$ \\
\hline 33 & 87 & 80 & 80 & $\mathrm{n} / \mathrm{a}$ \\
\hline 198 & 92 & 80 & 80 & $\mathrm{n} / \mathrm{a}$ \\
\hline 155 & 100 & 35 & 35 & $\mathrm{n} / \mathrm{a}$ \\
\hline 166 & 100 & 80 & 80 & $\mathrm{n} / \mathrm{a}$ \\
\hline 167 & 100 & 60 & 60 & $\mathrm{n} / \mathrm{a}$ \\
\hline 173 & 100 & 60 & 60 & $\mathrm{n} / \mathrm{a}$ \\
\hline 174 & 100 & 60 & 60 & $\mathrm{n} / \mathrm{a}$ \\
\hline 177 & 100 & 25 & 25 & $\mathrm{n} / \mathrm{a}$ \\
\hline 199 & 100 & 10 & 10 & $\mathrm{n} / \mathrm{a}$ \\
\hline 224 & 100 & 10 & 10 & $\mathrm{n} / \mathrm{a}$ \\
\hline 249 & 100 & 25 & 25 & $\mathrm{n} / \mathrm{a}$ \\
\hline 254 & 100 & 60 & 60 & $\mathrm{n} / \mathrm{a}$ \\
\hline 259 & 100 & 55 & 55 & $\mathrm{n} / \mathrm{a}$ \\
\hline 263 & 100 & 30 & 30 & $\mathrm{n} / \mathrm{a}$ \\
\hline 272 & 100 & 55 & 55 & $\mathrm{n} / \mathrm{a}$ \\
\hline 35 & 100 & 25 & 25 & $\mathrm{n} / \mathrm{a}$ \\
\hline 36 & 100 & 25 & 25 & $\mathrm{n} / \mathrm{a}$ \\
\hline 41 & 100 & 10 & 10 & $\mathrm{n} / \mathrm{a}$ \\
\hline 63 & 100 & 140 & 140 & $\mathrm{n} / \mathrm{a}$ \\
\hline 64 & 100 & 160 & 160 & $\mathrm{n} / \mathrm{a}$ \\
\hline 84 & 100 & 20 & 20 & $\mathrm{n} / \mathrm{a}$ \\
\hline 94 & 100 & 175 & 175 & $\mathrm{n} / \mathrm{a}$ \\
\hline \multicolumn{5}{|l|}{269} \\
\hline \multicolumn{5}{|l|}{271} \\
\hline \multicolumn{5}{|l|}{297} \\
\hline \multicolumn{5}{|l|}{268} \\
\hline \multicolumn{5}{|l|}{$99 \mathrm{~A}$} \\
\hline \multicolumn{5}{|l|}{258} \\
\hline \multicolumn{5}{|l|}{216} \\
\hline 43 & 2 & 10 & $\mathrm{n} / \mathrm{a}$ & 10 \\
\hline 38 & 13 & 35 & $\mathrm{n} / \mathrm{a}$ & 35 \\
\hline 176 & 17 & 5 & $\mathrm{n} / \mathrm{a}$ & 5 \\
\hline 226 & 20 & 45 & $\mathrm{n} / \mathrm{a}$ & 45 \\
\hline 154 & 18 & 15 & $\mathrm{n} / \mathrm{a}$ & 15 \\
\hline 265 & 32 & 25 & $\mathrm{n} / \mathrm{a}$ & 25 \\
\hline 79 & 54 & 95 & 95 & $\mathrm{n} / \mathrm{a}$ \\
\hline 99 & 14 & 10 & $\mathrm{n} / \mathrm{a}$ & 10 \\
\hline 107 & 58 & 50 & 50 & $\mathrm{n} / \mathrm{a}$ \\
\hline 270 & 57 & 10 & 10 & $\mathrm{n} / \mathrm{a}$ \\
\hline 102 & 39 & 5 & $\mathrm{n} / \mathrm{a}$ & 5 \\
\hline 260 & 58 & 70 & 70 & $\mathrm{n} / \mathrm{a}$ \\
\hline 267 & 69 & 25 & 25 & $\mathrm{n} / \mathrm{a}$ \\
\hline 97 & 30 & 145 & $\mathrm{n} / \mathrm{a}$ & 145 \\
\hline 92 & 67 & 60 & 60 & $\mathrm{n} / \mathrm{a}$ \\
\hline 106 & 74 & 35 & 35 & $\mathrm{n} / \mathrm{a}$ \\
\hline 93 & 68 & 50 & 50 & $\mathrm{n} / \mathrm{a}$ \\
\hline 171 & 91 & 45 & 45 & $\mathrm{n} / \mathrm{a}$ \\
\hline 175 & 62 & 10 & 10 & $\mathrm{n} / \mathrm{a}$ \\
\hline 274 & 94 & 40 & 40 & $\mathrm{n} / \mathrm{a}$ \\
\hline 102A & 88 & 70 & 70 & $\mathrm{n} / \mathrm{a}$ \\
\hline 273 & 95 & 140 & 140 & $\mathrm{n} / \mathrm{a}$ \\
\hline 256 & 98 & 70 & 70 & $\mathrm{n} / \mathrm{a}$ \\
\hline 169 & 98 & 115 & 115 & $\mathrm{n} / \mathrm{a}$ \\
\hline 91 & 97 & 195 & 195 & $\mathrm{n} / \mathrm{a}$ \\
\hline 90 & 99 & 35 & 35 & $\mathrm{n} / \mathrm{a}$ \\
\hline 152 & 100 & 75 & 75 & $\mathrm{n} / \mathrm{a}$ \\
\hline 39 & 100 & 40 & 40 & $\mathrm{n} / \mathrm{a}$ \\
\hline 165 & & & & \\
\hline 101 & & & & \\
\hline 83 & & & & \\
\hline$n$ & & 50 & & \\
\hline Median Value & & 45 & & \\
\hline Interpreted Best Fit Value & & 36 & & \\
\hline (A) \# of Undermined Springs & 3est Fit Value $w />/=50 \%$ Discharge Reduction & & 26 & \\
\hline (B) \# of Undermined Springs & Best Fit Value w $/<50 \%$ Discharge Reduction & & & 2 \\
\hline (C) \# of Undermined Springs & st Fit Value $w />/=50 \%$ Discharge Reduction & & 15 & \\
\hline (D) \# of Undermined Springs & st Fit Value $w /<50 \%$ Discharge Reduction & & & 7 \\
\hline Absolute Value (AD-BC) & & 152 & & \\
\hline Chi Square Value at 1 Degre & reedom & 3.54789 & & \\
\hline Error Probability as Derived & Chi Square Contingency Test & $0.10-0.05$ & & \\
\hline Error Probability as Derived & isher Exact Probability Test & 0.02951 & & \\
\hline
\end{tabular}




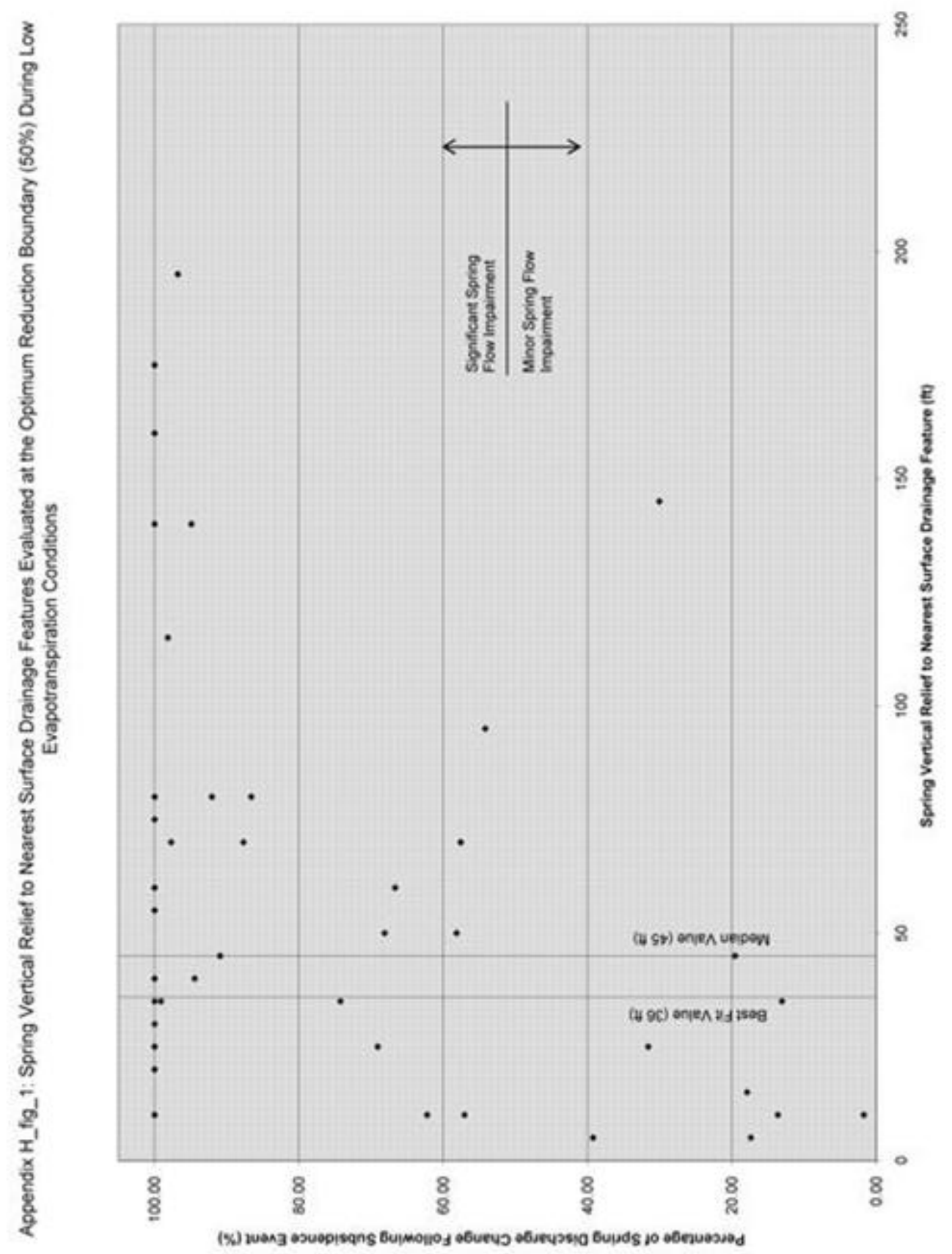


Appendix H_tab_2: Data Used to Determine the Statistical Significance of the Spring Vertical Relief to Headw ater, First and Second Order, Surface Drainage Feature Data Trend at the Optimum Discharge Reduction Boundary During Low Evapotranspiration Conditions.

\begin{tabular}{|c|c|c|c|c|}
\hline \multirow[t]{2}{*}{\begin{tabular}{|l} 
Spring No. \\
\end{tabular}} & \multirow{2}{*}{$\begin{array}{c}\text { Optimum Discharge Reduction Boundary } \\
\text { Low ET }(50 \%)\end{array}$} & \multicolumn{3}{|c|}{ Spring Vertical Relief to Headw ater Surface Drainage Features (ft) } \\
\hline & & All & $>/=50 \%$ & $<50 \%$ \\
\hline 33 & 87 & 80 & 80 & $\mathrm{n} / \mathrm{a}$ \\
\hline 198 & 92 & 80 & 80 & $\mathrm{n} / \mathrm{a}$ \\
\hline 155 & 100 & 35 & 35 & $\mathrm{n} / \mathrm{a}$ \\
\hline 166 & 100 & 80 & 80 & $\mathrm{n} / \mathrm{a}$ \\
\hline 167 & 100 & 60 & 60 & $\mathrm{n} / \mathrm{a}$ \\
\hline 173 & 100 & 60 & 60 & $\mathrm{n} / \mathrm{a}$ \\
\hline 174 & 100 & 60 & 60 & $\mathrm{n} / \mathrm{a}$ \\
\hline 177 & 100 & 25 & 25 & $\mathrm{n} / \mathrm{a}$ \\
\hline \multicolumn{5}{|l|}{199} \\
\hline 224 & 100 & 10 & 10 & $\mathrm{n} / \mathrm{a}$ \\
\hline 249 & 100 & 25 & 25 & $\mathrm{n} / \mathrm{a}$ \\
\hline 254 & 100 & 60 & 60 & $\mathrm{n} / \mathrm{a}$ \\
\hline \begin{tabular}{|l|}
259 \\
\end{tabular} & 100 & 55 & 55 & $\mathrm{n} / \mathrm{a}$ \\
\hline 263 & 100 & 30 & 30 & $\mathrm{n} / \mathrm{a}$ \\
\hline \begin{tabular}{|l|}
272 \\
\end{tabular} & 100 & 55 & 55 & $\mathrm{n} / \mathrm{a}$ \\
\hline 35 & 100 & 25 & 25 & $\mathrm{n} / \mathrm{a}$ \\
\hline 36 & 100 & 25 & 25 & $\mathrm{n} / \mathrm{a}$ \\
\hline 41 & 100 & 10 & 10 & $\mathrm{n} / \mathrm{a}$ \\
\hline 63 & 100 & 140 & 140 & $\mathrm{n} / \mathrm{a}$ \\
\hline 64 & 100 & 160 & 160 & $\mathrm{n} / \mathrm{a}$ \\
\hline \multicolumn{5}{|l|}{84} \\
\hline \multicolumn{5}{|l|}{94} \\
\hline \multicolumn{5}{|l|}{269} \\
\hline \multicolumn{5}{|l|}{271} \\
\hline \multicolumn{5}{|l|}{297} \\
\hline \multicolumn{5}{|l|}{268} \\
\hline 99A & & & & \\
\hline 258 & & & & \\
\hline 216 & & & & \\
\hline 43 & 2 & 10 & $\mathrm{n} / \mathrm{a}$ & 10 \\
\hline 38 & 13 & 35 & $\mathrm{n} / \mathrm{a}$ & 35 \\
\hline 176 & 17 & 5 & $\mathrm{n} / \mathrm{a}$ & 5 \\
\hline 226 & 20 & 45 & $\mathrm{n} / \mathrm{a}$ & 45 \\
\hline 154 & 18 & 15 & $\mathrm{n} / \mathrm{a}$ & 15 \\
\hline 265 & 32 & 25 & $\mathrm{n} / \mathrm{a}$ & 25 \\
\hline 79 & & & & \\
\hline 99 & 14 & 10 & $\mathrm{n} / \mathrm{a}$ & 10 \\
\hline 107 & 58 & 50 & 50 & $\mathrm{n} / \mathrm{a}$ \\
\hline 270 & 57 & 10 & 10 & $\mathrm{n} / \mathrm{a}$ \\
\hline 102 & 39 & 5 & $\mathrm{n} / \mathrm{a}$ & 5 \\
\hline 260 & 58 & 70 & 70 & $\mathrm{n} / \mathrm{a}$ \\
\hline 267 & 69 & 25 & 25 & $\mathrm{n} / \mathrm{a}$ \\
\hline 97 & 30 & 145 & $\mathrm{n} / \mathrm{a}$ & 145 \\
\hline 92 & 67 & 60 & 60 & $\mathrm{n} / \mathrm{a}$ \\
\hline 106 & 74 & 35 & 35 & $\mathrm{n} / \mathrm{a}$ \\
\hline 93 & 68 & 50 & 50 & $\mathrm{n} / \mathrm{a}$ \\
\hline 171 & 91 & 45 & 45 & $\mathrm{n} / \mathrm{a}$ \\
\hline 175 & 62 & 10 & 10 & $\mathrm{n} / \mathrm{a}$ \\
\hline 274 & 94 & 40 & 40 & $\mathrm{n} / \mathrm{a}$ \\
\hline $102 \mathrm{~A}$ & 88 & 70 & 70 & $\mathrm{n} / \mathrm{a}$ \\
\hline 273 & 95 & 140 & 140 & $\mathrm{n} / \mathrm{a}$ \\
\hline 256 & 98 & 70 & 70 & $\mathrm{n} / \mathrm{a}$ \\
\hline 169 & 98 & 115 & 115 & $\mathrm{n} / \mathrm{a}$ \\
\hline 91 & 97 & 195 & 195 & $\mathrm{n} / \mathrm{a}$ \\
\hline 90 & 99 & 35 & 35 & $\mathrm{n} / \mathrm{a}$ \\
\hline 152 & 100 & 75 & 75 & $\mathrm{n} / \mathrm{a}$ \\
\hline 39 & & & & \\
\hline 165 & & & & \\
\hline 101 & & & & \\
\hline 83 & & & & \\
\hline $\mathrm{n}$ & & 45 & & \\
\hline Median Value & & 45 & & \\
\hline Interpreted Best Fit Value & & 36 & & \\
\hline (A) \# of Undermined Sprin & Best Fit Value $w />/=50 \%$ Discharge Reduction & & 23 & \\
\hline (B) \# of Undermined Spring & Best Fit Value $\mathrm{w} /<50 \%$ Discharge Reduction & & & 2 \\
\hline (C) \# of Undermined Sprin & est Fit Value $w />/=50 \%$ Discharge Reduction & & 13 & \\
\hline (D) \# of Undermined Spring & est Fit Value w $/<50 \%$ Discharge Reduction & & & 7 \\
\hline Absolute Value (AD-BC) & & 135 & & \\
\hline Chi Square Value at 1 Deg & Freedom & 3.51563 & & \\
\hline Error Probability as Derive & Chi Square Contingency Test & $0.10-0.05$ & & \\
\hline Error Probability as Derive & Fisher Exact Probability Test & 0.02999 & & \\
\hline
\end{tabular}




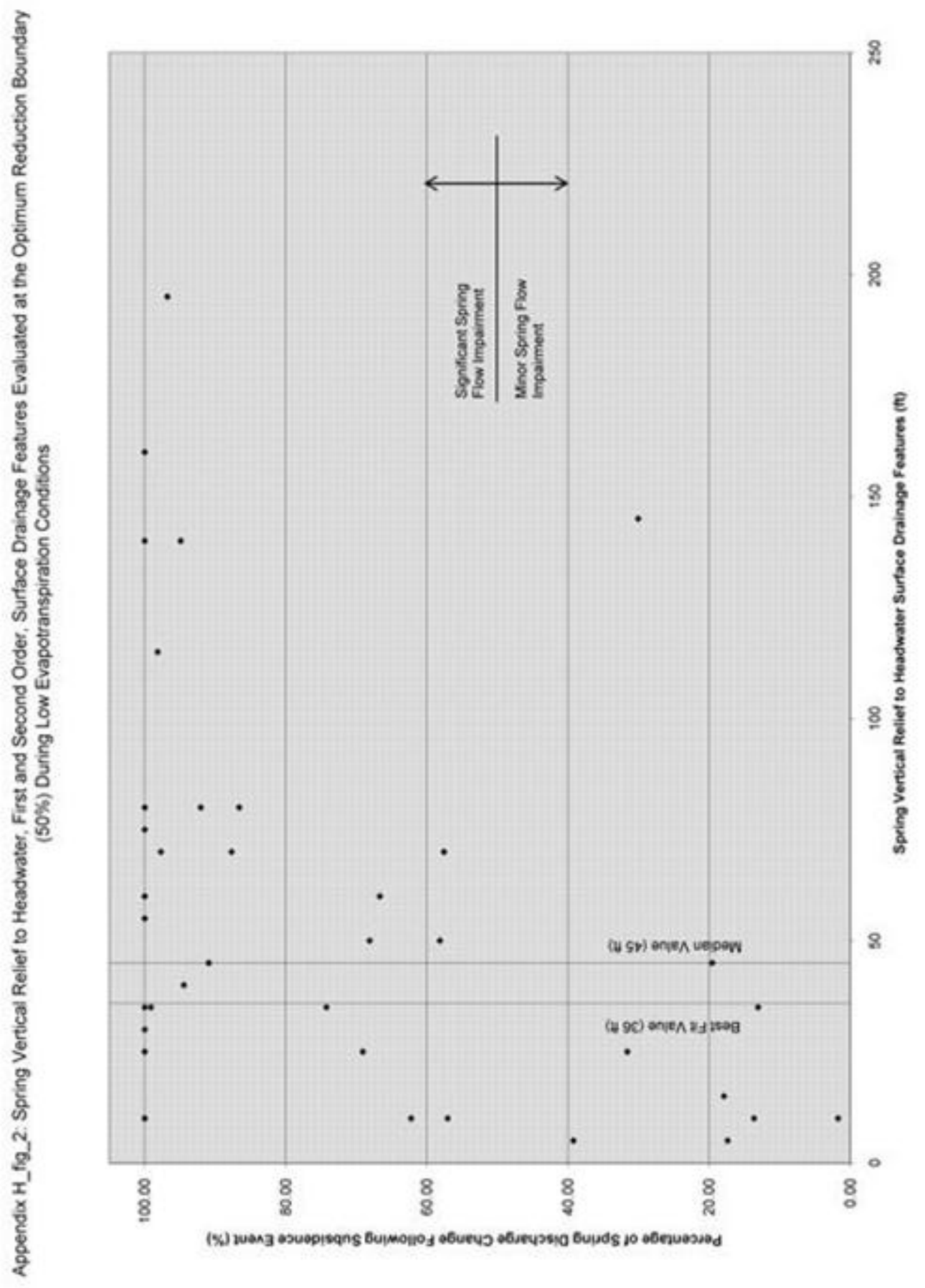


Appendix H_tab_3: Data Used to Determine the Statistical Significance of the Spring Vertical Relief to First Order Surface Drainage Feature Data Trend at the Optimum Discharge Reduction Boundary During Low Evapotranspiration Conditions.

\begin{tabular}{|c|c|c|c|c|}
\hline \multirow[t]{2}{*}{ Spring No. } & \multirow{2}{*}{$\begin{array}{c}\text { Optimum Discharge Reduction Boundary } \\
\text { Low ET }(50 \%)\end{array}$} & \multicolumn{3}{|c|}{ Spring Vertical Relief to First Order Surface Drainage Features ( $\mathrm{ft}$ ) } \\
\hline & & All & $>1=50 \%$ & $<50 \%$ \\
\hline \multicolumn{5}{|l|}{33} \\
\hline 198 & 92 & 80 & 80 & $\mathrm{n} / \mathrm{a}$ \\
\hline 155 & 100 & 35 & 35 & $n / a$ \\
\hline \multicolumn{5}{|l|}{166} \\
\hline 167 & 100 & 60 & 60 & $\mathrm{n} / \mathrm{a}$ \\
\hline 173 & 100 & 60 & 60 & $\mathrm{n} / \mathrm{a}$ \\
\hline 174 & 100 & 60 & 60 & $\mathrm{n} / \mathrm{a}$ \\
\hline \multicolumn{5}{|l|}{177} \\
\hline \multicolumn{5}{|l|}{199} \\
\hline 224 & 100 & 10 & 10 & $\mathrm{n} / \mathrm{a}$ \\
\hline 249 & 100 & 25 & 25 & $\mathrm{n} / \mathrm{a}$ \\
\hline 254 & 100 & 60 & 60 & $\mathrm{n} / \mathrm{a}$ \\
\hline \multicolumn{5}{|l|}{259} \\
\hline 263 & 100 & 30 & 30 & $\mathrm{n} / \mathrm{a}$ \\
\hline 272 & 100 & 55 & 55 & $\mathrm{n} / \mathrm{a}$ \\
\hline 35 & 100 & 25 & 25 & $\mathrm{n} / \mathrm{a}$ \\
\hline 36 & 100 & 25 & 25 & $\mathrm{n} / \mathrm{a}$ \\
\hline \multicolumn{5}{|l|}{41} \\
\hline \multicolumn{5}{|l|}{63} \\
\hline 64 & & & & \\
\hline 84 & & & & \\
\hline 94 & & & & \\
\hline 269 & & & & \\
\hline 271 & & & & \\
\hline 297 & & & & \\
\hline 268 & & & & \\
\hline $99 \mathrm{~A}$ & & & & \\
\hline 258 & & & & \\
\hline 216 & & & & \\
\hline 43 & 2 & 10 & $\mathrm{n} / \mathrm{a}$ & 10 \\
\hline 38 & 13 & 35 & $\mathrm{n} / \mathrm{a}$ & 35 \\
\hline 176 & 17 & 5 & $\mathrm{n} / \mathrm{a}$ & 5 \\
\hline 226 & 20 & 45 & $\mathrm{n} / \mathrm{a}$ & 45 \\
\hline 154 & 18 & 15 & $\mathrm{n} / \mathrm{a}$ & 15 \\
\hline 265 & & & & \\
\hline 79 & & & & \\
\hline 99 & 14 & 10 & $\mathrm{n} / \mathrm{a}$ & 10 \\
\hline 107 & 58 & 50 & 50 & $\mathrm{n} / \mathrm{a}$ \\
\hline 270 & 57 & 10 & 10 & $\mathrm{n} / \mathrm{a}$ \\
\hline 102 & 39 & 5 & $\mathrm{n} / \mathrm{a}$ & 5 \\
\hline 260 & & & & \\
\hline 267 & 69 & 25 & 25 & $\mathrm{n} / \mathrm{a}$ \\
\hline 97 & 30 & 145 & $\mathrm{n} / \mathrm{a}$ & 145 \\
\hline 92 & 67 & 60 & 60 & $\mathrm{n} / \mathrm{a}$ \\
\hline 106 & 74 & 35 & 35 & $\mathrm{n} / \mathrm{a}$ \\
\hline 93 & 68 & 50 & 50 & $\mathrm{n} / \mathrm{a}$ \\
\hline 171 & 91 & 45 & 45 & $\mathrm{n} / \mathrm{a}$ \\
\hline 175 & 62 & 10 & 10 & $\mathrm{n} / \mathrm{a}$ \\
\hline 274 & 94 & 40 & 40 & $\mathrm{n} / \mathrm{a}$ \\
\hline $102 \mathrm{~A}$ & 88 & 70 & 70 & $\mathrm{n} / \mathrm{a}$ \\
\hline 273 & 95 & 140 & 140 & $\mathrm{n} / \mathrm{a}$ \\
\hline 256 & 98 & 70 & 70 & $\mathrm{n} / \mathrm{a}$ \\
\hline 169 & 98 & 115 & 115 & $\mathrm{n} / \mathrm{a}$ \\
\hline 91 & 97 & 195 & 195 & $\mathrm{n} / \mathrm{a}$ \\
\hline 90 & 99 & 35 & 35 & $\mathrm{n} / \mathrm{a}$ \\
\hline 152 & 100 & 75 & 75 & $\mathrm{n} / \mathrm{a}$ \\
\hline 39 & & & & \\
\hline 165 & & & & \\
\hline 101 & & & & \\
\hline 83 & & & & \\
\hline $\mathrm{n}$ & & 36 & & \\
\hline Median Value & & 42.5 & & \\
\hline Interpreted Best Fit Value & & 36 & & \\
\hline (A) \# of Undermined Spring & Best Fit Value $\mathrm{w} />/=50 \%$ Discharge Reduction & & 17 & \\
\hline (B) \# of Undermined Spring & Best Fit Value w $/<50 \%$ Discharge Reduction & & & 2 \\
\hline (C) \# of Undermined Spring & st Fit Value $w />/=50 \%$ Discharge Reduction & & 11 & \\
\hline (D) \# of Undermined Spring & st Fit Value w/ <50\% Discharge Reduction & & & 6 \\
\hline Absolute Value (AD-BC) & & 80 & & \\
\hline Chi Square Value at 1 Degr & Freedom & 1.91265 & & \\
\hline Error Probability as Derived & Chi Square Contingency Test & $0.20-0.10$ & & \\
\hline Error Probability as Derived & Fisher Exact Probability Test & 0.08295 & & \\
\hline
\end{tabular}




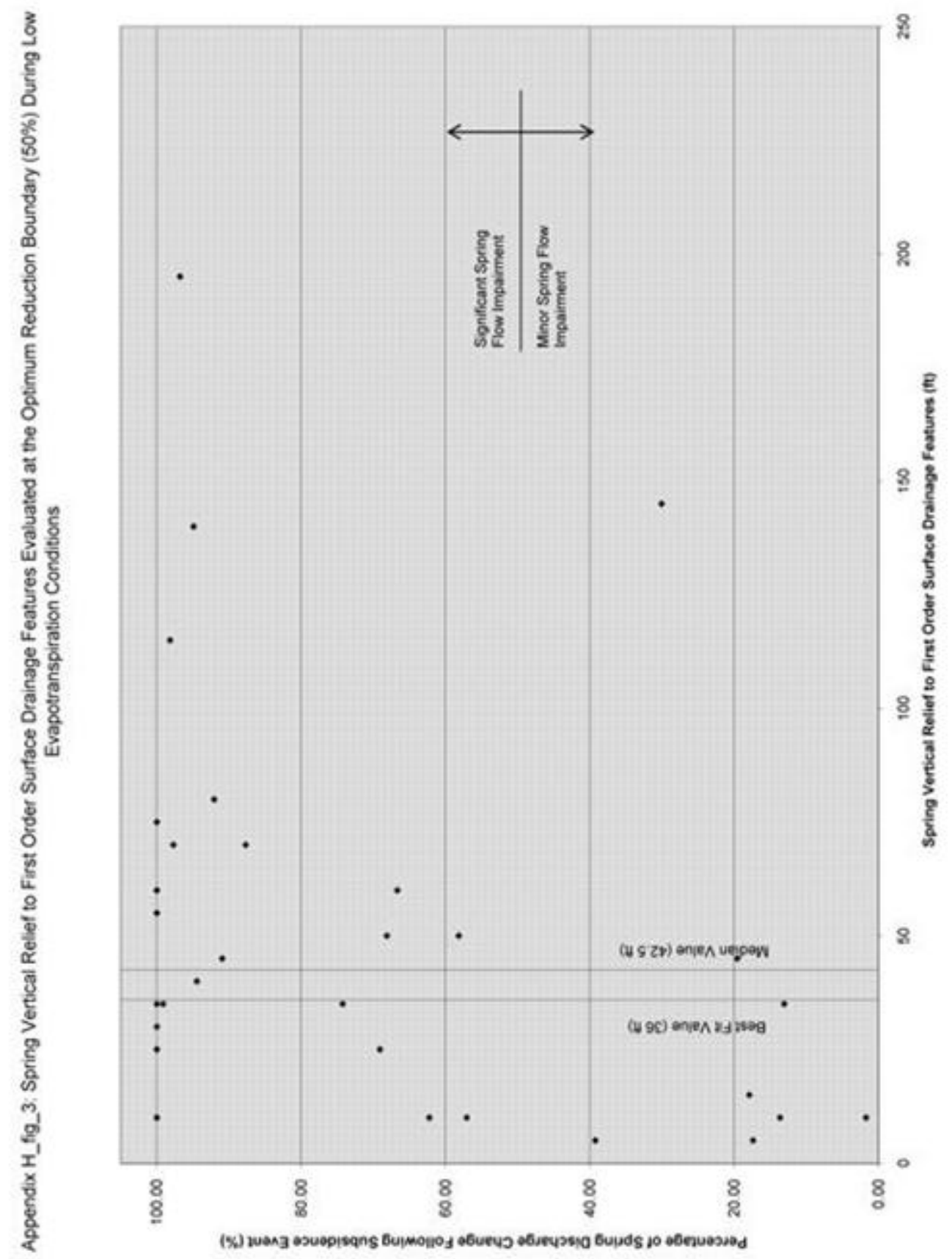


Appendix H_tab_4: Data Used to Determine the Statistical Significance of the Recharge Line Length Component Perpendicular to Longw all Face Data Trend at the Absolute Discharge Reduction Boundary During Low Evapotranspiration Conditions.

\begin{tabular}{|c|c|c|c|c|}
\hline \multirow[t]{2}{*}{ Spring No. } & \multirow{2}{*}{$\begin{array}{c}\text { Absolute Discharge Reduction Boundary } \\
\text { Low ET }(88 \%)\end{array}$} & \multicolumn{3}{|c|}{ Recharge Line Length Component Perpendicular to Longw all Face (ft) } \\
\hline & & All & $>1=88 \%$ & $<88 \%$ \\
\hline \multicolumn{5}{|l|}{33} \\
\hline 198 & 92 & 100 & 100 & $\mathrm{n} / \mathrm{a}$ \\
\hline 155 & 100 & 15 & 15 & $\mathrm{n} / \mathrm{a}$ \\
\hline 166 & 100 & 30 & 30 & $\mathrm{n} / \mathrm{a}$ \\
\hline 167 & 100 & 160 & 160 & $\mathrm{n} / \mathrm{a}$ \\
\hline 173 & 100 & 140 & 140 & $\mathrm{n} / \mathrm{a}$ \\
\hline \multicolumn{5}{|l|}{174} \\
\hline 177 & 100 & 280 & 280 & $\mathrm{n} / \mathrm{a}$ \\
\hline 199 & 100 & 220 & 220 & $\mathrm{n} / \mathrm{a}$ \\
\hline 224 & 100 & 120 & 120 & $\mathrm{n} / \mathrm{a}$ \\
\hline 249 & 100 & 350 & 350 & $\mathrm{n} / \mathrm{a}$ \\
\hline 254 & 100 & 360 & 360 & $\mathrm{n} / \mathrm{a}$ \\
\hline 259 & 100 & 100 & 100 & $\mathrm{n} / \mathrm{a}$ \\
\hline 263 & 100 & 15 & 15 & $\mathrm{n} / \mathrm{a}$ \\
\hline 272 & 100 & 30 & 30 & $\mathrm{n} / \mathrm{a}$ \\
\hline 35 & 100 & 70 & 70 & $\mathrm{n} / \mathrm{a}$ \\
\hline 36 & 100 & 50 & 50 & $\mathrm{n} / \mathrm{a}$ \\
\hline 41 & 100 & 40 & 40 & $\mathrm{n} / \mathrm{a}$ \\
\hline 63 & 100 & 370 & 370 & $\mathrm{n} / \mathrm{a}$ \\
\hline 64 & 100 & 300 & 300 & $\mathrm{n} / \mathrm{a}$ \\
\hline 84 & 100 & 220 & 220 & $\mathrm{n} / \mathrm{a}$ \\
\hline 94 & 100 & 50 & 50 & $\mathrm{n} / \mathrm{a}$ \\
\hline \multicolumn{5}{|l|}{269} \\
\hline \multicolumn{5}{|l|}{271} \\
\hline \multicolumn{5}{|l|}{297} \\
\hline \multicolumn{5}{|l|}{268} \\
\hline \multicolumn{5}{|l|}{$99 \mathrm{~A}$} \\
\hline 258 & & & & \\
\hline 216 & & & & \\
\hline 43 & 2 & 20 & $\mathrm{n} / \mathrm{a}$ & 20 \\
\hline 38 & 13 & 20 & $\mathrm{n} / \mathrm{a}$ & 20 \\
\hline 176 & 17 & 340 & $\mathrm{n} / \mathrm{a}$ & 340 \\
\hline 226 & 20 & 260 & $\mathrm{n} / \mathrm{a}$ & 260 \\
\hline 154 & 18 & 260 & $\mathrm{n} / \mathrm{a}$ & 260 \\
\hline 265 & 32 & 140 & $\mathrm{n} / \mathrm{a}$ & 140 \\
\hline 79 & 54 & 110 & $\mathrm{n} / \mathrm{a}$ & 110 \\
\hline 99 & 14 & 15 & $\mathrm{n} / \mathrm{a}$ & 15 \\
\hline 107 & & & & \\
\hline 270 & 57 & 380 & $\mathrm{n} / \mathrm{a}$ & 380 \\
\hline 102 & 39 & 280 & $\mathrm{n} / \mathrm{a}$ & 280 \\
\hline 260 & 58 & 310 & $\mathrm{n} / \mathrm{a}$ & 310 \\
\hline 267 & 69 & 250 & $\mathrm{n} / \mathrm{a}$ & 250 \\
\hline 97 & 30 & 100 & $\mathrm{n} / \mathrm{a}$ & 100 \\
\hline 92 & 67 & 170 & $\mathrm{n} / \mathrm{a}$ & 170 \\
\hline 106 & 74 & 220 & $\mathrm{n} / \mathrm{a}$ & 220 \\
\hline 93 & 68 & 220 & $\mathrm{n} / \mathrm{a}$ & 220 \\
\hline 171 & 91 & 160 & 160 & $\mathrm{n} / \mathrm{a}$ \\
\hline 175 & 62 & 30 & $\mathrm{n} / \mathrm{a}$ & 30 \\
\hline 274 & 94 & 440 & 440 & $\mathrm{n} / \mathrm{a}$ \\
\hline $102 \mathrm{~A}$ & 88 & 180 & $\mathrm{n} / \mathrm{a}$ & 180 \\
\hline 273 & 95 & 100 & 100 & $\mathrm{n} / \mathrm{a}$ \\
\hline 256 & 98 & 200 & 200 & $\mathrm{n} / \mathrm{a}$ \\
\hline 169 & 98 & 90 & 90 & $\mathrm{n} / \mathrm{a}$ \\
\hline 91 & 97 & 70 & 70 & $\mathrm{n} / \mathrm{a}$ \\
\hline 90 & 99 & 50 & 50 & $\mathrm{n} / \mathrm{a}$ \\
\hline 152 & 100 & 80 & 80 & $\mathrm{n} / \mathrm{a}$ \\
\hline 39 & 100 & 200 & 200 & $\mathrm{n} / \mathrm{a}$ \\
\hline 165 & & & & \\
\hline 101 & & & & \\
\hline 83 & & & & \\
\hline $\mathrm{n}$ & & 47 & & \\
\hline Median Value & & 140 & & \\
\hline Interpreted Best Fit Value & & 169 & & \\
\hline (A) \# of Undermined Spring & Best Fit Value $\mathrm{w} />/=50 \%$ Discharge Reduction & & 10 & \\
\hline (B) \# of Undermined Spring & Best Fit Value w $/<50 \%$ Discharge Reduction & & & 11 \\
\hline (C) \# of Undermined Spring & st Fit Value $w />/=50 \%$ Discharge Reduction & & 19 & \\
\hline (D) \# of Undermined Spring & st Fit Value w/ <50\% Discharge Reduction & & & 7 \\
\hline Absolute Value (AD-BC) & & 139 & & \\
\hline Chi Square Value at 1 Degr & Freedom & 2.19988 & & \\
\hline Error Probability as Derived & Chi Square Contingency Test & $0.20-0.10$ & & \\
\hline Error Probability as Derived & Fisher Exact Probability Test & 0.06894 & & \\
\hline
\end{tabular}




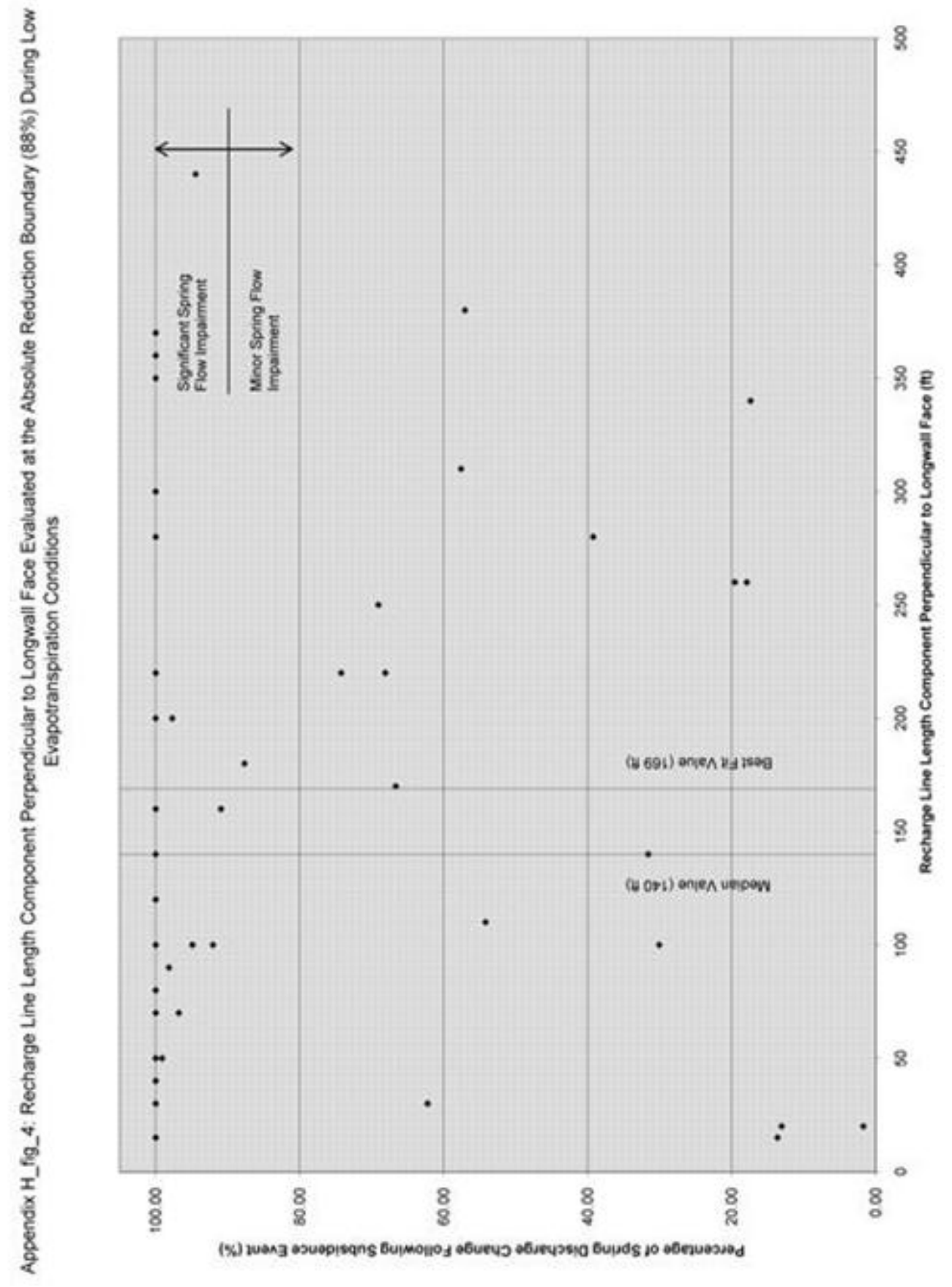


Appendix H_tab_5: Data Used to Determine the Statistical Significance of the Spring Vertical Relief to First Order Surface Drainage Feature Data Trend at the Absolute Discharge Reduction Boundary During Low Evapotranspiration Conditions.

\begin{tabular}{|c|c|c|c|c|}
\hline \multirow[t]{2}{*}{ Spring No. } & \multirow{2}{*}{$\begin{array}{c}\text { Absolute Discharge Reduction Boundary } \\
\text { Low ET }(88 \%)\end{array}$} & \multicolumn{3}{|c|}{ Spring Vertical Relief to First Order Surface Drainage Features ( $\mathrm{ft}$ ) } \\
\hline & & All & $>1=88 \%$ & $<88 \%$ \\
\hline \multicolumn{5}{|l|}{33} \\
\hline 198 & 92 & 80 & 80 & $\mathrm{n} / \mathrm{a}$ \\
\hline 155 & 100 & 35 & 35 & $n / a$ \\
\hline \multicolumn{5}{|l|}{166} \\
\hline 167 & 100 & 60 & 60 & $\mathrm{n} / \mathrm{a}$ \\
\hline 173 & 100 & 60 & 60 & $\mathrm{n} / \mathrm{a}$ \\
\hline 174 & 100 & 60 & 60 & $\mathrm{n} / \mathrm{a}$ \\
\hline \multicolumn{5}{|l|}{177} \\
\hline \multicolumn{5}{|l|}{199} \\
\hline 224 & 100 & 10 & 10 & $\mathrm{n} / \mathrm{a}$ \\
\hline 249 & 100 & 25 & 25 & $\mathrm{n} / \mathrm{a}$ \\
\hline 254 & 100 & 60 & 60 & $\mathrm{n} / \mathrm{a}$ \\
\hline \multicolumn{5}{|l|}{259} \\
\hline 263 & 100 & 30 & 30 & $\mathrm{n} / \mathrm{a}$ \\
\hline 272 & 100 & 55 & 55 & $\mathrm{n} / \mathrm{a}$ \\
\hline 35 & 100 & 25 & 25 & $\mathrm{n} / \mathrm{a}$ \\
\hline 36 & 100 & 25 & 25 & $\mathrm{n} / \mathrm{a}$ \\
\hline \multicolumn{5}{|l|}{41} \\
\hline \multicolumn{5}{|l|}{63} \\
\hline 64 & & & & \\
\hline 84 & & & & \\
\hline 94 & & & & \\
\hline 269 & & & & \\
\hline 271 & & & & \\
\hline 297 & & & & \\
\hline 268 & & & & \\
\hline $99 \mathrm{~A}$ & & & & \\
\hline 258 & & & & \\
\hline 216 & & & & \\
\hline 43 & 2 & 10 & $\mathrm{n} / \mathrm{a}$ & 10 \\
\hline 38 & 13 & 35 & $\mathrm{n} / \mathrm{a}$ & 35 \\
\hline 176 & 17 & 5 & $\mathrm{n} / \mathrm{a}$ & 5 \\
\hline 226 & 20 & 45 & $\mathrm{n} / \mathrm{a}$ & 45 \\
\hline 154 & 18 & 15 & $\mathrm{n} / \mathrm{a}$ & 15 \\
\hline 265 & & & & \\
\hline 79 & & & & \\
\hline 99 & 14 & 10 & $\mathrm{n} / \mathrm{a}$ & 10 \\
\hline 107 & 58 & 50 & $\mathrm{n} / \mathrm{a}$ & 50 \\
\hline 270 & 57 & 10 & $\mathrm{n} / \mathrm{a}$ & 10 \\
\hline 102 & 39 & 5 & $\mathrm{n} / \mathrm{a}$ & 5 \\
\hline 260 & & & & \\
\hline 267 & 69 & 25 & $\mathrm{n} / \mathrm{a}$ & 25 \\
\hline 97 & 30 & 145 & $\mathrm{n} / \mathrm{a}$ & 145 \\
\hline 92 & 67 & 60 & $\mathrm{n} / \mathrm{a}$ & 60 \\
\hline 106 & 74 & 35 & $\mathrm{n} / \mathrm{a}$ & 35 \\
\hline 93 & 68 & 50 & $\mathrm{n} / \mathrm{a}$ & 50 \\
\hline 171 & 91 & 45 & 45 & $\mathrm{n} / \mathrm{a}$ \\
\hline 175 & 62 & 10 & $\mathrm{n} / \mathrm{a}$ & 10 \\
\hline 274 & 94 & 40 & 40 & $\mathrm{n} / \mathrm{a}$ \\
\hline $102 \mathrm{~A}$ & 88 & 70 & $\mathrm{n} / \mathrm{a}$ & 70 \\
\hline 273 & 95 & 140 & 140 & $\mathrm{n} / \mathrm{a}$ \\
\hline 256 & 98 & 70 & 70 & $\mathrm{n} / \mathrm{a}$ \\
\hline 169 & 98 & 115 & 115 & $\mathrm{n} / \mathrm{a}$ \\
\hline 91 & 97 & 195 & 195 & $\mathrm{n} / \mathrm{a}$ \\
\hline 90 & 99 & 35 & 35 & $\mathrm{n} / \mathrm{a}$ \\
\hline 152 & 100 & 75 & 75 & $\mathrm{n} / \mathrm{a}$ \\
\hline 39 & & & & \\
\hline 165 & & & & \\
\hline 101 & & & & \\
\hline 83 & & & & \\
\hline $\mathrm{n}$ & & 36 & & \\
\hline Median Value & & 42.5 & & \\
\hline Interpreted Best Fit Value & & 36 & & \\
\hline (A) \# of Undermined Spring & Best Fit Value $w />/=50 \%$ Discharge Reduction & & 13 & \\
\hline (B) \# of Undermined Spring & Best Fit Value $\mathrm{w} /<50 \%$ Discharge Reduction & & & 6 \\
\hline (C) \# of Undermined Spring & est Fit Value $w />/=50 \%$ Discharge Reduction & & 7 & \\
\hline (D) \# of Undermined Spring & est Fit Value $w /<50 \%$ Discharge Reduction & & & 10 \\
\hline Absolute Value (AD-BC) & & 88 & & \\
\hline Chi Square Value at 1 Degr & Freedom & 1.70666 & & \\
\hline Error Probability as Derived & Chi Square Contingency Test & $0.20-0.10$ & & \\
\hline Error Probability as Derived & Fisher Exact Probability Test & 0.09551 & & \\
\hline
\end{tabular}




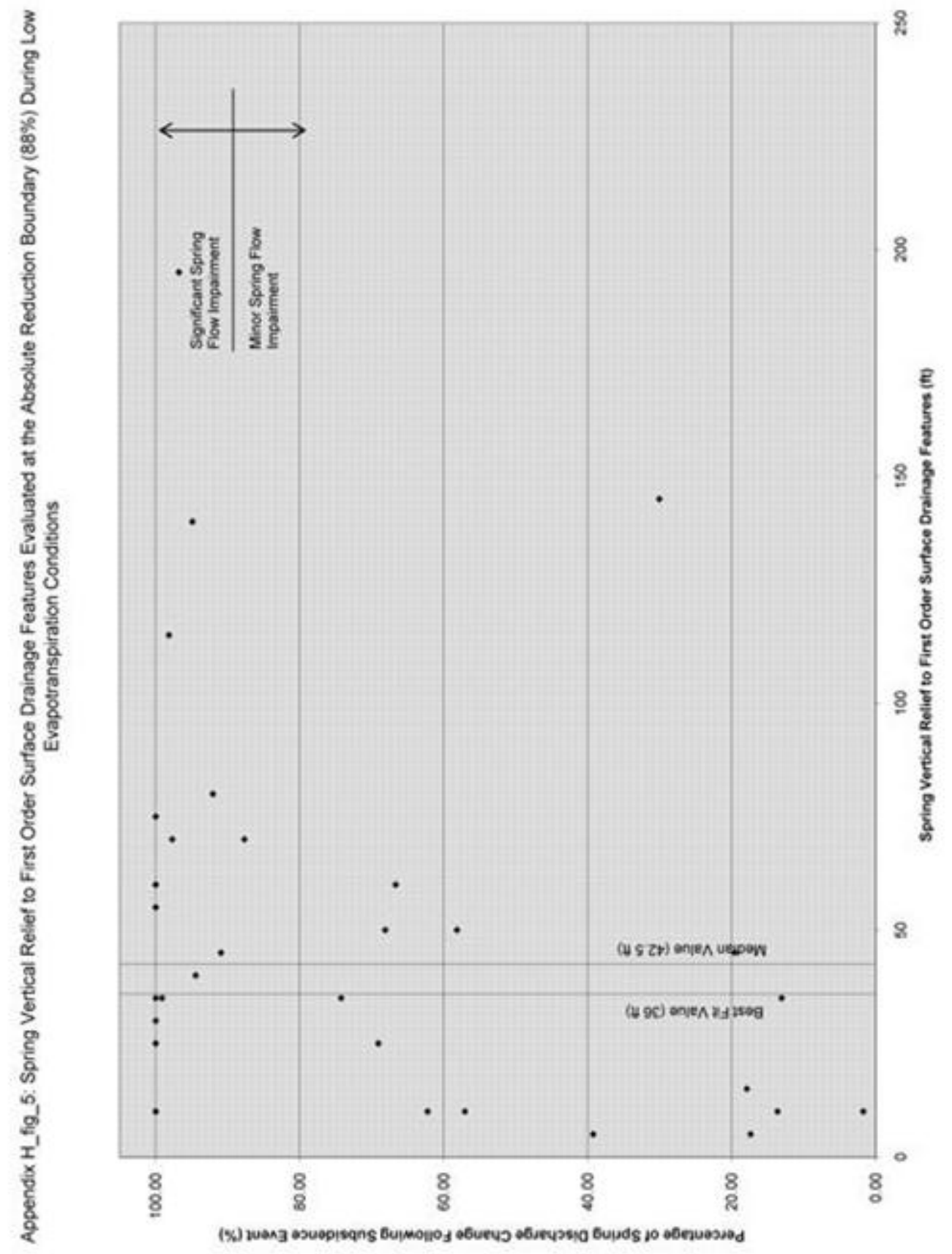


Appendix H_tab_6: Data Used to Determine the Statistical Significance of the Recharge Line Length Component Perpendicular to Longw all Face Data Trend at the Absolute Discharge Reduction Boundary During High Evapotranspiration Conditions.

\begin{tabular}{|c|c|c|c|c|}
\hline \multirow[t]{2}{*}{ Spring No. } & \multirow{2}{*}{$\begin{array}{c}\text { Absolute Discharge Reduction Boundary } \\
\text { High ET }(80 \%)\end{array}$} & \multicolumn{3}{|c|}{ Recharge Line Length Component Perpendicular to Longw all Face (ft) } \\
\hline & & All & $>1=80 \%$ & $<80 \%$ \\
\hline \multicolumn{5}{|l|}{33} \\
\hline \multicolumn{5}{|l|}{198} \\
\hline 155 & 100 & 15 & 15 & $\mathrm{n} / \mathrm{a}$ \\
\hline 166 & 100 & 30 & 30 & $\mathrm{n} / \mathrm{a}$ \\
\hline 167 & 100 & 160 & 160 & $\mathrm{n} / \mathrm{a}$ \\
\hline 173 & 100 & 140 & 140 & $\mathrm{n} / \mathrm{a}$ \\
\hline \multicolumn{5}{|l|}{174} \\
\hline 177 & 100 & 280 & 280 & $\mathrm{n} / \mathrm{a}$ \\
\hline 199 & 100 & 220 & 220 & $\mathrm{n} / \mathrm{a}$ \\
\hline 224 & 100 & 120 & 120 & $\mathrm{n} / \mathrm{a}$ \\
\hline 249 & 100 & 350 & 350 & $\mathrm{n} / \mathrm{a}$ \\
\hline 254 & 100 & 360 & 360 & $\mathrm{n} / \mathrm{a}$ \\
\hline \begin{tabular}{|l|}
259 \\
\end{tabular} & 100 & 100 & 100 & $\mathrm{n} / \mathrm{a}$ \\
\hline 263 & 100 & 15 & 15 & $\mathrm{n} / \mathrm{a}$ \\
\hline \begin{tabular}{|l|}
272 \\
\end{tabular} & 100 & 30 & 30 & $\mathrm{n} / \mathrm{a}$ \\
\hline 35 & 100 & 70 & 70 & $\mathrm{n} / \mathrm{a}$ \\
\hline 36 & 100 & 50 & 50 & $\mathrm{n} / \mathrm{a}$ \\
\hline 41 & 100 & 40 & 40 & $\mathrm{n} / \mathrm{a}$ \\
\hline 63 & 100 & 370 & 370 & $\mathrm{n} / \mathrm{a}$ \\
\hline 64 & 100 & 300 & 300 & $\mathrm{n} / \mathrm{a}$ \\
\hline 84 & 100 & 220 & 220 & $\mathrm{n} / \mathrm{a}$ \\
\hline 94 & 100 & 50 & 50 & $\mathrm{n} / \mathrm{a}$ \\
\hline \multicolumn{5}{|l|}{269} \\
\hline \multicolumn{5}{|l|}{271} \\
\hline 297 & 10 & 65 & $\mathrm{n} / \mathrm{a}$ & 65 \\
\hline \multicolumn{5}{|l|}{268} \\
\hline 99A & 100 & 75 & 75 & $\mathrm{n} / \mathrm{a}$ \\
\hline 258 & 100 & 225 & 225 & $\mathrm{n} / \mathrm{a}$ \\
\hline 216 & 100 & 40 & 40 & $\mathrm{n} / \mathrm{a}$ \\
\hline 43 & 80 & 20 & $\mathrm{n} / \mathrm{a}$ & 20 \\
\hline 38 & 100 & 20 & 20 & $\mathrm{n} / \mathrm{a}$ \\
\hline 176 & 100 & 340 & 340 & $\mathrm{n} / \mathrm{a}$ \\
\hline 226 & 100 & 260 & 260 & $\mathrm{n} / \mathrm{a}$ \\
\hline \multicolumn{5}{|l|}{154} \\
\hline 265 & 100 & 140 & 140 & $\mathrm{n} / \mathrm{a}$ \\
\hline 79 & 100 & 110 & 110 & $\mathrm{n} / \mathrm{a}$ \\
\hline 99 & 100 & 15 & 15 & $\mathrm{n} / \mathrm{a}$ \\
\hline 107 & & & & \\
\hline 270 & & & & \\
\hline 102 & 100 & 280 & 280 & $\mathrm{n} / \mathrm{a}$ \\
\hline 260 & & & & \\
\hline 267 & 96 & 250 & 250 & $\mathrm{n} / \mathrm{a}$ \\
\hline 97 & 45 & 100 & $\mathrm{n} / \mathrm{a}$ & 100 \\
\hline 92 & & & & \\
\hline 106 & 100 & 220 & 220 & $\mathrm{n} / \mathrm{a}$ \\
\hline 93 & 100 & 220 & 220 & $\mathrm{n} / \mathrm{a}$ \\
\hline 171 & & & & \\
\hline 175 & 100 & 30 & 30 & $\mathrm{n} / \mathrm{a}$ \\
\hline 274 & 100 & 440 & 440 & $\mathrm{n} / \mathrm{a}$ \\
\hline $102 \mathrm{~A}$ & 99 & 180 & 180 & $\mathrm{n} / \mathrm{a}$ \\
\hline 273 & & & & \\
\hline 256 & 88 & 200 & 200 & $\mathrm{n} / \mathrm{a}$ \\
\hline 169 & 65 & 90 & $\mathrm{n} / \mathrm{a}$ & 90 \\
\hline 91 & & & & \\
\hline 90 & 100 & 50 & 50 & $\mathrm{n} / \mathrm{a}$ \\
\hline 152 & 100 & 80 & 80 & $\mathrm{n} / \mathrm{a}$ \\
\hline 39 & & & & \\
\hline 165 & & & & \\
\hline 101 & 98 & 370 & 370 & $\mathrm{n} / \mathrm{a}$ \\
\hline 83 & 100 & 50 & 50 & $\mathrm{n} / \mathrm{a}$ \\
\hline $\mathrm{n}$ & & 44 & & \\
\hline Median Value & & 115 & & \\
\hline Interpreted Best Fit Value & & 101 & & \\
\hline (A) \# of Undermined Sprin & Best Fit Value $w />/=50 \%$ Discharge Reduction & & 23 & \\
\hline (B) \# of Undermined Spring & Best Fit Value $\mathrm{w} /<50 \%$ Discharge Reduction & & & 0 \\
\hline (C) \# of Undermined Sprin & est Fit Value $w />/=50 \%$ Discharge Reduction & & 17 & \\
\hline (D) \# of Undermined Spring & est Fit Value w $/<50 \%$ Discharge Reduction & & & 4 \\
\hline Absolute Value (AD-BC) & & 92 & & \\
\hline Chi Square Value at 1 Deg & Freedom & 2.78986 & & \\
\hline Error Probability as Derive & Chi Square Contingency Test & $0.10-0.05$ & & \\
\hline Error Probability as Derive & Fisher Exact Probability Test & 0.04409 & & \\
\hline
\end{tabular}




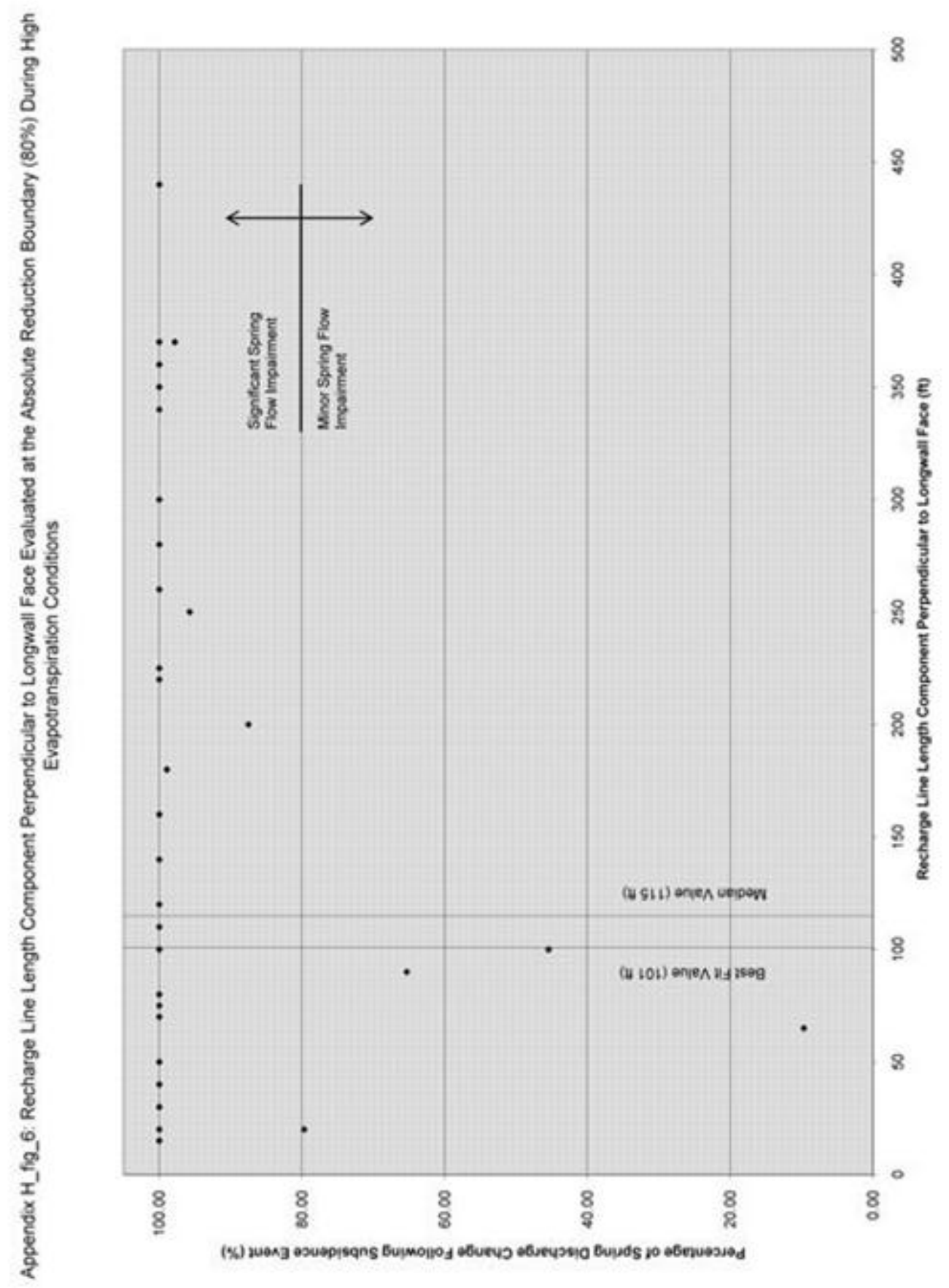

John

$\mathrm{H}$. Univestil brate

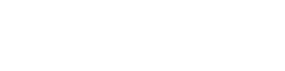

